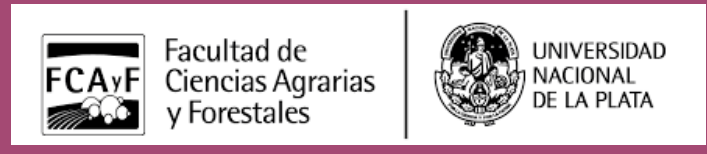

Tesis de Doctorado en Ciencias Agrarias

\title{
TERRITORIO EN MOVIMIENTO: LAS TRANSFORMACIONES TERRITORIALES DEL CINTURÓN HORTÍCOLA PLATENSE EN LOS ÚLTIMOS 30 AÑOS
}

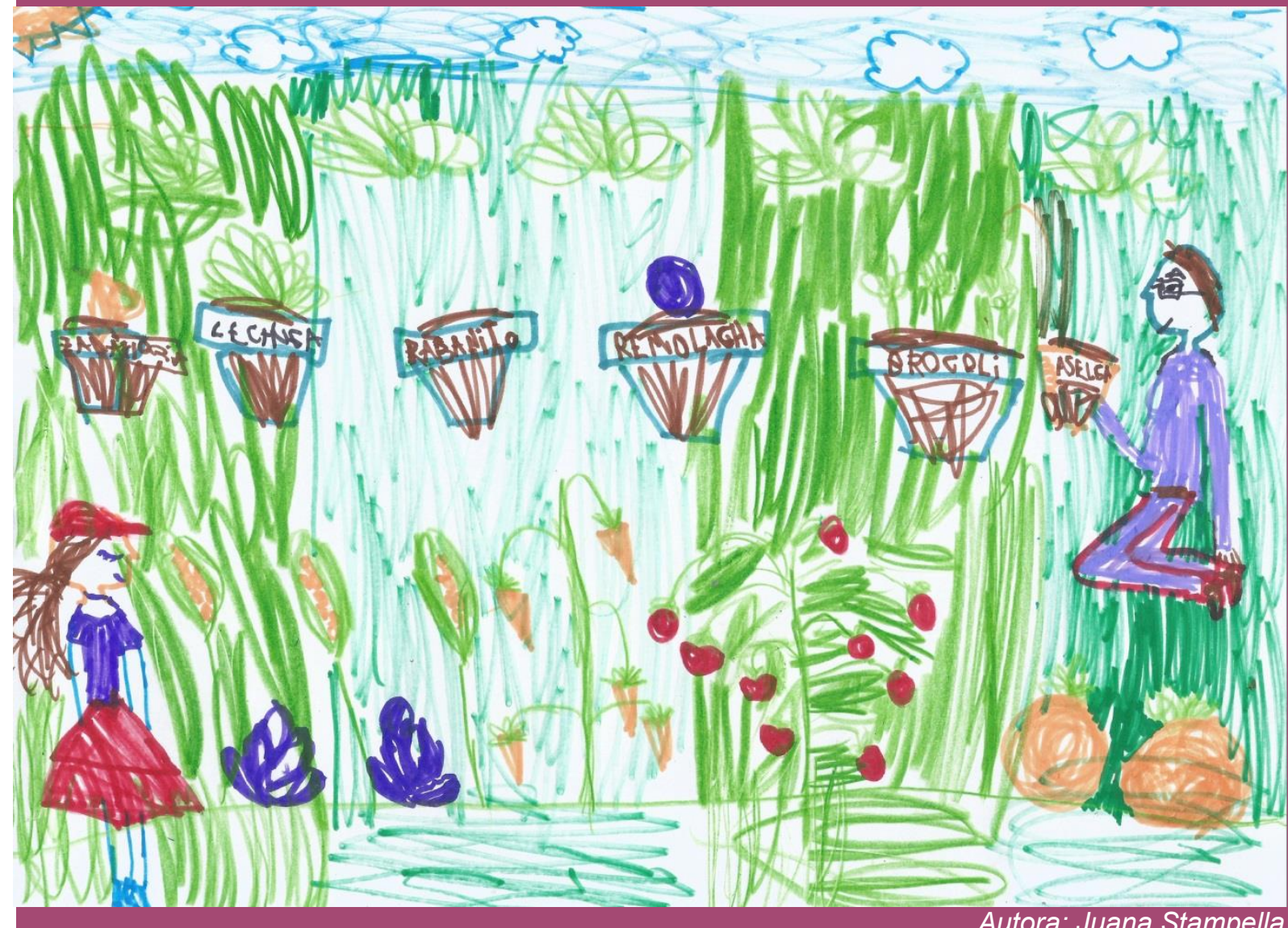

Lic. Carolina Baldini

Directora: Mariana Edith Marasas

Co-directora: Andrea Alejandra Drozd

Año 2020 


\section{RESUMEN}

En Argentina, las principales áreas de producción hortícola están sufriendo una fuerte retracción y el deterioro de ambientes proveedores de servicios ecosistémicos, como consecuencia principalmente de la presión que están ejerciendo la expansión urbana y el avance del agronegocio. El partido de La Plata (Provincia de Buenos Aires) toma relevancia en este contexto, ya que alberga uno de los principales cinturones hortícolas, que abastece con alimentos de proximidad a la región que concentra al $41 \%$ de la población del país (Ciudad Autónoma de Buenos Aires y el conurbano bonaerense) proveyendo entre el $60 \%$ y el $90 \%$ de las hortalizas frescas que consumen sus habitantes. Sin embargo, el avance urbano y el modelo de producción intensivo asociados con la "revolución verde" y basado en la tecnología del invernáculo e insumos externos que se implementó en esta región, han generado importantes transformaciones en el Cinturón Hortícola Platense (CHP), con consecuencias negativas tanto ecológicas como socio-económicas, llevándolo a una situación crítica. La expansión urbana se ha dado sobre tierras productivas de alta calidad, desplazando a la horticultura hacia áreas de uso tradicionalmente agropecuario, con suelos que no son aptos para dicha actividad. Por otro lado, la tecnología del invernáculo se ha expandido a un ritmo desenfrenado generado la impermeabilización de gran parte del suelo hortícola, problemas de contaminación por hiperfertilización y de salinización de los suelos bajo producción, contaminación por agroquímicos de agua, suelo y alimentos, una notable reducción de las áreas con cultivos al aire libre, la simplificación del agroecosistema y consecuentemente la pérdida de biodiversidad proveedora de bienes y de servicios ecológicos, entre otros problemas. A esto debemos sumar las consecuencias económicas y sociales, destacando las condiciones de vida y de trabajo, sumamente precarias de las familias productoras y el riesgo para la salud de productores y consumidores por el excesivo e inadecuado uso de agroquímicos. A través de este trabajo de tesis se buscó interpretar de forma más integral la problemática descripta para el CHP, a partir del análisis de las transformaciones territoriales ocurridas en el Cinturón Hortícola Platense durante los últimos 30 años y aportar nuevos conocimientos actualizados y herramientas que faciliten la toma de decisiones para una adecuada gestión y planificación del territorio en el marco de la sustentabilidad. Para ello me valí de los aportes principalmente de la ecología del paisaje y la agroecología. Trabajé con imágenes satelitales Landsat de los años 1986, 1996, 2005 y 2015, a partir de las cuales generé mapas de cobertura/usos del suelo, estimé el cambio en las áreas urbanas, productivas y semi-naturales y analicé los patrones de cambio del paisaje; al mismo tiempo realicé un análisis espacial para el año 2015 incorporando otras fuentes de información y generé mediante un análisis multicriterio mapas de aptitud de uso del suelo para los usos urbano, hortícola al aire libre y hortícola bajo invernáculo y de áreas críticas por superposición de aptitudes de uso. Complementariamente, abordé un análisis 
cualitativo, mediante la realización de entrevistas semi estructuradas, en el que evalué la percepción de distintos actores sociales sobre los cambios en el uso del suelo y las posibilidades de transformación del modelo productivo hacia un modelo de base agroecológica.

Como resultado, evidencié que por muchos años ha primado una lógica de "autogestión del territorio", donde las lógicas de mercado fueron las que mayor influencia ejercieron, plasmadas en un proceso de expansión urbana sin criterios aparentes y en la intensificación productiva especialmente vinculada a la horticultura bajo invernáculos. La urbanización experimentó un importante crecimiento entre 1986 y 2015, principalmente sobre pastizales y parquizaciones herbáceas, y en menor medida sobre zonas con horticultura al aire libre. Más de la mitad del área urbana se asentó sobre suelos de aptitud agrícola, y las producciones hortícolas bajo invernáculos y las producciones hortícolas al aire libre están comenzando a ocupar suelos de menor aptitud agrícola. Se confirmó la fuerte influencia de la urbanización a la hora de establecer en la práctica un uso del suelo en la zona de conflicto extremo, donde los tres usos del suelo (urbanización, horticultura al aire libre e invernáculos) tenían aptitud alta/muy alta.

La horticultura (horticultura al aire libre e invernáculos), no sufrió modificaciones sustanciales, por lo que se podría decir que el CHP mantuvo su extensión, aunque sí se evidenciaron desplazamientos en la actividad. La producción bajo invernáculos creció en todos los períodos estudiados, pero con especial énfasis en el período 2005-2015, a expensas principalmente de áreas con horticultura al aire libre y en menor medida zonas ganaderas. Para el año 2015 gran parte de los invernáculos se encontraron a una distancia inadecuada respecto a los centros urbanos y a los principales arroyos de la región según diversas regulaciones existentes. Se identificaron las delegaciones municipales con mayor concentración de invernáculos. Además, se comprobó que en la zona de aptitud muy alta para los invernáculos, la vegetación natural/semi-natural es escasa. La producción hortícola al aire libre disminuyó en superficie en todos los períodos estudiados, aunque en todos los períodos hubo zonas ganaderas que fueron reemplazadas por nuevas producciones hortícolas. Pese a la fuerte intensificación registrada, para el año 2015 prácticamente la mitad de la producción hortícola eran cultivos al aire libre. Se identificaron las delegaciones municipales con mayor superficie de producción al aire libre y se comprobó que existen suelos de aptitud alta para el desarrollo de producciones hortícolas al aire libre que aún no han sido aprovechados.

Se evidenció una tendencia de los ambientes semi-naturales a la urbanización. Para el año 2015 los ambientes riparios se encontraban desarrollados principalmente en la periferia del partido, con actividad casi exclusivamente ganadera, y los ambientes naturales o semi-naturales se encontraban mucho menos representados en la zona hortícola, y menos 
aún en aquella zona caracterizada por la concentración de producciones bajo invernáculo. Sin embargo, se observaron áreas de pastizal en las delegaciones de Arturo Segui, Melchor Romero y City Bell, de importancia para el mantenimiento de la biodiversidad, por su cercanía a los arroyos que atraviesan la zona, y por su potencial para conformar corredores biológicos que conecten con la zona de mayor densidad hortícola; y en Arana, donde estos ambientes juegan un rol importante como reservorios de biodiversidad en la zona hortícola.

El acceso a la propiedad de la tierra emergió como una de las principales necesidades para la continuidad de la actividad, junto con mejoras en las condiciones de vida y de trabajo y un mayor control por parte del Estado del mercado y los agentes especuladores, regulando los precios de los alimentos y facilitando el acceso a maquinarias, financiamiento de proyectos productivos, capacitación, etc. También se evidenció la necesidad de más diálogo con los funcionarios del Estado, de un espacio en el que se puedan trabajar propuestas para el sector y de contar con un proyecto de desarrollo territorial que trascienda los períodos de gestión municipal. Los escasos proyectos de planificación del territorio se han ido adaptando en general a los intereses de los funcionarios de turno, han estado sesgados a profesionales del ámbito de la arquitectura y la ingeniería, sin injerencia de profesionales de las ciencias agrarias y forestales, ni de las más de 5000 familias productoras. Las políticas públicas vinculadas a la agricultura familiar no han canalizado la experiencia ni las demandas de las familias productoras ni de los profesionales que trabajan en el territorio, y han intentado mejorar las condiciones de estas familias mediante un incentivo a la intensificación productiva. Se evidenciaron múltiples conexiones de distintos actores en el territorio, articulando trabajos y experiencias que integran a actores del ámbito universitario, del INTA, SENASA, militantes de organizaciones de base, organizaciones de productores familiares, entre otros. Los entrevistados consideraron como un potencial de la actividad hortícola en la región el alto grado de asociativismo, la presencia de familias productoras bolivianas con tradición campesina, la gran capacidad de trabajo y el número creciente de productores organizados con experiencia agroecológica y capacidad para transmitir sus conocimientos. Los distintos actores entrevistados han reconocido una multiplicidad de servicios ecosistémicos que brindan los ambientes semi-naturales e incluso los cultivos al aire libre, aunque de manera parcial. Existe un interés generalizado por la preservación de estos ambientes, que se consideran insuficientes, especialmente dentro del CHP.

Finalmente, en el marco de esta tesis, se generaron criterios y recomendaciones para avanzar hacia un territorio productivo más sustentable y resiliente, siguiendo los lineamientos de la agrocología.

Palabras clave: Usos del suelo/Territorio/Invernáculos/Periurbano/Agroecología 


\section{ABSTRACT}

In Argentina, the main areas of horticultural production are suffering a strong retraction and the deterioration of environments that provide ecosystem services, mainly as a result of the pressure exerted by urban expansion and agribusiness progress. The county of La Plata (Buenos Aires Province) takes relevance in this context, since it holds one of the main horticultural belts, which supplies food to a region that concentrates $41 \%$ of the country's population (CABA and Buenos Aires suburbs); providing between $60 \%$ and $90 \%$ of the fresh vegetables consumed by its inhabitants. However, the advance of urban areas and the intensive production model associated with the "green revolution" and based on the technology of the greenhouse and external inputs that were implemented in this region, have generated important transformations in the La Plata horticultural belt (LPHB), with negative consequences both ecological and socio-economic, leading to a critical situation. Urban expansion has occurred on high-quality productive lands, displacing horticulture towards areas of traditional agricultural use, with soils that are not suitable for such activity. On the other hand, the technology of the greenhouse has expanded at a rampant rate generating a waterproofing of a large part of the horticultural soil, problems of contamination by hyperfertilization and salinization of the soils under production, contamination by agrochemicals of water, soil and food, a notable reduction of areas with outdoor crops, the simplification of the agroecosystem and consequently the loss of biodiversity providing ecological goods and services, among other problems. Additionally, we have the economic and social consequences, highlighting the living and working conditions, extremely precarious of the producing families and the risk to the health of producers and consumers due to the excessive and inappropriate use of agrochemicals. Through this dissertation I sought to interpret in a more comprehensive way the problem described for the LPHB, based on the analysis of the territorial transformations that occurred in the area during the last 30 years; and provide new updated knowledge and tools that can facilitate decision-making for proper management and planning of the territory in the framework of sustainability. For this I used the contributions mainly of landscape ecology and agroecology. I worked with Landsat satellite images from 1986, 1996, 2005 and 2015, from which I generated land cover/land use maps, estimated the change in urban, productive and semi-natural areas and analyzed the change patterns of the landscape. Additionally, I carried out a spatial analysis for 2015 incorporating other sources of information and generated through a multicriteria analysis maps of land use aptitude for urban, outdoor horticultural and horticultural uses under hothouse and critical areas for overlapping skills of use. Complementarily, I addressed a qualitative analysis, by conducting semi-structured interviews, in which I evaluated the perception of different social actors about changes in land use and the possibilities of transforming the productive model towards an agroecological-based model. 
As a result, I evidenced that for many years a logic of "self-management of the territory" has prevailed, where the market logics were the ones that exerted the greatest influence, embodied in a process of urban expansion without apparent criteria and in the productive intensification especially linked to the production under green houses. The urbanization experienced an important growth between 1986 and 2015, mainly on grasslands and herbaceous parks, and to a lesser extent on areas with outdoor horticulture. More than half of the urban area settled on agriculturally suitable soils, and horticultural productions under greenhouses. Outdoor horticultural productions are beginning to occupy soils of lesser agricultural aptitude. The strong influence of urbanization was confirmed when establishing in practice a land use in the area of extreme conflict, where the three land uses (urbanization, outdoor horticulture and greenhouses) had high/very high aptitude.

Horticulture (outdoor horticulture and greenhouses), did not undergo substantial modifications, so it could be said that the LPHB maintained its extension, although there were evidenced shifts in activity. The production under greenhouses grew in all the studied periods, but with special emphasis in the period 2005-2015, at the expense mainly of areas with outdoor horticulture and to a lesser extent livestock area. By 2015, a large part of the greenhouses was found at an inadequate distance from the urban centers and the main streams of the region according to various existing regulations. I identified also municipal delegations with high concentration of greenhouses. In addition, I found that in areas of very high suitability for greenhouses, natural/semi-natural vegetation was scarce. Outdoor horticultural production decreased in area in all periods studied, although in all periods there were livestock areas that were replaced by new horticultural productions. Despite the strong intensification registered, by 2015 practically half of the horticultural production were outdoor crops. The municipal delegations with the largest outdoor production area were identified and it was found that there are high suitable soils for the development of outdoor horticultural productions that have not yet been used.

There was an evident tendency of semi-natural environments to be urbanized. By 2015, riparian environments were mainly developed on the periphery of the county, with almost exclusively livestock activity. The natural or semi-natural environments were much less represented in the horticultural zone, and even less in that area characterized by concentration of productions under hothouse. However, pasture areas were observed in the delegations of Arturo Segui, Melchor Romero and City Bell, of importance for the maintenance of biodiversity, for their proximity to the streams that cross the area, and for their potential to form biological corridors that connect with the area of highest horticultural density; and in Arana, where these environments play an important role as biodiversity reservoirs in the horticultural zone. 
Access to land ownership emerged as one of the main needs for the continuity of the activity, along with improvements in living and working conditions and greater control by the State of the market and speculating agents, regulating the food prices and facilitating access to machinery, financing of productive projects, training, etc. The need for more dialogue with state officials was also evident, for a space where proposals for the sector can be worked on and for a territorial development project that transcends the periods of municipal management. The few territorial planning projects have been adapted in general to the interests of the officials on duty, have been biased to professionals in the field of architecture and engineering, without interference from professionals in the agricultural and forestry sciences, or from the more than $\mathbf{5 0 0 0}$ families of small-scale producers. Public policies linked to family farming have not channeled the experience or demands of producer families or professionals working in the territory and have tried to improve the conditions of these families through an incentive to productive intensification. Multiple connections of different actors in the territory were evidenced, articulating works and experiences that integrate actors from the university, INTA, SENASA, militants from grassroots organizations, family producer organizations, among others. The interviewees considered as a potential of the horticultural activity in the region, the high degree of activism, the presence of Bolivian producing families with peasant tradition, the great capacity for work and the growing number of organized producers with agroecological experience and ability to transmit their knowledge. The different actors interviewed have recognized a multiplicity of ecosystem services that provide semi-natural environments and even outdoor crops, although partially. There is a widespread interest in the preservation of these environments, which are considered insufficient, especially within the LPHB.

Finally, within the framework of this dissertation, criteria and recommendations were generated to move towards a more sustainable and resilient productive territory, following the guidelines of agroecology.

Key words: Land uses/Territory/Greenhouses/Periurban/Agroecology 


\section{AGRADECIMIENTOS}

Al empezar a poner en palabras todos estos años de trabajo y recordar, reflexionar, revivir momentos fui descubriendo lo colectivo que fue este proceso y todos los aprendizajes que fui incorporando más que académicos de la vida y las relaciones humanas. Empecé esta tesis como muchos y muchas cuestionando el sistema científico, la precarización laboral, el academicismo extremo, la falta de conexión con las necesidades locales, la competencia entre colegas, entre tantos otros aspectos cuestionables del sistema. Sin embargo, pese a todo eso y después de todos estos años descubrí que el "mundo científico" está lleno de hermosas personas, solidarias, comprometidas con la realidad social, compañeras, que apuestan a otro mundo posible y a otra ciencia posible. Si bien esta tesis está escrita en primera persona, es una tesis realmente colectiva.

El primero de los agradecimientos es sin dudas para mi familia, que desde muy chica me dio libertad y me incentivó para que estudiara lo que realmente me gustaba, y más de una vez han tenido que darme una mano en momentos difíciles, bastante habituales entre quienes elegimos carreras como biología.

Infinito agradecimiento también por haberme ayudado a transitar todos mis estudios en escuelas y universidades públicas y gratuitas

A toda mi familia, los que están y los que ya no, por su interés, sus consejos y su ejemplo

A lo productores y productoras del MTE rural, parte esencial de esta tesis. Por darme un lugar en sus vidas, por enseñarme lo que es la vida de las familias productoras, por su tiempo, su alegría, sus enseñanzas, su creatividad, su compañerismo y su lucha por un mundo más justo

A Mariana Marasas por el apoyo constante, por entusiasmarse a la par mío con cada propuesta que le llevo, por la garra que le pone a todo lo que emprende, por su capacidad reflexiva y su gran capacidad de síntesis, sin la cual esta tesis hubiese tenido el doble de páginas!

A Andrea Drozd por acompañarme por el largo tránsito de las clasificaciones, por su dedicación y entusiasmo

A Paula Palacios que siempre estuvo atenta y bien predispuesta para darme una mano en lo que necesitara 
A los compañeros y compañeras de militancia del MTE rural, por enseñarme constantemente lo desafiante y lo gratificante que es construir colectivamente el mundo que queremos

A mis hermanas de la vida, Lau, Vicky, Pau, Lu, la Chula, Emi, Juli, Cintia por estar siempre acompañándome, aconsejándome, distrayéndome en los momentos difíciles.

A Lau un especial agradecimiento porque sin lugar a dudas tuviste mucho que ver en mis elecciones profesionales y de militancia que van casi de la mano.

Al Rama, otro hermano de la vida, compañero de infinidad de aventuras, con quien descubrí que la distancia no existe para la amistad. $Y$ otra persona que ha puesto mucho de sí en esta tesis, con larguísimas charlas, debates, lecturas compartidas, correcciones de trabajos, mates a la distancia en momentos de crisis.

A mis queridos "amigos del pocker" Andre, Dino, Leo y David, que siempre están presentes y acompañando aunque estemos desparramados por distintas partes del mundo

A Nadia y Andre, amigas y compañeras, por las largas charlas, los consejos y el aguante de estos tiempos...por enseñarme a vivir mas relajada!

Al inmenso equipo de agroecólogos/as del MTE que luchan incansablemente por ir haciéndonos lugar en este mundo. Lucas por enseñarme una hermosa forma de construir la agroecolgía, Vale, Andre, Leni, Flor, Nacho, todo el equipo de PaP CABA, Córdoba, Olavarria

A Luci, una hermanita más que me dejó esta tesis, una compañía y apoyo increíbles para transitar estos años

A Pablo por estar siempre haciendo el aguante y a mi ahijada Juana, que bancó mis momentos de ausencia y siempre me recibió llena de amor

A mis hermosos sobris que fui incorporando en estos años, Santi, Habi y Mia.

A Marina, Maria Rosa y Yuliana, hermosas amigas de este camino, que ayudaron a que gran parte de esta tesis fuera posible 
A Beatriz Giobellina que desde los inicios de esta tesis estuvo presente, acompañando y aconsejando desinteresadamente, abriéndome las puertas a miles de posibilidades, incluido mi proyecto de postdoc.

A Mati Garcia por sus innumerables horas de psicólogo, sus consejos, su predisposición, su claridad.

A Yoli por entusiasmarse con mi tesis y darme una mano con las clasificaciones

A Marga, Agus y Fer, hermosas agroecólogas y un gran equipo de laburo. Gracias por siempre estar dispuestas a dar una mano y prenderse en cuanto taller se me ocurre hacer

A Camila Gomez, Guido Principi, Maxi Perez, Guillermina Ferraris y muchos otros que también contribuyeron a que fuera conociendo el territorio, sus relaciones de poder y sus alianzas.

A Agustina Mendzabal, por las largas jornadas de mates y charlas mientras intentabamos avanzar en el mundo de la escritura

A Santiago Sarandón por facilitarme lugar de trabajo en la Cátedra de agroecología e incorporarme en diversos proyectos de la cátedra.

A la Facultad de Ciencias Agrarias y Forestales y a CONICET por brindarme el financiamiento y las herramientas necesarias para realizar el doctorado en el marco de instituciones del Estado y de manera gratuita

Y a muchas más personas que fui conociendo y con las que fui construyendo a lo largo de estos años 
CAPÍTULO 1 Introducción a las problemáticas del Cinturón Hortícola Platense y presentación de la tesis

1. INTRODUCCIÓN

2. MARCO CONCEPTUAL

2.1 Agroecología 24

2.2 Ecología del paisaje 29

2.3 Territorio 33

2.4 Ordenamiento territorial 34

2.5 Periurbano 39

3. AREA DE ESTUDIO

3.1 Características biofísicas 40

3.2 La conformación del CHP en el marco del desarrollo del partido de La 42 Plata

3.3 Principales actores sociales e instituciones públicas asociadas al CHP 47

3.4 Qué y cómo se produce en el CHP 51

3.5 Las políticas públicas que influyen en el desarrollo del CHP 57

4. HIPÓTESIS

4.1 Hipótesis general

5. OBJETIVO GENERAL Y OBJETIVOS ESPECÍFICOS

5.1 Objetivo general 66

5.2 Objetivos específicos 66

6. BIBLIOGRAFÍA 67

\section{CAPÍTULO 2 Transformaciones Territoriales}

1. INTRODUCCIÓN

89

2. METODOLOGÍA

2.1 Breve descripción del proceso de selección de las herramientas de clasificación consideradas más adecuadas

2.2 ¿Cómo se generaron los mapas definitivos de cobertura/usos del suelo? 95

2.3 ¿Cómo se validaron los mapas obtenidos?

2.4 ¿Cómo se analizaron los cambios de coberturas/usos del suelo? 100

3. RESULTADOS

3.1 Los mapas de coberturas/usos del suelo del partido de La Plata

3.1.1. ¿Qué validez tienen los mapas de cobertura/uso del suelo obtenidos?

3.1.2. Mapas de cobertura/uso del suelo del partido de La Plata en

diferentes momentos de su desarrollo

3.2 Los cambios en las coberturas/usos del suelo del partido de La Plata

3.2.1 ¿Cuáles fueron los principales cambios en las coberturas/usos del suelo entre 1986 y 2015 ?

3.2.2 ¿Cuáles fueron los cambios detectados en las coberturas/usos del 103 suelo en cada periodo

3.3 Una primer aproximación a los patrones de cambio del paisaje 
4.1 Las transformaciones del paisaje y sus implicancias para la gestión y planificación del territorio

5. CONCLUSIONES PARCIALES

6. BIBLIOGRAFÍA 124

7. ANEXOS

Anexo 1. Matrices de confusión

Anexo 2. Fotografías de las principales categorías de coberturas/usos del

suelo establecidas

\section{CAPÍTULO 3 Las coberturas del suelo en el año 2015 y su \\ implicancia para el Cinturón Hortícola Platense desde un enfoque agroecológico}

1. INTRODUCCIÓN

2. METODOLOGÍA

2.1 Metodología para el análisis de las relaciones espaciales entre las coberturas/usos del suelo y de estas con variables físicas

2.2 Metodología de análisis multi-criterio

3. RESULTADOS

3.1 Los municipios y la producción hortícola

3.2 La producción hortícola en relación a las cuencas

3.3 Los usos del suelo y la aptitud de los suelos para la agricultura 163

$\begin{array}{ll}3.4 & \text { Integrando variables a partir de un análisis multicriterio }\end{array}$

4. DISCUSIÓN

5. CONCLUSIONES PARCIALES 189

6. BIBLIOGRAFÍA 191

$\begin{array}{ll}\text { 7. ANEXOS } & 197\end{array}$

Anexo 1. Mapas de base utilizados para el análisis multicriterio

\section{CAPÍTULO 4 El partido de La Plata visto desde los actores sociales}

1. INTRODUCCIÓN

2. METODOLOGÍA

3. RESULTADOS Y DISCUSIÓN acercamiento a las posibilidades de cambio

3.2 La transición agroecológica en el CHP, sus dificultades y sus posibilidades de expansión

3.3 La gestión de la actividad productiva en uno de los principales cinturones hortícolas del país

3.4 Las condiciones históricas que dieron forma al actual CHP con sus deficiencias pero también con un enorme potencial

3.4.1 El gobierno de Alfonsín y un cinturón hortícola incipiente

3.4.2 El menemismo y los efectos de la desregulación

3.4.3 El kirchnerismo y el bum de la intensificación productiva

3.4.4 El macrismo y la decadencia

3.5 El territorio visto más allá del mercado. El Paisaje entendido por los 275 distintos actores del territorio 
3.6 Las principales transformaciones en el paisaje y los criterios de 285 ordenamiento territorial

4. CONCLUSIONES PARCIALES 292

5. BIBLIOGRAFÍA 296

6. ANEXOS 301

6.1 Anexo 1. Guías de pautas

6.2 Anexo 2. Modelo Grillados

CAPÍTULO 5 Reflexiones, discusión general, recomendaciones

\section{y conclusiones}

1. ALGUNAS REFLEXIONES PARA PENSAR LOS TERRITORIOS 314 PRODUCTIVOS

2. DISCUSIÓN GENERAL, CRITERIOS DE ORDENAMIENTO TERRITORIAL Y 321 RECOMENDACIONES

3. CONCLUSIONES GENERALES 332

4. BIBLIOGRAFÍA 339 


\section{CAPITULO 1}

\section{Introducción a las problemáticas del Cinturón Hortícola Platense y presentación de la tesis}




\section{INTRODUCCIÓN}

Los cambios en el uso/cobertura de la tierra (LULCC) impulsados por el desarrollo humano están transformando la biosfera en una escala sin precedentes (Millennium Ecosystem Assessment 2005, Wohlfart et al. 2017). Entre los principales impulsores de estos cambios en el uso de la tierra y de las amenazas ambientales a nivel global, se encuentran las expansiones urbana y agrícola (Foley et al. 2005, Sánchez 2009, Ramankutty et al. 2002, Rockström et al. 2009). La sustitución de las zonas con vegetación natural por estos nuevos usos del suelo se ha traducido en un aumento sustancial de los servicios de aprovisionamiento, como la producción de alimentos, y de servicios culturales (Millennium Ecosystem Assessment 2005), pero también ha conducido a importantes transformaciones trade-offs- en términos de biodiversidad, de emisiones de carbono y disminución de servicios ecosistémicos de provisión (Gibbs et al. 2010, Newbold et al. 2015, West et al. 2010, Hajdu et al. 2016). En los últimos años han surgido diversos trabajos que intentan medir de algún modo la intensidad de los impactos producto de la actividad humana y la capacidad del planeta para soportarlos. En este sentido, Rockström et al. (2009) y Steffen et al. (2015) identificaron nueve procesos críticos para el funcionamiento del planeta, que están siendo claramente modificados por la acción humana y encontraron que cuatro de ellos han trasgredido los límites planetarios; la integridad de la biosfera (asociada a la biodiversidad) y los flujos biogeoquímicos, que se ubicaron en la zona de alto riesgo, y los cambios en el sistema de tierras y el cambio climático, que se encuentran en la zona de riesgo creciente. La relevancia de los cambios que está atravesando el planeta ha hecho que la comprensión de los procesos de LULCC y de las fuerzas impulsoras implicadas en ellos, sea en la actualidad una de las principales prioridades para la investigación y para el correcto desarrollo de estrategias de gestión sostenible (Turner et al. 1993, Vitousek 1994).

Actualmente más de 4.000 millones de personas (el $50 \%$ de la población mundial) vive en áreas urbanas, y se espera que este valor aumente (World Bank 2018). Este proceso ha provocado una expansión de las zonas urbanas en todo el mundo y el consiguiente aumento de la demanda de alimentos de las familias que viven allí y que dependen casi exclusivamente de la compra de alimentos (United Nations 2015). Esta expansión ha ocurrido a expensas no sólo de tierras con coberturas naturales y seminaturales, sino también en tierras agrícolas de alta calidad, desplazando a la agricultura a suelos de calidad inferior (Ramankutty et al. 2008, Martellozzo et al. 2018, United Nations 2011); un proceso considerado como una de las fuerzas impulsoras más importantes de amenazas ambientales (Foley et al. 2005, Rockström et al. 2009). Lambin et al. (2003) analizaron las dinámicas de cambio en las coberturas y usos del suelo a nivel mundial, e identificaron a la conversión de bosques vírgenes para usos agrícolas (deforestación) y al 
deterioro de la vegetación natural por el pastoreo excesivo (desertificación), como los principales cambios en la superficie terrestre; las fuerzas impulsoras de estos cambios fueron atribuidas al crecimiento de la población local y, en menor medida, al aumento del consumo. Paradójicamente, las necesidades de tierras para la agricultura están aumentando considerablemente. Según Conijn et al. (2018), en 2010 el límite planetario para las tierras agrícolas ya se habían superado y, para el año 2050 la situación empeorará, ya que se necesitarían un $67 \%$ más de tierras de cultivo y un $78 \%$ más de pasturas para responder a las demandas futuras. Estos autores plantean que si este requerimiento extra de tierras se satisface a costa de la tala de bosques, la superficie forestal disminuirá de 4,0 a 0,5 Gha con efectos dramáticos sobre la biodiversidad y sobre las emisiones de gases de efecto invernadero. Además, como vimos anteriormente, la integridad de la biosfera, los flujos biogeoquímicos y los procesos de cambio en el sistema de tierras, aspectos estrechamente relacionados con la producción de alimentos, ya están transgrediendo los límites planetarios (Steffen et al. 2015).

América del Sur ha sido recientemente identificado como un punto caliente -hotspotmundial de expansión e intensificación agrícola, provocando grandes pérdidas en términos de diversidad biológica y de aquellos servicios ecosistémicos que no son de aprovisionamiento (Piquer-Rodríguez et al. 2018, Aide et al. 2012). El principal cambio en la cobertura/uso del suelo en esta región es provocado por la deforestación, transformando grandes extensiones de bosques en cultivos anuales (Vega et al. 2009). El 92\% de la deforestación en América Latina y el Caribe ocurre en Sudamérica, principalmente en Argentina, Brasil, Bolivia y Paraguay (Aide et al. 2012). Se calcula que Argentina ha perdido desde 1914, cuando se calculó una masa forestal de 106 millones de hectáreas, casi dos tercios de su patrimonio forestal nativo, estimando la superficie actual en menos de 44 millones de hectáreas (Pengue 2005). En cuanto a la superficie cultivada en Argentina, se estima que a principios de 1900 alcanzaba las $6 \times 10^{6}$ ha, aumentando a mediados del siglo XX un $400 \%$ (24 x 10 ha) (Pielke et al. 2011), presentando un patrón de conversión similar al del resto del continente. Esta expansión agrícola se ha dado principalmente por cultivos anuales (de un $4 \%$ a un 14,3\%, entre 1988 y 2002), particularmente por soja (Paruelo, 2006) provocando una amplia reducción en la superficie de bosques nativos, y afectando también notoriamente los cinturones verdes fruti-hortícolas de muchas ciudades de Argentina (Manuel-Navarrete et al. 2005 en Barchuk et al. 2017). En cuanto al crecimiento urbano, este se ha profundizado a lo largo del siglo XX en Argentina como en el resto del mundo, $y$ en línea con el proceso latinoamericano, este crecimiento urbano está ejerciendo una fuerte presión sobre las tierras productivas, como es el caso de la mayoría de los cinturones hortícolas del país, algunos de los cuales están desapareciendo rápidamente como resultado de la expansión urbana y del agronegocio (Barchuk et al. 2017, Giobellina 2017, Giobellina 2018, Medico 2016, Hurtado et al. 2006). En nuestro país, las principales 
provincias productoras de hortalizas son Buenos Aires, Mendoza, Córdoba, Santiago del Estero, Misiones, Santa Fe, Corrientes, Tucumán, Formosa, Salta, Chaco, Jujuy, San Juan y Río Negro; y en cuanto al desarrollo de áreas productivas en cercanías de las ciudades, se destacan los cinturones hortícolas del área metropolitana de Buenos Aires, La Plata, Rosario, Córdoba, Mar del Plata, Mendoza y Tucumán (Fernández Lozano 2012). Un caso emblemático y bien documentado, de las presiones que están sufriendo estas áreas productivas como resultado de los cambios en el uso del suelo, es el Cinturón Verde de Córdoba (CVC), el cual está sufriendo la pérdida acelerada de superficie bajo producción hortícola intensiva y el deterioro de ambientes que proveen de servicios ecosistémicos relevantes para la población urbana y periurbana (Barchuk et al. 2017, Giobellina 2018). Este cinturón pasó de tener 14.771 ha. hortícolas en 1987 a 3.167 ha. en el 2014 (Barchuk et al. 2017) Las transformaciones en esta zona productiva periurbana son el resultado de la presión por el avance del agronegocio, que reemplaza la producción de alimentos por la agricultura de commodities (principalmente soja); y el crecimiento urbano bajo una lógica de expansión difusa, asociada más a la especulación inmobiliaria que al crecimiento poblacional, reemplazando suelos hortícolas por urbanizaciones y desplazando la actividad hortícola intensiva hacia suelos menos productivos y más alejados del centro urbano (Boccolini et al. 2018, Giobellina 2018).

El partido de La Plata (Provincia de Buenos Aires) toma relevancia en este contexto, ya que alberga uno de los principales cinturones hortícolas, cerca de la zona más densamente poblada del país, la Ciudad Autónoma de Buenos Aires (CABA) y sus alrededores, denominado "Conurbano Bonaerense" (Fernández Lozano 2012, Sarandón et al. 2015). En Argentina el $89 \%$ de la población total se concentra en las zonas urbanas, y en conjunto, CABA y el Conurbano Bonaerense, representan el $41 \%$ de la población total del país, formando la tercera aglomeración urbana más grande de América Latina y el área urbana con la mayor densidad de población de Argentina (Bertoni et al. 2004). En el partido de La Plata, hubo un crecimiento de la superficie urbana y una aceleración del proceso de expansión urbana, como puede comprobarse analizando el período 1991-2001, donde el crecimiento de la población fue del $6 \%$, y el crecimiento de la superficie urbana fue de $12 \%$ (Frediani 2010). Hurtado et al. (2006) y Frediani (2010) sostienen que esta expansión urbana se ha dado sobre tierras productivas de alta calidad, desplazando a la horticultura hacia áreas de uso tradicionalmente agropecuario, con suelos que no son aptos para dicha actividad. El Cinturón Hortícola de La Plata (CHP) es uno de los sistemas agrícolas más importantes de la región, proveyendo entre el $60 \%$ y el $90 \%$ de las hortalizas frescas consumidas por CABA y el Conurbano Bonaerense (2.890.151 y 12.801.364 habitantes respectivamente) (Benencia 2002, INDEC 2010). Sin embargo, el avance urbano y el modelo de producción asociados con la "revolución verde" y basado en la tecnología del invernáculo e insumos externos (Sarandón 2002), que se implementó en esta región 
siguiendo como ejemplo el desarrollo hortícola de Almería en España (Sánchez Aznar 2011), han generado importantes transformaciones en el CHP, llevándolo a una situación crítica. Si bien la consolidación del Cinturón Hortícola Platense (CHP) fue posible gracias a la temprana incorporación de la tecnología del Invernáculo, asociada a una alta demanda y dependencia de agroquímicos (García 2012) desde la incorporación de esta tecnología, la superficie bajo invernáculo se ha expandido a un ritmo desenfrenado y sin una adecuada planificación, alcanzando entre 1998 y 2002 una tasa de crecimiento del 140\% (Nieto y Rivas 2006). Los relevamientos realizados hasta el momento muestran cifras que dan cuenta claramente de ello: en el año 2005 el Censo Hortiflorícola de Buenos Aires (CHFBA) indicó que el CHP poseía más del $79 \%$ de la superficie bajo cubierta del Cinturón Verde Bonaerense, del cual forma parte (CHFBA'05); en un trabajo posterior, al comparar los datos de 1998 y 2005, se observó un aumento del 83,3\% de cultivo bajo cubierta, mientras que el cultivo a campo disminuyó un 42,1\% (García y Mierez 2007); para el año 2006, el Consejo Federal de Inversiones (CFI) estimó que la superficie con invernáculos en el CHP llegaba a las 1300 has, y a principios del 2009 las principales empresas proveedoras de plásticos para la región inferían que la misma había superado las 3000 has (García 2011). Los sistemas hortícolas altamente tecnificados del CHP, son económicamente viables a corto plazo para los productores más capitalizados pero insustentables ecológica y socialmente en el largo plazo (Blandi y otros 2009), como podemos ver claramente al analizar algunas de las consecuencias negativas tanto ecológicas como socio-económicas de gran relevancia que generó, en solo 30 años, este modelo de producción ampliamente difundido en la región; haciendo a su vez, a los sistemas hortícolas altamente vulnerables a eventos de cambio climático (Pengue 2005, Martin-López et al. 2007).

Recientemente se han divulgado diversos estudios realizados por grupos de investigación de la UNLP en los que se evidencian las consecuencias más notorias del modelo de producción vigente, entre las que encontramos: problemas de contaminación por hiperfertilización y de salinización de los suelos bajo producción (Hurtado 2006); inundaciones cada vez más frecuentes agravadas por la impermeabilización generada por los invernáculos de gran parte del suelo hortícola (García 2011, Karol y San Juan 2018); contaminación por agroquímicos de agua, suelo y alimentos (Sarandón et al. 2015, Colombo et al. 2015, Alonso et al. 2015). Un estudio reciente que elaboró un índice de peligrosidad para los partidos de la Provincia de Buenos Aires, de acuerdo a la superficie relativa que ocupa la horticultura y al modelo de producción predominante, caracteriza a la zona hortícola de La Plata y General Pueyrredón como aquellas con mayores índices de peligrosidad de la provincia (Sarandón et al. 2015), advirtiendo que la tendencia a aumentar la superficie de cultivos bajo cubierta (invernáculos) tiende a agravar el panorama. A esto debemos sumar las consecuencias económicas y sociales, destacando las condiciones de vida y de trabajo, sumamente precarias de las familias productoras y el riesgo para la salud 
de productores y consumidores por el excesivo e inadecuado uso de agroquímicos. Los cultivos intensivos, como los que caracterizan actualmente al CHP, se consideran sistemas de alta sensibilidad para la población, por el intenso uso de agroquímicos que realizan (afectando la salud de los trabajadores y brindando alimentos de dudosa calidad a la población) y por su cercanía a los centros poblados, ya que se ha comprobado la presencia en la ciudad de agroquímicos utilizados en áreas hortícolas aledañas (Sarandón y otros 2015, Colombo y otros 2015). Sumado a los problemas de toxicidad, la evolución del uso de estos agroquímicos resulta preocupante, ya que no solo no ha resuelto de raíz el problema de las plagas, sino que el uso de insecticidas y herbicidas ha aumentado en los últimos años, pasando en Argentina de consumir 73 millones de $\mathrm{Kg}$. /l en 1995, a 236 millones de Kg. /l en el año 2005 (Casafe 2011). Al mismo tiempo, este incremento en el uso de agroquímicos está generando el debilitamiento del mecanismo de control biológico de plagas, favoreciendo la resurgencia de las mismas y la consecuente necesidad de intensificar el uso de los plaguicidas existentes o buscar nuevas formulaciones (Sarandón y otros 2015).

Otro aspecto a tener en cuenta es la resiliencia de los sistemas productivos, es decir su capacidad de recuperación frente a disturbios, tendiendo a mantener su estructura organizacional y productividad, (Sarandón 2014; Nicholls y Altieri 2012); lo cual adquiere especial relevancia considerando los cambios climáticos que están teniendo lugar en la región y la capacidad de respuesta del ambiente frente a acontecimientos como la fuerte inundación sufrida los días 2 y 3 de abril del 2013. Existen diferentes investigaciones (Machín-Sosa y otros, 2010; Philpott et al. 2009, Holt-Giménez 2001) que ponen de manifiesto como la resiliencia frente a los desastres climáticos está estrechamente relacionada con la biodiversidad de los sistemas productivos, estos trabajos a su vez enfatizan en la importancia de mejorar la diversidad vegetal y la complejidad en los sistemas agrícolas, para reducir la vulnerabilidad a eventos climáticos extremos (Altieri y Toledo 2010). Promover la diversidad funcional, es decir la presencia de múltiples especies que cumplen funciones similares pero tienen diferentes respuestas a la modificación del paisaje, es también un aspecto esencial para aumentar la resiliencia de los ecosistemas (Walker 1995 en Fischer et al. 2006). En el caso del CHP, la incorporación de los invernáculos ha generado una notable reducción de las áreas con cultivos al aire libre, una simplificación del agroecosistema y la consecuente pérdida de biodiversidad (Sarandón 2002), disminuyendo así la capacidad de recuperación del mismo, sumado a lo cual se pierden importantes bienes y servicios ecológicos que provee esta biodiversidad y que son esenciales para la agricultura (Martin-López y otros 2007). 
Es interesante destacar que muchas de las consecuencias de este modelo productivo insustentable identificadas en el CHP se registraron también en el caso de Almería, como resultado de su desarrollo agrícola (Galdeano-Gómez et al. 2012).

La actividad productiva en el CHP es realizada principalmente por Pequeños Agricultores Familiares (PAF), pertenecientes a la comunidad boliviana (principalmente originarios de Tarija), con fuerte presencia en el área desde la segunda mitad de la década de 1990. Este sector se ha visto forzado a dejar de lado sus prácticas agrícolas tradicionales, teniendo que incorporarse al modelo de producción intensiva, con todas las problemáticas que esto conlleva, algunas de las cuales se han mencionado anteriormente. Las condiciones actuales le impiden adoptar los paquetes tecnológicos completos que ofrece el mercado, ocasionándole perjuicios productivos, al no resolver los problemas de plagas, malezas y enfermedades, y socio-ambientales, al aplicar químicos muy tóxicos y de amplio espectro que suelen ser más económicos, pero más peligrosos (Marasas y otros 2012). Esta situación queda evidenciada al analizar los resultados del relevamiento realizado para la Defensoría del Pueblo, que dan cuenta de la peligrosidad de los agroquímicos utilizados e indican que en el CHP los cultivos bajo cubierta son los que utilizan mayor variedad de agroquímicos en su ciclo, y que en la mayoría de los cultivos, la mayor variedad de principios activos utilizados están vinculados al control de plagas animales (insectos, ácaros y/o nematodos) (Sarandón y otros 2015). Esta situación ha llevado a muchos productores a considerar nuevas estrategias productivas basadas en un enfoque agroecológico, centrado no sólo en la producción sino también en la sostenibilidad ecológica del sistema (Altieri 1999).

Visualizada esta problemática y como consecuencia de la creciente demanda de diversos actores sociales, en relación a una mayor regulación de la actividad agrícola, recientemente se han comenzado a generar cambios en el ámbito normativo, con la sanción de ordenanzas que restringen el uso de plaguicidas en las cercanías de centros urbanos y periurbanos (ordenanza municipal No 2671/10 aplicable al partido de Cañuelas y ordenanza municipal № 5953/11 aplicable al partido de Luján, ordenanza municipal No 18740/08 del partido de General Pueyrredón), posibilitando la apertura de un marco de discusión acerca del modelo de producción vigente y tomando a la agroecología como alternativa de producción estable y sustentable (Souza Casadinho 2012). El Partido de La Plata aún no ha avanzado en este sentido; sin embargo, diversas organizaciones de productores de la región, junto con técnicos de INTA e investigadores de la UNLP vienen avanzando en diversas experiencias de transición agroecológica.

Para implementar con éxito un modelo de transición hacia producciones agroecológicas, como el que se está comenzando a gestar en el CHP, es indispensable garantizar la sostenibilidad del mismo, y para ello la biodiversidad (diversidad de genes, de 20 Lic. Carolina Baldini

Tesis doctoral - Territorio en movimiento 
especies y de procesos ecológicos) es fundamental, por ser proveedora de servicios ecosistémicos como el control biológico de plagas, el reciclaje de nutrientes y la conservación de suelo y agua entre otros (Nicholls 2009, Fischer et al. 2006). Una disminución en la biodiversidad implica entre otras cosas la perdida de hábitat para aquellos individuos que actúan como control biológico de plagas, lo cual puede traducirse en serios problemas para los cultivos, ya que existen evidencias que demuestran un incremento de plagas en aquellos paisajes agrícolas homogéneos y por ende reducidos en biodiversidad (Altieri y Letourneau 1982).

Numerosas investigaciones realizadas en el CHP (Flores y otros 2007, Gargoloff y otros 2007, Bongiorno y otros 2009, Baloriani y otros 2009, Fernández y Marasas 2009, Blandi y otros 2011, Marasas y otros 2011, Marasas y otros 2014, Dubrovsky 2018, Fernandez 2015) conjuntamente con el trabajo de técnicos del IPAF-INTA y productores familiares, brindan información y herramientas de gran utilidad para la implementación de nuevas prácticas agrícolas con bases agroecológicas. Por ejemplo, para favorecer la expresión de servicios ecológicos de regulación, existen ciertas prácticas de manejo que debieran incentivarse, entre las que se puede mencionar la implementación de policultivos, el uso de cultivos de cobertura, el mantenimiento de cercos y corredores, la rotación de cultivos, los barbechos naturales y el mantenimiento de plantas silvestres, la cría de animales de granja y la eliminación de uso de agroquímicos (Pérez y Marasas 2013).

Estudios recientes han demostrado que el sector hortícola familiar menos capitalizado, aún mantiene cierta agrobiodiversidad en sus establecimientos, y que incluso los productores convencionales, cuentan con áreas que podrían actuar como refugio de biodiversidad y que probablemente estarían inhibidas en su accionar por el uso de agroquímicos (Marasas y otros 2014). Esto reviste gran importancia, ya que implica que si se reconociera el potencial biológico que poseen los productores en sus quintas y se implementaran estrategias de reconversión de las unidades productivas, se podría recuperar el rol de la biodiversidad en la regulación de plagas y prescindir paulatinamente de los insecticidas (Marasas y otros 2014).

La bibliografía consultada sostiene que diferentes tipos de borduras y coberturas vegetales proveen hábitat para la hibernación, refugio y fuentes de alimentos alternativos para la fauna benéfica (Asteraki et al. 2004, Marasas y otros 2001, Uetz et al. 1999), y que ésta realiza un permanente intercambio entre el cultivo y sus bordes (Marasas y otros 2011); esta información reviste importancia ya que dentro de la fauna benéfica podemos encontrar a los enemigos naturales de las plagas, es decir, parasitoides, depredadores, patógenos, herbívoros, que atacan a las plagas y que por lo tanto pueden actuar como control biológico de las mismas, reduciendo dichas poblaciones a densidades menores, ya sea temporal o permanentemente (Van Driesche et al. 2007). De este modo, recrear o conservar ambientes 
que estimulen la presencia de enemigos naturales permitiría disminuir el problema de plagas, a través de promover los mecanismos de regulación biótica (Marasas y otros 2011). Los estudios realizados en Sistemas de Producción Hortícola Familiar del Partido de la Plata confirman la importancia del mantenimiento de los bordes y fronteras de cultivos, por ser ambientes menos disturbados que aportan refugio y alimentación a los enemigos naturales de plagas; en estos mismos estudios se compararon sistemas agrícolas con producción convencional y con producción orgánica (sin uso de agroquímicos) y se observó que en los sistemas convencionales hay menor diversidad vegetal y de enemigos naturales asociados en los lotes cultivados en comparación con los bordes y fronteras de cultivos, mientras que en los sistemas orgánicos, la diversidad es similar en todos los ambientes, permitiendo la presencia de enemigos naturales en los lotes cultivados y contribuyendo al control biológico de plagas (Marasas y otros 2011). Estos estudios demuestran la importancia de trabajar en la implementación de prácticas agrícolas que incrementen la biodiversidad y en el mantenimiento de la vegetación natural circundante a los cultivos, así como los ambientes cultivados al aire libre, ya que todos ellos permiten mantener la biodiversidad a nivel de paisaje, necesaria para el control biológico de plagas (Nicholls 2009). El mantenimiento de la heterogeneidad en todas las escalas es considerado un factor determinante para la biodiversidad; y complementariamente, un aspecto clave en todos los paisajes productivos es la distribución espacial de los diferentes tipos de usos del suelo (Fischer et al. 2006).

A partir de lo expuesto anteriormente, podemos concluir que para garantizar la biodiversidad requerida para un modelo de producción agroecológico, es necesario abordar la gestión del área productiva a diferentes escalas, siendo de vital importancia tanto las prácticas agrícolas a nivel de las fincas como el manejo sistémico de los diferentes ambientes que componen el paisaje del territorio hortícola; para ello contamos con dos importantes herramientas, la teoría agroecológica, que provee información necesaria para el diseño y manejo de paisajes, permitiendo conservar e incrementar la efectividad de comunidades de enemigos naturales (Nicholls 2009) y la ecología de paisajes, que brinda múltiples herramientas de análisis espacial del territorio.

Actualmente, el modelo de producción vigente y las deficiencias en la gestión del territorio han dado como resultado una fuerte intervención en el paisaje, a su vez los sistemas más agresivos en el uso de la tierra, e intensivos en la aplicación de tecnologías (como el descripto para el CHP) ejercen un impacto más negativo sobre el hábitat y la vida silvestre (Sarandón y otros 2015). Muchos de los efectos ambientalmente significativos de la intensificación de la agricultura están conectados con el empobrecimiento o la simplificación de la estructura de los agroecosistemas (Ryszkowski 2001). Un abordaje del territorio a escala de paisaje, resulta entonces conveniente tanto para analizar los impactos del modelo de producción actual, como para evaluar potencialidades y requerimientos para el desarrollo 
de prácticas más sustentables, comprendidas en el marco de la noción de sustentabilidad fuerte planteada por Constanza y Daly (1992). En este sentido, la ecología de paisajes es una disciplina fundamental para realizar un abordaje del territorio desde un enfoque sistémico, ya que permite analizar la estructura espacial, el funcionamiento y la evolución del paisaje, así como también hacer predicciones acerca del efecto de los cambios de uso de la tierra y de la fragmentación de los ecosistemas sobre el funcionamiento del paisaje, lo cual puede traducirse en acciones de manejo y conservación (Dadon y Matteucci 2002), brindando un soporte para la toma de decisiones relacionadas a preguntas de servicios ecosistémicos y desarrollo-uso sustentable (Potschin y Haines-Young 2013). Como señala Matteucci (2002), la ecología del paisaje es una herramienta de la ingeniería ecológica, ya que permite diseñar el espacio, al modo de los arquitectos paisajistas, pero con el objetivo de lograr la perdurabilidad del Ecosistema Total (subsistemas natural y humano) en un estado deseable para la sociedad en su conjunto.

Por otro lado, considerando la amplitud de escalas a las cuales los problemas ecológicos se suceden, resulta importante comprender cómo los arreglos espaciales de los ecosistemas, hábitats y comunidades, y los cambios que sobrellevan en el tiempo-espacio, tienen implicancias en los aspectos funcionales de grandes áreas (Turner 1989, Wiens et al. 1993). El patrón espacial de los distintos componentes de un paisaje influye en los flujos y transferencias de organismos, materiales y/o energía entre dichos componentes (Risser y otros 1984). Comprender esto nos permite interpretar mejor las variables del paisaje que influyen en la biodiversidad del CHP y pensar en criterios de gestión que favorezcan los flujos de materia y energía en el mismo.

En los últimos tiempos han tomado predominancia las investigaciones enfocadas en servicios ecosistémicos (Nelson y otros 2009, Zhang y otros, 2007, Wu 2013, Koschke y otros 2012, entre otros), sin embargo, todavía son escasas aquellas que integran los procesos sociales a los procesos medioambientales y ecológicos (Cowling et al. 2008). En el CHP podemos ver claramente el vínculo existente entre dichos procesos y cómo, a su vez, las transformaciones socio-económicas que afectan a las actividades productivas, son el resultado tanto de las tendencias globales, como de las especificidades locales y de los actores sociales que influyen en éstas (Otero 2013). Por este motivo, es fundamental incorporar el análisis de los actores sociales involucrados en las transformaciones del CHP; esto nos permitirá conocer y comprender las variables que influyen en la toma de decisiones de los productores y que pueden influir en cambios futuros, detectar aquellas estrategias colectivas de organización que podrían fortalecer las decisiones que se vayan tomando y reconocer aquellas políticas públicas y redes institucionales, que podrían aportar a la perdurabilidad de nuevas prácticas agrícolas (Marasas y otros 2012, Cowling et al. 2008). En este sentido, un estudio de caso realizado recientemente a dos tipos de productores de 
tomate, que cultivan al aire libre y bajo invernáculo respectivamente, ha indagado en los factores que influyen en el desarrollo de comportamientos sustentables; dicho estudio ha encontrado que para el productor que utiliza invernáculo, los factores externos (destacando entre ellos la valoración que se da al producto en el mercado, el tipo de asesoramiento técnico y la falta de subsidios e incentivos al desarrollo de prácticas sustentables) son los principales impedimentos que este identifica para avanzar hacia una conducta sustentable (Blandi y otros 2013).

La crítica situación ambiental (Arias 2019, Mac Loughlin et al. 2017, García, 2011), económico-productiva (Cataldi y Flores 2019, Ennis 2019, Merchán 2016, García 2015a) y social (Ambort 2017, García 2015a) que está enfrentando el CHP, la escasez de información actualizada sobre la actividad productiva y sobre los cambios experimentados en el uso del suelo en la región (Hurtado et al. 2006), la creciente demanda de productores y de la sociedad en su conjunto, de un cambio en el modelo productivo (Foro Agrario 2019, UNLP 2019, UNLP 2017), y la certeza de que es posible y necesario recuperar aquellas formas de vincularnos más armónicamente con la naturaleza, de producir alimentos sanos y de desarrollar experiencias de comercio justo con vínculos más directos productor-consumidor, han sido los motores de este proyecto de investigación. A través de este trabajo de tesis se busca interpretar de forma más integral la problemática descripta para el CHP y aportar nuevos conocimientos actualizados y herramientas que faciliten la toma de decisiones para una adecuada gestión y planificación del territorio. Las mismas, serán un aporte a la hora de pensar la posibilidad de un cambio en el modelo productivo factible de ser implementado y sustentable en el espacio y en el tiempo.

\section{MARCO CONCEPTUAL}

\subsection{Agroecología}

La Agroecología es un concepto relativamente nuevo, que se remonta a la década del ochenta. Durante este periodo de tiempo ha ido asumiendo distintas significaciones, según los sujetos sociales que la estudian y la ponen en práctica, y la región en la que estos se encuentran.

En América Latina, los campesinos y las comunidades originarias han realizado durante siglos prácticas tendientes al mantenimiento de la producción, incluso en ecosistemas frágiles como los andinos y las zonas con grandes pendientes o inundables; estas experiencias ancestrales han sido la base del desarrollo de la noción de agroecología elaborada posteriormente desde las instituciones académicas (Marasas et al. 2012). Si bien el término "agroecología" fue usado por primera vez en 1930, durante las décadas de 1970 y 1980 tuvo lugar un cambio hacia una perspectiva ecosistémica de la agricultura, que 
permitió una enorme expansión del enfoque agroecológico en el mundo académico. En este período, la agroecología se vio influenciada por disciplinas como la antropología, la etnoecología, la sociología rural, los estudios del desarrollo y la economía ecológica, dándole una nueva impronta. Latinoamérica es la región del planeta donde más rápido progresó, adoptada en un primer lugar por organizaciones no gubernamentales (ONGs) con una propuesta de desarrollo rural construida de "abajo hacia arriba", de manera participativa y en base a los saberes y recursos locales (Rosset y Altieri 2018).

La historia latinoamericana y el surgimiento de la agroecología en esta región explican en gran medida las características de las experiencias agroecológicas desarrolladas en nuestro país. En Argentina, al igual que en el resto de Latinoamérica, ha sido importante la mirada sobre Agroecología propuesta por el marco teórico conceptual desarrollado por especialistas como Miguel Altieri y Eduardo Sevilla Guzmán.

La línea seguida por Altieri entiende a la agroecología como una disciplina científica que provee los conocimientos para la utilización de principios ecológicos básicos que permiten estudiar, diseñar y manejar agroecosistemas (Altieri y Nicholls 2000), de esta forma se busca favorecer procesos naturales e interacciones biológicas que optimizan sinergias, de modo tal que la agrobiodiversidad sea capaz de subsidiar por si misma procesos claves tales como la acumulación de materia orgánica, la fertilidad del suelo, los mecanismos de regulación biótica de plagas y la productividad de los cultivos (Gliessman 1998 en Altieri y Nicholls 2007). Para favorecer una transición a agroecosistemas de estas características es importante tener en cuenta que las funciones ecológicas que sustentan los servicios ecosistémicos de soporte y regulación operar a escalas más amplias que campos agrícolas o explotaciones individuales; lo cual implica pensar el diseño de agroecosistemas desde un enfoque de paisaje, para lo cual se requiere de la toma de decisiones colectiva (Tittonell 2014).

Desde otro enfoque, Sevilla Guzmán, plantea que la Agroecología funciona siguiendo tres dimensiones: una primer dimensión, que abarca los aspectos ecológicos y técnicoproductivos; una segunda dimensión que podríamos llamar de "desarrollo local", con una impronta más económica, basada en la búsqueda de soluciones y en el acceso a los recursos que permitan condiciones de vida adecuadas; y por último, una dimensión cultural y política, donde se integra a los movimientos sociales en la búsqueda de alternativas al sistema capitalista imperante que promueve la desigualdad social, llevando a grandes sectores de la sociedad a la marginalidad, impidiendo vivir dignamente. Además de las dimensiones definidas en función de criterios técnico científicos, esta concepción de la agroecología se apoya fundamentalmente en la sabiduría local campesina e indígena, es decir, en su construcción popular (Cuellar y Sevilla Guzmán 2010 en Broccoli 2011), promoviendo un "diálogo de saberes" en el cual no existe preeminencia de alguno de ellos sino una horizontalidad entre ambos (Broccoli 2011). Esto ha motivado que los movimientos 
sociales, campesinos e indígenas se apropien de esta noción en sus luchas por la instalación de otro modelo productivo de base agroecológica.

La Vía Campesina es contundente en este sentido, la agroecología es para este movimiento internacional un modo fundamental de resistencia al sistema capitalista, que sitúa el beneficio económico por delante de la vida. Según La Vía Campesina, los movimientos sociales usan la agroecología para desafiar los actuales esquemas de poder (como lo son la concentración de tierra y los monopolios), para resistir los múltiples ataques a la vida en las zonas rurales y sobre la Madre Tierra, y como una herramienta para la transformación social, económica, cultural, política y ecológica de las comunidades y los territorios. Este movimiento hace, a su vez, una fuerte crítica al uso que hacen de la agroecología ciertos sectores políticos, académicos y empresariales. En este sentido, sostienen que la presión popular ha propiciado que múltiples instituciones, gobiernos, universidades y centros de investigación, algunas ONG (Organizaciones No Gubernamentales) y demás organizaciones, finalmente reconozcan la importancia de la agroecología; sin embargo, estos actores han tratado de redefinirla como un conjunto exiguo de tecnologías, para ofrecer así algunas herramientas que aparentan mitigar la crisis de sostenibilidad de la producción alimentaria industrial, mientras las estructuras existentes de poder permanecen incólumes (La Vía Campesina 2016). Esta cooptación de la Agroecología ha recibido diversos nombres, tales como "agricultura adaptada al cambio climático", "intensificación sostenible" o "ecológica", producción industrial en monocultivo de alimentos "orgánicos", etc.

"Nosotros no reconocemos estas prácticas como Agroecología...las soluciones reales a las crisis climáticas, de desnutrición, etc., no pueden partir de un sometimiento al modelo industrial...nosotras/os contemplamos [la Agroecología] como una alternativa esencial a ese modelo y como el medio para transformar la manera en que producimos y consumimos los alimentos en algo mejor para la humanidad y para nuestra Madre Tierra". (La Vía Campesina 2016).

Finalmente sostienen:

"la Agroecología es política; exige que desafiemos y transformemos las estructuras de poder en la sociedad. Debemos poner el control de las semillas, la biodiversidad, la tierra y los territorios, el agua, el conocimiento, la cultura y el Bien Común en manos de los pueblos que alimentan al mundo" (La Vía Campesina 2016).

Algunas autoras, como Broccoli (2011), reflejan la complejización que ha tenido la noción de agroecología en los últimos años y la influencia de esta en las organizaciones 
sociales y de productores en Argentina y en la región. Desde este punto de vista, se presenta el enfoque poniendo en valor las dimensiones ambiental, socioeconómica, sociocultural y política, que el sistema productivista desestima totalmente; proponiendo una democratización y la toma de decisiones comunitarias respecto a la calidad de nuestra alimentación. En un contexto mundial en el cual la mitad de la población vive en centros urbanos, desde esta perspectiva se busca la construcción de sistemas agroalimentarios basados en la sustentabilidad de la producción y comercialización, apoyados en movimientos sociales con un alto grado de autonomía, equidad, y valorización de la diversidad natural y biocultural, condiciones que, en su conjunto, favorecen la soberanía alimentaria.

En la presente tesis me basé en las nociones de agroecología planteadas por autores como Sevilla Guzmán, La Vía Campesina y Broccoli, entre otros; entendiendo que estas definiciones son concepciones amplias, integradoras, que trascienden la mirada de la unidad productiva y las prácticas de quienes trabajan la tierra. Esta mirada permite realizar un abordaje territorial y multiescalar, desarrollando una mayor comprensión de los múltiples procesos y actores que a distintos niveles influyen en el desarrollo de un territorio productivo; pudiendo arribar a soluciones que contemplen la complejidad del territorio. Desde esta mirada, para promover un territorio donde la producción de alimentos se lleve adelante de manera agroecológica, es necesario contemplar no solo los aspectos técnicoproductivos, sino que debemos incorporar políticas públicas tendientes a mejorar los procesos de comercialización, la generación y/o conservación de ambientes saludables donde halla posibilidades de esparcimiento y recreación. Es necesario también pensar desde el ordenamiento territorial estrategias de valorización de la actividad productiva respetando y revalorizando las diversidades culturales y promoviendo la integración social. Finalmente, se requiere también promover estrategias organizativas tanto desde las familias productoras como desde la comunidad en general como consumidora de los alimentos que en cada territorio se generan, en pos de avanzar hacia la soberanía alimentaria. Para avanzar en este sentido se deben dar cambios en todo el sistema agroalimentario, incluyendo a los sistemas de producción y toda la cadena de valor alimentaria; la transición hacia la agroecología requiere que tanto las transiciones en pequeña escala como los cambios estructurales de las instituciones y normas en mayor escala se lleven a cabo de manera coordinada e integrada (HLPE 2019). La agroecología tal como ha sido planteada anteriormente, propone un enfoque alternativo al de la ciencia convencional para el desarrollo rural. El sistema agroalimentario actual ha venido a romper el equilibrio propio de los sistemas agrarios tradicionales vinculados a comunidades campesinas; ante esta realidad la agroecología proponer un desarrollo rural alternativo, a partir de la recuperación de los elementos culturales y ecológicos positivos asociados al campesinado, 
enriqueciéndolos a través del diálogo con distintas disciplinas científicas sociales y naturales (Sevilla Guzmán y Montiel 2009).

La agroecología viene ganando reconocimiento a nivel mundial (IPES-Food 2016, HLPE 2019), incluso por organismos internacionales como la FAO; lo cual tiene sus ventajas pero también sus peligros, como el riesgo de ser desprovista de sus principales contenidos, simplificada a unos pocos contenidos técnicos y transformada en un concepto vacío, como ocurrió con el desarrollo sustentable (Rosset y Altieri 2018). Más allá de este aspecto, son abundantes las investigaciones científicas que demuestran su factibilidad y los múltiples beneficios que genera, y varios los casos en los que la implementación de prácticas agroecológicas ha crecido más allá de experiencias locales aisladas (Mier et al. 2019). Como resultado de estos avances, hoy nos encontramos frente al desafío de ir hacia un proceso de escalonamiento que conduzca a la masificación de la agroecología como modelo productivo y de desarrollo territorial. Este proceso de masificación es entendido como el proceso que lleva a incrementar el número de familias que practican la agroecología y a ampliar el territorio bajo este paradigma productivo; pero que también involucra a más personas en el procesamiento, distribución y consumo de alimentos producidos agroecológicamente (Mier et al. 2019).

Mier et al. (2019) identifican 8 impulsores claves en el proceso de llevar la agroecología a mayor escala: (1) el reconocimiento de una crisis que motiva la búsqueda de alternativas, (2) la organización social, (3) el procesos de aprendizaje constructivista, (4) las prácticas agroecológicas efectivas, (5) los discursos movilizadores, (6) los aliados externos, (7) los mercados favorables y (8) oportunidades políticas y marcos políticos favorables; y que serán tenidos en cuenta a lo largo de esta tesis. Rosset y Altieri (2018) destacan que para superar los obstáculos que impiden el escalamiento de la agroecología, se requiere organización, sin la cual no se puede ejercer la presión necesaria para cambiar las políticas, para generar los cambios necesarios en los planes de estudio, ni para la construcción de procesos efectivos de transmisión horizontal de los conocimientos.

Contrariamente a la idea extendida de que la agricultura industrial es la única capaz de producir suficientes alimentos para alimentar a todo el planeta, las evidencias empíricas demuestran que las quintas de familias campesinas manejadas con métodos agroecológicos pueden ser tan (o más) productivas que la agricultura industrial (Rosset y Altieri 2018). Al mismo tiempo, al promover el aumento de la diversidad estructural y funcional, fomentar los sistemas de pensamiento adaptativo, ampliar la participación y promover sistemas de governanza policéntricos, entre otros aspectos (Biggs et al. 2012), la agroecología genera agroecosistemas mas resilientes, capaces de recuperarse aun después de sufrir perturbaciones ambientales como una sequia o una tormenta, así como perturbaciones producto de la actividad humana, como un incremento repentino de los precios del petróleo o una escasez de insumos externos (Nicholls y Altieri 2012) permitiendo mantener la 
producción de alimentos. Desde una mirada de paisaje, Rosset y Altieri (2018) plantean que una matriz agrícola compuesta de pequeñas fincas sostenibles intercaladas con áreas de bosque y vegetación rupestre puede constituirse en una solución capaz de enfrentar tanto la crisis alimentaria actual, como la crisis de biodiversidad.

\subsection{Ecología del paisaje}

La Ecología del Paisaje es una disciplina relativamente nueva, surgida en la década del 60' en Europa, que ha sido conformada con el aporte de muchas otras disciplinas, como la geografía, la ecología y la arquitectura, entre otras. Esta disciplina estudia la estructura, la función y el cambio en una superficie de tierra determinada, compuesta por ecosistemas heterogéneos e interactuantes. A su vez, la ecología del paisaje aborda el estudio de los efectos que tienen los patrones espaciales de los ecosistemas sobre los procesos ecológicos, a diferentes escalas espaciales y temporales. Otro aspecto importante que aborda esta disciplina tiene que ver con los efectos que el patrón espacial y los cambios en la estructura del paisaje (por ejemplo, la fragmentación del hábitat) tienen sobre la distribución, circulación y persistencia de las especies.

El concepto de paisaje es un concepto muy dinámico y aún en construcción, por lo que existen diversas definiciones, dependiendo del enfoque disciplinar. Algunas definiciones priorizan lo geográfico, morfológico, económico y ecológico, mientras que otras hacen hincapié en lo percibido, socializado y construido (Medico 2016). Las nociones de paisaje más clásicas y más difundidas entre la población, son aquellas que lo conciben como un género pictórico con reglas específicas de composición, o desde el punto de vista del diseño de espacios exteriores y la reconstrucción deliberada de cierta naturaleza a través de los parques y jardines. Desde otro enfoque, el geógrafo Santos (2000) define al paisaje como el "conjunto de formas que en un momento dado expresa las herencias que representan las sucesivas relaciones localizadas entre hombre y naturaleza", entendiéndolo como un sistema material, relativamente inmutable, cuyas formas han sido creadas en momentos históricos diferentes y que coexisten en el momento actual; este autor a su vez hace una diferenciación entre paisaje y espacio y entre paisaje y configuración territorial. La Convención Europea del Paisaje realizada en el año 2000, considera por su parte, que paisaje es cualquier parte del territorio tal como la percibe la población, cuyo carácter sea el resultado de la acción y la interacción de factores naturales y/o humanos; una visión que involucra la percepción social como condición para definir el paisaje (Medico, 2016). El geógrafo Nogué (2007), por su parte, sostiene que paisaje es un concepto integrador donde no solo la morfología territorial importa sino, además, hay miradas, vivencias, proyecciones de los habitantes que configuran el paisaje. Desde el marco teórico de la ecología de paisaje, el significado científico de paisaje ha sido modificado numerosas veces. Inicialmente, el paisaje era entendido como la superficie de la tierra y sus hábitats asociados 
a escalas que van desde pocas hectáreas a muchos kilómetros cuadrados (Turner 1989), una definición sencilla que posteriormente se fue complejizando. Silvia Matteucci, una investigadora de gran trayectoria en el campo de la ecología del paisaje, considera más apropiado el concepto que entiende al paisaje como "un territorio genéticamente homogéneo, en el cual se observa la recurrencia regular y típica de las mismas combinaciones de interrelaciones entre estructura geológica, forma de relieve, agua superficial y subterránea, microclima, variedades de suelo y fito y zoocenosis (comunidades vegetales y animales)". Para comprender mejor los alcances de esta definición existen, según esta autora, cuatro condiciones que un paisaje debe cumplir para ser considerado como tal: 1) el mismo conjunto de ecosistemas (y usos de la tierra) se repite a través del espacio; 2) los flujos o interacciones entre los ecosistemas que conforman el paisaje son los mismos en todas las interfaces; 3 ) en toda su extensión está sujeto el mismo tipo climático y tiene geología común; esto es, la misma roca madre y origen común, por lo tanto igual conjunto de geoformas; y 4) está sometido a un conjunto único de regímenes de perturbación (Matteucci 2004).

Turner (1989), a su vez, diferencia tres características del paisaje de utilidad para su estudio: la estructura, la función y el cambio. La estructura hace referencia a las relaciones espaciales entre ecosistemas particulares, es decir, la distribución de energía, materiales y especies en relación con los tamaños, las formas, los números, los tipos y configuraciones de los componentes. En cuanto a la función, esta se refiere a la interacción entre los elementos espaciales, es decir, el flujo de energía, materiales y organismos entre los componentes de los ecosistemas. Por último, el cambio se refiere a la alteración en la estructura y función del mosaico ecológico a través del tiempo.

Otra definición muy utilizada en ecología del pasaje es la de mosaico. Según Matteucci (2004), un mosaico, a diferencia del paisaje, es independiente de su tamaño, origen, evolución o condiciones climáticas, y puede ser recurrente o no, natural o humanizado; puede ser una región, un paisaje, una parcela, un municipio y está delimitado por el investigador en función de los objetivos de su trabajo. La flexibilidad de este concepto hace que en muchas investigaciones de ecología del paisaje se prefiera este término.

Se entiende que todo mosaico (o paisaje) está conformado por diferentes elementos, los cuales tienen un ordenamiento en el espacio, un patrón espacial (sinónimo de configuración y de estructura espacial). Los elementos son unidades territoriales que, independientemente de su tamaño, forma y contenido, son internamente homogéneas a la escala de observación y diferentes de los elementos vecinos en cuanto a su contenido (Matteucci 2004). Forman (1995) propuso para analizar la estructura de un mosaico el modelo "matriz-parche-corredor", el cual sigue vigente en la actualidad. Según este modelo los elementos del mosaico se clasifican en matriz, parche y corredor, dependiendo de sus características físicas y funcionales. Los parches son unidades espaciales relativamente 
singulares en relación con el entorno, y su rol en el mosaico depende de su tamaño, su contenido, su forma y las propiedades de su borde. La matriz constituye la base del mosaico, es el tipo de ecosistema en el cual se insertan los parches y corredores, y suele estar constituida por el ambiente original y dominante; sin embargo, en casos de ambientes muy modificados, esta puede estar constituida por un nuevo ambiente definido por la actividad humana, y el ambiente original quedar reducido a parches aislados (ej. zonas donde domina el monocultivo de soja extensivo). La matriz puede funcionar como corredor o como barrera entre parches de acuerdo al grado de contraste de contenidos entre parches y matriz, y a los hábitos de cada especie (Matteucci 2004). Los corredores son fragmentos alargados que atraviesan el mosaico y cuyo contenido difiere del de los elementos vecinos, pueden ser naturales (por ejemplo cursos de agua) o antrópicos (por ejemplo vías de comunicación o cortinas forestales); su rol en el mosaico es incrementar la conectividad del mismo facilitando los flujos de materia y energía. Durante mucho tiempo, la matriz fue considerada como un elemento del mosaico relativamente homogéneo y en cierto modo ecológicamente neutro, donde irrumpían los parches y corredores; sin embargo, en la actualidad se está reviendo su rol, ya que se ha visto que esta puede influir en el grado de aislamiento de los fragmentos, debido a que su estructura puede actuar facilitando o impidiendo el movimiento de los organismos a través del mosaico (Herrera 2010).

Poder interpretar un paisaje es importante porque los arreglos espaciales (también llamados patrones espaciales) de los distintos elementos que componen un paisaje y los cambios en su estructura influyen en los flujos y transferencias de organismos, materiales y/o energía entre dichos elementos (Risser y otros 1984, Forman 1989), afectando la biodiversidad y los servicios ecosistémicos que esta provee; por este motivo, el modelo de matriz-parche-corredor es de gran utilidad para la planificación del uso del suelo (Forman 2008). A su vez, la calidad de los servicios ecosistémicos depende en gran medida de las condiciones en las que se encuentren los sistemas naturales y el manejo que se haga de los mismos. El uso del suelo y el tipo de coberturas vegetales (agrícolas y naturales) son aspectos importantes a ser analizados, ya que su distribución a nivel espacial y temporal pone de manifiesto el ritmo productivo de una región, la estabilidad de los agroecosistemas y sus capacidades de brindar servicios ecosistémicos (Volante et al. 2009). Otro aspecto importante para analizar del paisaje es la heterogeneidad, ya que el grado de heterogeneidad se vincula a su vez con la biodiversidad. En este sentido, como describen Fahrig et al. (2011), es posible diferenciar entre heterogeneidad composicional (un paisaje con una gran variedad de diferentes tipos de coberturas) y heterogeneidad configuracional (cuando los patrones espaciales de los diferentes tipos de coberturas se organizan de manera mas compleja). Por otro lado, es importante distinguir en las investigaciones de ecología del paisaje entre aquellas que hacen foco en la heterogeneidad estructural del paisaje, donde los distintos tipos de cubierta son identificados por sus características físicas, 
sin referencia a una determinada especie o grupo de especies, y aquellos focalizados en la heterogeneidad funcional del paisaje, donde los distintos tipos de coberturas se identifican en función de las diferencias en las demandas de recursos, de especies o grupos de especies (Fahrig et al. 2011). En este último caso es necesario tener en cuenta que tipos de coberturas que podemos considerar como diferentes no necesariamente son funcionalmente diferentes para estos grupos de especies. A su vez, los paisajes agrícolas cuentan con un grado más de complejidad, ya que coberturas que en principio podrían considerarse homólogas, pueden tener diferencias sustanciales a nivel funcional. Así, en paisajes agrícolas más intensivos (como es el caso del Cinturón Hortícola Platense) prácticas como la aplicación de plaguicidas, el manejo de suelos, la aplicación de fertilizantes y la historia productiva del lugar pueden tener grandes efectos en la calidad tanto de los parches manejados como de los parches más naturales cercanos (Fahrig et al. 2011).

En la presente tesis, y por ser esta el primer análisis que se realiza de este tipo y desde este marco teórico en el CHP, abordé aspectos de la estructura del paisaje principalmente vinculados a su composición, que se pretenden profundizar posteriormente incorporando análisis de aspectos configuracionales.

El crecimiento poblacional, la expansión urbana sobre ambientes naturales, el deterioro de los suelos, la pérdida de biodiversidad, el agotamiento de los "recursos naturales" no renovables, la falta de acceso a alimentos de una parte importante de la población, son algunos de los grandes problemas que estamos viviendo a nivel mundial, desde pequeños pueblos hasta grandes ciudades, países, regiones. Para abordar la resolución de problemas tan amplios como los mencionados anteriormente, orientar las investigaciones y esfuerzos de gestión a escalas espaciales como paisajes y regiones, pareciera ser la opción más prometedora, combinando la posibilidad de tener efectos visibles del esfuerzo y al mismo tiempo una oportunidad razonable de éxito (Forman 2008). La ecología del paisaje es una disciplina cada vez más valorada e incorporada en los procesos de planificación del territorio, contribuyendo a obtener planificaciones eficaces. Su cualidad radica en ser una disciplina que trabaja a una escala espacial adecuada, que explícitamente integra a la naturaleza y las personas, cuyos principios son válidos para múltiples escenarios (desde el paisaje urbano, los bosques y tierras de cultivo, al desierto), con un lenguaje espacial simple, que facilita la comunicación respecto de los usos del suelo entre los decisores, profesionales y estudiosos de muchas disciplinas (Forman 2008). Este autor plantea la necesidad de cambiar la antigua tradición de planificación del territorio, basada en el desarrollo económico y de infraestructura, para comenzar a pensar la planificación del territorio partiendo de analizar de qué forma podemos dar un mejor uso a los principales y muchas veces escasos recursos naturales locales para el futuro de una región. 
En las últimas décadas, y en estrecha vinculación con el crecimiento de las grandes ciudades y las áreas periurbanas, vienen creciendo los estudios vinculados al diseño de paisajes, relacionados con propuestas de planificación de la agricultura urbana y periurbana y con el desarrollo de estrategias para incrementar los espacios verdes en estas grandes ciudades, junto con la biodiversidad y los servicios ecosistémicos asociados (ej: Uy y Nakagoshi 2008, Yang y Jinxing 2007, Tian et al. 2011, Szlavecz et al. 2011, Vergnes et al. 2013).

La solución de los problemas ambientales suele requerir una comprensión de los aspectos físicos y ecológicos de los sistemas ambientales, y de la forma en la que interactúan con los factores económicos, sociales y políticos; la ecología del paisaje aporta con sus herramientas a esta visión integrada (Haines-Young y Green 1993).

Una herramienta fundamental en los estudios de ecología del paisaje es la teledetección; la misma es un excelente complemento de los trabajos de campo, facilitando la obtención de datos sobre zonas de difícil acceso, además de brindar información a un bajo costo, con una cobertura global y periódica de la superficie terrestre (Chuvieco 1990). Actualmente existen bases de datos espaciales que cubren prolongados períodos de tiempo, facilitando el seguimiento de múltiples fenómenos naturales, la detección de cambios en la superficie terrestre y la integración de datos espaciales para análisis relacionales y de causalidad entre variables (Liu et al. 2012, Martínez-Vega et al. 2010, Verbesselt et al. 2010). Al trabajar con datos espaciales, los estudios de ecología del paisaje requieren del procesamiento de grandes volúmenes de datos y su integración con datos de otras fuentes. El desarrollo de los sistemas de información geográfica (SIG) para la manipulación de datos geográficos o espaciales, permitió trabajar mucho más fácilmente a escala regional, con datos sobre la superficie de la Tierra y su cubierta que hasta hace unos años eran difíciles de obtener, costosos y requería de mucho tiempo (Haines-Young y Green 1993).

En nuestro país vienen teniendo un importante crecimiento las investigaciones en ecología del paisaje, y especialmente aquellas vinculadas al manejo de áreas productivas, haciendo un importante aporte a la gestión sustentable de estos territorios (ej: Drozd y otros 2010, Eliano y otros 2010, Silva 2003, Torrella y otros 2007, Dadon y Matteucci 2002, Pacha et al 2007, Argañaraz et al. 2015, Vázquez et al. 2017, Piquer-Rodríguez et al. 2018, Sans et al. 2018).

\subsection{Territorio}

Al igual que con el término paisaje, existen diversas acepciones para referirse al territorio. En el presente trabajo nos referimos al territorio concebido como el espacio construido por los sujetos en su devenir histórico, resultado de la interacción de las sociedades con la materialidad, un espacio dinámico, en permanente proceso de creación o redefinición (Ceceña 2012); formado a partir de la apropiación, del uso y dominio por elementos y 
procesos económicos, culturales, políticos y ambientales, y que por lo tanto tiene un carácter multidimensional (Saquet 2015). Desde esta perspectiva, las territorialidades creadas, los modos de ordenamiento, uso y convivencia de los elementos que componen el territorio, dependen de la concepción del mundo y de los fundamentos sobre los que se erige la sociedad. El territorio entendido de este modo no es sólo el lugar de asiento de la cultura, y a la vez su resultado, sino que es el espacio de disputa civilizatoria más profundo y más abarcante (Ceceña 2012). En este sentido, cada proyecto territorial implica una negociación, en la que los grupos de poder ven las atracciones, los riesgos, el precio a pagar y las ventajas. A su vez, el territorio no se moldea exclusivamente por los procesos locales, en él existen relaciones internas y externas, que forman redes que ligan individuos y lugares en niveles trans-multiescalares (Saquet 2015). En el presente, los territorios llevan impresas nuevas características que obligan a pensarlos como territorios de la globalización (Manzanal 2014). Como resultado del proceso de globalización capitalista, en el territorio existe una constante relación entre lo que se denomina las "localidades" y las "globalidades", generando procesos de desterritorialización y reterritorialización concomitantemente. En la actualidad, como resultado de la fuerte influencia del proceso de desterritorialización, se comienza a hablar de un sistema-mundo "glocalizado", donde lo local experimenta los efectos de una estrategia de globalización que excluye y aniquila la vida de millones de seres humanos y que provoca desastres ecológicos (Coraggio 2009). Es importante considerar, como plantean Rosset y Altieri (2018), que las relaciones sociales generan territorios y espacios que se reproducen en situaciones de conflicto, lo que origina espacios de dominación y espacios de resistencia; y que además, la disputa territorial se lleva a cabo en todos los frentes posibles: económico, social, político, cultural, teórico e ideológico (Rosset y Altieri 2018). No existen territorios materiales en disputa que no estén asociados a la contestación de los territorios inmateriales; la disputa sobre los territorios reales y tangibles y sus recursos va necesariamente en paralelo con la disputa sobre los territorios inmateriales, es decir, los espacios de la ideología y las ideas (Rosset y Altieri 2018)

El territorio está atravesado por relaciones de poder y de dominación, más o menos explícitas; relaciones asimétricas, de desigualdad entre los diversos actores, a partir del control diferencial de ciertos recursos (económicos, de información, ideológicos, científicostecnológicos); y en él, la producción social del espacio no es otra cosa que el resultado del ejercicio de relaciones de poder (Manzanal 2014). A su vez, los diferentes modos en que los actores utilizan su territorio son un reflejo de las diferentes formas en que estos valoran la naturaleza (Botana 2004).

\subsection{Ordenamiento Territorial}

En base a lo expuesto anteriormente, se evidencia cómo en función de la noción de territorio que se tenga en consideración, se podrán desarrollar estrategias de planificación muy 
diferentes. Las estrategias tradicionales de ordenamiento territorial (OT) son estrategias que suelen estar construidas de manera verticalista, con una mirada fragmentada del territorio y sesgada a los intereses y necesidades de unos pocos actores, desconociendo la historia local y los intereses y necesidades de la población, habitualmente focalizadas en el desarrollo urbano-industrial. Este tipo de estrategias, con el paso del tiempo, suele dejar al territorio en manos del mercado, por lo que se las puede denominar como estrategias de "des-planificación territorial"; generando territorios donde existe una dejadez de planificación (o sea una ausencia de voluntad de planificar), y donde el uso del suelo es muchas veces librado a los modelos macroeconómicos. En estos escenarios de des-planificación lo que se evidencia es la construcción capitalista del territorio, afianzando las condiciones de apropiación y las relaciones de poder, imposibilitando otras formas de vivir, rediseñando el espacio, disciplinándolo, reduciéndolo a sus elementos simples, y al mismo tiempo descomponiéndolo (Ceceña 2012). Desde otra concepción, que entiende al territorio como espacio de movilización, organización, lucha y resistencia política; y donde la territorialidad como praxis de transformación del territorio, se construye en la búsqueda de autonomía, justicia social, distribución de la riqueza, protección ambiental (Saquet 2015); podemos entender al OT como un instrumento de "gobernanza y planificación del desarrollo sustentable", concebido desde una perspectiva sistémica, prospectiva, democrática y participativa; tratando de reducir los procesos de subordinación y explotación, así como también los de concentración de riqueza, centralización de poder y degradación del ambiente (Saquet 2015).

En Argentina, se desarrollaron dos planes estratégicos a nivel nacional, que involucran aspectos territoriales y que habrían sido construidos de manera participativa: el Plan Estratégico Agroalimentario y Agroindustrial Participativo y Federal 2010-2020, generado en el año 2009 por el entonces Ministerio de Agricultura Ganadería y Pesca de la Nación (MAGyP) y el Plan Estratégico Territorial Argentina 2016, llevado adelante por el Ministerio de Planificación Federal, Inversión Pública y Servicios en dicho año.

“El Plan Estratégico Agroalimentario y Agroindustrial Participativo y Federal 2010-2020, apunta a posicionar al país como líder mundial en la producción de bienes y servicios agroalimentarios y agroindustriales, con valor agregado, asegurando tanto la provisión de alimentos a nivel nacional, como la demanda de los mercados internacionales, en un marco de equidad territorial, inclusión social y sustentabilidad ambiental, económica y social, promoviendo el desarrollo de la Nación y sus regiones" (Paruelo et al. 2014: 5).

A nivel nacional existe también un proyecto FAO TCP/ARG/3302 llamado "Fortalecimiento de las capacidades que permitan abordar los procesos de Ordenamiento Territorial Rural de forma participativa e iterativa", en articulación con el Instituto Nacional de Tecnología Agropecuaria (INTA) y la Facultad de Agronomía de la Universidad de Buenos Aires. A través de este proyecto se buscó generar capacitaciones para el diseño de planes 
de ordenamiento territorial y conformar una guía metodológica para la aplicación de estos procesos en todo el país (Paruelo et al. 2014). Otro hito a nivel nacional que destacan estos autores es la generación del documento "Bases para el ordenamiento del territorio rural argentino" generado en el año 2010 por la entonces Secretaría de agricultura y pesca, junto con el INTA, la Facultad de Agronomía de la Universidad de Buenos Aires, la Universidad de Mar del Plata y la Universidad de San Luis.

El INTA ha tenido un rol activo en estos procesos, y entre varias iniciativas, el Programa Nacional Ecorregiones, apuntó a contribuir mediante procesos, técnicas e información estratégica con el Ordenamiento Territorial Rural.

Desde las esferas públicas y en el momento en el que se desarrollaron estas diversas iniciativas, el Ordenamiento Territorial (OT) fue definido como:

“Un proceso político-técnico-administrativo orientado a la organización, planificación y gestión del uso y ocupación del territorio, en función de las características y restricciones biofísicas, culturales, socioeconómicas y político-institucionales. Este proceso debe ser participativo e interactivo y basarse en objetivos explícitos que propicien el uso inteligente y justo del territorio, aprovechando oportunidades, reduciendo riesgos, protegiendo los recursos en el corto, mediano y largo plazo y repartiendo de forma racional los costos y beneficios del uso territorial entre los usuarios del mismo" (MAGyP 2012: 19).

Para interpretar los diferentes territorios y avanzar en procesos de OT, un abordaje que proponen Paruelo et al. (2014) es el de sistemas territoriales entendidos como Sistemas Socio-Ecológicos (SSE). Una definición de SSE es aquella que los concibe como sistemas sociales "en los cuales las relaciones de interdependencia entre humanos están mediadas por interacciones con componentes biofísicos y biológicos no humanos" (Anderies et al. 2004 en Paruelo et al. 2014). Según López et al. (2018) un SSE se compone de una unidad biofísica asociada con los actores sociales y las instituciones; en este sentido, un sistema agrícola (por ejemplo agricultores, ganaderos) puede analizarse como un SSE, ya que incluye una unidad de tierra administrada por una familia o propietario cuyo objetivo es producir bienes y servicios agroforestales. Según estos autores, el SSE-agrícola familiar representa la unidad mínima donde se toman las decisiones, está integrado por los atributos biofísicos de una determinada unidad de tierra y un hogar rural que gestiona la unidad de producción, que también está vinculado con las redes sociales, y se lo puede desagregar en cinco sub-sistemas que representan distintos medios de subsistencia de los hogares rurales: natural, humano, social, fabricado y financiero. Para alcanzar SSE resilientes Nelson et al. (2007) sostienen que los sistemas sociales y ecológicos no pueden ser considerados en ausencia uno del otro, sino que deben entenderse como sistemas acoplados; y que estos sistemas suelen enfrentarse a cambios, por lo que deben ser manejados de manera de proporcionar flexibilidad durante las épocas de disturbios, permitiendo aprovechar la diversidad latente dentro del sistema y la gama de oportunidades presentes con 
posterioridad a los disturbios. Finalmente, López et al. (2018) sostienen que ningún sistema puede ser entendido o gestionado centrandose en una sola escala, ya que los SSE agrícolas no están aislados en el paisaje, sino que comparten algunos recursos y están conectados por flujos de materia y energía, y/o por redes sociales con otros SSE que habitan el mismo paisaje. A su vez, estos autores destacan que las decisiones de gestión adoptadas en el plano local pueden afectar gravemente a la resiliencia de SSE a nivel de paisaje, por lo tanto, es esencial adoptar una perspectiva analítica más amplia, considerando los posibles impactos de las prácticas de gestión en otros SSE dentro del paisaje; y. Bestelmeyer et al. (2012) sostienen que en el nivel SSE de paisaje, las prácticas de gestión deberían coordinarse con los otros usuarios del paisaje, incluidos los distintos SSEs agrícolas, para evitar un aumento de la vulnerabilidad de estos SSEs y la degradación de todo el paisaje. Esta mirada de SSE ha sido incorporada en ciertos proyectos del INTA vinculados por ejemplo al ordenamiento ambiental en zonas rurales (ej: Cavallero et al. 2019).

Otro aspecto que es importante destacar al abordar las políticas que se han tenido desde instituciones estatales en relación al ordenamiento territorial rural es el del enfoque de Desarrollo Territorial Rural (DTR). En el INTA particularmente, este enfoque se incorpora de manera temprana a partir del Programa Federal de Apoyo al Desarrollo Rural Sustentable (ProFeder) (INTA 2007). La incorporación de este enfoque habría implicado un cambio paradigmático en términos de cómo se concibe el territorio, entendido no ya como un espacio productivo únicamente, sino tomando en cuenta la globalidad del mismo (Ambort 2016). Según esta autora, si bien esta línea de trabajo más ligada a lo social es incipiente y minoritaria dentro de la institución, en la región de La Plata el enfoque de desarrollo territorial tuvo mayor difusión conformándose como una línea prioritaria de intervención; así el espacio productivo no es pensado ya de manera aislada, sino como parte de un territorio, involucrado con la política local y con una multiplicidad de actores sociales, poseedor de una identidad y una historia.

Más allá del aporte que implicó la incorporación del DTR en instituciones públicas que tenían tradicionalmente un abordaje muy fragmentado del territorio, este enfoque es cuestionado desde distintos sectores académicos especializados en el territorio y las políticas públicas de planificación. Siguiendo a Manzanal (2014), el DTR emergió como una alternativa superadora de las tradicionales metodologías de intervención pública (y privada) para el desarrollo de áreas rurales pobres, y fue incorporado por diversos organismos internacionales de cooperación, teniendo como meta lograr que los territorios sean competitivos, fortaleciendo entre otros aspectos la articulación con los mercados globales y el desarrollo institucional como forma de alcanzar la cohesión social. EI DTR se basa en el desarrollo económico local derivado de la literatura sobre clusters y contextos competitivos, junto con la literatura sobre economía institucional; las estrategias de desarrollo rural 
deberían contemplar desde esta perspectiva los conceptos de economías de escala, entornos de aprendizaje y gobernanza (Ruiz Rivera y Delgado Campos 2008 en Souto et al. 2011). Manzanal (2014) cuestiona este enfoque por considerar que no tiene en cuenta la carencia de recursos humanos, ambientales y materiales característica de los ámbitos rurales pobres de nuestro país, y de América latina en general; una limitante para cualquier tipo de inserción competitiva en el contexto global, salvo particulares excepciones. Además, según esta autora, el DTR ignora las relaciones de poder y dominación presentes en los respectivos territorios y la histórica inserción subordinada de campesinos, productores familiares y trabajadores rurales en la misma; y considera que no necesariamente para generar oportunidades de mejora social en el ámbito rural, se requiera su inserción en mercados dinámicos, por el contrario, el foco según esta autora debe estar en generar políticas públicas permitan ir transformando las relaciones de poder existentes históricamente.

En la presente tesis, se reconocen los avances se han hecho a nivel institucional en cuanto a comenzar a definir una estrategia nacional de OT, de manera articulada entre diversas instituciones y especialistas, estableciendo criterios y estrategias metodológicas comunes para su implementación; se considera sin embargo, que el Ordenamiento Territorial tiene que ir en el sentido de poder superar la visión tradicional de desarrollo, tiene que ser cuestionadora de la aspiración a la "inserción competitiva en el contexto global" como forma de garantizar una sociedad más justa, igualitaria y enfocada en el desarrollo sustentable. Al mismo tiempo, se hace especial hincapié en las relaciones de poder desiguales existentes en todo territorio, y la imposibilidad por ende de pensar en una planificación del territorio desde el "consenso". Por el contrario, se considera que el rol del Estado tiene que ser justamente el de generar condiciones que permitan "neutralizar" el poder de aquellos actores con un rol dominante y con un control diferencial de los recursos locales, favoreciendo el desarrollo de los sectores históricamente oprimidos. Al mismo tiempo, como señala Ostrom (2009) lo que se observa en el mundo es que ni el Estado ni el mercado han logrado con éxito que los individuos mantengan un uso productivo, de largo plazo, de los sistemas de recursos naturales. En este sentido y siguiendo las reflexiones de esta autora, para el caso del CHP, la perspectiva que se desarrolla en esta tesis apunta a avanzar hacia planes de OT que sean gestados de manera colectiva entre quienes forman parte de ese territorio, con un rol activo de las familias productoras, y que los mecanismos de gestión de los bienes comunes y de regulación de las actividades que en ese territorio se desarrollen sean construidos y sostenidos en el tiempo colectivamente, con las instituciones del Estado coordinando y dando apoyo a esos procesos. 


\subsection{Periurbano}

El periurbano es un complejo territorial de difícil definición conceptual y delimitación (recibiendo diversas denominaciones como periferia urbana, rururbano, interface, exurbia, entre otros), un ámbito en constante transformación y de una gran heterogeneidad en los usos del suelo, que con el paso del tiempo se suele extender, relocalizar (Barsky 2013).

El periurbano, asiento de los principales cinturones hortícolas, es un espacio diverso y complejo; que como bien destaca Barsky (2013) se encuentra sometido a una valoración capitalista del suelo, por ser un espacio que puede contribuir con sus tierras, real o potencialmente, a la expansión de la ciudad. El periurbano es un ámbito muy desarrollado en las grandes capitales latinoamericanas, cuyo crecimiento en esta región suele darse de manera no planificada, y que contiene elementos tanto urbanos como rurales; en él se registran una serie de transformaciones relacionadas con diversos procesos de periurbanización, como el fraccionamiento del suelo, subdivisión y venta de campos, loteos para quintas, emprendimientos agroproductivos con tecnologías intensivas, establecimiento de parques industriales y urbanizaciones cerradas de distinto tipo, entre otros (Ávila 2009, Barsky 2007). Ávila (2009) destaca, a su vez, que la práctica de las actividades agrícolas y pecuarias ha adquirido un papel creciente en las zonas periurbanas de las ciudades de casi todo el mundo.

Desde un enfoque ecológico, el periurbano es definido como un ecotono, una zona de transición entre el campo y la ciudad, donde se producen profundas alteraciones ecológicas y ambientales; es una frontera asimétrica en la que la ciudad domina al campo, actuando como un sistema parasitario, que requiere de estas áreas para el suministro de energía y productos, y como receptoras de los residuos que la ciudad genera (Barsky 2013). En estos sistemas de transición entre lo urbano y lo rural, quedan fragmentos de los ecosistemas nativos, entremezclados con ambientes antrópicos, la biodiversidad natural se reduce y se destruyen los controles homeostáticos naturales (Morello y Matteucci 2000).

El sistema periurbano, según Morello, se trata de "una interfase donde se atenúan o disminuyen varios servicios del sistema urbano y también servicios ecológicos, inherentes al campo, como la capacidad de absorber dióxido de carbono, de fijar energía solar en forma de energía química y transformarla en alimentos, de descomponer materia orgánica, reciclar nutrientes, controlar el balance de poblaciones de animales y plantas evitando la explosión de plagas, regular el flujo de agua, atemperar los extremos climáticos a niveles micro y meso climáticos, absorber, retener y distribuir flujos pluviales de corta duración, formar suelo, etc." (Morello 2000: 7 en Botana 2004).

La periurbanización es definida como los procesos de estructuración del espacio periurbano, guiados por la racionalidad de los actores sociales que interactúan; en este sentido, el conjunto de acciones e intereses de estos actores en dicho espacio, generan desajustes o desequilibrios entre la actividad humana y ciertos recursos físicos, 
determinando problemas y conflictos ambientales (Botana 2004). Según Morello y Matteucci (2000), los cambios más dramáticos y más rápidos del paisaje se producen en las fronteras urbano-rurales. Estos autores sostienen a su vez, que los problemas ambientales de las ciudades provienen de su crecimiento espontáneo y de los fenómenos de deterioro que tienen lugar en el periurbano, entre los cuales destacan los asentamientos precarios en los tributarios cercanos a las urbes, la ocupación de los valles de inundación por basurales ilegales a cielo abierto, la contaminación de acuíferos por desechos urbanos y agroquímicos, la falta de adecuación de las redes cloacales y de agua potable, las montañas de residuos sólidos que taponan los desagües, entre otros.

\section{AREA DE ESTUDIO}

\subsection{Características biofísicas}

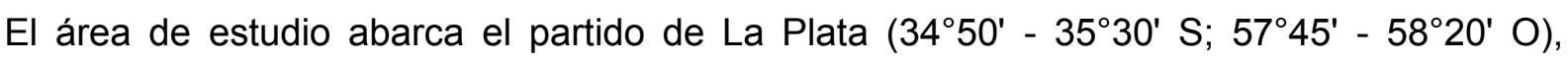
situado en el noreste de la provincia de Buenos Aires, Argentina. El fundamento para la definición del área de estudio basado en los límites del partido se vincula con los alcances de las políticas de gestión y planificación del territorio. El partido de La Plata está limitado por los partidos de Ensenada, Berisso, Magdalena, Brandsen, San Vicente, Florencio Varela y Berazategui, tiene una extensión de 893 km2 y una población de 654.324 habitantes (INDEC 2010), distribuidos en 19 delegaciones municipales (Fig. 1), con una concentración del $98 \%$ en las zonas urbanas (Hurtado et al. 2006). Junto con Ensenada y Berisso forma el denominado Gran La Plata, la sexta aglomeración urbana argentina después de Buenos Aires, Córdoba, Rosario, Mendoza y Tucumán (Bozzano 2014). 


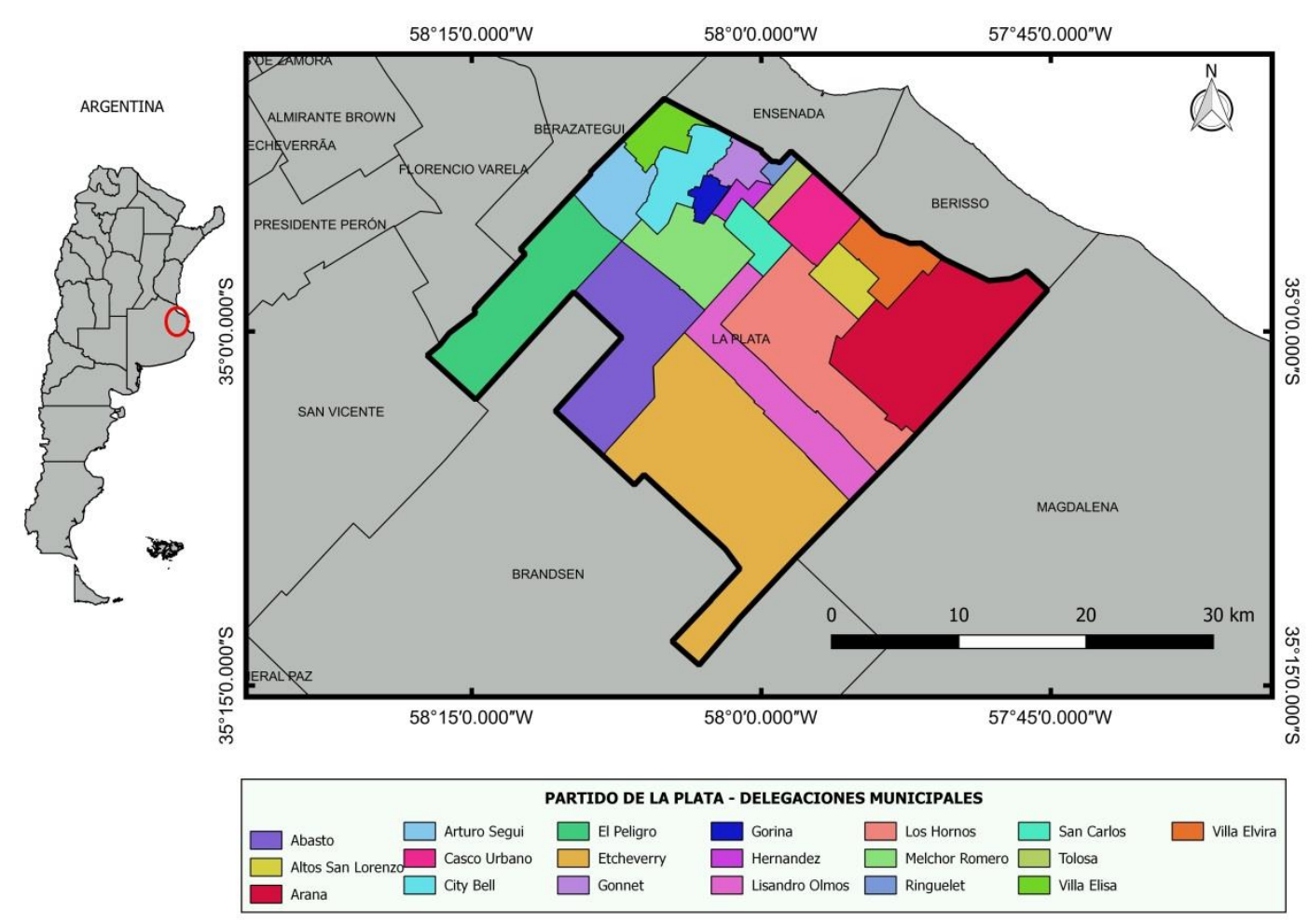

Fig. 1. Localización del área de estudio (partido de La Plata).

El partido de La Plata está situado en el complejo de Pampa Ondulada (eco-región Pampa), (Morello et al. 2012). El clima es subtropical templado húmedo sin estación seca marcada, el total de precipitaciones anuales está entre 1000 y $1200 \mathrm{~mm}$ y la temperatura media anual es de entre 14 y $20{ }^{\circ} \mathrm{C}$ (Morello y Matteucci 1997). Los suelos son predominantemente molisoles, suelos típicamente agrícolas, con un horizonte superficial rico en materia orgánica. La vegetación se encuentra dominada por formas del tipo de las gramíneas (Stipa, Piptochaetium, Aristida, Melica, Briza, Bromus, Poa and Eragrostis) (Matteucci et al. 1999); en los arroyos domina la vegetación herbácea y en las zonas costeras se pueden desarrollar selvas en galería de especies nativas o matorrales ribereños (Morello et al. 2012). La eco-región pampeana es la zona de producción agrícola y ganadera más antigua de la Argentina. Debido al desarrollo prolongado e intensivo de las actividades productivas, el pastizal natural pampeano ha sufrido grandes pérdidas de paisajes, hábitat naturales y biodiversidad, incluidos los insectos polinizadores los cuales desempeñan un papel esencial (Medan et al. 2011).

El área de estudio se caracteriza por la presencia de un acuífero semi-confinado llamado "Puelches", el acuífero principal en la eco-región pampeana. En cuanto a la hidrografía superficial, posee dos vertientes principales, la vertiente del Río de la Plata hacia el norte, con 14 arroyos principales y la vertiente del río Samborombón hacia el sur con un arroyo principal (Morello et al. 2012). Las zonas urbanas y hortícolas son atravesadas por numerosos arroyos que forman parte de la vertiente del Río de la Plata. El partido de La Plata posee suelos de alta calidad para la actividad agrícola, principalmente en las áreas 
ubicadas en los interfluvios de los arroyos de la vertiente que drena al Río de la Plata; mientras que los suelos situados hacia el sur del partido, pertenecientes a la cuenca del Río Samborombón, son en gran parte anegables y tienen alto contenido de sodio intercambiable, lo que implica un obstáculo para la expansión de la horticultura hacia estas áreas si esta actividad fuera desplazada por la urbanización o las actividades extractivas (Hurtado 2006).

El sector periurbano de La Plata es un ámbito muy dinámico y heterogéneo, de gran fragilidad ambiental (Frediani 2010), en el que se pueden diferenciar lugares con producciones intensivas (hortícolas, florícolas, frutícolas, avícolas, de granja, viveros, etc.), lugares de esparcimiento y segunda residencia (clubes de campo, casas quinta, etc.), parajes rurales (subcentros urbanos de segundo y tercer rango, centro de servicios rurales, etc.), áreas de economía urbana periférica (industrias, depósitos, cementeras, etc.), zonas de grandes equipamientos (hospitales, escuelas, etc.) y una periferia débil (lotes baldíos o casi desocupados, cavas, canteras, suelos decapitados) (Botana 2004). Este espacio abarca una franja de territorio de aproximadamente 5 a $12 \mathrm{Km}$. de ancho y $36.738 \mathrm{ha}$. de extensión, un tercio del cual es de carácter productivo (hortícola y florícola); según Bozzano, el $15 \%$ de la superficie del partido de La Plata correspondería a espacios urbanos (ciudad y suburbios), el $39 \%$ a espacios periurbanos (cinturón verde) y el $46 \%$ al espacio rural (agropecuario pampeano) (Bozzano 2002 en Frediani 2010). En este periurbano se desarrolla el cinturón hortícola de La Plata, una de las principales áreas hortícolas del país, cuya actividad productiva se encuentra en manos de pequeños agricultores familiares, principalmente de origen boliviano, que provee entre el $60 \%$ y el $90 \%$ de las hortalizas frescas consumidas por CABA y el "Conurbano Bonaerense", abasteciendo a más de catorce millones de habitantes (Benencia 2002, INDEC 2010).

\subsection{La conformación del CHP en el marco del desarrollo del partido de La Plata}

En el presente apartado realizaré una breve reseña de la historia de conformación del CHP, que no pretende ser una descripción exhaustiva, sino que busca destacar los aspectos más relevantes, especialmente para el período estudiado en esta tesis. Para ello me basé, aunque no exclusivamente, en los trabajos de García (2015b), García (2012), García (2011); García y Lemmi (2011), entre otros.

El periurbano productivo de La Plata, como todo territorio, es un espacio constituido predominantemente por relaciones sociales capitalistas, relaciones desiguales de poder y dominación que lo van moldeando (García y Lemmi 2011). Estos autores identifican dos grandes períodos en la conformación del CHP; un primer momento de horticultura doméstica 
y de abastecimiento local (1850-1940) y un segundo momento de expansión e intensificación de la producción (1940-Actualidad).

La ciudad de La Plata, fundada en el año 1882, tiene la particularidad de ser una ciudad planificada desde sus comienzos, con el objetivo de conformar la capital de la provincia, y de haber sido elegida para estos fines, una zona de montes, lomas y bañados que servían de pastoreo a las haciendas de las estancias cercanas, a tan solo $56 \mathrm{~km}$ de la capital federal, actualmente Ciudad Autónoma de Buenos Aires (CABA). Al planificarse, la ciudad fue diseñada como un cuadrado perfecto, y desde sus inicios se destinó una zona para el establecimiento de fincas y chacras para la producción de alimentos de cercanía que abastecerían a los habitantes de la futura ciudad. Este área productiva fue planificada siguiendo la lógica de distribución espacial de los sistemas productivos alrededor de las ciudades, establecida por Johann Von Thünen, que seguía una secuencias de intensividades decrecientes en el uso del suelo; estableciendo así la distancia óptima que le permitiera al productor maximizar sus ganancias según el precio del producto y los costos del alquiler de la tierra y del transporte (García 2012). En base a estos criterios, los lotes lindantes al casco urbano fueron destinados para las quintas productoras de hortalizas y frutas, mientras que en los más distantes fueron ubicadas las chacras (producción de ganado, aves de corral, cereales, etc.). Es interesante destacar que en este primer momento de desarrollo del área productiva, los predios destinados a esta actividad, cuyas dimensiones debían estar entre 1 y 5 Ha., tenían que cumplir con cierta reglamentación, que incluía la obligación de plantar árboles en el predio (Coni 1885 en García 2012).

Horticultura doméstica y abastecimiento local (1850-1940): en un primer momento, la ciudad contaba con muy pocos habitantes que tenían pequeñas huertas en sus propias casas, destinadas al autoabastecimiento. Con el crecimiento de la ciudad en la primer mitad del siglo XX, se incrementó la población y la producción de alimentos de autoabastecimiento ya no fue suficiente, debiendo incrementar la producción y dar un salto hacia la comercialización local. En este período, las unidades productivas estaban a cargo de familias productoras de origen europeo, principalmente italianos, recientemente llegadas al país a partir de la fuerte migración que tuvo lugar entre 1880 y 1889 (García 2012). Estas familias productoras se asentaban en la zona inicialmente en condiciones de precariedad en cuanto al acceso a la tierra. Pese a la planificación original del área productiva de La Plata, las lógicas capitalistas fueron modificando los límites establecidos, llevando a que la producción se concentrara en las zonas de Los Hornos, Gorina, Abasto, Olmos, Romero e incluso Etcheverry (García y Lemmi 2011).

Por su cercanía a la capital federal, a medida que se fue conformando su área metropolitana, la ciudad de La Plata quedó establecida en la tercer corona del Gran Buenos Aires, constituyendo su límite perimetral externo. A mediados de la década de 1940 se consolidó el Cinturón Verde Bonaerense (CVB) rodeando a la ciudad de Buenos Aires y el 
Conurbano Bonaerense (García y Le Gall 2009, Le Gall y García 2010), dentro del cual se encuentra inserta la zona hortícola del Partido de La Plata. Frente al abrupto crecimiento poblacional, la expansión urbana y el desarrollo industrial que tuvo lugar en la ciudad de Buenos Aires durante el período de Industrialización por Sustitución de Importaciones (ISI), entre 1940 y 1950, la ciudad de La Plata pudo mantener su carácter de productor hortícola. Esto fue posible por dos motivos principales, además de la autonomía que le brindaba el hecho de ser la capital provincial; por un lado la separación física del resto del Gran Buenos aires a través del Parque Pereyra Iraola, y por otro la sanción en 1978 de una ordenanza que busca proteger el uso rural del suelo. En este contexto, la expansión poblacional del conurbano bonaerense generó un incremento de la demanda de alimentos, que fue canalizado por el área productiva de La Plata posicionándose como el principal abastecedor de la región (García y Lemmi 2011). Para ese entonces, ya se comenzaba a diferenciar cierta zonificación en La Plata, que en términos generales se mantiene hasta la actualidad; ubicándose hacia el sector noroeste las viviendas residenciales, hacia el sudeste viviendas consideradas de segunda categoría y hacia el sudoeste, la actividad agrícola, en suelos altos y fértiles.

Expansión e intensificación de la producción (1940- Actualidad): A partir de 1940, una serie de políticas favorecen la posibilidad de que en un período relativamente corto de tiempo las familias productoras accedan a la propiedad de la tierra, constituyéndose unidades productivas de entre 4 y $7 \mathrm{Ha}$. Hacia 1960 se incorporan al trabajo en la horticultura familias migrantes del norte del país, que comienzan a trabajar de forma más o menos temporal para los productores de origen europeo, bajo distintas formas (medieros, jornaleros, tanteros). La producción hasta ese momento era principalmente estival, con un importante trabajo manual y baja utilización de insumos externos de origen orgánico. La propiedad de la tierra, los bajos costos de producción, precios altos de venta, una estrategia de comercialización más directa y la baja competencia con otras zonas productoras del país, fueron algunas de las condiciones que permitieron un avance en las condiciones de vida y de trabajo de estas familias productoras de origen europeo.

Hacia 1970 se comienzan a incorporar en el territorio productivo de La Plata, ciertos cambios tecnológicos propios de la Revolución Verde, iniciada y difundida a nivel mundial a partir de 1940, entre ellos las semillas híbridas, los sistemas de riego, los agroquímicos de síntesis para el control de plagas y enfermedades, los fertilizantes inorgánicos y la utilización de tractores de mayor potencia; esto posibilitó el incremento del área hortícola, su productividad, producción y seguridad de cosecha (García 2012). A su vez, en la década del $80^{\prime}$ comienza una nueva oleada migratoria, de familias provenientes en este caso de Bolivia, que al igual que sus pares italianos se dedicarían a la producción hortícola, inicialmente como peones en quintas de los productores italianos ya instalados en la región. La incorporación de nueva tecnología a la producción, la llegada de las familias productoras de 
Bolivia y la retracción de los sectores productivos norte y oeste del Cinturón Verde Bonaerense (CVB) como consecuencia de la expansión urbana, contribuyeron a la consolidación del CHP como el principal de la región. La presencia de una ordenanza municipal que impedía el desarrollo de emprendimientos urbanísticos en áreas rurales contribuyó a que el CHP no corriera la misma suerte que el resto del cinturón verde bonaerense.

A partir de los $90^{\prime}$ este proceso de tecnologización del agro que comenzó en los 70'80' creció exponencialmente. Una de las incorporaciones tecnológicas que se dio incipientemente en los $80^{\circ}$, pero que marcó el desarrollo que siguió en adelante el CHP, fue la tecnología del invernáculo. Al analizar los cambios que esto acarreó, García (2011) identifica tres momentos denominados "oleadas de invernáculos" con características particulares y que influirían fuertemente en el desarrollo de este área productiva:

- 1er oleada (mediados de los 80'). Marca el inicio de la Incorporación de los invernáculos, aún en número reducido. Entrando en los $90^{\circ}$, con el régimen de apertura de importaciones y un tipo de cambio favorable crece paulatinamente la superficie de invernáculos en la región.

- 2da oleada (mediados de los 90'). Se da en este momento un incremento exponencial de la superficie bajo invernáculos, favorecido por el bajo costo de los plásticos, un efecto imitación de otros productores que se integran al grupo de innovadores de la $1^{\circ}$ oleada, la necesidad de diferenciación del producto por la caída en la demanda y por las nuevas exigencias de calidad que genera el ingreso del supermercadismo al país.

- 3er oleada (a partir del 2002). Con posterioridad a la crisis del 2001, se reactiva la economía y comienza un nuevo proceso de crecimiento de la superficie bajo cubierta, con una expansión aún mayor que en el período anterior.

Desde la incorporación de esta tecnología, la superficie bajo invernáculo se ha expandido a un ritmo desenfrenado y sin una adecuada planificación, alcanzando entre 1998 y 2002 una tasa de crecimiento del 140\% (Nieto y Rivas 2006). Los relevamientos realizados hasta el momento muestran cifras que dan cuenta claramente de ello: en el año 2005 el Censo Flori-hortícola indicó que el CHP poseía más del $79 \%$ de la superficie bajo cubierta del Cinturón Verde Bonaerense, del cual forma parte (CHFBA'05); en un trabajo posterior, al comparar los datos de 1998 y 2005, se observó un aumento del 83,3\% de cultivo bajo cubierta, mientras que el cultivo a campo disminuyó un 42,1\% (García y Mierez 2007); para el año 2006, el Consejo Federal de Inversiones (CFI) estimó que la superficie con invernáculos en el CHP llegaba a las 1300 has, y a principios del 2009 las principales empresas proveedoras de plásticos para la región inferían que la misma había superado las 3000 has (García 2011). Por otro lado, Stavisky (2010) estimó que para el año 2010 existían 
$4000 \mathrm{Ha}$. de invernáculos en toda la república Argentina, $2600 \mathrm{Ha}$. pertenecientes a producciones bajo cubierta (hortalizas, flores, viveros y aromáticas) en la provincia de Buenos Aires, de las cuales el 75\% (1.950 Has) se ubicaban en el Gran La Plata. El invernáculo no es solo una herramienta productiva más, es la condensación de un proceso de modernización agrícola que incluye cambios en el manejo, en la mano de obra, en la demanda y dependencia de insumos, entre otros (Selis 2000 en García 2015b).

Este modelo de producción de alimentos que en el CHP tiene como ícono la producción bajo invernáculo, se enmarca en el proceso de expansión del capitalismo, que con sus políticas de liberalización de la economía ha afectado a muchos países de la región. En Argentina, la adopción de las Políticas de Estabilización y Ajuste Estructural (PEAE), la expansión de las grandes Corporaciones Transnacionales Agroindustriales (CTA) y la integración de la agricultura en el nuevo sistema agroalimentario mundial, han generado grandes transformaciones en el Sistema Agroalimentario Argentino (SAA), modificando drásticamente la estructura y las condiciones de producción del sector agrícola (Teubal 2001, Tapella 2004). La concentración, la "extranjerización" de diversos complejos productivos a partir de la fusión y de la compra por parte de empresas agroindustriales transnacionales, y la integración vertical, transformaron las características y la naturaleza de las relaciones de poder dentro del SAA, lo que se ha visto traducido en precarización del empleo rural, multiocupación, expulsión de medianos y pequeños productores del sector, continuas migraciones campo-ciudad y una creciente orientación de la producción agropecuaria hacia los mercados (Teubal 2001, Teubal y Rodriguez 2002).

Este proceso de expansión capitalista no solo afectó el modelo de producción de alimentos, otra importante transformación que generó en el territorio tuvo que ver con el avance del mercado inmobiliario. En el partido de La Plata, desde la década de los 90' las tierras que se destinaban a la producción agrícola intensiva comenzaron a presentar otros usos del suelo propios de un área urbana, generando nuevos loteamientos y una revalorización del suelo, que desencadenó una acelerada especulación por parte de los agentes inmobiliarios (Frediani 2010). El incremento en el valor del suelo, sumado a los altos costos de la producción, con insumos dolarizados y alimentos destinados principalmente al consumo interno, sumado a la retracción en el consumo de la población, llevaron a que hacia finales de los 90' muchos productores de origen italiano abandonaran su producción, comenzando a arrendar sus tierras a productores bolivianos o vendiendo sus campos y volcandose a otros emprendimientos. Hang et al. (2013) sostienen que desde la década de los 90, se observa en la región una disminución de los agricultores descendientes de europeos que cultivan al aire libre y un aumento de los agricultores de origen boliviano que cultivan bajo invernáculo. Paralelamente, el avance urbano también parece estar generando en los últimos años un desplazamiento de la actividad productiva, que comienza a ocupar áreas tradicionalmente utilizadas para uso agropecuario (agricultura extensiva, ganadería de 
cría, tambo, haras, etc.) (Hurtado et al. 2006). Como sostiene Baudron (2011), el abandono de la planificación o al menos de la regulación urbana por parte del Estado, propia de mediados del siglo XX, y la vigencia del principio de subsidiaridad y neutralidad estatal, han promovido el protagonismo de la inversión privada y el consecuente predominio de los intereses de propietarios de inmuebles y dueños del capital; el crecimiento de megaproyectos inmobiliarios inconexos y fragmentados que impactan en la estructura y el paisaje de las ciudades receptoras es una constante en la Región.

El CHP ha experimentado un crecimiento económico, productivo, tecnológico y comercial ininterrumpido; destacándose la magnitud de las transformaciones de la horticultura platense en los últimos años. Esto ha llevado a que en la actual, aunque atravesada por un debate incipiente, la dinámica de la horticultura platense esté siendo abordada como un aglomerado económico o de empresas, bajo la noción de Sistemas Productivos Locales (García 2016).

Finalmente, es importante destacar a los fines de esta tesis que, entre los cambios ocurridos durante el desarrollo del CHP, la tecnificación de las prácticas agrícolas y el uso de dosis masivas de insumos costosos y/o escasos, como los combustibles fósiles, plaguicidas, fertilizantes, semillas híbridas, agua para riego, etc. (Sarandón 2002) que caracterizan a la producción hortícola en la región, han generado un notable aumento en el rendimiento de las cosechas pero también grandes consecuencias ambientales, económicas y sociales (Pengue 2005, Foley 2005).

\subsection{Principales actores sociales e instituciones públicas asociadas al CHP}

El CHP históricamente se ha caracterizado por absorber un gran flujo de trabajadores migrantes, quienes salen de sus países en busca de mejores condiciones y toleran situaciones de explotación que los nativos no admitirían (Ambort 2017). En este sentido, la actividad hortícola ha estado siempre en manos de la agricultura familiar, y mayormente de pequeños agricultores familiares. Inicialmente impulsada por familias campesinas pobres de Europa (principalmente italianos, aunque también portugueses y españoles), llegadas al país a partir de la fuerte migración que tuvo lugar entre 1880 y 1889; y más recientemente, a partir de la segunda mitad de la década del 90', por familias migrantes internas del norte de nuestro país y de Bolivia (principalmente de Tarija) (García y Le Gall 2009, García 2012, Ambort 2017).

A principios de los 90' los productores de origen europeo, habían podido acceder a la tierra e invertido en un alto grado de tecnificación de su actividad, alcanzando un importante nivel de capitalización y convirtiéndose muchos de ellos en grandes productores. Paradójicamente, la gran mayoría de estos productores no pudieron sobrellevar la crisis de finales de los 90', abandonando la actividad. Como consecuencia, a partir de comienzos del 2000 y hasta la actualidad, son unos pocos productores europeos o descendientes de 
europeos, dueños de la tierra y poseedores de grandes unidades productivas, los que persisten; por el contrario, el CHP está conformado principalmente por pequeños productores familiares originarios de Bolivia, siendo los principales proveedores de verduras frescas del cinturón hortícola (Ambort 2017, Benencia 2002, García y Lemmi 2011).

Según estimaciones realizadas por técnicos de la región y referentes de organizaciones, en el CHP existirian en la actualidad no menos de 5000 familias produciendo (Ambort 2017). Para las familias productoras bolivianas, con las condiciones actuales de producción y comercialización y el alto valor del suelo, resulta casi imposible poder acceder a una tierra propia; por el contrario, la forma más difundida actualmente es el arrendamiento (o incluso el subarrendamiento) de pequeñas parcelas, quedando las antiguas quintas de 4-7 ha subdivididas en fracciones de entre 0,5 y 1,5 ha (Ambort, 2017, García 2015b). Las distintas modalidades de peón, mediero/a o productor/a familiar arrendatario existentes a la fecha comparten la precariedad en las condiciones de vida y de trabajo, la contracción del consumo y la superexplotación de la fuerza de trabajo como principales estrategias de acumulación (García 2016b). La precariedad tanto en las condiciones de vida como de trabajo de estas familias productoras va de la mano de un alto grado de informalidad, generando expresas jornadas de trabajo, trabajo infantil, remuneraciones por debajo del salario mínimo, dificultades para el acceso a créditos, carencia de prestaciones sociales como aportes jubilatorios y obra social, viviendas muy precarias, falta de acceso a agua potable y dificultades para el acceso a la educación, entre otros aspectos (Ambort 2017, Botana 2004).

El sector de la agricultura familiar es un actor indispensable hoy en día, por el potencial que posee para lograr la sostenibilidad perdida por el modelo productivo vigente. En este sentido, algunas características fundamentales de la Pequeña Agricultura Familiar (PAF) tienen que ver con la valoración del agricultor y sus funciones, el arraigo que mantiene al territorio, sus sistemas diversificados de producción y el bagaje de prácticas y conocimientos heredados con los que cuenta. Las características mencionadas anteriormente son indispensables a la hora de pensar en el rediseño de los sistemas productivos, y evidencian la enorme contribución que los agricultores familiares pueden hacer a la estabilidad de los ecosistemas en que están insertos y a la seguridad alimentaria de la población en general, mediante la generación de sistemas alimentarios de bajo impacto ambiental, sustentables, diversificados, que contribuyan a dietas saludables, apoyen la producción de alimentos agroecológicos y las redes de producción-consumo de corta distancia para el comercio justo (Salcedo et al. 2014, Pengue 2005b). La PAF cumple a su vez, un rol esencial en la seguridad alimentaria, en la absorción de mano de obra en la actividad agrícola y en la retención de la migración campo - ciudad, que es el principal aportante a la formación de cordones peri - urbanos de pobreza (Cipaf 2005). Sin embargo, ante su condición de extrema vulnerabilidad frente a relaciones de poder muy desiguales, 
este sector se ha visto forzado a dejar de lado sus prácticas agrícolas tradicionales, teniendo que incorporarse al modelo de producción intensiva, con todas las problemáticas que esto conlleva, algunas de las cuales se han mencionado a lo largo de este capítulo.

Ambort (2017) relaciona la vulnerabilidad de las familias productoras con algunas condiciones propias de estas (condición migrante, pobreza material), con el bajo capital cultural (asociado al analfabetismo o la poca familiaridad con las instituciones), y con algunas condiciones estructurales en las cuales intervienen distintos actores que componen la cadena productiva, y frente a los cuales los horticultores y horticultoras se encuentran en una posición subordinada. En este sentido, se puede ver que existen una serie de actores con gran influencia en el territorio, que es importante considerar. Ambort (2017) plantea, siguiendo a García (2014), la existencia de cuatro mercados que operan como estructuras de poder y que garantizan la reproducción y rentabilidad de la actividad externalizando los costos de producción a través del trabajo: el mercado inmobiliario, el mercado financiero, el mercado de agroinsumos, y el mercado de hortalizas. Los actores representantes de estos cuatro mercados son los principales modeladores en la actualidad de la actividad productiva y del territorio hortícola. García (2014) plantea que frente a la precarización laboral mayoritaria en la horticultura platense y la superexplotación a la que se ve sometido el productor boliviano, hay un importante traspaso del valor de su fuerza de trabajo a las empresas de insumos, a los terratenientes vía la renta de la tierra, a los sujetos de la comercialización, y a la sociedad en su conjunto, que se beneficia a través de precios bajos. En relación a estos actores, Blandi (2016), Seibane et al. (2014) y Bonnicatto (2019) evidenciaron la gran influencia que tienen sobre los agricultores las empresas que producen semillas y agroquímicos en el CHP, a través de las casas de ventas de agroquímicos y de la organización de ensayos y demostraciones para difundir sus productos en la región. En relación a los agentes del mercado inmobiliario, diversos autores plantean la fuerte especulación que ejercen estos actores sobre el uso del suelo en el CHP; planteando que en ausencia o deficiencia de políticas adecuadas de planificación del uso del suelo, los conflictos se han resuelto a través de las políticas de los mercados concentradores y la especulación de las empresas constructoras (Frediani 2010, Hurtado et al. 2006, Merchán 2016). En cuanto al mercado de hortalizas, es necesario considerar en este punto la larga cadena de intermediarios que forman parte actualmente de las principales modalidades de comercialización en el cinturón hortícola, que fijan precios y establecen las variedades y la calidad comercial de las hortalizas plausibles de ser comercializadas; entre estos actores se destacan los camioneros que buscan la verdura en las quintas bajo la modalidad a "culata de camión", los puesteros y "changarines" del mercado central y los verduleros (Ambort 2017, Ennis 2019).

En los últimos años, un aspecto destacable de la actividad hortícola local, y que establece una diferencia cualitativa importante respecto a otras regiones del país, es el 
fuerte impulso que ha tenido el asociativismo, evidenciado en la emergencia de un amplio número y diversidad de formas asociativas (organizaciones de productores, cooperativas, asociaciones, etc.). Según Ambort (2017), hasta la década del 2000 los procesos asociativos en la horticultura platense eran relativamente escasos y atomizados. Esta autora, al analizar dicho proceso hace una diferenciación entre aquellas organizaciones conformadas por horticultores de origen europeo, hoy integradas mayoritariamente por medianos y grandes productores; y las organizaciones surgidas cuando el asalariamiento y la mediería se vuelven prácticas más afianzadas y los horticultores bolivianos se incorporan como un actor clave en la actividad. Seibane (2013) identifica hasta el año 2013 tres experiencias asociativas que considera relevantes en el territorio: la Asociación de Productores Hortícolas de La Plata (creada en 1983, representa a pequeños, medianos y grandes productores hortícolas y frutícolas de la región), la Asociación de Medieros y Afines (ASOMA) (creada en 1979, nuclea a campesinos pobres y medianos, pequeños productores de verduras y flores de La Plata, y la Asociación Platense de Horticultores Independientes (creada en 2007, nuclea a pequeños productores de la región, la gran mayoría arrendatarios de origen boliviano). Lemmi (2010), por su parte, al analizar el período 1994-2004 identifica cuatro organizaciones principales: la Unión Argentina de Trabajadores Rurales y Estibadores (UATRE) y a la Asociación de Medieros y Afines (ASoMA), representantes de la clase trabajadora; y la Asociación de Quinteros de La Plata y la Asociación de Productores Hortícolas de La Plata, que responden a sectores de la pequeña burguesía. Ferraris y Bravo (2014), al analizar el crecimiento en el proceso de asociativismo en la región que tuvo lugar en los últimos años, identifican alrededor de 30 organizaciones, y sostienen junto con Ambort (2017) que este crecimiento tiene que ver con un proceso impulsado desde el Estado, frente al incremento en las exigencias de formalidad hacia las diferentes formas asociativas para ser destinatarias de las políticas públicas. El surgimiento de muchas de estas organizaciones tendría sus orígenes en grupos conformados a partir del programa Cambio Rural, y estaría vinculado también a situaciones de conflicto en un período de crisis y descapitalización (posterior al 2001); en este contexto, las demandas inicialmente estarían centradas en que el Estado cumpla su rol regulador, sin cuestionar el orden social establecido, y la organización les permitiría tener presencia en diferentes instancias de negociación y acuerdos con organismos estatales (nacionales, provinciales, municipales) (Cieza et al. 2015, Ambort 2017). Sin embargo, Ambort (2017) sostiene que en la medida en que estas organizaciones se van consolidando y tomando visibilidad, se radicalizan y masifican algunas medidas de lucha y que las demandas comienzan a incluir cuestiones estructurales y universales relacionadas con la regulación de las tarifas, la regulación de los precios de las hortalizas y del valor de los alquileres, la creación de mercados propios o el acceso a la propiedad de la tierra, entre otros. De esta forma, estas organizaciones se 
constituyen como actores políticos, con un rol y una capacidad de representación y de disputa en la escena pública (Ambort 2017)

Por otro lado, una característica distintiva de La Plata, además de ser la capital provincial y de su cercanía a la Ciudad Autónoma de Buenos Aires, es la de ser una "ciudad universitaria", sede de una de las principales universidades del país, con numerosas instituciones asociadas y ofertas de formación. Los aspectos mencionados contribuyen a que haya un amplio abanico de instituciones articulando con el sector productivo de la ciudad. En este sentido, Seibane (2013) y Ambort (2017) identifican en la zona hortícola platense un conjunto de instituciones del Estado que, con distintas acciones, contribuyen a promover el desarrollo territorial; entre las que se destacan las siguientes:

- INTA. Destacando el Programa Cambio Rural, el Programa Federal de Apoyo al Desarrollo Rural Sustentable (ProFeder), el Centro de Investigación y Desarrollo Tecnológico para la Agricultura Familiar (CIPAF), los Institutos de Investigación para la Agricultura Familiar (IPAF)

- Facultad de Ciencias Agrarias y Forestales (UNLP). Haciendo hincapié en diversos proyectos de extensión universitaria que han tenido un rol relevante en la zona hortícola (ej: Banco Social, Proyecto de revalorización de las producciones típicas locales), y en el Boletín Hortícola (publicación trabajada en conjunto por la FCAyF, el INTA y el Ministerio de Asuntos Agrarios)

- Municipalidad de La Plata

- (ex) Ministerio de Asuntos Agrarios de la Provincia de Buenos Aires (Dirección de Horticultura, Floricultura y Fruticultura).

\section{- SENASA}

Otros actores institucionales importantes que vienen teniendo en los últimos años una importante articulación con el sector productivo son:

- UNLP (Consejo Social, Centro Regional de Extensión Universitaria-CREU con su Escuela de Oficios, Unidad Promocional de Investigación y Desarrollo de Semillas Hortícolas Locales del Cinturón Verde Platense-UPID, Espacio Multidisciplinario de Interacción Socio Ambiental-EMISA, Banco de Germoplasma de la Agricultura Familiar)

- INTA (ProHuerta)

\subsection{Qué y cómo se produce en el CHP}

En los últimos años se ha acrecentado el interés por el desarrollo productivo de los periurbanos, considerándolos estratégicos para la producción de bienes y servicios para las ciudades (Cieza, 2018). En el partido de La Plata, pese a que la ciudad de La Plata suele ser reconocida como la "ciudad universitaria", o por tener asentado en sus cercanías a un importante polo petroquímico; aunque menos reconocido por la comunidad local, el partido 
de La Plata es un partido en el que se desarrolla un importante abanico de actividades productivas primarias, tanto intensivas como extensivas. Es importante destacar que no se cuenta con datos censales provenientes del Estado actualizados, el último Censo Nacional Agropecuario data del 2002 y el último Censo Flori-Hortícola de La Provincia de Buenos Aires con datos fidedignos data del 2005. A continuación se describen brevemente las actividades productivas del partido, tomando como referencia el trabajo de Cieza et al. (2015) y Cieza (2018).

$\mathrm{Si}$ bien los datos censales con los que se cuenta están extremadamente desactualizados, solo a modo comparativo, es interesante destacar que por ejemplo, según el Censo Nacional del año 2002 el partido contaba con 1183 Explotaciones Agropecuarias (EAPs), lo que en ese momento superaba a la mayoría de los distritos de neto carácter agropecuario de la Provincia de Buenos Aires (Cieza et al., 2015). En el periurbano de La Plata, asiento del CHP, se desarrollan diversas actividades productivas; sin embargo, a diferencia de otros partidos de la provincia, la actividad hortícola está tomando un rol protagónico en la zona, relegando a las otras actividades a un lugar marginal.

Entre las actividades extensivas, concentradas principalmente en el sector suroeste del partido, se destacan la ganadería de cría y en menor medida la presencia de sistemas productivos lecheros. La producción ganadera, principalmente de cría bovina, para el año 2013 se contabilizaban unos 285 establecimientos, ubicados al sur y al oeste del partido, establecimientos extensivos con muy baja inversión de capital. En cuanto a La producción lechera, esta no es una actividad significativa en el partido, encontrándose 19 establecimientos ubicados en lo que se conoce como cuenca lechera Abasto Sur, integrada también por partidos vecinos, con más desarrollo de esta actividad. Un aspecto relevante que evidencian Cieza et al. (2015), Baldini y Cieza (2017) y Cieza (2018) es la existencia de una disputa en el uso del suelo con las actividades intensivas, dado el aumento de los precios de alquiler de las actividades intensivas que compiten con una actividad menos rentable como la ganadería. Sin embargo, estos autores destacan que la mayor competencia por el uso de la tierra se produce por la presión inmobiliaria, que compite por el espacio y aumenta significativamente los valores. Cieza (2018) explica la amplia superficie que aún se mantiene bajo uso ganadero extensivo en el partido, por la baja aptitud de los suelos y la falta de infraestructura acorde (especialmente caminos), restringiendo la posibilidad de avance de las actividades intensivas y la instalación de urbanizaciones.

Las producciones intensivas, ubicadas principalmente en el sector oeste y noroeste del partido, incluyen la horticultura y la floricultura (flores de corte), ambas con un alto porcentaje de su producción bajo cubierta. La floricultura es una actividad que se ha mantenido relativamente estable en el tiempo, llevada adelante por productores japoneses y portugueses, dueños de la tierra y generalmente con muchos años en la actividad; sus producciones son casi en su totalidad bajo cubierta, y en las unidades productivas suele 
quedar parte de la tierra en forma ociosa. Según Cieza et al. (2015), para el año 2012 se estimaba una superficie de $200 \mathrm{Ha}$. de floricultura. Otra actividad intensiva desarrollada en la zona es la avicultura, concentrada principalmente al oeste del partido, en El Peligro y Abasto; según datos de la municipalidad de La Plata existen 30 establecimientos productivos de este tipo y el 95\% corresponde a producción de huevos para consumo.

Existen una serie de producciones menos significativas, que representan un porcentaje menor de la superficie del partido, en comparación con las otras actividades, y que se mantienen estables en el tiempo; estas incluyen a las producciones forestales (viveros con destino a arbolado y unas pocas plantaciones añosas sin aprovechamiento productivo) y plantaciones de kiwis asociadas a altas inversiones realizadas por empresarios del rubro industrial o comercial (Cieza, 2018; Baldini y Cieza, 2017)

Hurtado et al. (2006) calcularon para el año 2006 que la agricultura intensiva (en el mencionado trabajo incluye la horticultura, floricultura y fruticultura, avicultura, apicultura y granja de pequeños animales) representaba el 12,44\% (11115 Ha.) del partido. Por otro lado, Stavisky (2010) estimó que para el año 2010 existían $4000 \mathrm{Ha}$. de invernáculos en toda la república Argentina, de las cuales $2600 \mathrm{Ha}$. pertenecian a producciones bajo cubierta (hortalizas, flores, viveros y aromáticas) de la provincia de Buenos Aires, y el 75\% (1.950 Has) de estas últimas se ubicaban en el Gran La Plata.

Dentro de las actividades productivas existentes en la zona, la horticultura por su magnitud, por el modelo productivo hegemónico bajo el cual se desarrolla y por el impacto económico, social y ambiental que está teniendo, merece ser abordada con más detenimiento.

En base a datos provenientes de diversas fuentes estadísticas, Sarandón et al. (2015) calculan que en toda la Provincia de Buenos Aires existen $31765 \mathrm{Ha}$. cultivadas; y que en el Cinturón Verde Bonaerense (CVB) existen 1500 empresas hortícolas ocupando $16000 \mathrm{Ha}$. y cubriendo el $30 \%$ de la demanda urbana. En este contexto, el partido de La Plata se ubica en tercer lugar en superficie hortícola entre los partidos de la provincia (3709 Ha.), antecedido por Villarino (4217 Ha.) y General Pueyrredón (4948 Ha.), en base a datos del año 2005 (Sarandón et al., 2015). A su vez, estos autores registraron $208 \mathrm{Ha}$. de floricultura y $32 \mathrm{Ha}$. de fruticultura en el partido. Los productores familiares del CHP producen 23 variedades de hortalizas; de las cuales, si consideramos la superficie cultivada de cada una de estas variedades, los principales cultivos son la lechuga (1349 Has), el tomate (395 has),el alcaucil (306 Has), la acelga (230 Has), la espinaca (175 Has), el maíz dulce (165 Has), el pimiento (156 has), el brócoli (106 has) y el repollo (100 has) (Sarandón et al., 2015).

La actividad hortícola en el CHP se encuentra en manos de pequeños productores familiares de origen boliviano, que desarrollan su actividad principalmente a través del arrendamiento de sus unidades productivas. Según un informe del Consulado Boliviano el 
85\% de los productores hortícolas de La Plata son de Bolivia; y si bien no existen datos censales actualizados, la información proveniente del Registro Nacional de la Agricultura Familiar (ReNAF) indica que La Plata es el partido del AMBA con mayor cantidad de Núcleos de la Agricultura Familiar (NAFs) registrados (Ambort, 2017). En cuanto a la forma de tenencia de la tierra, según el CHFBA (2005) un 60,8\% de los productores hortícolas arriendan la tierra; sin embargo, este porcentaje se habría incrementado notablemente en los últimos años, producto del ascenso en la "escalera boliviana" de medieros a arrendatarios (Ambort, 2017; Cieza et al., 2015). Como resultado de este cambio en la forma de tenencia de la tierra, y de las difíciles condiciones de producción actuales, las dimensiones de las unidades productivas actualmente se han reducido, y se ha hecho habitual el subarrendamiento de las quintas; las antiguas quintas de 6-8 ha. se han subdividido en fracciones de entre 0,5 y 1,5 ha. aproximadamente (Ambort, 2017).

El modelo productivo platense se asienta según García (2015b) en tres pilares: el rol del horticultor boliviano, la explotación de la fuerza de trabajo y la tecnología del invernáculo. Según este autor el alto grado de informalidad de la actividad (con pésimas condiciones laborales y paupérrimas remuneraciones), la autoexplotación y capacidad de contracción del consumo (como una forma de acumulación de capital), y la incorporación de la tecnología del invernáculo (posibilitando una mayor productividad, acortamiento de los tiempos de cosecha y mejor calidad "estética" de los productos) han sido aspectos relevantes en la consolidación del modelo productivo que prevalece en el CHP.

Este modelo hípercompetitivo pareciera ser un callejón sin salida, ya que como describe García (2015b) tiene un funcionamiento en espiral, en el que la mayor tecnología genera una mayor producción, que reduce los precios (aunque no necesariamente esa reducción llega al consumidor) y en consecuencia las ganancias, induciendo a una mayor incorporación tecnológica que reinicia y potencia el ciclo. Ante esta situación, y especialmente en momentos de crisis, los productores familiares elaboran estrategias productivas que les permita continuar en el circuito productivo; por ejemplo realizando cultivos de ciclo más corto (como las hortalizas de hoja) y de bajo costo de implantación o cultivos de ciclo largo y con altas costos (tomate, pimiento), según las capacidades económico financieras de cada productor (Cieza et al., 2015). Según estos autores, a medida que van incrementando el grado de capitalización de las unidades familiares, existe una tendencia a la producción de hortalizas de fruto, pero de ninguna manera se deja de producir lo que se denomina verdura liviana (de hoja), ya que estas últimas les permiten aumentar el número de cosechas por año, intensificando el uso del suelo y logrando ingresos en periodos de tiempo más breves; un aspecto trascendental para la mayoría de las familias, que deben cubrir gastos fijos elevados como el alquiles, el servicio de luz eléctrica y los costosos insumos agroquímicos (Cieza et al., 2015; Ambort, 2017; Ennis, 2019). Ambort (2017) sostiene que el cultivo de variedades de hoja o de fruto, es un factor 
de diferenciación entre productores/as. Mientras que los cultivos de hoja (lechugas, acelga, espinaca, etc.) son de bajo costo, de ciclos cortos y con un manejo relativamente sencillo, implicando una rápida circulación de capital y bajos riesgos; los cultivos de fruto (tomate, pimiento, berenjena, pepino) implican un alto costo en insumos, un ciclo largo de producción, la asunción de mayores riesgos y un conocimiento técnico más complejo y especializado; esto hace que producir hortalizas de fruto sea percibido también como haber alcanzado cierto estatus social (Ambort, 2017).

La comercialización de la producción hortícola local está en manos de una larga cadena de intermediarios; en este contexto, la principal forma de comercialización entre los pequeños productores familiares del CHP es la venta a "culata de camión", en la cual las familias productoras son tomadoras de precios, entregando la mercadería a intermediarios que pasan por las quintas y llevan la verdura a los mercados concentradores. Este mecanismo de comercialización es un factor de vulnerabilidad para las familias productoras, agravado por la falta de regulación de los precios de las hortalizas, los cuales varían diariamente en función de la oferta y la demanda (Ambort, 2017; Ennis, 2019). Actualmente, el peso que tiene la comercialización en las decisiones productivas posiciona a los consignatarios con un poder importante sobre el sector productivo (Seibane, 2014). Pese a ello, Ambort (2017) y Ennis (2019) destacan el reciente surgimiento de formas más directas de comercialización, como la venta directa en ferias o la venta de bolsones en ferias o con entrega a domicilio, sin embargo estas modalidades son acotadas aún, y cubren un porcentaje menor de la producción de las quintas.

El modelo de producción del CHP es un modelo altamente intensivo, fundamentado en los criterios productivos de la Revolución Verde, que promovían la tecnificación de las prácticas agrícolas y el uso de dosis masivas de insumos costosos y/o escasos, como los combustibles fósiles, agroquímicos de síntesis para el control de plagas y enfermedades, fertilizantes inorgánicos, semillas híbridas, agua para riego, etc. (Sarandón 2002; García 2012). En el CHP este modelo productivo está fuertemente asociado a la tecnología del invernáculo, la cual ha crecido exponencialmente, llegando a cubrir una amplia superficie del área hortícola. Como se mencionó a lo largo de este capítulo, no existen datos actualizados de la superficie en producción bajo invernáculos, lo que ha llevado a numerosas estimaciones, que muchas veces se contradicen entre sí. Lo cierto es que la incorporación de esta tecnología posibilitó el incremento del área hortícola, su productividad, producción y seguridad de cosecha, diferenciando al CHP del resto de las áreas hortícolas del país, pero también acarreó grandes consecuencias negativas ambientales, económicas y sociales (García 2012; Pengue 2005a, Foley 2005).

A continuación se mencionan algunas de las principales consecuencias negativas de la expansión del invernáculo en la región: 
- Impermeabilización de gran parte del suelo hortícola, obstaculizando la infiltración en la tierra del agua de lluvia. Esto trae aparejado otras consecuencias, como la dificultad en la recarga del acuífero del cual se extrae agua para el cultivo, la generación de importantes anegamientos interrumpiendo la actividad social y económica de la región y la afectación de la producción al favorecer la aparición de enfermedades fúngicas en los cultivos hortícolas (García, 2011).

- Dificultades en el riego. Los cultivos bajo cubierta requieren de riego, y si bien no existen hasta el momento estudios que evalúen la recarga del Acuífero Puelche en la zona, se ha observado que las bombas que extraen agua para riego, la están obteniendo a profundidades cada vez mayores, lo que indica indirectamente una disminución del recurso hídrico (García, 2011).

- Problemas de contaminación del suelo por hiperfertilización y de salinización de los primeros $10 \mathrm{~cm}$ del suelo en invernáculos de la región, como consecuencia de la fertilización y el riego con aguas subterráneas, agravado a su vez por la falta de lavado de sales que produce el agua de lluvia (Hurtado, 2006).

- Contaminación por el uso de agroquíicos. En un reciente relevamiento de la utilización de agroquímicos en la Provincia de Buenos Aires, realizado por la UNLP a pedido del Defensor del Pueblo de la Provincia de Buenos Aires, se observó que más del $40 \%$ de los productores encuestados utilizan principios activos que pertenecen a clases toxicológicas de extremada o alta toxicidad (la, lb y II) según los parámetros establecidos por SENASA en su Resolución 302/2012 (Sarandón y otros, 2015); y lo que es más grave aún, se han detectado en suelo y aire agroquímicos prohibidos a nivel nacional, como el Dieldrin y el DDT (Colombo y otros, 2015). Sarandón y otros (2015) elaboraron un índice de peligrosidad para los partidos de la Provincia de Buenos Aires, de acuerdo a la superficie relativa que ocupa la horticultura y al modelo de producción predominante, caracterizando a la zona hortícola de La Plata como aquella con el segundo mayor índice de peligrosidad de la provincia.

- Contaminación de alimentos. El Espacio Multidisciplinario de Interacción Socio Ambiental (EMISA) detectó presencia de agroquímicos en más del $70 \%$ de las muestras tomadas de verduras que se consumen en la ciudad (Alonso y otros 2015).

- Contaminación de cursos de agua que atraviesan el área. Se encontró que la presencia de plaguicidas es continua y generalizada en algunos arroyos de la zona (Mac Loughlin et al., 2017)

- Afectación de la biodiversidad de arroyos de la zona hortícola. Se encontró un cambio en los ensambles de invertebrados y pérdida de grupos taxonómicos sensibles por efecto del uso de fertilizantes y pesticidas (Arias, 2019)

- Pérdida del patrimonio natural, deterioro paisajístico y fragmentación territorial (Botana, 2004). 
Como se puede observar en este apartado, la agricultura industrial modernizadora, responsable del modelo productivo del CHP, atenta contra la diversidad de los sistemas productivos, a la vez que va afectando la trama cultural, homogeneizando y licuando las identidades territoriales de los alimentos, restando autonomía a los consumidores en cuanto a su capacidad de decidir sobre su alimentación e imponiendo el consumo de productos de dudosa calidad y bajo valor nutricional (May y Ciocchini, 2018).

A su vez, las condiciones actuales les impiden a las familias productoras adoptar los paquetes tecnológicos completos que ofrece el mercado, ocasionándoles perjuicios productivos, al no resolver los problemas de plagas, malezas y enfermedades, y socioambientales, al aplicar químicos muy tóxicos y de amplio espectro que suelen ser más económicos, pero más peligrosos (Marasas y otros, 2012). Esta situación ha llevado a muchos productores a considerar nuevas estrategias productivas basadas en un enfoque agroecológico, centrado no sólo en la producción sino también en la sostenibilidad ecológica del sistema (Altieri, 1999).

\subsection{Las políticas públicas que influyen en el desarrollo del CHP}

Las políticas públicas han mostrado en Argentina una contradicción persistente entre las reformas económicas que generan concentración económica y exclusión de los más débiles, y las políticas sociales que, lejos de consolidar a la pequeña agricultura como sector activo dentro del proceso de desarrollo, han funcionado sólo como un alivio temporal frente a los efectos de la política económica (Tapella, 2004). En cuanto a las políticas públicas agroecológicas, no existe en Argentina una política integral a favor de la agroecología, en tanto "conjunto más o menos coherente de acciones y decisiones estatales para el desarrollo de formas de producción y de consumo vinculadas a los conceptos agroecológicos" (Cittadini et al, 2017).

Al igual que en otros países de Latinoamérica, como describen Sarandón y Marasas (2015), la propuesta agroecológica surge en las diferentes organizaciones e instituciones, como una reacción a las consecuencias de un modelo productivo ambientalmente insustentable y socialmente excluyente. Ante las dificultades de encontrar soluciones a los problemas dentro del mismo sistema que los originó, comienzan a surgir vías alternativas, que al contraponerse al modelo hegemónico fueron por mucho tiempo resistidas desde las instituciones; lo cual hizo que aquellas experiencias innovadoras se mantuvieran por muchos años en un lugar de marginalidad tanto entre los agricultores, como entre los técnicos e investigadores (García 2011, Sarandón y Marasas 2015). En este sentido, Broccoli (2011) sostiene que el enfoque de la agroecología a nivel estatal se dio de una forma más lenta y con diferentes grados de compromiso y de impacto en el territorio. 
Durante muchos años, desde este lugar marginal, fueron creciendo proyectos y experiencias en torno a la agroecología, tanto institucionales (ej: INTA, UNLP) como desde distintas organizaciones de productores, centros, redes (ej: CEDEPO ${ }^{1}$, RADA $^{2}$, MAELA $^{3}$, UNICAM-SURI ${ }^{4}$, MOCASE$^{5}$ ), ampliamente documentadas por Souza Casadinho (2013), Sarandón y Marasas (2015) y Tito y Marasas (2014), las cuales con su trayectoria de trabajo sentaron un fuerte precedente para la generación de políticas públicas agroecológicas.

Sin tener como objetivo hacer un punteo detallado de las políticas públicas agroecológicas, se mencionan a continuación una serie de programas e instituciones (nacionales, provinciales municipales) que han tenido relevancia en el CHP para avanzar en mejoras para las familias productoras y en procesos de transición agroecológica; siguiendo para ello a Sarandón y Marasas (2015), Tito y Marasas (2014), Ambort (2017), Seibane (2013), Fernández (2019), Barsky (2013):

Ministerio de Agricultura, Ganaderia y Pesca (actualmente Agroindustria)

- PSA (Programa Social Agropecuario). Un programa que se desarrolló en todo el país desde el año 1993 al 2013, orientado a la agricultura familiar, que con el tiempo fue desarrollando un enfoque más integral del que tuvo en sus inicios. Este programa derivó posteriormente en la Subsecretaría, que luego se transformaría en Secretaría de Agricultura Familiar (SAF) en el 2009 y hasta el año 2018. Este programa se orientó al trabajo con agricultores/as de menores recursos, aunque no siempre con el enfoque de la Agroecología (Sarandón y Marasas, 2015).

- ReNAF (Registro Nacional de Agricultura Familiar). Se crea en el 2007, la inscripción es voluntaria, pero estar registrado/a aparece en la Ley de Agricultura Familiar como condición para el acceso a las políticas sociales orientadas al sector.

- MSA (Monotributo Social Agropecuario). Se lanza en 2009 y está destinado a formalizar a la agricultura familiar como actividad económica y garantizar el acceso a derechos sociales.

- Área de Agroecología dentro de la SAF. Creada en el 2013 para promocionar la agroecología en todo el país, con una propuesta metodológica basada en el rescate e intercambio de saberes y conocimientos, y el apoyo a los procesos de transición agroecológica.

- Ley Nacional de Reparación histórica de la Agricultura Familiar (Nro. 27.118) para la construcción de una nueva ruralidad en la Argentina. Es aprobada a fines del año 2014 pero se encuentra aún sin reglamentar.

\footnotetext{
${ }^{1}$ Centro Ecuménico de Educación Popular

${ }^{2}$ Red Argentina de Agroecología

${ }^{3}$ Movimiento Agroecológico Latinoamericano

${ }^{4}$ Universidad Campesina, Sistemas Universitarios Rurales Indocampesinos

${ }^{5}$ Movimiento Campesino de Santiago del Estero

58 Lic. Carolina Baldini

Tesis doctoral - Territorio en movimiento
} 
- Programa Nacional de Agricultura Periurbana Creado a partir del año 2010, bajo la órbita de la SAF y ejecutado a través de los municipios con la intervención de las organizaciones de productores locales y organismos como el INTA. Apuntó a promover el ordenamiento territorial, la producción de alimentos y la generación de puestos de trabajo en áreas periurbanas. Este programa fomentó explícitamente el avance de la producción hortícola bajo cubierta.

\section{SENASA}

- Comisión para la Agricultura Familiar. Esta comisión, creada en el 2009, reconoce las particularidades de la producción familiar, generando propuestas para abordar sus problemáticas, dentro de lo cual se contemplan las prácticas agroecológicas.

- RENSPA (Registro Nacional de Productores Agropecuarios). Iniciado en el año 2008. INTA

En el caso del INTA, es importante recordar que años atrás atravesó una etapa de reflexión sobre sus prácticas, a raíz de lo cual reconoció que el gran desarrollo tecnológico producido en las últimas décadas e incentivado por esta institución, centrado principalmente en tecnología de insumos y capital intensiva, generó el desplazamiento del sector de los pequeños productores/as (INTA 2005, en Sarandón y Marasas, 2015). Si bien actualmente se retomó esta política de desarrollo y al mismo tiempo el sector de la agricultura familiar perdió representatividad en las instituciones estatales, el proceso de reflexión que algunas de ellas atravesaron facilitó en su momento la introducción del enfoque de la agroecología en las universidades y otras instituciones de investigación y transferencia gubernamentales.

- Programa ProHuerta. Surge en 1990, en articulación con el Ministerio de Desarrollo Social de Nación. Inicialmente orientado a brindar herramientas a los sectores más vulnerables para que tuviesen acceso a una alimentación adecuada, mediante el desarrollo de huertas familiares. Actualmente tiene una fuerte línea de trabajo con organizaciones de productores del CHP, apoyando proyectos de transición agroecológica.

- Programa Cambio Rural. Surge en el año 1993 orientado al trabajo con las pymes del sistema agropecuario, aunque en la práctica en los últimos años se trabajó con el sector menos capitalizado. En 2014, en el marco del fortalecimiento de las políticas para la agricultura familiar, el programa es relanzado (Cambio Rural II). Este programa es considerado por numerosos autores como una de las principales políticas públicas implementada en el CHP y orientada directamente a fortalecer procesos asociativos.

- Programa Federal de Apoyo al Desarrollo Rural Sustentable (ProFeder). Integra en el año 2003 al programa Cambio Rural como un instrumento más de intervención, bajo un enfoque de Desarrollo Territorial Rural (DTR), que habría implicado un cambio paradigmático en términos de cómo se concibe el territorio, entendido no ya como un 
espacio productivo únicamente, sino tomando en cuenta la globalidad del mismo (Ambort, 2017). En la región de La Plata este enfoque de desarrollo territorial tuvo mayor difusión, propiciado el trabajo en redes y conformándose como una línea prioritaria de intervención (Seibane, 2014).

- Programa Nacional de Apoyo al Desarrollo de los Territorios (PNTER). Creado en el año 2006. Ese mismo año, se financia el proyecto "Desarrollo de tecnologías de procesos y gestión para la producción periurbana de hortalizas", que se centra fundamentalmente en estudiar aspectos tecnológicos y de impacto ambiental de la horticultura en el espacio de influencia metropolitano de Buenos Aires, en el que se encuentra el partido de La Plata (Barsky, 2013).

- Programa Nacional de Investigación y Desarrollo Tecnológico para la Pequeña Agricultura Familiar" (PNPAF). Se implementa en el año 2006, y en este marco se crea el Centro de Investigación y Desarrollo Tecnológico para la Pequeña Agricultura Familiar (CIPAF), uno de los Centros tiene como ámbito de acción la región pampeana, y tiene su sede en la localidad de Villa Elisa.

- EEA-INTA AMBA. Estación Experimental especializada en agricultura periurbana para el área metropolitana de Buenos Aires, creada en el año 2006.

- Consejo Local Asesor (CLA) de la Estación Experimental INTA AMBA. Un espacio transversal que refuerza el trabajo del productor rural del Área Metropolitana de Buenos Aires (AMBA). Tiene representantes de organizaciones de productores, de instituciones educativas, de ciencia y técnica municipales, provinciales y/o nacionales cuya función es asesorar al INTA en aspectos relacionados a su labor en el territorio.

- Instituto para la Agricultura Familiar (IPAF) Región Pampeana. Creado en el 2008 y localizado en La Plata, es la única dependencia del INTA que desarrolló un marco teórico basado en el enfoque agroecológico y que tuvo y tiene gran influencia en la región.

- Proyectos Regionales con Enfoque Territorial. Están enmarcados en la Red de Agroecología (REDAE), creada en el año 2013, y buscan aportar a la innovación en los territorios.

- Escuela Periurbana de Agroecología. Un espacios de formación en agroecología para las familias productoras, con una metodología de educación popular, llevado adelante entre el 2014 y el 2016. Esta escuela tuvo una amplia inserción en la región.

Universidades Nacionales

Dentro del sistema educativo, la incorporación de la agroecología fue uno de los procesos más largos y resistidos. En unos pocos casos se logró incorporar la temática como asignatura obligatoria u optativa en el plan de estudios de Ingeniería Agronómica, se desarrollaron diversos cursos de posgrado y maestrías, se constituyeron algunas cátedras Libres de Soberanía alimentaria y Agroecología, y en el año 2014 se creó la primer 60 Lic. Carolina Baldini Tesis doctoral - Territorio en movimiento 
Licenciatura en Agroecología de la Universidad Nacional de Rio Negro. En estos últimos años estos logros institucionales han permitido la formación de muchos profesionales que actualmente están trabajando para la implementación de la agroecología en los territorios.

- Cátedra de Agroecología de la Facultad de ciencias Agrarias y Forestales (FCAyF), UNLP. Incorporada como materia obligatoria dentro de la carrera.

- Boletín Hortícola. Creada en 1993, es una publicación trabajada en conjunto por la FCAyF, el INTA; y el entonces Ministerio de Asuntos Agrarios.

- Proyectos de extensión universitaria. En el CHP existen numerosos proyectos de la FCAyF en el territorio, entre los que se puede mencionar el Banco Social (implementado desde el año 2005), el Proyecto de revalorización de las producciones típicas locales (desde 1999), el proyecto de Sistemas Participativos de Garantía (desde 2018) y el proyecto de Biofábrica Escuela (desde 2018).

- Feria de Pequeños Productores Familiares Manos de la Tierra. Iniciada en el 2008 con el objetivo de crear una feria de comercio justo, que funciona hasta la actualidad en el espacio público de la Facultad de Ciencias Agrarias y Forestales de la UNLP.

- Centro de Atención Jurídica gratuita para productores agropecuarios familiares. Creado en el año 2011, atiende de forma gratuita en la FCAyF.

- Especialización en Agroecología. Creada en el año 2015 en el marco de las carreras de postgrado de la Universidad Nacional de La Matanza.

- Paseo de la Economía Popular, Social y Solidaria. Creado en el año 2018 como una estrategia más para fortalecer la comercialización directa productor-consumidor.

- Sociedad Argentina de Agroecología (SAAE). Conformada en el año 2018 en el marco del I Seminario Argentino de Agroecología realizado en La Plata. A partir del 2019 la comisión directiva tiene vocales en representación de los pequeños productores familiares.

Municipalidad de La Plata (MLP)

- Programa de Fortalecimiento Hortiflorícola Platense. Iniciado en el año 2008 a partir de un lineamiento del Ministerio de Agricultura de Nación.

(ex) Ministerio de Asuntos Agrarios de la Provincia de Buenos Aires - Dirección de Horticultura, Floricultura y Fruticultura

- Programa de Fortalecimiento Hortiflorícola articulando con la Municipalidad de La Plata.

- Cambio Rural Bonaerense (CRB). Inicia en el 2000 y consiste en un programa de promoción del asociativismo similar al de Cambio Rural impulsado por el INTA.

- Dirección Provincial de Agricultura Periurbana. Creada en el año 2007, es la única de su tipo en todo el territorio nacional y fue creada con la intención de poner en agenda pública y fortalecer los cultivos intensivos periurbanos y agrupar dependencias que hasta el momento se encontraban dispersas (Barsky, 2013). Esta dirección condensó la 
dirección de Mercados, Calidad y comercialización, y la dirección de Horticultura, Floricultura y Fruticultura. Esta dirección de desactivó ese mismo año.

Según Seibane (2013), a nivel local, la mirada más estratégica acerca de las potencialidades que tiene el territorio, hoy la tiene el INTA, fundamentalmente desde el Programa Cambio Rural, que con un trabajo de base con los productores, desarrolla acciones no solo en temas técnicos productivos, sino además en la promoción de la organización y su fortalecimiento, como en la búsqueda de canales alternativos de comercialización, y en el abordaje de temas transversales que hacen al desarrollo territorial. Fernández (2019), al analizar comparativamente las políticas públicas para las familias productoras en La Plata y Oberá, concluye que se apunta a fortalecer a los pequeños productores mediante acciones que sostengan o aumenten su productividad, antes que a revertir las dificultades estructurales; a su vez, las acciones en lo comercial van en dirección de mantener a la agricultura familiar en espacios alternativos que ocupan un espacio intersticial dentro del mercado. En el análisis realizado hasta el año 2014, Seibane (2014) destaca al INTA y en menor medida a la UNLP, como dos de las instituciones del Estado con fuerte peso en las relaciones interinstitucionales, con una posición destacada en las redes y en los vínculos que establece con las otras instituciones públicas. Al mismo tiempo, esta autora identifica que la incorporación de una perspectiva de desarrollo territorial ha permitido una mayor apertura de las instituciones, avanzando en la conformación de diversas redes sociotécnicas que comienzan a realizar proyectos conjuntos; tanto en el plano interinstitucional como en la relación con el sector productivo, las redes identificadas son tipo malla, en las que se visualizan relaciones de horizontalidad, propiciando diferentes niveles de participación de los productores, brindando instancias de organización y fortalecimiento, y de circulación de diversos conocimientos. Finalmente, es importante remarcar que esta autora considera estratégico en la construcción y gestión de estas redes el rol de los técnicos en terreno, por contar con una visión más estratégica, relacionada con la gestación de procesos colectivos, considerando las problemáticas locales y las agendas institucionales.

Luego de esta breve reseña, es necesario remarcar que con la llegada al gobierno de la alianza Cambiemos en el año 2015, de manera progresiva se fueron dando de baja muchas de las políticas mencionadas, como la SAF, el programa Cambio Rural y el Monotributo Social Agropecuario; al mismo tiempo, las instituciones que tenían áreas destinadas a trabajar con este sector debieron replegarse por falta de apoyo institucional y/o financiamiento.

En cuanto a las políticas públicas vinculadas a la producción hortícola es importante destacar dos aspectos de suma relevancia, que requieren de políticas públicas concretas y que no han sido abordados hasta el momento. Un primer aspecto tiene que ver con la 
regulación en el uso de agroquímicos. En los últimos años han proliferado muchas leyes y ordenanzas tanto para la restricción como para la prohibición de uso de agroquímicos y para el fomento de las producciones agroecológicas. Independientemente de las dificultades para su aplicación, la Ordenanza 18.740/08 del Municipio de General Pueyrredón es un ejemplo en cuanto a la regulación de fumigaciones en áreas de producción intensiva periurbana, estableciendo un área de 1000 metros al ejido urbano, donde no se puede fumigar con agroquímicos. El municipio de La Plata, pese a las deficiencias en el modelo de producción, no ha avanzado en ese sentido, más allá del discurso punitivista de la actual gestión, que ha sido acompañado con intentos de políticas acotadas a la formalización y a la capacitación en Buenas Prácticas Agrícolas, que concentran las responsabilidades exclusivamente en las familias productoras y que por otro lado no han podido implementar (Ambort, 2017). Otro aspecto importante en la actualidad que requiere ser abordado, tiene que ver con la deficiencia en los controles en la comercialización de los agroquímicos, lo que ha quedado evidenciado a través de organismos del Estado e investigadores que han detectado en alimentos y en el ambiente agroquímicos prohibidos (Alonso et al., 2015; Arias, 2019; Colombo y otros, 2015; Sarandón y otros, 2015; Mac Loughlin et al., 2017); y con la regulación de la disposición final de los envases de agroquímicos (Selis, 2000; Garcia, 2011).

Ringuelet sostiene que desde la década de 1980 han existido acciones públicas, aunque sin una política clara y coordinada, implementando diversos tipo de acciones que se fueron superponiendo y que, desde el punto de vista de muchos productores y en ocasiones de los mismos técnicos, no acompañaron oportuna y suficientemente el crecimiento del sector, contrastando con los reclamos de los productores referidos a las políticas macrosociales (Ringuelet, 2009 en Seibane 2013). En relación a las políticas públicas para la agricultura familiar generadas durante los gobiernos kirchneristas, Ambort (2017) sostiene que a pesar de ser propuestas superadoras respecto de las políticas focalizadas del modelo de desarrollo rural previo, por su carácter universal e inclusivo, éstas presentan algunas limitaciones. En este sentido, y en sintonía con Tapella (2004), la autora encuentra limitaciones estructurales que tienen que ver con la convivencia de las iniciativas orientadas a la agricultura familiar con un modelo agropecuario fuertemente anclado en los agronegocios y en la producción de commodities para la exportación, en el cual la agricultura familiar se inserta como un actor subordinado y destinado a desaparecer (Ambort, 2017). Hang et al. (2015) al analizar las políticas públicas (nacionales, provinciales y municipales) de los últimos 25 años, evidencian la superposición y en parte la desarticulación entre herramientas implementadas en un mismo territorio, así como los distintos enfoques con que son concebidas gran parte de esas estrategias. Al mismo tiempo, estos autores encuentran que una proporción importante de funcionarios de los ámbitos nacional, provincial y/o municipal, carecen de una adecuada capacitación para poder 
manejar las políticas, que podría en parte ser explicado por la movilidad que se produce en la ocupación de determinados cargos o puestos jerárquicos en la administración pública (Hang et al. 2015).

Otra serie de políticas públicas de incumbencia para esta tesis son aquellas referidas a la regulación del uso del suelo en el partido de La Plata. La ciudad de La Plata, al ser creada de cero, tiene en sus orígenes una primer planificación, en la que se establecieron zonas destinadas a las distintas actividades productivas y habitacionales; una planificación que sin embargo, con el desarrollo de la ciudad y los múltiples intereses en pugna, se fue modificando y alejando de ese plan inicial (García y Lemmi, 2011).

Una de las primeras políticas en torno a la producción de alimentos, destacada por diversos autores, es la creación de colonias agrícolas de abastecimiento de productos frescos al área metropolitana, a instancias del Consejo Agrario Nacional en el marco del segundo plan quinquenal en los inicios de la década de 1950 (Cieza et al., 2015).

El primer plan específico orientado a generar un ordenamiento físico-funcional para la región, es el Plan Regulador Conjunto para los Partidos de La Plata y Ensenada (Plan URBIS), elaborado en el año 1961. Este plan se centraba en la densificación de casco histórico de La Plata y en la promoción del crecimiento de los núcleos urbanos alrededor de las estaciones de la línea ferroviaria en el área norte de la ciudad, impulsando un modelo de "ciudad lineal" (City Bell, Gonnet y Villa Elisa) (Frediani, 2010). Al igual que lo ocurrido en la etapa fundacional de la ciudad, esta autora pone en evidencia que contradictoriamente a las propuestas del plan, el mayor crecimiento urbano se produjo en las periferias, una tendencia que no se logró revertir; por el contrario se fue consolidando un modelo urbano de libre mercado que sigue hasta la actualidad.

En este mismo período se dio un impulso para el desarrollo de la industria de la construcción, acompañado por una política de viviendas de interés social. Esto permitió a los sectores asalariados de medios y bajos recursos acceder a la propiedad de la tierra en la periferia de la ciudad, construyéndose los barrios Aeropuerto, Villa Elisa, Villa Elvira y Tolosa (Frediani, 2010). A partir de estos procesos de urbanización ya se puede ver un proceso de segregación social, con la conformación de barrios residenciales al norte del partido y barrios populares al sur (García y Lemmi, 2011).

En 1977 se promulga la Ley de Ordenamiento Territorial y Usos del Suelo de la Provincia de Buenos Aires y en 1978 la Ordenanza 4495 de "Adecuación Preliminar". El incremento poblacional en áreas periféricas y extraurbanas hasta comienzos de la década del '90 genera finalmente el desborde de los límites propuestos en dicha Ordenanza (Frediani, 2010). Nuevamente se pueden ver las dificultades para implementar políticas de planificación del territorio. 
Posteriormente, y ante la necesidad de resguardar y proteger los buenos suelos productivos, se reglamentó en 1983 el Código Rural de la Provincia de Buenos Aires (Decreto Ley 2081), con un claro enfoque conservacionista (Hurtado, 2006)

En 1997, luego de casi 20 años sin cambios en la regulación y fuertes transformaciones urbanas y territoriales, se produce la actualización del código de ordenamiento urbano y territorial vigente desde 1979, con aportes de distintos actores de la academia, dando origen a un nuevo plan de ordenamiento territorial, aprobado en el año 2000 (Bozzano, 2014). Si bien en este nuevo plan habrían participado, como destaca Bozzano (2014), Colegios Profesionales (Arquitectura e Ingeniería), la Universidad (Arquitectura y Geografía) y la Cámara Argentina de la Construcción; es claro el sesgo profesional de los actores intervinientes en esta planificación, careciendo de los aportes de actores relevantes en el territorio como el INTA, la FCAyF, las organizaciones de productores familiares, entre otros.

En el año 2000 con la sanción de la Ordenanza 9231 de Ordenamiento Territorial y Usos del Suelo que reemplaza a la Ordenanza 4495/78, de Adecuación Preliminar de la Zonificación según Usos, se declara como área protegida la Zona Rural Intensiva, declarándola como área de protección para el uso hortícola y prohibiendo nuevos usos que no se correspondan con las actividades agrícola, hortícola y servicios asociados a ellas (Frediani, 2010). Esta autora destaca que a través de esta ordenanza se crean también zonas de preservación patrimonial, de protección de arroyos y bañados y de recuperación territorial (en cavas y canteras).

En el año 2010 se estableció el Código de Ordenamiento Urbano (COU), por Ordenanza Nro. 10703, el cual establece un ordenamiento del territorio, a partir de la diferenciación en tres áreas: urbana, complementaria y rural. Según el COU, en el área rural se diferencian una zona de subcentros rurales, una zona de clubes de campo, una zona rural intensiva y una zona rural extensiva. Este nuevo código es cuestionado por diversos sectores, por entender que responde a una lógica de obtención de ganancias del sector privado, prevaleciendo sus intereses por sobre la necesidad del sector público y la ciudadanía (Frediani, 2010).

En los últimos años, vienen creciendo diversas propuestas de desarrollo de una planificación colectiva del territorio, surgidas tanto desde ámbitos académicos como desde organizaciones de productores y productoras, y retroalimentadas a partir de numerosas instancias de articulación, que han reunido a productores, académicos, extensionistas, técnicos, funcionarios, entre otros. En el marco de estos encuentros, se ha generado un diagnóstico de las problemáticas actuales del territorio, se han esbozado posibles soluciones y definido aspectos prioritarios para proyectar el territorio; como se puede observar al 
analizar el documento final del "Re-encuentro periurbano: propuestas colectivas para la acción" ${ }^{\text {y }}$ del "Primer Foro Nacional por un Programa Agrario Soberano y Popular"7.

\section{HIPÓTESIS}

En la presente tesis pretendo realizar un abordaje amplio de las transformaciones ocurridas en el CHP y su situación actual, buscando alcanzar conclusiones que integren información proveniente de diferentes fuentes, considerando tanto los resultados cualitativos derivados del uso de sensores remotos y herramientas de Sistemas de Información Geográfica, como la percepción que del territorio tienen distintos actores sociales. Por este motivo, a diferencia de otros trabajos en los que cada capítulo se corresponde con una hipótesis, en este caso las hipótesis formuladas fueron generales y las abordé en más de un capítulo de manera parcial. En el capítulo de conclusiones, a partir de la integración de toda la información generada, analicé nuevamente cada hipótesis llegando a conclusiones definitivas.

\subsection{Hipótesis general}

1) La amplia expansión de la tecnología del invernáculo, que tuvo lugar en los últimos 30 años en el CHP, fue posible a expensas de la ocupación de áreas semi naturales y del reemplazo de cultivos al aire libre; afectando su distribución, conectividad y superficie total.

2) La estructura del paisaje remanente permite sostener y profundizar estrategias de manejo y planificación de base agroecológica, tendientes a generar un cambio en el modelo productivo.

3) En las condiciones actuales los productores no cuentan con estrategias de gestión del territorio adecuadas para generar y sostener en el tiempo un cambio en el modelo productivo hacia un modelo de bases agroecológicas.

\section{OBJETIVOS GENERAL Y OBJETIVOS ESPECÍFICOS}

\subsection{Objetivo general}

Analizar las transformaciones territoriales ocurridas en el Cinturón Hortícola Platense (CHP) durante los últimos 30 años, como consecuencia de los cambios en el modelo productivo, a fin de generar conocimientos y herramientas de utilidad para una planificación de uso sustentable del territorio.

\subsection{Objetivos específicos}

\footnotetext{
${ }^{6}$ https://owncloud.rio20.net/index.php/s/mxcpl26uQZcBg17

7 http:// foroagrario.org/ 
1) Identificar, caracterizar e interpretar los ambientes que componen el paisaje del CHP en cuatro momentos clave de los últimos 30 años de desarrollo del territorio.

2) Analizar los cambios temporales y espaciales ocurridos en los ambientes cultivados y no cultivados que componen el paisaje del CHP.

3) Identificar los actores sociales claves vinculados al CHP e indagar acerca de su visión respecto del modelo productivo actual, las problemáticas del mismo y las posibilidades de transitar un cambio hacia otro modelo de base agroecológica

4) Detectar fortalezas y debilidades de los cambios producidos en el territorio, desde un enfoque agroecológico.

5) Generar criterios que puedan ser utilizados en el rediseño de las áreas productivas y semi naturales presentes en el territorio, como estrategias de manejo, gestión y planificación del CHP y como herramienta para el desarrollo de políticas públicas, en el marco de la sustentabilidad.

\section{BIBLIOGRAFIA}

Aide TM, Clark ML, Grau HR, López-Carr D, Levy MA, Redo D, ... y Muñiz M (2013). Deforestation and Reforestation of Latin America and the Caribbean (2001-2010). Biotropica, 45(2), 262-271.

Alonso L, Bernasconi C, Ciciarelli A, De Castro C, Esteban C, Etchegoyen A, MacLoughlin T, Muntaner L, Ledesma R, Orofino L, Percudani C, Piccinini A, Rojo M, Santillán JM, Vittori S (2015). Plaguicidas: los condimentos no declarados. XIII jornadas de jóvenes investigadores grupo Montevideo. Ciencia, tecnología e innovación para la inclusión social. La Plata, Buenos Aires.

Altieri MA, Letourneau DL (1982). Vegetation management and biological control in agroecosistems. Crop Protection 1: 405-430. DOI: https://doi.org/10.1016/0261$\underline{\text { 2194(82)90023-0 }}$

Altieri MA (1999). Agroecología: bases científicas para una agricultura sustentable. Editorial Nordan Comunidad, Montevideo. Capítulo 3, pp. 47-70.

Altieri MA y Nicholls Cl (2000) Agroecología. Teoría y práctica para una agricultura sustentable. Serie Textos Básicos para la Formación Ambiental. Programa de las Naciones Unidas para el Medio Ambiente Red de Formación Ambiental para América Latina y el Caribe México D.F. 235pp.

Altieri MA y Nicholls Cl (2007). Conversión agroecológica de sistemas convencionales de producción: teoría, estrategias y evaluación. Revista ecosistemas, 16(1).Altieri MA, 
Toledo VM (2010). La revolución agroecológica de América Latina: rescatar la naturaleza, asegurar la soberanía alimentaria y empoderar al campesino. En: El Otro Derecho, $\mathrm{N}^{\circ} 42$.

Altieri MA, VM Toledo (2010). La revolución agroecológica de América Latina: rescatar la naturaleza, asegurar la soberanía alimentaria y empoderar al campesino. En: El Otro Derecho, № 42.

Ambort ME (2017). Procesos asociativos en la agricultura familiar: un análisis de las condiciones que dieron lugar al surgimiento y consolidación de organizaciones en el cinturón hortícola platense, 2005-2015 (Bachelor's thesis, Universidad Nacional de La Plata. Facultad de Humanidades y Ciencias de la Educación).

Argañaraz,JP, Pizarro GG, Zak M Landi MA, Bellis LM (2015). Human and biophysical drivers of fires in Semiarid Chaco mountains of Central Argentina. Science of the Total Environment, 520, 1-12.

Arias M (2019). Efecto del uso de fertilizantes y pesticidas sobre organismos acuáticos en arroyos de la zona hortícola de La Plata. Tesis Doctoral. Facultad de Ciencias Naturales y Museo, Universidad Nacional de La Plata. 147 pp.

Asteraky EJ, Hart BJ, Ings T, Manley WJ (2004). Factors influencing the plant and invertebrate diversity of arable field margins. Agriculture ecosystems and Environment 102: $219-231$.

Ávila H (2009). Periurbanización y espacios rurales en la periferia de las ciudades. Estudios Agrarios. Revista de la Procuraduría Agraria del Gobierno Federal Mexicano. Agosto. www.pa.gob.mx/publica/rev41/ANALISIS/7HECTORAVILA.pdf.

Aznar Sánchez JÁ (2011). El Clúster agroindustrial de la horticultura intensiva de Almería: Surgimiento, dinámica y perspectivas. Cuadernos de Estudios Agroalimentarios (CEA), (2), $199-217$.

Baldini C y Cieza RI (2017). Construcción de un mapeo participativo del periurbano de La Plata. En Periurbanos Hacia el Consenso: ciudad, ambiente y producción de alimentos: propuestas para reordenar el territorio. 1er Encuentro Nacional sobre Periurbanos e Interfases Críticas. INTA, Ciudad de Córdoba. 12 al 14 de septiembre del 2017.

Baloriani G, Paleologos MF, Marasas ME, Sarandón SJ (2009). Abundancia y Riqueza de la Macrofauna Edáfica (Coleoptera y Araneae), en Invernáculos Convencionales y en Transición Agroecológica. Arana, Argentina. Revista Brasilera de Agroecología. 4(2): $1733-1737$. 
Barchuk A, Suez L, Locati L (2017). Cobertura y uso de la tierra en el área periurbana de la ciudad de Córdoba, Argentina. Aportes a la planificación territorial. Revista de la asociación Argentina de ecología de paisajes, 7(1): 15-30.

Barsky A (2007). Globalización y Agricultura periurbana en Argentina. Escenarios, recorridos y problemas. Ada Svetlitza de Nemirovsky (coordinadora). Maestría en Estudios Sociales Agrarios. SerieMonografías ISSN, 2(2), 1.

Barsky A y Vio M (2007) La Problemática del Ordenamiento Territorial en Cinturones Verdes Periurbanos sometidos a Procesos de Valorización Inmobiliaria. El caso del Partido del Pilar, Región Metropolitana de Buenos Aires. IX Coloquio Internacional de Neocrítica. Universidade Federal do Rio Grande do Sul. Porto Alegre.

Barsky, A. (2013). Gestionando la diversidad del territorio periurbano desde la complejidad de las instituciones estatales implementación de políticas públicas para el sostenimiento de la agricultura en los bordes de la región metropolitana de Buenos Aires (2000-2013). Universitat Autónoma de Barcelona. Tesis doctoral. 340 Pp.

Baudrón S (2011). El mundo global y la transformación de las áreas metropolitanas de América latina de Nemirovsky, A.S. (Coord.): Globalización y agricultura periurbana en la Argentina. Escenarios, recorridos y problemas. Serie Monografías, Maestría en Estudios Sociales Agrarios, Flacso, Argentina.

Benencia R (2002). Transformaciones territoriales en la horticultura periurbana bonaerense en los últimos 50 años. El papel de la tecnología y la mano de obra. XIII Economic History Congress. Buenos Aires.

Bertoni JC, Ambrosino S, Barbeito O, Daniele A, Maza JA, Paoli CU, Serra JJ (2004). Inundaciones urbanas en la Argentina. GWP-SAMTAC; Programa Asociado de Gestión de Crecidas; Universidad Nacional de Córdoba. Secretaría de Ciencia y Técnica, SECyT; Comité Permanente de los Congresos Nacionales del Agua, Argentina; Arg CAP-NET.

Bestelmeyer BT, Goolsby D, Archer S (2012). Spatial perspectives in state-and-transition models: a missing link to land management? J Appl Ecol 48:746-757.

Biehl L y D Landgrebe (2002). MultiSpec, a tool for multispectral-hyperspectral image data analysis. Computers \& Geosciences, 28(10): 1153-1159.

Biggs R, Schlüter M, Biggs D, Bohensky EL, BurnSilver S, Cundill G, ... y Leitch AM (2012). Toward principles for enhancing the resilience of ecosystem services. Annual review of environment and resources, 37, 421-448. 
Blandi ML (2016). Tecnología del invernáculo en el Cinturón Hortícola Platense: análisis de la sustentabilidad y los factores que condicionan su adopción por parte de los productores (Doctoral dissertation, Facultad de Ciencias Agrarias y Forestales).

Blandi ML, Gargoloff NA, Sarandón SJ (2009). Análisis de la Sustentabilidad de la Producción Hortícola Bajo Invernáculo en la Zona de la Plata, Argentina. Revista Brasilera de Agroecología. 4(2):1635-1638.

Blandi ML, Sarandón SJ, Pereira Veiga IJ (2011). La "autoeficacia": un indicador de la conducta sustentable. Su importancia para el logro de sistemas hortícolas sustentables en La Plata, Argentina. VII Congreso Brasilero de Agroecología. Cuadernos de Agroecología, 6 (2):1-6.

Blandi ML, Paleologos MF, Sarandón SJ, Veiga IJ (2013). Identificación de impedimentos para avanzar hacia una "conducta sustentable" en pequeños horticultores de La Plata, Argentina. VIII Congreso Brasilero de Agroecología. Cuadernos de Agroecología, 8 (2).

Boccolini SM, Giobellina BL (2018). Reconstrucción histórica del territorio periurbano de producción hortícola de Córdoba, Argentina (1573-1900). Eutopía: Revista de Desarrollo Económico Territorial, (14), 83-110.

Bonicatto, M. M. (2018). Sustentabilidad y agrobiodiversidad: análisis de la conservación de semillas y conocimientos asociados en agroecosistemas familiares del Cinturón Hortícola Platense. Doctoral dissertation, Universidad Nacional de La Plata. 260 Pp.

Bongiorno M, Larrosa C, Maidana A, Arenas M, Cruz Y, López R Gianuzzi L, Cap GB (2009). Biofumigación con recursos locales: el caso de la producción hortícola de los quinteros del Parque Pereyra Iraola. Revista Leisa, 25 (4): 25-28.

Botana MI (2004). Aportes a la sustentabilidad ambiental de tierras productivas en espacios periurbanos. In Anales LINTA (Vol. 3). Laboratorio de Investigaciones del Territorio y el Ambiente (LINTA).

Bozzano H (2002). El Cinturón Verde Platense: Sistemas de objetos, sistemas de acciones. Foro CIVEBA, Cinturón Verde Metropolitano de Buenos Aires. Jornadas AADER de Argentina y el Mercosur, Facultad de Agronomía, UNLP, La Plata, 2002.

Bozzano H (2014). Ordenamiento del territorio e Inteligencia Territorial. Un enfoque aplicado a casos en La Plata (Argentina) y Minas (Uruguay). Polígonos, (26), 181-222.

Broccoli AM (2011). Agroecologia y la construcción de sistemas agroalimentarios sustentables. En: Seguridad y soberanía alimentaria. De Gorban K Miryam, et al. 1a 
ed. Buenos Aires: Colección Cuadernos, 2011. 192 p. ISBN 978-987-27283-1-1 1. Pag: 153-168.

CASAFE (2011). Cámara de Sanidad Agropecuaria y Fertilizantes. Guía de Productos Fitosanitarios. $15^{\circ}$ Edición. 2000 pp.

Carmo APC (2000). Evaluación de un paisaje fragmentado para la conservación y recuperación de biodiversidad - Área Demostrativa Miraflor Moropotente, Estelí, Nicaragua. Tesis de Maestría. CATIE, Turrialba, Costa Rica.137 p.

Cataldi VI, Flores C (2019). Análisis comparativo entre sistemas convencionales y en transición agroecológica desde el punto de vista de la economía convencional y de la economía del medio ambiente en el Cinturón Hortícola de La Plata. Buenos

Cavallero L, Mari NA, Carranza CA (2019) Ordenamiento Ambiental de Bosques y Ecosistemas Asociados para el Desarrollo Sustentable en el ejido del Municipio de Nono, Valle Traslasierra, Córdoba (Argentina). Ediciones INTA, Buenos Aires, 48 Pp.

Ceceña AE 2012. Dominar la naturaleza o vivir bien: disyuntiva sistémica. Debates urgentes, 1(1): 117-129.

CHFBA (2005). Censo Hortiflorícola de Buenos Aires. Ministerio de Asuntos Agrarios y Ministerio de Economía de la Prov. de Buenos Aires. Disponible en: http://www.maa.gba.gov.ar/agricultura_ganaderia/archivos/resultadofinal.pdf

Chuvieco E (1990). Fundamentos de teledetección espacial (Vol. 453). Madrid: Ediciones Rialp. 449 Pp.

Cieza RI (2018). Sistemas productivos periurbanos en el sur del Área Metropolitana de Buenos Aires. Cieza, R.I. (Coord). Ciudad Autónoma de Buenos Aires: Ediciones Ciccus. $175 \mathrm{Pp}$.

Cieza RI, Ferraris G, Seibane C, Larrañaga G, Mendicino L (2015). Aportes a la caracterización de la agricultura familiar en el Partido de La Plata Revista de la Facultad de Agronomía de La Plata. Vol. 114 (Núm. Esp.1). Agricultura Familiar, Agroecología y Territorio: 129-142.

CIPAF (2005). "Programa nacional de investigación y Desarrollo tecnológico para la pequeña Agricultura familiar. Documento base". (En línea) http://www.inta.gov.ar/cipaf/noa/infoboletin/ documentobase.pdf (1 de mayo de 2008).

Cittadini E, Cittadini R, Patrouilleau MM y LE Martínez (2017). Políticas públicas y desarrollo de la agroecología en Argentina. Pp. 33-72. En: Eric Sabourin ... [et al.] (organizadores). Políticas públicas a favor de la agroecología en América Latina y EI 
Caribe. Porto Alegre: Evangraf / Criação Humana, Red PP-AL: FAO, 412 Pp. Disponible en: http://www.fao.org/3/a-i8067s.pdf

Colombo JC, Astoviza M, Bilos C, Cappelletti N, Migoya C, Morrone M, Skorupka, C, Speranza E, Tatone L (2015). Subproyecto "Biogeoquímica de contaminantes". En: Relevamiento de la utilización de agroquímicos en la Provincia de Buenos Aires. Mapa de situación e incidencias sobre la salud. Defensor del Pueblo de la Provincia de Buenos Aires y UNLP.

Costanza R, Daly HE (1992). Natural capital and sustainable development. Conservation Biology 6:37-46.

Coraggio JL (2010). Territorio y economías alternativas. Revista de ciencias sociales, segunda época. 7 (18): 7-30

Cowling RM, Egoh B, Knight AT (2008). An operational model for mainstreaming ecosystem services for implementation. PNAS 105(28):9483-9488.

Dadon JR, Matteucci SD (Eds.). (2002). Zona Costera de la Pampa Argentina. Recursos Naturales, Sustentabilidad, Turismo, Gestión y Derecho Ambiental. Lugar Editorial, 224 pp. ISBN 950-892-140-4

Drozd A, Arturi M, Torrusio S (2010). Distribución de remanentes (1985-2006) de la Selva Atlántica Interior (SAI) en el centro de Misiones, Argentina en función de variables topográficas y edafológicas. RASADEP 1-Nº Especial 51: Cambios de uso de la tierra. Causas, consecuencias y mitigación. Pp.: 51-66. Asociación Argentina de Ecología de Paisajes.

Dubrovsky Berensztein N (2018). Estudio de la entomofauna en agroecosistemas del Cinturón Hortícola de La Plata, para el diseño participativo de estrategias de control biológico por conservación (Doctoral dissertation, Universidad Nacional de La Plata). On line: http://sedici.unlp.edu.ar/handle/10915/71094

Eliano GD, Somma D, Quintana R (2010). Análisis y evaluación del proceso de fragmentación de hábitat en un sector de Yungas argentinas. RASADEP 1-Número Especial 67: Cambios de uso de la tierra. Causas, consecuencias y mitigación. Pp.: 67-76. Asociación Argentina de Ecología de Paisajes

Ennis RC (2019). Una aproximación a la pérdida y desperdicio de alimentos a partir de la producción del Cinturón Hortícola Platense (Doctoral dissertation, Universidad Nacional de La Plata. Facultad de Humanidades y Ciencias de la Educación). 
Fahrig L, Baudry J, Brotons L, Burel FG, Crist TO, Fuller RJ, Sirami C, Siriwardena GM, Martin JL (2011). Functional landscape heterogeneity and animal biodiversity in agricultural landscapes. Ecology letters, 14(2), 101-112.

Fernández Lozano J (2012). La producción de hortalizas en Argentina. Gerencia de Calidad y Tecnología. Mercado Central de Bs. As. On line: https://www.academia.edu/23974120/La produccion de hortalizas en argentina

Fernández L (2019) Análisis de las políticas públicas para la agricultura familiar. Estudio de casos: La Plata y Oberá, 2008-2015. Revista Estudios Socioterritoriales. Editada por el Centro de Investigaciones Geográficas (CIG), Instituto de Geografía, Historia y Ciencias Sociales (IGEHCS), Facultad de Ciencias Humanas, UNCPBA/CONICET. (En prensa).

Fernández V, Marasas ME (2009). Estudio Preliminar de la Riqueza de Vegetación Arvense en Fincas de Producción Hortícola con Manejo Convencional y Bajo Principios Agroecológicos. Su Aporte al Proceso de Transición. Revista Brasileira de Agroecología. 4(2):3599-3603.

Fernández V, Marasas ME (2015). Análisis comparativo del componente vegetal de la biodiversidad en sistemas de producción hortícola familiar del Cordón Hortícola de La Plata (CHLP), provincia de Buenos Aires, Argentina. Revista de la Facultad de Agronomía, 114 (Núm. Esp. 1): 15-29.

Ferraris G, Bravo ML (2014). Organizaciones de productores hortícolas del Cinturón Verde de La Plata. Ensenada: VIII Jornadas de Sociología UNLP.

Fischer J, Lindenmayer DB, Manning AD (2006). Biodiversity, ecosystem function, and resilience: ten guiding principles for commodity production landscapes. Frontiers in Ecology and the Environment, 4(2), 80-86.

Flores C, Sarandón SJ, lermanó MJ (2007). Eficiencia energética en sistemas hortícolas familiares del partido de La Plata, Buenos Aires, Argentina. Revista Brasileira de Agroecología. 2(1):1060-1064.

Foley JA, DeFries R, Asner GP, Barford C, Bonan G, Carpenter SR (2005). Global consequences of land use. Science, 309(5734), 570-574. DOI: 10.1126/science.1111772

Forman, R. T. (1995). Some general principles of landscape and regional ecology. Landscape ecology, 10(3), 133-142.

Forman RT (2008). Urban regions: ecology and planning beyond the city. Cambridge: University Press. $478 \mathrm{Pp}$. 
Foro Agrario (2019). Foro Nacional por un Programa Agrario Soberano y Popular. Buenos Aires, Argentina. Primeras conclusiones. Disponible en: http://foroagrario.org/wpcontent/uploads/2019/06/Programa-Agrario-Soberano-y-Popular-Propuestas.pdf

Frediani JC (2010). Lógicas y tendencias de la expansión residencial en áreas periurbanas. El Partido de La Plata, Buenos Aires, Argentina, entre 1990 y 2010 (Doctoral dissertation, Universidad Nacional de La Plata. Facultad de Humanidades y Ciencias de la Educación). On line: http://sedici.unlp.edu.ar/handle/10915/3203

Galdeano-Gómez E, Aznar-Sánchez JA, Pérez-Mesa JC. (2012). Sustainability dimensions of agricultural development in Almería (Spain): The experience of 50 years. On line: https://www.econstor.eu/handle/10419/120533

García M (2011). El cinturón hortícola platense: ahogándonos en un mar de plásticos. Un ensayo acerca de la tecnología, el ambiente y la política. THEOMAI $n^{\circ} 23$, primer semestre 2011.

García M (2012). Análisis de las transformaciones de la estructura agraria hortícola platense en los últimos 20 años. El rol de los horticultores bolivianos. Tesis doctoral de la Facultad de Ciencias Agrarias y Forestales, UNLP.

García M (2014). Fuerza de trabajo en la horticultura de La Plata (Buenos Aires, Argentina): Razones y consecuencias de su competitividad. Trabajo y Sociedad, Núm. 22: 67-85.

García M. (2015a). Colonia hortícola o Barbarie: Diagnóstico y propuestas de cambio para el área hortícola platense. Boletín hortícola. 19 (53): 20-26.

García M (2015b). Horticultura de La Plata (Buenos Aires): Modelo productivo irracionalmente exitoso. Rev. Fac. Agron. La Plata, Vol 114 (Núm. Esp.1) Agricultura Familiar, Agroecología y Territorio: 190-201.

García, M. (2016). Capacidad competitiva y dinamismo en la horticultura de La Plata interpretada desde el enfoque basado en los aglomerados de empresas. Huellas, (20), 100-124.

García M (2016b). Acerca de la sustentabilidad y racionalidad del modelo productivo hortícola platense. FÉLIZ, M. LÓPEZ, E. y GARCÍA, M.(Comps.) Desarmando el modelo. Desarrollo, conflicto y cambio social tras una década de neodesarrollismo. Editorial el Colectivo, Buenos Aires, Argentina.

García M, Mierez L (2007). "Cultivos al aire libre. Importancia y razones en la región hortícola más capitalizada". Boletín Hortícola. Año 12, № 35. 
García M, Le Gall J (2009). Reestructuraciones en la Horticultura del AMBA: tiempos de boliviano. IV Congreso argentino y latinoamericano de antropología rural. Marzo de 2009.

García M, Lemmi S (2011). Territorios pensados, territorios migrados. Una historia de la formación del territorio hortícola platense. Párrafos Geográficos, 10(1), 245-274.

Gargoloff NA, Sisterna M, Bonicatto MM, Scelso L, Velarde I, Tejerina Alfaro C, Barrionuevo C, Baldini C, Cataldi V, Delgado I (2019). Transición Agroecológica y Sistema Participativo de Garantía en la Horticultura Platense. Primer Congreso Argentino de Agroecología. Facultad de Ciencias Agrarias de la Universidad Nacional de Cuyo.

Gibbs HK, Ruesch AS, Achard F, Clayton MK, Holmgren P, Ramankutty N (2010). Tropical forests were the primary sources of new agricultural land in the 1980s and 1990s. Proceedings of the National Academy of Sciences, 107, 16732-16737. DOI: https://doi.org/10.1073/pnas.0910275107

Giobellina B (2017). El cinturón verde de Córdoba: hacia un plan integral para la preservación, recuperación y defensa del área periurbana de producción de alimentos. Coordinadora Beatriz Giobellina; producción cartográfica Nicolás Mari, et al. 1a ed. Manfredi, Córdoba : Ediciones INTA. On line: https://inta.gob.ar/sites/default/files/intael-cinturon-verde-de-cordoba $0 . p d f$

Giobellina, B. (2018). Dinámicas territoriales del cinturón verde de Córdoba: Entre la extinción y su transformación en un parque agrario planificado y sustentable. En Giobellina, B. (Comp.) La alimentación de las ciudades. Ediciones INTA, Buenos $\begin{array}{lllll}\text { Aires. } & 258 & \text { Pp. } & \text { On }\end{array}$ https://inta.gob.ar/sites/default/files/inta la alimentacion de las ciudades.pdf

Gliessman SR, Rosado-May FJ, Guadarrama-Zugasti C, Jedlicka J, Cohn A, Méndez VE, Jaffe R (2007). Agroecología: promoviendo una transición hacia la sostenibilidad. Revista Ecosistemas, 16(1).

Gurrutxaga, M y Lozano PJ (2008). Ecología del Paisaje. Un marco para el estudio integrado de la dinámica territorial y su incidencia en la vida silvestre. Estudios Geográficos, LXIX, 265, pp. 519-543.

Haines-Young R, Green DR (1993). Landscape ecology and geographic information systems. Haines-Young R. \& D.R. Green (eds.). New York: Taylor and Francis. 329 Pp. 
Hajdu F, Penje O, Fischer K (2016). Questioning the use of 'degradation' in climate mitigation: A case study of a forest carbon CDM project in Uganda. Land Use Policy, 59, 412-422. DOI: https://doi.org/10.1016/j.landusepol.2016.09.016

Hang G, Bravo ML, Ferraris G, Larrañaga GF, Seibane C, Kebat CA, ... Blanco V (2013). Modalidades de trabajo y tenencia de la tierra en Sistemas Hortícolas localizados en el territorio Platense. República Argentina. Revista de la Facultad de Agronomía, 112(2), 131-140.

Hang GM, Bravo ML, Ferraris G, Larrañaga G, Seibane C, Kebat C (2015). El contexto, las políticas públicas y su relación con la horticultura en La Plata, Argentina. Revista de la Facultad de Agronomía, 114.

Herrera JM (2011). El papel de la matriz en el mantenimiento de la biodiversidad en hábitats fragmentados. De la teoría ecológica al desarrollo de estrategias de conservación. Revista Ecosistemas, 20(2-3).

HLPE (2019). High-Level Panel of Experts. Informe del Grupo de alto nivel de expertos en seguridad alimentaria y nutrición. Enfoques agroecológicos y otros enfoques innovadores en favor de la sostenibilidad de la agricultura y los sistemas alimentarios que mejoran la seguridad alimentaria y la nutrición. Fragmento del informe: resumen y recomendaciones. Comité de seguridad alimentaria mundial. FAO. Disponible en: http://www.fao.org/fileadmin/user upload/hlpe/hlpe documents/HLPE S and R/HLP E 2019 Agroecological-and-Other-Innovative-Approaches S-R ES.pdf

Holt Giménez E (2001). Measuring farms agroecological resistance to Hurricane Mitch. LEISA 17: 18-20.

Hurtado MA, Gimenez JE, Cabral MG (eds) (2006). Análisis ambiental del partido de La Plata: Aportes al ordenamiento territorial. Consejo Federal de Inversiones, $1^{\text {a }}$ ed.

INDEC (2010). Instituto Nacional de Estadística y Censos de la República Argentina. Censo Nacional de Población, Hogares y Viviendas (2010). On line: https://www.indec.gov.ar/nivel4 default.asp?id tema 1=2\&id tema 2=41\&id tema $3=$ $\underline{135}$

INTA (2007). Enfoque de Desarrollo Territorial. Programa Nacional de Apoyo Al Desarrollo de Los Territorios. Documento de Trabajo Nº 1.

IPES-Food. (2016). From uniformity to diversity: A paradigm shift from industrial agriculture to diversified agroecological systems. International Panel of Experts on Sustainable Food systems. http://www.ipes-food.org/ img/upload/files/CS2 web ES.pdf 
Karol JL, San Juan GA (2018). Saber qué hacer: construcción de un sistema para la gestión integrada del riesgo hídrico en la región del Gran La Plata. Eds. Jorge L. Karol; Gustavo San Juan. - 1a edición especial - Universidad Nacional de La Plata. Facultad de Arquitectura y Urbanismo, La Plata. On line:

Koschke L, Fuerst C, Frank S, Makeschin F (2012). A multi-criteria approach for an integrated land-cover-based assessment of ecosystem services provision to support landscape planning. Ecological Indicators, 21, pp: 54-66.

La Vía Campesina (2016). Declaración del Foro Internacional de Agroecología. Boletín Nyéléni, nro. 28, diciembre 2016. Disponible en: https://viacampesina.org/es/laagroecologia-en-una-encrucijada-boletin-nyeleni-num-28/

Lambin EF, Geist, HJ, Lepers, E. (2003). Dynamics of land-use and land-cover change in tropical regions. Annual review of environment and resources, 28(1), 205-241.

Le Gall J, García M (2010). "Reestructuraciones de las periferias hortícolas de Buenos Aires y modelos espaciales, ¿Un archipiélago verde?”. En EchoGéo, №11, Paris. Disponible en: <http://echogeo.revues.org/index11539.html>.

Lemmi S (2010). Horticultores platenses en la década del 90. Conflictos y enfrentamientos. Ponencia presentada en VI Jornadas de Sociología de la UNLP.

Liu ZH, Yang J Chang Y Weisberg PJ, He HS. (2012). Spatial patterns and drivers of fire occurrence and its future trend under climate change in a boreal forest of Northeast China. Glob Chang Biol; 18:2041-56.

López DR, Cavallero L, Easdale MH, Carranza C, Ledesma M y P Peri (2018). Chapter 5: resilience management at the landscape level: an approach to tackling socialecological vulnerability of agroforestry systems. In: Integrating Landscapes: Agroforestry for Biodiversity Conservation and Food Sovereignty (F Montagnini ed.), Advances in Agroforestry 12, Chapter 19, pp. 453-478. Springer International Publishing. ISSN 1875-1199.

Mac Loughlin TM, Peluso L, Marino DJ (2017). Pesticide impact study in the peri-urban horticultural area of Gran La Plata, Argentina. Science of the Total Environment, 598: 572-580.

Machin-Sosa B, Roque-Jaime AR, Avila-Lozano DR, Rosset P (2010). Revolución Agroecológica: el Movimiento de Campesino a Campesino de la ANAP en Cuba, Habana, ANAP. 
Manzanal MA (2014). Desarrollo: Una perspectiva crítica desde el análisis del poder y del territorio. Realidad Económica (283): 17-48.

Marasas ME, Sarandón SJ, Cicchino AC (2001). Changes in soil arthropod functional group in a wheat crop under conventional and no tillage systems in Argentina. Applied soil Ecology 18, pp: 61-68.

Marasas ME, Fernandez V, Baloriani G, Cap G Larrosa C, Rouaux J (2011). Estudio de la Agrobiodiversidad en Sistemas de Producción Hortícola Familiar. Buenos Aires, Argentina. VII Congreso Brasilero de Agroecología. Cuadernos de Agroecología, 6 (2):1-5.

Marasas ME, Cap G, Luca L, Pérez M, Pérez R (2012). El camino de la transición agroecológica. Ediciones INTA, Ciudad Autónoma de Buenos Aires.

Marasas ME, Fernández V, Dubrovsky Berensztein N (2014). Agrobiodiversidad en sistemas hortícolas familiares. Revista Leisa, 30 (1): 26-28.

Martens, F. (2012). Los envases "vacíos" de plaguicidas. En: Manual de horticultura periurbana. Mitidieri M.S y G.B. Corbino (Eds.). Ediciones INTA: San Pedro, Buenos Aires. $163 \mathrm{Pp}$.

Martínez-Vega J, Martín MP, Díaz Montejo JM, López Vizoso JM, Muñoz Recio FJ (2010). Guía didáctica de teledetección y medio ambiente. Madrid: Ministerio de Ciencia e Innovación. $197 \mathrm{Pp}$.

Martin-López B, González J, Díaz S, Castro I, García Llorente M (2007). Biodiversidad y bienestar humano: el papel de la diversidad funcional. Ecosistemas. 2007/3. On line: https://revistaecosistemas.net/index.php/ecosistemas/article/view/94

Matteucci SD (2002). La creciente importancia de los estudios del medio ambiente. Fronteras, Publicación del GEPAMA, Año1, №1.

Matteucci SD (2004). Los índices de configuración del mosaico como herramienta para el estudio de las relaciones patrón-proceso. Memorias del Primer Seminario Argentino de Geografía Cuantitativa, Fronteras, 1-29.

Matteucci, S.D.; J. Morello; A. Rodríguez; G.D. Buzai y C. Baxendale. 1999. El crecimiento de la metrópoli y los cambios de biodiversidad: el caso de Buenos Aires. En: S.D. Matteucci; O.T. Solbrig; J.Morello y G. Halffter. 1999. Biodiversidad y uso de la tierra. Conceptos y ejemplos de Latinoamérica. EUDEBA-UNESCO, Buenos Aires. Pp. 549580. 
May MP, Ciocchini I (2018). Hortalizas locales y amaranto, producciones identitarias en el periurbano platense ¿una alternativa a la homogeneización de la producci"on y de las dietas?. En: Sistemas productivos periurbanos en el sur del Área Metropolitana de Buenos Aires. Cieza, R.I. (Coord). Ciudad Autónoma de Buenos Aires: Ediciones Ciccus. $175 \mathrm{Pp}$.

McGarigal K y Cushman SA (2012). FRAGSTATS v4: Spatial Pattern Analysis Program for Categorical and Continuous Maps. Computer software program produced by the authors at the University of Massachusetts, Amherst. Available at the following web site: http://www.umass.edu/landeco/research/fragstats/fragstats.html

Medan D, Torretta JP, Hodara K, de la Fuente EB, Montaldo NH (2011). Effects of agriculture expansion and intensification on the vertebrate and invertebrate diversity in the Pampas of Argentina. Biodiversity and Conservation 20: 3077-3100. DOI: https://doi.org/10.1007/s10531-011-0118-9

Médico CM (2016). La vegetación como posibilidad de integración espacial, ambiental y social en los paisajes de interfase urbano-rural de la provincia de Mendoza. Revista de las Facultades de Arquitectura e Ingeniería. On line: http://www.um.edu.ar/ojsnew/index.php/FAl/article/view/794

Merchán AG (2016). Valorización de la tierra en el Cinturón Hortícola Platense Facultad de Ciencias Agrarias y Forestales. On line: http://sedici.unlp.edu.ar/handle/10915/53577

Mier M, Giménez-Cacho T, Giraldo OF, Aldasoro M, Morales H, Ferguson BG, Rosset P, Khadse A, Campos C (2019). Escalamiento de la agroecología: impulsores clave y casos emblemáticos. Cuaderno de trabajo No. 1. Grupo en masificación de la agroecología. Disponible en: https://www.researchgate.net/profile/Omar Giraldo/publication/333852555 Escalamien to de la agroecologia impulsores clave y casos emblematicos/links/5d08ef4f299bf 1f539cd1a7c/Escalamiento-de-la-agroecologia-impulsores-clave-y-casosemblematicos.pdf

Millennium Ecosystem Assessment (2005). Ecosystems and human well-being. Current state and trends. Washington, D.C.: Island Press.

MAGyP, Ministerio de Agricultura, Ganadería y Pesca. (2012). Bases para el ordenamiento del territorio rural argentino. Buenos Aires, Argentina.

Morello J, Matteucci SD (1997). El modelo agrícola del Núcleo Maicero como sistema complejo. En: J. Morello y O.T. Solbrig (comps.), La Pampa Ondulada: granero del mundo hasta cuando?. Orientación Gráfica Editora, SRL, Buenos Aires. Pp. 201-231 
Morello J, Matteucci SD (2000). Singularidades territoriales y problemas ambientales de un país asimétrico y terminal. Realidad Económica, 169, 70-96

Morello J, Matteucci SD, Rodriguez AF, Silva ME, Mesopotámica P, Llana P, Medanosa P (2012). "Ecorregiones y complejos Ecosistémicos de Argentina". Orientación Gráfica Editora, Buenos Aires

Nelson E, Mendoza G, Regetz J, Polasky S, Tallis H, Cameron D, Shaw M (2009). Modeling multiple ecosystem services, biodiversity conservation, commodity production, and tradeoffs at landscape scales. Frontiers in Ecology and the Environment, 7(1): 4-11.

Newbold T, Hudson LN, Hill SL, Contu S, Lysenko I, Senior RA, Day J (2015). Global effects of land use on local terrestrial biodiversity. Nature, 520(7545), 45. DOI: https://doi.org/10.1038/nature14324

Nicholls Cl (2009). Bases agroecológicas para diseñar e implementar una estrategia de manejo de hábitat para control biológico de plagas. En: Vertientes del pensamiento agroecológico: fundamentos y aplicaciones (Comp. Altieri, M.), pp. 207-228. SOCLA. Medellín, Colombia.

Nelson DR, Adger WN, Brown K (2007) Adaptation to environmental change: contributions of a resilience framework. Annu Rev Environ Resour 32:395-419

Nicholls Cl y Altieri MÁ (2012). Modelos ecológicos y resilientes de producción agrícola para el siglo XXI. Agroecología, 6, 28-37.

Nieto DP, Rivas GA (2006). Estudio socio-territorial de la actividad hortícola en el partido de La Plata 1998-2002. Geograficando: Revista de Estudios Geográficos, 2(2).

Nogué J (2007). La construcción social del paisaje. Barcelona: Biblioteca Nueva

Otero J, Larrañaga G, Hang GM (2013). La organización del trabajo en la horticultura familiar de La Plata (Argentina). Revista de la Facultad de Agronomía. 112 (2): 79-90.

Pacha MJ, Luque S, Galetto L, y Iverson L (Eds.) (2007). Understanding biodiversity loss: an overview of forest fragmentation in South America. Landscape Research and Management papers. International Association of Landscape Ecology.

Paruelo JM, Guerschman JP, Piñeiro G, Jobbagy EG, Verón SR, Baldi G, Baeza S (2006). Cambios en el uso de la tierra en Argentina y Uruguay: marcos conceptuales para su análisis. agrociencia, 10(2), 47-61.

Paruelo J, Jobbágy EG, Laterra P, Dieguez H, García Collazo MA, Panizza A (2014). Ordenamiento territorial rural. Conceptos, métodos y experiencias. Buenos Aires: 
Universidad de Buenos Aires, Ministerio de Agricultura, Ganadería y Pesca, Organización de las Naciones Unidas para la Alimentación y la Agricultura. Consultado el, 26(07), 2016.

Pengue W (2005a). Agricultura industrial y transnacionalización en América Latina ¿La transgénesis de un continente? Serie Textos Básicos para la Formación Ambiental. Grupo de Ecología del Paisaje y Medio Ambiente (GEPAMA). Universidad de Buenos Aires.

Pengue W (2005b). La importancia de la agricultura familiar en el desarrollo rural sostenible.

La Tierra, Año XCIII, Numero 7426. Rosario, Suplemento Especial Técnico Económico.

Pérez M, Marasas ME (2013). Servicios de regulación y prácticas de manejo: aportes para una horticultura de base agroecológica. Ecosistemas, 22(1):36-43.

Philpott SM, Lin BB, Jha S, Brines SJ (2009). "A multiscale assessment of hurricane impacts on agricultural landscapes based on land use and topographic features". Agriculture, Ecosystems and Environment, 128(1-2): 12-20.

Pielke RA, Pitman A, Niyogi D, Mahmood R, McAlpine C, Hossain F, ... de Noblet, N (2011). Land use/land cover changes and climate: Modeling analysis and observational evidence. Wiley Interdisciplinary Reviews: Climate Change, 2(6), 828-850. http://doi.org/10.1002/wcc.144

Piquer-Rodríguez M, Butsic V, Gärtner P, Macchi L, Baumann M, Pizarro GG, Kuemmerle T (2018). Drivers of agricultural land-use change in the Argentine Pampas and Chaco regions. Applied geography, 91, 111-122.

Potschin M, Haines-Young R (2013). Landscapes, sustainability and the place-based analysis of ecosystem services. Landscape Ecology, 28(6): 1053-1065.

QGIS, P. (2014). Quantum GIS.

Ramankutty N, Foley JA, Norman J, Mcsweeney K (2002). The global distribution of cultivable lands: Current patterns and sensitivity to possible climate change. Global Ecology and Biogeography, 11, 377-392. DOI: https://doi.org/10.1046/j.1466$\underline{822 x .2002 .00294 . x}$

Ramankutty N, Amato E, Monfreda TC, Foley JA (2008). Farming the planet: 1. Geographic distribution of global agricultural lands in the year 2000. Global Biogeochemical Cycles, 22. DOI: https://doi.org/10.1029/2007GB002952 
Risser PG, Karr JR, Forman RTT (1984). Landscape ecology: directions and approaches. Illinois Natural History Survey Special Publ. 2, Champaign.

Rockström J, Steffen W, Noone K, Persson Å, Chapin FS, Lambin E (2009). Planetary boundaries: Exploring the safe operating space for humanity. Ecology and Society, 14 (2):32.

Rosset P, Altieri MA (2018). Agroecología: ciencia y política. Sociedad Científica Latinoamericana de Agroecología (SOCLA), Ecuador. 208 Pp.

Ryszkowski L (2001). Landscape ecology in agroecosystems management. CRC Press. Estados Unidos. $379 \mathrm{Pp}$.

Salcedo S, A Sánchez y MJ Coloma (2014). Agricultura familiar y seguridad alimentaria. El exitoso caso del proyecto Forsandino, en: S. Salcedo \& L. Guzmán (editores). La Agricultura Familiar en América Latina y El Caribe. Recomendaciones de Políticas. FAO 3:57-78.

Sánchez H (2009). Periurbanización y espacios rurales en la periferia de las ciudades. Procuraduría Agraria, Estudios Agrarios. On line: http://www.pa.gob.mx/publica/rev 41/analisis/7\%20hector\%20avila.pdf

Sandoval, J.C. y J.F. Mas (2000). Análisis de la fragmentación del paisaje en el área protegida "Los Petenes", Campeche, México. Investigaciones Geográficas. Boletín del instituto de Geografía, UNAM Núm. 43, pp. 42-59.

Sans GHC, Aguiar S, Vallejos M, Paruelo JM (2018). Assessing the effectiveness of a land zoning policy in the Dry Chaco. The Case of Santiago del Estero, Argentina. Land Use Policy, 70, 313-321.

Santos M (2000). La naturaleza del espacio: técnica y tiempo, razón y emoción. España. Ed. Ariel. $345 \mathrm{Pp}$.

Saquet MA 2015. Por una geografía de las territorialidades y las temporalidades: una concepción multidimensional orientada a la cooperación y el desarrollo territorial. La Plata, Facultad de Humanidades y Ciencias de la Educación. 153 pp.

Sarandón SJ (2002). "La agricultura como actividad transformadora del ambiente. El Impacto de la Agricultura intensiva de la Revolución Verde". En Agroecología: El camino hacia una agricultura sustentable. S. J. Sarandón (Editor), Ediciones Científicas Americanas, La Plata. Cap. 1: 23-48. 
Sarandón SJ, Flores CC (2014). Agroecología: bases teóricas para el diseño y manejo de agroecosistemas sustentables. Ed. EDULP, La Plata. 466 p. Disponible en: https://libros.unlp.edu.ar/index.php/unlp/catalog/view/72/54/181-1.

Sarandón SJ, Flores CC, Abbona E, lermanó MJ, Blandi ML, Oyhamburu MM, Presutti (2015). Subproyecto "Análisis del uso de agroquímicos asociado a las actividades agropecuarias de la Provincia de Buenos Aires". En: Relevamiento de la utilización de agroquímicos en la Provincia de Buenos Aires. Mapa de situación e incidencias sobre la salud. Defensor del Pueblo de la Provincia de Buenos Aires y UNLP.

Sarandón SJ, Marasas ME (2015). Breve historia de la agroecología en la Argentina: orígenes, evolución y perspectivas futuras. Agroecología 10 (2), 93-102.

Sautu, R. (comp.); Boniolo, P; Dalle, P; Elbert, R. (2004). Manual de metodologína. Construcción del marco teórico, formulación de los objetivos y elección de la metodología. Consejo Latinoamericano de Ciencias Sociales, Buenos Aires.

Seibane C (2013). Estrategias de intervención públicas para el desarrollo territorial en el Cinturón Hortícola Platense: reflexiones y aportes sobre la dimensión comunicacional (Doctoral dissertation, Facultad de Periodismo y Comunicación Social), UNLP.

Seibane C, Larrañaga G, Kebat C, Hang G, Ferraris G, Bravo ML (2014). Redes para la promoción del desarrollo territorial en el cinturón hortícola platense: Reflexiones y aportes. Mundo agrario, 15(29).

Seibane C, Larrañaga G, Kebat C, Hang G, Ferraris G, Bravo ML (2014). Redes para la promoción del desarrollo territorial en el cinturón hortícola platense. Mundo Agrario 15 (28):19.

Selis D (2000) Los envases vacíos de agroquímicos en la República Argentina. En Congreso Latinoamericano de Ingeniería Agrícola y X Congreso Nacional de Ingeniería Agrícola, México.

Sevilla Guzmán ES, Montiel MS (2009). Del desarrollo rural a la agroecología. Hacia un cambio de paradigma. Documentación social, 155: 23-39.

Silva ME (2003). Efectos ecológicos de la expansión urbana sobre las tierras agrícolas de la Pampa Ondulada, Buenos Aires, Argentina. Tesis de Maestría en Ciencias Ambientales. Universidad de Buenos Aires. Facultad de Ciencias Exactas y Naturales.

Souza Casadinho J (2012). Las modificaciones en las estrategias productivas y comerciales de los productores hortícolas del AMBA frente a cambios estructurales. VII Jornadas de Sociología de la Universidad Nacional de La Plata. 
Souza Casadinho J (2013). La agroecología: bases científicas, historia local y estrategias productivas en la construcción de un espacio de desarrollo integral, ético y humano. pp. 13-29.

Staviski A (2010). Situación de la plasticultura en Argentina. En actas XXXIII Congreso Argentino de Horticultura. Rosario. Santa Fe. ASAHO.

Steffen W, Richardson K, Rockström J, Cornell SE, Fetzer I, Bennett EM, Folke C (2015). Planetary boundaries: Guiding human development on a changing planet. Science, 347(6223), 1259855. DOI: 10.1126/science.1259855

Szlavecz K, Warren P, Pickett S (2011). Biodiversity on the urban landscape. In Human Population (pp. 75-101). Springer, Berlin, Heidelberg.

Tadeo, N. (2001). "Cambios y persistencias en los nuevos procesos de organización del trabajo rural en la Argentina de los '90. El caso de la producción citrícola en el Nordeste Argentino". Proyecto enmarcado en el Programa de Incentivos a la Investigación, Secretaría de Políticas Universitarias, Ministerio de Cultura y Educación.

Tapella E (2004). "Reformas Estructurales en Argentina y su Impacto sobre la Pequeña Agricultura. ¿Nuevas Ruralidades, Nuevas Políticas?”. En Estudios Sociológicos, 22(3): 669-700. Revista del Colegio de México. Disponible en: http://www.redalyc.org/articulo.oa?id=59806606.

Teubal, M. (2001). "Globalización y nueva ruralidad en América Latina”. En: Giarraca, N. (Comp.) ¿Una nueva ruralidad?. CLACSO, Buenos Aires. Disponible en: http://bibliotecavirtual.clacso.org.ar/ar/libros/rural/teubal.pdf.

Tian Y, Jim C Y, Tao Y, Shi T (2011). Landscape ecological assessment of green space fragmentation in Hong Kong. Urban Forestry \& Urban Greening, 10(2), 79-86.

Tito G, Marasas ME (2014). “Actividad agropecuaria y desarrollo sustentable: ¿Qué nuevos paradigmas para una agricultura agroecológica? La Agroecología desde el concepto a la política pública". Pp. 89-100. En HERNÁNDEZ, V; GOULET, F; MAGDA, D. y GIRARD, N. (Comp.). La agroecología en Argentina y en Francia: miradas cruzadas. Ediciones INTA. Buenos Aires. 147 pp. Disponible en: https://inta.gob.ar/sites/default/files/script-tmp-inta agroecologia en argentina $y$ en francia miradas.pdf

Tittonell P (2014). Ecological intensification of agriculture-sustainable by nature. Current Opinion in Environmental Sustainability, 8, 53-61. 
Torrella SA, Ginzburg RG, Adámoli JM (2007). Análisis multitemporal de la fragmentación y reducción del Bosque de Tres Quebrachos. En: "Understanding biodiversity loss: an overview of forest fragmentation in South America". IALE Landscape Research and Management papers. International Association of Landscape Ecology.

Turner MG (1989). Landscape ecology: the effect of pattern on process. Annual review of ecology and systematics, pp. 171-197

Turner BL, Moss RH, Skole DL (1993). Relating land use and global land-cover change: A proposal for an IGBP-HDP core project. Report from the IGBPHDP Working Group on Land-Use/Land-Cover Change. Joint publication of the International GeosphereBiosphere Programme (Report No. 24) and the Human Dimensions of Global Environmental Change Programme (Report No. 5). Stockholm: Royal Swedish Academy of Sciences.

Uetz GW, Halaj J, Cady AB (1999). Guild Structure of Spider in Major Crops. The Journal of Arachnology, 27:270-280.

United Nations (2011). The great green technological transformation. United Nations publication.

United Nations (2015). The 2030 Agenda for Sustainable Development and its Sustainable Development Goals. On line: https://www.un.org/sustainabledevelopment/development-agenda/

United Nations (2019). Visita a la Argentina. Informe de la Relatora Especial sobre el derecho a la alimentación. A/HRC/40/56/Add.3 (16 de enero de 2019). On line: http://ap.ohchr.org/documents/dpage e.aspx?si=A/HRC/40/56/Add.3

UNLP (2017) Universidad Nacional de La Plata. La protección del cordón flori-hortícola debe ser una política de Estado. Comisión de soberanía alimentaria. Disponible en: https://unlp.edu.ar/frontend/media/46/2046/b99306f5d035c8e833921f7f8421d11a.pdf

UNLP (2019). Segundo Informe de sitios de distribución de alimentos, año 2019. Consejo Social, Universidad Nacional de La Plata. Disponible en: https://unlp.edu.ar/frontend/media/70/23370/b312f939d45c083884e441f55d837e52.pdf

Uy PD, Nakagoshi N (2008). Application of land suitability analysis and landscape ecology to urban greenspace planning in Hanoi, Vietnam. Urban Forestry \& Urban Greening, 7(1), 25-40. 
Van Driesche RG, Hoddle MS, Center TD (2007). Control de plagas y malezas por enemigos naturales. Forest Health Technology Enterprise Team (FHTET). U.S. Department of Agriculture (USDA). Traducido por: Enrique Ruiz Cancino y Juanita Coronada Blanca.

Vázquez P, Zulaica L, Sequeira N. (2017). Tasas de cambio de uso del suelo y agriculturización en el partido de Lobería, Argentina. Ciencias Agronómicas, Revista XXIX, Año 17: 028 - 036.

Vega E, Baldi G, Jobbágy EG, Paruelo J (2009). Land use change patterns in the Río de la Plata grasslands: The influence of phytogeographic and political boundaries. Agriculture, Ecosystems and Environment, 134(3-4), 287-292. http://doi.org/10.1016/i.agee.2009.07.011

Verbesselt J, Hyndman R, Newnham G, Culvenor D (2010). Detecting trend and seasonal changes in satellite image time series. Remote Sensing of Environment, 114(1), 106115.

Vergnes A, Kerbiriou C, Clergeau P (2013). Ecological corridors also operate in an urban matrix: a test case with garden shrews. Urban Ecosystems, 16(3), 511-525.

Vitousek PM (1994). Beyond global warming: ecology and global change. Ecology, 75(7), 1861-1876. DOI: https://doi.org/10.2307/1941591

Volante J (2009). Monitoreo de la cobertura y el uso del suelo a partir de sensores remotos, resultados 2006-2009. Informe Técnico Unificado. Programa Nacional de Ecorregiones (PNECO1643), INTA. Disponible en: https://www.researchgate.net/publication/278962502 Monitoreo de la Cobertura y e I Uso del Suelo a partir de sensores remotos

West PC, Gibbs H.K, Monfreda C, Wagner J, Barford CC, Carpenter SR (2010). Trading carbon for food: Global comparison of carbon stocks vs. crop yields on agricultural land. Proceedings of the National Acadademy of Sciences: Vol. 107, (pp. 1964519648). DOI: https://doi.org/10.1073/pnas.1011078107

Wiens JA, Stenseth NC, Van Horne B, Anker Ims R (1993). "Ecological mechanisms and landscape ecology". Oikos, 66 (3): 369-380.

Wohlfart C, Mack B, Liu G, Kuenzer C (2017). Multi-faceted land cover and land use change analyses in the Yellow River Basin based on dense Landsat time series: Exemplary analysis in mining, agriculture, forest, and urban areas. Applied Geography, 85, 73-88. DOI: https://doi.org/10.1016/j.apgeog.2017.06.004 
World Bank, 2018. Understanding poverty. Land topic. On line: http://www.worldbank.org/en/topic/land

Wu J (2013). Landscape sustainability science: ecosystem services and human well-being in changing landscapes. Landscape Ecology, 28(6): 999-1023.

Yang J, Jinxing Z (2007). The failure and success of greenbelt program in Beijing. Urban forestry \& urban greening, 6(4), 287-296.

Zhang W, Ricketts TH, Kremen C, Carney K, Swinton SM (2007). Ecosystem services and dis-services to agriculture. Ecological economics, 64(2): 253-260. 


\section{CAPITULO 2}

\section{TRANSFORMACIONES TERRITORIALES}

"Antes eran grandes quintas y no habia pequeños productores... empieza a cambiar el tema de la tierra... Primero fue la zona de El Peligro, que había mucha gente apaisanada que empezó a alquilar...y todo se fue acaparando en dos inmobiliarias, y eso también es un problema... hoy por hoy son monstruos esas inmobilirias...fueron viniendo más paisanos y fueron acaparando todo lo que es Etcheverry, Olmos. Así fue, fue de allá de Abasto...después fue por la ruta 36, después Arana... en los últimos tres años, fue toda la zona... tipo Oliden para allá... Esa zona era todo soja. Yo que recuerdo que iba mi hija, no habian

invernaderos por ahi. Ahora si vos vas es impresionante la cantidad de invernaderos que hay... La ganaderia se fue como alejando, más arrinconando, hacia las afueras. Lo que son granjas se fueron yendo más afuera, porque el pueblo también avanza... está lo urbano ahi al lado y la quinta está al lado... cada vez nos van pateando más lejos y el día de mañana no sé dónde vamos a ir a parar porque la producción hoy por hoy sale del campo, y todo lo que se come en la ciudad sale del campo"

Pequeño Productor Agroecológico 
El Partido de La Plata, y su área periurbana han sufrido notables cambios en las últimas décadas, que han delineado el actual uso/cobertura del suelo y generado conflictos socio-ambientales, en parte como resultado de los diferentes intereses y capacidades de intervención de los actores sociales presentes en el territorio (Botana 2004). Estas transformaciones territoriales están ineludiblemente vinculadas con los cambios políticoeconómicos que atravesó el país entre 1976 y 2001, con especial énfasis en la década de los 90'. Este período se caracterizó por la instalación de un modelo de carácter neoliberal basado en la especulación financiera, a través de un plan de gobierno que siguiendo los lineamientos del Consenso de Washington, impulsó el Plan de Convertibilidad desarrollado por el entonces Ministro de Economía Domingo Cavallo, en conjunto con un proceso de desregulación de los mercados, apertura al exterior y privatizaciones, en sintonía con un Estado que replegó su intervención en el sector productivo y en el espacio público convirtiéndose en promotor del capital privado (Ambort 2017, Frediani 2010, Teubal y Rodriguez 2002). En este contexto, la transnacionalización del agro (el ingreso de capital financiero en la producción), el proceso de revolución tecnológico-científica, el auge del supermercadismo y el creciente proceso de integración vertical, generaron fuertes transformaciones en el Sistema Agroalimentario Argentino, lo que conllevó a una creciente simplificación y homogeneización de los agroecosistemas, favoreciendo a las economías de gran escala; esto impactó especialmente en el sector de los pequeños productores, generando un fuerte deterioro de su tejido social, desplazando tanto a estos actores como a sus modelos tradicionales de producción (Feito 2014, Tapella 2004, Teubal y Rodriguez 2002). En el partido de La Plata, las nuevas formas de fragmentación socio-territorial son reflejo de este modelo de expansión económica basado en políticas neoliberales, como ejemplo de ello "este fenómeno general de privatización del espacio no hace más que reforzar el poder de los incluidos y el abandono de los excluidos" (Frediani 2010).

Entre las principales consecuencias de las transformaciones territoriales experimentadas en el área de estudio se destacan los procesos de degradación y erosión de suelos (Hurtado et al. 2006), pérdida de suelos productivos por actividades extractivas (Hurtado et al. 2006) y nuevas lógicas de ocupación (Botana 2004, Frediani 2010), cambios tecnológicos que han conducido al desarrollo de producciones hortícolas insustentables (García 2011, Sarandón et al. 2015, Blandi et al. 2015, Blandi 2016), contaminación de alimentos (Alonso et al. 2015), del suelo (Colombo et al. 2015) y cursos de agua que atraviesan el área (Mac Loughlin et al. 2017, Arias 2019), falta de cobertura de servicios e infraestructura, pérdida del patrimonio natural, deterioro paisajístico y fragmentación territorial (Botana 2004). Las consecuencias mencionadas anteriormente, derivadas de la forma en que se ha hecho uso del suelo en las últimas décadas, son también el resultado de 89 Lic. Carolina Baldini

Tesis doctoral - Territorio en movimiento 
deficiencias en cuanto a las políticas públicas orientadas a la planificación territorial; una problemática que viene siendo abordada por diversos autores. En este sentido, Bozzano (2014) sostiene que en América Latina, y por ende en nuestra región, gran parte de las regulaciones no son respetadas, lo que resulta en un ordenamiento territorial que termina desvirtuándose y desvalorizándose. Otros autores evidencian las deficiencias en la planificación del territorio en cuanto a la valoración de las áreas naturales y el rol que estas cumplen en la provisión de servicios ecosistémicos y en el mantenimiento de la capacidad productiva del territorio; Karol y San Juan (2018), Liscia et al. (2013) y Hurtado et al. (2006) evidencian la falta de una política de protección de los arroyos y ambientes riparios y la tendencia al entubamiento y la canalización de los arroyos cercanos al área urbana, eliminando la vegetación asociada y sus funciones. A su vez, Fingermann (2018) sostiene que las diversas ordenanzas municipales de ordenamiento territorial que han existido en el partido de La Plata, han sido pautadas en general a partir de los intereses en pugna, delineadas desde una mesa chica, sin intervención de los distintos actores y sin legitimación. En este contexto, la actividad productiva primaria no habría sido parte integrante en el momento de fijar los lineamientos para la planificación del territorio (Fingermann 2018). Botana (2004) por su parte sostiene que "el Estado ha actuado con una lógica <ausente>, debido a que no ha sido el facilitador e impulsor de concertaciones con y entre actores sociales con demandas, intereses y poderes de intervención diferentes sobre el espacio periurbano y sobre el medio ambiente. En ciertas ocasiones ha dejado de controlar, valorizar y no ha fomentado la equidad social, ya que ciertos grupos sociales se han visto favorecidos en desmedros de otros".

Otro aspecto que ha sido mencionado como problemático es la falta de información actualizada sobre los diversos usos del suelo y los cambios que estos han experimentado (Frediani 2010, García 2012). En muchas oportunidades, la falta de información lleva a que los proyectos de planificación y gestión ambiental se lleven a cabo en estado de emergencia, haciendo que obras que deberían haber generado una mayor calidad de vida, generen consecuencias negativas sobre los recursos naturales y los habitante (Hurtado et al. 2006). En este sentido, en los últimos años se empezaron a generar trabajos de investigación a escala territorial, con distinto grado de interdisciplinariedad en su desarrollo, que aportaron información interesante y de calidad para repensar un proyecto de planificación colectiva del territorio. Hurtado et al. (2006) realizaron un diagnóstico ambiental del partido de La Plata, con un interesante análisis espacial a partir de imágenes satelitales y un exhaustivo trabajo de campo, focalizado principalmente en aspectos geológicos e hidrológicos. Carut (2006) analizó los territorios en transición que surgen del proceso de dispersión suburbana en La Plata. Nieto y Rivas (2006) por su parte, analizaron las transformaciones territoriales del Cinturón Hortícola Platense entre 1998 y 2002 a partir de los datos censales existentes, y García (2012) realizó una profunda investigación sobre el 
proceso de conformación y consolidación de dicho cinturón hortícola en base a entrevistas, datos bibliográficos y estadísticos. En relación a los procesos de urbanización, Frediani (2010) desarrolló un extenso análisis sobre la expansión residencial en el periurbano de La Plata entre 1990 y 2010, recurriendo para ello a entrevistas, bibliografía existente y herramientas de SIG (Sistemas de Información Geográfica). Bozzano (2014) realizó un diagnóstico del proceso de ordenamiento territorial en el Municipio de La Plata entre 1995 y 2000. Los trabajos de Birche y Jersen (2018, 2018b) y de Jersen y Birche (2018) analizaron los espacios verdes urbanos y periurbanos existentes en la actualidad en el partido de La Plata, y el potencial rol de los arroyos en la conformación de una red de espacios verdes, mediante un relevamiento a campo y herramientas de SIG. Por otro lado, a partir de la inundación sufrida los días 2 y 3 de abril del 2013, se desarrollaron diversos proyectos de investigación con el fin de aportar conocimientos sobre el riesgo hídrico del partido de La Plata y establecer lineamientos para la planificación del territorio desde esta mirada; los trabajos de Liscia et al. (2013), Etulain y López (2017) y Karol y San Juan (2018) realizan aportes en este sentido, incorporando análisis de información meteorológica, caracterización de principales usos del suelo asociados a los arroyos, modelados hidrológico de la cuenca, diagnóstico de las principales obras hidráulicas realizadas, entre otros. Los trabajos mencionados anteriormente han hecho importantes aportes al conocimiento de las problemáticas del territorio. Sin embargo, no existen hasta el momento datos actualizados del uso del suelo en el partido, tanto en relación a la actividad hortícola como a la urbanización, tampoco se han realizado análisis de los cambios en el uso del suelo, que permitan identificar claramente las transformaciones ocurridas y visualizarlas espacialmente. Las aproximaciones realizadas en este sentido son en general basadas en análisis de datos censales, que suelen presentan un grado de error importante. Los análisis realizados a partir de imágenes satelitales datan del año 2006 y han estado enmarcados en un proyecto, como se mencionó anteriormente, mas focalizado en aspectos geomorfológicos e hidrológicos. La generación de información de los cambios en el uso del suelo, mediante herramientas de teledetección, que permita arribar a información más precisa y espacialmente explicita, se torna especialmente importante al ser La Plata el partido en el que se desarrolla el principal cinturón hortícola del país.

A partir de los datos existentes hasta el momento se han podido identificar algunos cambios en el territorio que se detallan a continuación. Desde mediados de la década del 80'y principios de la década del 90', el CHP ha experimentado un fuerte proceso de intensificación productiva (García y Mierez 2007). Esto ha sido resultado principalmente de la instalación de un modelo de producción intensivo acorde a los principios de la "Revolución Verde", que en nuestra región ha tenido características diferenciales producto de la incorporación de la tecnología del invernáculo (García 2015, García 2011, Sarandón 2002). Según García (2012) se generó una retracción y relocalización del área hortícola, en el 
marco de una mayor productividad por unidad de superficie, existiendo una movilización hacia el Sur (Poblet y Etcheverry). En el marco del proceso de intensificación productiva hubo un amplio crecimiento en la región de la producción bajo invernáculos, estimada por diversos autores a partir de datos censales e información secundaria. Según Nieto y Rivas (2006) este tipo de producción alcanzó entre 1998 y 2002 una tasa de crecimiento del 140\%. García y Mierez (2007) sostienen que entre 1998 y 2005 se observó un aumento del 83,3\% de cultivo bajo cubierta, mientras que el cultivo a campo disminuyó un 42,1\%. El Consejo Federal de Inversiones (CFI) estimó que para el año 2006, la superficie con invernáculos en el CHP llegaba a las 1300 has, y a principios del 2009 las principales empresas proveedoras de plásticos para la región inferían que la misma había superado las 3000 has (García 2011). Hurtado et al. (2006) a partir del análisis de imágenes satelitales calcularon que para esa fecha la agricultura intensiva representaba el 12,44\% (11115 Ha.) del partido, lo agropecuario extensivo un 59,22\% (52414 Ha.) y lo urbano $13,85 \%$ (12372 Ha.). Por otro lado, Stavisky (2010) estimó que para el año 2010 existían $4000 \mathrm{Ha}$. de invernáculos en toda la república Argentina, $2600 \mathrm{Ha}$. pertenecientes a producciones bajo cubierta (hortalizas, flores, viveros y aromáticas) en la provincia de Buenos Aires, de las cuales el 75\% (1.950 Has) se ubicaban en el Gran La Plata. Más allá de las diversas estimaciones, los datos oficiales más actualizados datan del CHFBA del año 2005. Sumado a esta información, Hurtado et al. (2006) analizaron la pérdida de suelos de alta calidad para la agricultura producto de la decapitación de suelos para la industria ladrillera, alertando respecto a la necesidad de implementar de manera urgente medidas de protección, conservación y, si es posible, recuperación, de los suelos productivos que aún quedan en el partido. Respecto al proceso de urbanización, Frediani (2010) expone la aceleración del proceso de dispersión urbana, evidenciado al identificar en el período intercensal 1991-2001 un crecimiento poblacional del $6 \%$ y un incremento de la superficie urbana del $12 \%$. Al mismo tiempo, esta autora plantea que tierras que se destinaban a explotaciones primarias intensivas presentan ahora otros usos del suelo propios de un área urbana, generando nuevos loteamientos y una revalorización del suelo; e identifica dos tendencias de expansión urbana, la localización de urbanizaciones cerradas fundamentalmente sobre los ejes noroeste y sudoeste, y la expansión urbana informal hacia el sector sur del Partido (principalmente en Romero, Los Hornos, San Lorenzo y Villa Elvira.

Como vimos, en el partido de La Plata tanto el uso extractivo como el crecimiento urbano se han desarrollado en detrimento del uso hortícola, afectando suelos de buena aptitud para la agricultura intensiva (Hurtado et al. 2006). Si bien desde sus orígenes el área bajo producción hortícola rodeaba al aglomerado urbano, razón por la cual era y sigue siendo denominado "cinturón hortícola", el área urbana ha ejercido una muy fuerte presión sobre este sector productivo, haciendo que se concentrara en un abanico desde la zona Sudoeste (delegaciones de Arturo Seguí, Melchor Romero, Lisandro Olmos y Abasto) y 
hasta el Sudeste (Arana) (García 2012). A su vez, al verse desplazado cada vez más hacia el sudeste, la horticultura estaría comenzando a ocupar áreas tradicionalmente utilizadas para uso agropecuario (agricultura extensiva, ganadería de cría, tambo, haras, etc.) (Frediani 2010, Hurtado et al. 2006).

En las últimas décadas viene adquiriendo importancia el estudio de los cambios en la cobertura terrestre y en la forma en que las personas hacen uso de ella; y el vínculo que esto tiene con problemas ambientales como el cambio climático y el ciclo del carbono, la pérdida de la biodiversidad, la sostenibilidad de la agricultura, y el suministro de agua potable, entre otros (Turner 2002, Lepers et al. 2005). La teledetección hace importantes aportes en este sentido, por su capacidad para monitorear procesos dinámicos; los análisis de cambio de cobertura/usos del suelo permiten detectar aquellas zonas estables y aquellas dinámicas, y al mismo tiempo identificar las tendencias de cambio o dicho de otra manera, las transiciones que se han producido en el tiempo entre distintas coberturas del suelo (Chuvieco 1998). El análisis de los datos del pasado permite comprender cómo y en que magnitud se ha transformado la composición de un paisaje, e identificar algunas de las dinámicas de cambio prevalecientes (Martellozzo 2018). En este sentido, poder explicar las dinámicas de un territorio y modelar el pasado, presente y futuro de una determinada región es sumamente importante para la toma de decisiones y la formulación de políticas públicas a diferentes escalas (NRC y GSC 2014). Existen numerosas investigaciones a nivel mundial y en nuestro país, que incorporan el análisis de cambio de coberturas/usos del suelo para analizar algunos de los principales procesos de cambio, como el crecimiento urbano, las transformaciones en paisajes agrícolas o la deforestación; brindando herramientas para la formulación de políticas públicas (ej: Piquer-Rodríguez et al. 2018, Martellozzo et al. 2018, Barchuk et al. 2017, Vallejos et al. 2015, Schulz et al. 2010). En una región con un amplio desarrollo periurbano, donde existen constantes tensiones por el uso del suelo, con una población en constante crecimiento que convive con importantes zonas productoras de alimentos, no existen hasta el momento análisis de este tipo, que permitan comprender las dinámicas territoriales que han modelado los periurbanos de esta región y que aporten elementos para proyectar un territorio más sustentable.

En el presente capítulo abordé las primeras dos hipótesis de esta tesis, que sostienen los siguientes postulados:

Hipótesis 1: La amplia expansión de la tecnología del invernáculo, que tuvo lugar en los últimos 30 años en el CHP, fue posible a expensas de la ocupación de áreas semi naturales y del reemplazo de cultivos al aire libre; afectando su distribución, conectividad y superficie total. 
Hipótesis 2: La estructura del paisaje remanente permite sostener y profundizar estrategias de manejo y planificación de base agroecológica, tendientes a generar un cambio en el modelo productivo.

Al mismo tiempo, avancé en parte de los primeros dos objetivos específicos de esta tesis:

Objetivo específico 1: Identificar, caracterizar e interpretar los ambientes que componen el paisaje del CHP en cuatro momentos clave de los últimos 30 años de desarrollo del territorio.

Objetivo específico 2: Analizar los cambios temporales y espaciales ocurridos en los ambientes cultivados y no cultivados que componen el paisaje del CHP

$Y$ finalmente generé información de utilidad para avanzar posteriormente en el desarrollo de los objetivos específicos nro. 4 y 5 .

Objetivo específico 4: Detectar fortalezas y debilidades de los cambios producidos en el territorio, desde un enfoque agroecológico.

Objetivo específico 5: Generar criterios que puedan ser utilizados en el rediseño de las áreas productivas y semi naturales presentes en el territorio, como estrategias de manejo, gestión y planificación del CHP y como herramienta para el desarrollo de políticas públicas, en el marco de la sustentabilidad.

\section{METODOLOGÍA}

2.1 Breve descripción del proceso de selección de las herramientas de clasificación consideradas más adecuadas

Las herramientas técnicas y metodológicas utilizadas en la clasificación a partir de imágenes satelitales, para generar mapas de coberturas/usos del suelo, son muy diversas en la actualidad, y su elección depende entre otros aspectos de los conocimientos técnicos de quienes realizan el trabajo, la capacidad de financiación (ya que algunas estrategias requieren un mayor financiamiento que otras para su concreción) y por supuesto, las características del área de estudio y los objetivos del trabajo. Teniendo en cuenta que el presente trabajo buscó desde sus inicios analizar los cambios en el uso del suelo en un periodo de tiempo de 30 años, entre 1985 y 2015, esto determinó que recurriera a la utilización de imágenes satelitales Landsat, por ser las únicas disponibles en la ventana temporal definida para el estudio. Otro de los aspectos a considerar fue la selección de los años a analizar dentro del periodo temporal mencionado anteriormente. En ese sentido, teniendo en cuenta la relevancia que el desarrollo de los invernáculos tiene para este estudio, definí trabajar con cuatro fechas (1985-1995-2005-2015), considerando los tres momentos clave en el desarrollo de la tecnología del invernáculo en el CHP, que Matías García define como "Oleadas de Invernáculos" (García 2011) y el momento en el que comencé la investigación (año 2015). En el transcurso de la investigación, teniendo en 
cuenta la disponibilidad de imágenes satelitales Landsat para el área de estudio, fuí ajustando dichas fechas, optando finalmente por analizar los años 1986, 1996, 2005 y 2015.

Inicialmente realicé clasificaciones no supervisadas para los años establecidos, con el software libre Qgis, utilizando una combinación de las bandas 2 a 7 de una imagen satelital Landsat 8 OLI para el año 2015 y una combinación de las bandas 1 a 6 de imágenes satelitales Landsat 5 ETM para los años previos, y analicé la respuesta espectral de distintas coberturas/usos del suelo. A partir de esto y del conocimiento general que tenía sobre el territorio, pude determinar once categorías de cobertura/usos del suelo, denominadas inicialmente: bosques, árboles y arbustos, vegetación intensa, vegetación débil, suelo semi-desnudo, suelo desnudo, suelo anegado, agua, invernáculos y urbano. Una vez obtenido este resultado preliminar, realicé salidas exploratorias al área de estudio, consulté a diversos especialistas y comencé a indagar diversas estrategias de clasificación para obtener resultados más ajustados a los objetivos del trabajo. Inicialmente evalué métodos simples de clasificación con imágenes de la estación más contrastante y al no presentar resultados satisfactorios fui complejizando los métodos, agregando variables externas como Modelos Digitales de Elevación (DEM) e Índices de Vegetación de Diferencia Normalizada (NDVI), filtros y bandas de distintas estaciones del año; de igual manera evalué diferentes algoritmos de clasificación (Maximum Likelihood, Spectral Angle Mapping, Parallelepiped, Mahalanobis Distance, Minimum Distance y Support Vector Machine) y herramientas de segmentación. Finalmente la metodología con la que obtuve mejores resultados implicó la clasificación conjunta de imágenes de distintas fechas del mismo año, como propone Chuvieco (1998), utilizando las bandas correspondientes al rojo, infrarrojo cercano e infrarrojo medio de cada fecha; y la utilización del algoritmo Support Vector Machine. Como estrategia para obtener una mejor diferenciación de categorías de cobertura/uso del suelo, fragmenté las imágenes a clasificar en tres zonas que clasifiqué separadamente (Área Rural Intensiva, Área Rural Extensiva y Área Urbana). Las área Rural Intensiva y Rural Extensiva fueron definidas tomando como referencia la zonificación presente en el Sistema de Información Ambiental provincial "Urbasig", basado en la Ley 8912/77 y el área urbana se digitalizó. Como paso final generé un mosaico de las clasificaciones resultantes para obtener un único producto.

\section{2 ¿Cómo se generaron los mapas definitivos de cobertura/usos del suelo?}

Para la generación de los mapas de coberturas/usos del suelo obtuve imágenes satelitales Landsat (path/row 224/084) de diferentes meses, para los años 1986, 1996, 2005 y 2015, con el fin de cubrir las diferencias estacionales. Las imágenes seleccionadas fueron aquellas bajo condiciones de cielo relativamente despejado ( $<10 \%$ nubosidad). A partir de ello, generé una combinación de las bandas del rojo, infrarrojo cercano e infrarrojo medio para cada año (Cuadro 1) y posteriormente las dividí en las sub-regiones, para clasificarlas 
por separado. Para la generación de los mapas de coberturas/usos del suelo definí 13 categorías: urbanización de alta densidad, urbanización de baja densidad, parquizaciones herbáceas, parquizaciones arboladas, agua, invernáculos, horticultura, agricultura, ganadería, plantaciones forestales, pastizales, vegetación ribereña y árboles y arbustos (Cuadro. 2). Teniendo en cuenta estas categorías realicé clasificaciones supervisadas con el algoritmo Support Vector Machine, utilizando el software ENVI (Mountrakis et al. 2011) (ENVI 4.7). Los resultados de la clasificación de las sub-región fueron unificados en un único producto para obtener un mapa de las coberturas/usos del suelo para cada año, realizado a una escala de análisis 1:50000.

\section{Cuadro 1}

Características de las imágenes Landsat utilizadas en el proceso de clasificación para obtener los mapas de coberturas/usos del suelo del Partido de La Plata.

\begin{tabular}{|c|c|c|c|}
\hline \multirow{2}{*}{$\begin{array}{l}\text { COMPOSICION } \\
\text { RASTER }\end{array}$} & \multirow{2}{*}{ SATÉLITE } & \multirow{2}{*}{$\begin{array}{c}\text { BANDAS } \\
\text { COMBINADAS }\end{array}$} & \multirow{2}{*}{$\begin{array}{c}\text { FECHA DE } \\
\text { ADQUISICIÓN }\end{array}$} \\
\hline & & & \\
\hline \multirow{3}{*}{$\begin{array}{l}\text { COMPOSICIÓN } \\
\text { RASTER } 1986\end{array}$} & \multirow{3}{*}{ Landsat 5 TM } & 3,4 y 5 & 13-Ene-1986 \\
\hline & & 3,4 y 5 & 24-Jul-1986 \\
\hline & & 3,4 y 5 & 13-Nov-1986 \\
\hline \multirow{6}{*}{$\begin{array}{l}\text { COMPOSICIÓN } \\
\text { RASTER } 1996\end{array}$} & \multirow{6}{*}{ Landsat 5 TM } & 3,4 y 5 & 13-Mar-1996 \\
\hline & & 3,4 y 5 & 1-Jun-1996 \\
\hline & & & \\
\hline & & 3,4 y 5 & 7-Oct-1996 \\
\hline & & 3,4 y 5 & 24-Nov-1996 \\
\hline & & 3,4 y 5 & 26-Dic-1996 \\
\hline \multirow{4}{*}{$\begin{array}{l}\text { COMPOSICIÓN } \\
\text { RASTER } 2005\end{array}$} & \multirow{4}{*}{ Landsat 5 TM } & 3,4 y 5 & 17-Ene-2005 \\
\hline & & 3,4 y 5 & 2-Feb-2005 \\
\hline & & 3,4 y 5 & 30-Sept-2005 \\
\hline & & 3,4 y 5 & 17-Nov-2005 \\
\hline \multirow{6}{*}{$\begin{array}{l}\text { COMPOSICIÓN } \\
\text { RASTER } 2015\end{array}$} & \multirow{6}{*}{ Landsat $8 \mathrm{OLI}$} & 4,5 y 6 & 29-Ene-2015 \\
\hline & & 4,5 y 6 & 18-Mar-2015 \\
\hline & & 4,5 y 6 & 19-Abr-2015 \\
\hline & & 4,5 y 6 & 5-May-2015 \\
\hline & & 4,5 y 6 & 24-Jul-2015 \\
\hline & & 4,5 y 6 & 29-Nov-2015 \\
\hline
\end{tabular}


Posteriormente, realicé una evaluación visual de la precisión de las clasificaciones resultantes y un procesamiento manual posterior para mejorarlas (Congedo 2016, Qgis 2016). Para interpretar las diferentes coberturas en las imágenes satelitales, tomé 252 puntos GPS (Sistema de Posición Georeferenciada) distribuidos regularmente en el partido de La Plata, entre julio y octubre de 2016 y entre abril y mayo de 2017. Cada cobertura/uso del suelo se caracterizó en el terreno y se observó la firma espectral en las imágenes Landsat de la misma época. Para aquellas áreas de difícil acceso se utilizaron imágenes de alta resolución SPOT 6 / Worldview de Google Earth. Complementariamente realicé entrevistas informales a los propietarios/arrendatarios de la tierra, funcionarios públicos, investigadores y técnicos especialistas en el área de estudio, para obtener información sobre los usos/coberturas del suelo actuales y pasados.

En la zona de estudio existen granjas (principalmente para la producción de huevos) e invernaderos utilizados para la floricultura, cuyas estructuras tienen una respuesta espectral similar a la de los invernaderos hortícolas. Como ambas producciones son menos representativas en el partido de La Plata y relativamente estables en el tiempo (treinta granjas correspondientes a pequeñas y medianas empresas familiares y $200 \mathrm{Ha}$. de floricultura) (Cieza et al. 2015), se unificaron bajo la categoría Invernáculos. Además, la categoría Ganadería incluía a granjas de producción de leche por ser menos representativas en el área de estudio (Cieza et al. 2015). Finalmente, existe en el partido de La Plata un aeródromo, que funciona principalmente como sede de escuelas de vuelo, dentro del cual se identificaron diferentes usos/coberturas del suelo (vegetación con un alto grado de intervención antrópica, vegetación semi-natural de crecimiento espontáneo y cultivos extensivos). Para los objetivos del presente trabajo consideré más adecuado incluir cada sector del aeródromo en la categoría de cobertura/uso identificada a partir del análisis y de las observaciones a campo.

\section{Cuadro 2.}

Categorías de coberturas/usos del suelo en el Partido de La Plata CATEGORIAAS DE

COBERTURAS/USOS DEL

SUELO

URBANIZACIÓN DE ALTA DENSIDAD

\section{DESCRIPCIÓN}

MUESTRAS DE IMÁGENES

SATELITALES

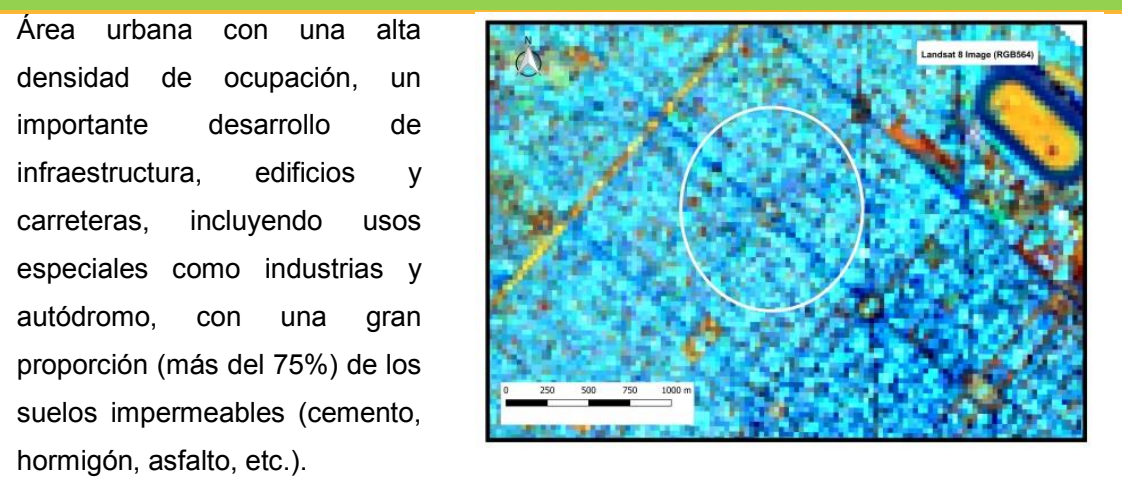




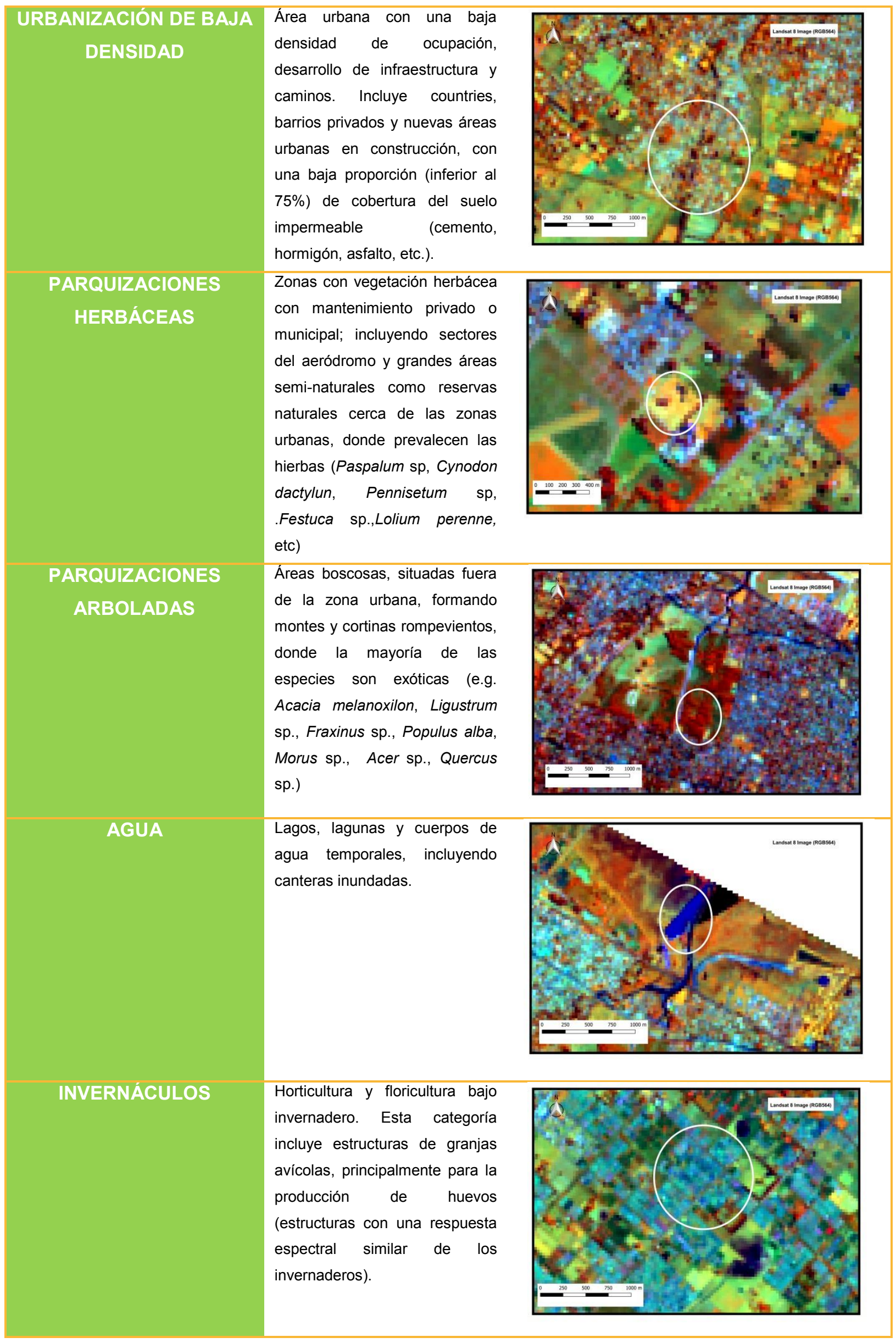




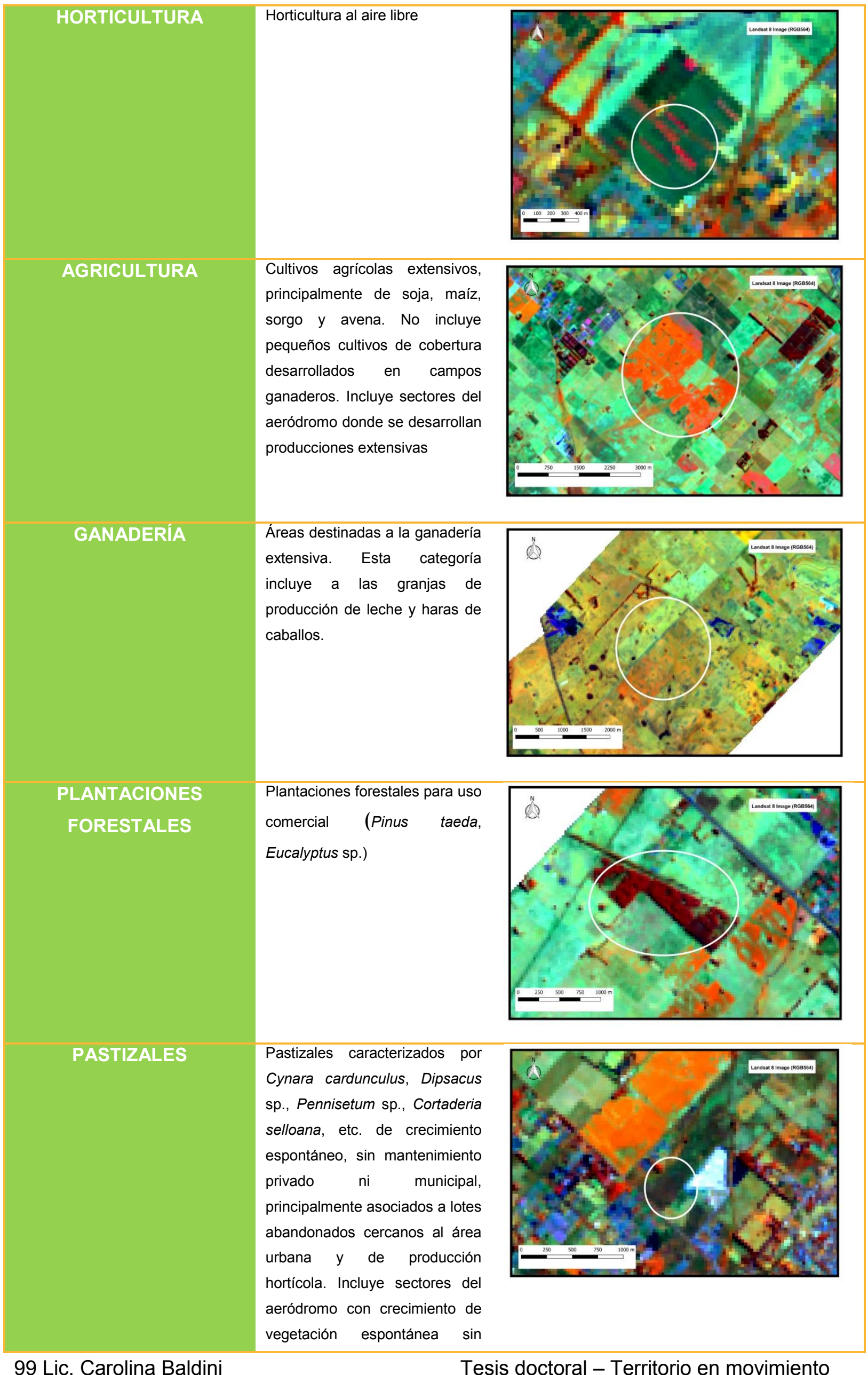




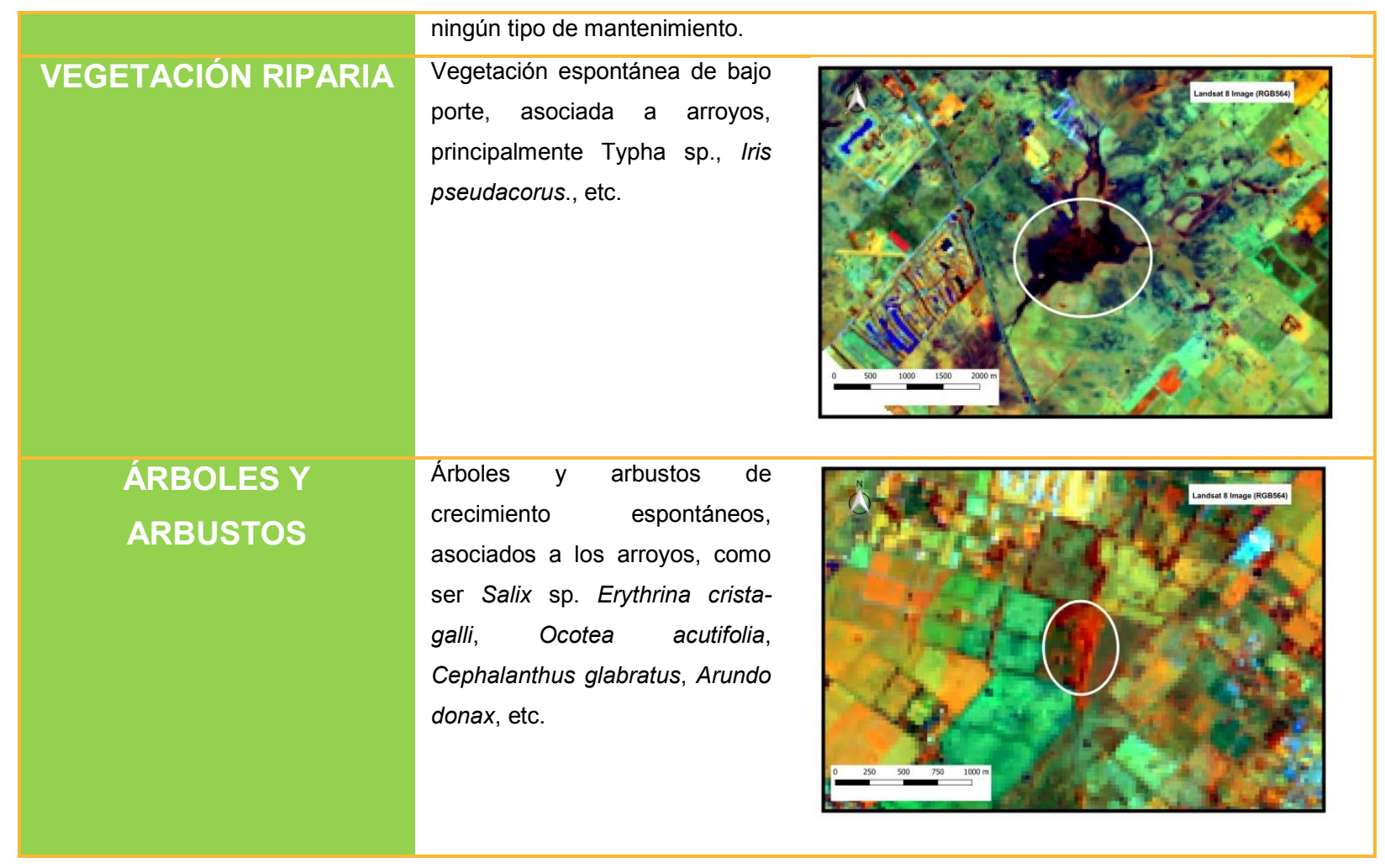

\section{3 ¿Cómo se validaron los mapas obtenidos?}

Los mapas de cobertura/usos del suelo definitivos obtenidos para cada año fueron validados con una serie de polígonos seleccionados en cada clasificación y contrastados con los mismos puntos en imágenes Google Earth del mismo año, y en imágenes Landsat, cuando las imágenes de alta resolución espacial estaban ausentes. Los polígonos se definieron siguiendo dos criterios: 1 . Cubrir al menos un $1 \%$ de la superficie de cada categoría y 2. Que la distribución de los polígonos sea lo más homogénea posible dentro del partido de La Plata. Los polígonos fueron hechos sobre la base de la respuesta espectral de las distintas coberturas y complementados con viajes de campo y conocimiento de expertos. Se elaboraron matrices de confusión, y se calcularon la precisión global y el coeficiente Kappa para cada clasificación (Congalton y Green 2008) (Anexo 1).

\section{4 ¿Cómo se analizaron los cambios de coberturas/usos del suelo?}

Una vez obtenidos los mapas de coberturas/usos del suelo procedí a analizar los cambios en dichas coberturas/usos para tres períodos (1986-1996/1996-2005/2005-2015). Para cada período analizado obtuve una matriz de cambios a partir de un procedimiento de tabulación cruzada entre clasificaciones, y calculé el cambio neto, las pérdidas, las ganancias, las persistencias y las contribuciones relativas de cada cobertura/uso al cambio, para cada período, con la extensión de IDRISI Land Change Modeler (Eastman et al. 2005). Luego calculé las tasas de crecimiento y decrecimiento para cada categoría y para cada período. Finalmente, analicé los Procesos de Cambio de Paisaje (LCP, Land Change Process) para cada categoría y para cada período de cambio, con la herramienta de Análisis 
de Patrones y Procesos de Cambio del Paisaje (Landscape Pattern and Change Process Analysis) disponible en la extensión Land Change Modeler de IDRISI. Esta herramienta comparalos mapas de cobertura/uso del suelo anterior y posterior y mide la naturaleza del cambio en curso dentro de cada clase de cobertura del suelo, siendo posible identificar hasta diez posibles procesos de cambio (Cuadro 3 ).

Cuadro 3. Categorías de procesos de cambio del paisaje para cada clase, en la que los procesos se pueden clasificar. Basado en Bogaert (2004) y en Eastman (2012).

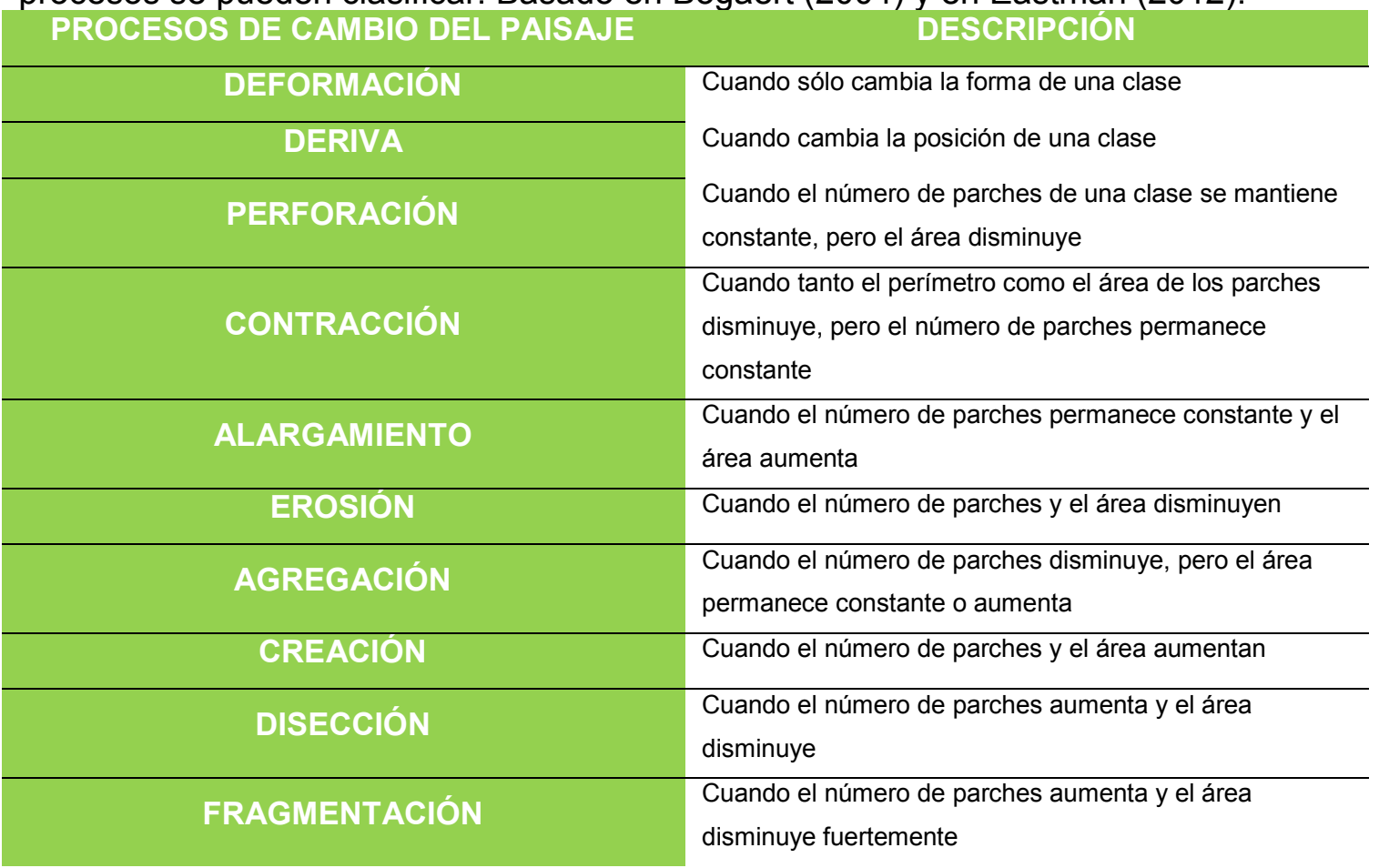

\section{RESULTADOS}

\subsection{LOS MAPAS DE COBERTURAS/USOS DEL SUELO DEL PARTIDO DE LA PLATA}

\subsection{1 ¿Qué validez tienen los mapas de cobertura/uso del suelo obtenidos?}

Como resultado de las clasificaciones supervisadas se obtuvieron mapas de cobertura/uso del suelo con 13 categorías, para 1986, 1996, 2005 y 2015. La clasificación de 1986 presentó una precisión global de $94.26 \%$ y un coeficiente kappa de 0,92. La clasificación de 1996 mostró una precisión global de $91.97 \%$ y un coeficiente kappa de 0,90. La clasificación del 2005 presentó una precisión global de $95.50 \%$ y un coeficiente kappa de 0,95. Por último, la clasificación del año 2015 presentó una precisión global de 95.55\% y un coeficiente kappa de 0,95 (Cuadro 4). Las matrices de confusión resultantes se presentan en el Anexo 1, junto con fotografías de las principales categorías de cobertura/uso del suelo establecidas. 
Cuadro 4. Análisis de precisión de los mapas de coberturas/usos del suelo generados para el partido de La Plata para 1986, 1996, 2005 y 2015, mostrando los valores de precisión del productor, precisión del usuario y coeficiente kappa obtenidos para cada clase de cobertura/uso; y la precisión global y el coeficiente kappa para cada mapa de coberturas/usos del suelo.

\begin{tabular}{|c|c|c|c|c|c|c|c|c|c|c|c|c|}
\hline \multirow{2}{*}{$\begin{array}{c}\text { CLASES DE } \\
\text { COBERTURA/USO } \\
\text { DEL SUELO }\end{array}$} & \multicolumn{4}{|c|}{$\begin{array}{c}\text { PRECISIÓN DE } \\
\text { PRODUCTOR [\%] }\end{array}$} & \multicolumn{4}{|c|}{$\begin{array}{c}\text { PRECISIÓN DE USUARIO } \\
{[\%]}\end{array}$} & \multicolumn{4}{|c|}{ COEFICIENTE KAPPA } \\
\hline & 1986 & 1996 & 2005 & 2015 & 1986 & 1996 & 2005 & 2015 & 1986 & 1996 & 2005 & 2015 \\
\hline $\begin{array}{l}\text { Urbanización de } \\
\text { Alta Densidad }\end{array}$ & 97.81 & 99.90 & 100 & 99.10 & 89.72 & 94.65 & 95.54 & 94.83 & 0.89 & 0.94 & 0.95 & 0.94 \\
\hline Invernáculos & 98.11 & 90.51 & 99.60 & 100 & 100 & 100 & 100 & 99.58 & 1.00 & 1.00 & 1.00 & 1.00 \\
\hline Agua & 100 & 100 & 100 & 99.07 & 100 & 93.33 & 76.27 & 81.54 & 1.00 & 0.93 & 0.76 & 0.81 \\
\hline $\begin{array}{c}\text { Parquizaciones } \\
\text { Arboladas }\end{array}$ & 89.86 & 83.04 & 93.91 & 94.85 & 91.10 & 95.88 & 96.43 & 92.47 & 0.91 & 0.96 & 0.96 & 0.92 \\
\hline $\begin{array}{c}\text { Parquizaciones } \\
\text { Herbáceas }\end{array}$ & 65.91 & 66.10 & 81.01 & 93.58 & 97.48 & 91.00 & 96.24 & 90.22 & 0.97 & 0.91 & 0.96 & 0.90 \\
\hline Árboles y Arbustos & 81.51 & 86.83 & 93.68 & 94.79 & 72.93 & 90.63 & 94.77 & 98.91 & 0.73 & 0.90 & 0.95 & 0.99 \\
\hline Pastizales & 91.11 & 89.06 & 90.17 & 96.66 & 92.76 & 90.48 & 96.20 & 94.44 & 0.92 & 0.90 & 0.96 & 0.94 \\
\hline $\begin{array}{c}\text { Plantaciones } \\
\text { Forestales }\end{array}$ & 100 & 100 & 100 & 100 & 72.73 & 100 & 100 & 100 & 0.73 & 1.00 & 1.00 & 1.00 \\
\hline Vegetación Riparia & 81.23 & 93.61 & 96.73 & 91.09 & 86.09 & 77.10 & 88.02 & 89.19 & 0.85 & 0.74 & 0.86 & 0.88 \\
\hline Horticultura & 98.19 & 98.31 & 99.72 & 98.14 & 95.64 & 96.79 & 96.75 & 96.34 & 0.95 & 0.97 & 0.97 & 0.96 \\
\hline Agricultura & 91.26 & 96.23 & 97.92 & 97.27 & 95.26 & 86.73 & 97.56 & 99.07 & 0.95 & 0.86 & 0.97 & 0.99 \\
\hline Ganadería & 98.10 & 89.91 & 94.35 & 95.96 & 96.86 & 95.83 & 98.02 & 96.78 & 0.94 & 0.93 & 0.97 & 0.96 \\
\hline $\begin{array}{l}\text { Urbanización de } \\
\text { Baja Densidad }\end{array}$ & 91.98 & 96.07 & 97.52 & 92.41 & 92.99 & 94.31 & 96.14 & 97.95 & 0.92 & 0.93 & 0.96 & 0.97 \\
\hline $\begin{array}{c}\text { Precisión Global } \\
{[\%]}\end{array}$ & 94.26 & 91.97 & 95.50 & 95.55 & & & & & & & & \\
\hline $\begin{array}{l}\text { Coeficiente Kappa } \\
\text { de la clasificación }\end{array}$ & 0.92 & 0.90 & 0.94 & 0.95 & & & & & & & & \\
\hline
\end{tabular}




\subsubsection{Mapas de cobertura/uso del suelo del partido de La Plata en diferentes momentos de su desarrollo}

A partir del mapa de coberturas/usos del suelo obtenido para el año 1986 (Fig. 1) podemos identificar que la principal cobertura/uso en ese momento era la Ganadería, ocupando un $53,50 \%$ de la superficie del partido, seguida por la Horticultura $(9,83 \%)$, la Urbanización de Baja Densidad (9,20\%), la Vegetación Riparia (7,06\%), el Pastizal (6,84\%) y la Urbanización de Alta Densidad (6,49\%). En conjunto la Urbanización de Alta Densidad y la Urbanización de Baja Densidad representaban en dicha fecha el 15,68\% de la superficie del partido (Cuadro 5)

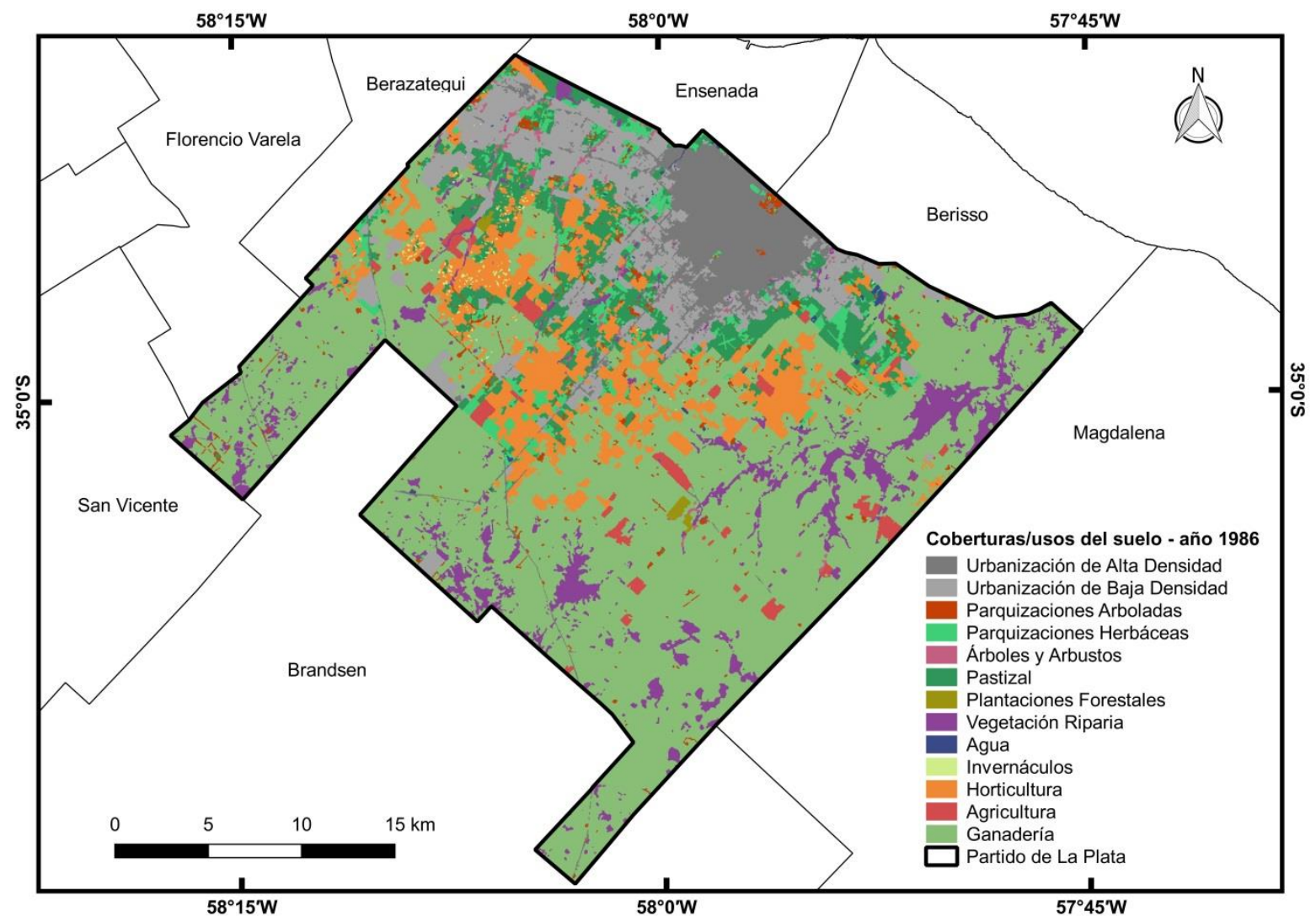

Fig 1. Mapa de coberturas/usos del suelo para el partido de La Plata para 1986, generado mediante clasificaciones supervisadas de imágenes Landsat en el software ENVI.

Para el año 1996 vemos que la Ganadería sigue siendo la principal cobertura/uso del suelo en el partido, ocupando un $41,41 \%$ de su superficie, seguida por la Vegetación Riparia (11,56\%), la Urbanización de Baja Densidad (11,41\%), el Pastizal $(9,14 \%)$, la Horticultura (8,19\%) y la Urbanización de Alta Densidad (6,58\%) (Fig. 2, Cuadro 5). Al considerar la Urbanización Total (Urbanización de Alta Densidad y Urbanización de Baja Densidad), estas alcanzan un porcentaje de $17,99 \%$ de la superficie del partido. 


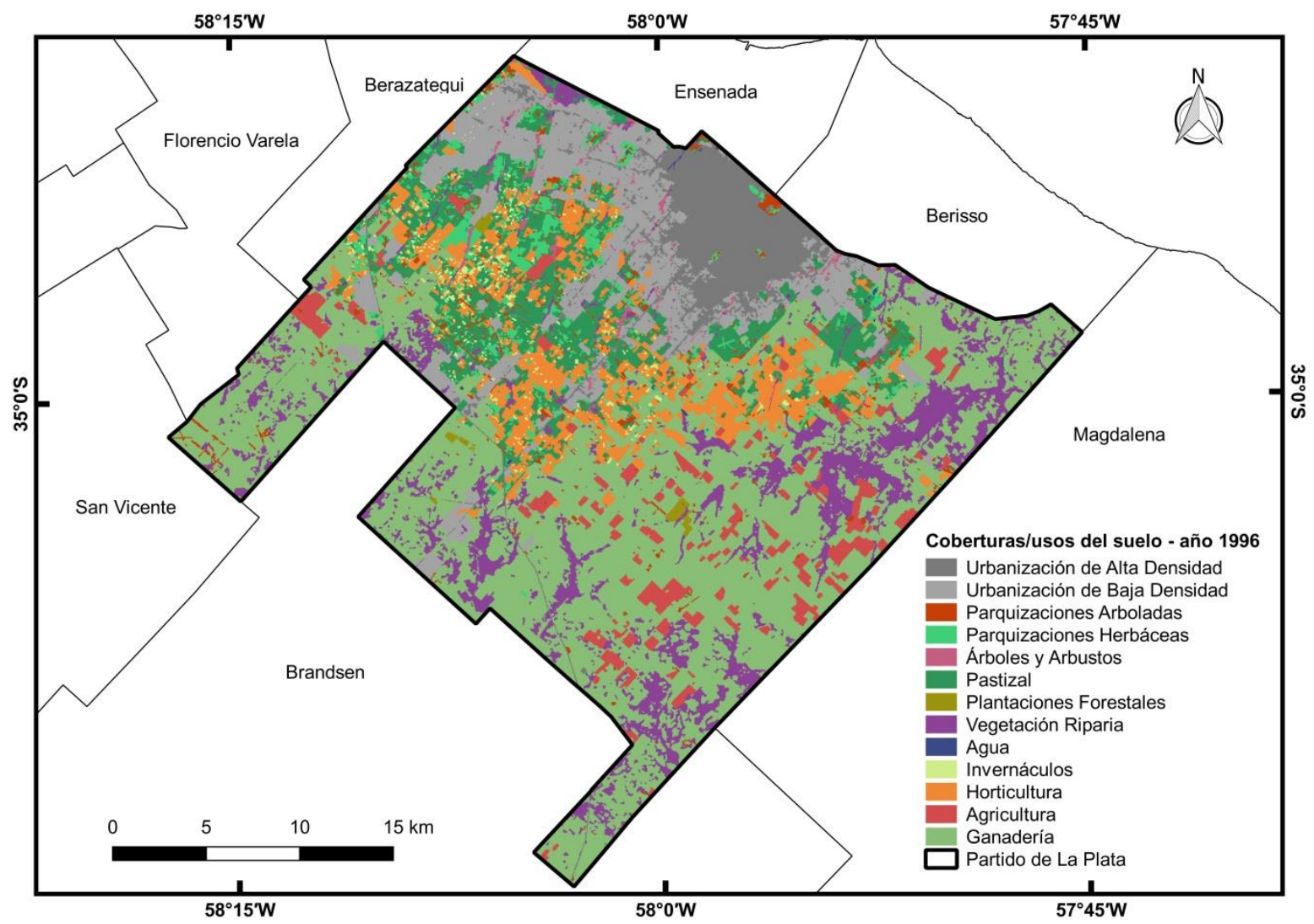

Fig 2. Mapa de coberturas/usos del suelo para el partido de La Plata para 1996, generado mediante clasificaciones supervisadas de imágenes Landsat en el software ENVI.

Analizando el mapa de coberturas/usos del suelo del año 2005 (Fig. 3) se destacan, la Ganadería ocupando un $42,38 \%$ del partido, seguida por la Urbanización de Baja Densidad (13,11\%), la Vegetación Riparia (9,75\%), el Pastizal (9,16\%), la Urbanización de Alta Densidad $(7,32 \%)$ y la Horticultura $(6,04 \%)$ (Cuadro 5). En este caso la Urbanización Total representa un $20,43 \%$. 


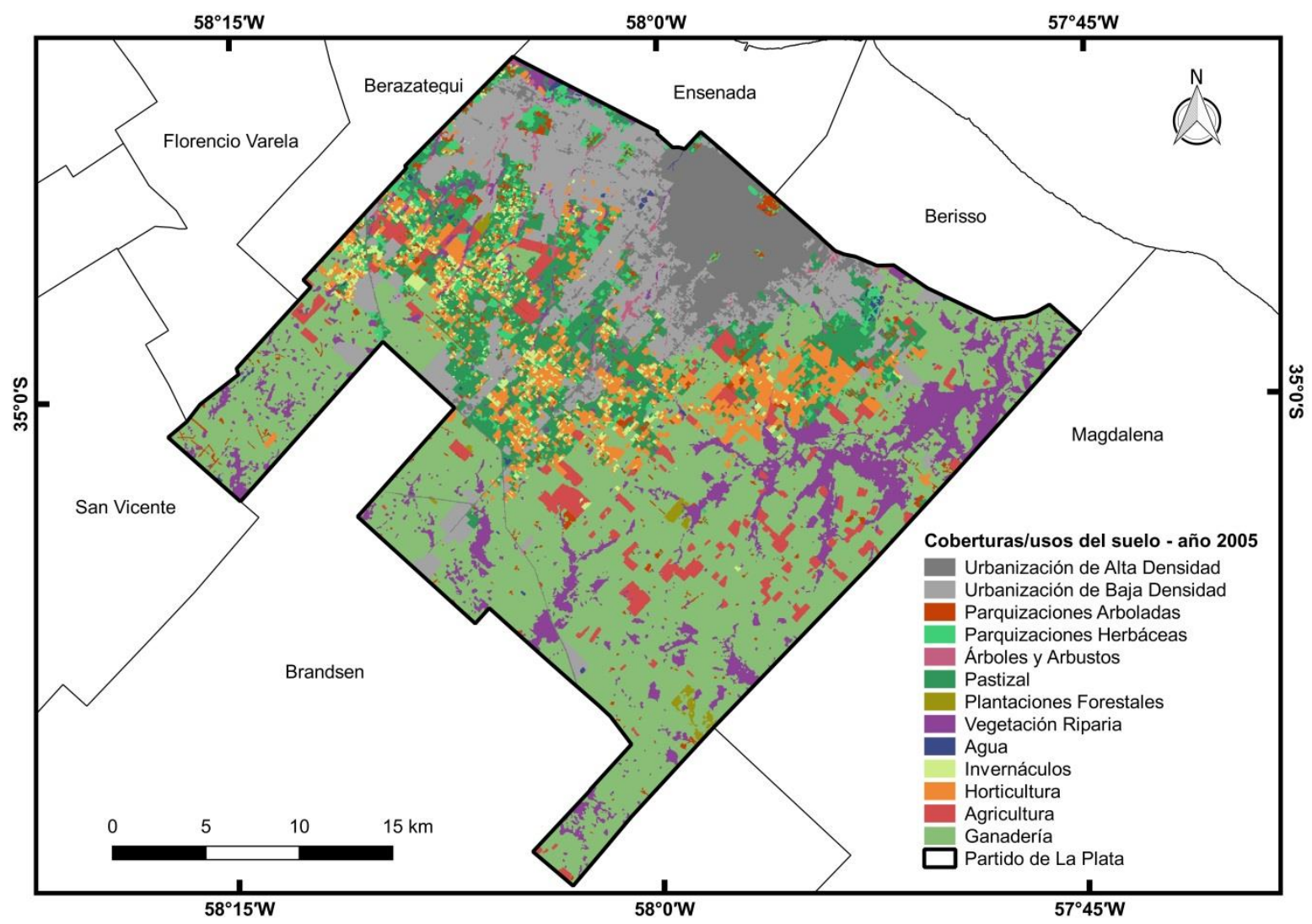

Fig 3 Mapa de coberturas/usos del suelo para el partido de La Plata para 2005, generado mediante clasificaciones supervisadas de imágenes Landsat en el software ENVI.

Finalmente en el mapa de coberturas/usos del suelo del año 2015 (Fig. 4) vemos que la Ganadería sigue siendo la cobertura/uso más representativa, con un $34,72 \%$ de la superficie del partido, seguida por la Urbanización de Alta Densidad (13,74\%), la Vegetación Riparia (11,51\%), la Urbanización de Baja Densidad (9,38\%) y el Pastizal (9,28\%) (Cuadro 5). La Urbanización Total en esta fecha abarca el $23,12 \%$ del partido. 


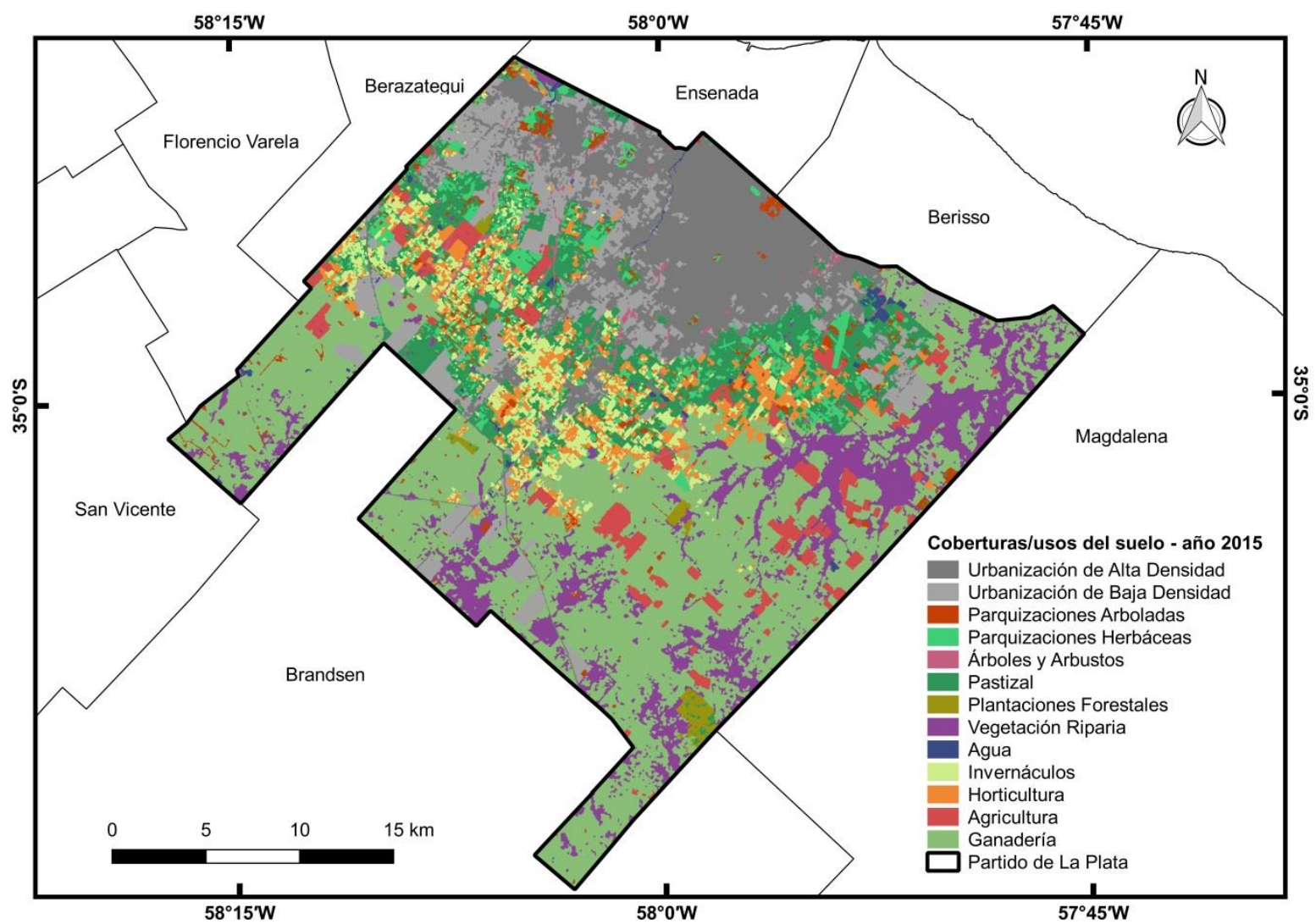

Fig 4. Mapa de coberturas/usos del suelo para el partido de La Plata para 2015, generado mediante clasificaciones supervisadas de imágenes Landsat en el software ENVI.

Cuadro 5. Superficie (en hectáreas) y porcentaje de cada cobertura/uso del suelo para cada año analizado, obtenido de los mapas de cobertura/uso del suelo del Partido de La Plata.

\begin{tabular}{|c|c|c|c|c|c|c|c|c|}
\hline COBERTURAVUSO & \multicolumn{2}{|l|}{1986} & \multicolumn{2}{|l|}{1996} & \multicolumn{2}{|l|}{2005} & \multicolumn{2}{|l|}{2015} \\
\hline DEL SUELO & Hectáreas & $\%$ & Hectáreas & $\%$ & Hectáreas & $\%$ & Hectáreas & $\%$ \\
\hline \multicolumn{9}{|l|}{ URBANIZACIÓN } \\
\hline DE ALTA & 5765.4 & 6.49 & 5849.19 & 6.58 & 6503.85 & 7.32 & 12198.69 & 13.74 \\
\hline \multicolumn{9}{|l|}{ DENSIDAD } \\
\hline \multicolumn{9}{|l|}{ URBANIZACIÓN } \\
\hline DE BAJA & 8174.61 & 9.20 & 10137.42 & 11.41 & 11646.99 & 13.11 & 8331.21 & 9.38 \\
\hline \multicolumn{9}{|l|}{ DENSIDAD } \\
\hline PARQUIZACIONES & \multirow{2}{*}{1216.89} & \multirow{2}{*}{1.37} & \multirow{2}{*}{1635.93} & \multirow{2}{*}{1.84} & \multirow{2}{*}{1681.2} & \multirow{2}{*}{1.89} & \multirow{2}{*}{1747.53} & \multirow{2}{*}{1.97} \\
\hline ARBOLADAS & & & & & & & & \\
\hline PARQUIZACIONES & \multirow[b]{2}{*}{2604.15} & \multirow{2}{*}{2.93} & \multirow[b]{2}{*}{2964.78} & \multirow[b]{2}{*}{3.34} & \multirow[b]{2}{*}{2671.92} & \multirow[b]{2}{*}{3.01} & \multirow[b]{2}{*}{3666.96} & \multirow[b]{2}{*}{4.13} \\
\hline HERBÁCEAS & & & & & & & & \\
\hline AGUA & 163.89 & 0.18 & 107.1 & 0.12 & 213.84 & 0.24 & 427.5 & 0.48 \\
\hline PASTIZALES & 6082.11 & 6.84 & 8121.69 & 9.14 & 8138.07 & 9.16 & 8240.76 & 9.28 \\
\hline ÁRBOLES Y & \multirow{2}{*}{507.96} & \multirow{2}{*}{0.57} & \multirow{2}{*}{675.72} & \multirow{2}{*}{0.76} & \multirow{2}{*}{659.25} & \multirow{2}{*}{0.74} & \multirow{2}{*}{712.98} & \multirow{2}{*}{0.80} \\
\hline ARBUSTOS & & & & & & & & \\
\hline 106 Lic. Carolina & Baldini & & & Tes & doctoral - & errito & io en movin & iento \\
\hline
\end{tabular}




\begin{tabular}{ccccccccc}
\hline $\begin{array}{c}\text { REGETACIÓN } \\
\text { RIPARIA }\end{array}$ & 6275.61 & $\mathbf{7 . 0 6}$ & 10270.35 & $\mathbf{1 1 . 5 6}$ & 8666.91 & $\mathbf{9 . 7 5}$ & 10215.45 & $\mathbf{1 1 . 5 1}$ \\
\hline $\begin{array}{c}\text { PLANTACIONES } \\
\text { FORESTALES }\end{array}$ & 186.66 & 0.21 & 239.4 & 0.27 & 322.56 & 0.36 & 570.06 & 0.64 \\
\hline HORTICULTURA & 8741.52 & $\mathbf{9 . 8 3}$ & 7275.33 & $\mathbf{8 . 1 9}$ & 5365.17 & 6.04 & 4241.97 & 4.78 \\
\hline INVERNACULOS & 158.76 & 0.18 & 855.54 & 0.96 & 1854.36 & 2.09 & 4370.4 & 4.92 \\
\hline AGRICULTURA & 1461.96 & 1.64 & 3928.41 & 4.42 & 3478.05 & 3.91 & 3241.53 & 3.65 \\
\hline GANADERIA & 47556.36 & $\mathbf{5 3 . 5 0}$ & 36796.68 & $\mathbf{4 1 . 4 1}$ & 37658.79 & $\mathbf{4 2 . 3 8}$ & 30823.74 & $\mathbf{3 4 . 7 2}$ \\
\hline
\end{tabular}

\subsection{LOS CAMBIOS EN LAS COBERTURAS/USOS DEL SUELO EN EL PARTIDO DE LA PLATA}

\subsection{1 ¿Cuáles fueron los principales cambios en las coberturas/usos del suelo entre 1986 y $2015 ?$}

A lo largo de todo el período de estudio (1986 a 2015), la ganadería fue el tipo de cobertura/uso del suelo predominante, a pesar de que disminuyó de 53,50\% del partido de La Plata en 1986 a $34,72 \%$ en 2015. Los cinco tipos de coberturas/usos predominantes en 1986, fueron Ganadería, seguida por Horticultura $(9.83 \%$ del partido de La Plata), Urbanización de Baja Densidad (9,20\%), Vegetación Riparia (7,06\%) y Pastizales (6,84\%). A través de todo el período, Horticultura disminuyó del 9,83\% en 1986 al 4,78\% en 2015; teniendo una tasa de decrecimiento de $51,47 \%$ (16,77\% en el período 1986-1996, 26,26\% en $1996-2005$ y $20,94 \%$ en $2005-2015)$. La tasa anual de decrecimiento de la Hortícultura fue de 1,77\%. La Urbanización de Baja Densidad aumentó durante los dos primeros períodos, representando el 9,20\% del partido de La Plata en 1986, el 11,41\% en 1996 y el $13,11 \%$ en el 2005; luego esta cobertura disminuyó a 9,38\%. La Vegetación Riparia aumentó en todo el período de 7,06\% en 1986 a 11,51\% en 2015. El Pastizal aumentó del $6,01 \%$ en 1986 al 9,44\% en 2015. Aunque la Urbanización de Alta Densidad no estaba dentro de los cinco tipos de coberturas/usos del suelo predominantes en 1986, esta experimentó una fuerte expansión, especialmente en el periodo 2005-2015 en el que alcanzó una tasa de crecimiento del 87,56\%, alcanzando en 2015 el segundo lugar en predominio (13,74\% del partido). La tasa de crecimiento anual de la Urbanización de Alta Densidad fue de 3,85\% (Cuadro 5).

Existen otros tipos de coberturas/usos del suelo menos representativas, que experimentaron un incremento en el porcentaje de cobertura, como en el caso de la Agricultura, que aumentó del 1,64\% en 1986 al 3,65\% en 2015; y los Invernáculos que 
aumentaron del $0,18 \%$ en 1986 al $4,92 \%$ en 2015 . Los Invernáculos mostraron la mayor tasa de crecimiento, con una tasa de $438,89 \%$ en el período 1986-1996, 116,75\% en 1996-2005 y $135,68 \%$ en el período $2005-2015$, alcanzando una tasa de crecimiento anual de $91,48 \%$.

La urbanización total (Urbanización de Alta Densidad y Urbanización de Baja Densidad) aumentó de $15,68 \%$ del partido de La Plata en 1986 a 23,12\% en 2015, con una tasa de crecimiento anual del $1,63 \%$ y una tasa de crecimiento para todo el período de estudio de $47,27 \%$. En el caso del total de horticultura (horticultura al aire libre e invernáculos), el porcentaje de cobertura no se modificó sustancialmente (del 10,01\% en 1986 al $9,70 \%$ en 2015). La tasa anual de decrecimiento fue de $0,11 \%$, y la tasa de decrecimiento para todo el periodo de estudio fue de $3,23 \%$.

\subsection{2 ¿Cuáles fueron los cambios detectados en las coberturas/usos del suelo en cada periodo?}

Los cambios de las coberturas/usos del suelo no ocurren de la misma forma en todos los intervalos de tiempo. Entre 1986 y 1996 el análisis de Cambio Neto mostró que los principales tipos de coberturas/usos del suelo que experimentaron un aumento fueron la Vegetación Riparia (+3999 hectáreas Ha.), seguido por la Agricultura (+2465 Ha.), Pastizales (+2044 Ha.) y Urbanización de Baja Densidad (+1970 ha.). La mayor disminución observada de las coberturas/usos del suelo en el primer período fue en la Ganadería (10736 Ha.). En relación con la producción hortícola, se observa una disminución en la Horticultura (-1465 ha.) y un aumento en los Invernáculos (+697 Ha.). Mientras que en 1986 los Invernáculos representaban 1,78\% de la superficie hortícola total, para 1996 ese tipo de cobertura/uso del suelo alcanzó el 10,52\%. La tasa de crecimiento de los Invernáculos en el período 1986-1996 fue de 438,89\% (Fig. 5). Analizando la contribución relativa de cada cobertura al cambio neto en ese período, la Vegetación Riparia y la Agricultura crecieron en zonas ganaderas. Los Pastizales se desarrollaron en áreas ganaderas y hortícolas. La Urbanización de Baja Densidad sustituyó coberturas de Pastizales (36,98\%, 768 Ha.), así como Parquizaciones Herbáceas (26,24\%, 545 Ha.) y Ganadería (22,92\%, 476 Ha.); un aspecto destacable es que la Urbanización de Baja Densidad creció en zonas hortícolas, sustituyendo $130 \mathrm{Ha}$. (6,26\%). La Urbanización de Alta Densidad creció en las zonas urbanas de baja densidad, como se esperaba. El aumento de los Invernáculos tuvo lugar en zonas Hortícolas (67,38\%, 469 Ha.), y en menor medida en zonas Ganaderas (22,27\%, 155 hectáreas). A pesar de que la Horticultura disminuyó durante ese período, hubo zonas Ganaderas y Agrícolas que se convirtieron a Hortícolas. La Ganadería hizo la principal contribución al crecimiento de la Horticultura representando el $82 \%$ de esa cobertura (669 hectáreas). Otro aspecto interesante fue el aumento del Pastizal en zonas con Ganadería y Horticultura (Fig. 6) 


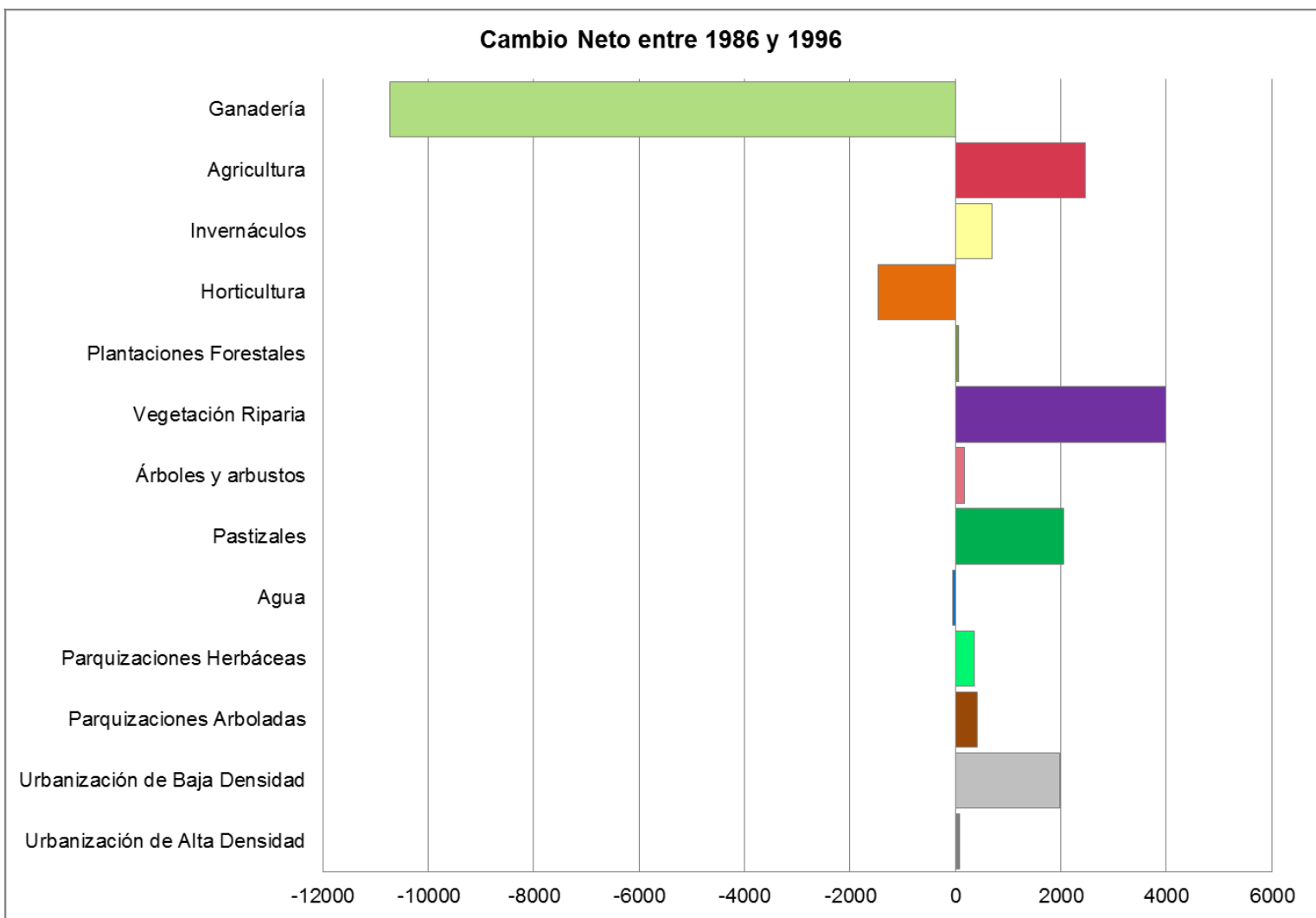

Fig 5. Cambio neto para cada cobertura/uso del suelo en el partido de La Plata, en el período entre 1986-1996, medido en hectáreas.

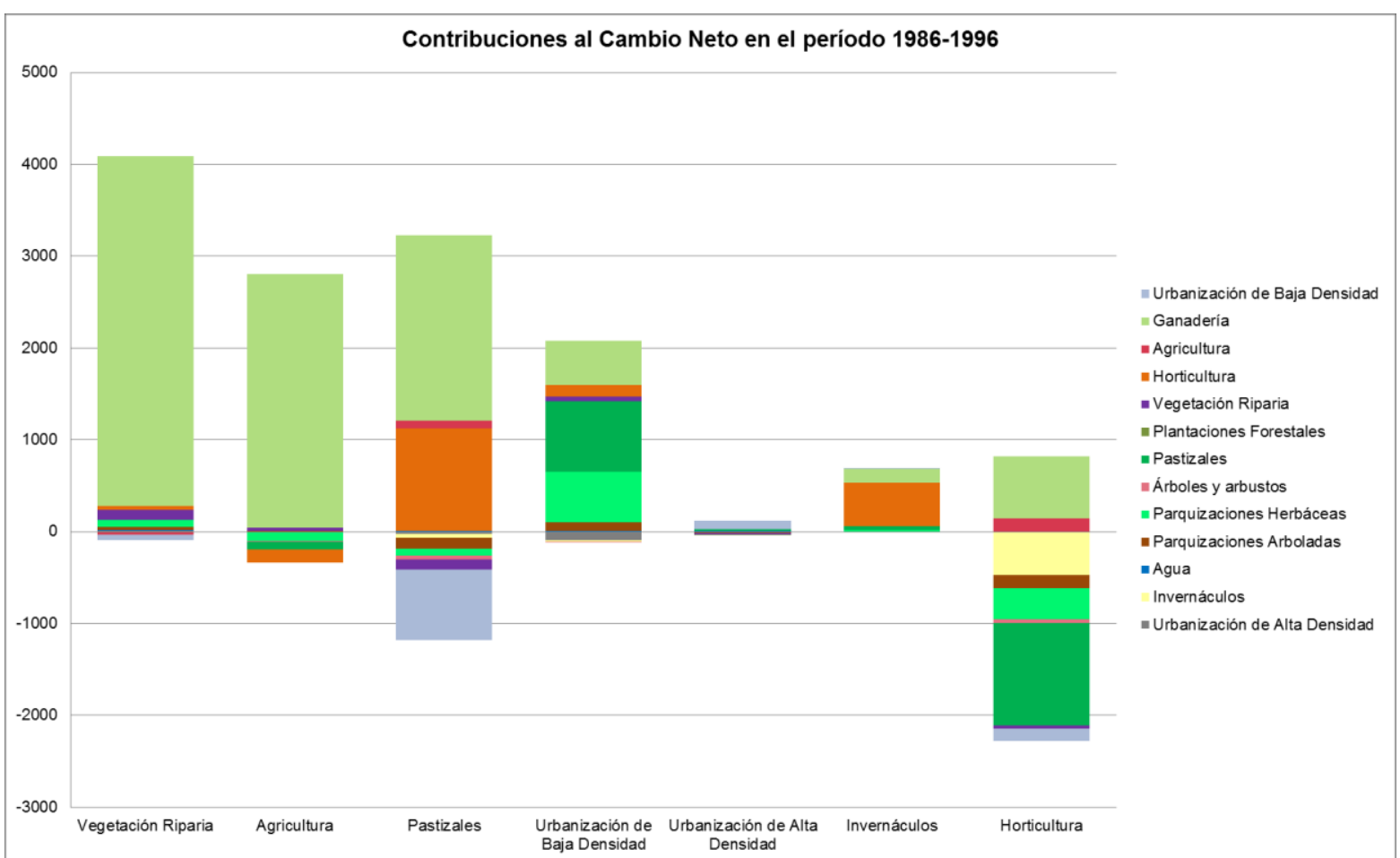

Fig 6. Contribuciones relativas al cambio de las coberturas/usos del suelo, de las principales coberturas entre 1986-1996 en el partido de La Plata, medido en hectáreas.

El Cambio Neto durante el período 1996-2005 estuvo relacionado con un aumento en la Urbanización de Baja Densidad (+1505 Ha.), los Invernáculos (+999 Ha.), la Ganadería (+857 На.) y la Urbanización de Alta Densidad (+659 На.). Los principales tipos de 
coberturas/usos del suelo que disminuyeron fueron Horticultura (-1910 ha.), Vegetación Riparia (-1605 ha.) y en menor grado Agricultura (-449 hectáreas). Focalizando en la actividad hortícola, los Invernáculos mostraron un gran aumento de la superficie, mientras que en 1996 representaban el 10,52\% del total del área hortícola, su superficie aumentó a un $25,68 \%$ en 2005 . La tasa de crecimiento de los Invernáculos en el período mencionado fue de $116.75 \%$ (Fig. 7). Las principales contribuciones al Cambio Neto en ese período fueron la conversión de Pastizales (33,12\%, 710 Ha.) y Parquizaciones Herbáceas (28,54\%, 612 Ha.) a Urbanización de Baja Densidad, y secundariamente, la conversión de Ganadería (12,5\%, 268 Ha.) y Horticultura (10,82\%, 232 Ha.), en Urbanización de Baja Densidad. La ganancia en Invernáculos fue relacionada con la conversión de la Horticultura $(59,52 \%, 600$ Ha.) y secundariamente por la conversión de Ganadería (16,67\%, 168 hectáreas), Pastizales y Parquizaciones Herbáceas. La Ganadería creció en zonas con Vegetación riparia y con Agricultura. Como en el período anterior, la Urbanización de Baja Densidad representa la principal contribución al incremento de la Urbanización de Alta Densidad (626 Ha.). Pese a que la Horticultura disminuyó en ese período (-1910 ha.), hubo algunas zonas ganaderas que experimentaron una conversión a Horticultura. La Ganadería representó el $100 \%$ de la contribución al crecimiento de la Horticultura en este período (114 hectáreas). (Fig. 8)

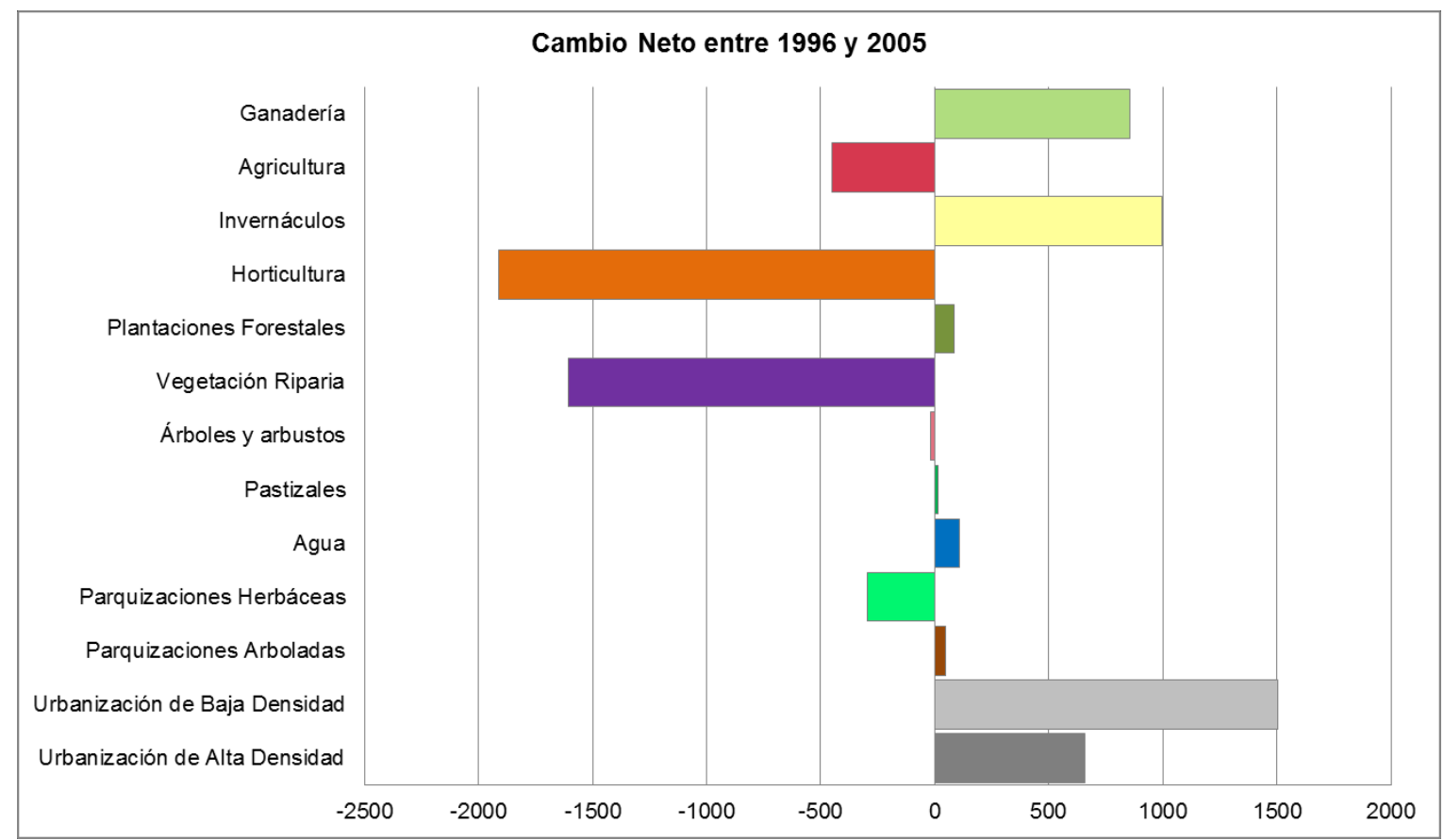

Fig 7. Cambio Neto para cada cobertura/uso del suelo en el partido de La Plata, en el período entre 1996-2005, medido en hectáreas. 


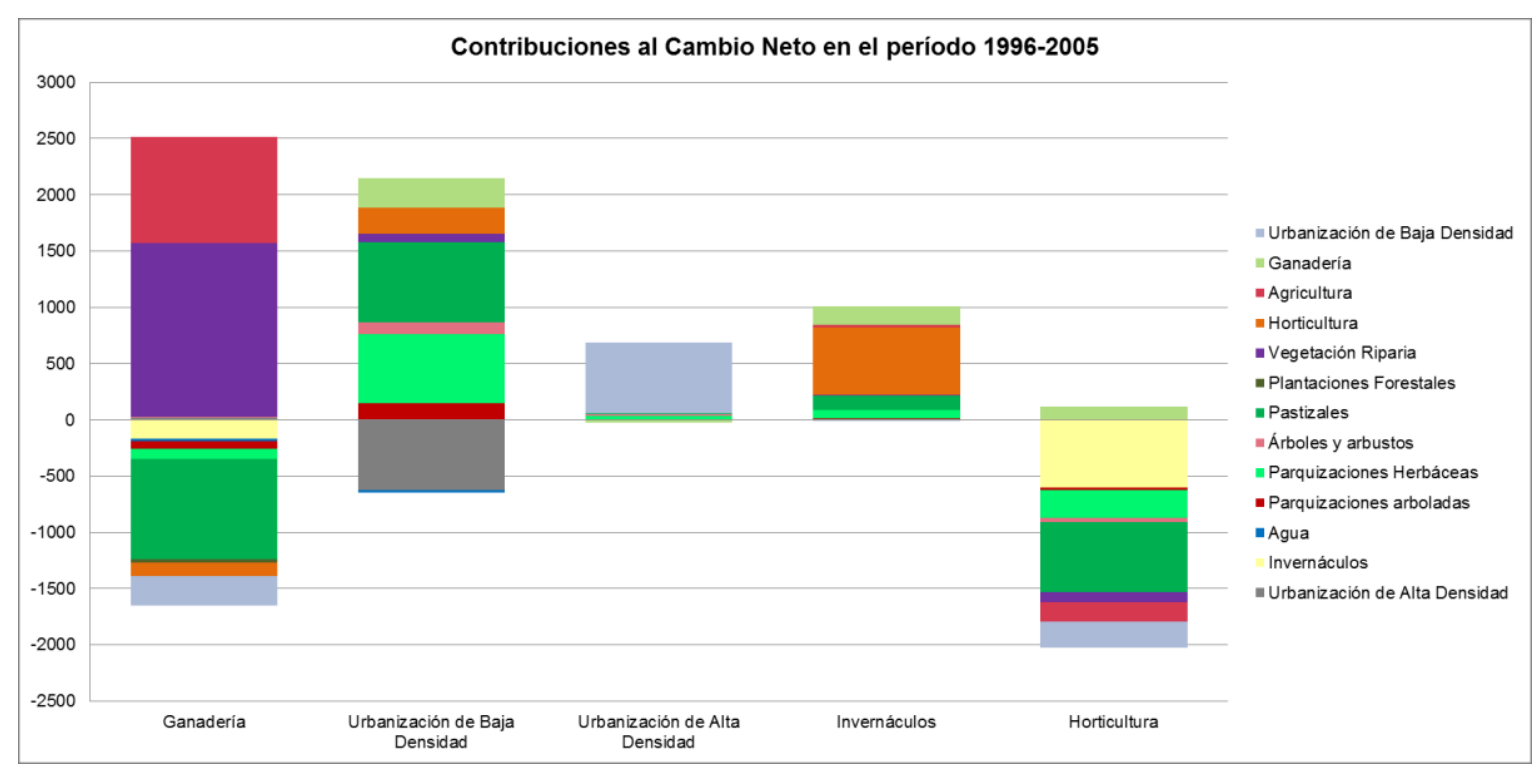

Fig 8. Contribuciones relativas al cambio de las coberturas/usos del suelo, de las principales coberturas entre 1996-2005 en el partido de La Plata, medido en hectáreas.

Finalmente, entre 2005 y 2015 el análisis de Cambio Neto mostró que los tipos de coberturas/usos del suelo que más crecieron fueron la Urbanización de Alta Densidad (+5702 Ha.), los Invernáculos (+2516 Ha.) y secundariamente, la Vegetación Riparia (+1555 Ha.) y las Parquizaciones Herbáceas (+1003 herbácea Ha.). Las principales coberturas que experimentaron una reducción en superficie fueron la Ganadería (-6801 ha.), la Urbanización de Baja Densidad (-3314 ha.) y la Horticultura (-1119 ha.). En relación a la producción hortícola, la Horticultura perdió 1.119 hectáreas y los Invernáculos experimentaron una ganancia de 2516 hectáreas. Mientras que en 2005 los Invernáculos representaban un $25,68 \%$ de la horticultura total, en 2015 este tipo de producción hortícola alcanzó el 50,74\% del total del área hortícola. Los Invernáculos alcanzaron una tasa de crecimiento de $135,68 \%$ en ese período. La Urbanización de Alta Densidad también experimentó una alta tasa de crecimiento en ese período alcanzando el 87,56\% (Fig. 9). La Urbanización de Alta Densidad se desarrolló en las zonas Urbanas de Baja Densidad (5129 Ha.), al igual que en períodos anteriores. Los Invernáculos sustituyeron áreas Hortícolas $(44,24 \%, 1126$ Ha.) y en menor medida, la Ganadería (19,37\%, 493ha.) y áreas de Pastizales (510 hectáreas). La Vegetación Riparia creció en zonas Ganaderas (2308 hectáreas). Las Parquizaciones Herbáceas reemplazaron Pastizales (852 hectáreas) y Ganadería (600 hectáreas). Mientras, la Horticultura experimentó una reducción de área (1119 ha.), algunas zonas de Ganadería experimentaron una conversión a la Horticultura (270 hectáreas), lo que representa el 92,15\% de la contribución a nuevas zonas hortícolas. Mientras que al analizar el Cambio Neto, la Urbanización de Baja Densidad disminuyó en ese período, la Ganadería $(39,71 \%, 714 \mathrm{Ha}$.) y en un menor grado el Pastizal $(20,36 \%, 366$ Ha.), las Parquizaciones Herbáceas (11,23\%, 202 Ha.) y la Horticultura (6,84\%, 123 Ha.), sufrieron una conversión a Urbanización de Baja Densidad (Fig. 10). 


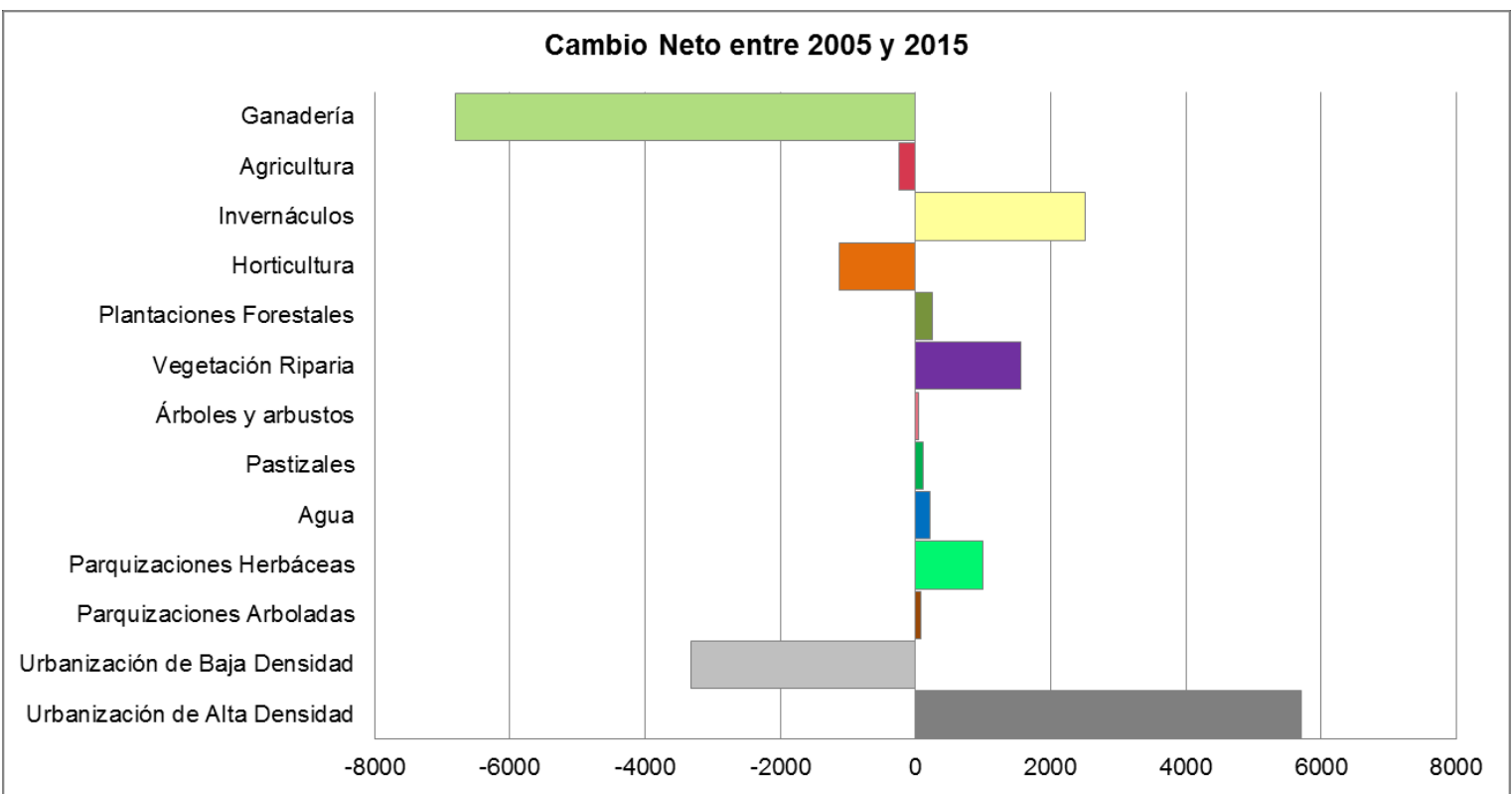

Fig 9. Cambio neto para cada cobertura/uso del suelo en el partido de La Plata, en el período entre 2005-2015, medido en hectáreas.

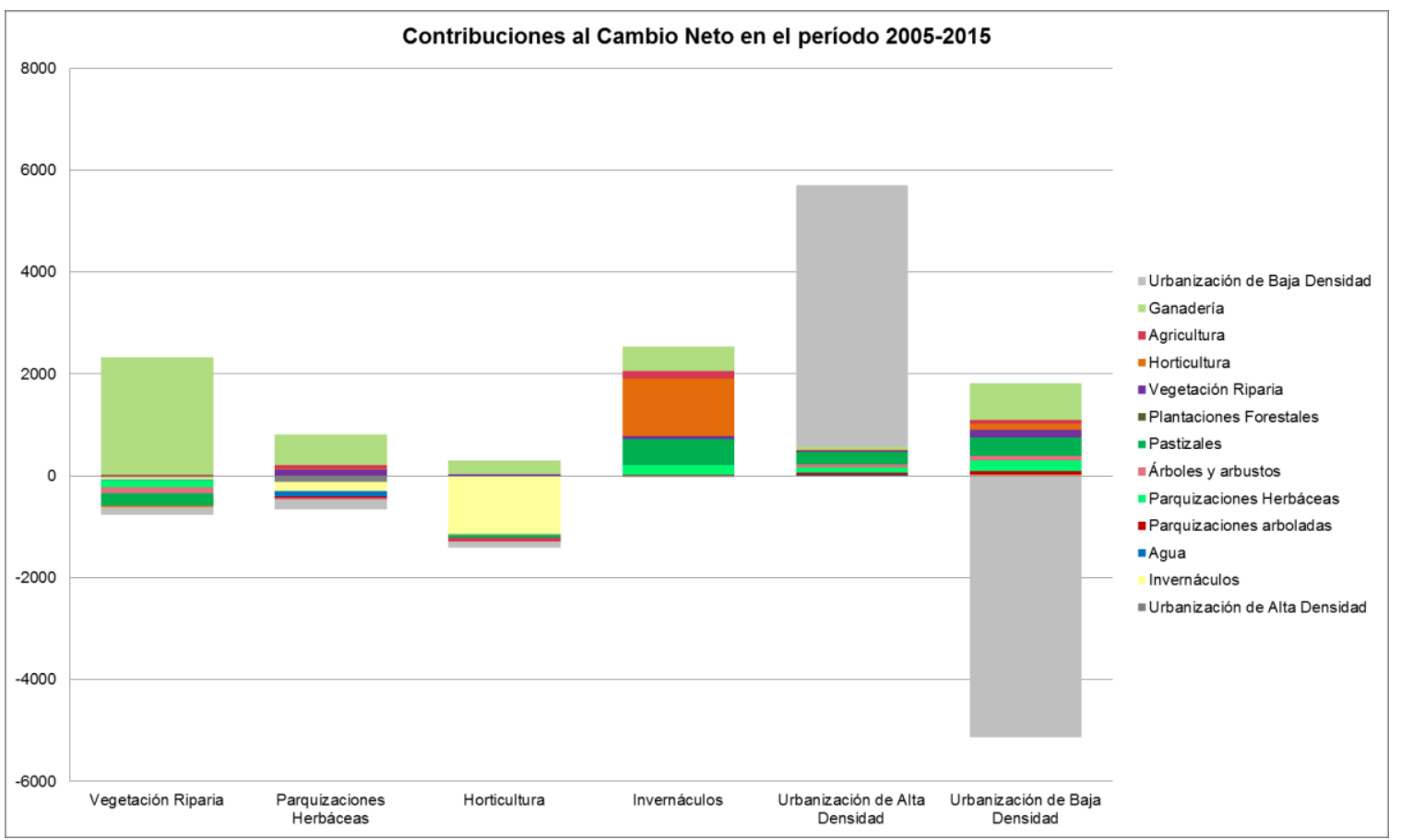

Fig 10. Contribuciones relativas al cambio de las coberturas/usos del suelo, de las principales coberturas entre 2005-2015 en el partido de La Plata, medido en hectáreas.

Más allá de las particularidades experimentadas en cada período, hubo un patrón general de cambio en todo el período de estudio, relacionado con los principales procesos de transición entre las coberturas/usos del suelo, mostrando una clara tendencia a la urbanización y la intensificación productiva (Fig. 11). Las zonas ganaderas desempeñaron un papel clave en este proceso, siguiendo dos caminos, uno que condujo a la urbanización y otro que llevó a la intensificación de la horticultura. En relación con el proceso de urbanización, la Ganadería experimentó una conversión directa a Urbanización de Baja Densidad o indirecta, a través de la conversión a Pastizales, que luego siguieron el camino 
de la urbanización. Por otro lado, la Ganadería fue la principal cobertura que contribuyó a la expansión de la Horticultura y, junto con la Horticultura, contribuyeron al crecimiento del área bajo Invernáculos (Fig.12). Focalizando en el último año del período analizado, los Invernáculos mostraron un desarrollo más pronunciado en ciertos sectores del partido (Fig. 13).
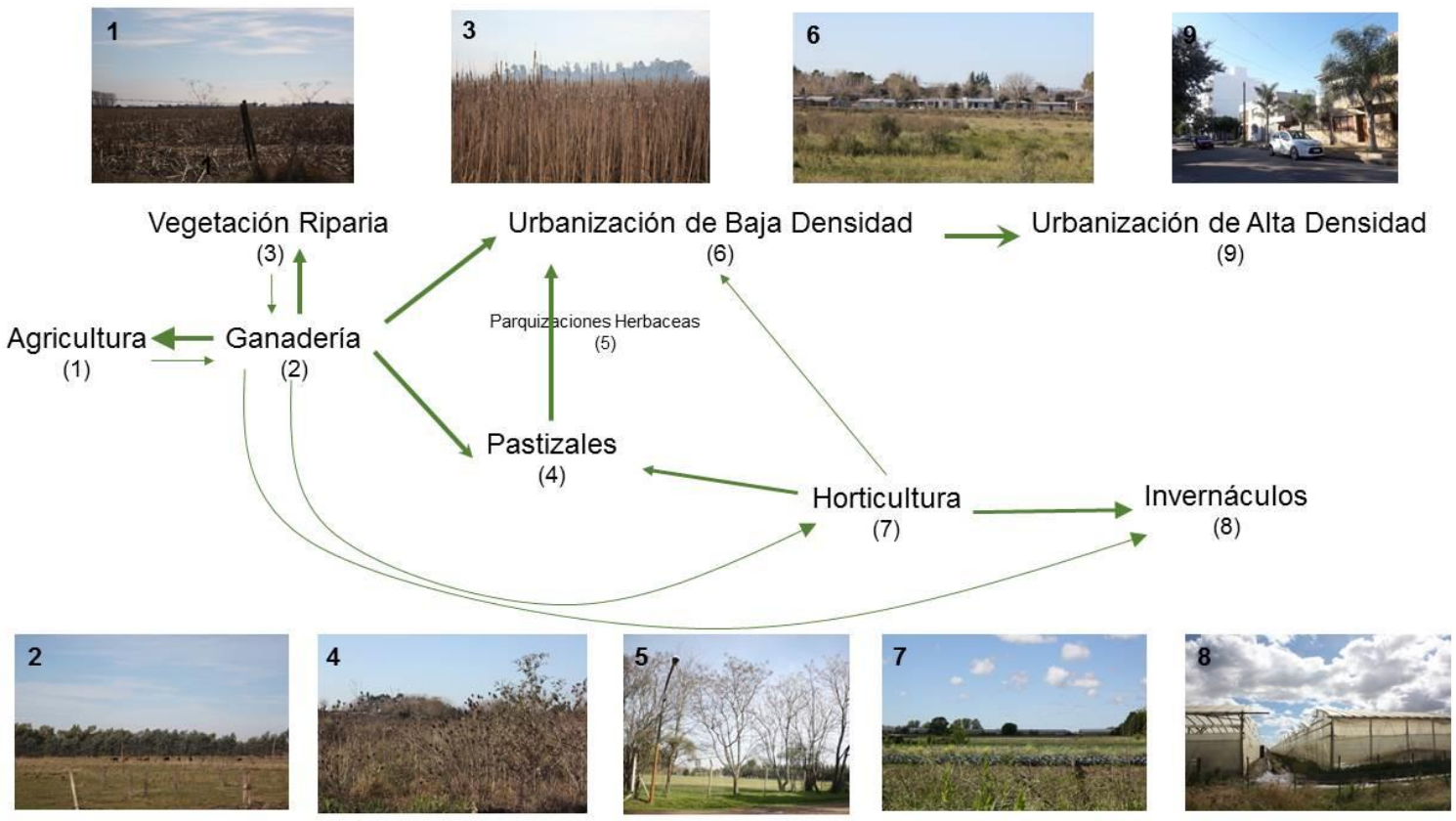

Fig 11. Diagrama que muestra los principales procesos de transición entre las coberturas/usos del suelo en el partido de La Plata entre 1986 y 2015 . El grosor de las flechas refleja la intensidad de los cambios. El diagrama puede ser leído comenzando a partir de cualquier cobertura/uso del suelo y a partir de allí identificar las principales transformaciones que esta sufrió.

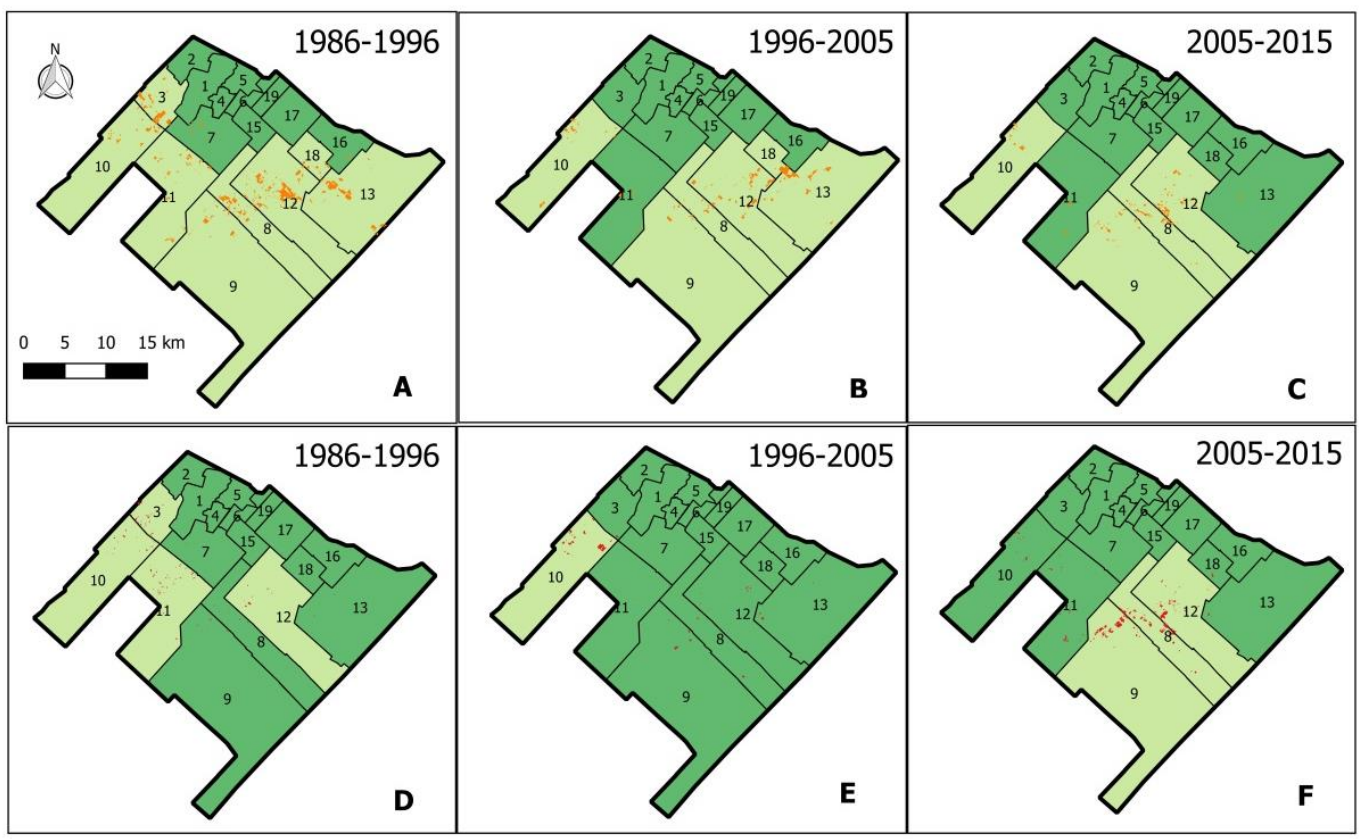

Fig 12. Conversión de áreas Ganaderas a Horticultura (mapas A, B y C) e Invernáculos (mapas D, E y F) en los periodos 1986-1996, 1996-2005 y 2005-2015. Las delegaciones 113 Lic. Carolina Baldini

Tesis doctoral - Territorio en movimiento 
municipales fueron identificadas como: 1-City Bell, 2-Villa Elisa, 3-Arturo Segui, 4-Gorina, 5Gonnet, 6-Hernández, 7-Melchor Romero, 8-Lisandro Olmos, 9-Etcheverry, 10-El Peligro, 11-Abasto, 12-Los Hornos, 13-Arana, 14-Ringuelet, 15-San Carlos, 16-Villa Elvira, 17-Casco Urbano, 18-Altos de San Lorenzo, 19-Tolosa. El color verde claro indica las delegaciones municipales más afectadas por el proceso de conversión.

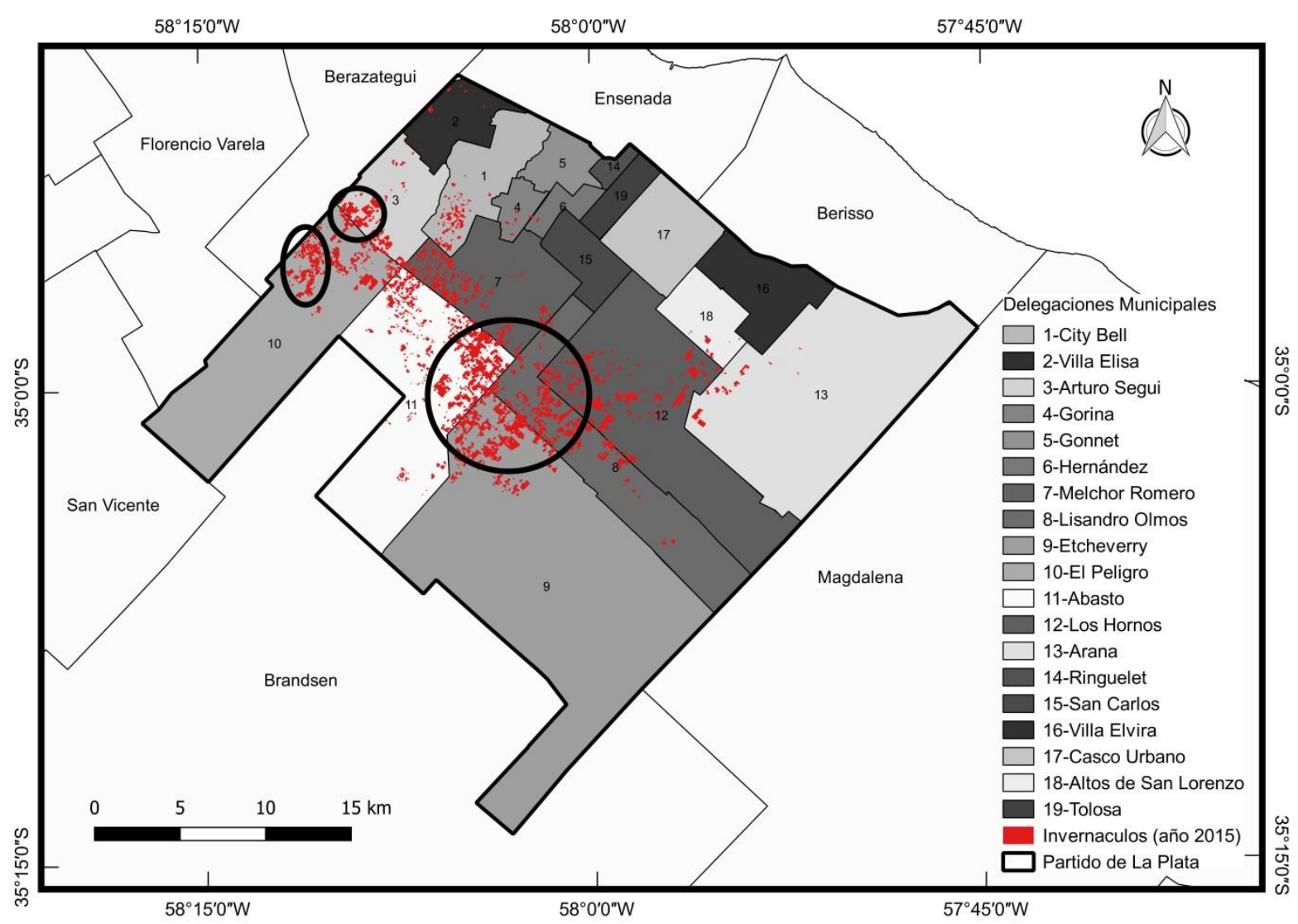

Fig 13. Distribución de Invernáculos en el año 2015 en el partido de La Plata.

\subsection{UNA PRIMER APROXIMACIÓN A LOS PATRONES DE CAMBIO DEL PAISAJE}

A partir del análisis de los procesos de cambio en el paisaje se identificaron cuatro patrones de cambio en todo el período estudiado: erosión, agregación, creación y disección.

En relación con el proceso de urbanización, la Urbanización de Baja Densidad ha experimentado un proceso de agregación en el primer período, un proceso de creación en el segundo periodo y disección en el tercero. La Urbanización de Alta Densidad experimentó un proceso de creación en el primer período y agregación en el segundo y tercero. Considerando el área urbana total (Urbanización de Baja Densidad y Urbanización de Alta Densidad) experimentó un proceso de agregación en los dos primeros períodos y un proceso de creación en el último.

Aunque la Horticultura y los Invernáculos no fueron las principales coberturas involucradas en los patrones de paisaje identificados, los Invernáculos experimentaron un 
patrón de creación en los dos primeros períodos y agregación en el tercero. Por otro lado, la Horticultura sufrió un proceso de disección en los tres períodos analizados.

Considerando las coberturas de vegetación, es interesante analizar el Pastizal, que ha experimentado un proceso de creación en el primer y tercer períodos y agregación en el segundo.

\section{DISCUSIÓN}

\subsection{Las transformaciones del paisaje y sus implicancias para la gestión y planificación del territorio}

La creciente urbanización es uno de los principales temas de preocupación en todo el mundo (Evaluación de los Ecosistemas del Milenio 2005). En el partido de La Plata pude evidenciar este crecimiento al analizar la Urbanización Total, cuya superficie se incrementó en todos los períodos estudiados. A su vez, Hurtado et al. (2006) y Frediani (2010) afirman que la expansión urbana tuvo lugar en el partido de La Plata sobre tierras productivas de alta calidad, moviendo la horticultura hacia áreas de uso tradicionalmente agropecuario (agricultura extensiva, ganadería, tambos, haras, etc.) que no son apropiados para dicha actividad. Mi análisis confirma parcialmente estas afirmaciones y complementa los resultados de estos investigadores, con información acerca de la expansión urbana en áreas semi-naturales. El análisis LULCC reveló que la Urbanización de Baja Densidad creció principalmente en áreas de Pastizales, Parquizaciones Herbáceas, zonas con Ganadería y Horticultura. Esto significa que las áreas urbanas crecieron durante las últimas tres décadas principalmente a expensas de áreas semi-naturales y productivas. Sin embargo, el porcentaje de la Urbanización de Baja Densidad que creció sobre suelos con Horticultura no fue tan significativo $(6,26 \%$ del total de la nueva superficie bajo Urbanización de Baja Densidad para el período 1986-1996, 10,82\% para el período $1996-2005$ y $6,84 \%$ en el período 2005-2015). Igualmente, es importante tener en consideración que la Urbanización de Baja Densidad puede haber crecido sobre suelos de buena calidad para la producción hortícola pero que aún no estaban bajo uso productivo; para investigar esto se requiere otro análisis que se realizará en capítulos posteriores. Los Pastizales fueron una de las coberturas que más disminuyó a expensas del crecimiento de la Urbanización de Baja Densidad, con la consecuente transformación irreversible de una zona semi-natural en un medio urbano. Esto implica la pérdida de los servicios ecosistémicos propios de un ambiente natural/semi-natural como el pastizal (Hajdu et al. 2016; Newbold et al. 2015). La conversión de la Ganadería a Urbanización de Baja Densidad puede explicarse por el desarrollo de barrios privados (Frediani 2010, urBAsig) y por el programa del gobierno nacional de préstamos hipotecarios "ProCreAr" (Merchán 2016). Considerando la expansión de la Urbanización de Baja Densidad hacia áreas de Horticultura y Ganadería, el análisis de los 
cambios en las coberturas/usos del suelo permitió identificar cierta competencia por el uso del suelo entre la urbanización y la producción de alimentos. Algunos autores anticiparon este proceso declarando que el negocio de la compra de tierras agrícolas para construir comunidades cerradas, se ha convertido en uno de las operaciones de mercado más especulativas en la región, y llamando a los cinturones hortícolas como "cinturones de especulación inmobiliaria" por los fuertes intereses de estas empresas en ellos (Frediani 2010, Morello 2000, Barsky 2007). En ausencia o deficiencia de políticas adecuadas de planificación del uso del suelo, estos conflictos se han resuelto a través de las políticas de los mercados concentradores y la especulación de las empresas constructoras (Frediani 2010, Hurtado et al. 2006, Merchán 2016). Respecto a la categoría de Urbanización de Alta Densidad, esta evidencia el proceso de consolidación y densificación de las zonas urbanizadas. El aumento en superficie de la Urbanización de Alta Densidad fue sobre áreas de Urbanización de Baja Densidad, en todos los periodos analizados; esto significaba que la Urbanización de Baja Densidad experimentó un proceso de densificación que finalizó en la conversión a Urbanización de Alta Densidad. En el último periodo la expansión de la Urbanización de Alta Densidad fue más relevante, con una tasa de crecimiento del $87,56 \%$. Los patrones identificados en el análisis de los procesos de cambio en el paisaje experimentados por las zonas urbanas lo han reafirmado, ya que el área urbana total (Urbanización de Baja Densidad y Urbanización de Alta Densidad) experimentó patrones de agregación (entre 1986 y 2005) y creación (entre 2005 y 2015), relacionados con la consolidación y expansión de las zonas urbanas.

El CHP se caracterizó por un fuerte proceso de intensificación productiva, junto con un alto desarrollo de producciones bajo invernáculos y una disminución de la producción hortícola al aire libre. Diferentes investigadores han identificado este proceso de intensificación a través del análisis bibliográfico, de entrevistas y de datos censales disponibles (e.g. García y Mierez 2007, García 2011, García 2012, Nieto y Rivas 2006, Sarandón et al. 2015, Blandi 2009). El informe oficial más actualizado, perteneciente al Censo Horti-Floricola de la Provincia de Buenos Aires (CHFBA) estimó en 2005, 1887,89 hectáreas de horticultura al aire libre y 991,97 hectáreas de invernáculos. El Consejo Federal de Inversiones (CFI) estimó 1.300 hectáreas de invernáculos en 2006, y los principales proveedores de plásticos para invernáculos de la región estimaron más de 3.000 hectáreas para el año 2009. (García 2011). Hurtado et al. (2006) calcularon para el año 2006 que la agricultura intensiva (en el mencionado trabajo incluye la horticultura, floricultura y fruticultura, avicultura, apicultura y granja de pequeños animales) representaba el $12,44 \%$ (11115 Ha.) del partido y Stavisky (2010) estimó para el año 2010 una superficie bajo invernáculos de 1.950 Has. En el presente estudio realicé un análisis exhaustivo del proceso que tuvo lugar en producciones hortícolas bajo invernáculos y al aire libre, encontrando que los invernáculos experimentaron altas tasas de crecimiento, mientras que la horticultura 116 Lic. Carolina Baldini

Tesis doctoral - Territorio en movimiento 
decreció en todos los periodos estudiados; el incremento de los cultivos bajo invernáculo y la reducción de los cultivos al aire libre fue registrado también por García y Mierez (2007). Mis resultados para el 2005 difieren de aquellos provenientes del CHFBA descritos anteriormente, ya que encontré 5365,17 hectáreas de horticultura (que podría compararse con la horticultura al aire libre) y 1854,36 hectáreas de invernaderos. Además, esta comparación revela que el área total bajo producción hortícola fue considerablemente mayor que la reflejada por el censo oficial (7219,53 hectáreas. en el presente estudio versus 2879,86 hectáreas. en el censo de 2005); lo cual es relevante si consideramos que las políticas productivas gubernamentales y los recursos que se destinan se definen (o debieran definirse) teniendo en consideración la magnitud de las áreas productivas. En cuanto a las estimaciones de Hurtado et al., si bien no son exactamente comparables las categorías utilizadas, mis resultados arrojan valores menores $(7219.53 \mathrm{Ha}$. de horticultura total, frente a las $11115 \mathrm{Ha}$. estimadas en dicho trabajo), si tenemos en cuenta que la apicultura y las granjas de animales pequeños no son tan representativas dentro del partido. Las estimaciones de los proveedores de plásticos de invernáculos y del CFI se acercan más a mis resultados que aquellos provenientes del CHFBA. El incremento en la superficie bajo invernáculos y la disminución en la superficie hortícola al aire libre coinciden a su vez con los procesos de cambio identificados para las coberturas Invernáculos (procesos de creación y agregación) y Horticultura (proceso de disección), El proceso de agregación identificado para la cobertura Invernáculos en el último período analizado implica la concentración de los mismos, generando zonas con una amplia superficie del suelo impermeabilizada, lo que refuerza los planteos de García (2011) y Karol y San Juan (2018) respecto a la impermeabilización del suelo hortícola. Por otra parte, encontré que el crecimiento de los Invernáculos tuvo lugar principalmente en zonas con Horticultura, indicando la intensificación de la producción de alimentos, como era de esperarse. En segundo lugar, otras conversiones tuvieron lugar de zonas con Ganadería, Pastizales y Parquizaciones Herbáceas a Invernáculos. Es interesante mencionar que de los tres períodos estudiados, aquel en el que se generó un crecimiento más importante de invernáculos fue el período 2005-2015, con la generación de 2516.04 nuevas hectáreas; esto coincide con el período de gobierno kirchnerista, en el cual diversos autores identifican un proceso de intensificación de la actividad productiva, destacando incluso ciertas políticas públicas a nivel nacional de apoyo a la agricultura familiar que buscaron incrementar la productividad mediante la intensificación ${ }^{8}$ (Ambort 2017, Barsky 2013). Por otro lado, si bien algunos autores como García y Kebat (2008) plantean un creciente proceso de

\footnotetext{
${ }^{8}$ El Programa Nacional de Agricultura Periurbana fue creado a partir del año 2010, bajo la órbita de la Secretaría de Agricultura Familiar, y ejecutado a través de los municipios con la intervención de las organizaciones de productores locales y organismos como el INTA. Apuntó a promover el ordenamiento territorial, la producción de alimentos y la generación de puestos de trabajo en áreas periurbanas. Este programa fomentó explícitamente el avance de la producción hortícola bajo cubierta.

117 Lic. Carolina Baldini

Tesis doctoral - Territorio en movimiento
} 
intensificación productiva desde comienzos de los 90', que habría decaído a finales de esa década con el ingreso a un período recesivo y finalmente la crisis del 2001, para luego volver a repuntar a partir del 2002; estos cambios no pudieron ser evaluados en este trabajo por los períodos de tiempo establecidos en el análisis. Retomando los resultados de esta investigación, en cuanto a la Horticultura, en todos los periodos estudiados las principales pérdidas de esta cobertura se produjeron por conversión a Invernáculos. En los dos primeros períodos (1986-2005 y 2005-2015) la conversión a Pastizales también fue importante, probablemente asociado al abandono de la actividad productiva; así como la conversión a Parquizaciones Herbáceas, asociado al proceso de urbanización, ya que este tipo de cobertura tuvo una fuerte tendencia a urbanizarse. La conversión de zonas con Horticultura a Urbanizaciones de Baja Densidad fue importante, especialmente en el período 1996-2005. La sustitución de las coberturas por Invernáculos y por usos urbanos, implican una simplificación del ecosistema y la progresiva conversión en paisajes agrícolas homogéneos, la pérdida de diversidad biológica y, por tanto, una mayor propensión al incremento de las plagas, la pérdida de los servicios ecosistémicos, y la disminución en la resiliencia de los sistemas productivos (Altieri y Letourneau 1982, Sarandón 2002). Al mismo tiempo, el análisis de los procesos de cambio del paisaje evidenció que la Horticultura experimento un proceso de disección, es decir un incremento en el número de parches con actividad hortícola al aire libre y una disminución en el área, lo que implicaría una reducción en su conectividad estructural; aspectos que pueden influir en el flujo de materiales y energía entre los parches y por ende en la provisión de servicios ecosistémicos. Lopez et al. (2018) sostienen que los sistémas socio-ecológicos agrícolas (en este caso las quintas hortícolas) comparten algunos recursos y están conectados por flujos de materia y energía, y/o por las redes sociales con otros sistémas socio-ecológicos agrícolas que habitan el mismo paisaje; razón por la cual destacan la importancia de analizar las interacciones entre los diferentes socio-ecosistémas agrícolas a nivel de paisaje, para avanzar hacia la gestión de paisajes resilientes. En relación con ello, numerosos estudios realizados en el CHP demuestran la importancia de mantener la horticultura al aire libre, incrementando la biodiversidad en los cultivos y manteniendo la vegetación semi-natural alrededor de ellos (e.g. Dubrovsky Berensztein 2018, Baloriani et al. 2009, Fernández y Marasas 2015, Stupino et al. 2009). Por otro lado, la Horticultura siempre creció en zonas con Ganadería. Esto indica que no sólo los Invernáculos ocuparon zonas con Ganadería, sino también la Horticultura, mostrando un desplazamiento de la actividad hortícola más alejado del centro de la ciudad, hacia zonas con suelos de menor calidad. Este cambio probablemente se deba a varias razones: la degradación de los suelos de la actual zona hortícola (Com. pers. Productores familiares del CHP, 2018), debido al intenso uso que se hace de ellos; y el aumento en los precios de arrendamiento de las tierras, asociado también a la falta de regulación de los contratos de alquiler. En el primer período, la expansión de los 
Invernáculos hacia zonas con Ganadería fue principalmente hacia el noroeste y en menor medida hacia el sureste; en el segundo período la expansión fue principalmente hacia el noroeste y en el tercer período se produjo un fuerte crecimiento hacia el suroeste (Fig. 12). En relación con la Horticultura, en el primer período la expansión hacia zonas con Ganadería fue bastante homogénea en todo el cinturón hortícola y en los dos últimos períodos la expansión fue principalmente hacia el sur (Fig. 12). De los párrafos anteriores se desprende que en el último período analizado, la horticultura total (invernáculos y horticultura al aire libre) avanzó hacia el sur/sur-oeste del partido. En el presente trabajo encontré que no hubo una retracción (al menos considerable) en la superficie bajo producción hortícola, pero si hubo un desplazamiento de la actividad; esto coincide parcialmente con García (2012), quien postula que se generó una retracción y relocalización del área hortícola, en el marco de una mayor productividad por unidad de superficie, existiendo una movilización hacia el Sur (Poblet y Etcheverry). Este desplazamiento es preocupante por varios motivos; por un lado el irse desplazando la actividad hortícola hacia suelos menos aptos puede conducir a una mayor intensificación como una forma de suplir la baja productividad generada por la calidad de los suelos, por otro lado el desplazamiento hacia zonas sin infraestructura adecuada puede incrementar los problemas actuales de acceso a una vivienda digna, salud, educación, comercialización, entre otros (Ambort, 2017). En conclusión, si no hay cambios en las políticas de planificación del uso de la tierra y sobre las políticas de producción de alimentos, existe el riesgo de trasladar el modelo de producción hortícola intensiva y los problemas asociados a este tipo de producción, que experimenta actualmente el CHP, hacia otras zonas, especialmente hacia el sur del partido.

Otras de las actividades productivas presentes en la región fueron la Ganadería, y en menor grado la Agricultura. La Agricultura se desarrolló principalmente en zonas más alejadas del centro de la ciudad, donde también tuvo lugar la Ganadería. Esta investigación revela la estrecha relación entre estas actividades. Si bien hay zonas del partido de La Plata, donde sólo se realizó Agricultura, y zonas exclusivamente Ganaderas, también existen algunas zonas donde estas actividades rotaron en el tiempo. Sin embargo, entre 2005 y 2015, las pérdidas de la Agricultura se asociaron principalmente a la conversión a Pastizales e Invernáculos. La misma dinámica descripta entre la Agricultura y la Ganadería tuvo lugar entre la Vegetación Riparia y la Ganadería. La Vegetación Riparia se expandió sobre la Ganadería en períodos húmedos, mientras que en períodos secos se retrajo y la Ganadería la sustituyó. A pesar de esta dinámica cíclica entre la Ganadería, la Agricultura y la Vegetación Riparia, en todo el período (1986-2015) se observó una disminución de la Ganadería, principalmente por conversión en Pastizales; esto puede tener que ver con un avance de la urbanización con loteos sobre suelos ganaderos pero que demoran unos años en urbanizarse (por ejemplo por falta de servicios públicos), dando lugar durante ese lapso de tiempo al surgimiento de pastizales. Aunque en menor medida, la superficie con 
Ganadería también sufrió una reducción en todos los períodos analizados, por conversión en Urbanización de Baja Densidad, y por conversión en Horticultura y en Invernáculos. El proceso descripto de reducción de la Ganadería, refuerza la dinámica de expansión de la urbanización y de la producción hortícola, mencionada anteriormente.

Los ambientes semi naturales son de gran valor para que los paisajes sean resilientes y como proveedores de servicios ecosistemicos de provisión y regulación (ej: formación de suelos, infiltración del agua de lluvia, polinización, fuente de enemigos naturales de las plagas). Actores internacionales, como la Organización para la Agricultura y la Alimentación de las Naciones Unidas (FAO), han planteado la agricultura sustentable como una solución a los problemas actuales en la producción de alimentos. La conservación de la biodiversidad es esencial para desarrollar producciones agrícolas sustentables, ya que ésta hace una gran contribución a las funciones y los servicios de los ecosistemas, para el mantenimiento de la resiliencia de los agro-ecosistemas y, por ende, para el desarrollo de territorios productivos sustentables y para el bienestar humano (Martin-López et al. 2007). Para este propósito, no sólo es importante el mantenimiento de la vegetación natural que rodea los cultivos y los cultivos al aire libre, sino también el mantenimiento de las coberturas de vegetación semi-naturales a escala de paisaje, por ser considerados como proveedores de biodiversidad (Nicholls 2009). Los modelos desarrollados por Newbold et al. (2015) sugieren que los cambios y la intensidad en el uso del suelo y las presiones asociadas, generan una fuerte reducción en la biodiversidad terrestre local, lo cual trae aparejado profundas consecuencias. En el presente trabajo los Pastizales, la Vegetación Riparia y los Árboles y arbustos, podrían considerarse ambientes semi-naturales. En este sentido, encontré que en todo el período analizado las tres coberturas aumentaron sus superficies. La Vegetación Riparia y los Árboles y arbustos al comienzo experimentaron un patrón de creación y luego hacia el final del período estudiado, un proceso de agregación; mientras que los Pastizales experimentaron procesos de creación y de agregación alternadamente. Los Árboles y arbustos no representaron en ninguna de las fechas estudiadas un porcentaje significativo de la superficie del partido, siendo siempre menor al 1\%. Aunque la Vegetación Riparia experimentó un mayor crecimiento respecto a las otras coberturas de vegetación semi-natural, este fue principalmente en el oeste y el sur del partido, focalizado en tierras bajas, zonas típicamente ganaderas. En contraste, la política gubernamental con respecto a los ambientes riparios en el área urbana y peri-urbana, tradicionalmente consistió en el entubamiento y la canalización, eliminando la vegetación asociada (Karol y San Juan 2018, Liscia et al. 2013, Hurtado et al. 2006). La reducción de la vegetación y la impermeabilización causada por el desarrollo de infraestructura urbana y por los invernáculos cercanos a los arroyos, afectan a los servicios ecosistémicos tales como la protección de los suelos, la regulación de la escorrentía superficial, la infiltración del agua de lluvia, la purificación del agua y los refugios de biodiversidad (Karol y San Juan 2018, 
Rositano et al. 2012). Además, el asentamiento de población vulnerable en las márgenes de los arroyos y en las planicies de inundación aumenta su exposición a las inundaciones y la contaminación derivada de las actividades industriales y la horticultura (Karol y San Juan 2018, Liscia et al. 2013, Hurtado et al. 2006). Es interesante resaltar que no sólo la población vulnerable sino también clases de alto poder adquisitivo, vinculadas a la instalación de countries y barrios privados, se asienta en las planicies de inundación de los arroyos (Karol y San Juan 2018). Por otro lado, este estudio mostró que los Pastizales se desarrollaron en áreas peri-urbanas, donde también se desarrolló el CHP, y que su crecimiento se produjo sobre áreas con Ganadería lindantes con áreas urbanas y sobre áreas con actividad hortícola al aire libre. El crecimiento de los Pastizales, especialmente durante los dos primeros períodos, sobre áreas Hortícolas, podría deberse al abandono de los cultivos por la erosión de los suelos, producto de la forma intensiva en la que se desarrolló esta actividad y/o al costo de los alquileres, principal forma de acceso a la tierra de las familias productoras. Estos ambientes podrían funcionar como potenciales pulmones verdes periurbanos, proporcionando refugio para la biodiversidad, por ejemplo para los enemigos naturales de plagas de los cultivos, necesaria para el desarrollo de una producción hortícola más sustentable; siempre y cuando estas coberturas no siguieran la tendencia identificada a transformarse en Parquizaciones Herbáceas y finalmente a urbanizarse. Con este objetivo, más parches de Pastizales distribuidos en toda la zona periurbana podrían ser más adecuados que los patrones de aglomeración como los que identifiqué que experimentó esta cobertura del suelo. Las pérdidas relativas de la superficie de Pastizales estuvieron relacionadas con el crecimiento de la Urbanización de Baja Densidad, y en algunos períodos con las Parquizaciones Herbáceas y los Invernáculos, esto último es para tener en cuenta, ya que implica un avance de la urbanización y la producción intensiva sobre ambientes semi-naturales (Fig. 11). Al mismo tiempo, la identificación, a través de esta investigación, de áreas en las que existía un fuerte desarrollo de Invernáculos y un proceso de aglomeración de estos, indica que en dichas áreas hay actualmente menos ambientes naturales proveedores de biodiversidad (Fig.13).

Es pertinente resaltar la tendencia a la urbanización y a la intensificación productiva identificada para todo el periodo de estudio, mediante el análisis de los principales procesos de transición entre las coberturas/usos del suelo. Además, en este análisis encontré que tanto las zonas urbanas como las áreas de invernaderos, experimentaron procesos de creación y agregación, lo que se puede ver traducido en problemas derivados de la impermeabilización del suelo y problemas ambientales derivados de la concentración espacial de producciones muy intensivas. Esta tendencia parece ser un proceso lineal y unidireccional de LULCC. Sin embargo, es importante aclarar que en el caso de la producción hortícola, podría haber situaciones específicas en las que sería posible retornar de áreas de Invernáculos a Horticultura (al aire libre) y de Horticultura a Pastizal. Áreas con 
Horticultura podrían volver a presentar coberturas de Pastizales debido al abandono de los cultivos por la erosión de los suelos y la consiguiente pérdida de productividad. Por otro lado, en el caso de Invernáculos, a pesar del hecho de que en este estudio no observé un retorno a la Horticultura, después del año 2015 y hasta la fecha, hubo una serie de severas tormentas que destruyeron una gran cantidad de Invernáculos, y los agricultores que no tuvieron capacidad de inversión optaron por el abandono de estas tierras, así como por la producción al aire libre (Obs.Pers. 2016). Además, los patrones identificados en la zona periurbana del partido de La Plata, donde se encuentra el Cinturón Hortícola, estuvieron asociados a una simplificación del paisaje (por la convergencia de diversas coberturas/usos del suelo ya sea en áreas urbanizadas o en cultivos bajo invernáculos) y a una reducción de la cubierta vegetal, afectando el suministro de servicios ecosistémicos; problemas que otros países, como los europeos, ya han atravesado (Tecco et al. 2017). La diversidad de paisajes contribuye a mejorar procesos como la polinización, el control de plagas y el ciclo de nutrientes, importantes en la producción de alimentos (Rositano et al. 2012, Martin-López et al. 2007). La cubierta vegetal también es un importante regulador de la erosión y degradación del suelo, el balance hídrico y el clima regional (Karol y San Juan 2018). Por lo tanto, cabría esperar que los cambios identificados en la zona, llevaran a una reducción en la capacidad de infiltración del suelo, pérdida de nutrientes y de estructura del suelo y una reducción en el control biológico de plagas y en la polinización. Esto podría resultar en un aumento de las inundaciones y una degradación en las condiciones de productividad en el área, llevando a los productores a migrar a otras regiones. En un contexto mundial de cambio climático que afecta a la región cada vez con mayor intensidad (Karol y San Juan 2018, Barros et al. 2005), los cambios identificados en el paisaje se traducen en una reducción en la resiliencia de las áreas productivas y en el paisaje. Investigadores, técnicos y organizaciones de productores de la región han comenzado a registrar las consecuencias de esta situación (UNLP 2017, Karol y San Juan 2018, Hurtado et al. 2006, UTT 2018), así como actores internacionales (Naciones Unidas 2019), ya que afectan la seguridad y la soberanía alimentaria, poniendo en riesgo los niveles de provisión de alimentos en cantidad y calidad, de uno de los cinturones hortícolas más importantes del país, que abastece a millones de personas. El cambio de uso de la tierra sin políticas adecuadas de planificación y sin una gestión que garantice su implementación, podría conducir a la intensificación de los problemas actuales.

\section{CONCLUSIONES PARCIALES}

A través de este análisis se corroborado los procesos de crecimiento urbano y de intensificación hortícola descriptos por diferentes autores. También pude mapear y cuantificar estos procesos, haciendo una contribución a una mejor comprensión de los procesos que están teniendo lugar en la región, desde la óptica de la ecología del paisaje Este análisis también demostró que todavía hay un potencial para la mejora de las 
condiciones de la producción hortícola y para el desarrollo urbano, si se aborda un proceso adecuado de planificación territorial que considere los procesos ecológicos y las áreas con cobertura de vegetación semi-natural.

Algunas de las principales conclusiones a las que llegué son:

La urbanización total (Urbanización de Alta Densidad y Urbanización de Baja Densidad) experimentó un importante crecimiento en todo el período de estudio (tasa de crecimiento anual del 1,63\%). En el caso del total de horticultura (horticultura al aire libre e invernáculos), el porcentaje de cobertura no sufrió modificaciones sustanciales, experimentando una leve reducción en su superficie (tasa anual de decrecimiento de $0,11 \%)$. Sin embargo, se detectó una intensificación productiva extremadamente elevada, reflejada en un crecimiento exponencial en la superficie de cultivos bajo invernáculos (tasa de crecimiento anual de $91,48 \%$ ) y en los procesos de crecimiento y agregación identificados para dicha cobertura. En consonancia con este proceso, la Horticultura (horticultura al aire libre) sufrió un proceso de disección, caracterizado por el incremento en el número de parches y la reducción en área.

En relación a la producción hortícola observé que los invernáculos crecieron en todos los períodos estudiados, pero con especial énfasis en el período 2005-2015, y que el aumento en superficie siempre se dio a expensas principalmente de áreas con horticultura al aire libre y en menor medida en zonas ganaderas. La producción hortícola al aire libre disminuyó en superficie en todos los períodos estudiados, especialmente en el período 1996-2005; sin embargo, en todos los períodos hubo zonas ganaderas que fueron reemplazadas por nuevas producciones hortícolas. La actividad hortícola (al aire libre y bajo invernáculos) sufrió un progresivo desplazamiento hacia el sur/sudoeste del partido, avanzando sobre suelos ganaderos.

La Urbanización de Baja Densidad tuvo un amplio crecimiento en los primeros dos períodos estudiados y una reducción en el último período; el crecimiento se dio principalmente sobre pastizales y parquizaciones herbáceas, aunque en menor medida también avanzó sobre zonas con hortícultura al aire libre. La Urbanización de Alta Densidad se desarrolló en todos los períodos sobre zonas de Urbanización de Baja Densidad.

En cuanto a las coberturas vegetales, si bien en todos los períodos estudiados creció la superficie de Pastizales, se ve una tendencia en dicho período a la conversión de pastizales a parquizaciones herbáceas y a urbanizaciones de baja densidad. De la misma manera, las parquizaciones herbáceas muestran una tendencia a convertirse en urbanizaciones de baja densidad. La Vegetación Riparia también se incrementó en todo el período de estudio, pero lo hizo pincipalmente en la periferia del partido, asociadas a zonas bajas, con actividad principalmente ganadera. 
Los patrones identificados en la zona periurbana del partido de La Plata, donde se encuentra el Cinturón Hortícola, estuvieron asociados a una simplificación del paisaje (por la convergencia de diversas coberturas/usos del suelo ya sea en áreas urbanizadas o en cultivos bajo invernáculos), a una agregación de los parches de invernáculos, un incremento en el número de parches de horticultura al aire libre y una reducción en área, y a una agregación de los Pastizales. Los cambios identificados en el paisaje se traducen en una reducción en la resiliencia de las áreas productivas y en el paisaje.

A partir de los resultados obtenidos en este capítulo, se acepta parcialmente la hipótesis 1, que plantea que la amplia expansión de la tecnología del invernáculo, que tuvo lugar en los últimos 30 años en el CHP, fue posible a expensas de la ocupación de áreas semi naturales y del reemplazo de cultivos al aire libre; afectando su distribución, conectividad y superficie total. Los análisis realizados en este capítulo se consideran insuficientes para determinar el grado de conectividad de las áreas semi-naturales.

De la misma manera se acepta parcialmente la hipótesis 2, que plantea que la estructura del paisaje remanente permite sostener y profundizar estrategias de manejo y planificación de base agroecológica, tendientes a generar un cambio en el modelo productivo. Si bien el análisis del cambio en las coberturas/usos del suelo expone una tendencia a la homogeneización del paisaje, con pérdida de cultivos al aire libre y concentración de algunas coberturas semi-naturales en ciertos sectores del partido, también se observa que para el año 2015 aún se conserva un porcentaje importante de cultivos al aire libre, que los ambientes riparios y los pastizales se han incrementado y que existen pastizales cercanos a las zonas hortícolas que podrían funcionar como pulmones verdes; esto es un potencial a la hora de pensar en un cambio en el modelo productivo.

\section{BIBLIOGRAFÍA}

Alonso L, Bernasconi C, Ciciarelli A, De Castro C, Esteban C, Etchegoyen A, MacLoughlin T, Muntaner L, Ledesma R, Orofino L, Percudani C, Piccinini A, Rojo M, Santillán JM, Vittori S (2015). Plaguicidas: los condimentos no declarados. XIII jornadas de jóvenes investigadores grupo Montevideo. Ciencia, tecnología e innovación para la inclusión social. La Plata, Buenos Aires.

Altieri MA, Letourneau DL (1982). Vegetation management and biological control in agroecosistems. Crop Protection 1: 405-430. DOI: https://doi.org/10.1016/02612194(82)90023-0

Arias M (2019). Efecto del uso de fertilizantes y pesticidas sobre organismos acuáticos en arroyos de la zona hortícola de La Plata. Tesis Doctoral. Facultad de Ciencias Naturales y Museo, Universidad Nacional de La Plata. 147 pp. 
Aznar Sánchez JÁ (2011). El Clúster agroindustrial de la horticultura intensiva de Almería: Surgimiento, dinámica y perspectivas. Cuadernos de Estudios Agroalimentarios (CEA), (2), 199-217.

Baloriani G, Paleologos MF, Marasas ME, Sarandón SJ (2009). Abundancia y Riqueza de la Macrofauna Edáfica (Coleoptera y Araneae), en Invernáculos Convencionales y en Transición Agroecológica. Arana, Argentina. Revista Brasilera de Agroecología. 4(2): 1733-1737.

Barchuk A, Suez L, Locati Y (2017). Cobertura y uso de la tierra en el área periurbana de la ciudad de Córdoba, Argentina. Aportes a la planificación territorial. Revista de la asociación Argentina de ecología de paisajes, 7: 15-30.

Barros V, Menéndez Á, Nagy G (2005). El cambio climático en el Río de la Plata. Buenos Aires. Facultad de Ciencias Exactas y Naturales (UBA), CIMA-Conicet.

Barsky A (2007). Globalización y Agricultura periurbana en Argentina. Escenarios, recorridos y problemas. Ada Svetlitza de Nemirovsky (coordinadora). Maestría en Estudios Sociales Agrarios. SerieMonografías ISSN, 2(2), 1.

Barsky A, Vio M (2007) La Problemática del Ordenamiento Territorial en Cinturones Verdes Periurbanos sometidos a Procesos de Valorización Inmobiliaria. El caso del Partido del Pilar, Región Metropolitana de Buenos Aires. IX Coloquio Internacional de Neocrítica. Universidade Federal do Rio Grande do Sul. Porto Alegre.

Benencia R (2002). Transformaciones territoriales en la horticultura periurbana bonaerense en los últimos 50 años. El papel de la tecnología y la mano de obra. XIII Economic History Congress. Buenos Aires.

Bertoni JC, Ambrosino S, Barbeito O, Daniele A, Maza JA, Paoli CU, Serra JJ (2004). Inundaciones urbanas en la Argentina. GWP-SAMTAC; Programa Asociado de Gestión de Crecidas; Universidad Nacional de Córdoba. Secretaría de Ciencia y Técnica, SECyT; Comité Permanente de los Congresos Nacionales del Agua, Argentina; Arg CAP-NET.

Birche M, Jensen KC (2018b). El paisaje en el espacio público como medio de integración entre la ciudad y el agua: el caso de la región La Plata, Argentina. Revista de Urbanismo, (39), 1-16.

Birche ME, Jensen KC (2018). Relevamiento y catalogación de los espacios verdes de uso público de la ciudad de La Plata, Argentina. Urbano, 21. 
Blandi ML, Gargoloff NA, Sarandón SJ (2009). Análisis de la Sustentabilidad de la Producción Hortícola Bajo Invernáculo en la Zona de la Plata, Argentina. Revista Brasilera de Agroecología. 4(2):1635-1638.

Blandi ML, Sarandón SJ, Pereira Veiga IJ (2011). La "autoeficacia": un indicador de la conducta sustentable. Su importancia para el logro de sistemas hortícolas sustentables en La Plata, Argentina. VII Congreso Brasilero de Agroecología. Cuadernos de Agroecología, 6 (2):1-6.

Blandi ML, Sarandón SJ, Flores CC, Veiga I (2015). Evaluación de la sustentabilidad de la incorporación del cultivo bajo cubierta en la horticultura platense. Revista de la Facultad de Agronomía, La Plata, 114(2), 251-264.

Blandi ML (2016). Tecnología del invernáculo en el Cinturón Hortícola Platense: análisis de la sustentabilidad y los factores que condicionan su adopción por parte de los productores (Doctoral dissertation, Facultad de Ciencias Agrarias y Forestales).

Bogaert J, Ceulemans R, Salvador-Van Eysenrode D (2004) Decision tree algorithm for detection of spatial processes in landscape transformation. Environmental Management, 33, 1, 62-73. DOI: https://doi.org/10.1007/s00267-003-0027-0

Bongiorno M, Larrosa C, Maidana A, Arenas M, Cruz Y, López R, Gianuzzi L, Cap GB (2009). Biofumigación con recursos locales: el caso de la producción hortícola de los quinteros del Parque Pereyra Iraola. Revista Leisa, 25 (4): 25-28.

Botana MI (2004). Aportes a la sustentabilidad ambiental de tierras productivas en espacios periurbanos. In Anales LINTA (Vol. 3). Laboratorio de Investigaciones del Territorio y el Ambiente (LINTA).

Bozzano H (2014). Ordenamiento del territorio e Inteligencia Territorial. Un enfoque aplicado a casos en La Plata (Argentina) y Minas (Uruguay). Polígonos, (26), 181-222.

Cabral MG, Hurtado MA, Giménez JE, Sánchez CA, Muntz D, da Silva M (2002). Índices de afectación territorial en la planificación estratégica del partido de La Plata, provincia de Buenos Aires, Argentina. Jornadas Geológicas and Geofísicas Bonaerenses.

Carut C (2006). Territorios en transición: las transformaciones territoriales de la periferia de la ciudad de La Plata (Argentina). Cuadernos de investigación geográfica (32), 123146.

CHFBA (2005). Censo Hortiflorícola de Buenos Aires. Ministerio de Asuntos Agrarios y Ministerio de Economía de la Prov. de Buenos Aires. Disponible en: http://www.maa.gba.gov.ar/agricultura_ganaderia/archivos/resultadofinal.pdf 
Chuvieco, E (1998). El factor temporal en teledetección: evolución fenomenológica y análisis de cambios. Revista de teledetección, 10: 1-9.

Cieza RI, Ferraris G, Seibane C, Larrañaga G, Mendicino L (2015). Aportes a la caracterización de la agricultura familiar en el Partido de La Plata. Revista de la Facultad de Agronomía de La Plata. Vol. 114 (Núm. Esp.1). Agricultura Familiar, Agroecología y Territorio: 129-142.

Clark Labs (2012). IDRISI Selva (version 17.00). Worcester: Clark Labs, Clark University.

Colombo JC, Astoviza M, Bilos C, Cappelletti N, Migoya C, Morrone M, Skorupka, C, Speranza E, Tatone L (2015). Subproyecto "Biogeoquímica de contaminantes". En: Relevamiento de la utilización de agroquímicos en la Provincia de Buenos Aires. Mapa de situación e incidencias sobre la salud. Defensor del Pueblo de la Provincia de Buenos Aires y UNLP.

Congalton RG, Green K (2008). Assessing the accuracy of remotely sensed data: principles and practices. CRC press.

Congedo L 2016. Semi-Automatic Classification Plugin Documentation. DOI:http://dx.doi.org/10.13140/RG.2.2.29474.02242/1

Conijn JG, Bindraban PS, Schröder JJ, Jongschaap REE (2018). Can our global food system meet food demand within planetary boundaries?. Agriculture, Ecosystems \& Environment, 251, 244-256. DOI: https://doi.org/10.1016/j.agee.2017.06.001

Dadon JR, Matteucci SD (Eds.). (2002). Zona Costera de la Pampa Argentina. Recursos Naturales, Sustentabilidad, Turismo, Gestión y Derecho Ambiental. Lugar Editorial, 224 pp. [ISBN 950-892-140-4].

Dansero E, Pettenati G, Toldo A (2017). The relationship between food and cities and urban food policies: a space for geography?. Bollettino della società geografica italiana. 13 (5): 4-19.

Dubrovsky Berensztein N (2018). Estudio de la entomofauna en agroecosistemas del Cinturón Hortícola de La Plata, para el diseño participativo de estrategias de control biológico por conservación (Doctoral dissertation, Universidad Nacional de La Plata). On line: http://sedici.unlp.edu.ar/handle/10915/71094

Eastman JR (2012) IDRISI Selva Tutorial. IDRISI Production, Clark Labs-Clark University, Worcester, 45. 
Eastman JR, Solorzano L, Van Fossen M (2005). Transition Potential Modeling for LandCover Change. In David J. Maguire, Michael batty and Michael F. Goodchild (Eds.), GIS, Spatial Analysis and Modeling, 357-385. Redlands, CA: ESRI Press.

Etulain JC, López I (2017). Inundaciones urbanas: mapas de riesgo y lineamientos de ordenamiento territorial en la región del gran La Plata. Estudios del Hábitat, 15 (2).

FAO (2016). El estado mundial de la agricultura y la alimentación. Cambio climático, agricultura y seguridad alimentaria. Organización de las Naciones Unidas para la Alimentación y la Agricultura. Disponible en: http://www.fao.org/3/a-i6030s.pdf

Feito MC (2014). Ruralidades, agricultura familiar y desarrollo: territorio del periurbano norte de la Provincia de Buenos Aires. Editorial La Colmena, Buenos Aires. 156 pp.

Fernández V, Marasas ME (2009). Estudio Preliminar de la Riqueza de Vegetación Arvense en Fincas de Producción Hortícola con Manejo Convencional y Bajo Principios Agroecológicos. Su Aporte al Proceso de Transición. Revista Brasileira de Agroecología. 4(2):3599-3603.

Fernández V, Marasas ME (2015). Análisis comparativo del componente vegetal de la biodiversidad en sistemas de producción hortícola familiar del Cordón Hortícola de La Plata (CHLP), provincia de Buenos Aires, Argentina. Revista de la Facultad de Agronomía, 114 (Núm. Esp. 1): 15-29.

Fernández Lozano, J (2012). La producción de hortalizas en Argentina. Gerencia de Calidad y Tecnología. Mercado Central de Bs. As. On line: https://www.academia.edu/23974120/La produccion de hortalizas en argentina

Fingerman N (2018). La agricultura familiar en el Área Hortícola de La Plata, Berazategui y Florencio Varela. Diversas formas de dependencia y el camino de construcción de su autonomía. Ediciones INTA, La Plata, Buenos Aires. 111 pp.

Flores C, Sarandón SJ, lermanó MJ (2007). Eficiencia energética en sistemas hortícolas familiares del partido de La Plata, Buenos Aires, Argentina. Revista Brasileira de Agroecología. 2(1):1060-1064.

Frediani JC (2010). Lógicas y tendencias de la expansión residencial en áreas periurbanas. El Partido de La Plata, Buenos Aires, Argentina, entre 1990 y 2010 (Doctoral dissertation, Universidad Nacional de La Plata. Facultad de Humanidades y Ciencias de la Educación). On line: http://sedici.unlp.edu.ar/handle/10915/3203 
Foley JA, DeFries R, Asner GP, Barford C, Bonan G, Carpenter SR, et al. (2005). Global consequences of land use. Science, 309(5734), 570-574. DOI: 10.1126/science. 1111772

Galdeano-Gómez E, Aznar-Sánchez JA, Pérez-Mesa JC (2012). Sustainability dimensions of agricultural development in Almería (Spain): The experience of 50 years. On line: https://www.econstor.eu/handle/10419/120533

García M (2011). El cinturón hortícola platense: ahogándonos en un mar de plásticos. Un ensayo acerca de la tecnología, el ambiente y la política. THEOMAI $n^{\circ} 23$, primer semestre 2011.

García M (2012). Análisis de las transformaciones de la estructura agraria hortícola platense en los últimos 20 años. El rol de los horticultores bolivianos. Tesis doctoral de la Facultad de Ciencias Agrarias y Forestales, UNLP.

García M (2015a). Horticultura de La Plata (Buenos Aires): Modelo productivo irracionalmente exitoso. Rev. Fac. Agron. La Plata, Vol 114 (Núm. Esp.1) Agricultura Familiar, Agroecología y Territorio: 190-201.

García M, Mierez L (2007). "Cultivos al aire libre. Importancia y razones en la región hortícola más capitalizada". Boletín Hortícola. Año 12, № 35.

García M. (2015b). Colonia hortícola o Barbarie: Diagnóstico y propuestas de cambio para el área hortícola platense. Boletín hortícola. 19 (53): 20-26.

Gargoloff NA, Riat P, Abbona EA, Sarandón SJ (2007). Análisis de la Racionalidad Ecológica en 3 grupos de horticultores en La Plata, Argentina. Revista Brasileira de Agroecología. 2(2): 468-471.

Gibbs HK, Ruesch AS, Achard F, Clayton MK, Holmgren P, Ramankutty N, et al. (2010). Tropical forests were the primary sources of new agricultural land in the 1980s and 1990s. Proceedings of the National Academy of Sciences, 107, 16732-16737. DOI: https://doi.org/10.1073/pnas.0910275107

Giobellina B (2017). El cinturón verde de Córdoba: hacia un plan integral para la preservación, recuperación y defensa del área periurbana de producción de alimentos. Coordinadora Beatriz Giobellina; producción cartográfica Nicolás Mari, et al. 1a ed. Manfredi, Córdoba : Ediciones INTA. On line: https://inta.gob.ar/sites/default/files/inta-el-cinturon-verde-de-cordoba $0 . p d f$

Giobellina B et al. (2018). La alimentación de las ciudades: transformaciones territoriales y cambio climático en el Cinturón Verde de Córdoba. Compiladora: Beatriz Giobellina. 
1a ed. Ciudad Autónoma de Buenos Aires. Ediciones INTA. On line: https://inta.gob.ar/sites/default/files/inta_la_alimentacion_de_las_ciudades.pdf

Godfray HCJ (2011). Food and biodiversity. Science, 333, 1231-1232. DOI: $10.1126 /$ science. 1211815

Hajdu F, Penje O, Fischer K (2016). Questioning the use of 'degradation' in climate mitigation: A case study of a forest carbon CDM project in Uganda. Land Use Policy, 59, 412-422. DOI: https://doi.org/10.1016/j.landusepol.2016.09.016

Hurtado MA, Gimenez JE, Cabral MG (eds) (2006). Análisis ambiental del partido de La Plata: Aportes al ordenamiento territorial. Consejo Federal de Inversiones, $1^{\mathrm{a}}$ ed.

Instituto Nacional de Estadística y Censos de la República Argentina (INDEC) (2010). Censo Nacional de Población, Hogares y Viviendas (2010). On line: https://www.indec.gov.ar/nivel4_default.asp?id_tema_1=2\&id_tema_2=41\&id_tema_ $3=135$

ITT Visual Information Solutions, 2007. ENVI (versión) User's Guide.

Jensen K, Birche M (2018). El paisaje y la forma de expansión en la ciudad de La Plata: lineamientos y estrategias para la planificación del crecimiento urbano. In $\mathrm{X}$ Seminario Internacional de Investigación en Urbanismo, Barcelona-Córdoba, Junio 2018. Departament d'Urbanisme i Ordenació del Territori. Universitat Politècnica de Catalunya.

Karol JL, San Juan GA (2018). Saber qué hacer: construcción de un sistema para la gestión integrada del riesgo hídrico en la región del Gran La Plata. Eds. Jorge L. Karol; Gustavo San Juan. - 1a edición especial - Universidad Nacional de La Plata. Facultad de Arquitectura y Urbanismo, La Plata. On line: http://sedici.unlp.edu.ar/handle/10915/67730

Lepers E, Lambin EF, Janetos AC, DeFries R, Achard F, Ramankutty N, Scholes RJ (2005). A synthesis of information on rapid land-cover change for the period 1981-2000. BioScience, 55(2), 115-124.

Liscia S, Amarilla R, Bacchiega D, Brea D, Carner J, Cielli P, Zarate F (2013). Estudio sobre la inundación ocurrida los días 2 y 3 de abril de 2013 en las ciudades de La Plata, Berisso y Ensenada. La Plata: UNLP, Facultad de Ingeniería, Departamento de Hidráulica. Recuperado de http://sedici. unlp. edu. ar/handle/10915/27334.

López DR, Cavallero L, Easdale MH, Carranza C, Ledesma M y P Peri (2018). Chapter 5: resilience management at the landscape level: an approach to tackling social- 
ecological vulnerability of agroforestry systems. In: Integrating Landscapes: Agroforestry for Biodiversity Conservation and Food Sovereignty (F Montagnini ed.), Advances in Agroforestry 12, Chapter 19, pp. 453-478. Springer International Publishing. ISSN 1875-1199.

Mac Loughlin TM, Peluso L, Marino DJ (2017). Pesticide impact study in the peri-urban horticultural area of Gran La Plata, Argentina. Science of the Total Environment, 598: $572-580$.

Marasas ME, Fernandez V, Baloriani G, Cap G, Larrosa C, Rouaux J (2011). Estudio de la Agrobiodiversidad en Sistemas de Producción Hortícola Familiar. Buenos Aires, Argentina. VII Congreso Brasilero de Agroecología. Cuadernos de Agroecología, 6 (2):1-5.

Marasas ME, Fernández V, Dubrovsky Berensztein N (2014). Agrobiodiversidad en sistemas hortícolas familiares. Revista Leisa, 30 (1): 26-28.

Martellozzo F, Amato F, Murgante B, Clarke KC (2018). Modelling the impact of urban growth on agriculture and natural land in Italy to 2030. Applied Geography, 91, 156167.DOI: https://doi.org/10.1016/j.apgeog.2017.12.004

Martin-López B, González J, Díaz S, Castro I, García Llorente M (2007). Biodiversidad y bienestar humano: el papel de la diversidad funcional. Ecosistemas. 2007/3. Disponible en: http://www.revistaecosistemas. net/articulo.asp?ld=500\&ld_Categoria=1\&tipo=portada)

Matteucci SD, Morello J, Rodríguez A, Buzai GD, Baxendale C (1999). El crecimiento de la metrópoli y los cambios de biodiversidad: el caso de Buenos Aires. En: S.D. Matteucci; O.T. Solbrig; J.Morello y G. Halffter. 1999. Biodiversidad y uso de la tierra. Conceptos y ejemplos de Latinoamérica. EUDEBA-UNESCO, Buenos Aires. Pp. 549580.

Medan D, Torretta JP, Hodara K, de la Fuente EB, Montaldo NH (2011). Effects of agriculture expansion and intensification on the vertebrate and invertebrate diversity in the Pampas of Argentina. Biodiversity and Conservation 20: 3077-3100. DOI: https://doi.org/10.1007/s10531-011-0118-9

Médico CM (2016). La vegetación como posibilidad de integración espacial, ambiental y social en los paisajes de interfase urbano-rural de la provincia de Mendoza. Revista de las Facultades de Arquitectura e Ingeniería. On line: http://www.um.edu.ar/ojsnew/index.php/FAl/article/view/794 
Merchán AG (2016). Valorización de la tierra en el Cinturón Hortícola Platense Facultad de Ciencias Agrarias y Forestales. On line: http://sedici.unlp.edu.ar/handle/10915/53577

Millennium Ecosystem Assessment (2005). Ecosystems and human well-being. Current state and trends. Washington, D.C.: Island Press.

Morello J, Matteucci SD (1997). El modelo agrícola del Núcleo Maicero como sistema complejo. En: J. Morello y O.T. Solbrig (comps.), La Pampa Ondulada: granero del mundo hasta cuando?. Orientación Gráfica Editora, SRL, Buenos Aires. Pp. 201-231.

Morello JH, Buzai GD, Baxendale C, Rodríguez A, Matteucci SD, Godagnone RE, Casas RR (2000). Urbanización y consumo de tierra fértil. Ciencia Hoy, 10(55), 50-61.

Morello J, Matteucci SD, Rodriguez AF, Silva ME, Mesopotámica P, Llana P, ...Medanosa P (2012). "Ecorregiones y complejos Ecosistémicos de Argentina". Orientación Gráfica Editora, Buenos Aires.

Mountrakis G, Im J, Ogole C (2011). Support vector machines in remote sensing: A review. Journal of Photogrammetry and Remote Sensing. 66: 247-259. DOI: https://doi.org/10.1016/.j.isprsiprs.2010.11.001

Newbold T, Hudson LN, Hill SL, Contu S, Lysenko I, Senior RA, Day J (2015). Global effects of land use on local terrestrial biodiversity. Nature, 520(7545), 45. DOI: https://doi.org/10.1038/nature14324

Nicholls Cl (2009). Bases agroecológicas para diseñar e implementar una estrategia de manejo de hábitat para control biológico de plagas. En: Vertientes del pensamiento agroecológico: fundamentos y aplicaciones (Comp. Altieri, M.), pp. 207-228. SOCLA. Medellín, Colombia.

Nieto DP, Rivas GA (2006). Estudio socio-territorial de la actividad hortícola en el partido de La Plata 1998-2002. Geograficando: Revista de Estudios Geográficos, 2(2).

NRC y GSC (National Research Council, \& Geographical Sciences Committee) (2014). Advancing land change modeling: opportunities and research requirements. National Academies Press.

Pengue W (2005). Agricultura industrial y transnacionalización en América Latina ¿La transgénesis de un continente? Serie Textos Básicos para la Formación Ambiental. Grupo de Ecología del Paisaje y Medio Ambiente (GEPAMA). Universidad de Buenos Aires. 
Piquer-Rodríguez M, Butsic V, Gärtner P, Macchi L, Baumann M, Pizarro GG, ...Kuemmerle $\mathrm{T}$ (2018). Drivers of agricultural land-use change in the Argentine Pampas and Chaco regions. Applied geography, 91, 111-122.

QGIS Development Team, (2016). QGIS Geographic Information System. Open Source Geospatial Foundation Project. https://qgis.org

Ramankutty N, Foley JA, Norman J, Mcsweeney K (2002). The global distribution of cultivable lands: Current patterns and sensitivity to possible climate change. Global Ecology and Biogeography, 11, 377-392. DOI: https://doi.org/10.1046/j.1466822x.2002.00294.x

Ramankutty N, Amato E, Monfreda TC, Foley JA (2008). Farming the planet: 1. Geographic distribution of global agricultural lands in the year 2000. Global Biogeochemical Cycles, 22. DOI: https://doi.org/10.1029/2007GB002952

Rockström J, Steffen W, Noone K, Persson Å, Chapin FS, Lambin E, et al. (2009). Planetary boundaries: Exploring the safe operating space for humanity. Ecology and Society, $14(2): 32$

Rositano F, López M, Benzi P, Ferraro DO (2013). Servicios de los ecosistemas: un recorrido por los beneficios de la naturaleza. Agronomía \& Ambiente, 32(1-2). On line: http://agronomiayambiente.agro.uba.ar/index.php/AyA/article/view/5

Sánchez H (2009). Periurbanización y espacios rurales en la periferia de las ciudades. Procuraduría Agraria, Estudios Agrarios. On line: http://www.pa.gob.mx/publica/rev 41/analisis/7\%20hector\%20avila.pdf

Sarandón SJ (2002). "La agricultura como actividad transformadora del ambiente. El Impacto de la Agricultura intensiva de la Revolución Verde". En Agroecología: El camino hacia una agricultura sustentable. S. J. Sarandón (Editor), Ediciones Científicas Americanas, La Plata. Cap. 1: 23-48.

Sarandón SJ, Flores CC, Abbona E, lermanó MJ, Blandi ML, Oyhamburu MM, Presutti (2015). Subproyecto "Análisis del uso de agroquímicos asociado a las actividades agropecuarias de la Provincia de Buenos Aires". En: Relevamiento de la utilización de agroquímicos en la Provincia de Buenos Aires. Mapa de situación e incidencias sobre la salud. Defensor del Pueblo de la Provincia de Buenos Aires y UNLP.

Schulz JJ, Cayuela L, Echeverria C, Salas J, Benayas JMR (2010). Monitoring land cover change of the dryland forest landscape of Central Chile (1975-2008). Applied Geography, 30(3), 436-447. 
Staviski A (2010). Situación de la plasticultura en Argentina. En actas XXXIII Congreso Argentino de Horticultura. Rosario. Santa Fe. ASAHO.

Stupino S, Sarandón SJ, Frangi J (2009). Características de la Diversidad Cultivada y su Relación con la Diversidad Vegetal Asociada en Fincas Hortícolas Bajo Diferente Manejo en La Plata, Argentina. Cadernos de Agroecologia, 4(1): 213-216.

Tapella E (2004). "Reformas Estructurales en Argentina y su Impacto sobre la Pequeña Agricultura. ¿Nuevas Ruralidades, Nuevas Políticas?”. En Estudios Sociológicos, 22(3): 669-700. Revista del Colegio de México. Disponible en: http://www.redalyc.org/articulo.oa?id=59806606.

Tecco N, Bagliani M, Dansero E, Peano C (2017). Toward the local territorial food system: spaces of analysis and action. Bollettino della Società Geografica Italiana: serie xiii, vol. X, pp. 20-38. On line: http://societageografica.net/wp/wpcontent/uploads/2016/08/BSGI-1-2-eng BR.pdf\#page=22

Teubal M, Rodríguez J (2002). Agro y alimentos en la globalización: una perspectiva crítica. Ed. La Colmena, Buenos Aires. 208 pp.

Turner BL, Moss RH, Skole DL (1993). Relating land use and global land-cover change: A proposal for an IGBP-HDP core project. Report from the IGBPHDP Working Group on Land-Use/Land-Cover Change. Joint publication of the International GeosphereBiosphere Programme (Report No. 24) and the Human Dimensions of Global Environmental Change Programme (Report No. 5). Stockholm: Royal Swedish Academy of Sciences.

Turner BL (2002). Toward integrated land-change science: Advances in 1.5 decades of sustained international research on land-use and land cover change. In Challenges of a Changing Earth. Steffen W, Jäger J, Carson DJ, Bradhsaw C (Eds.). Berlin: Springer.

United Nations (2011). The great green technological transformation. United Nations publication.

United Nations (2015). The 2030 Agenda for Sustainable Development and its Sustainable Development Goals.

On line: https://www.un.org/sustainabledevelopment/development-agenda/

United Nations (2019). Visita a la Argentina. Informe de la Relatora Especial sobre el derecho a la alimentación. A/HRC/40/56/Add.3 (16 de enero de 2019). On line: http://ap.ohchr.org/documents/dpage e.aspx?si=A/HRC/40/56/Add.3 
UNLP (2017). La protección del cordón flori-hortícola debe ser una política de Estado. Comisión de soberanía alimentaria, Universidad Nacional de La Plata. Disponible en: https://unlp.edu.ar/frontend/media/46/2046/b99306f5d035c8e833921f7f8421d11a.pdf

urBAsig. Servidor de Mapas. Ministerio de Infraestructura y Servicios Públicos http://www.urbasig.minfra.gba.gov.ar/urbasig/

UTT (2018) Unión de Trabajadores de la Tierra. Ante la crisis, pequeños productores agrarios de todo el país exigimos políticas urgentes al gobierno nacional. On line: http://uniondetrabajadoresdelatierra.com.ar/2018/07/24/ante-la-crisis-pequenosproductores-agrarios-de-todo-el-pais-exigimos-politicas-urgentes-al-gobiernonacional/

Vallejos M, Volante JN, Mosciaro MJ, Vale LM, Bustamante ML, Paruelo JM (2015). Transformation dynamics of the natural cover in the Dry Chaco ecoregion: a plot level geo-database from 1976 to 2012. Journal of Arid Environments, 123, 3-11.

Vitousek PM (1994). Beyond global warming: ecology and global change. Ecology, 75(7), 1861-1876. DOI: https://doi.org/10.2307/1941591

West PC, Gibbs HK, Monfreda C, Wagner J, Barford CC, Carpenter SR, et al. (2010). Trading carbon for food: Global comparison of carbon stocks vs. crop yields on agricultural land. Proceedings of the National Acadademy of Sciences: Vol. 107, (pp. 19645-19648). DOI: https://doi.org/10.1073/pnas.1011078107

Wohlfart C, Mack B, Liu G, Kuenzer C (2017). Multi-faceted land cover and land use change analyses in the Yellow River Basin based on dense Landsat time series: Exemplary analysis in mining, agriculture, forest, and urban areas. Applied Geography, 85, 7388. DOI: https://doi.org/10.1016/j.apgeog.2017.06.004

World Bank 2018. Understanding poverty. Land topic. On line: http://www.worldbank.org/en/topic/land

\section{ANEXOS}

\section{Anexo 1. Matrices de confusión}

En el presente anexo se detallan las matrices de confusión pertenecientes a las cuatro clasificaciones realizadas a partir de imágenes satelitales Landsat. La numeración de las matrices se corresponde a las siguientes categorías: 1-Urbanización de Alta Densidad, 2Invernáculos, 3-Agua, 4-Parquizaciones Arboladas, 5-Parquizaciones Herbáceas, 6-Árboles 
y arbustos, 7-Pastizal, 8-Plantaciones forestales, 9-Vegetación Ribereña, 10-Horticultura, 11-Agricultura, 12-Ganadería y 13-Urbanización de Baja Densidad.

\begin{tabular}{|c|c|c|c|c|c|c|c|c|c|c|c|c|c|c|c|}
\hline \multicolumn{16}{|c|}{ MATRIZ DE CONFUSIÓN DE LA CLASIFICACIÓN DEL AÑO 1986} \\
\hline \multirow{2}{*}{\multicolumn{2}{|c|}{ Clasificación }} & \multicolumn{14}{|c|}{ Referencia } \\
\hline & & 1 & 2 & 3 & 4 & 5 & 6 & 7 & 8 & 9 & 10 & 11 & 12 & 13 & Total \\
\hline & 1 & 759 & 0 & 0 & 2 & 3 & 0 & 0 & 0 & 0 & 0 & 0 & 2 & 80 & 846 \\
\hline & 2 & 0 & 52 & 0 & 0 & 0 & 0 & 0 & 0 & 0 & 0 & 0 & 0 & 0 & 52 \\
\hline & 3 & 0 & 0 & 38 & 0 & 0 & 0 & 0 & 0 & 0 & 0 & 0 & 0 & 0 & 38 \\
\hline & 4 & 0 & 0 & 0 & 133 & 7 & 0 & 4 & 0 & 2 & 0 & 0 & 0 & 0 & 146 \\
\hline & 5 & 0 & 0 & 0 & 0 & 232 & 0 & 1 & 0 & 4 & 1 & 0 & 0 & 0 & 238 \\
\hline & 6 & 0 & 0 & 0 & 0 & 0 & 97 & 3 & 0 & 33 & 0 & 0 & 0 & 0 & 133 \\
\hline & 7 & 0 & 0 & 0 & 0 & 23 & 4 & 615 & 0 & 10 & 10 & 0 & 0 & 1 & 663 \\
\hline & 8 & 0 & 0 & 0 & 0 & 0 & 0 & 0 & 48 & 18 & 0 & 0 & 0 & 0 & 66 \\
\hline & 9 & 0 & 0 & 0 & 0 & 3 & 18 & 0 & 0 & 662 & 0 & 0 & 86 & 0 & 769 \\
\hline & 10 & 0 & 1 & 0 & 0 & 7 & 0 & 39 & 0 & 0 & 1032 & 0 & 0 & 0 & 1079 \\
\hline & 11 & 0 & 0 & 0 & 0 & 0 & 0 & 0 & 0 & 0 & 0 & 261 & 13 & 0 & 274 \\
\hline & 12 & 0 & 0 & 0 & 5 & 46 & 0 & 0 & 0 & 85 & 8 & 25 & 5221 & 0 & 5390 \\
\hline & 13 & 17 & 0 & 0 & 8 & 31 & 0 & 13 & 0 & 1 & 0 & 0 & 0 & 929 & 999 \\
\hline Total & & 776 & 53 & 38 & 148 & 352 & 119 & 675 & 48 & 815 & 1051 & 286 & 5322 & 1010 & 10693 \\
\hline
\end{tabular}

\begin{tabular}{|c|c|c|c|c|c|c|c|c|c|c|c|c|c|c|c|}
\hline \multicolumn{16}{|c|}{ MATRIZ DE CONFUSIÓN DE LA CLASIFICACIÓN DEL AÑO 1996} \\
\hline \multirow{2}{*}{\multicolumn{2}{|c|}{ Clasificación }} & \multicolumn{14}{|c|}{ Referencia } \\
\hline & & 1 & 2 & 3 & 4 & 5 & 6 & 7 & 8 & 9 & 10 & 11 & 12 & 13 & Total \\
\hline & 1 & 1043 & 0 & 0 & 0 & 0 & 0 & 0 & 0 & 0 & 0 & 0 & 0 & 59 & 1102 \\
\hline & 2 & 0 & 143 & 0 & 0 & 0 & 0 & 0 & 0 & 0 & 0 & 0 & 0 & 0 & 143 \\
\hline & 3 & 0 & 0 & 28 & 0 & 0 & 0 & 0 & 0 & 2 & 0 & 0 & 0 & 0 & 30 \\
\hline & 4 & 0 & 0 & 0 & 186 & 0 & 0 & 3 & 0 & 3 & 0 & 2 & 0 & 0 & 194 \\
\hline & 5 & 0 & 1 & 0 & 2 & 273 & 3 & 11 & 0 & 9 & 1 & 0 & 0 & 0 & 300 \\
\hline & 6 & 0 & 0 & 0 & 9 & 0 & 145 & 6 & 0 & 0 & 0 & 0 & 0 & 0 & 160 \\
\hline & 7 & 0 & 11 & 0 & 1 & 68 & 2 & 855 & 0 & 0 & 8 & 0 & 0 & 0 & 945 \\
\hline & 8 & 0 & 0 & 0 & 0 & 0 & 0 & 0 & 85 & 0 & 0 & 0 & 0 & 0 & 85 \\
\hline & 9 & 0 & 0 & 0 & 2 & 5 & 17 & 15 & 0 & 1202 & 0 & 0 & 318 & 0 & 1559 \\
\hline & 10 & 0 & 3 & 0 & 0 & 8 & 0 & 12 & 0 & 0 & 815 & 0 & 4 & 0 & 842 \\
\hline & 11 & 0 & 0 & 0 & 0 & 0 & 0 & 0 & 0 & 0 & 3 & 562 & 83 & 0 & 648 \\
\hline & 12 & 0 & 0 & 0 & 3 & 34 & 0 & 38 & 0 & 68 & 2 & 20 & 3788 & 0 & 3953 \\
\hline & 13 & 1 & 0 & 0 & 21 & 25 & 0 & 20 & 0 & 0 & 0 & 0 & 20 & 1441 & 1528 \\
\hline Total & & 1044 & 158 & 28 & 224 & 413 & 167 & 960 & 85 & 1284 & 829 & 584 & 4213 & 1500 & 11489 \\
\hline
\end{tabular}

\begin{tabular}{|c|c|c|c|c|c|c|c|c|c|c|c|c|c|c|c|}
\hline \multicolumn{16}{|c|}{ MATRIZ DE CONFUSIÓN DE LA CLASIFICACIÓN DEL AÑO 2005} \\
\hline \multirow[t]{2}{*}{ Clasificación } & & \multicolumn{14}{|c|}{ Referencia } \\
\hline & & 1 & 2 & 3 & 4 & 5 & 6 & 7 & 8 & 9 & 10 & 11 & 12 & 13 & Total \\
\hline & 1 & 835 & 0 & 0 & 0 & 0 & 0 & 0 & 0 & 0 & 0 & 0 & 0 & 39 & 874 \\
\hline & 2 & 0 & 247 & 0 & 0 & 0 & 0 & 0 & 0 & 0 & 0 & 0 & 0 & 0 & 247 \\
\hline
\end{tabular}




\begin{tabular}{rrrrrrrrrrrrrrrr}
\hline & $\mathbf{3}$ & 0 & 0 & 45 & 0 & 0 & 0 & 3 & 0 & 11 & 0 & 0 & 0 & 0 & $\mathbf{5 9}$ \\
\hline & $\mathbf{4}$ & 0 & 0 & 0 & 216 & 0 & 4 & 4 & 0 & 0 & 0 & 0 & 0 & 0 & $\mathbf{2 2 4}$ \\
\hline & $\mathbf{5}$ & 0 & 0 & 0 & 0 & 256 & 0 & 10 & 0 & 0 & 0 & 0 & 0 & 0 & $\mathbf{2 6 6}$ \\
\hline & $\mathbf{6}$ & 0 & 0 & 0 & 1 & 0 & 163 & 8 & 0 & 0 & 0 & 0 & 0 & 0 & $\mathbf{1 7 2}$ \\
\hline & $\mathbf{7}$ & 0 & 0 & 0 & 0 & 35 & 0 & 963 & 0 & 0 & 2 & 0 & 0 & 1 & $\mathbf{1 0 0 1}$ \\
\hline & $\mathbf{8}$ & 0 & 0 & 0 & 0 & 0 & 0 & 0 & 125 & 0 & 0 & 0 & 0 & 0 & $\mathbf{1 2 5}$ \\
\hline & $\mathbf{9}$ & 0 & 0 & 0 & 2 & 0 & 2 & 25 & 0 & 1955 & 0 & 0 & 237 & 0 & $\mathbf{2 2 2 1}$ \\
\hline & $\mathbf{1 0}$ & 0 & 1 & 0 & 1 & 0 & 0 & 5 & 0 & 0 & 715 & 17 & 0 & 0 & $\mathbf{7 3 9}$ \\
\hline & $\mathbf{1 1}$ & 0 & 0 & 0 & 1 & 4 & 0 & 0 & 0 & 0 & 0 & 800 & 15 & 0 & $\mathbf{8 2 0}$ \\
\hline & $\mathbf{1 2}$ & 0 & 0 & 0 & 5 & 16 & 0 & 13 & 0 & 55 & 0 & 0 & 4407 & 0 & $\mathbf{4 4 9 6}$ \\
\hline Total & $\mathbf{1 3}$ & 0 & 0 & 0 & 4 & 5 & 5 & 37 & 0 & 0 & 0 & 0 & 12 & 1571 & $\mathbf{1 6 3 4}$ \\
\hline & & $\mathbf{8 3 5}$ & $\mathbf{2 4 8}$ & $\mathbf{4 5}$ & $\mathbf{2 3 0}$ & $\mathbf{3 1 6}$ & $\mathbf{1 7 4}$ & $\mathbf{1 0 6 8}$ & $\mathbf{1 2 5}$ & $\mathbf{2 0 2 1}$ & $\mathbf{7 1 7}$ & $\mathbf{8 1 7}$ & $\mathbf{4 6 7 1}$ & $\mathbf{1 6 1 1}$ & $\mathbf{1 2 8 7 8}$ \\
\hline
\end{tabular}

\section{MATRIZ DE CONFUSIÓN DE LA CLASIFICACIÓN DEL AÑO 2015}

\section{Clasificación Referencia}

\begin{tabular}{rrrrrrrrrrrrrrrr} 
& & $\mathbf{1}$ & $\mathbf{2}$ & $\mathbf{3}$ & $\mathbf{4}$ & $\mathbf{5}$ & $\mathbf{6}$ & $\mathbf{7}$ & $\mathbf{8}$ & $\mathbf{9}$ & $\mathbf{1 0}$ & $\mathbf{1 1}$ & $\mathbf{1 2}$ & $\mathbf{1 3}$ & Total \\
\hline & $\mathbf{1}$ & 1652 & 0 & 0 & 0 & 0 & 0 & 0 & 0 & 0 & 0 & 0 & 0 & 90 & $\mathbf{1 7 4 2}$ \\
\hline & $\mathbf{2}$ & 0 & 478 & 1 & 0 & 0 & 0 & 0 & 0 & 0 & 1 & 0 & 0 & 0 & $\mathbf{4 8 0}$ \\
\hline $\mathbf{3}$ & 0 & 0 & 106 & 0 & 0 & 0 & 0 & 0 & 17 & 0 & 0 & 0 & 7 & $\mathbf{1 3 0}$ \\
\hline & $\mathbf{4}$ & 0 & 0 & 0 & 221 & 0 & 0 & 0 & 0 & 4 & 0 & 0 & 0 & 14 & $\mathbf{2 3 9}$ \\
\hline & $\mathbf{5}$ & 0 & 0 & 0 & 0 & 452 & 0 & 14 & 0 & 3 & 3 & 0 & 16 & 13 & $\mathbf{5 0 1}$ \\
\hline & $\mathbf{6}$ & 0 & 0 & 0 & 0 & 0 & 91 & 1 & 0 & 0 & 0 & 0 & 0 & 0 & $\mathbf{9 2}$ \\
\hline & $\mathbf{7}$ & 0 & 0 & 0 & 4 & 0 & 0 & 985 & 0 & 6 & 2 & 15 & 16 & 15 & $\mathbf{1 0 4 3}$ \\
\hline & $\mathbf{8}$ & 0 & 0 & 0 & 0 & 0 & 0 & 0 & 172 & 0 & 0 & 0 & 0 & 0 & $\mathbf{1 7 2}$ \\
\hline & $\mathbf{9}$ & 0 & 0 & 0 & 1 & 0 & 1 & 0 & 0 & 1073 & 0 & 0 & 106 & $\mathbf{2 2}$ & $\mathbf{1 2 0 3}$ \\
\hline & $\mathbf{1 0}$ & 0 & 0 & 0 & 0 & 0 & 0 & 15 & 0 & 0 & 579 & 0 & 6 & 1 & $\mathbf{6 0 1}$ \\
\hline & $\mathbf{1 1}$ & 0 & 0 & 0 & 1 & 0 & 0 & 2 & 0 & 2 & 0 & 534 & 0 & 0 & $\mathbf{5 3 9}$ \\
\hline & $\mathbf{1 2}$ & 0 & 0 & 0 & 6 & 0 & 4 & 0 & 0 & $\mathbf{7 3}$ & 5 & 0 & 3422 & 26 & $\mathbf{3 5 3 6}$ \\
\hline Total & $\mathbf{1 3}$ & 15 & 0 & 0 & 0 & 31 & 0 & 2 & 0 & 0 & 0 & 0 & 0 & $\mathbf{2 2 8 9}$ & $\mathbf{2 3 3 7}$ \\
\hline
\end{tabular}

Anexo 2. Fotografías de las principales categorías de coberturas/usos del suelo establecidas 


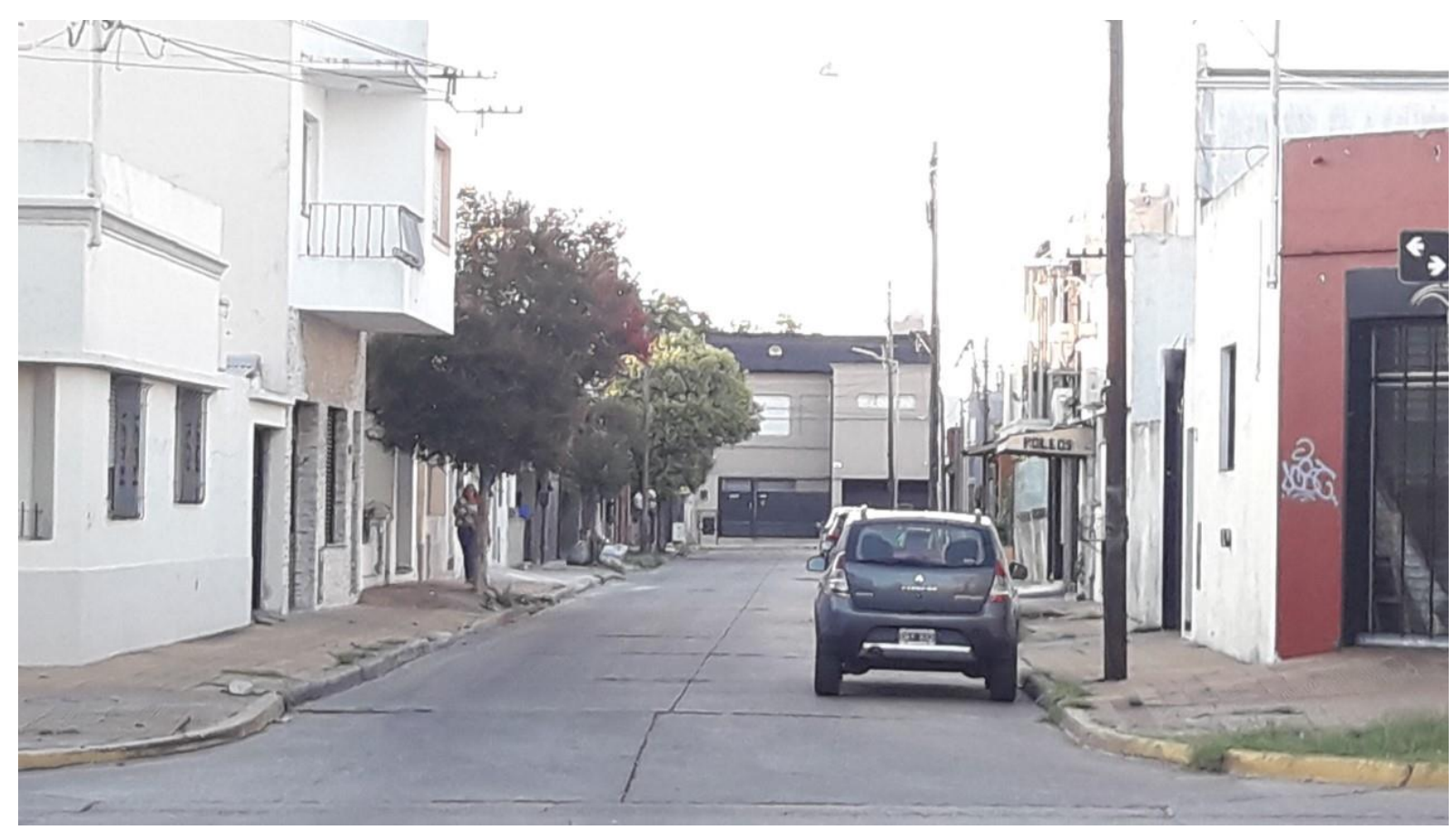

Fig 1. Urbanización de Alta Densidad.

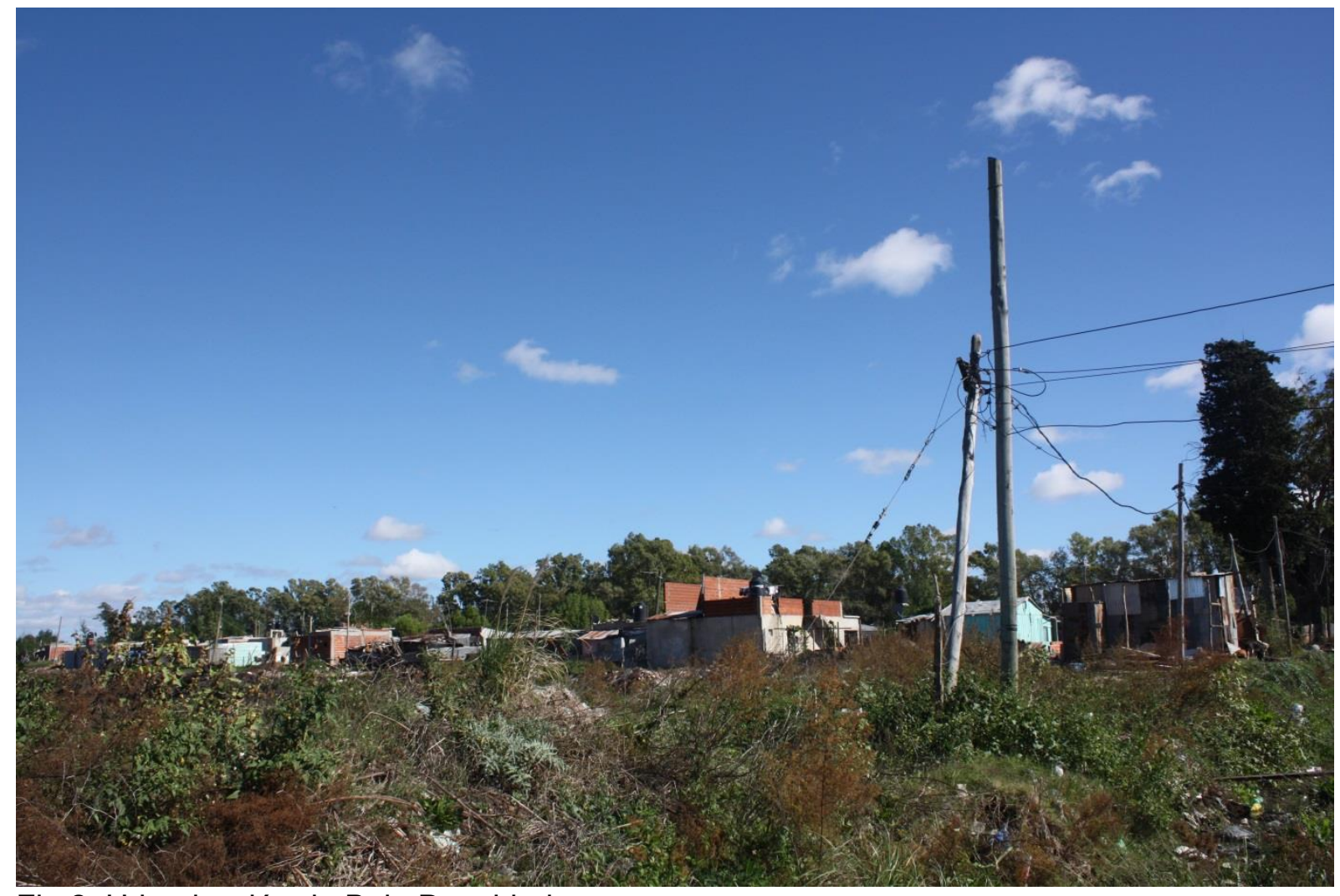

Fig 2. Urbanización de Baja Densidad. 


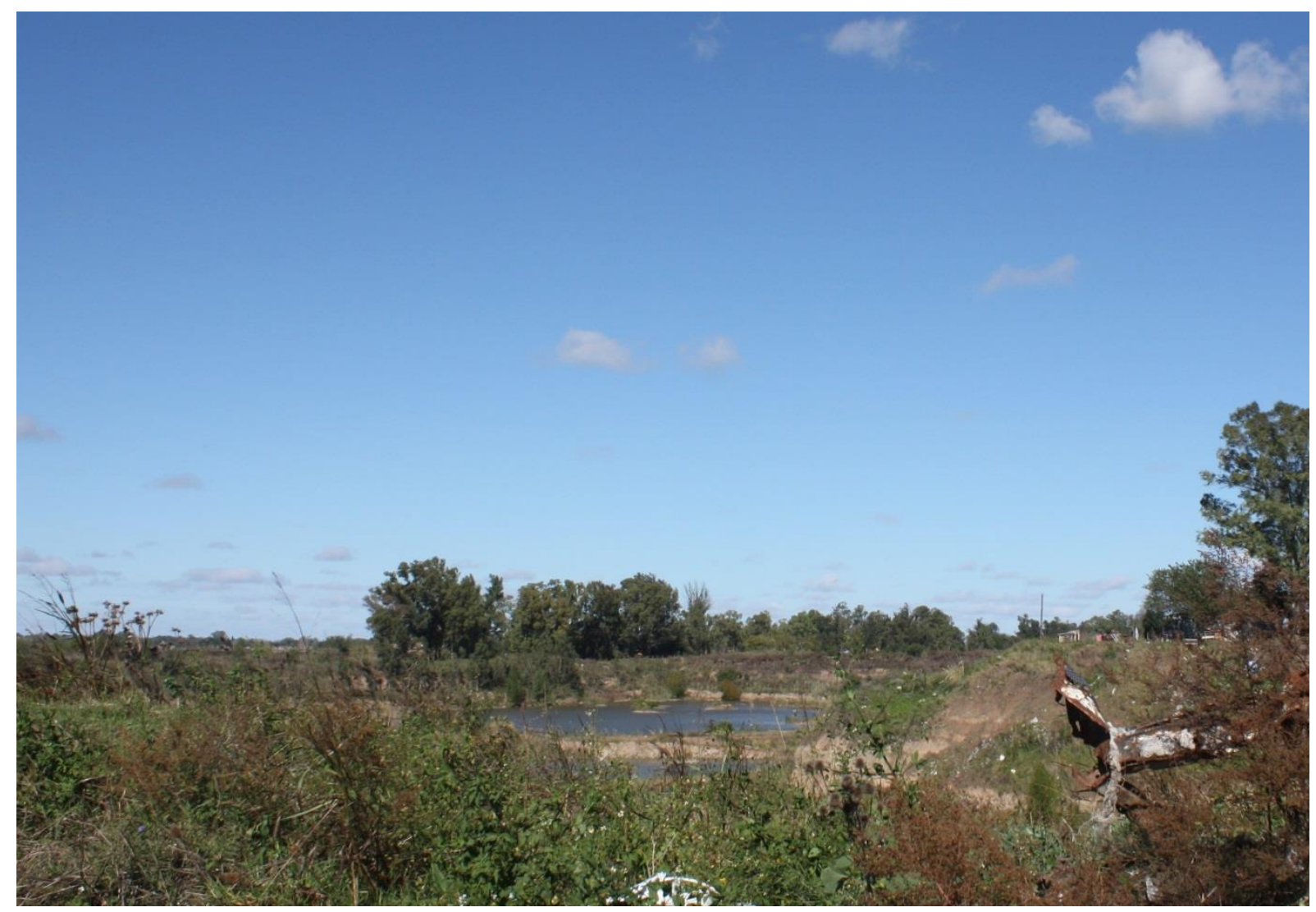

Fig 3. Agua.

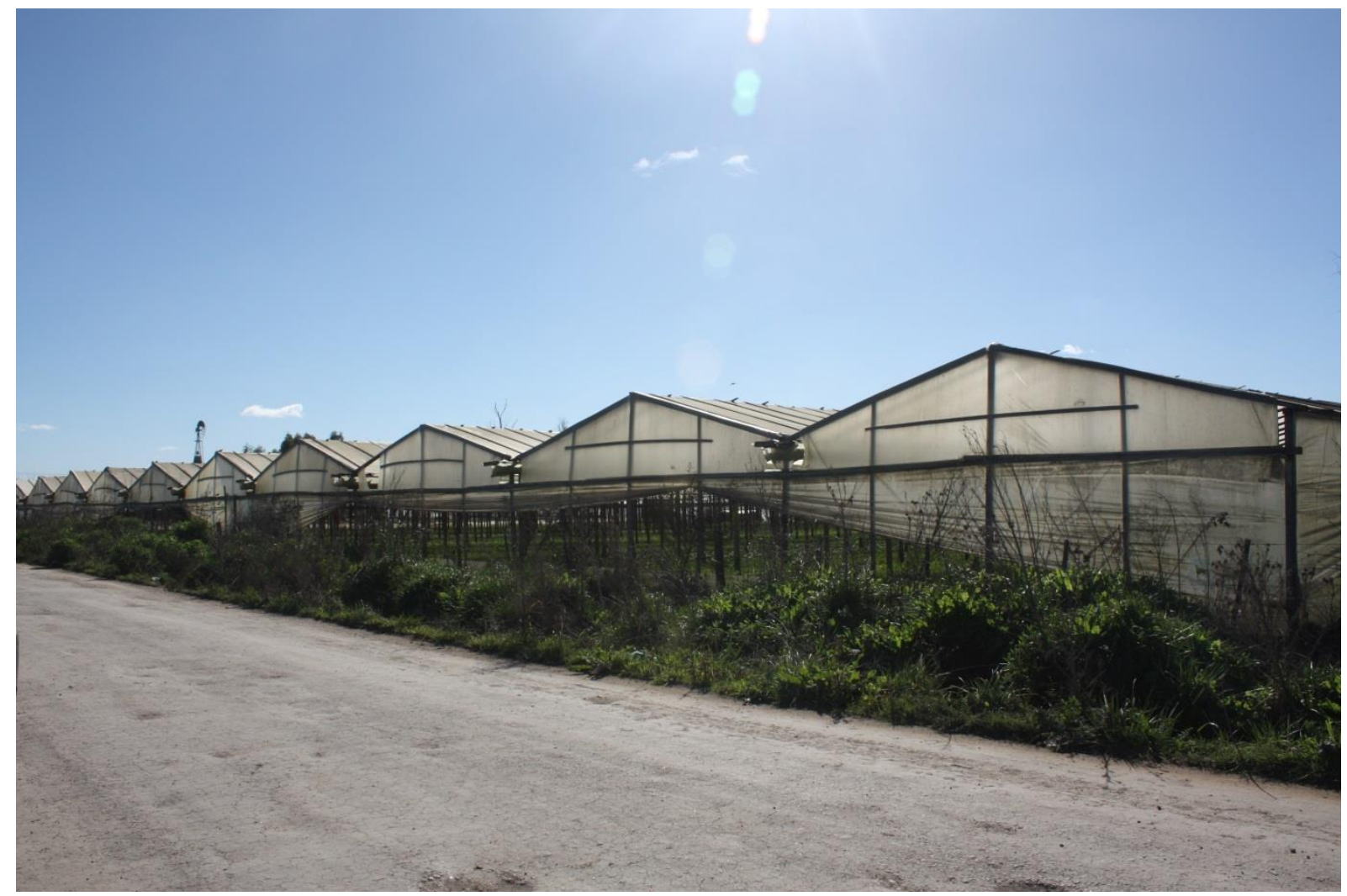

Fig 4. Invernáculos. 


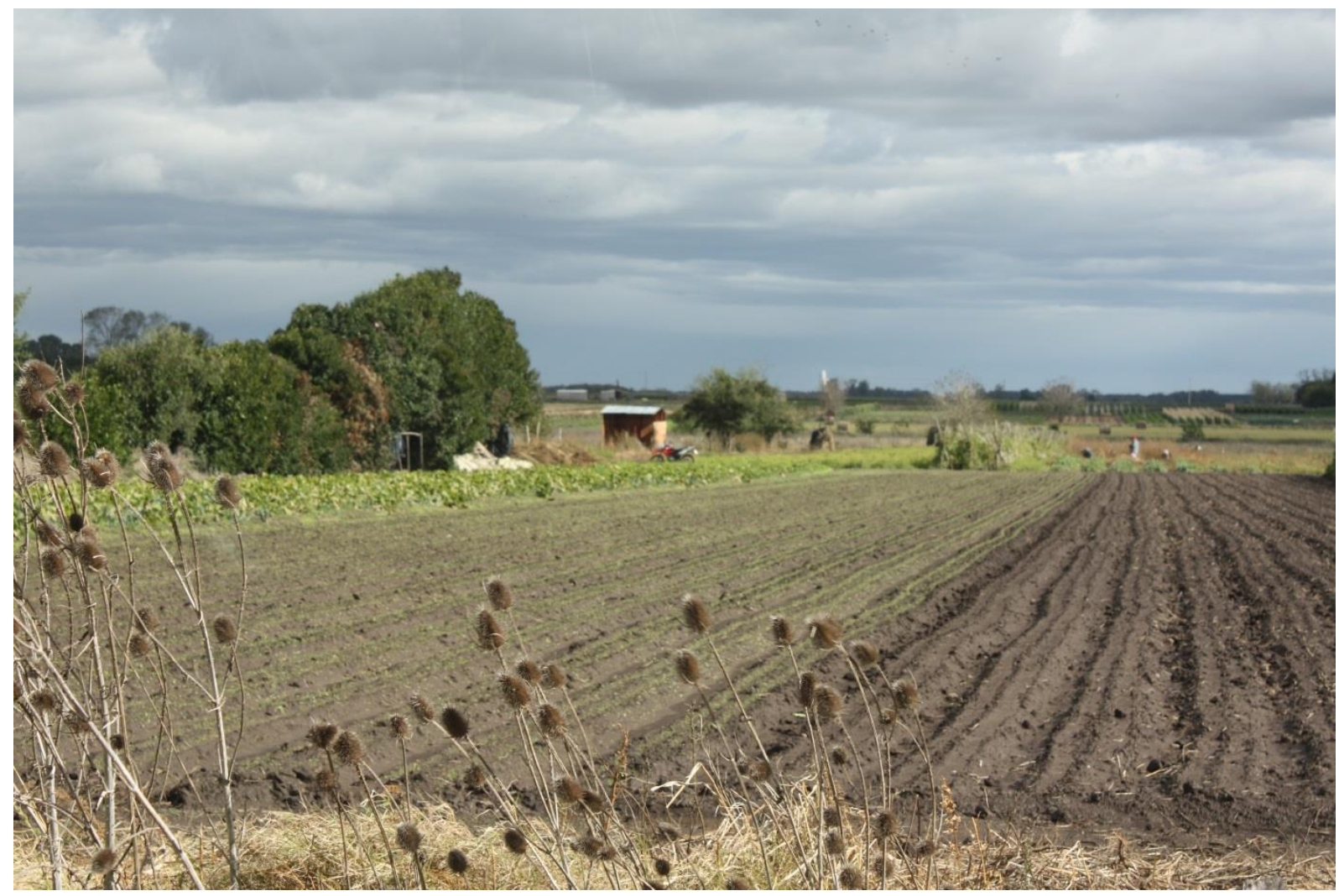

Fig 5. Horticultura.

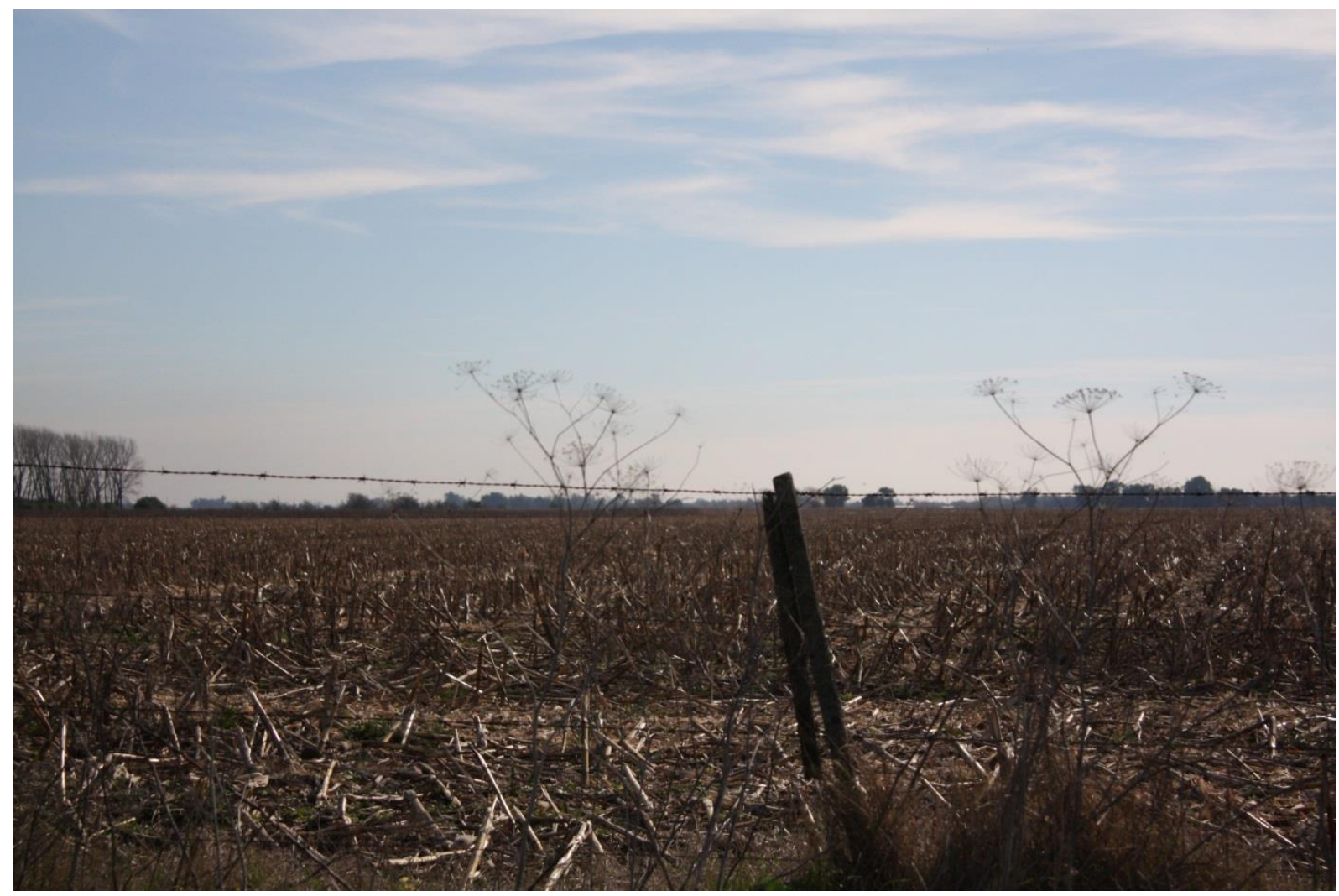

Fig 6. Agricultura. 


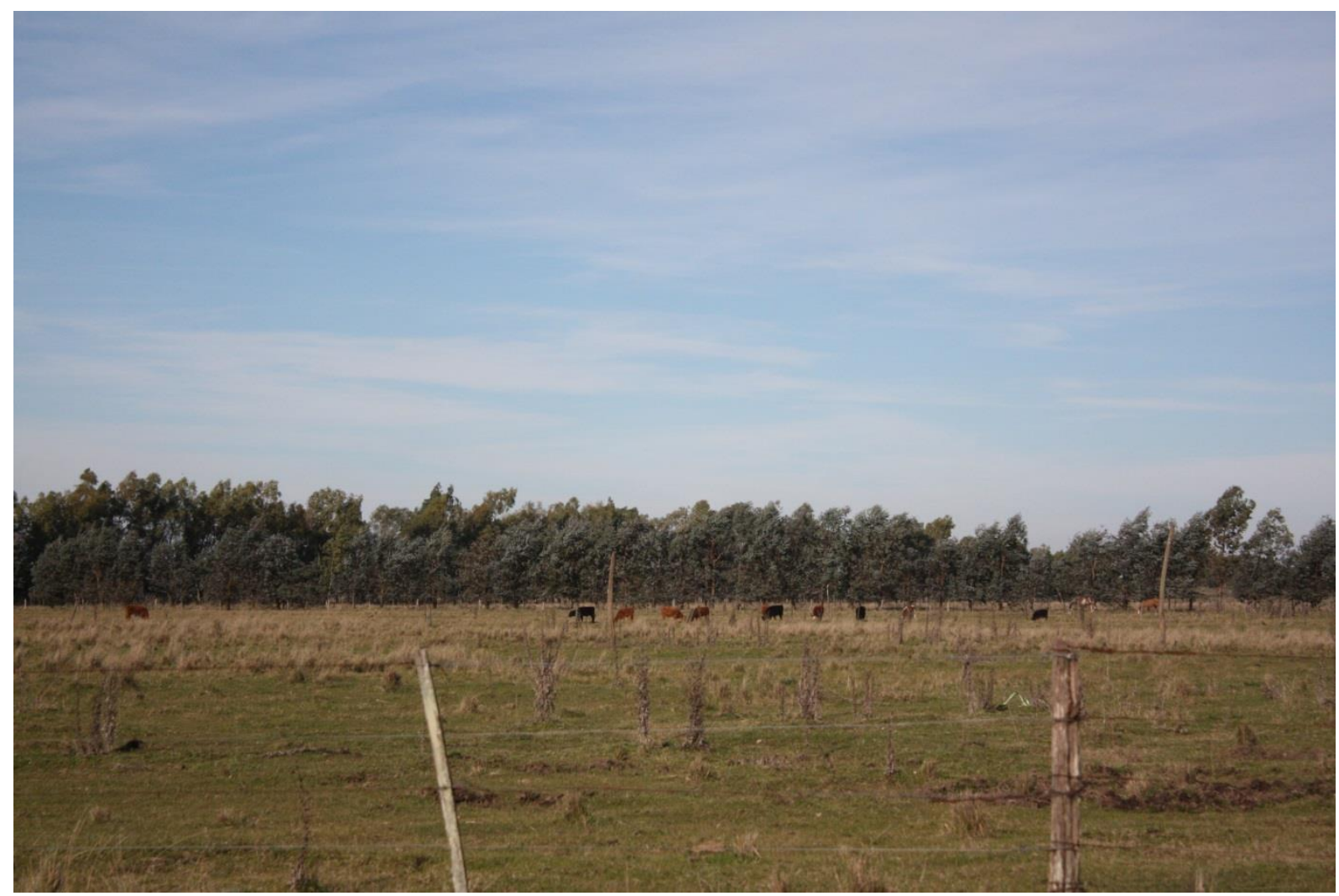

Fig 7. Ganadería.

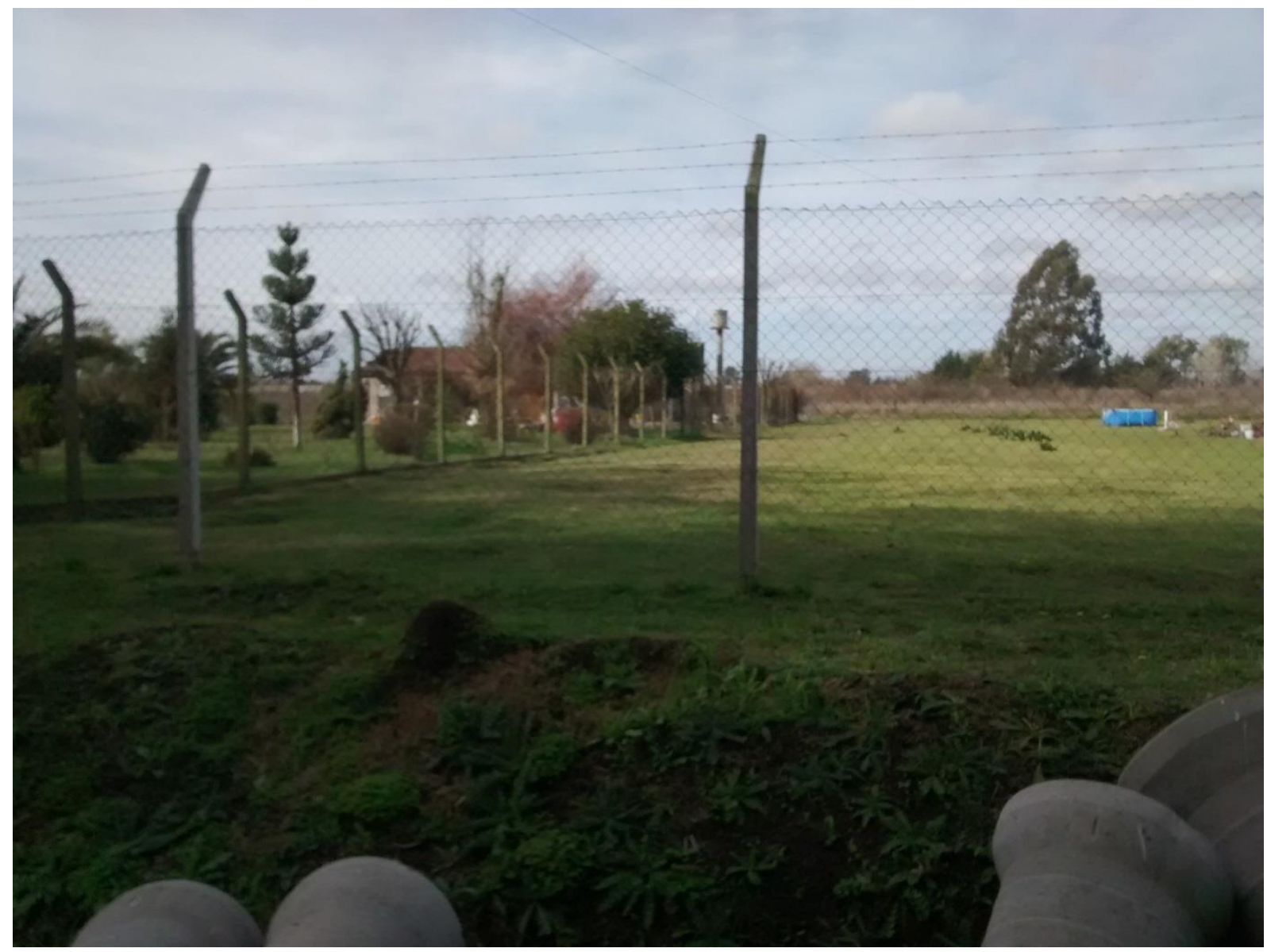

Fig 8. Parquizaciones Herbáceas. 


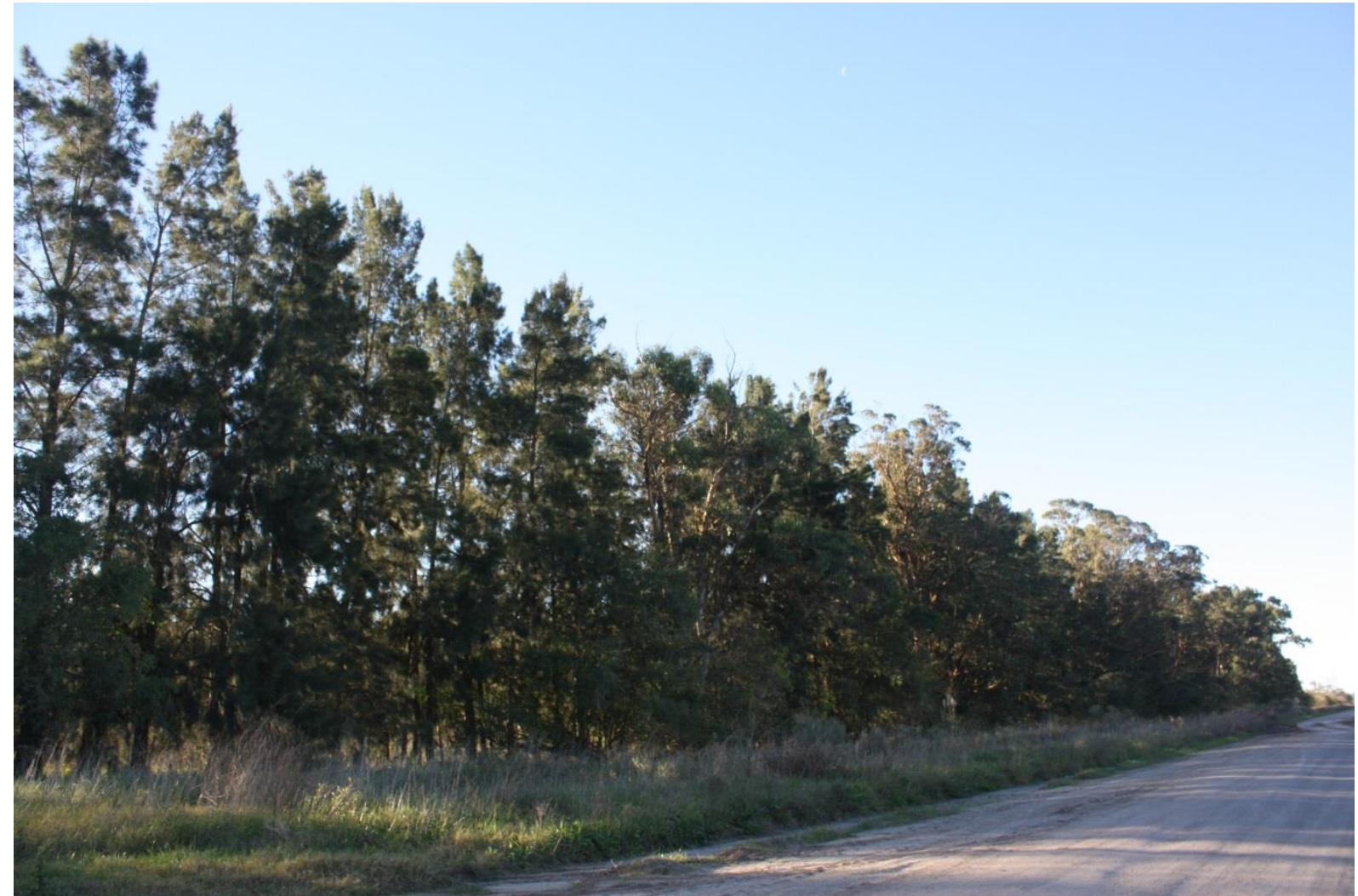

Fig 9. Parquizaciones arboladas.

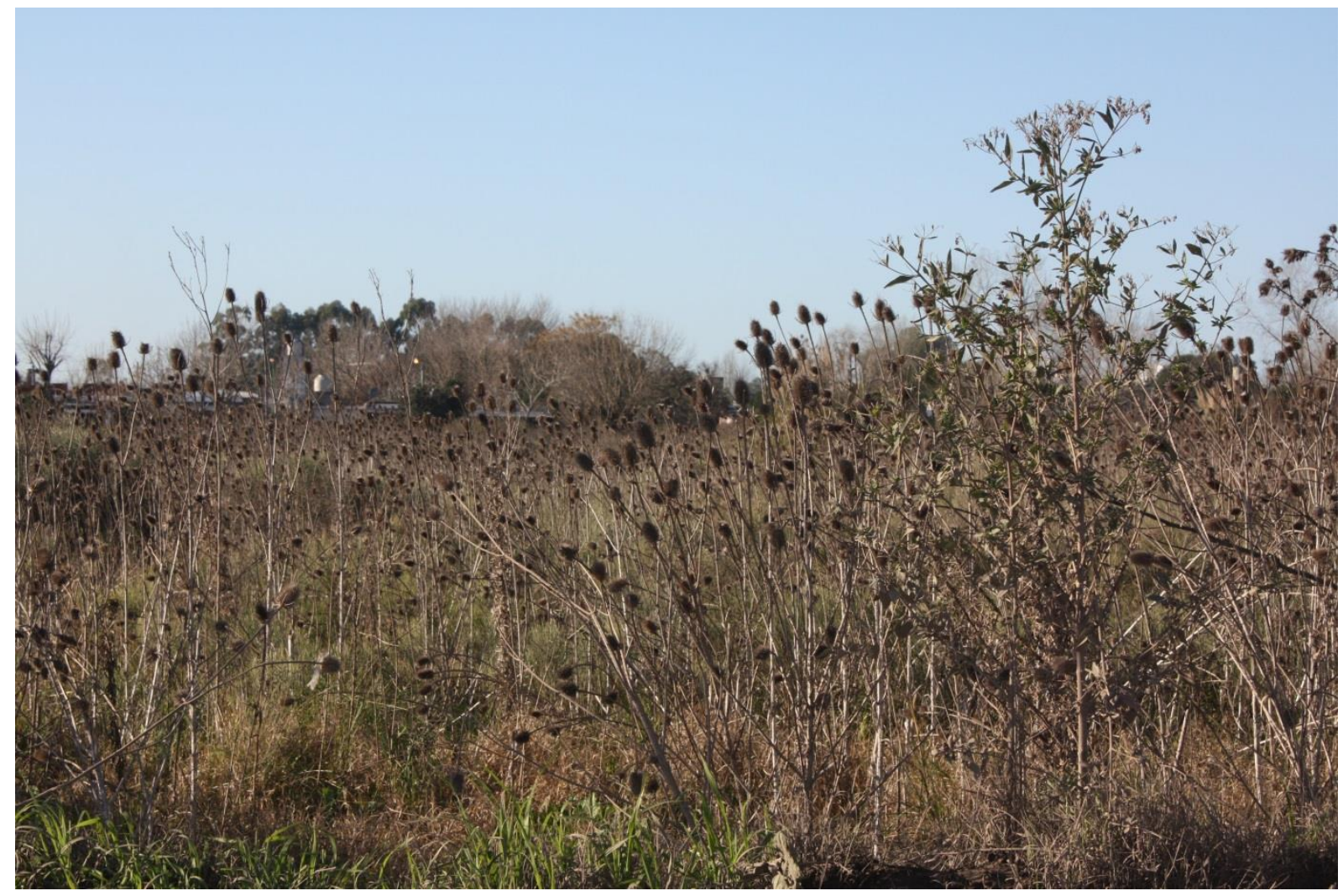

Fig 10. Pastizal. 


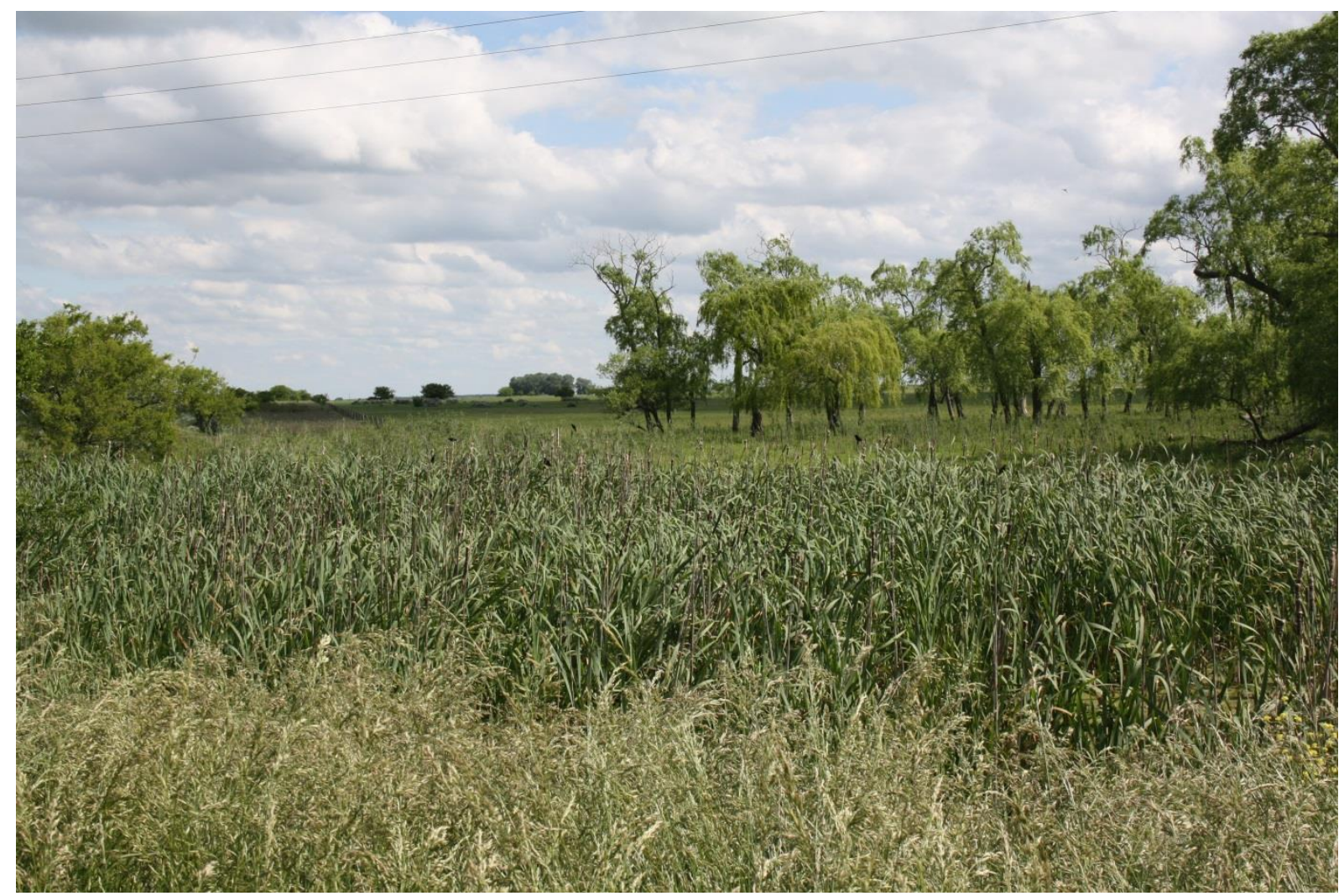

Fig 11. Vegetación Riparia.

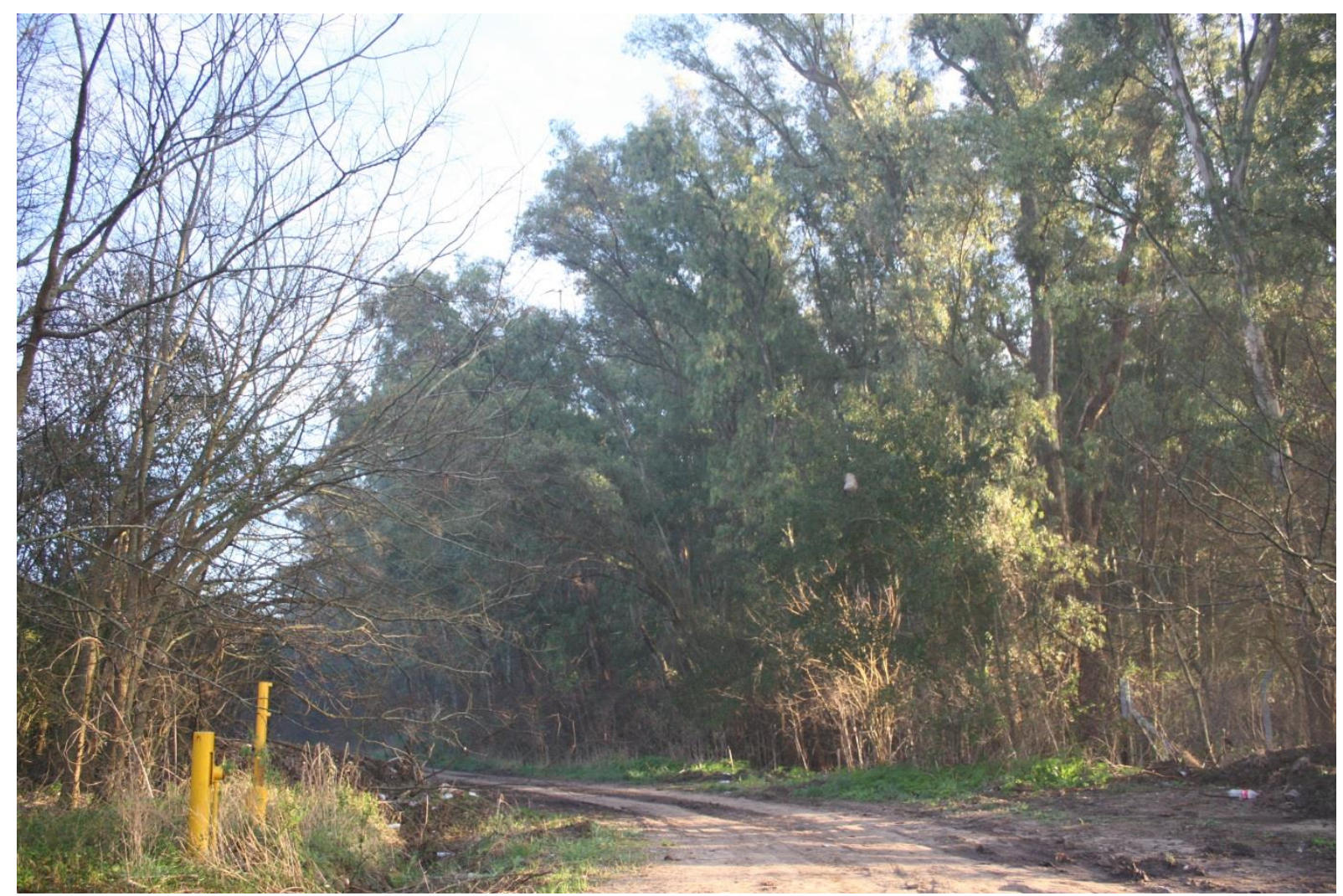

Fig 12. Plantaciones Forestales. 


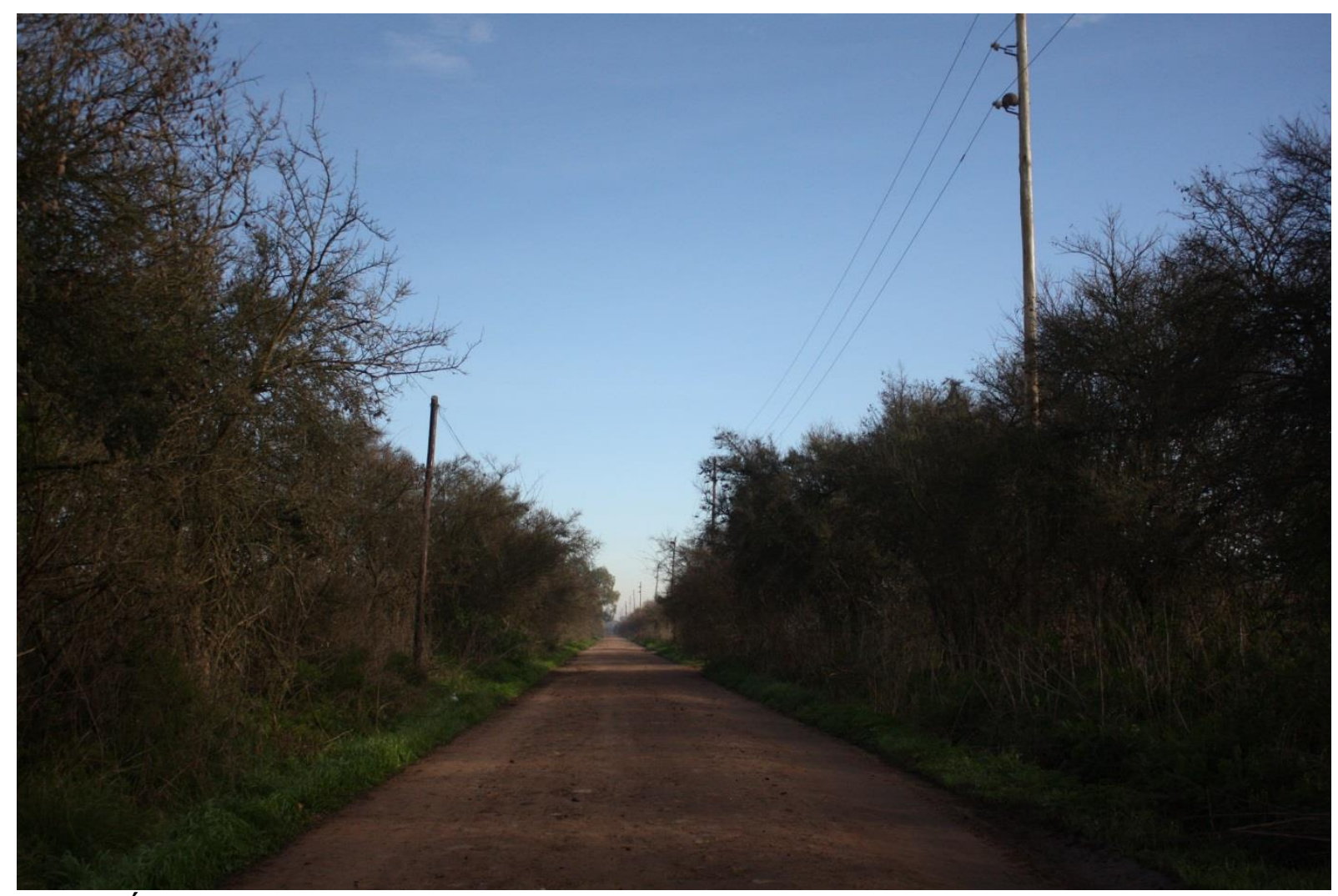

Fig 13. Árboles y arbustos. 


\section{CAPITULO 3}

\section{LAS COBERTURAS/USOS DEL SUELO EN EL AÑO 2015 Y SU IMPLICANCIA PARA EL CINTURÓN HORTÍCOLA PLATENSE DESDE UN ENFOQUE AGROECOLÓGICO}

"(El Cinturón Horticola Platense Ideal) A mi me gustaria que estuviera la misma gente que está. Porque son mis compañeros, porque hace mucho tiempo que trabajo con ellos y me parece que tienen una garra terrible para laburar y que se merecen vivir en mejores condiciones. Pero me imagino que puedan tener acceso a la

tierra. Ese sería el sueño. Y comprobado, porque lo he visto en productores que acceden a la tierra... la agroecología... O sea, cuando ellos tienen acceso a la tierra producen su papa, producen la quinoa, producen amaranto, hacen producción escalonada, variada, diversificada. Como que surge, la agroecología surge. Entonces me parece que el acceso a la tierra sería el sueño". 
En el capítulo anterior pude constatar las fuertes transformaciones territoriales que experimentó el partido de La Plata en tan solo tres décadas (período 1986-2015). Entre los principales cambios identificados se destacan la importante expansión y consolidación de la superficie urbana, una transformación identificada también por Frediani (2010); y la reducción en la superficie con cultivos hortícolas al aire libre, acompañada por una intensificación de la actividad productiva, reflejada en el incremento de la superficie de cultivos bajo invernáculo, transformaciones identificadas por múltiples autores (ej: García y Mierez 2007, Nieto y Rivas 2006, Hurtado et al. 2006, Stavisky 2010). Diversos estudios realizados en los últimos años por grupos de investigación de la UNLP comienzan a evidenciar las consecuencias negativas más notorias del modelo de producción vigente, entre las que encontramos: problemas de contaminación por hiperfertilización y de salinización de los suelos bajo producción (Hurtado 2006); inundaciones cada vez más frecuentes agravadas por la impermeabilización generada por los invernáculos de gran parte del suelo hortícola (García 2011, Karol y San Juan 2018); contaminación por agroquímicos de agua, suelo y alimentos (Sarandón et al. 2015, Colombo et al. 2015, Alonso et al. 2015). Un estudio elaborado por Sarandón et al. (2015) a pedido de la Defensoría del Pueblo de la provincia de Buenos Aires, elaboró un índice de peligrosidad para los partidos de dicha provincia de acuerdo a la superficie relativa que ocupa la horticultura y al modelo de producción predominante, caracterizando a la zona hortícola de La Plata como aquella con el segundo mayor índice de peligrosidad de la provincia. A lo descripto anteriormente se debe sumar las consecuencias económicas y sociales, destacando las condiciones de vida y de trabajo, sumamente precarias de las familias productoras y el riesgo para la salud de productores y consumidores por el excesivo e inadecuado uso de agroquímicos.

Sumado a estas problemáticas derivadas de los cambios en las coberturas/usos de suelo, la deficiente planificación del territorio suele ignorar el rol de las áreas naturales (muchas veces consideradas como áreas "vacantes" o cuanto mucho como áreas recreativas) en la provisión de servicios ecosistémicos y en el mantenimiento de la capacidad productiva del territorio, lo que se traduce en problemáticas ambientales y en la reducción de estos servicios. En el análisis realizado en el capítulo anterior pude constatar una tendencia en todo el período estudiado a la conversión de pastizales a parquizaciones herbáceas (lo que implica una simplificación del ambiente por el manejo antrópico de la vegetación) y a urbanizaciones de baja densidad; de la misma manera, las parquizaciones herbáceas mostraron una tendencia a convertirse en urbanizaciones de baja densidad. Esto mostró que en un largo plazo se pierden coberturas con vegetación natural y se reduce la biodiversidad como consecuencia de la modificación antrópica del paisaje. En relación a los ambientes riparios presentes en el partido, en mi análisis de cambio en las coberturas/usos 
del suelo identifiqué una disminución en la superficie de la vegetación riparia. La falta de una política adecuada de protección de los arroyos y ambientes riparios, ha llevado al entubamiento y la canalización de los arroyos cercanos al área urbana, eliminando la vegetación asociada (Karol y San Juan 2018, Liscia et al. 2013, Hurtado et al. 2006); al mismo tiempo, en la zona productiva se desarrollaron producciones hortícolas al aire libre y bajo invernáculos muy cercanas a los mismos. La reducción de la vegetación y la impermeabilización por la infraestructura urbana y los invernaderos cercanos a los arroyos, afectan a servicios ecosistémicos tales como la protección de los suelos, la regulación de la escorrentía superficial, la infiltración del agua de lluvia, la purificación del agua y los refugios de biodiversidad (Gómez et al. 2017, Karol y San Juan 2018, Rositano et al. 2012). En este contexto, en los últimos años viene creciendo la preocupación por los posibles efectos del modelo productivo en los arroyos de la zona, por lo que diversos grupos de investigación vienen realizando estudios al respecto. Mac Loughlin et al. (2017) estudió 36 compuestos de plaguicidas en sedimentos del arroyo Carnaval, y encontró que la presencia de plaguicidas es continua y generalizada, mostrando un incremento en las concentraciones aguas abajo como consecuencia de la creciente actividad hortícola. Otro estudio reciente analizó los efectos del uso de fertilizantes y pesticidas sobre organismos acuáticos en arroyos de la zona hortícola de La Plata, encontrando un cambio en los ensambles de invertebrados, con pérdida de grupos taxonómicos sensibles y aumento de aquellos resistentes a los agroquímicos (Arias 2019).

Un aspecto a tener en cuenta para el desarrollo de territorios sustentables es la biodiversidad y el rol que juegan los ambientes con vegetación natural/semi-natural en su mantenimiento. Los modelos desarrollados por Newbold et al. (2015) sugieren que los cambios y la intensidad de uso del suelo y las presiones asociadas, generan una fuerte reducción en la biodiversidad terrestre local, con profundas consecuencias. Nicholls (2009) rescata la importancia del mantenimiento de las coberturas de vegetación semi-natural a escala de paisaje, por ser considerada como proveedora de biodiversidad, que contribuye al mantenimiento de las funciones y los servicios de los ecosistemas, la resiliencia de los agroecosistemas y, por ende, el desarrollo de territorios sustentables (Martin-López et al. 2007). Numerosos estudios realizados en el CHP demuestran la importancia de mantener la horticultura al aire libre, incrementando la biodiversidad en los cultivos y manteniendo la vegetación semi-natural alrededor de ellos (ej: Dubrovsky Berensztein 2018, Baloriani et al. 2009; Fernández y Marasas 2015, Stupino et al. 2009). Sin embargo, los estudios realizados hasta el momento se restringen a las unidades productivas y sus alrededores, sin contemplar la escala de paisaje.

Frente a las múltiples problemáticas que atraviesan los territorios y la necesidad de mejorar las políticas de planificación del territorio, existen distintas herramientas que 
permiten establecer criterios basados en estudios científicos, para dicha planificación. El tipo de estudios que se desarrollen y los criterios derivados de estos van a depender de los objetivos iniciales de cada investigación. Difícilmente una única investigación, aun siendo gestada desde la interdisciplina, pueda abordar todos los aspectos que es necesario tener en cuenta a la hora de pensar el desarrollo de un territorio; lo que refuerza la necesidad de contar con espacios de encuentro e intercambio de los distintos actores territoriales para poder contemplar las distintas visiones y necesidades de la población. En este sentido, diversos equipos de investigación han generado mapas de riesgo, mapas de vulnerabilidad y predictivos para el partido de La Plata, cada uno desde diferentes lugares. Karol y San Juan (2018) realizaron análisis multivariados enfocados en la generación de diversos escenarios con el fin de generar un Plan de Gestión del Riesgo Hídrico. Hurtado et al. (2006) por su parte realizaron análisis basados en características geológicas, hidrológicas y del suelo, detectaron los principales riesgos para el partido y generaron un mapa de riesgo hídrico; finalmente definieron Unidades Territoriales de Planificación generando una propuesta para aportar al ordenamiento del territorio.

En el presente capítulo, a partir del diagnóstico expuesto en los párrafos precedentes y a los resultados del análisis de cambio en las coberturas/usos del suelo realizado en el capítulo anterior, abordé las primeras dos hipótesis de esta tesis, que sostienen los siguientes postulados:

Hipótesis 1: La amplia expansión de la tecnología del invernáculo, que tuvo lugar en los últimos 30 años en el CHP, fue posible a expensas de la ocupación de áreas semi naturales y del reemplazo de cultivos al aire libre; afectando su distribución, conectividad y superficie total.

Hipótesis 2: La estructura del paisaje remanente permite sostener y profundizar estrategias de manejo y planificación de base agroecológica, tendientes a generar un cambio en el modelo productivo.

Al mismo tiempo, abordé parte de los primeros dos objetivos específicos de la tesis, con especial énfasis en el objetivo específico nro. 2.

Objetivo 1: Identificar, caracterizar e interpretar los ambientes que componen el paisaje del CHP en cuatro momentos clave de los últimos 30 años de desarrollo del territorio.

Objetivo 2: Analizar los cambios temporales y espaciales ocurridos en los ambientes cultivados y no cultivados que componen el paisaje del CHP

Finalmente, los resultados que arrojaron los análisis de este capítulo aportaron al desarrollo de los objetivos específicos nro. 4 y 5 . 
Objetivo 4: Detectar fortalezas y debilidades de los cambios producidos en el territorio, desde un enfoque agroecológico.

Objetivo 5: Generar criterios que puedan ser utilizados en el rediseño de las áreas productivas y semi naturales presentes en el territorio, como estrategias de manejo, gestión y planificación del CHP y como herramienta para el desarrollo de políticas públicas, en el marco de la sustentabilidad.

Inicialmente realicé un análisis espacial de las distintas coberturas/usos del suelo presentes en el año 2015, generando información desde el enfoque de la ecología del paisaje sobre las relaciones espaciales entre los usos/coberturas del suelo y de estos con variables físicas. En un segundo momento realicé un análisis multi-criterio a fin de brindar un diagnóstico más profundo a escala territorial, analizando la aptitud del territorio para diferentes usos y estableciendo zonas de riesgo en base a la superposición de aptitudes de uso, lo que permitió delimitar algunos sectores del partido que requieren un mayor esfuerzo en cuanto a la generación de políticas públicas de planificación.

\section{METODOLOGÍA}

Para el análisis territorial espacial utilicé sensores remotos y herramientas de sistemas de información geográfica (SIG). Tomando como base el mapa de coberturas/usos del suelo generado para el año 2015, realicé una serie de análisis secundarios mediante la utilización de herramientas disponibles en el software libre Quantum Gis (QGIS, 2016).

\subsection{Metodología para el análisis de las relaciones espaciales entre las coberturas/usos del suelo y de estas con variables físicas}

A partir del mapa de cobertura/uso del suelo del año 2015 unifiqué las categorías Urbanización de Baja Densidad y Urbanización de Alta Densidad bajo la categoría Urbanización; las categorías Árboles y arbustos y Vegetación riparia se unificaron bajo la categoría Vegetación ribereña, por referirse ambas categorías a vegetación que se encuentra asociada a los márgenes de los arroyos. Posteriormente calculé la superficie en hectáreas (Ha.) de cada categoría. Luego, con el objetivo de estimar la superficie de producción hortícola bajo invernáculos cercana a las zonas urbanas, extraje del mapa de usos/coberturas del suelo las categorías Urbanización e Invernáculos. A continuación, confeccioné áreas buffer de 250, 500, 750 y 1000 metros en torno a dicha categoría, considerando que según diversas regulaciones la distancia de las producciones hortícolas intensivas a los centros urbanos debería ser mayor a 1000 metros (Dávila, 2012). Posteriormente, realicé intersecciones para cruzar la información proveniente de las capas con las áreas buffer y de la capa Invernáculos, y calculé la superficie de cultivos bajo invernáculos presentes en cada una de las áreas buffer definidas. 
Para estimar la superficie hortícola bajo invernáculo por delegación municipal crucé la información proveniente del mapa de delegaciones municipales y la distribución de invernáculos obtenida del mapa de coberturas/usos del suelo; calculé la superficie total de invernáculos por delegación municipal y luego estimé la superficie relativa de invernáculos por delegación en relación a la superficie total de cada delegación municipal y a la superficie total bajo invernáculos. Un procedimiento equivalente fue utilizado para el cálculo de la superficie hortícola al aire libre por delegación municipal y para el cálculo de la superficie hortícola total por delegación.

Por otro lado, obtuve un Modelo Digital de Elevación (DEM) del área de estudio, a través de la página de la United States Geological Survey (USGS), a partir del cual delimité las cuencas presentes en el partido de La Plata y la red de drenajes (SAGA - QGIS). EI modelo de drenaje generado fue comparado con el mapa de hidrografía superficial construido por el Centro de Investigación de Suelos y Aguas de Uso Agrícola (CISAUA). Dicho mapa se basó en fotointerpretación sobre fotogramas aéreos, con apoyo en las curvas de nivel, y mapeo de modificaciones antrópicas (zanjas, canales, rectificaciones) mediante trabajo de campo (Hurtado, 2006), dando como resultado un mapa con un detalle mucho mayor que la red de drenaje obtenida a partir del DEM. Al comparar, observé una gran superposición en el patrón general del drenaje que modeló las cuencas naturales; por ese motivo y dado que la escala de la red de drenajes proveniente del DEM era la utilizada para el mapeo de coberturas y usos, decidí utilizar dicho producto. A partir de la red de drenajes generé áreas buffer de 50,100, 150 y 200 metros en torno a la misma, para lo cual consideré las distancias establecidas en diversas legislaciones. Luego realicé una intersección entre las áreas buffer generadas y la capa de Invernáculos y calculé la superficie de estos para cada zona delimitada.

Finalmente, analicé la superficie de las coberturas Urbanización, Invernáculos y Horticultura asentada sobre suelos con aptitud agrícola. Para ello trabajé con el mapa de Suelos generado por el Centro de Investigación de Suelos y Aguas de Uso Agrícola (CISAUA) (Hurtado, 2006), en el que se evaluaron los suelos de acuerdo con su aptitud para su uso agropecuario-forestal, adoptando el sistema de clasificación de tierras por capacidad de uso del Servicio de Conservación de Suelos de los EE.UU (Klingebiel y Montgomery, 1961 en Hurtado, 2006). Para el presente trabajo, extraje las clases I a IV, que se aplican a suelos aptos para los cultivos agrícolas, pero con limitaciones que se van incrementando, desde los suelos de clase I que carecen de limitaciones, o ellas son leves y no requieren prácticas especiales de manejo y conservación, hasta aquéllos en los cuales las condiciones desfavorables hacen que dichas prácticas sean imprescindibles (clase IV). No tuve en cuenta aquí los suelos de las clases $\mathrm{V}$ a VII, los cuales tienen limitantes tan importantes que los tornan inaptos para un uso agrícola rentable, pero se pueden utilizar para pasturas, 
campos naturales de pastoreo y forestación (Hurtado, 2006). Una vez obtenidas las clases I a IV, realicé intersecciones con las capas Urbanización, Invernáculos y Horticultura, y calculé la superficie ocupada por cada una de ellas, el porcentaje en relación a la superficie total de cada cobertura y en relación a la superficie total de cada clase de suelo.

\subsection{Metodología de análisis multi-criterio}

Con el fin de identificar las áreas dentro del Partido de La Plata, de mayor aptitud para el crecimiento urbano, para el desarrollo de producciones hortícolas bajo invernáculos y de producciones al aire libre, utilicé la metodología de análisis multicriterio. Una vez identificadas las áreas de mayor aptitud para la transformación a cada uno de los tres usos mencionados anteriormente, trabajé con herramientas de análisis espacial de Qgis con el fin de identificar las zonas de conflicto, donde más de uno de estos usos es posible, y que por lo tanto requieren una regulación más urgente. Los métodos de análisis multicriterio buscan proporcionar a los tomadores de decisiones una herramienta que les permita avanzar en la solución de problemas para los cuales deben ser tenidos en cuenta varios criterios (Zardari et al., 2015), mediante la utilización de reglas de decisión, es decir, procedimientos que permiten elegir y combinar diferentes criterios en un proceso de evaluación de diversas alternativas (Eastman, 2012). Existen diversos métodos de análisis multicriterios, en nuestro caso utilizamos el Proceso de Análisis Jerárquico (AHP, por sus siglas en inglés), el cual trabaja a través de la agregación de diferentes criterios en un solo índice (Zardari et al., 2015).

Tanto el preprocesamiento de la información como los análisis multicriterio se realizaron en el software Idrisi. Para el análisis multicriterio utilicé la herramienta de Idrisi "Multi-criteria/Multi-objective Decision Wizard", esta herramienta permite integrar múltiples capas con información espacial, a partir de criterios de selección explicitados en el proceso de análisis de la información, obteniendo diversos productos intermedios y un mapa final resultado del análisis multicriterio definido. Al tratarse de datos continuos, Idrisi utiliza el procedimiento de Combinación Lineal Ponderada (WLC, por sus siglas en inglés), donde los factores (criterios) son estandarizados en un rango numérico común y luego combinados mediante un promedio ponderado (aplicando un peso a cada uno, seguido por una sumatoria de los resultados), obteniendo como resultado un mapa de adecuación continuo.

$$
\begin{aligned}
& S=\sum W_{i} X_{i} \quad \text { Donde } S=\text { adecuación } \\
& \qquad W_{i}=\text { peso de factor } i \\
& X_{i}=\text { valor del criterio del factor } i
\end{aligned}
$$

En el presente caso generé mapas de aptitud de uso, por lo que los datos contenidos en ellos son datos continuos, en un rango establecido por default entre 0 y 255 , donde 0 
representa menor aptitud y 255 máxima aptitud. Los mapas obtenidos fueron posteriormente recategorizados en un rango del 1 al 100 para poder analizar más adecuadamente los resultados y compararlos más fácilmente.

Para establecer los criterios para identificar las áreas de mayor aptitud tuve en cuenta las variables: hidrografía, red vial, tipo de suelo, Modelo Digital de Elevación (DEM) y probabilidad de transición a urbano, a invernáculos y a horticultura al aire libre.

El mapa de hidrografía lo generé en base a la red de drenaje obtenida a partir del Modelo Digital de Elevación (DEM) (Anexo 1). A partir del mapa de red de drenaje calculé la distancia euclidiana, obteniéndose un mapa raster donde cada pixel tiene un valor que refleja la distancia de dicho pixel al cuerpo de agua más cercano.

La capa de caminos la descargué de manera gratuita del Open Street Maps y realicé un procesamiento posterior, en el que seleccioné solo los caminos principales, descartando por ejemplo las ciclo vías y los caminos internos de los barrios privados (Anexo 1). Posteriormente generé un mapa raster con la distancia euclidiana a los caminos.

A partir del mapa de aptitud de suelos (Hurtado, 2006) (Anexo 1) generé un nuevo mapa en el que le asigné un valor del 1 al 10 a cada tipo de suelo, mediante un proceso de reclasificación, según el grado de aptitud para el uso agrícola, definido en base al sistema de clasificación de tierras por capacidad de uso del Servicio de Conservación de Suelos de los EE.UU (Klingebiel y Montgomery, 1961 en Hurtado, 2006); así los valores más bajos reflejan una alta aptitud para la agricultura mientras que valores cercanos a 10 reflejan una escasa a nula aptitud para la agricultura (Cuadro 1).

Cuadro 1. Reclasificación del mapa de aptitud de suelos (Hurtado 2006) según grado de aptitud para uso agrícola. Las categorías de aptitud de uso provienen de (Klingebiel y Montgomery, 1961 en Hurtado, 2006)

\begin{tabular}{|c|c|c|}
\hline APTITUD DE & GRADO DE APTITUD & TIPO DE SUELO \\
\hline USO & PARA USO & \\
\hline & AGRÍCOLA & \\
\hline \multirow{6}{*}{$\begin{array}{l}\text { AGRICOLA } \\
\text { (Categorías I a } \\
\text { IV) }\end{array}$} & \multirow[t]{2}{*}{1 (alta aptitud) } & $\begin{array}{l}\text { 2-As. Consociación Serie Arturo Seguí (Argiudoles vérticos, fina, } \\
\text { montmorillonítica, térmica) }\end{array}$ \\
\hline & & $\begin{array}{l}\text { 9-Ec. Asociación Series Estancia Chica (Argiudoles vérticos, } \\
\text { fina, illítica, térmica) }(80 \%) \text { y Los Hornos (Argiaboles vérticos, } \\
\text { muy fina, térmica (20\%) }\end{array}$ \\
\hline & \multirow[t]{4}{*}{2} & 3-As1. Consociación Serie Arturo Seguí, fase inclinada. \\
\hline & & $\begin{array}{l}\text { 4-As2. Consociación Serie Arturo Seguí, fase imperfectamente } \\
\text { drenada. }\end{array}$ \\
\hline & & $\begin{array}{l}\text { 5-As3. Complejo Serie Arturo Seguí }(60 \%) \text { Serie Gorina } \\
\text { (Hapludertes típicos, fina montmorillonítica, térmica) }(40 \%)\end{array}$ \\
\hline & & $\begin{array}{l}\text { 10-EN-LC. Complejo Series Esquina Negra (Hapludoles tapto- } \\
\text { árgicos, fina, illítica, térmica) y La Cigüeña (Hapludoles tapto- }\end{array}$ \\
\hline 152 Lic. Caroli & 3aldini & Tesis doctoral - Territorio en movimiento \\
\hline
\end{tabular}




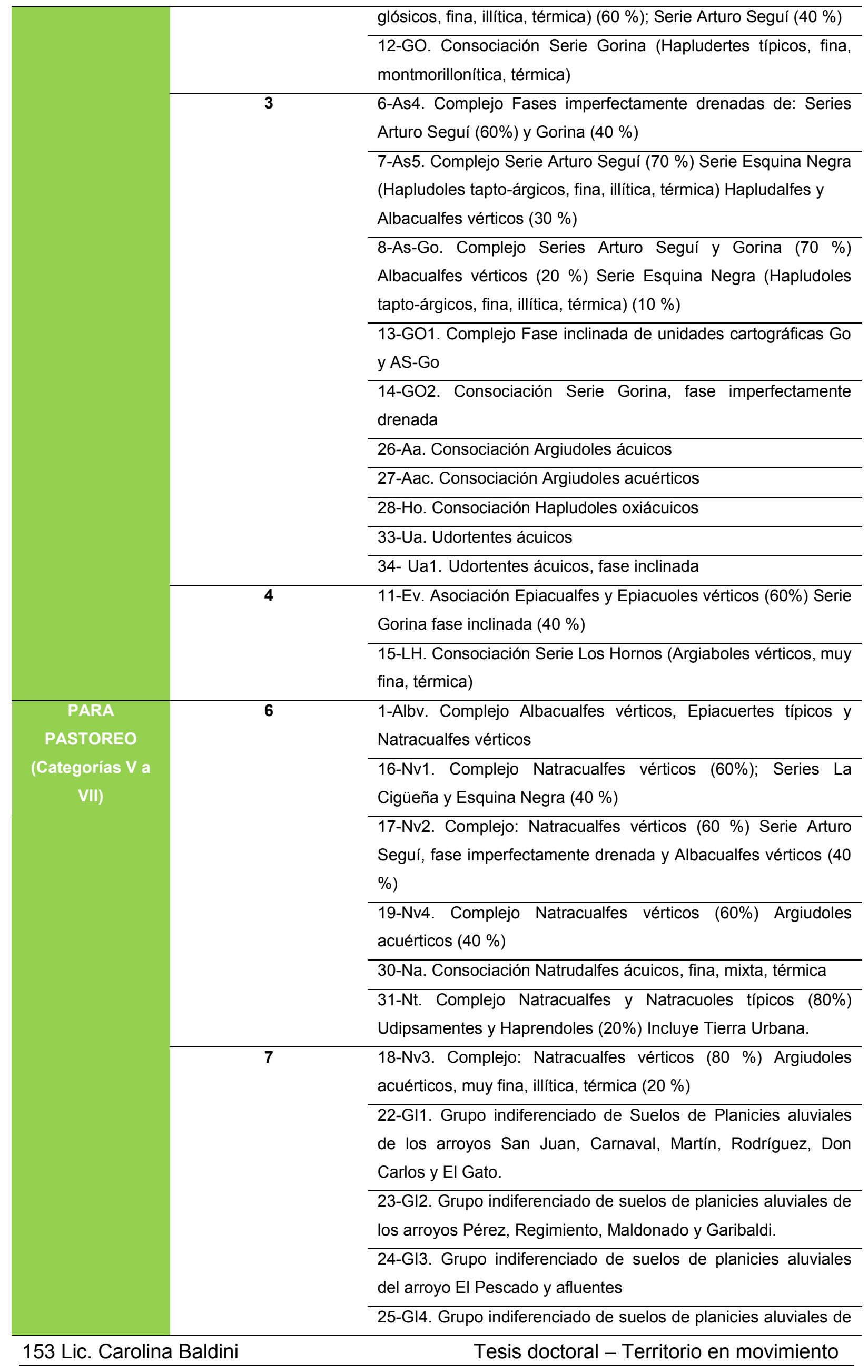




\begin{tabular}{|c|c|c|}
\hline & & arroyos de la cuenca del río \\
\hline & & Samborombón. \\
\hline & & $\begin{array}{l}\text { 32-Nv5. Complejo Natracualfes vérticos (80\%) Natracuoles, } \\
\text { Argiacuoles y Argialboles (20\%). Incluye Tierra Urbana. }\end{array}$ \\
\hline & & $\begin{array}{l}\text { 35-GI-S. Grupo indiferenciado de suelos de planicies aluviales } \\
\text { de las Areas de Origen Mixto y Estuárico-Marino }\end{array}$ \\
\hline NO APTOS & 10 & 20-U-As-Go. Complejo Tierra Urbana y Series Gorina-Seguí. \\
\hline & (escasa a nula aptitud) & 21-U-PA. Complejo Tierra Urbana y planicies aluviales. \\
\hline & & $\begin{array}{l}\text { 29-Ht-U. Complejo Haprendoles típicos, franca gruesa sobre } \\
\text { fragmentaria, carbonática, térmica - Tierra Urbana. }\end{array}$ \\
\hline & & 36-F. Consociación de Fluvacuentes típicos \\
\hline & & $\begin{array}{l}\text { 37-M1a. Complejo de Natracuentes típicos, } \\
\text { imperfecta/drenada/epiacuertes sódicos (sustato aencol) }\end{array}$ \\
\hline & & $\begin{array}{lccc}\text { 38-M1b. Complejo de Natracuentes típicos, } & \text { fase } \\
\text { imperfecta/drenada/epiacuertes sódicos (sustato loégico) } & \end{array}$ \\
\hline & & $\begin{array}{l}\text { 39-M2. Complejo de Natracuentes típicos, fase probablemente } \\
\text { drenada }\end{array}$ \\
\hline & & $\begin{array}{l}\text { 40-M3. Complejo de Natracuentes típicos, fase muy } \\
\text { probablemente drenada/epiacuertes típicos y hálicos }\end{array}$ \\
\hline & & 41-M4. Consociación de Haprendoles típicos \\
\hline & & 42-L. Lagunas y bañados \\
\hline & & 43-C. Canteras o cavas \\
\hline
\end{tabular}

El mapa de coberturas/usos del suelo obtenido para el año 2015 a partir del proceso de clasificación, fue reclasificado para obtener un mapa de probabilidad de transición de las distintas clases a la clase urbano. Los valores de probabilidad utilizados para esa reclasificación, fueron obtenidos a partir de los resultados del análisis de cambio de uso del suelo entre 2005 y 2015. De esta forma se obtuvo un mapa con valores del 1 al 10 , donde 1 es la probabilidad más baja y 10 la probabilidad más alta de transformarse en la clase urbana. Un procedimiento similar se realizó para obtener un mapa de probabilidad de transición a Invernáculos y para la probabilidad de transición a Horticultura.

Todas las variables utilizadas para el análisis multicriterio fueron estandarizadas a una escala de 0 a 255, para su comparación. Esto se realizó con la herramienta "Fuzzy member function". Esta herramienta permite aplicar distintas funciones para reescalar los valores a enteros de 8 bits (entre valores de 0 a 255). Entre las funciones podemos encontrar: a) monotónica (lineal) creciente, decreciente o simétrica; b) en forma de $\mathrm{J}$ (exponencial) ascendente, descendente, simétrica; c) sigmoideal (logística) ascendente, descendente, simétrica; d) especificada por el usuario. Si la variable en consideración tiene una relación positiva con el criterio a ponderar, entonces el 0 significará que no tiene incidencia y el 255 que tiene máxima incidencia. Para las tres primeras funciones existen los valores máximos y mínimos de la variable a partir de la cual escalará los parámetros entre 0 154 Lic. Carolina Baldini Tesis doctoral - Territorio en movimiento 
y 255, denominados puntos de control. Cuando la relación es creciente los puntos de control mínimo y máximo son a y b. Cuando es decreciente los puntos de control mínimo y máximo son d y c. Y si es simétrica, los puntos de control son a, b, c y d. Las funciones, como los puntos de control aplicados a cada variable se asignaron en función de criterios técnicos como lo detalla el Cuadro 2.

Cuadro 2. Estandarización de las variables

\begin{tabular}{|c|c|c|c|}
\hline VARIABLES & $\begin{array}{l}\text { FORMA DE LA } \\
\text { FUNCIÓN }\end{array}$ & TIPO DE FUNCIÓN & $\begin{array}{l}\text { PUNTOS DE } \\
\text { CONTROL }\end{array}$ \\
\hline \multicolumn{4}{|c|}{ Objetivo de análisis: Aptitud para crecimiento urbano } \\
\hline $\begin{array}{l}\text { Probabilidad de } \\
\text { transición a Urbano } \\
\text { (PTU) }\end{array}$ & $\begin{array}{l}\text { crecimiento } \\
\text { monotónico }\end{array}$ & Lineal & $a=0, b=10$ \\
\hline DEM & $\begin{array}{l}\text { crecimiento } \\
\text { monotónico }\end{array}$ & Sigmoidal & $a=5, b=15$ \\
\hline $\begin{array}{l}\text { Distancia } \\
\text { euclidiana a rutas y } \\
\text { caminos (DERC) }\end{array}$ & $\begin{array}{l}\text { decrecimiento } \\
\text { monotónico }\end{array}$ & Sigmoidal & $c=0, d=1000$ \\
\hline $\begin{array}{l}\text { Distancia } \\
\text { euclidiana a } \\
\text { cuerpos de agua } \\
\text { (DECA) }\end{array}$ & $\begin{array}{l}\text { crecimiento } \\
\text { monotónico }\end{array}$ & Sigmoidal & $a=30, b=300$ \\
\hline $\begin{array}{l}\text { Suelos con aptitud } \\
\text { para uso agrícola } \\
\text { (SAUA) }\end{array}$ & $\begin{array}{l}\text { crecimiento } \\
\text { monotónico }\end{array}$ & Sigmoidal & $a=1, b=8$ \\
\hline
\end{tabular}

\begin{tabular}{llll}
\hline \multicolumn{4}{l}{ Objetivo de análisis: Aptitud para crecimiento de invernáculos } \\
\hline $\begin{array}{l}\text { Probabilidad de } \\
\text { transición a }\end{array}$ & $\begin{array}{l}\text { crecimiento } \\
\text { monotónico }\end{array}$ & Lineal & \\
Invernáculos & & & \\
\hline DEM & crecimiento & Sigmoidal & $\mathrm{a}=20, \mathrm{~b}=30$ \\
& monotónico & & \\
\hline $\begin{array}{l}\text { Distancia } \\
\text { euclidiana a rutas y y }\end{array}$ & decrecimiento & Sigmoidal & $\mathrm{c}=0, \mathrm{~d}=2000$ \\
caminos & & & \\
\hline $\begin{array}{l}\text { Distancia } \\
\text { euclidiana a }\end{array}$ & crecimiento & Sigmoidal & $\mathrm{a}=30, \mathrm{~b}=120$ \\
cuerpos de agua & & & \\
\hline $\begin{array}{l}\text { Suelos con aptitud } \\
\text { para uso agrícola }\end{array}$ & decrecimiento & Sigmoidal & $\mathrm{a}=1, \mathrm{~b}=8$ \\
\end{tabular}




\section{Objetivo de análisis: Aptitud para crecimiento de horticultura al aire libre}

\begin{tabular}{llll}
\hline $\begin{array}{l}\text { Probabilidad de } \\
\text { transición a }\end{array}$ & $\begin{array}{l}\text { crecimiento } \\
\text { monotónico }\end{array}$ & Lineal & $\mathrm{a}=0, \mathrm{~b}=10$ \\
$\begin{array}{l}\text { Horticultura al aire } \\
\text { libre }\end{array}$ & & & \\
\hline DEM & crecimiento & Sigmoidal & $\mathrm{a}=20, \mathrm{~b}=30$ \\
& monotónico & & \\
\hline $\begin{array}{l}\text { Distancia } \\
\text { euclidiana a rutas y } \\
\text { caminos }\end{array}$ & $\begin{array}{l}\text { mecrecimiento } \\
\text { mistancia }\end{array}$ & Sigmoidal & $\mathrm{c}=0, \mathrm{~d}=2000$ \\
euclidiana a & crecimiento & Sigmoidal & $\mathrm{a}=30, \mathrm{~b}=120$ \\
cuerpos de agua & & & \\
\hline $\begin{array}{l}\text { Suelos con aptitud } \\
\text { para uso agrícola }\end{array}$ & decrecimiento & lineal & $\mathrm{a}=1, \mathrm{~b}=8$ \\
\hline
\end{tabular}

Una vez estandarizadas las variables, le asigné pesos relativos a las mismas (Cuadro 3, 4 y 5), a través del proceso de comparación por pares, que implica la comparación de cada criterio con todos los otro criterio de a pares; esto trae aparejada la necesidad de examinar detenidamente todos los elementos de un problema de decisión (Zardari et al., 2015). Como resultado generé una matriz de comparación por pares, cuyos puntajes asigné en base a criterios técnico-científicos, sobre una escala continua de 9 puntos, establecida de la siguiente manera:

\begin{tabular}{|c|c|c|c|c|c|c|c|c|}
\hline $1 / 9$ & $1 / 7$ & $1 / 5$ & $1 / 3$ & 1 & 3 & 5 & 7 & 9 \\
\hline Sumamente & $\begin{array}{c}\text { Muy } \\
\text { Fuertemente }\end{array}$ & Fuertemente & Moderadamente & Igualmente & Moderadamente & Fuertemente & $\begin{array}{c}\text { Muy } \\
\text { Fuertemente }\end{array}$ & Sumamente \\
\hline \multicolumn{3}{|c|}{ Menos Importante } & Importante & \multicolumn{5}{c|}{ Más Importante } \\
\hline
\end{tabular}

Cuadro 3. Matriz de comparación por pares del análisis de aptitud para crecimiento urbano

\begin{tabular}{lccccc}
\hline \multicolumn{1}{c}{ PTU } & \multicolumn{1}{c}{ DEM } & DECA & SAUA & DERC \\
\hline PTU & 1 & & & & \\
\hline DEM & $1 / 7$ & 1 & & & \\
\hline DECA & $1 / 3$ & 5 & 1 & 1 & \\
\hline SAUA & $1 / 5$ & 3 & $1 / 3$ & 3 & 1 \\
\hline DERC & $1 / 3$ & 5 & 1 & \\
\hline
\end{tabular}

Cuadro 4. Matriz de comparación por pares del análisis de aptitud para crecimiento de invernáculos 


\begin{tabular}{llllll}
\hline & DEM & SAUA & DECA & DERC & PTI \\
\hline DEM & 1 & & & & \\
\hline SAUA & 5 & 1 & & & \\
\hline DECA & 3 & $1 / 3$ & 1 & 1 & \\
\hline DERC & 5 & 1 & 3 & 3 & 1 \\
\hline PTI & 7 & 3 & 5 & & \\
\hline
\end{tabular}

Cuadro 5. Matriz de comparación por pares del análisis de aptitud para crecimiento de horticultura al aire libre

\begin{tabular}{llllll}
\hline & DEM & DECA & SAUA & DERC & PTH \\
\hline DEM & 1 & & & & \\
\hline DECA & 3 & 1 & & & \\
\hline SAUA & 7 & 5 & 1 & 1 & \\
\hline DERC & 5 & 3 & $1 / 3$ & 5 & 1 \\
\hline PTH & 9 & 7 & 3 & 5 & \\
\hline
\end{tabular}

Una vez realizada la comparación por pares el módulo de Idrisi calcula el peso de cada variable y un índice llamado "Tasa de Consistencia" (CR, por sus siglas en inglés), que establece la probabilidad de que los puntajes de la matriz se generen de manera aleatoria; valores de $\mathrm{CR}$ mayores a 0.10 son inconsistentes por lo que los puntajes asignados deben ser reevaluados (Zardari et al., 2015). Una vez asignado el peso a cada variable, le asigné peso de orden, que controla la manera en la cual los factores ponderados son agregados, mediante la técnica de Promedio Ponderado Ordenado (OWA, por sus siglas en inglés), el cual brinda un espectro amplio de estrategias de decisión entre el rango de intercambio involucrado y el grado de riesgo en la solución (Eastman, 2012) (Cuadro 6).

Cuadro 6. Pesos ponderados ordenados (OWA) para las aptitudes de uso urbano, de invernáculos y hortícola.

\begin{tabular}{|c|c|c|c|c|}
\hline $\begin{array}{l}\text { PESO DE ORDEN } \\
\text { PTU/PTI/PTH }\end{array}$ & $\begin{array}{l}\text { PESO DE } \\
\text { ORDEN DEM }\end{array}$ & $\begin{array}{c}\text { PESO DE } \\
\text { ORDEN DECA }\end{array}$ & $\begin{array}{l}\text { PESO DE } \\
\text { ORDEN SAUA }\end{array}$ & $\begin{array}{c}\text { PESO DE } \\
\text { ORDEN DERC }\end{array}$ \\
\hline \multicolumn{5}{|c|}{ Peso Ponderado Ordenado Para Aptitud De Uso Urbano } \\
\hline 0.4 & 0.1 & 0.2 & 0.1 & 0.2 \\
\hline \multicolumn{5}{|c|}{ Peso Ponderado Ordenado Para Aptitud De Invernáculos } \\
\hline 0.3 & 0.1 & 0.2 & 0.2 & 0.2 \\
\hline \multicolumn{5}{|c|}{ Peso Ponderado Ordenado Para Aptitud Horticola } \\
\hline 0.3 & 0.1 & 0.2 & 0.2 & 0.2 \\
\hline
\end{tabular}

Una vez obtenidos los mapas de aptitud, reclasifiqué en 5 categorías de aptitud (muy baja, baja, media, alta y muy alta). Posteriormente extraje las categorías 4 y 5 de cada mapa, y crucé con el mapa de usos del suelo del año 2015, para identificar los usos actuales 157 Lic. Carolina Baldini Tesis doctoral - Territorio en movimiento 
del suelo en las zonas identificadas como más aptas para cada uno de los tres usos analizados. Paralelamente, las categorías de los mapas de aptitud fueron reagrupadas, fusionando por un lado las categorías muy bajo y bajo, y por otro las categorías alto y muy alto; dando como resultado mapas con 3 categorías (1-Baja aptitud, 2-Media aptitud, 3-Alta aptitud). Luego le asigné valores a dichas categorías, a la más baja le asigné un valor de 1 , a la media un valor de 5 y a la alta un valor de 10. Una vez asignados estos valores generé un mapa aditivo, en el que integré el mapa de aptitud urbana, el de aptitud de invernáculos y el de aptitud hortícola. Como resultado obtuve un mapa que denominé "mapa de conflicto" donde se pueden identificar las zonas con mayor y menor aptitud de uso para las tres variables en conjunto. En este mapa cada pixel tiene un valor, llamado valor de conflictividad, que es el resultado de la sumatoria del valor asignado para ese pixel en cada mapa independiente, según la categoría a la que correspondiera (Cuadro 7). El mapa aditivo se intersectó con el mapa de usos del suelo del año 2015 para analizar los usos del suelo existentes en las zonas con mayor conflictividad.

Cuadro 7. Resumen de categorías asignadas en las distintas etapas del análisis.

\begin{tabular}{|c|c|c|c|c|}
\hline $\begin{array}{l}\text { CATEGORIAA } \\
\text { MAPA } \\
\text { APTITUD DE } \\
\text { USO }\end{array}$ & $\begin{array}{c}\text { VALOR } \\
\text { ASIGNADO A } \\
\text { CADA } \\
\text { CATEGORÍA }\end{array}$ & $\begin{array}{l}\text { COMBINACIONES } \\
\text { RESULTADO DE } \\
\text { MAPAADITIVO } \\
\text { (MAPA DE } \\
\text { CONFLICTO) }\end{array}$ & $\begin{array}{c}\text { VALOR DE } \\
\text { CONFLICTIVIDAD }\end{array}$ & $\begin{array}{l}\text { NIVELL DE } \\
\text { CONFLICTO }\end{array}$ \\
\hline \multirow[t]{2}{*}{ 1-Muy Baja } & \multirow{4}{*}{1} & $1,1,1=3$ & 3 & 3-Muy Bajo conflicto \\
\hline & & $1,1,5=7$ & 7 & 7-Muy Bajo conflicto \\
\hline \multirow[t]{2}{*}{ 2-Baja } & & $1,5,5=11$ & 11 & 11-Muy Bajo conflicto \\
\hline & & $10,1,1=12$ & 12 & 12-Muy Bajo conflicto \\
\hline \multirow[t]{2}{*}{ 3-Media } & \multirow{2}{*}{5} & $5,5,5=15$ & 15 & 15-Bajo Conflicto \\
\hline & & $10,5,1=16$ & 16 & 16-Bajo Conflicto \\
\hline \multirow[t]{2}{*}{ 4-Alta } & \multirow{4}{*}{10} & $10,5,5=20$ & 20 & 20-Conflicto Medio \\
\hline & & $10,10,1=21$ & 21 & 21-Conflicto Alto \\
\hline \multirow[t]{2}{*}{ 5-Muy Alta } & & $10,10,5=25$ & 25 & 25-Conflicto Muy Alto \\
\hline & & $10,10,10=30$ & 30 & 30-Conflicto Extremo \\
\hline
\end{tabular}

Finalmente contemplando los mapas de aptitud de uso y de nivel de conflicto generados, analicé la relación de estos con el mapa de áreas buffer de arroyos y con las diversas áreas de vegetación natural-seminatural presentes en el partido de La Plata. Para estos análisis la vegetación fue agrupada en dos grandes categorías: vegetación espontánea y vegetación antrópica. La vegetación espontánea agrupa las categorías de uso del suelo Parquizaciones Arboladas y Parquizaciones Herbáceas; por su parte, la vegetación espontánea agrupa las categorías Pastizal y Vegetación Ribereña.

\section{RESULTADOS}

\subsection{Los municipios y la producción hortícola}


Como resultado de la recategorización del mapa de coberturas/usos del suelo generado para el año 2015 obtuve 11 coberturas/usos del suelo (Fig.1) y calculé la superficie ocupada por cada una de ellas. Las principales en cuanto a su extensión fueron, la Ganadería $(34,72 \%$ del partido), seguido por la Urbanización $(23,12 \%)$, la Vegetación Ribereña (12,31\%) y el Pastizal $(9,28 \%)$. En cuanto a la producción hortícola, la superficie hortícola total representó el 9,70\% del partido (8612,37Ha.); de la misma el $49,25 \%$ fue cubierta por la Horticultura y $50,75 \%$ por los Invernáculos (Cuadro 8). Dentro de las coberturas que correspondieron, en mayor o menor medida, a vegetación semi-natural, la Vegetación Ribereña fue la más representativa (12,31\%), seguida por el Pastizal (9,28\%), las Parquizaciones Herbáceas (4,13\%), y en menor medida las Parquizaciones Arboladas $(1,97 \%)$.

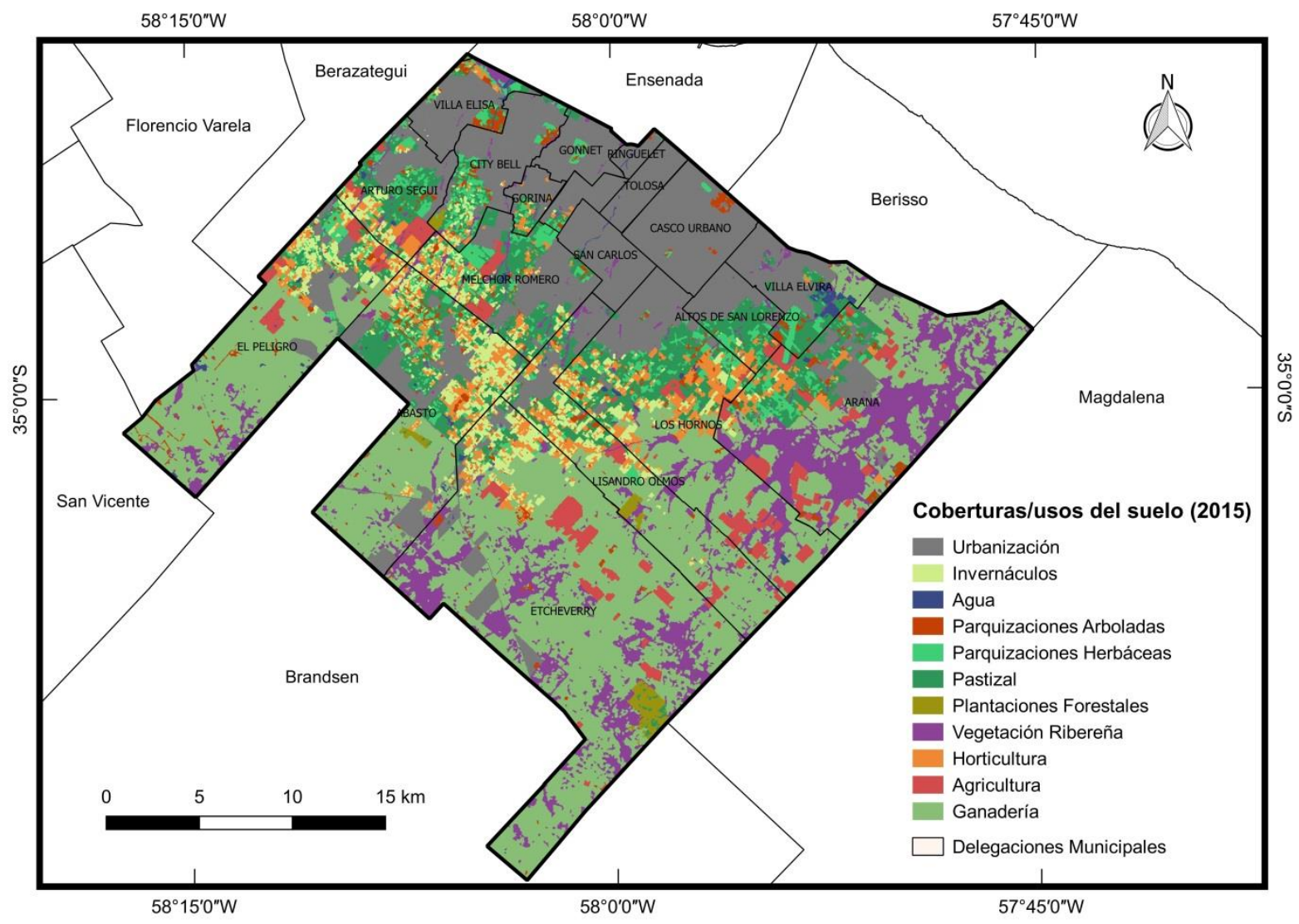

Fig 1. Mapa de Coberturas/usos del suelo del Partido de La Plata para el año 2015.

Cuadro 8. Superficie (en hectáreas) y porcentaje de cada categoría de cobertura/uso del suelo, para el año 2015, obtenidas de la recategorización del mapa de coberturas/usos del suelo del partido de La Plata de dicho año.

\begin{tabular}{lrc}
$\begin{array}{c}\text { CATEGORIAS DE } \\
\text { COBERTURAMSO DEL } \\
\text { SUELOO }\end{array}$ & $\begin{array}{c}\text { SUPERFICIE } \\
\text { (HECTAREAS) }\end{array}$ & $\begin{array}{c}\text { PORCENTAJE DEL } \\
\text { PARTIDO DE LA PLATA }\end{array}$ \\
\hline Urbanización & 20529,9 & 23,12 \\
\hline ParquizacionesArboladas & 1747,53 & 1,97 \\
\hline 159 Lic. Carolina Baldini & & Tesis doctoral - Territorio en movimiento \\
\hline
\end{tabular}




\begin{tabular}{lcc}
\hline ParquizacionesHerbáceas & 3666,96 & 4,13 \\
\hline Agua & 427,5 & 0,48 \\
\hline Pastizal & 8240,76 & 9,28 \\
\hline VegetaciónRibereña & 10928,43 & 12,31 \\
\hline PlantacionesForestales & 570,06 & 0,64 \\
\hline Horticultura & 4241,97 & 4,78 \\
\hline Invernáculos & 4370,4 & 4,92 \\
\hline Agricultura & 3241,53 & 3,65 \\
\hline Ganadería & 30823,74 & 34,72 \\
\hline
\end{tabular}

La zona hortícola estuvo integrada por un 49\% (4241,97 ha) de horticultura al aire libre y un 51\% (4370,4 ha) de horticultura bajo invernáculos (Fig.2).

Al analizar la distribución de las áreas hortícolas en relación a la distancia de los centros urbanos, identifiqué que el $20,58 \%$ de los Invernáculos se hallaron ubicados a una distancia menor a los 250 metros del área urbana, que más de la mitad de los Invernáculos $(54,82 \%)$ se encontraron dentro de los 750 metros y que el $67,93 \%$ se encontraron dentro de los 1000 metros del área urbana. Datos similares hallé al analizar la distribución de la Horticultura (Cuadro 9).

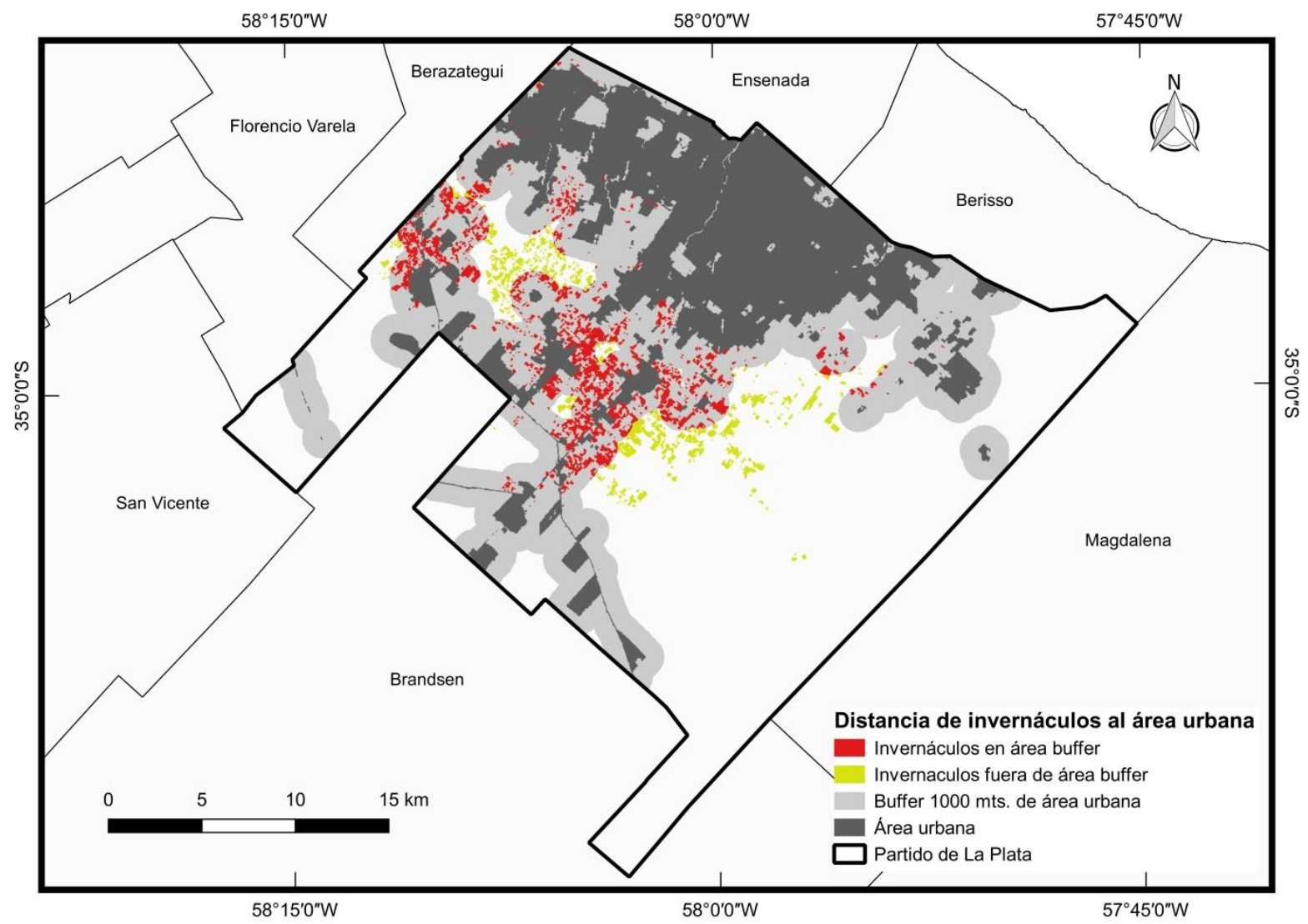

Fig 2. Distribución de Invernáculos en relación al área buffer de 1000 mts. generada en torno al área Urbana, para el Partido de La Plata, en el año 2015.

Cuadro 9. Superficie (en hectáreas) y porcentaje de Invernáculos y de Horticultura en relación a cuatro áreas buffer generadas en torno al área Urbana, para el Partido de La Plata, en el año 2015. 


\begin{tabular}{ccccccccc}
\hline Invernáculos & $899,58 \mathrm{Ha}$. & $20,58 \%$ & $1658,22 \mathrm{Ha}$. & $37,94 \%$ & $2395,74 \mathrm{Ha}$. & $54,82 \%$ & $2968,88 \mathrm{Ha}$. & $67,93 \%$ \\
\hline Horticultura & $723,34 \mathrm{Ha}$. & $17,05 \%$ & $1369,63 \mathrm{Ha}$. & $32,29 \%$ & $1914,63 \mathrm{Ha}$. & $45,14 \%$ & $2444,81 \mathrm{Ha}$. & $57,63 \%$ \\
\hline
\end{tabular}

Para evaluar con más profundidad la distribución de los cultivos al aire libre y bajo invernáculo, partiendo de la superficie identificada para cada uno de ellos en el mapa de coberturas/usos del suelo analicé la distribución de estos por delegación municipal (Cuadro 10). Como resultado, al evaluar la superficie de Invernáculos en relación a la superficie total de Invernáculos para el partido de La Plata, observé que las delegaciones que concentraron la mayor proporción de Invernáculos fueron, en orden decreciente, Abasto (23,47\% del total de Invernáculos), Etcheverry (15,65\%), El Peligro (12,93\%), Lisandro Olmos (12,90\%), Los Hornos (12,79\%) y Melchor Romero (9,91\%). Al analizar la superficie de Invernáculos en relación a la superficie total de cada delegación municipal, las delegaciones con mayor superficie relativa de Invernáculos fueron, en orden decreciente, Abasto $(11,72 \%$ de la superficie de la delegación), Arturo Segui (10,17\%), Melchor Romero (10,08\%), Lisandro Olmos $(9,33 \%)$, El Peligro (6,57\%) y Los Hornos (5,85\%); en este caso la importancia relativa de cada delegación municipal varía, pero la principal diferencia radica en que Etcheverry pierde relevancia (por ser la delegación con mayor superficie del partido) y toma importancia Arturo Segui (Fig.3). En cuanto a la Horticultura, se puede ver que al analizar su superficie en relación a la superficie total de Horticultura para el partido de La Plata, las delegaciones que concentraron mayor superficie de Horticultura fueron Los Hornos $(24,17 \%$ del total de Horticultura), Abasto (18,10\%), Etcheverry (10,09\%), Lisandro Olmos (9,55\%), Arana $(8,48 \%)$, El Peligro $(8,40 \%)$ y Melchor Romero $(8,28 \%)$. Al comparar lo que ocurre con los Invernáculos, Los Hornos y Arana son dos delegaciones que adquieren mayor relevancia al analizar la Horticultura, es decir que hay una mayor tendencia en esas delegaciones a realizar producciones hortícolas al aire libre.

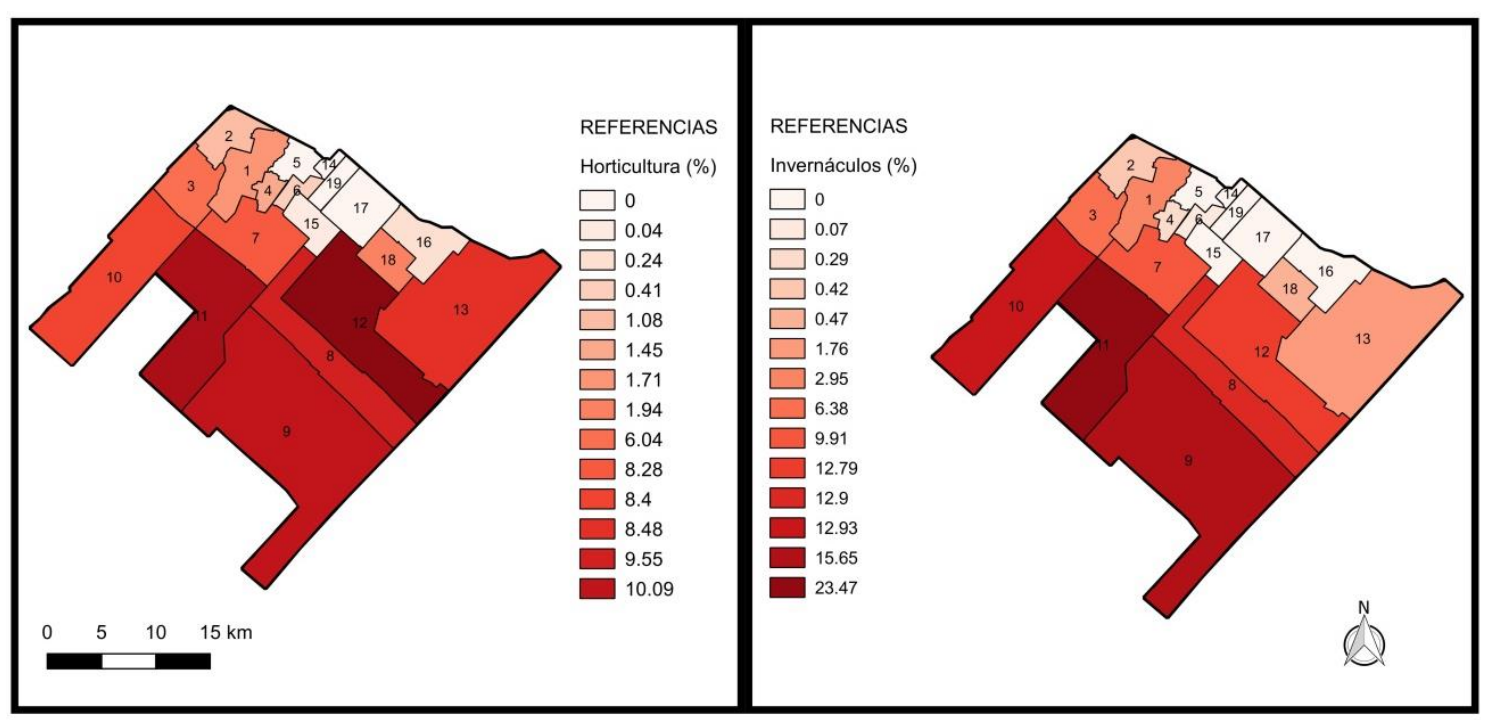

Fig 3. Porcentaje de Horticultura e Invernáculos en relación a su superficie total, por delegación municipal para el Partido de La Plata, en el año 2015. Las delegaciones 161 Lic. Carolina Baldini Tesis doctoral - Territorio en movimiento 
municipales se han identificado como: 1-City Bell, 2-Villa Elisa, 3-Arturo Segui, 4-Gorina, 5Gonnet, 6-Hernández, 7-Melchor Romero, 8-Lisandro Olmos, 9-Etcheverry, 10-El Peligro, 11-Abasto, 12-Los Hornos, 13-Arana, 14-Ringuelet, 15-San Carlos, 16-Villa Elvira, 17-Casco Urbano, 18-Altos de San Lorenzo, 19-Tolosa.

Cuadro 10. Superficie (en hectáreas) y porcentaje relativo de Invernáculos, de Horticultura y de Horticultura Total por delegación municipal en función de la superficie de cada delegación y de las categorías de cobertura, para el Partido de La Plata, en el año 2015. AB-Abasto, ASL-Altos de San Lorenzo, AR-Arana, AS-Arturo Segui, CB-City Bell, EP-El Peligro, ETEtcheverry, GO-Gorina, HE-Hernández, LH-Los Hornos, LO-Lisandro Olmos, MR-Melchor Romero, VELI-Villa Elisa, VELV-Villa Elvira, SC-San Carlos. SD-Superficie de la Delegación, Inv-Invernáculos, STID-Superficie de Invernáculos en relación a la superficie de la Delegación, STI-Superficie de Invernáculos en relación a la superficie total de Invernáculos, Hortic-Horticultura, STHD- Superficie de Horticultura en relación a la superficie de la Delegación, STH-Superficie de Horticultura en relación a la superficie total de Horticultura, HT-Superficie Total de Horticultura, STHD- Superficie de Horticultura Total en relación a la superficie de la delegación y STHT-Superficie Total Horticultura Total.

\begin{tabular}{lcccccccccc}
\hline DELEG. & $\begin{array}{c}\text { SD } \\
\text { (Ha.) }\end{array}$ & $\begin{array}{c}\text { Inv } \\
\text { (Ha.) }\end{array}$ & $\begin{array}{c}\% \\
\text { STID }\end{array}$ & $\begin{array}{c}\% \\
\text { STI }\end{array}$ & $\begin{array}{c}\text { Hortic } \\
\text { (Ha.) }\end{array}$ & $\begin{array}{c}\% \\
\text { STHD }\end{array}$ & $\begin{array}{c}\% \\
\text { STH }\end{array}$ & $\begin{array}{c}\text { HT } \\
\text { (Ha.) }\end{array}$ & $\begin{array}{c}\text { STHD } \\
\text { STHT }\end{array}$ \\
\hline AB & 8749,07 & 1025,67 & 11,72 & 23,47 & 768,82 & 8,79 & 18,10 & 1794,49 & 20,51 & 20,82 \\
\hline ARL & 1681,5 & 20,67 & 1,23 & 0,47 & 82,62 & 4,91 & 1,94 & 103,29 & 6,14 & 1,20 \\
\hline AS & 11966,83 & 76,77 & 0,64 & 1,76 & 360,36 & 3,01 & 8,48 & 437,13 & 3,65 & 5,07 \\
\hline CB & 2743,02 & 279,04 & 10,17 & 6,38 & 256,65 & 9,36 & 6,04 & 535,69 & 19,53 & 6,22 \\
\hline EP & 2823,7 & 129,11 & 4,57 & 2,95 & 72,67 & 2,57 & 1,71 & 201,78 & 7,15 & 2,34 \\
\hline ET & 8594,1 & 565,02 & 6,57 & 12,93 & 356,93 & 4,15 & 8,40 & 921,95 & 10,73 & 10,70 \\
\hline GO & 19948,08 & 684,08 & 3,43 & 15,65 & 428,81 & 2,15 & 10,09 & 1112,89 & 5,58 & 12,91 \\
\hline HE & 657,57 & 12,68 & 1,93 & 0,29 & 61,50 & 9,35 & 1,45 & 74,18 & 11,28 & 0,86 \\
\hline LH & 649,04 & 3,06 & 0,47 & 0,07 & 17,46 & 2,69 & 0,41 & 20,52 & 3,16 & 0,24 \\
\hline LO & 9554,54 & 558,95 & 5,85 & 12,79 & 1026,78 & 10,75 & 24,17 & 1585,73 & 16,60 & 18,40 \\
\hline MR & 6042,15 & 563,94 & 9,33 & 12,90 & 405,74 & 6,72 & 9,55 & 969,68 & 16,05 & 11,25 \\
\hline VELI & 4298,86 & 433,28 & 10,08 & 9,91 & 351,77 & 8,18 & 8,28 & 785,05 & 18,26 & 9,11 \\
\hline VELV & 1823,31 & 18,32 & 1,00 & 0,42 & 45,99 & 2,52 & 1,08 & 64,31 & 3,53 & 0,75 \\
\hline SC & 2596,05 & -------- & ----- & ----- & 10,35 & 0,40 & 0,24 & 10,35 & 0,40 & 0,12 \\
\hline
\end{tabular}

\subsection{La producción hortícola en relación a las cuencas}

Finalmente, me propuse analizar la distancia de los Invernáculos a arroyos (Fig. 4), encontrando que de las 4370,4 hectáreas de Invernáculos, el 10,19\% se encuentran a menos de 50 metros de los arroyos, el $21,14 \%$ se encuentra a una distancia menos a los 100 metros, el $32,94 \%$ a una distancia menor a los 150 metros y el $45,06 \%$ a una distancia menor a los 200 metros (Cuadro 11). 


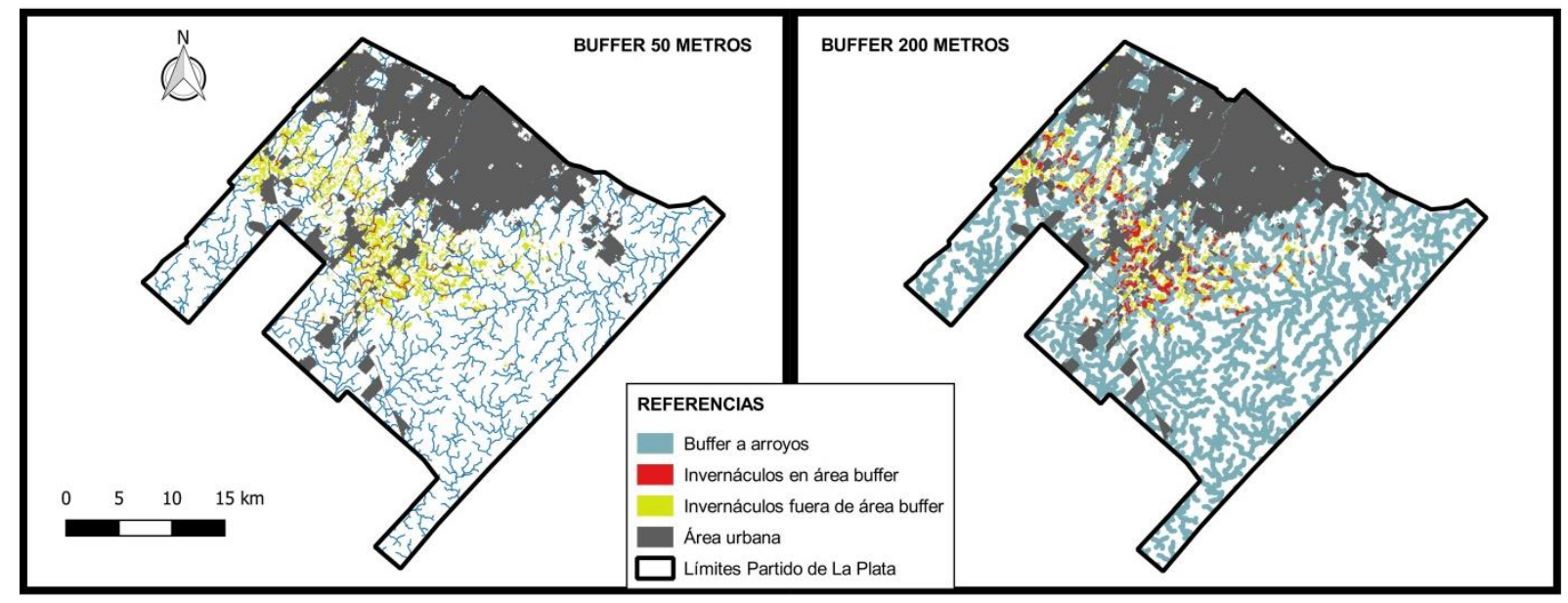

Fig 4. Distribución de Invernáculos en relación a áreas buffer de 50 y 200 metros generadas en torno a la red de drenaje (arroyos) para el Partido de La Plata, en el año 2015.

Cuadro 11. Superficie de Invernáculos (en hectáreas) y porcentaje relativo en relación al área total de Invernáculos, dentro de cuatro áreas buffer generadas a ambos lados de los arroyos presentes en el partido de La Plata.

\begin{tabular}{ccccc}
\hline & BUFFER 50 M. & BUFFER 100 M. & BUFFER 150 M. & BUFFER 200 M. \\
\hline $\begin{array}{c}\text { Superficie } \\
\text { de }\end{array}$ & $445,36 \mathrm{Ha}$. & $924 \mathrm{Ha}$. & $1439,54 \mathrm{Ha}$. & $1969,45 \mathrm{Ha}$. \\
$\begin{array}{c}\text { Invernáculos } \\
\% \text { de }\end{array}$ & 10,19 & 21,14 & 32,94 & 45,06 \\
\hline \begin{tabular}{c} 
Invernáculos \\
\hline
\end{tabular}
\end{tabular}

\subsection{Los usos del suelo y la aptitud de los suelos para la agricultura}

Al analizar la distribución de los usos Urbanización, Invernáculos y Horticultura, en relación a la aptitud agrícola de los suelos (Cuadro 12), identifiqué que del total de la superficie urbana el $21,59 \%$ se encuentra asentado sobre los suelos de clase I y el $24,35 \%$ sobre los suelos de clase II; sumando la ocupación de las cuatro clases de suelos analizadas, el 51,16\% del área urbana se asentó sobre suelos de aptitud agrícola. Por otro lado, se puede ver que los Invernáculos y la Horticultura están comenzando a ocupar suelos de menor aptitud agrícola; el 4,04\% de los Invernáculos y el 7,93\% de la Horticultura se encuentran en suelos de las clases $\mathrm{V}$ a VII, que no son aptos para uso agrícola.

Cuadro 12. Distribución de los usos Urbanización, Invernáculos y Horticultura, en relación a la aptitud agrícola de los suelos. Urb-Urbanización, Inv-Invernáculos, Horti-Horticultura, Suelos-Aptitud de suelos, Sup-superficie medida en hectáreas (Has.).

\begin{tabular}{|c|c|c|c|c|c|c|c|c|c|}
\hline \multirow{3}{*}{$\begin{array}{l}\text { APTITUD } \\
\text { DE } \\
\text { SUELOS }\end{array}$} & \multicolumn{3}{|c|}{ URBANIZACION } & \multicolumn{3}{|c|}{ INVERNACULOS } & \multicolumn{3}{|c|}{ HORTICULTURA } \\
\hline & SUP. & $\%$ & $\%$ & SUP. & $\%$ & $\%$ & SUP. & $\%$ & $\%$ \\
\hline & URB & URB & SUELOO & INV. & INV. & SUELO & HORTI. & HORTI. & SUELO \\
\hline Clase I & 4433,21 & 21,59 & 22,18 & 3553,71 & 81,31 & 17,78 & 2523,51 & 59,49 & 12,63 \\
\hline Clase II & 4999,67 & 24,35 & 31,83 & 461,37 & 10,56 & 2,94 & 1160,1 & 27,35 & 7,39 \\
\hline Clase III & 1035,55 & 5,04 & 9,06 & 168,22 & 3,85 & 1,47 & 211,77 & 4,99 & 1,85 \\
\hline Clase IV & 33,71 & 0,16 & 4,48 & 10,48 & 0,24 & 1,39 & 10,16 & 0,24 & 1,35 \\
\hline Total & 10502,14 & 51,16 & ------ & 4370,4 & 95,96 & ------- & 4241,97 & 92,07 & ------- \\
\hline
\end{tabular}


A su vez, pude identificar diversos ambientes semi-naturales presentes aún en el partido, con diverso grado de representatividad y variadas distribuciones (Fig. 1). Las Parquizaciones Arboladas (1747,53 Has., 1,97\%), y Parquizaciones Herbáceas (3666,96 Has., 4,13\%) caracterizadas por tener un fuerte manejo antrópico y estar asociadas a ambientes en proceso de urbanización o a cortinas rompeviento; el Pastizal (8240,76 Has., 9,28\%), y la Vegetación Riparia (10928,43 Has., 12,31\%), esta última si bien ocupa una superficie considerable del partido, se desarrolla en sectores marginales, con suelos bajos y actividad principalmente ganadera.

\subsection{Integrando variables a partir de un análisis multicriterio}

Como resultado del análisis multicriterio obtuve un Mapa de Aptitud de Uso Urbano (Fig. 5), un Mapa de Aptitud de Invernáculos (Fig. 6) y un Mapa de Aptitud Hortícola (Fig. 7), en los cuales se puede observar que las áreas urbanas e invernáculos se encuentran ubicadas en las zonas de aptitud alta y muy alta para dichos usos, mientras que en el caso de la horticultura, sólo un valor cercano a la mitad de dicha cobertura se encuentra en la zona de alta aptitud para dicho uso. En la elaboración de los mapas de aptitud de uso, los valores de CR obtenidos de las matrices de comparación por pares estuvieron todos dentro de los valores aceptables (aptitud de uso urbano $C R=0.03$, aptitud de invernáculos $C R=0.03$ y aptitud hortícola $\mathrm{CR}=0.05$ ).

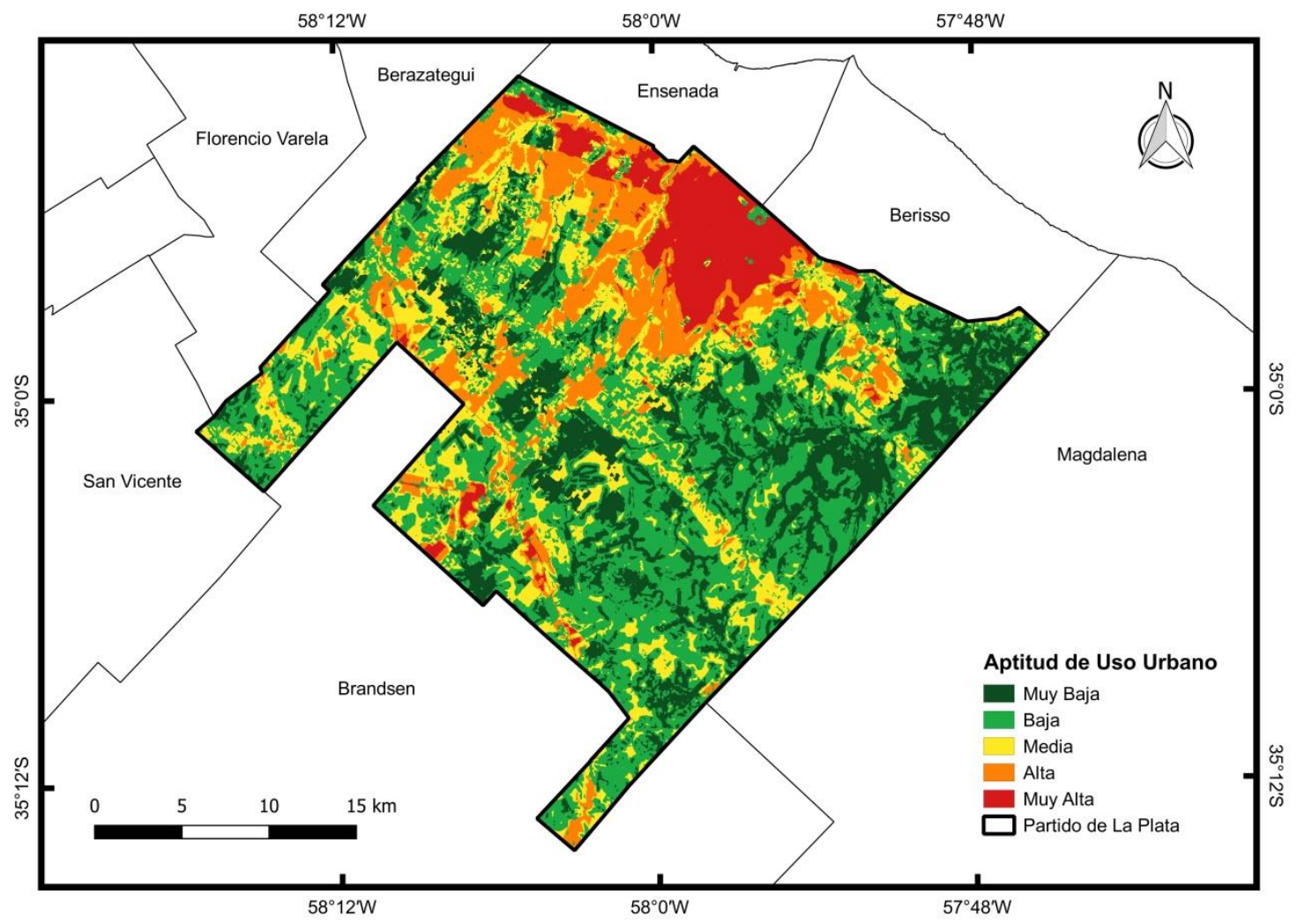

Fig 5. Mapa de aptitud de uso urbano para el Partido de La Plata 


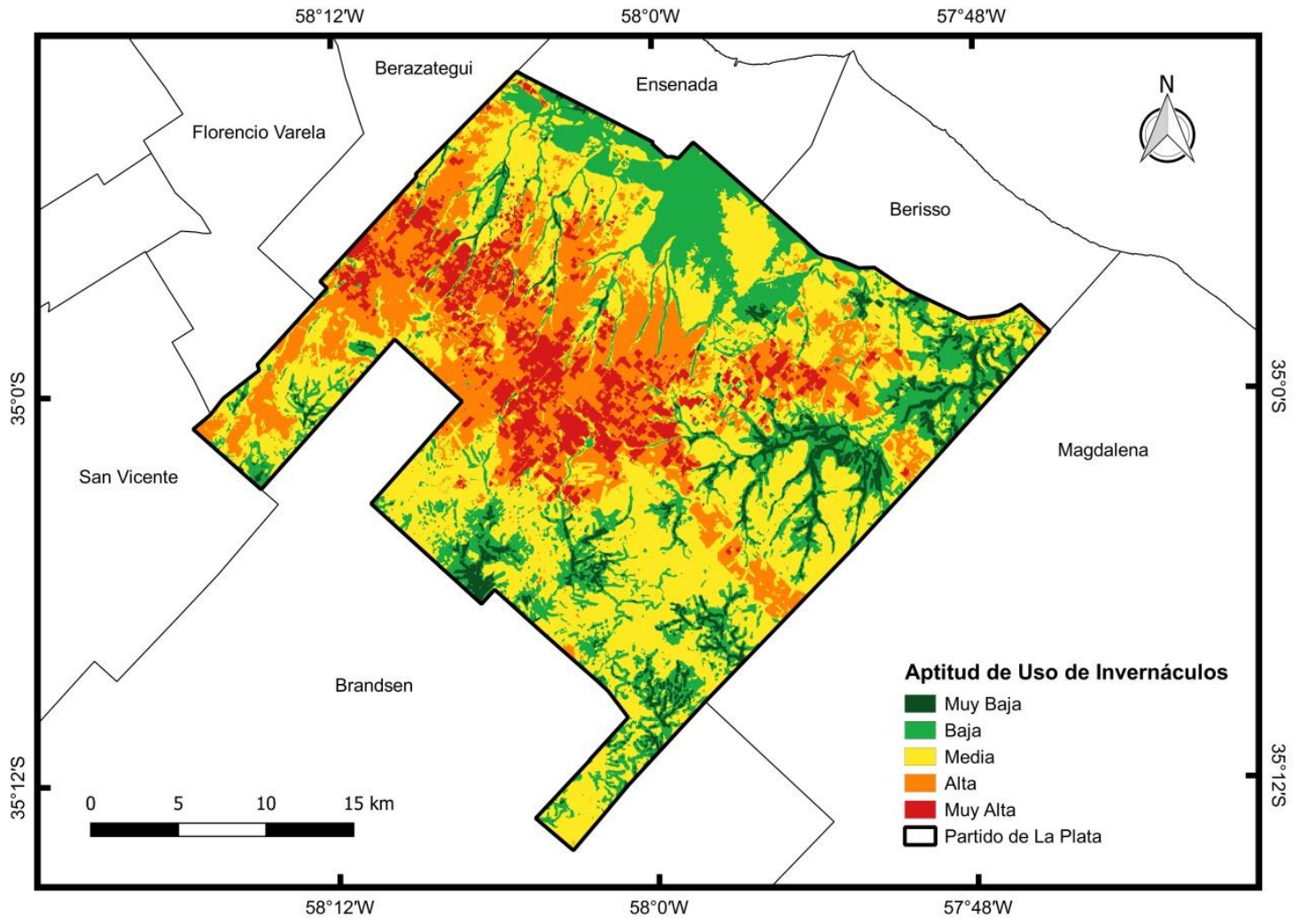

Fig 6. Mapa de aptitud de invernáculos para el Partido de La Plata

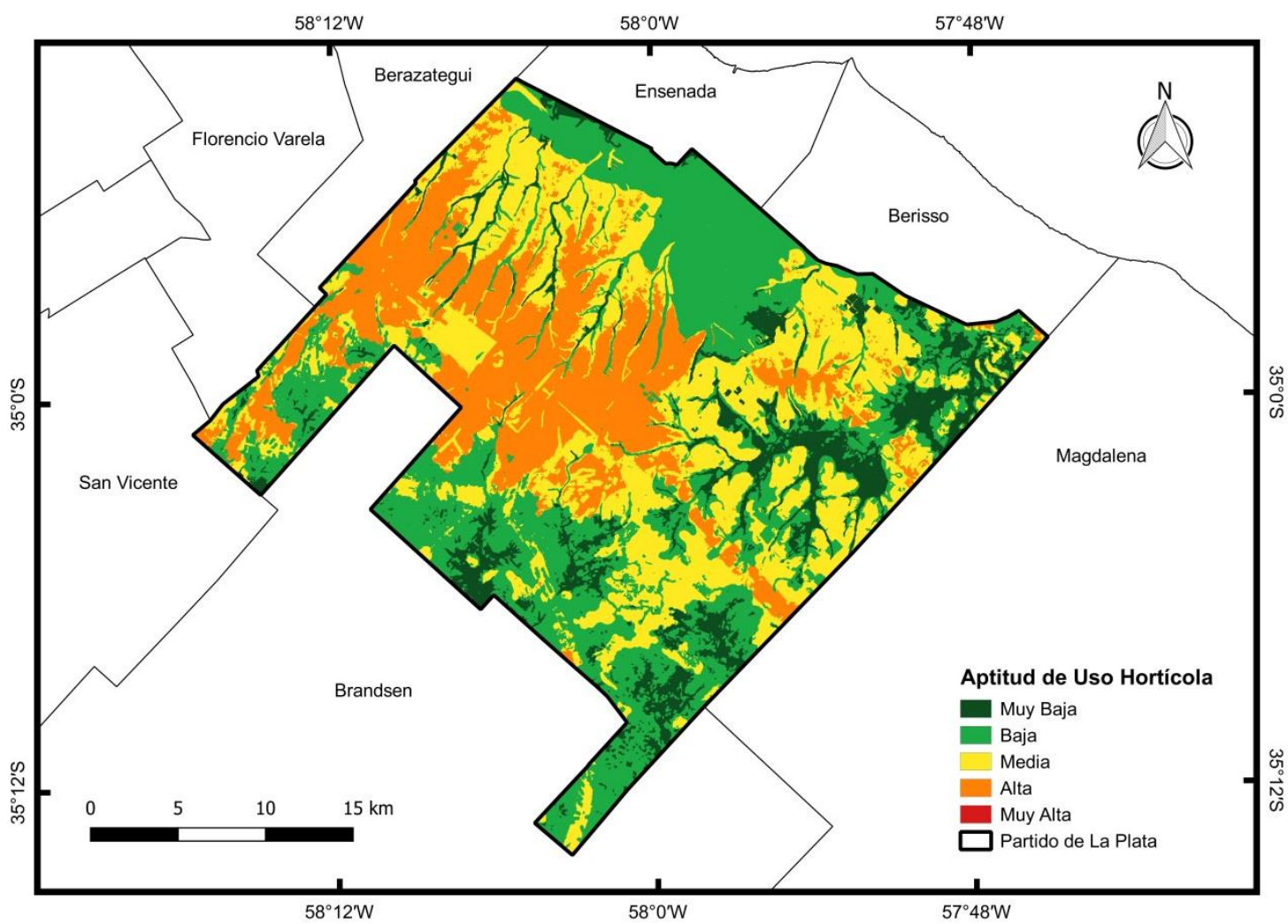

Fig 7. Mapa de aptitud hortícola para el Partido de La Plata

Al analizar el Mapa de Aptitud de Uso Urbano, identifiqué que el área con aptitud de uso urbano alta ocupaba una superficie de 11541.69 ha. y el área de aptitud muy alta 165 Lic. Carolina Baldini 
ocupaba 6458.18 ha. Considerando en conjunto estas dos áreas, al identificar los usos del suelo reales existentes para el año 2015 en dicha área, observé que el $90.8 \%$ de dicha superficie estaba efectivamente urbanizada; representando el $79.61 \%$ del área urbana total existente para el año 2015. El 9.2\% restante de la superficie con aptitud para uso urbano alta y muy alta, estaba ocupado principalmente por Ganadería y en menor medida Pastizales (Fig. 8, Cuadro 13). Al analizar la vegetación presente en la zona de mayor aptitud de uso urbano, se puede ver que la vegetación espontánea representaba el $1.29 \%$ de la superficie total de esta cobertura en el partido de La Plata, y que la vegetación antrópica representaba el $0.92 \%$ de su superficie total. En el área de aptitud urbana media, en cambio, solo el $22.5 \%$ estaba efectivamente urbanizado, mientras que un $45.19 \%$ estaba ocupado por Ganadería y un $23.89 \%$ por Pastizales (Fig. 9, Cuadro 13). 


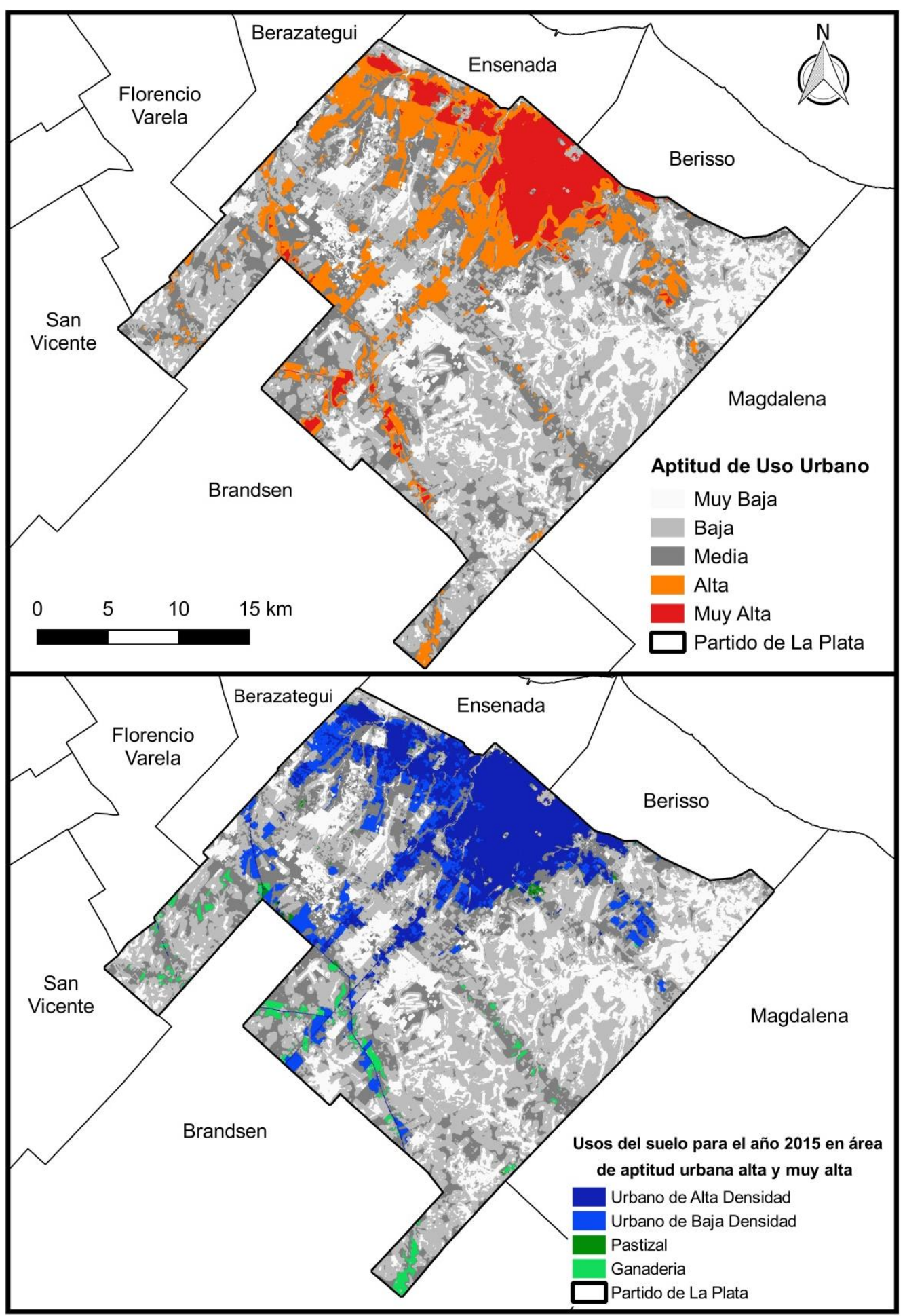

Fig 8. Mapa delimitando aptitud de uso urbano alto y muy alto, y usos del suelo presentes en esa área en el año 2015.

Cuadro 13. Superficie de usos del suelo en áreas de aptitud urbana media, alta y muy alta; medida en hectáreas ( $\mathrm{Ha}$.).

\begin{tabular}{|c|c|c|c|c|c|c|}
\hline APTITUD USO URBANO & ALTA & MUY ALTA & \multirow[b]{2}{*}{ TOTAL } & \multirow[b]{2}{*}{$\%$} & \multicolumn{2}{|c|}{ MEDIA } \\
\hline $\begin{array}{l}\text { CATEGORIAAS DE USO DEL } \\
\text { SUELO PARA EL ANO } 2015\end{array}$ & HA. & HA. & & & HA. & $\%$ \\
\hline Agricultura & 2.76 & 0.02 & 2.78 & 0.02 & 25.93 & 0.15 \\
\hline Agua & 5.97 & 0.74 & 6.71 & 0.04 & 22.1 & 0.13 \\
\hline ArbolesyArbustos & 11.74 & 2.3 & 14.04 & 0.08 & 76.27 & 0.44 \\
\hline Ganaderia & 1324.48 & 5.45 & 1329.93 & 7.39 & 7855.27 & 45.19 \\
\hline 167 Lic. Carolina Baldini & & & is docto & Terri & o en mo & niento \\
\hline
\end{tabular}




\begin{tabular}{lcccccc}
\hline Horticultura & 7.85 & 0.31 & 8.16 & 0.05 & 69.41 & 0.40 \\
\hline Invernaculos & 11.45 & 0.02 & 11.47 & 0.06 & 83.17 & 0.48 \\
\hline ParquizacionesArboladas & 11.59 & 9.47 & 21.06 & 0.12 & 59.21 & 0.34 \\
\hline ParquizacionesHerbaceas & 22.56 & 6.05 & 28.61 & 0.16 & 1009.23 & 5.81 \\
\hline Pastizal & 209.26 & 5.7 & 214.96 & $\mathbf{1 . 1 9}$ & 4153.82 & $\mathbf{2 3 . 8 9}$ \\
\hline PlantacionesForestales & 0.86 & 0.19 & 1.05 & 0.01 & 4.08 & 0.02 \\
\hline UrbanizacionAltaDensidad & 5168.78 & 5807.73 & 10976.51 & $\mathbf{6 0 . 9 8}$ & 1134.92 & $\mathbf{6 . 5 3}$ \\
\hline UrbanizacionBajaDensidad & 4747.62 & 619.34 & 5366.96 & $\mathbf{2 9 . 8 2}$ & 2775.89 & $\mathbf{1 5 . 9 7}$ \\
\hline VegetacionRiparia & 16.77 & 0.86 & 17.63 & 0.10 & 114.86 & 0.66 \\
\hline
\end{tabular}

Superficie Urbana Total del Partido de La Plata para el año $2015=20529.9$ ha.

Superficie de Vegetación Espontánea del Partido de La Plata para el año $2015=19169.19$ ha. Superficie de Vegetación Antrópica del Partido de La Plata para el año $2015=5414.49$ ha.

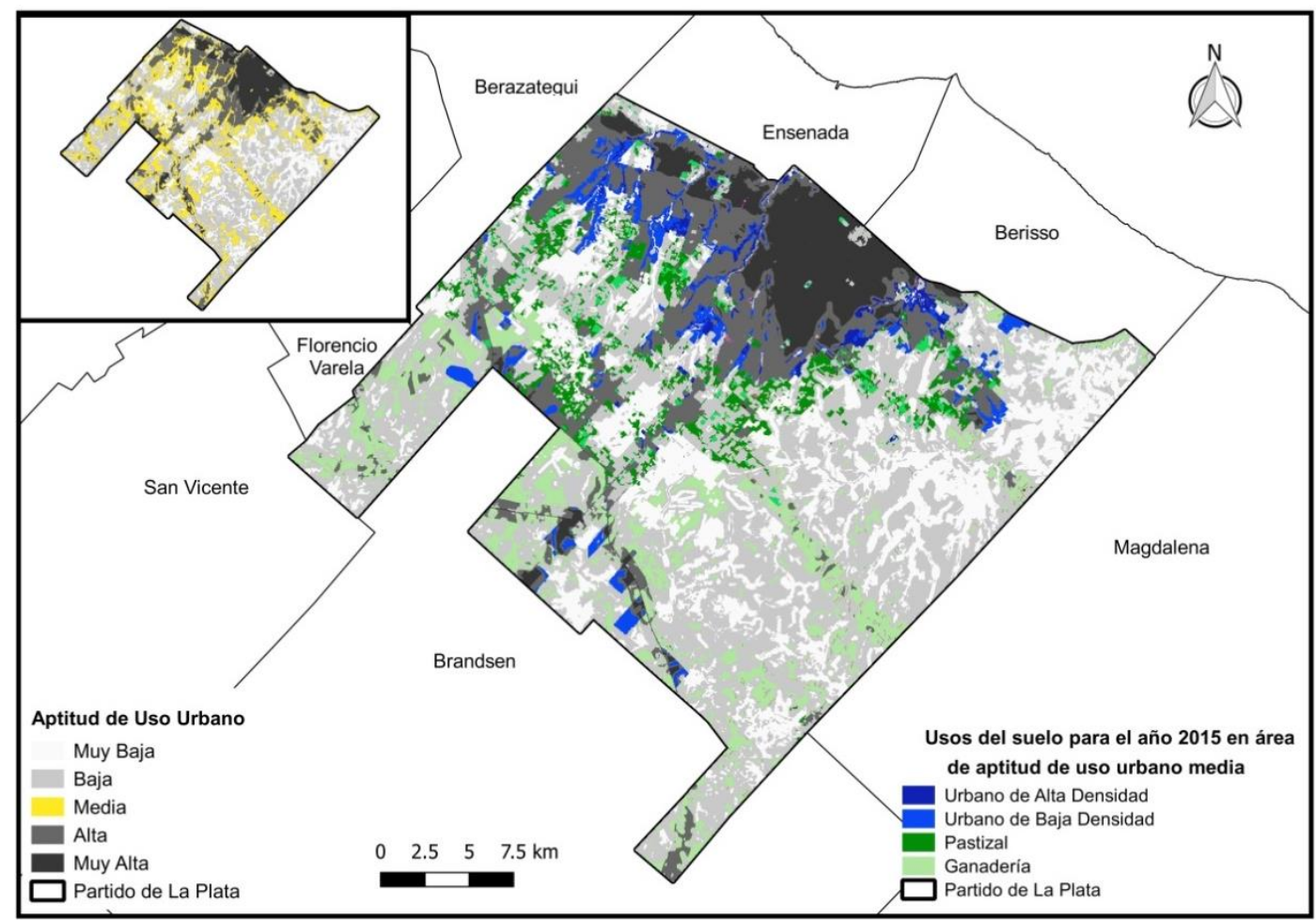

Fig 9. Mapa delimitando aptitud de uso urbano medio, y usos del suelo presentes en esa área en el año 2015.

Al analizar el Mapa de Aptitud de Uso de Invernáculos, identifiqué que el área con aptitud de uso alta ocupaba 18995.14 ha. y aquella con aptitud muy alta ocupaba 7583.93 ha. Considerando en conjunto estas dos áreas, al identificar los usos del suelo reales existentes para el año 2015 en dicha área, observé que el 16.24 \% de la misma estaba ocupada por Invernáculos, lo que representaba el $98.74 \%$ de la superficie total de Invernáculos presente en el partido en el año 2015. A su vez, de ese $98.74 \%$, el $92.07 \%$ estaba en la zona de aptitud muy alta. Considerando el total de superficie con aptitud alta y muy alta para Invernáculos, se puede ver que los principales usos del suelo presentes en esta zona fueron la Ganadería (19.22 \%), el Pastizal (18.51\%), la Urbanización (17.01\%), 
los Invernáculos (16.24 \%), la Horticultura (15.36 \%) y en menor medida las Parquizaciones Herbáceas (8.06 \%) (Fig. 10 Cuadro 14). En cuanto a la vegetación se puede ver que en la zona de aptitud alta y muy alta para Invernáculos se encontraba el $49.69 \%$ de la superficie total de vegetación antrópica presente en el partido $(26.05 \%$ en la zona de aptitud alta y $0.74 \%$ en la zona de aptitud muy alta), y el $26.79 \%$ del total de vegetación espontánea ( $48.24 \%$ en la zona de aptitud alta y $1.46 \%$ en la zona de aptitud muy alta). Considerando el área con aptitud de uso media, se puede ver que solo el $0.13 \%$ de la misma estaba ocupada por Invernáculos, siendo los principales usos del suelo la Ganadería (54.4\%) y la Urbanización (22.38\%), seguidos en menor medida por el Pastizal (7.42\%) y la Agricultura (5.37\%) (Fig. 11, Cuadro 14). 


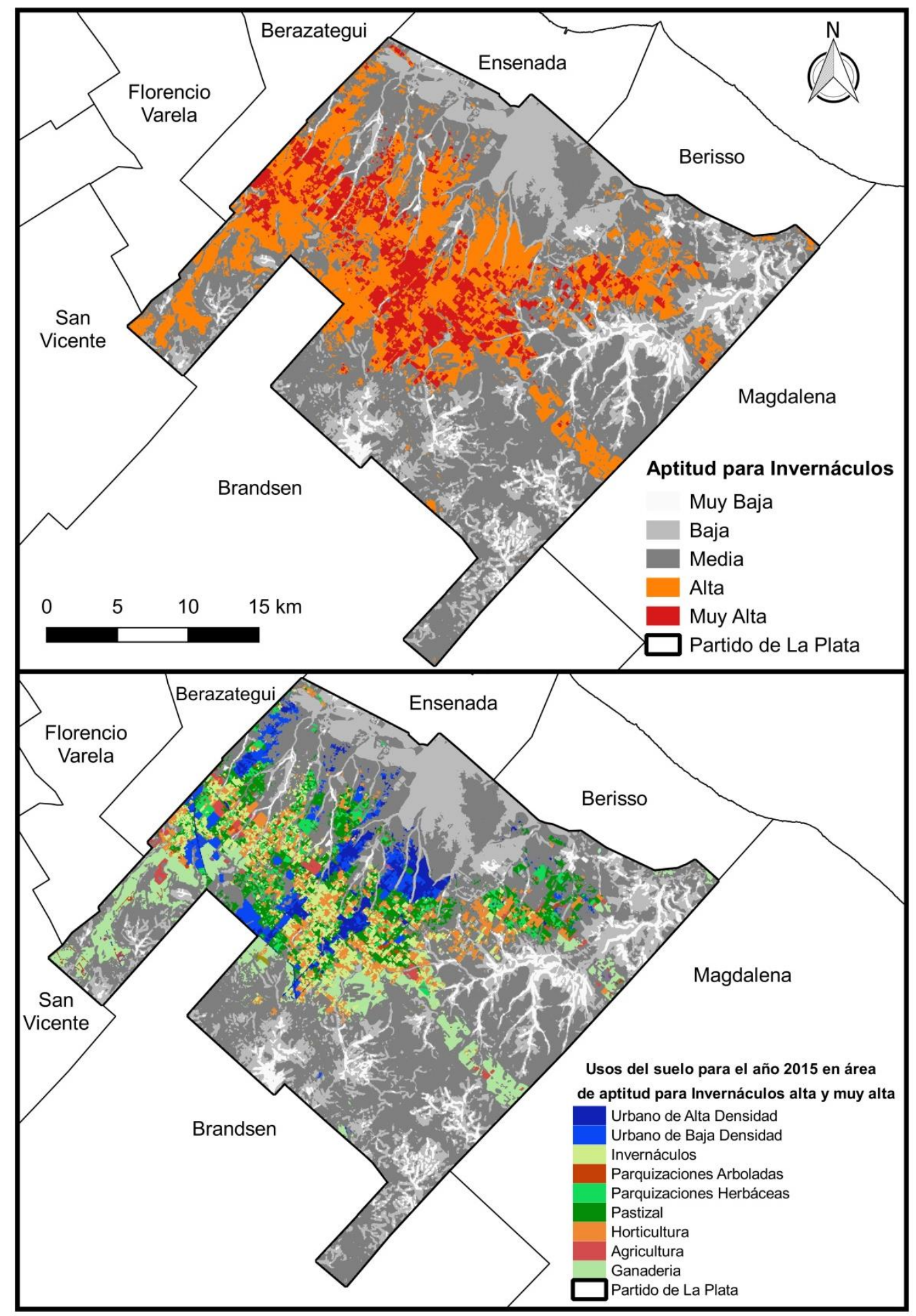

Fig 10. Mapa delimitando aptitud para invernáculos alto y muy alto, y usos del suelo presentes en esa área en el año 2015

Cuadro 14. Superficie de usos del suelo en áreas de aptitud para invernáculos media, alta y muy alta; medida en hectáreas (Ha.).

\begin{tabular}{|c|c|c|c|c|c|c|}
\hline APTITUD PARA & ALTA & MUY & \multirow{2}{*}{ TOTAL } & \multirow[b]{2}{*}{$\%$} & \multicolumn{2}{|c|}{ MEDIA } \\
\hline $\begin{array}{l}\text { CATEGORIAAS DE USO DEL } \\
\text { SUELO PARA EL AÑO } 2015\end{array}$ & HA. & HA. & & & HA. & $\%$ \\
\hline Agricultura & 661.62 & 7.57 & 669.19 & 2.52 & 2050.42 & 5.37 \\
\hline Agua & 17.46 & 1.5 & 18.96 & 0.07 & 63.88 & 0.17 \\
\hline ArbolesyArbustos & 77.23 & 5.08 & 82.31 & 0.31 & 185.64 & 0.49 \\
\hline
\end{tabular}




\begin{tabular}{lcccccc}
\hline Ganaderia & 5071.35 & 36.95 & 5108.3 & $\mathbf{1 9 . 2 2}$ & 20764.22 & $\mathbf{5 4 . 4 0}$ \\
\hline Horticultura & 810.78 & 3271.79 & 4082.57 & $\mathbf{1 5 . 3 6}$ & 144.71 & 0.38 \\
\hline Invernaculos & 291.45 & 4023.99 & 4315.44 & $\mathbf{1 6 . 2 4}$ & 49.18 & 0.13 \\
\hline ParquizacionesArboladas & 523.38 & 23.72 & 547.1 & 2.06 & 787.15 & 2.06 \\
\hline ParquizacionesHerbaceas & 2088.39 & 55.13 & 2143.52 & 8.06 & 1244.18 & 3.26 \\
\hline Pastizal & 4786.24 & 134.2 & 4920.44 & $\mathbf{1 8 . 5 1}$ & 2831.67 & $\mathbf{7 . 4 2}$ \\
\hline PlantacionesForestales & 36.98 & 0.21 & 37.19 & 0.14 & 147.58 & 0.39 \\
\hline UrbanizacionAltaDensidad & 1970.64 & 8.03 & 1978.67 & $\mathbf{7 . 4 4}$ & 4827.38 & $\mathbf{1 2 . 6 5}$ \\
\hline UrbanizacionBajaDensidad & 2529.02 & 13.36 & 2542.38 & $\mathbf{9 . 5 7}$ & 3712.87 & $\mathbf{9 . 7 3}$ \\
\hline VegetacionRiparia & 130.6 & 2.4 & 133 & 0.50 & 1359.76 & 3.56 \\
\hline
\end{tabular}

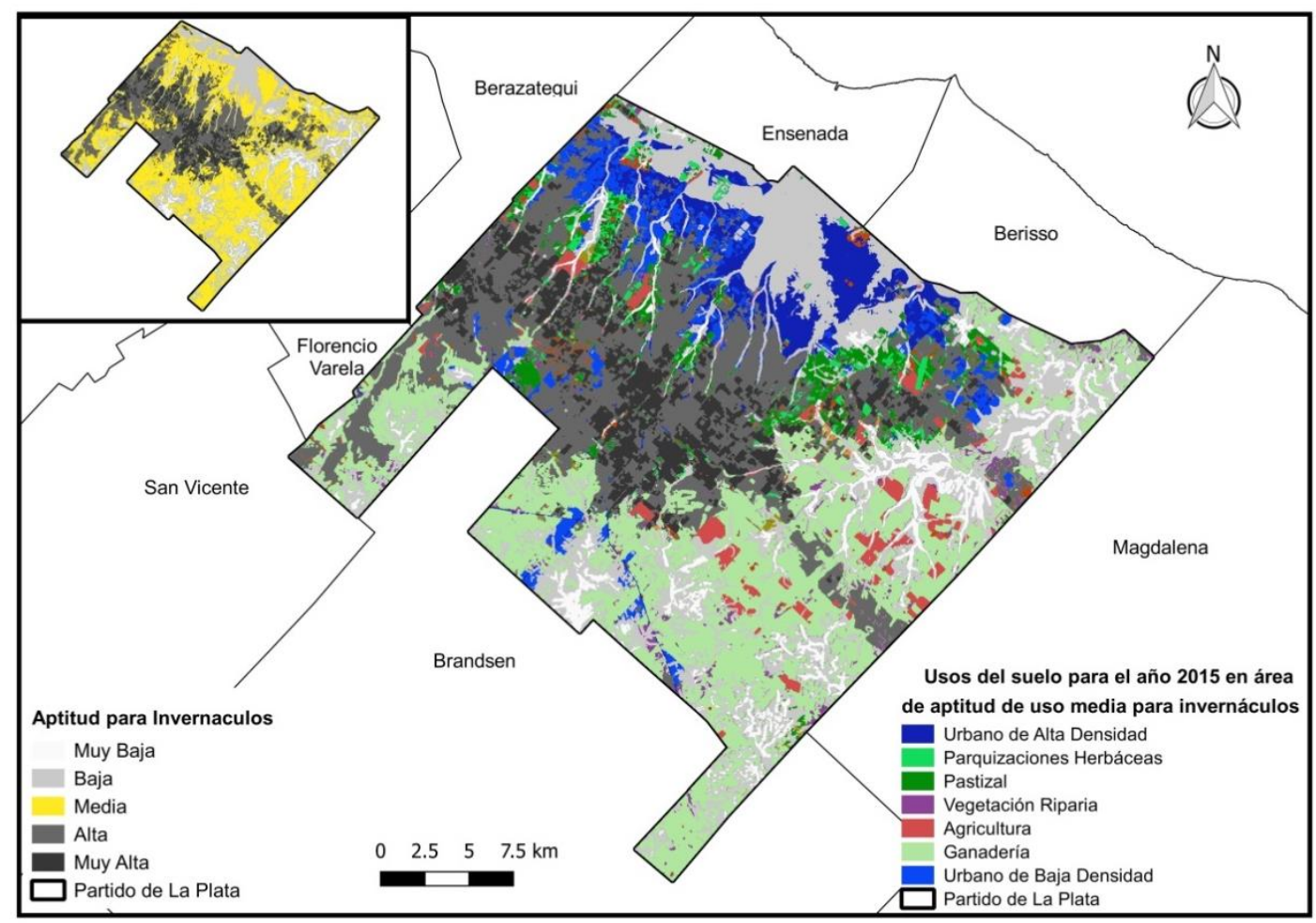

Fig 11. Mapa delimitando aptitud para invernáculos media, y usos del suelo presentes en esa área en el año 2015

Al analizar el Mapa de Aptitud Hortícola, identifiqué que el área con aptitud de uso alta representaba 20155.3 ha., no habiendo zonas con aptitud muy alta. Observé que el $54.97 \%$ del total de Horticultura presente en el partido de La Plata se encontraba en la zona de aptitud hortícola alta. Al analizar los usos del suelo reales para el año 2015, detecté que el $23.04 \%$ de la zona de aptitud alta estaba urbanizada y que el $26.82 \%$ tenía algún tipo de producción hortícola (ya sea al aire libre o bajo invernáculos). Los principales usos del suelo presentes en la zona de aptitud alta fueron, en orden de prioridad, la Urbanización (23.04\%), la Ganadería (21.07\%), los Invernáculos (15.25\%), el Pastizal (15.06\%), la Horticultura (11.57\%) y en menor medida las Parquizaciones Herbáceas (7.55\%) (Fig. 12, Cuadro 15). En cuanto a la vegetación se puede ver que en la zona de aptitud hortícola alta se 
encontraba el $38.48 \%$ de la superficie total de vegetación antrópica presente en el partido, y el $16.91 \%$ del total de vegetación espontánea. Para la zona de aptitud hortícola media, solo el $5.58 \%$ se encontraba efectivamente ocupada por dicha actividad, mientras que el $39.08 \%$ estaba bajo uso ganadero, el $21.93 \%$ se encontraba urbanizado, y un $12.33 \%$ ocupado por pastizales (Fig. 13, Cuadro 15).

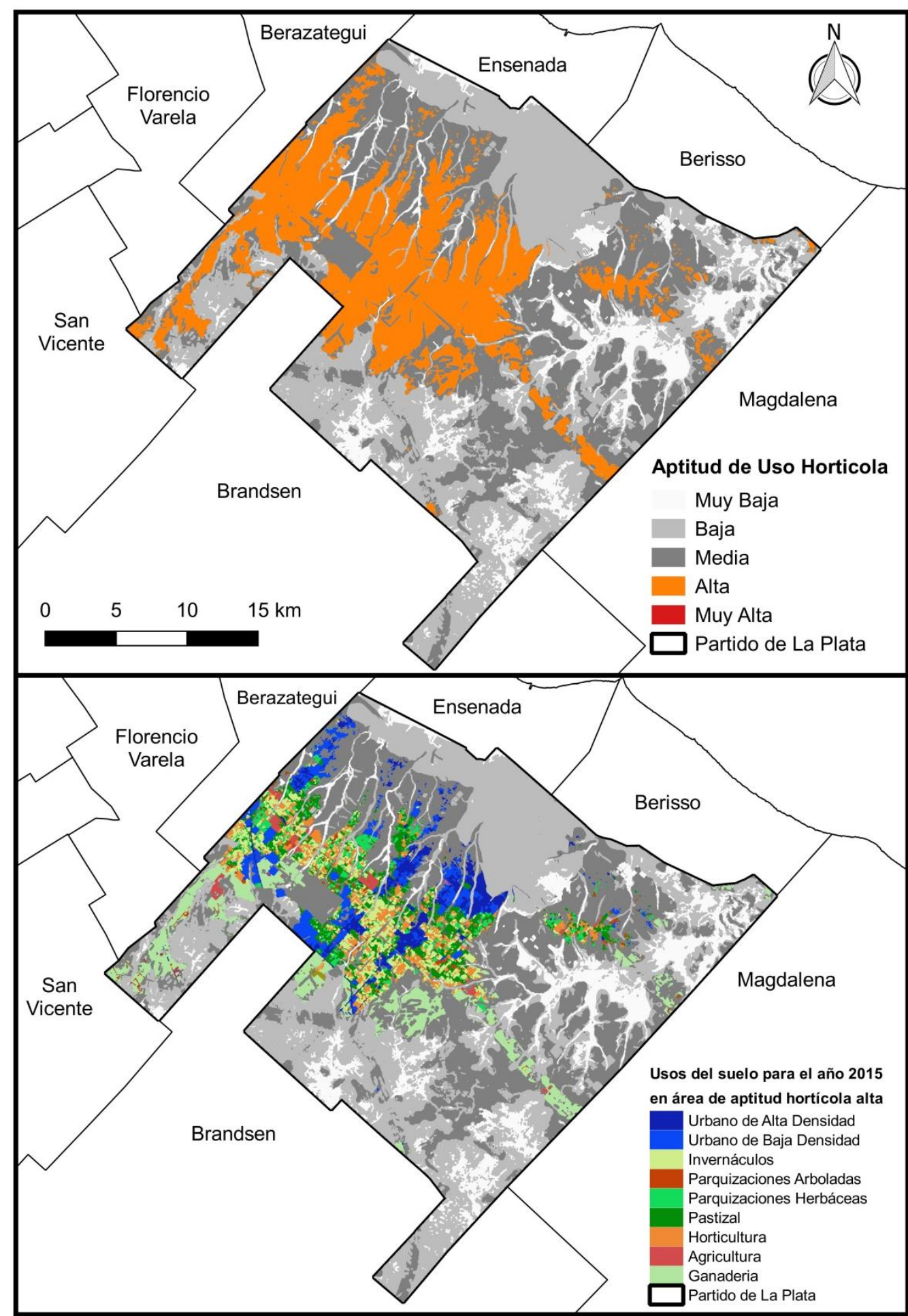

Fig 12. Mapa delimitando aptitud hortícola alta, y usos del suelo presentes en esa área en el año 2015 
Cuadro 15. Superficie de usos del suelo en áreas de aptitud hortícola media y alta; medida en hectáreas (Ha.).

\begin{tabular}{lcccc}
\multicolumn{1}{c}{ APTITUD HORTICOLA } & \multicolumn{2}{c}{ ALTA } & MEDIA \\
\hline $\begin{array}{l}\text { CATARAR DE USO DEL SUELO } \\
\text { PgNO 2015 }\end{array}$ & HA. & $\%$ & $\%$ \\
\hline Agricultura & 474.61 & 2.35 & 1426.33 & 5.19 \\
\hline Agua & 17.39 & 0.09 & 36.7 & 0.13 \\
\hline ArbolesyArbustos & 72.31 & 0.36 & 184.95 & 0.67 \\
\hline Ganaderia & 4247.13 & $\mathbf{2 1 . 0 7}$ & 10750.73 & $\mathbf{3 9 . 0 8}$ \\
\hline Horticultura & 2331.77 & $\mathbf{1 1 . 5 7}$ & 1536.22 & 5.58 \\
\hline Invernaculos & 3073.83 & $\mathbf{1 5 . 2 5}$ & 1107.82 & 4.03 \\
\hline ParquizacionesArboladas & 562.08 & 2.79 & 702.75 & 2.55 \\
\hline ParquizacionesHerbaceas & 1521.24 & $\mathbf{7 . 5 5}$ & 1493.7 & 5.43 \\
\hline Pastizal & 3035.83 & $\mathbf{1 5 . 0 6}$ & 3392.89 & $\mathbf{1 2 . 3 3}$ \\
\hline PlantacionesForestales & 43.16 & 0.21 & 109.88 & 0.40 \\
\hline UrbanizacionAltaDensidad & 1964.34 & $\mathbf{9 . 7 5}$ & 2708.46 & $\mathbf{9 . 8 5}$ \\
\hline UrbanizacionBajaDensidad & 2678.56 & $\mathbf{1 3 . 2 9}$ & 3324.5 & $\mathbf{1 2 . 0 9}$ \\
\hline VegetacionRiparia & 133.05 & $\mathbf{0 . 6 6}$ & 733.13 & 2.67 \\
\hline
\end{tabular}

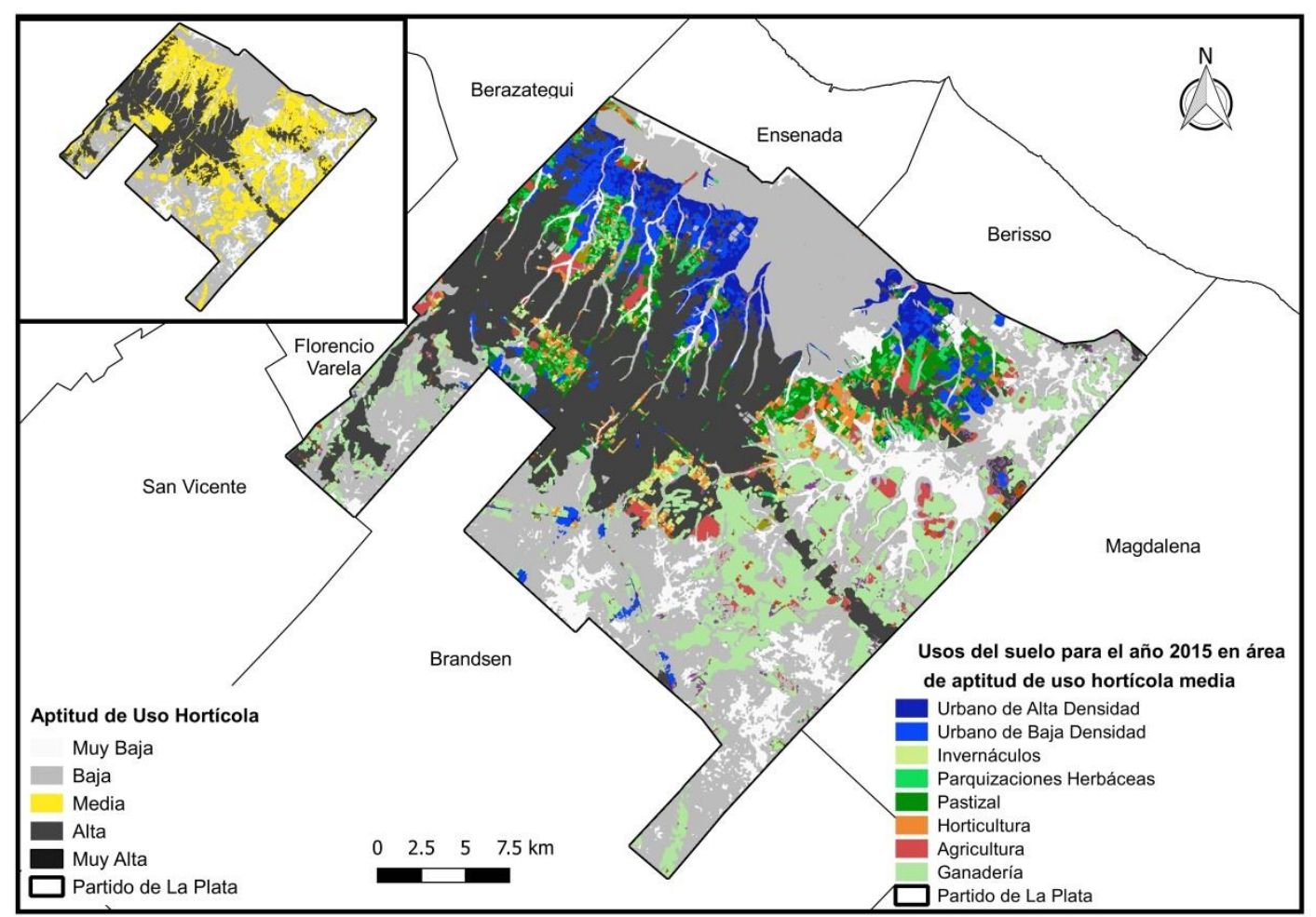

Fig 13. Mapa delimitando aptitud hortícola media, y usos del suelo presentes en esa área en el año 2015 
Como resultado de la suma de los mapas de aptitud de uso categorizados obtuve un Mapa de Conflictos, con 10 categorías en función de las aptitudes de uso baja, media y alta de cada uso (Urbano, Invernáculos y Hortícola), cada categoría representa un valor de conflictividad diferente (Fig. 14); este mapa fue simplificado al reagrupar los 10 valores de conflictividad según el nivel de conflicto de los mismos generando un Mapa de Niveles de Conflicto, y superponer a este mapa la zona urbanizada para el año 2015, y que por lo tanto se asume como un cambio irreversible (Fig. 15a y 15b).

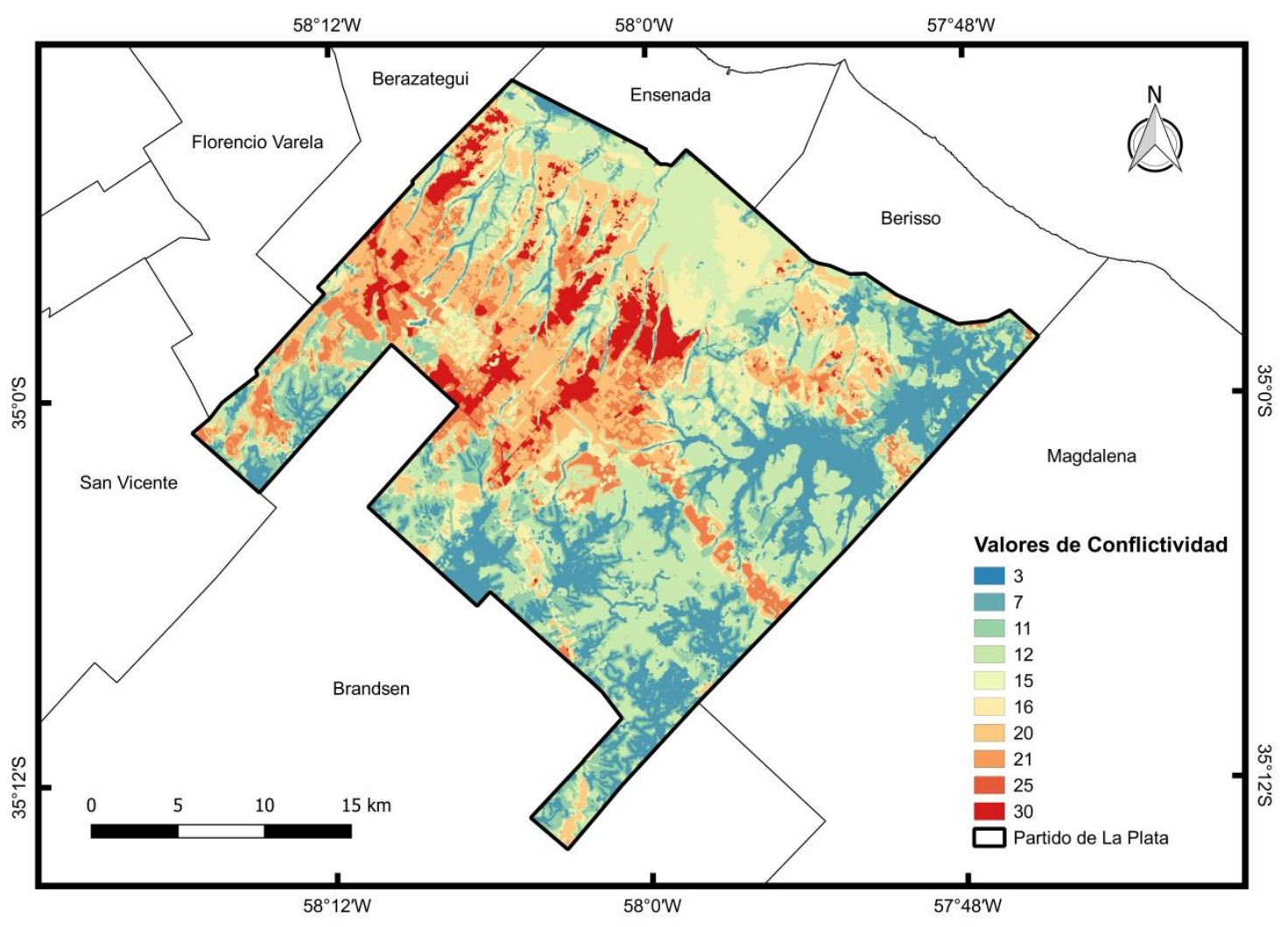

Fig 14. Mapa de conflicto. Los valores de conflictividad reflejan la superposición de aptitudes de uso en relación al grado de aptitud para cada uso y surgen de la suma de los valores de aptitud asignados a cada mapa individual. Aptitud baja $=1$, aptitud media $=5$ y aptitud alta $=$ 10. 


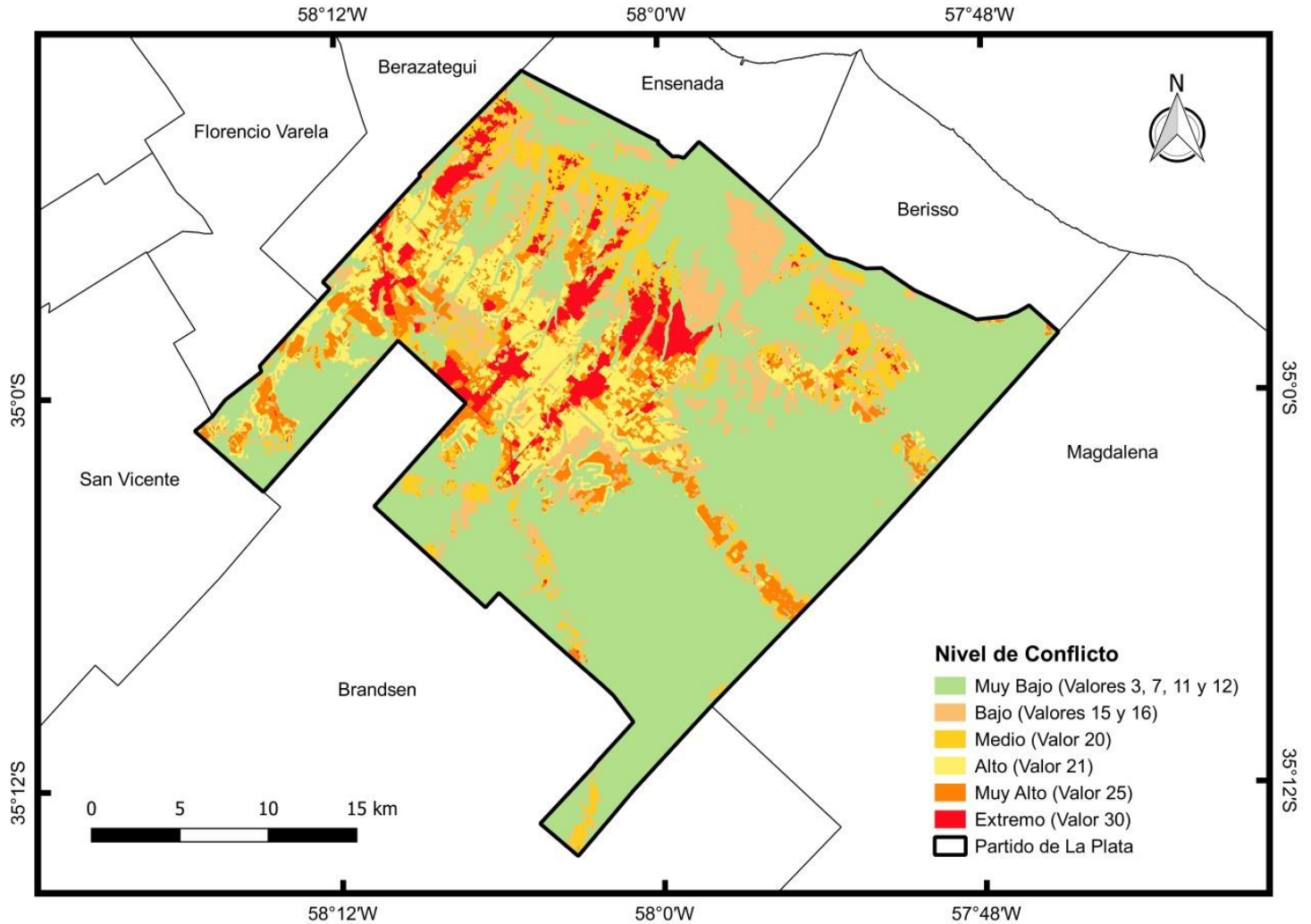

Fig 15a. Mapa de Niveles de Conflicto. Los valores de las referencias surgen de la suma de los valores de aptitud asignados a cada mapa individual. Aptitud baja $=1$, aptitud media $=$ 5 y aptitud alta $=10$.

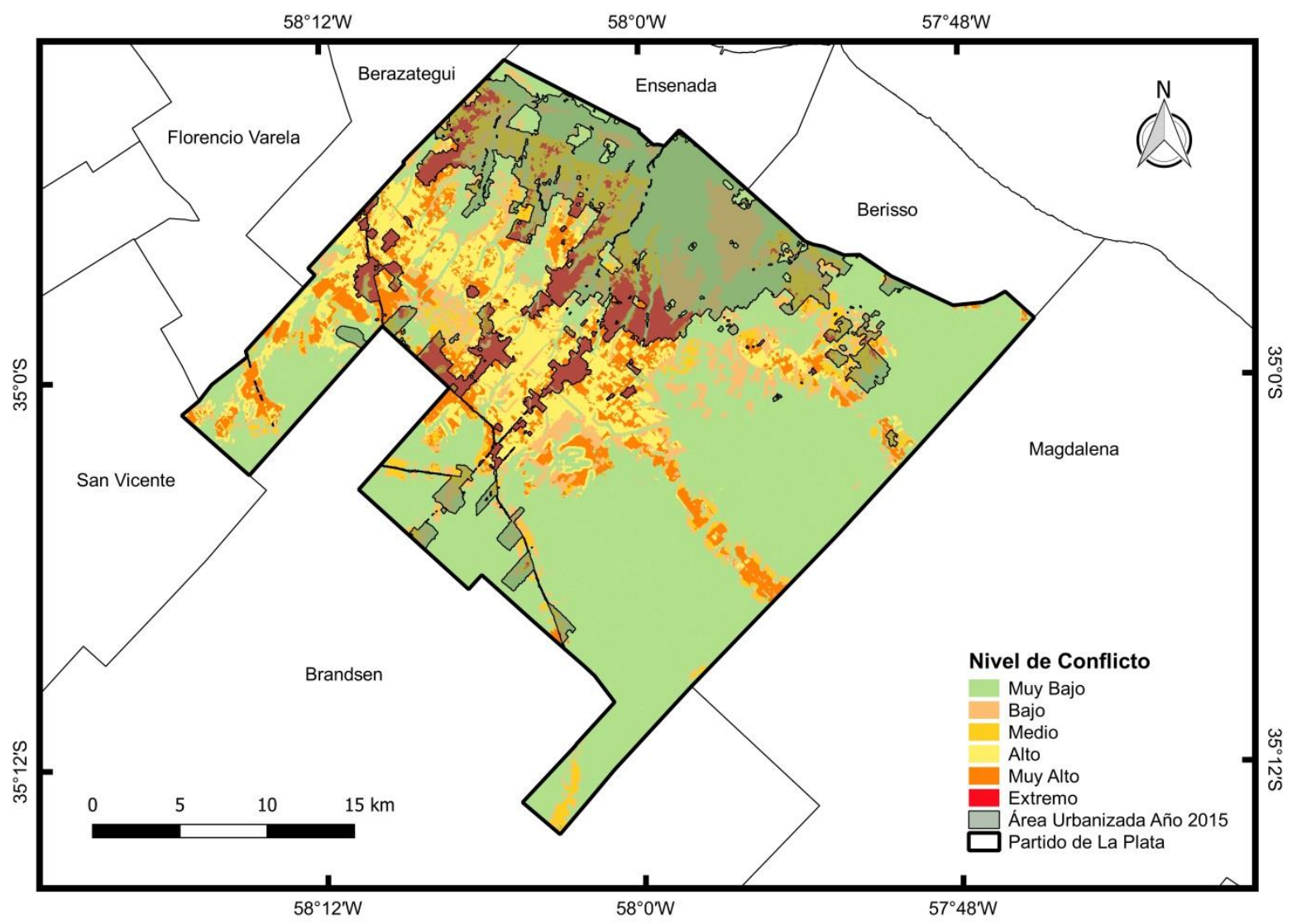


Fig 15b. Mapa de Niveles de Conflicto con delimitación de la zona urbana para el año 2015. Los valores de las referencias surgen de la suma de los valores de aptitud asignados a cada mapa individual. Aptitud baja $=1$, aptitud media $=5$ y aptitud alta $=10$.

A partir del Mapa de Niveles de Conflicto decidí analizar con más detalle las zonas con nivel de conflicto extremo, muy alto, alto y medio; estas zonas incluyen situaciones en las que los tres usos del suelo tienen aptitud alta, donde dos de los usos tienen aptitud alta y donde uno de los usos tiene aptitud alta y los otros dos tienen aptitud media (ver cuadro 7). Analicé el uso del suelo real en cada una de estas zonas para el año 2015. En la Fig. 16 se puede ver el mapa con los usos del suelo presentes en el año 2015 en la zona con nivel de conflicto extremo, donde la aptitud de uso urbano, hortícola y de invernáculos es alta. En ese sector del partido de La Plata observé que el 98.57\% estaba ocupado en el 2015 por Urbanización, y solo un $0.11 \%$ por Horticultura y un $0.22 \%$ por Invernáculos (Cuadro 16).

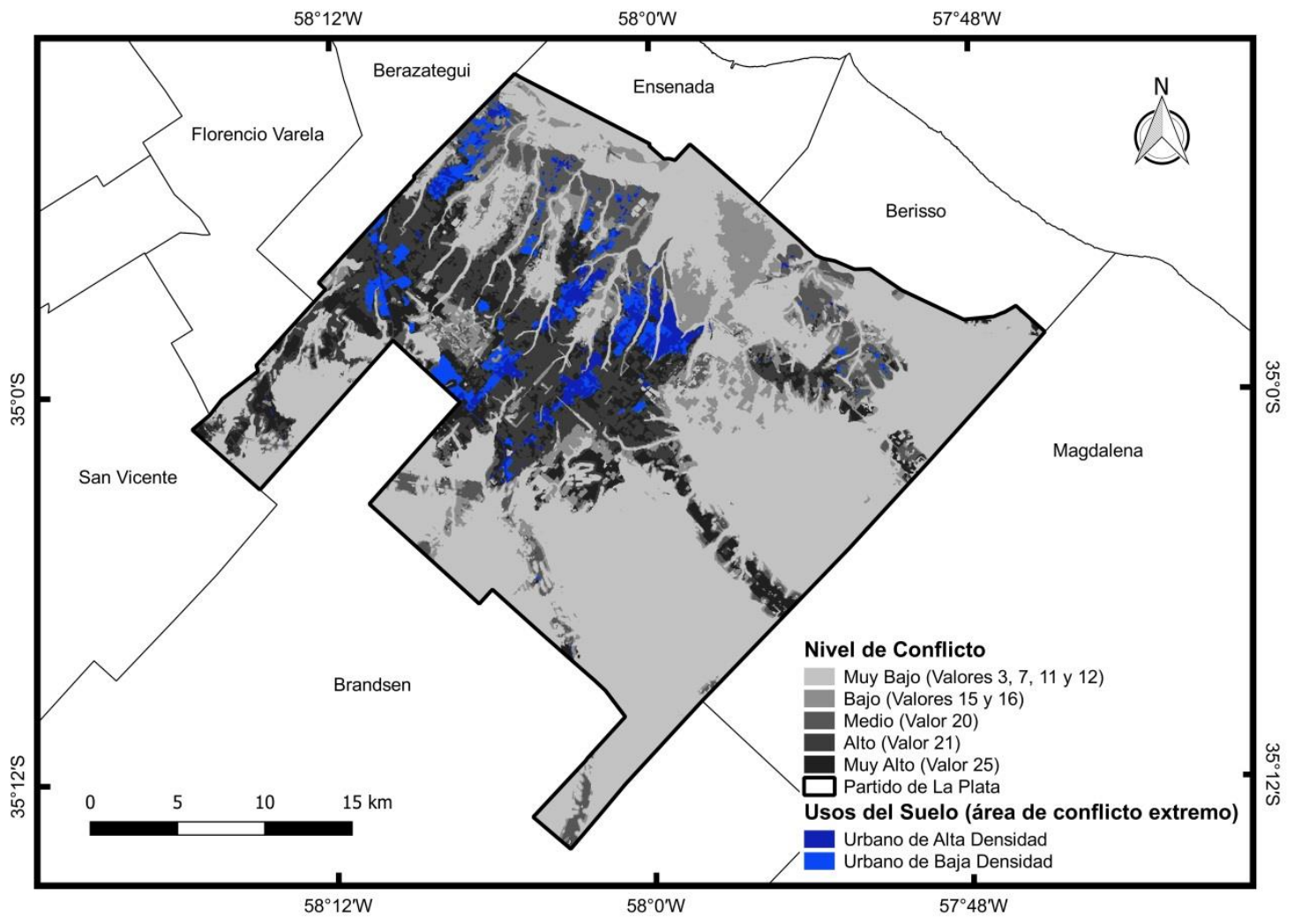

Fig 16. Mapa con los usos del suelo presentes en el año 2015, en la zona de nivel de conflicto extremo, donde la aptitud de uso urbano, hortícola y de invernáculos es alta.

Cuadro 16. Usos del suelo para el año 2015 en área con Nivel de Conflicto extremo (valor de conflictividad 30)

\begin{tabular}{lcc}
\hline \multicolumn{2}{c}{ AREA DE NIVEL DE CONFLICTO EXTREMO (VALOR DE CONFLICTIVIDAD 30) } \\
\hline USOS DEL SUELO (ANO 2015) & HA & $\%$ \\
\hline Agricultura & 0.37 & 0.01 \\
\hline Agua & 0.44 & 0.01 \\
\hline Árboles y Arbustos & 3.14 & 0.07 \\
\hline Ganadería & 4.36 & 0.10 \\
\hline
\end{tabular}




\begin{tabular}{lcc}
\hline Horticultura & 4.69 & 0.11 \\
\hline Invernáculos & 9.16 & 0.22 \\
\hline Parquizaciones Arboladas & 4.23 & 0.10 \\
\hline Parquizaciones Herbáceas & 8.1 & 0.19 \\
\hline Pastizal & 24.99 & 0.59 \\
\hline Urbanización Alta Densidad & $\mathbf{1 8 7 7 . 1}$ & 44.47 \\
\hline Urbanización Baja Densidad & $\mathbf{2 2 8 3 . 6 5}$ & 54.10 \\
\hline Vegetación Riparia & 0.97 & 0.02 \\
\hline
\end{tabular}

Al analizar el área con nivel de conflictividad muy alto (valor de conflictividad de 25), donde se solapan dos zonas de aptitud alta y una zona de aptitud media, se puede ver que los principales usos del suelo para el año 2015 fueron la Ganadería (44.79\%), el Pastizal (36.09\%), y en menor medida las Parquizaciones Herbácea (9.73\%) y la Urbanización (6.18\%) (Fig. 17, Cuadro 17). Por otro lado, analicé en qué proporción contribuyó la Aptitud de Uso Urbano Alta/Muy alta al valor de conflictividad de 25, y encontré que representa sólo el $6.35 \%$ del área.

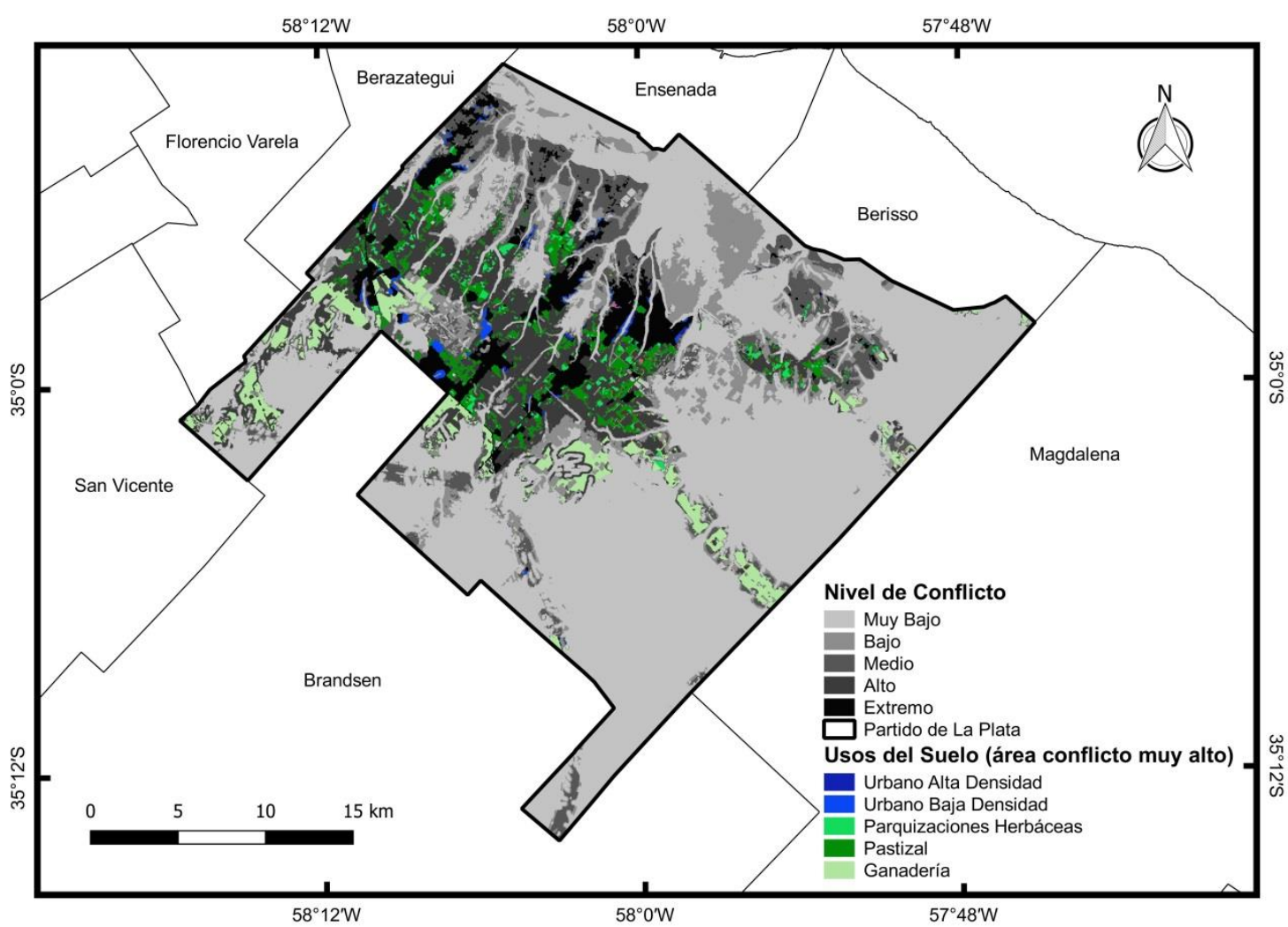

Fig 17. Mapa con los usos del suelo presentes en el año 2015, en la zona de nivel de conflicto muy alto, donde se solapan dos zonas de aptitud alta y una zona de aptitud media.

Cuadro 17. Usos del suelo para el año 2015 en área con Nivel de Conflicto muy alto (valor de conflictividad 25)

\begin{tabular}{lcc}
\hline AREA DE NIVEL DE CONFLICTO MUY ALTO (VALOR DE CONFLICTIVIDAD 25) \\
\hline USOS DEL SUELO (ANO 2015) & HA & $\%$ \\
\hline Agricultura & 13.07 & 0.19 \\
\hline Agua & 1.46 & 0.02 \\
\hline
\end{tabular}




\begin{tabular}{lcc}
\hline Árboles y Arbustos & 25.26 & 0.38 \\
\hline Ganadería & 3013.36 & 44.79 \\
\hline Horticultura & 50.04 & 0.74 \\
\hline Invernáculos & 68.81 & 1.02 \\
\hline Parquizaciones Arboladas & 31.59 & 0.47 \\
\hline Parquizaciones Herbáceas & 654.87 & 9.73 \\
\hline Pastizal & 2427.82 & 36.09 \\
\hline Plantaciones Forestales & 0.37 & 0.01 \\
\hline Urbanización Alta Densidad & $\mathbf{7 0 . 3 7}$ & 1.05 \\
\hline Urbanización Baja Densidad & $\mathbf{3 4 5 . 1 7}$ & 5.13 \\
\hline Vegetación Riparia & $\mathbf{2 5 . 5 8}$ & 0.38 \\
\hline
\end{tabular}

En cuanto al área con nivel de conflicto alto (valor de conflictividad de 21), donde se solapan dos aptitudes de uso altas y una baja, observé que los principales usos del suelo en el año 2015 en esa zona fueron los Invernáculos (33.09\%), la Horticultura (25.13\%) y la Ganadería (13.58\%), seguidos en menor medida por las Parquizaciones Herbáceas (8.92\%), el Pastizal (7.10\%), las Parquizaciones Arboladas (5.14\%) y la Agricultura (4.92\%). Por otro lado, analicé en qué proporción contribuyó cada aptitud de uso del suelo alta al valor de conflictividad de 21 , y encontré que la aptitud de uso urbano alta representaba solo $14.18 \mathrm{Ha}$. (0.16\% del área total), lo que indica que en esta zona la mayor superposición de aptitud de uso alta estaba dada por la aptitud de uso hortícola y para invernáculos (Fig.18, Cuadro 18).

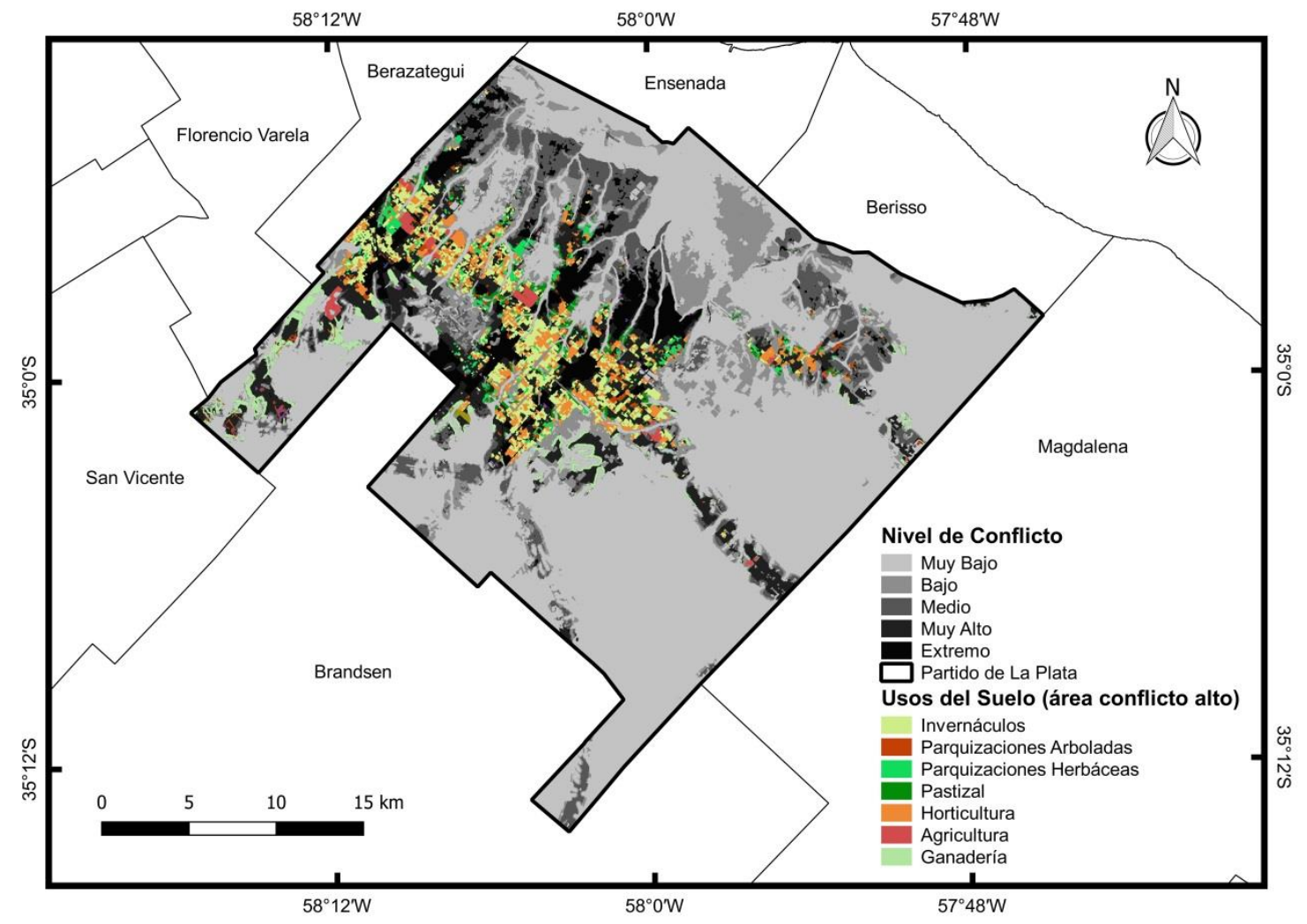

Fig 18. Mapa con los usos del suelo presentes en el año 2015, en la zona de nivel de conflicto alto, donde se solapan dos aptitudes de uso altas y una baja. Niveles de gris crecientes en el mapa de base reflejan niveles de conflicto crecientes. 
Cuadro 18. Usos del suelo para el año 2015 en área con Nivel de Conflicto alto (valor de conflictividad 21)

\begin{tabular}{lcc}
\multicolumn{1}{c}{ AREA DE NIVEL DE CONFLICTO ALTO (VALOR DE CONFLICTIVIDAD 21) } \\
\hline USOS DEL SUELO (ANO 2015) & HA & $\%$ \\
\hline Agricultura & 445.48 & 4.92 \\
\hline Agua & 14.91 & 0.16 \\
\hline Árboles y Arbustos & 39.59 & 0.44 \\
\hline Ganadería & 1229.09 & 13.58 \\
\hline Horticultura & 2274.17 & 25.13 \\
\hline Invernáculos & 2993.79 & 33.09 \\
\hline Parquizaciones Arboladas & 464.94 & 5.14 \\
\hline Parquizaciones Herbáceas & 807.11 & 8.92 \\
\hline Pastizal & 642.54 & 7.10 \\
\hline Plantaciones Forestales & 35.75 & 0.40 \\
\hline Urbanización Alta Densidad & 11.37 & 0.13 \\
\hline Urbanización Baja Densidad & 19.94 & 0.22 \\
\hline Vegetación Riparia & 69.95 & 0.77
\end{tabular}

Por último, al analizar el área con nivel de conflicto medio (valor de conflictividad de 20), donde se solapan dos aptitudes de uso medias y una alta, observé que los principales usos del suelo en el año 2015 en esa zona fueron la Urbanización (60.85\%), la Ganadería (19.40\%) y el Pastizal (15.44\%), seguidos en menor medida por las Parquizaciones Herbáceas (3.25\%) (Fig. 19). Al analizar en qué proporción contribuyó cada aptitud de uso del suelo alta al valor de conflictividad de 20 , encontré que la aptitud de uso urbano alta representaba el $72.85 \%$ (4847.92 ha.), y que de esa superficie, 3992.04 ha. (82,35\%) eran efectivamente urbanas; el $17.65 \%$ restante se encontraba concentrado en el sur-oeste del partido, en áreas con actividad principalmente ganadera (Fig. 20). 


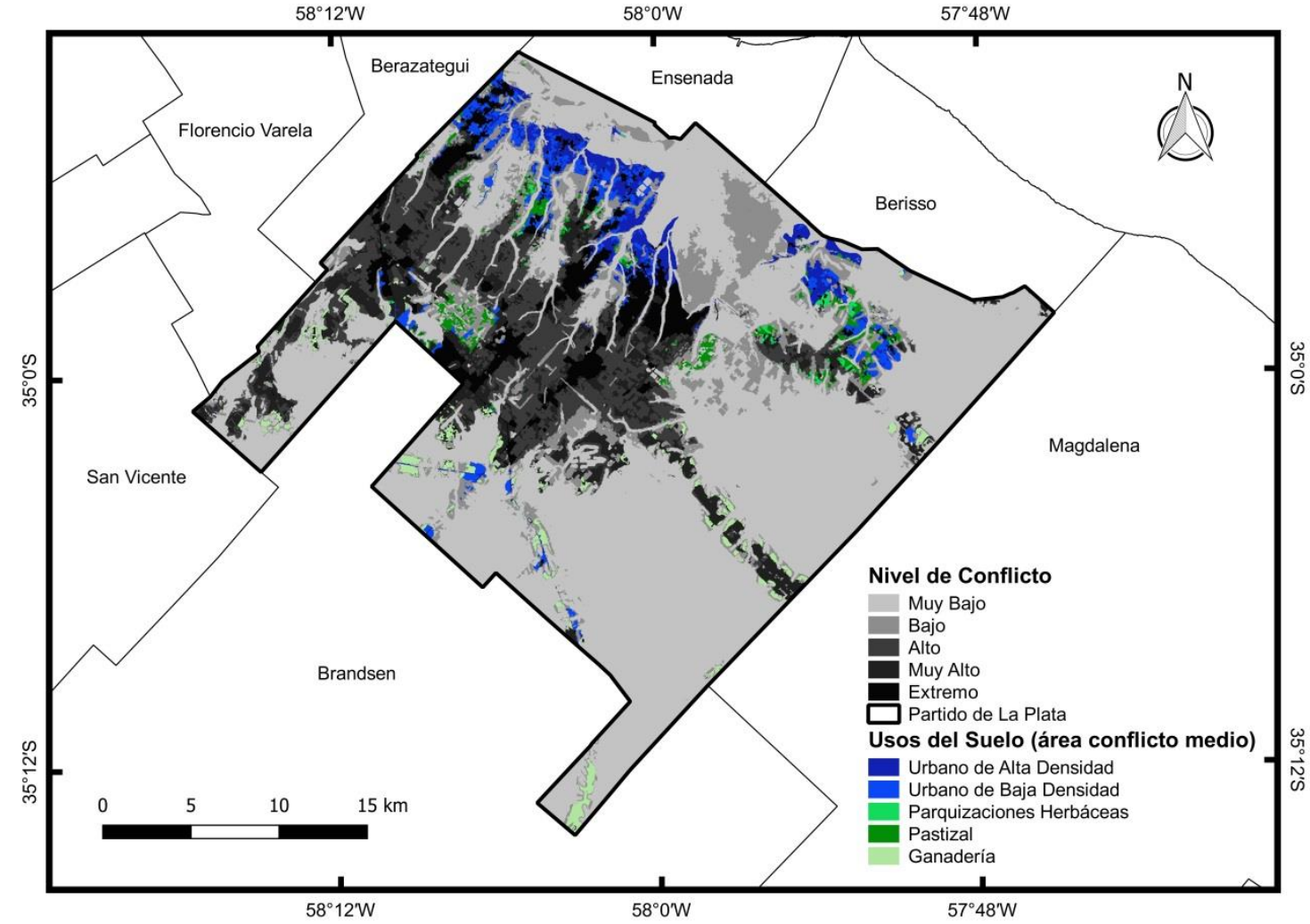

Fig 19. Mapa con los usos del suelo presentes en el año 2015, en la zona de nivel de conflicto medio, donde la aptitud de uso urbano, hortícola y de invernáculos es alta. Niveles de gris crecientes en el mapa de base reflejan niveles de conflicto crecientes.

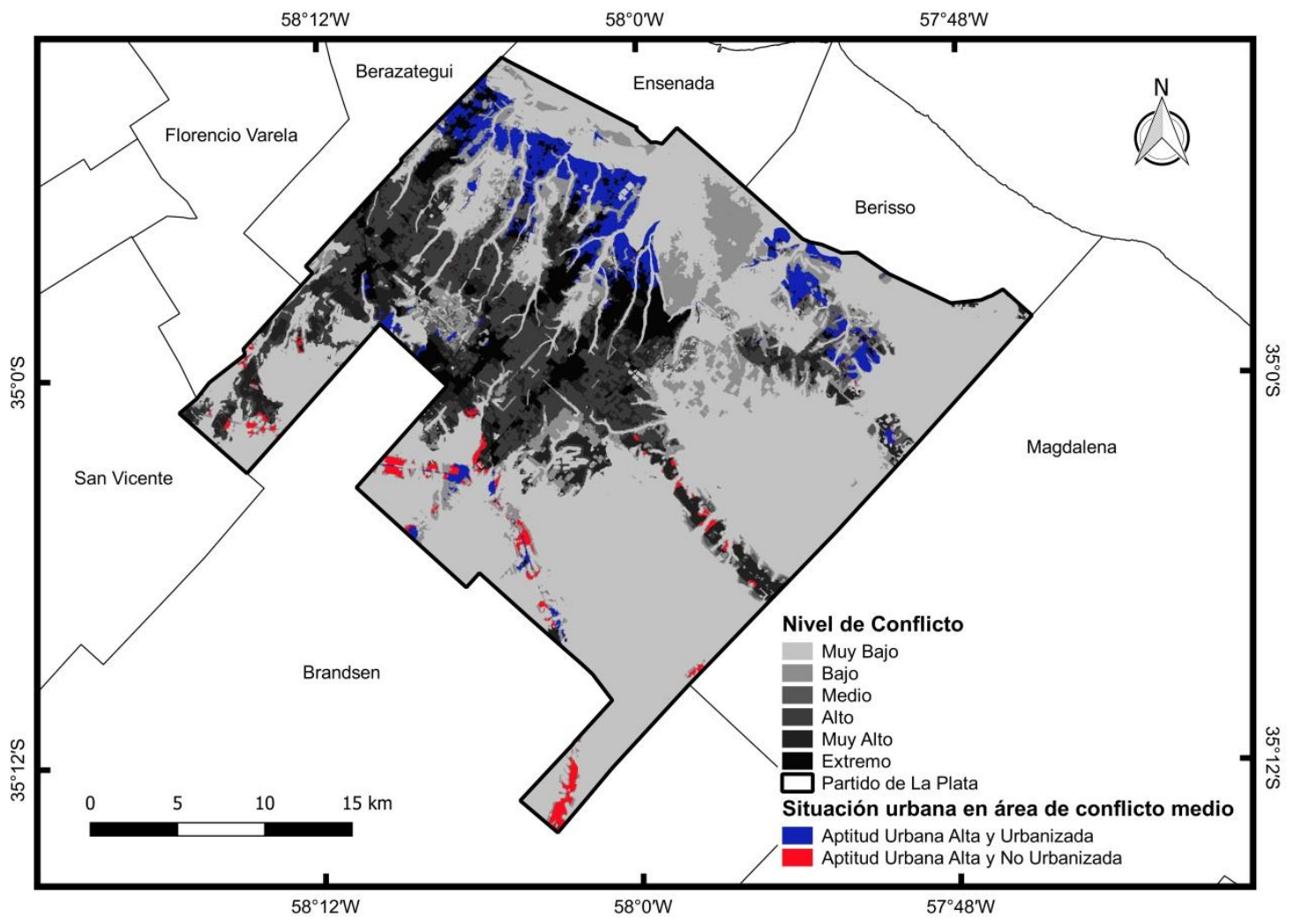

Fig 20. Zona de aptitud urbana alta, presente en el área de conflictividad media (valor 20), que aún no se encuentra urbanizada 
El mapa de coberturas/usos del suelo generado para el partido de La Plata en el año 2015, brindó una línea de base concreta para analizar la situación actual y poder generar nueva información derivada de esta, que contribuya en un futuro proceso de planificación orientado al desarrollo de un territorio productivo sustentable y resiliente, basado en los pilares de la agroecología.

Esta información permitió conocer la superficie urbana existente en el partido y su distribución espacial. Al mismo tiempo se pudo poner en valor la existencia de una amplia superficie del partido bajo actividad ganadera y en cuanto a la actividad hortícola, establecer la superficie ocupada por el CHP y dentro de este la superficie de cultivos bajo invernáculos y al aire libre, evidenciando que aún se conserva una amplia superficie de cultivos al aire libre.

En el análisis realizado en este capítulo corroboré que el uso urbano acaparó más de la mitad de los suelos aptos para la agricultura y que un porcentaje, reducido hasta la fecha analizada, de cultivos bajo invernáculos y hortícolas al aire libre se están desarrollando en suelos no aptos para dicha actividad $(4,04 \%$ de los Invernáculos y el $7,93 \%$ de la Horticultura). Esto reafirma los resultados obtenidos en el capítulo 2 y los planteos de Hurtado et al. (2006) y Frediani (2010) quienes sostienen que la expansión urbana tuvo lugar en el partido de La Plata sobre tierras productivas de alta calidad, moviendo la horticultura hacia áreas de uso tradicionalmente agropecuario (agricultura extensiva, ganadería, tambos, haras, etc.) que no son apropiados para dicha actividad. Este avance urbano sobre lo rural queda evidenciado también al ver la cercanía espacial entre la actividad hortícola (horticultura al aire libre e invernáculos) y el área urbana. Dávila (2012) considera que, según diversas regulaciones, la distancia de las producciones hortícolas intensivas a los centros urbanos debería ser mayor a 1000 metros. Sin embargo, un muy alto porcentaje $(67,93 \%)$ de invernáculos se hallaron a menos de 1000 metros de las zonas urbanas. A su vez, se evidenció que casi el $25 \%$ del partido estaba ocupado por áreas urbanas y que parte de estas (asociado a la construcción de countries y barrios privados) se encontraban inmersos en una zona preponderantemente ganadera.

Por otro lado, para el año 2015 más de la mitad del área hortícola (51\%) se encontraba ocupada por producciones bajo invernáculo. Al analizar la distribución de estos, las delegaciones municipales con mayor concentración de Invernáculos fueron Abasto, seguida por Etcheverry, El Peligro, Lisandro Olmos y Los Hornos, sectores del partido donde es recomendable implementar en el corto plazo políticas públicas que promuevan un proceso de reconversión de las unidades productivas hacia producciones con un mayor 181 Lic. Carolina Baldini Tesis doctoral - Territorio en movimiento 
porcentaje de cultivos al aire libre, considerando que como señala Blandi (2016) los cultivos bajo invernáculo son altamente insustentables ecológica, económica y socialmente. La insustentabilidad ecológica de este tipo de cultivos, es especialmente importante si pensamos en avanzar hacia un territorio agrícola más sustentable, donde se promueva la agroecología, debido al efecto negativo que la producción bajo invernáculo tiene sobre el ambiente (predial y extrapredial); según esta autora la biodiversidad sufre una severa degradación frente a este tipo de manejo productivo (Blandi 2016). Al mismo tiempo al analizar la distancia al drenaje se evidenció que un $21 \%$ de los invernáculos se hallaron a menos de 50 metros de los arroyos, mientras que un 45\% se encontraron a menos de 200 metros, lo que demuestra la necesidad de implementar políticas de resguardo de los arroyos. Además del riesgo de contaminación que implica tener una amplia superficie de producción intensiva tan cerca de los arroyos, se suman los problemas derivados de la impermeabilización como consecuencia de la amplia superficie bajo invernáculos, agravada por el proceso de aglomeración de los mismos identificado en el capitulo 2 de esta tesis; un aspecto relevante si tenemos en cuenta que los procesos de densificación y expansión urbana ya redujeron la capacidad de los bañados de la región para proveer sus servicios ecosistémicos de retención, absorción y operación de agua, que son de gran relevancia a la hora de reducir el impacto de las inundaciones (Karol y San Juan, 2018). Por otro lado, si bien identifiqué una amplia superficie con ambientes naturales o semi-naturales, se puede ver que los ambientes riparios se encontraban desarrollados principalmente en la periferia del partido, con actividad casi exclusivamente ganadera; y que por otro lado, los ambientes naturales o semi-naturales se encontraban mucho menos representados en la zona hortícola, y menos aún en aquella zona caracterizada por la concentración de producciones bajo invernáculo. Para que las producciones hortícolas puedan aprovechar las funciones y servicios ecosistémicos que la biodiversidad provee y de esta forma desarrollar producciones más sanas, es necesario asegura la presencia en el paisaje agrícola de parches de vegetación semi-natural de diversos tamaños y ambientes que puedan funcionar como corredores para el flujo de organismos y materiales (Fischer et al. 2006). Esto plantea la necesidad de pensar estrategias para incrementar este tipo de ambientes en los entornos productivos donde son escasos, manteniendo niveles de biodiversidad, que subsidien el funcionamiento de los agroecosistemas al contribuir con el reciclado de nutrientes, el control biológico de plagas, la conservación del agua y del suelo, entre otros servicios ecosistémicos (Swift et al. 2004, Nicholls y Altieri 2012).

A partir del análisis de aptitud de usos, identifiqué que la urbanización se desarrolló principalmente en zonas de aptitud urbana alta/muy alta (79.61\%). La zona de aptitud urbana alta/muy alta sin urbanizar era una zona principalmente ganadera, para la cual no sería adecuado pensar una estrategia de urbanización, ya que implicaría un crecimiento urbano disperso, promoviendo un proceso de expansión urbana vinculado a lo que se ha 
denominado como "ciudad difusa", y que numerosos especialistas coinciden en identificar como un modelo de ciudad asociado a la insustentabilidad ambiental, la fragmentación territorial, y la segregación socioespacial (Frediani, 2010). De hecho, las áreas urbanas existentes actualmente en dichas zonas con matriz ganadera son countries y barrios privados, de baja densidad habitacional

Al analizar las zonas donde se superpusieron aptitudes de uso pude identificar que en la zona de conflicto extremo, donde los tres usos del suelo tenían aptitud alta/muy alta, claramente la urbanización tuvo un peso mucho mayor a la hora de establecer en la práctica un uso del suelo en ese sector, ya que fue ocupado casi en su totalidad por este uso. Esta superposición de aptitudes de uso y la consecuente competencia entre actividades explica también la cercanía encontrada entre el uso urbano y el hortícola (al aire libre y bajo invernáculos).

En cuanto a la zona de conflicto muy alto, pese a ser una zona conflictiva, es también una zona con un enorme potencial para la planificación del territorio. Por un lado porque la zona de aptitud urbana alta/muy alta está poco representada (6.35\%), es decir que no está dentro de las zonas de mayor aptitud para urbanizar; y para el año 2015 la superficie efectivamente urbanizada era relativamente baja (6.18\%). Por otro lado, fue una zona ocupada principalmente por actividad ganadera y pastizales, lo que demuestra que pese a tener aptitud alta para la actividad hortícola, tampoco fue aprovechada para este uso. Por sus características, esta zona sería apta para planificar el desarrollo de actividad hortícola al aire libre que coexista con producciones ganaderas y zonas de pastizal, que se preserven como reservorios de biodiversidad, propiciando el desarrollo de emprendimientos productivos sustentables, basados en prácticas agroecológicas. En esta zona existen unos pocos sectores ganaderos inmersos en una matriz principalmente hortícola, que por su cercanía a este uso del suelo, podría evaluarse su reconversión a producciones hortícolas al aire libre, si fuese necesario incrementar la superficie hortícola, favoreciéndose a su vez por la infraestructura existente en esa zona que facilita la distribución de la producción. En cuanto a la zona de conflicto alto, también se observó que la aptitud de uso urbano alta estaba poco representada y que la superficie efectivamente urbanizada también era baja. En esta zona el principal conflicto se da entre la actividad hortícola al aire libre y bajo invernáculos, ya que es una zona de alta aptitud para ambas actividades. A su vez, vemos que la actividad hortícola bajo invernáculos está más representada y concentrada espacialmente. En esta zona se ve claramente cómo frente a la posibilidad de producir al aire libre o bajo invernáculo, se impone en el territorio la producción bajo invernáculos, que a su vez tiende a concentrarse espacialmente, otras de las tendencias identificadas en el capítulo 2. Tener sectores del cinturón hortícola con amplia concentración de invernáculos potencia el fuerte deterioro del ambiente propio de este tipo de producciones intensivas, al 
concentrar un consumo mayor de agua de riego, generando sobre explotación del acuífero; incrementar la contaminación por hiperfertilización y salinización de los suelos bajo producción; constituir amplias superficies impermeabilizadas que impiden la infiltración del agua de lluvia; aumentar la contaminación del agua y el suelo por un mayor uso de agroquímicos; generar una fuerte degradación de la biodiversidad y homogeneizar los hábitats a través del uso de fertilizantes y herbicidas y la producción de unos pocos cultivos, impactando sobre la diversidad de plantas espontáneas (Hurtado 2006, García 2011, Karol y San Juan 2018, Sarandón et al. 2015, Colombo et al. 2015, Alonso et al. 2015, Blandi 2016, Stupino 2019). Este tipo de situaciones lleva a una degradación ambiental cuya remediación implicará un prolongado tiempo y altos costos sociales, económico-productivos y ambientales.

Al observar que la cobertura urbana es aquella que presentó mayor cobertura en las áreas de mayor conflicto, se espera que al ampliarse la infraestructura vial en aquellas zonas aptas para esta actividad, la misma se desarrolle impidiendo las actividades productivas. Por otro lado, existieron zonas aptas al uso que no están siendo utilizadas por la producción ni el desarrollo urbano. Sin embargo, si el factor limitante es el desarrollo vial, la competencia por el espacio se observará también en estas áreas.

Estos resultados exponen la fuerte influencia que tienen los procesos de urbanización y en la definición de los usos del suelo, lo cual se podría esperar que esté influenciado en gran medida por el negocio inmobiliario. Esto concuerda con lo planteado por otros autores, quienes plantean que, en ausencia o deficiencia de políticas adecuadas de planificación del uso del suelo, estos conflictos urbano-rurales se han resuelto a través de las políticas de los mercados concentradores y la especulación de las empresas constructoras (Frediani, 2010; Hurtado et al., 2006; Merchán, 2016). En el mismo sentido, recientemente Fingermann (2018) plantea que las zonas fijadas como áreas de producción agropecuaria vienen siendo constantemente transformadas en áreas urbanas, y que la legislación que fija el ordenamiento territorial se ha ido adecuando a lo que ocurre de hecho. La actividad hortícola está inutilizando sus mejores suelos en manos de procesos de urbanización que son obviamente irreversibles, por lo que son suelos que se pierden definitivamente; siendo desplazada esta actividad hacia zonas marginales del partido, con suelos de menor calidad, y baja infraestructura de caminos y servicios básicos, deteriorando aún más las precarias condiciones de vida de las familias productoras, dificultando los procesos de transporte y comercialización y poniendo en riesgo el acceso de la población local a alimentos de proximidad.

El conflicto urbano-rural expuesto en los párrafos anteriores y el alto porcentaje de cultivos bajo invernáculo aledaños a zonas urbanas, a menos de $1000 \mathrm{mts}$, hacen necesario pensar en la delimitación de una franja de no fumigación, especialmente considerando el 
elevado uso de agroquímicos (Sarandón et al., 2015) y la cercanía entre el área productiva y el área urbana. En los últimos años han surgido en distintas partes del país ordenanzas que delimitan franjas de no fumigación y legislaciones que promueven procesos de transición agroecológica. Las ordenanzas que delimitan franjas de no fumigación en torno a la urbanización y a escuelas rurales, han sido promovidas principalmente por las consecuencias en la salud derivadas de la producción agrícola extensiva que circunda muchos de los pueblos y ciudades del país. Sin embargo, es menos reconocida esta necesidad en torno a áreas bajo producción hortícola. Una ordenanza a destacar en la provincia de Buenos Aires, es la Ordenanza 18.740/08 del municipio de General Pueyrredón, que pese a las deficiencias en su cumplimiento, establece un área de 1000 metros al ejido urbano, donde no se puede fumigar con agroquímicos. Esta ordenanza reviste importancia ya que el municipio de General Pueyrredón es el principal partido hortícola de la Provincia de Buenos Aires en cuanto a su superficie, y junto con el de La Plata tienen el mayor índice de peligrosidad, de acuerdo a la superficie relativa que ocupa la horticultura y al modelo de producción predominante (Sarandón et al., 2015). En el partido de La Plata, pese a albergar uno de los principales cinturones hortícolas del país y al índice de peligrosidad establecido para este, carece de ordenanzas que regulen las distancias de aplicación. Es indispensable la elaboración de una ordenanza de este tipo, pero para garantizar su cumplimiento es necesario que la misma sea realizada en conjunto con las organizaciones de productores y los propietarios; y que haya un compromiso real por parte del municipio en desarrollar políticas públicas que faciliten la transición hacia producciones agroecológicas de aquellas unidades productivas afectadas.

A fin de lograr una transición exitosa hacia producciones más sustentables es necesario también resguardar los ambientes que sirvan como reservorio de biodiversidad. Los patrones espaciales, es decir la ubicación en el espacio de los distintos elementos que componen un paisaje, y los cambios en su estructura influyen en los flujos y transferencias de organismos, materiales y energía (Risser et al., 1984) afectando la biodiversidad, que es considerada como un elemento imprescindible para el mantenimiento de los servicios ecosistémicos que la naturaleza provee (Rositano, 2012). En este sentido, en el presente trabajo se observó que si bien en la zona de aptitud muy alta para invernáculos los ambientes naturales son escasos, en las zonas de aptitud alta (para la horticultura y para los invernáculos, existe aún un importante porcentaje de áreas semi-naturales factibles de ser ocupados por actividad hortícola y relevantes también para la constitución de corredores biológicos. A su vez, también se observó que en las zonas menos aptas al desarrollo urbano y producción hortícola, los ambientes naturales constituyeron grandes extensiones y permanecieron estables a lo largo del tiempo. En este sentido, la ganadería, que en este partido es una actividad extensiva y de bajo impacto (Cieza et al. 2015), que por lo tanto permite la presencia de vegetación espontánea y corredores, se halla concentrada 185 Lic. Carolina Baldini

Tesis doctoral - Territorio en movimiento 
principalmente en zonas de baja aptitud para otros usos. Sin embargo, no es suficiente con tener una amplia superficie con vegetación natural o semi-natural en el partido sino que es sumamente importante la distribución de estos ambientes, y la conectividad entre ellos y entre estos ambientes y los cultivos al aire libre, para garantizar la provisión de servicios ecosistémicos como el control de plagas, el control de la erosión y la formación de suelos, facilitando de este modo el desarrollo de producciones sustentables. En este sentido Uy (2008) plantea la necesidad de pensar la conectividad a distintas escalas de paisaje; pensando en la conectividad de los ambientes semi-naturales en la quinta (ej: cultivos con vegetación de bordes y fronteras), en el barrio (ej: pequeños montes con plazas, jardines y arbolado de calles) y partido (ej: plazas con arbolado urbano y con corredores riparios que atraviesan el partido). Este autor plantea también la necesidad de conectar los ambientes semi-naturales urbanos con el periurbano. Una forma de mejorar la conectividad entre estos ambientes, proveedores de biodiversidad, podría ser el diseño de una red de espacios verdes, que incluya corredores a lo largo de ríos y caminos, parches de vegetación natural/semi-natural de diversos tamaños y elementos aislados (ej: árboles) que sirvan como "piedra de paso" brindando fuentes de alimento y refugio momentáneo para que los organismos se puedan desplazar a través de esta red (Uy 2008, Tian 2011). En la zona de conflicto muy alto, existen áreas de pastizal presentes en las delegaciones de Arturo Segui y Melchor Romero, que son muy importantes para el mantenimiento de la biodiversidad, ya que se encuentran muy cercanas a los arroyos que atraviesan la zona, y pueden conformar corredores biológicos que conecten con la zona de mayor densidad hortícola; a su vez, al encontrarse en una zona de aptitud hortícola alta, algunos de estos predios podrían reconvertirse a producciones hortícolas al aire libre. Sin embargo, es importante destacar que estos ambientes se mantienen probablemente por la falta de caminos que conecten esta zona con la urbanización existente. Con el desarrollo de la autopista Buenos Aires-La Plata que facilita el acceso a quienes trabajan en la Ciudad Autónoma de Buenos Aires, y más recientemente con la búsqueda de tierras a partir de la posibilidad de acceder a créditos PRO.CRE.AR para la vivienda propia, las delegaciones de Arturo Segui y City Bell, están experimentando un crecimiento de la urbanización, con la conformación de nuevos barrios pero también con el desarrollo de barrios privados y countries. Esto es importante tenerlo en consideración ya que si no se pone en valor esta zona como zona de alta aptitud productiva y con un potencial para el establecimiento de corredores de biodiversidad, probablemente sea una zona que en un corto plazo se termine urbanizando. En la zona de conflicto medio, de manera similar a la zona de conflicto muy alto, una gran parte de su superficie ya se encuentra efectivamente urbanizada. De lo que queda aún sin urbanizar, es importante destacar la zona con pastizales, ya que en delegaciones como City Bell y Melchor Romero es importante poder mantener esos pastizales por su aporte a los corredores de biodiversidad que se pueden constituir en consonancia con el recorrido de los 
arroyos; en el caso de Arana, sería conveniente mantener parte del pastizal presente en esa delegación en la zona de conflicto medio, como reservorios de biodiversidad en la zona hortícola.

La fragmentación del hábitat ha sido considerada por muchos investigadores como la mayor amenaza a la biodiversidad (Noss, 1991) y como un proceso que influye directamente en el desarrollo y la restauración de los ecosistemas (Tian, 2011). En contextos fuertemente antropizados, Uy (2008) y Tian (2011) destacan la importancia de tomar medidas para mejorar la conectividad entre estos ambientes proveedores de biodiversidad, mediante el diseño de una red de espacios verdes, que incluya corredores a lo largo de ríos y caminos, parches de vegetación natural/semi-natural de diversos tamaños y elementos aislados (ej: árboles) que sirvan como "piedra de paso". Al mismo tiempo, Uy (2008) plantea la necesidad de pensar la conectividad a distintas escalas, que en nuestro caso de estudio podríamos identificar como escala de quinta, barrio o delegación municipal y partido, y la necesidad de conectar los ambientes semi-naturales urbanos con el periurbano. A su vez, los corredores incrementan notablemente el movimiento de plantas y animales entre hábitats (GilbertNorton et al., 2010).Yang (2007), por su parte, destaca la importancia de considerar a las granjas (quintas en este caso) como elementos que contribuyen a la conectividad entre espacios verdes. En este sentido, se pudo establecer que las delegaciones de Los Hornos (pese a destacarse también por su porcentaje de invernáculos) y Arana tienen una mayor tendencia a producir al aire libre, lo que nos indica que son dos delegaciones prioritarias a la hora de pensar en políticas de protección de áreas productivas, evitando el desarrollo de amplias superficies de producción bajo invernadero y resguardando ambientes potenciales proveedores de biodiversidad. En relación a la zona de aptitud hortícola alta, se observa un porcentaje considerable de producción bajo invernáculos, lo que evidencia la necesidad de regular el avance de este tipo de producciones y evaluar la posibilidad de reconversión de parte de estas producciones a cultivos al aire libre. En cuanto a los invernáculos la zona de aptitud muy alta es una zona con una concentración muy grande de invernáculos y pocos ambientes con vegetación natural/semi-natural, lo que lo hace un sector clave para pensar estrategias que permitan incorporar vegetación a nivel de paisaje (ej: arbolado en las calles) y a nivel de las quintas (ej: fronteras y borduras a nivel de parcelas), que provean de biodiversidad y aporten a las funciones ecológicas que ella provee (Baloriani et al. 2010, Paleologos et al. 2015, Dubrovsky Berensztein 2018). Al mismo tiempo la heterogeneidad de hábitats en las quintas favorece el aumento de la diversidad $\beta$ y $y$ de especies espontáneas, y se sabe que las quintas con cultivos bajo invernáculo suelen tener una menor heterogeneidad de hábitats (Stupino 2019, Blandi 2016), otro aspecto por el cual sería propicio trabajar en pos de una reconversión de parte de estos cultivos a cultivos al aire libre. Finalmente en el área de aptitud alta para los invernaderos es también un área relevante para la conservación de vegetación natural-seminatural, por lo que es importante 
incorporar estrategias de planificar del crecimiento de estos cultivos. Considerando la insustentabilidad que han demostrado tener aquellos sistemas hortícolas familiares con amplias superficies de producción bajo invernáculos y la intensificación en el uso de agroquímicos asociado a este tipo de producciones (Blandi, 2016; Sarandón et al., 2015), sería recomendable promover la reconversión de parte de estas producciones fomentando la producción al aire libre, la diversificación de cultivos y la sustitución de insumos químicos por bioinsumos. Esto a su vez ayudaría a aumentar la conectividad entre los corredores de biodiversidad y las quintas, favoreciendo una transición a producciones agroecológicas y la sustentabilidad de los sistemas productivos. Estos autores, junto con las numerosas investigaciones locales sobre el rol de la vegetación espontánea y los cultivos al aire libre sin uso de agroquímicos, en el mantenimiento de enemigos naturales de las plagas (e.g. Dubrovsky Berensztein, 2018; Baloriani et al., 2009; Fernández y Marasas, 2015; Marasas et al., 2011; Marasas et al., 2014; Paleologos et al., 2008; Stupino et al., 2007; Stupino et al., 2009), nos brindan criterios generales para pensar una planificación territorial más adecuada, que promueva un desarrollo territorial sustentable.

Por otra parte, gran parte de la superficie hortícola bajo invernáculo se halló muy cercana al drenaje (el 45,06\% se halló a una distancia menor a los 200 metros). La cercanía de la actividad productiva intensiva a los arroyos, tiene importantes implicancias especialmente si se considera que el área hortícola se encuentra emplazada en la cabecera de estos arroyos, por lo que su efecto puede tener repercusión aguas abajo. Las distancias buffer consideradas para proteger a los arroyos del transporte de agroquímicos provenientes de la actividad agrícola varían mucho en países de la región como Argentina, Brasil y Paraguay. Mientras que en Brasil se contemplan distancias de $30 \mathrm{~m}$. en promedio, en Paraguay el criterio es de $100 \mathrm{~m}$. y en Argentina no existe una legislación de carácter nacional al respecto, existiendo decretos reglamentarios en las provincias de Chaco, Formosa y Rio Negro (Hunt et al., 2016). Además del riesgo de contaminación que implica tener una amplia superficie de producción intensiva tan cerca de los arroyos, se suman los problemas derivados de la impermeabilización como consecuencia de la amplia superficie bajo invernáculos; un aspecto relevante si tenemos en cuenta que los procesos de densificación y expansión urbana ya redujeron la capacidad de los bañados de la región para proveer sus servicios ecosistémicos de retención, absorción y operación de agua, que son de gran relevancia a la hora de reducir el impacto de las inundaciones (Karol et al., 2018). En base a estas consideraciones se podría pensar en políticas diferenciadas en cuanto a la protección de los cursos de agua, restringiendo la actividad productiva al menos dentro de los 50 metros de los arroyos, y estableciendo que regulen las superficies de producción bajo invernáculos y que fomenten la transición de aquellas unidades productivas ubicadas dentro de los 100-200 metros de los arroyos, hacia producciones agroecológicas. Este tipo de medidas deberían desarrollarse en espacios en los que esté representada la voz de las 188 Lic. Carolina Baldini Tesis doctoral - Territorio en movimiento 
pequeñas familias productoras y los propietarios de grandes producciones, más capitalizadas. Yan y Jinxing (2007) también consideran fundamental que se contemplen mecanismos de compensación para las familias productoras. Este tipo de medidas tiene un doble beneficio, ya que por un lado protege los ambientes riparios y la biodiversidad presente en ellos, y por otro, al proteger estas zonas y mejorar sus condiciones ambientales, potencia su función como ambientes conectores, corredores biológicos con un rol estratégico en la conformación de una red de espacios verdes, resguardando la biodiversidad necesaria en una transición hacia un modelo productivo agroecológico. Al mismo tiempo, proteger la vegetación propia de los ambientes riparios tiene la ventaja diferencial de aportar estabilidad frente a las inclemencias climáticas como la lluvia y el viento, cada vez más frecuentes en la zona, al actuar como una cubierta protectora del suelo y contribuir al mantenimiento de su capacidad de escurrimiento y absorción (Karol et al., 2018). Gilbert-Norton et al. (2010) consideran más efectivo proteger las características naturales del paisaje que funcionan como corredores que intentar crear nuevos corredores; si bien estas medidas no son excluyentes, las conclusiones de estos autores refuerza la importancia de proteger y gestionar adecuadamente los ambientes semi-naturales que aún se conservan en el partido y que podrían funcionar como corredores naturales. En este sentido, el trabajo de Gómez et al. (2017) destaca la existencia en la cuenca alta del arroyo del Gato, de bañados de desborde fluvial, cuya conservación reviste importancia por la diversidad vegetal que alberga, la provisión de hábitat para variadas especies animales y la función de retención del agua de lluvia. Así mismo, Birche y Jersen (2018b) señalan que en el área periurbana más del $90 \%$ de los arroyos permanecen a cielo abierto; esto implica un gran potencial para pensar en estrategias de intervención tendientes a generar espacios públicos asociados a ellos, que al mismo tiempo los protejan como fuente de biodiversidad y de servicios ecosistémicos. En otro trabajo en el que analizan los arroyos en el área urbana, Jersen y Birche (2018) proponen la conversión de las planicies de inundación de estos arroyos, en espacios verdes integrados al sistema de espacios públicos; esta estrategia junto con la propuesta planteada anteriormente de delimitar una zona intangible y una de producción agroecológica en los tramos de los arroyos que atraviesan el área productiva, serían un complemento ideal para promover la conectividad entre los ambientes seminaturales urbanos y periurbanos y para aportar áreas de esparcimiento para la población local.

\section{CONCLUSIONES PARCIALES}

Los resultados de los análisis realizados en este capítulo se pueden condensar en una serie de conclusiones generales, entre las que podemos destacar: 
Se confirmó la fuerte influencia de la urbanización a la hora de establecer en la práctica un uso del suelo en la zona de conflicto extremo, donde los tres usos del suelo (urbanización, hortícultura e invernáculos) tenían aptitud alta/muy alta. Más de la mitad del área urbana $(51,16 \%)$ se asentó sobre suelos de aptitud agrícola, y las producciones hortícolas bajo invernáculos y las producciones hortícolas al aire libre están comenzando a ocupar suelos de menor aptitud agrícola.

Se registró una distancia inadecuada de las producciones bajo invernáculo respecto a los centros urbanos y a los principales arroyos de la región según diversas regulaciones existentes. En este sentido se encontró que más de la mitad (67,93\%) de los Invernáculos se ubicaron dentro de los 1000 metros del área urbana; y que casi la mitad (45,06\%) se hallaron a una distancia menor a los 200 metros de los arroyos.

Se identificó a la zona de conflicto muy alto como una zona con un enorme potencial para la planificación del territorio; por la baja representación en esta zona de áreas con aptitud urbana alta/muy alta y la baja superficie efectivamente urbanizada para el año 2015, y por ser una zona ocupada principalmente por actividad ganadera y pastizales, permitiendo planificar el desarrollo de actividad hortícola al aire libre en convivencia con estos usos del suelo funcionando como reservorios de biodiversidad. En esta zona existen aún suelos de aptitud alta para el desarrollo hortícola que aún no han sido aprovechados.

Se evidenció que aún se conserva una amplia superficie de cultivos al aire libre, encontrándose que el porcentaje de cultivos al aire libre y cultivos bajo invernáculos es prácticamente igual, diferenciándose en cuanto a la distribución espacial de los mismos. Sin embargo en la zona de conflicto alto se comprobó la competencia por el uso del suelo entre la horticultura al aire libre y los invernáculos, por ser una zona de alta aptitud para ambas actividades y donde los invernáculos están más representados.

Se establecieron las delegaciones municipales con mayor concentración de Invernáculos, a partir de lo cual podemos identificar que Abasto es la delegación más comprometida, seguida por Etcheverry, El Peligro, Lisandro Olmos y Los Hornos. A su vez se identificó a Los Hornos y Arana como dos delegaciones con una mayor tendencia a realizar producciones hortícolas al aire libre. Al mismo tiempo se comprobó que en la zona de aptitud muy alta para los invernáculos, que concentra el $92.07 \%$ del total de invernáculos presentes en el partido, existen pocos ambientes con vegetación natural/semi-natural.

Se identificó que los ambientes riparios se encuentran desarrollados principalmente en la periferia del partido, con actividad casi exclusivamente ganadera; y que por otro lado, los ambientes naturales o semi-naturales se encuentran mucho menos representados en la zona hortícola, y menos aún en aquella zona caracterizada por la concentración de producciones bajo invernáculo. Sin embargo, se observaron áreas de pastizal en las 190 Lic. Carolina Baldini

Tesis doctoral - Territorio en movimiento 
delegaciones de Arturo Segui y Melchor Romero de importancia para el mantenimiento de la biodiversidad, por su cercanía a los arroyos que atraviesan la zona, y por su potencial para conformar corredores biológicos que conecten con la zona de mayor densidad hortícola.

Finalmente, la cercanía evidenciada de los invernáculos a los arroyos, ocupando ambientes propicios para el desarrollo de vegetación riparia; la concentración de los invernáculos en ciertas delegaciones municipales, quedando la actividad hortícola al aire libre concentrada en delegaciones más alejadas y de baja infraestructura; la baja presencia de vegetación semi-natural en la zona de aptitud muy alta para los invernáculos; y la competencia entre la horticultura al aire libre y bajo invernáculo en zonas de conflicto por la aptitud de uso, complementan los resultados obtenidos en el capítulo 2 y permiten aceptar parcialmente la hipótesis 1. Esta plantea que la amplia expansión de la tecnología del invernáculo, que tuvo lugar en los últimos 30 años en el CHP, fue posible a expensas de la ocupación de áreas semi naturales y del reemplazo de cultivos al aire libre; afectando su distribución, conectividad y superficie total.

La detección de zonas de aptitud alta para la horticultura que aún no están siendo explotadas y donde la urbanización aún no ha avanzado, junto con la detección de zonas productivas donde la producción bajo invernáculos no ha avanzado tanto; y la identificación de sectores con vegetación semi-natural en zonas aptas para la horticultura, que pueden contribuir a la conformación de una red de espacios verdes que funcionen como reservorio de biodiversidad y favorezcan el flujo de la misma en el entramado productivo, son algunos de los resultados que junto con los resultados del capítulo 2 permiten aceptar la hipótesis 2 de esta tesis. Esta plantea que la estructura del paisaje remanente permite sostener y profundizar estrategias de manejo y planificación de base agroecológica, tendientes a generar un cambio en el modelo productivo.

\section{BIBLIOGRAFIA}

Alonso L, Bernasconi C, Ciciarelli A, De Castro C, Esteban C, Etchegoyen A, Mac Loughlin T, Muntaner L, Ledesma R, Orofino L, Percudani C, Piccinini A, Rojo M, Santillán JM, Vittori S (2015). Plaguicidas: los condimentos no declarados. XIII jornadas de jóvenes investigadores grupo Montevideo. Ciencia, tecnología e innovación para la inclusión social. La Plata, Buenos Aires.

Arias M (2019). Efecto del uso de fertilizantes y pesticidas sobre organismos acuáticos en arroyos de la zona hortícola de La Plata. Tesis Doctoral, Facultad de Ciencias Naturales y Museo, Universidad Nacional de La Plata. 147 pp.

Baloriani G, Paleologos MF, Marasas ME, Sarandón SJ (2009). Abundancia y Riqueza de la Macrofauna Edáfica (Coleoptera y Araneae), en Invernáculos Convencionales y en Transición Agroecológica. Arana, Argentina. Revista Brasilera de Agroecología. 4(2): 1733-1737. 
Barsky A, Vio M (2007). La Problemática del Ordenamiento Territorial en Cinturones Verdes Periurbanos sometidos a Procesos de Valorización Inmobiliaria. El caso del Partido del Pilar, Región Metropolitana de Buenos Aires. IX Coloquio Internacional de Neocrítica. Universidade Federal do Rio Grande do Sul. Porto Alegre.

Benencia R (2002). Transformaciones territoriales en la horticultura periurbana bonaerense en los últimos 50 años. El papel de la tecnología y la mano de obra. XIII Economic History Congress. Buenos Aires.

Bertoni JC, S Ambrosino, O Barbeito, A Daniele, JA Maza, CU Paoli, Serra JJ (2004). Inundaciones urbanas en la Argentina. GWP-SAMTAC; Programa Asociado de Gestión de Crecidas; Universidad Nacional de Córdoba. Secretaría de Ciencia y Técnica, SECyT; Comité Permanente de los Congresos Nacionales del Agua, Argentina; Arg CAP-NET.

Birche ME, Jensen KC (2018). Relevamiento y catalogación de los espacios verdes de uso público de la ciudad de La Plata, Argentina. Urbano, 21pp.

Birche M, Jensen KC, (2018b). El paisaje en el espacio público como medio de integración entre la ciudad y el agua: el caso de la región La Plata, Argentina. Revista de Urbanismo 39: 1-16.

Blandi ML, Sarandón SJ, Flores CC, Veiga I (2016). Evaluación de la sustentabilidad de la incorporación del cultivo bajo cubierta en la horticultura platense. Revista de la Facultad de Agronomía, La Plata, 114 (2): 251-264.

Bryant MM (2006). Urban landscape conservation and the role of ecological greenways at local and metropolitan scales. Landscape and urban planning 76: 23-44.

Ceceña $A E$ (2012). Dominar la naturaleza o vivir bien: disyuntiva sistémica. Debates urgentes, 1(1): 117-129.

Cieza RI, G Ferraris, C Seibane, G Larrañaga y L Mendicino (2015). Aportes a la caracterización de la agricultura familiar en el Partido de La Plata Revista de la Facultad de Agronomía de La Plata. Vol. 114 (Núm. Esp.1). Agricultura Familiar, Agroecología y Territorio: 129-142.

Colombo JC, Astoviza M, Bilos C, Cappelletti N, Migoya C, Morrone M, Skorupka C, Speranza E, Tatone L (2015). Subproyecto "Biogeoquímica de contaminantes". En: Relevamiento de la utilización de agroquímicos en la Provincia de Buenos Aires. Mapa de situación e incidencias sobre la salud. Defensor del Pueblo de la Provincia de Buenos Aires y UNLP. 497-533 pp.

Congedo L (2016). Semi-Automatic Classification Plugin Documentation. DOI:http://dx.doi.org/10.13140/RG.2.2.29474.02242/1

Congalton RG y K Green (2008). Assessing the accuracy of remotely sensed data: principles and practices. CRC press. $183 \mathrm{pp}$.

Conijn JG, PS Bindraban, JJ Schröder, REE Jongschaap (2018). Can our global food system meet food demand within planetary boundaries?. Agriculture, Ecosystems \& Environment, 251: 244-256. DOI: https://doi.org/10.1016/j.agee.2017.06.001 
Dansero E, G Pettenati, A Toldo (2017). The relationship between food and cities and urban food policies: a space for geography?. Bollettino della società geografica italiana. 13 (5): 4-19.

Dávila M (2012). Documentos de Trabajo: La política sobre uso de agroquímicos en Argentina y Uruguay. Universidad de Belgrano, Departamento de Investigaciones, Área de Estudios Agrarios, Vol. 277.

Dubrovsky Berensztein N (2018). Estudio de la entomofauna en agroecosistemas del Cinturón Hortícola de La Plata, para el diseño participativo de estrategias de control biológico por conservación. Tesis Doctoral, Universidad Nacional de La Plata. 391 pp. On line: http://sedici.unlp.edu.ar/handle/10915/71094

Eastman JR (2012). IDRISI Selva. Guía para SIG y procesamiento de imágenes. Clark University. Ravello, C.A. (Ed. Trad.). Facultad de Ciencias Agropecuarias, Universidad Nacional de Córdoba, Argentina.

Fernández Lozano J (2012). La producción de hortalizas en Argentina. Gerencia de Calidad y Tecnología. Mercado Central de Bs. As. On line: https://www.academia.edu/23974120/La produccion de hortalizas en argentina

Fernández V, Marasas ME (2015). Análisis comparativo del componente vegetal de la biodiversidad en sistemas de producción hortícola familiar del Cordón Hortícola de La Plata (CHLP), provincia de Buenos Aires, Argentina. Revista de la Facultad de Agronomía, 114 (Núm. Esp. 1): 15-29.

Fingerman N (2018). La agricultura familiar en el Área Hortícola de La Plata, Berazategui y Florencio Varela. Diversas formas de dependencia y el camino de construcción de su autonomía. Ediciones INTA, La Plata, Buenos Aires. 111 pp.

Frediani JC (2010). Lógicas y tendencias de la expansión residencial en áreas periurbanas. El Partido de La Plata, Buenos Aires, Argentina, entre 1990 y 2010 D. Tesis, Universidad Nacional de La Plata. Facultad de Humanidades y Ciencias de la Educación. 459 pp. On line: http://sedici.unlp.edu.ar/handle/10915/3203

García M (2011). El cinturón hortícola platense: ahogándonos en un mar de plásticos. Un ensayo acerca de la tecnología, el ambiente y la política. THEOMAI $n^{\circ} 23$, primer semestre 2011.

García M (2012). Análisis de las transformaciones de la estructura agraria hortícola platense en los últimos 20 años. El rol de los horticultores bolivianos. Tesis doctoral de la Facultad de Ciencias Agrarias y Forestales, UNLP.

García M. (2015). Horticultura de La Plata (Buenos Aires). Modelo productivo irracionalmente exitoso. Revista de la Facultad de Agronomía, La Plata 114 (3): 190201.

García M, Mierez L (2007). "Cultivos al aire libre. Importancia y razones en la región hortícola más capitalizada". Boletín Hortícola 12 (35): 7-14.

Gilbert-Norton L, Wilson R, Stevens JR, Beard KH (2010). A meta-analytic review of corridor effectiveness. Conservation biology 24(3): 660-668. 
Giobellina B (2017). El cinturón verde de Córdoba: hacia un plan integral para la preservación, recuperación y defensa del área periurbana de producción de alimentos. Coordinadora Beatriz Giobellina; producción cartográfica Nicolás Mari, et al. 1a ed. Manfredi, Córdoba: Ediciones INTA. 35 pp. On line: https://inta.gob.ar/sites/default/files/inta-el-cinturon-verde-de-cordoba $0 . p d f$

Giobellina B (2018). La alimentación de las ciudades: transformaciones territoriales y cambio climático en el Cinturón Verde de Córdoba. Compiladora: Beatriz Giobellina. 1a ed. Ciudad Autónoma de Buenos Aires. Ediciones INTA. 258 pp. On line: https://inta.gob.ar/sites/default/files/inta la alimentacion de las ciudades.pdf

Gómez N, Rodrigues Capítulo A, Colautti DC, Mariñelarena AJ, Licursi M, Cochero J, García de Souza J (2017). La puesta en valor de los servicios ecosistémicos que ofrecen los arroyos de llanura como una medida de mitigación de las inundaciones: el caso del $A^{\circ}$ Del Gato en el Partido de La Plata. Ecología y Manejo de Ecosistemas Acuáticos Pampeanos (EMEAP), 8.

Hunt L, Bonetto C, Resh VH, Buss DF, Fanelli S, Marrochi N, Lydy MJ (2016). Insecticide concentrations in stream sediments of soy production regions of South America. Science of the Total Environment, 547: 114-124.

Hurtado MA, Giménez JE, Cabral MG (2006). Análisis ambiental del partido de La Plata: Aportes al ordenamiento territorial. Consejo Federal de Inversiones, La Plata. 124 pp.

Instituto Nacional de Estadística y Censos de la República Argentina (INDEC) (2010). Censo Nacional de Población, Hogares y Viviendas (2010). On line: https://www.indec.gov.ar/nivel4 default.asp?id tema 1=2\&id tema 2=41\&id tema $\underline{3=135}$

Jensen K, Birche M (2018). El paisaje y la forma de expansión en la ciudad de La Plata: lineamientos y estrategias para la planificación del crecimiento urbano. In $X$ Seminario Internacional de Investigación en Urbanismo, Barcelona-Córdoba. Departamentd' Urbanisme i Ordenació del Territori. Universitat Politècnica de Catalunya.

Karol JL, San Juan GA (2018). Saber qué hacer: construcción de un sistema para la gestión integrada del riesgo hídrico en la región del Gran La Plata. Eds. Jorge L. Karol; Gustavo San Juan. - 1a edición especial - Universidad Nacional de La Plata. Facultad de Arquitectura y Urbanismo, La Plata. 347 pp. On line: http://sedici.unlp.edu.ar/handle/10915/67730

Liscia S, Amarilla R, Bacchiega D, Brea D, Carner J, Cielli P, Zarate F (2013). Estudio sobre la inundación ocurrida los días 2 y 3 de abril de 2013 en las ciudades de La Plata, Berisso y Ensenada. La Plata: UNLP, Facultad de Ingeniería, Departamento de Hidráulica. 53 pp. Recuperado de http://sedici. unlp. edu. ar/handle/10915/27334.

Mac Loughlin TM, Peluso L, Marino DJ (2017). Pesticide impact study in the peri-urban horticultural area of Gran La Plata, Argentina. Science of the Total Environment 598: 572-580.

Marasas ME, Fernandez V, Baloriani G, Cap G, Larrosa C, Rouaux J (2011). Estudio de la Agrobiodiversidad en Sistemas de Producción Hortícola Familiar. Buenos Aires, 
Argentina. VII Congreso Brasilero de Agroecología. Cuadernos de Agroecología 6 (2).

Marasas ME, Fernández V, Dubrovsky Berensztein N. (2014). Agrobiodiversidad en sistemas hortícolas familiares. Revista Leisa, 30 (1): 26-28.

Martellozzo F, Amato F, B Murgante, KC Clarke (2018). Modelling the impact of urban growth on agriculture and natural land in Italy to 2030. Applied Geography, 91: 156167.DOI: https://doi.org/10.1016/j.apgeog.2017.12.004

Martin-López B, González J, Díaz S, Castro I, García Llorente M (2007). Biodiversidad y bienestar humano: el papel de la diversidad funcional. Ecosistemas. 2007/3. Disponible en: (URL:http://www.revistaecosistemas. net/articulo.asp?ld=500\&ld_Categoria=1\&tipo=portada)

Matteucci SD, J Morello, A Rodríguez, GD Buzai, C Baxendale (1999). El crecimiento de la metrópoli y los cambios de biodiversidad: el caso de Buenos Aires. En: S.D. Matteucci; O.T. Solbrig; J.Morello y G. Halffter. 1999. Biodiversidad y uso de la tierra. Conceptos y ejemplos de Latinoamérica. EUDEBA-UNESCO, Buenos Aires. Pp. 549580.

Médico CM (2016). La vegetación como posibilidad de integración espacial, ambiental y social en los paisajes de interfase urbano-rural de la provincia de Mendoza. Revista de las Facultades de Arquitectura e Ingeniería. On line: http://www.um.edu.ar/ojsnew/index.php/FAl/article/view/794

Merchán AG (2016). Valorización de la tierra en el Cinturón Hortícola Platense D. Tesis, Facultad de Ciencias Agrarias y Forestales. 174 pp. On line: http://sedici.unlp.edu.ar/handle/10915/53577

Morello J y SD Matteucci (1997). El modelo agrícola del Núcleo Maicero como sistema complejo. En: J. Morello y O.T. Solbrig (comps.), La Pampa Ondulada: granero del mundo hasta cuando?. Orientación Gráfica Editora, SRL, Buenos Aires. Pp. 201-231

Morello JH, Buzai GD, Baxendale C, Rodríguez A, Matteucci SD, Godagnone RE, Casas RR (2000). Urbanización y consumo de tierra fértil. Ciencia Hoy 10(55): 50-61.

Morello J, SD Matteucci, AF Rodriguez, ME Silva, P Mesopotámica, P Llana, ... P Medanosa (2012). "Ecorregiones y complejos Ecosistémicos de Argentina". Orientación Gráfica Editora, Buenos Aires.

Newbold T, Hudson LN, Hill SL, Contu S, Lysenko I, Senior RA, Day J (2015). Global effects of land use on local terrestrial biodiversity. Nature, 520(7545), 45. DOI: https://doi.org/10.1038/nature14324

Nicholls Cl (2009). Bases agroecológicas para diseñar e implementar una estrategia de manejo de hábitat para control biológico de plagas. En: Vertientes del pensamiento agroecológico: fundamentos y aplicaciones (Comp. Altieri, M.), pp. 207-228. SOCLA. Medellín, Colombia.

Nicholls CI, MA Altieri (2012) Modelos ecológicos y resilientes de producción agrícola para el siglo XXI. Agroecología 6: 28-37. 
Nieto DP, Rivas GA (2006). Estudio socio-territorial de la actividad hortícola en el partido de La Plata 1998-2002. Geograficando: Revista de Estudios Geográficos 2 (2).

Noss RF (1991). Landscape connectivity: different functions at different scales. Landscape linkages and biodiversity. Island Press, Washington, DC, USA, 27-39 pp.

Paleologos MF, Flores CC, Sarandon SJ, Stupino SA, Bonicatto MM (2008). Abundancia y diversidad de la entomofauna asociada a ambientes semi-naturales en fincas hortícolas de La Plata, Buenos Aires, Argentina. Revista Brasileira de agroecología, $3(1)$.

Paleologos MF, Pereyra P, Cicchino A y Sarandon SJ (2015). El rol de los ambientes seminaturales en la abundancia y diversidad de coleópteros edáficos en los viñedos de la Costa de Berisso, Argentina. Revista de la Facultad de Agronomía, 114.

QGIS Development Team. (2016). QGIS Geographic Information System. Open Source Geospatial Foundation Project. https://qgis.org

Ramankutty N, E Amato, TC Monfreda y JA Foley (2008). Farming the planet: 1. Geographic distribution of global agricultural lands in the year 2000. Global Biogeochemical Cycles, 22. DOI: https://doi.org/10.1029/2007GB002952

Risser PG, Karr JR, Forman RTT. 1984. Landscape ecology: directions and approaches. Illinois Natural History Survey Special Publ. 2, Champaign.

Rositano F, López M, Benzi P, Ferraro DO (2013). Servicios de los ecosistemas: un recorrido por los beneficios de la naturaleza. Agronomía y Ambiente, 32:1-2. On line: http://agronomiayambiente.agro.uba.ar/index.php/AyA/article/view/5

Saquet MA (2015). Por una geografía de las territorialidades y las temporalidades: una concepción multidimensional orientada a la cooperación y el desarrollo territorial. La Plata, Facultad de Humanidades y Ciencias de la Educación. 153 pp.

Sarandón SJ, Flores CC, Abbona E, lermanó MJ, Blandi ML, Oyhamburu M, Presutti M (2015). Subproyecto "Análisis del uso de agroquímicos asociado a las actividades agropecuarias de la Provincia de Buenos Aires". En: Relevamiento de la utilización de agroquímicos en la Provincia de Buenos Aires. Mapa de situación e incidencias sobre la salud. Defensor del Pueblo de la Provincia de Buenos Aires y UNLP. 16-495 pp.

Staviski A (2010). Situación de la plasticultura en Argentina. En actas XXXIII Congreso Argentino de Horticultura. Rosario. Santa Fe. ASAHO.

Stupino SA, Ferreira AC, Frangi J, Sarandón SJ (2007). Agrobiodiversidad vegetal en sistemas hortícolas orgánicos y convencionales (La Plata, Argentina). Cuadernos de Agroecologia, 2(1).

Stupino S, Sarandón SJ, Frangi J (2009). Características de la Diversidad Cultivada y su Relación con la Diversidad Vegetal Asociada en Fincas Hortícolas Bajo Diferente Manejo en La Plata, Argentina. Cuadernos de Agroecologia, 4(1): 213-216.

Swift MJ, MN Izac, M. van Noordwijk (2004) Biodiversity and ecosystem services in agricultural landscapes- are we asking the right questions? Agriculture, Ecosystems and Environment 104: 113-134. 
Tian Y, Jim CY, Tao Y, Shi T (2011).Landscape ecological assessment of green space fragmentation in Hong Kong. Urban Forestry y Urban Greening, 10(2): 79-86.

United Nations. (2011). The great green technological transformation. United Nations publication.

United Nations. (2015). The 2030 Agenda for Sustainable Development and its Sustainable Development Goals. On line: https://www.un.org/sustainabledevelopment/development-agenda/

Uy PD, Nakagoshi N (2008). Application of land suitability analysis and landscape ecology to urban greenspace planning in Hanoi, Vietnam. Urban Forestry y Urban Greening, 7(1): $25-40$.

World Bank. (2018). Understanding poverty. Land topic. On line: http://www.worldbank.org/en/topic/land

Yang J, Jinxing Z (2007). The failure and success of greenbelt program in Beijing. Urban forestry y urban greening, 6(4): 287-296.

Zardari NH, Ahmed K, Shirazi SM, Yusop ZB (2015).Weighting methods and their effects on multi-criteria decision making model outcomes in water resources management.Springer.

\section{ANEXOS}

\section{Anexo 1. Mapas de base utilizados para el análisis multicriterio}

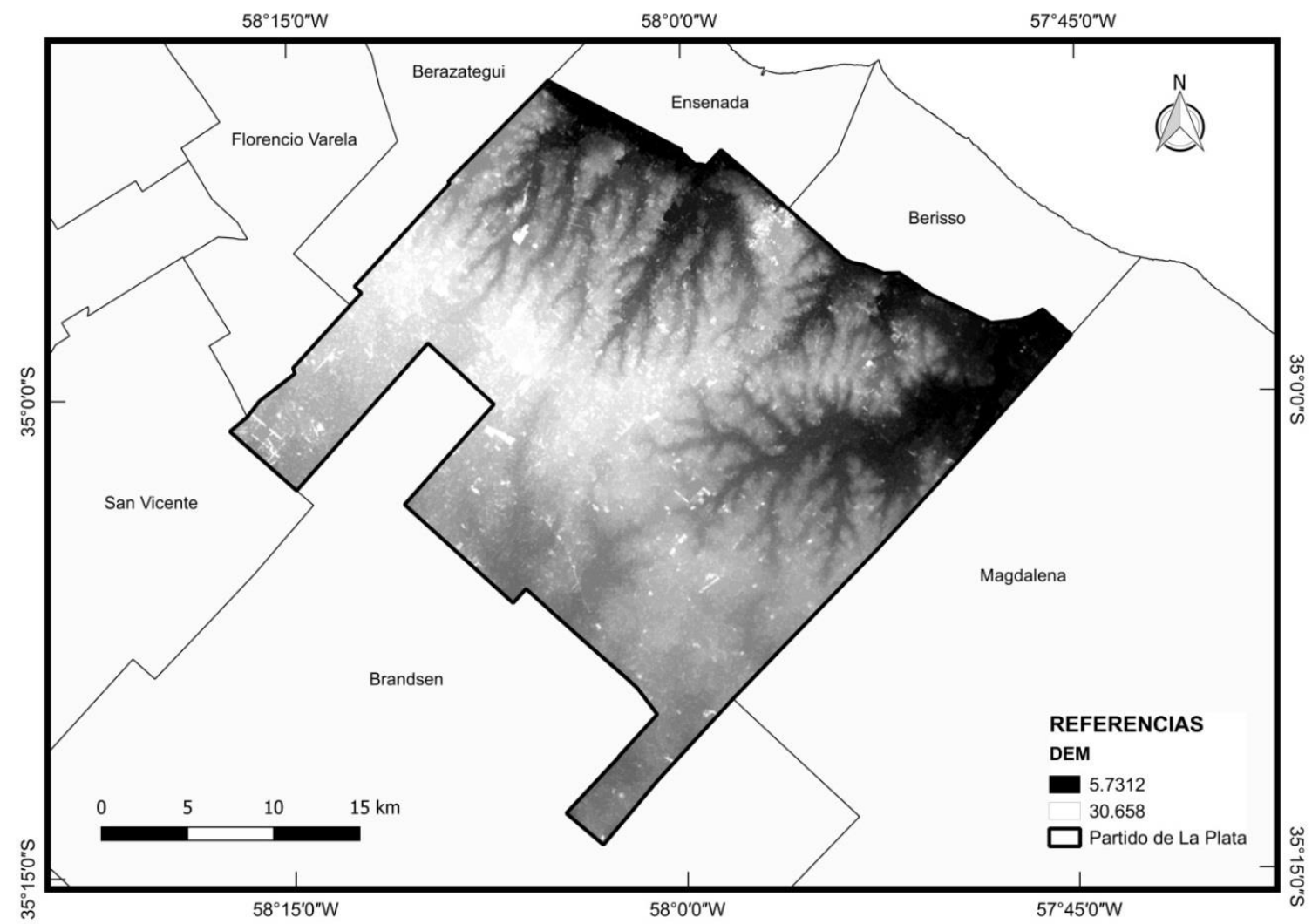

Fig 1. Modelo Digital de Elevación (DEM) 


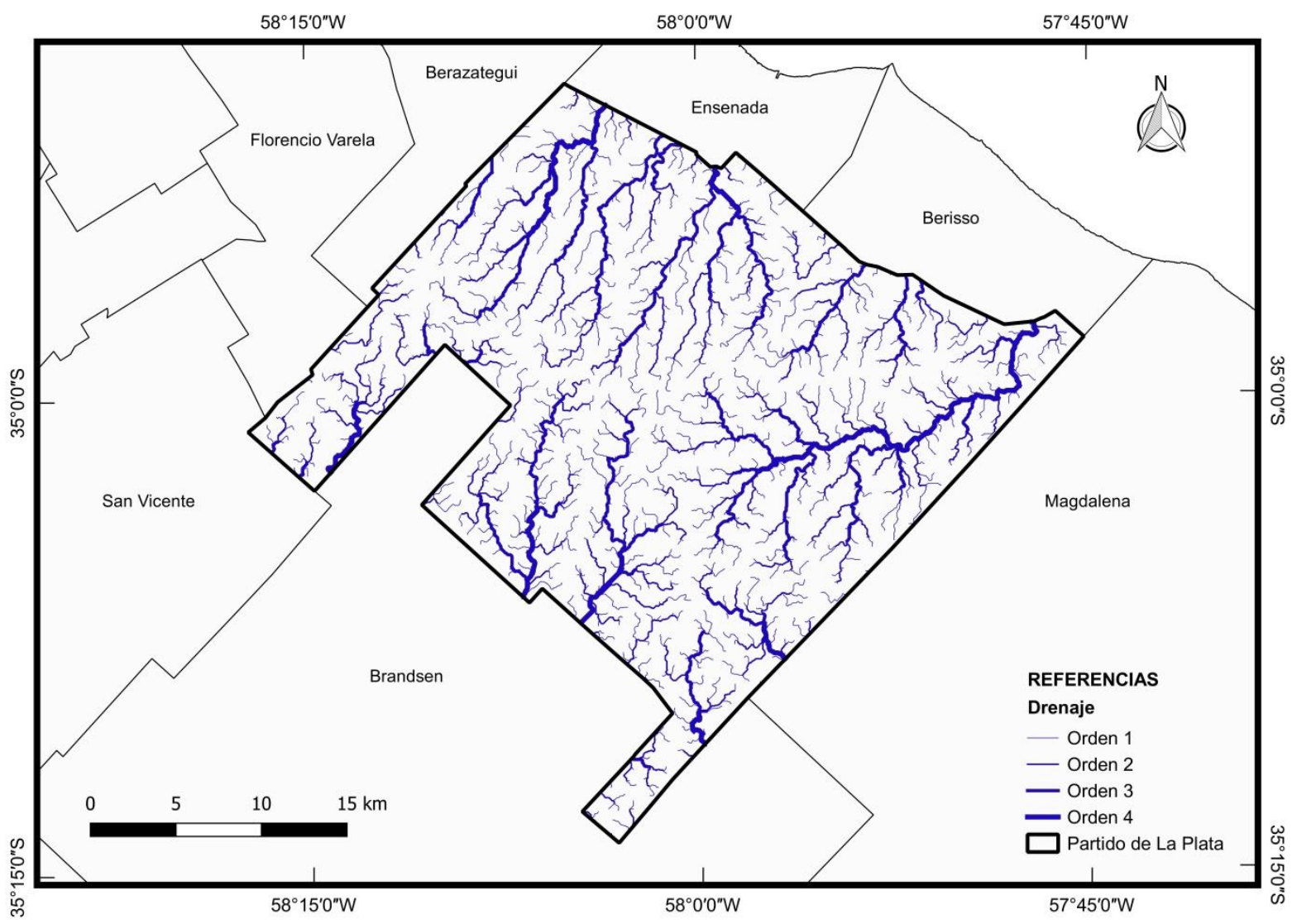

Fig 2. Drenaje obtenido a partir del DEM

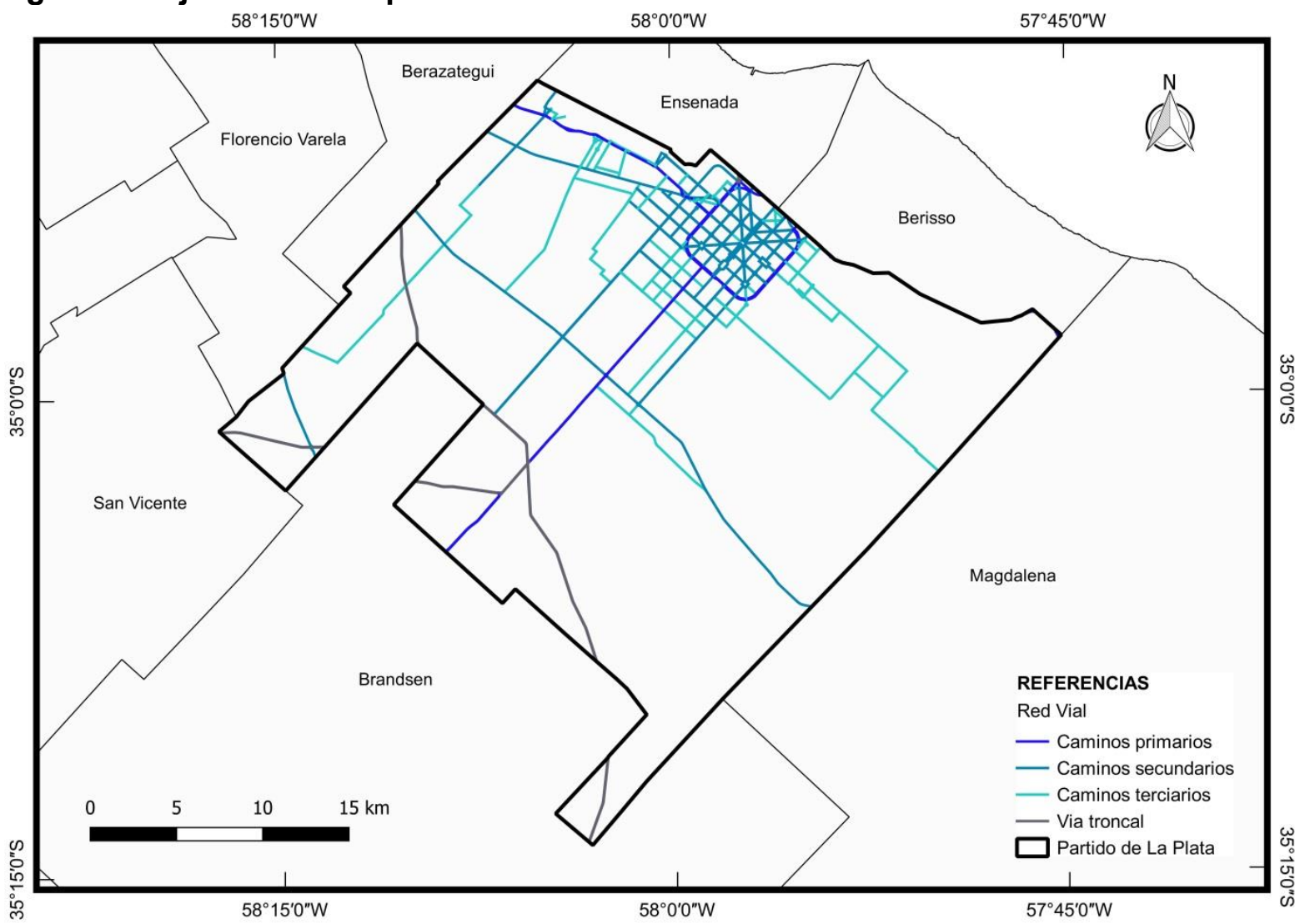

Fig 3. Red Vial obtenida a partir del Open Street Map 


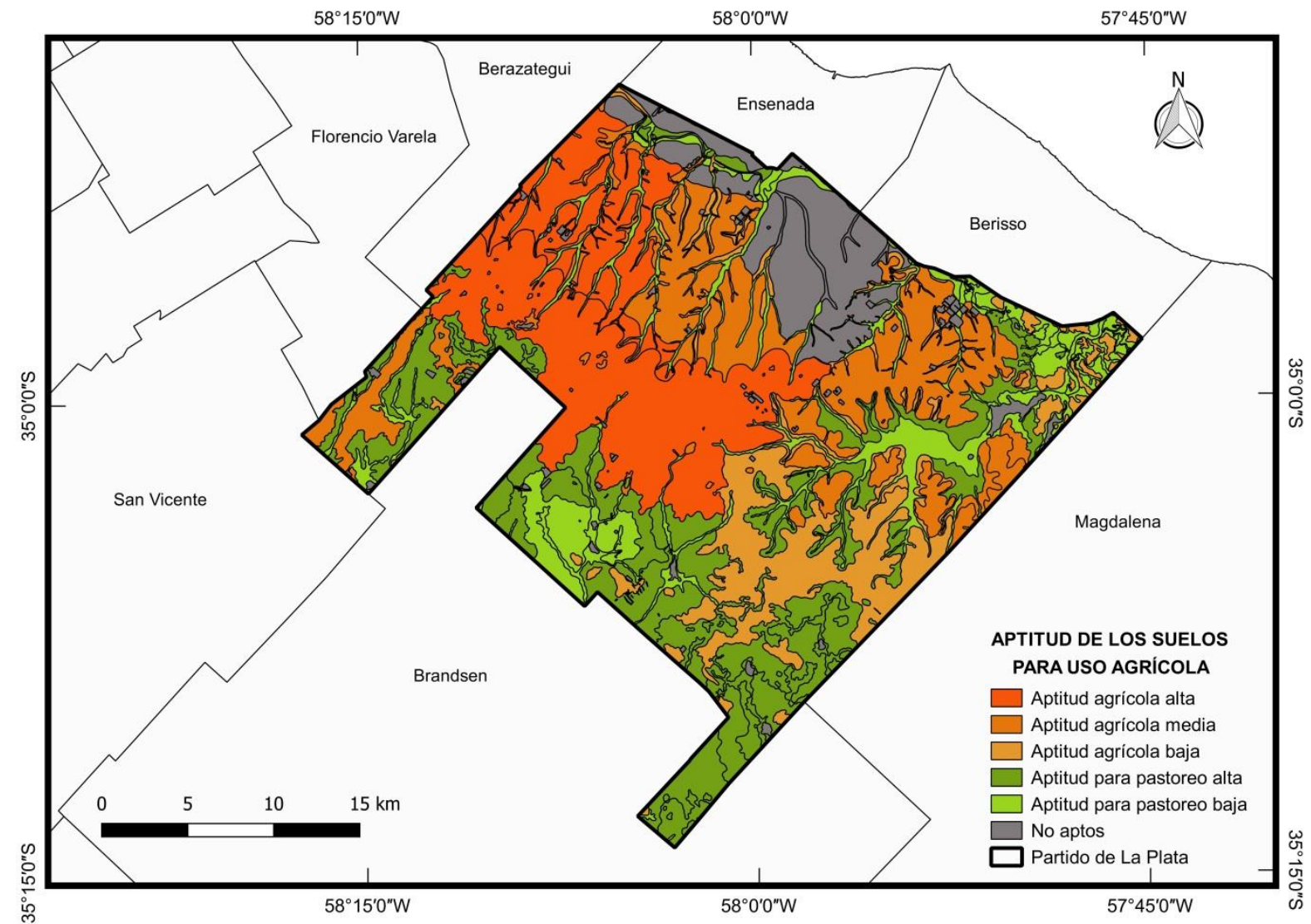

Fig 4. Mapa de aptitud de los suelos para uso agrícola en base al mapa de suelos obtenido de Hurtado et al. (2006). Para mas detalle del tipo de suelos ver el Capítulo 3, Cuadro 1. 


\section{CAPITULO 4}

\section{ANALISIS DE ACTORES SOCIALES}

"Y para mi es una alegría enorme (producir agroecológico) porque antes... antes produciamos ponele, todo este invernadero, tomate y todo tomate era, y no teniamos la lechuga para hacer la ensalada y era como algo... antes vos decias qué sé yo, -bueno me voy al campo a desestresarme-y el que está en el campo vivia más estresado porque lo único que sabia era del tomate y los químicos y ahí, nada más". 


\section{INTRODUCCION}

Si partimos de entender, como plantea Ceseña (2012), al territorio como el espacio construido por los sujetos en su devenir histórico, resultado de la interacción de las sociedades con la materialidad; el espacio de disputa civilizatoria más profundo y más abarcante, dinámico y en permanente proceso de creación o redefinición. En este sentido, cada proyecto territorial implica una negociación, en la que los grupos de poder ven las atracciones, los riesgos, el precio a pagar y las ventajas. A su vez, el territorio no se moldea exclusivamente por los procesos locales; sino que en él existen relaciones internas y externas, que forman redes que ligan individuos y lugares en niveles trans-multiescalares (Saquet 2015). De la misma manera, las transformaciones socio-económicas que afectan a las actividades productivas, son el resultado tanto de las tendencias globales, como de las especificidades locales y de los actores sociales que influyen en estas (Otero 2013).

Todos los territorios tienen su ordenamiento, ya sea por acción o por omisión, es decir por un "dejar hacer" por parte del Estado. Las estrategias tradicionales de ordenamiento territorial (OT), son estrategias que suelen estar construidas de manera verticalista, con una mirada fragmentada del territorio y sesgada a los intereses y necesidades de unos pocos actores, desconociendo la historia local y los intereses y necesidades de la población, habitualmente focalizadas en el desarrollo urbano-industrial. Este tipo de estrategias, con el paso del tiempo, suele dejar al territorio en manos del mercado, generando escenarios de des-planificación que evidencian la construcción capitalista del territorio, como podemos ver claramente en el partido de La Plata. Sin embargo, son cada vez más los actores del territorio que vienen demandando otra estrategia de planificación, concebida desde una perspectiva sistémica, prospectiva, participativa, que regule los procesos de subordinación y explotación, así como también los de concentración de riqueza, centralización de poder y degradación del ambiente; un ordenamiento territorial que actúe como un instrumento de gobernanza y planificación del desarrollo sustentable (Saquet 2015). Para ello, es necesario conocer y trabajar sobre la percepción que tienen los distintos actores del territorio que habitan, como se proyectan en ese territorio, como lo conciben en su imaginario ideal.

Según Hang et al. (2015), la década del 90 en nuestro país se caracterizó por una ausencia de políticas por parte de un Estado marcadamente neoliberal, tanto a nivel nacional, como provincial y municipal. En materia de política agropecuaria, este período se caracterizó por el estímulo de la producción extensiva de granos y commodities aprovechando sus ventajas comparativas para la exportación, en detrimento de otras actividades como la ganadería, o las producciones intensivas o de pequeña escala; esto se dio de la mano de una reconversión productiva alineada con el modelo extractivista de la revolución verde (Ambort 2017). Las políticas públicas productivas en este período 
estuvieron en general orientadas a la intensificación productiva. Si bien, en relación a la producción primaria, a partir del 2002 se pusieron en marcha algunas políticas relacionadas con la agricultura familiar, Hang et al. (2015) plantean que los resultados de estas políticas pueden demorar entre 10 y 15 años en visibilizarse, lo cual contrasta con los cortos tiempos de los gobiernos de turno, generando contradicciones dentro de las instituciones (Blandi 2016).

Respecto a las estrategias de intervención pública para el desarrollo territorial del CHP, Seibane (2013) evidencia una forma de gestionar la intervención, con un enfoque de construcción de arriba hacia abajo. Esta autora plantea que hay un predominio de la visión transferencista y asistencialista desde las instituciones del Estado para promover desarrollo territorial y que las acciones que estas desarrollan en el territorio suelen realizarse en función de las distintas situaciones que se van presentando, generándose superposiciones. Finalmente plantea que para poder implementar una estrategia de desarrollo territorial, es indispensable consensuar un proyecto político regional, y que las instituciones del Estado deben promover una mesa de diálogo con representantes de todos los grupos de productores y trabajadores del sector, generando espacios de escucha, de participación y búsqueda de consensos, para facilitará la acumulación de poder político colectivo (Seibane, 2013).

Autores como Hurtado (2006), Frediani (2010), García (2015b), Merchán (2016), Jensen y Birche (2018) y Karol y San Juan (2018) entre otros, vienen exponiendo las deficiencias de las planificaciones del territorio generadas hasta el momento, y desarrollando propuestas para avanzar en un ordenamiento territorial más adecuado. Para generar una política de desarrollo territorial adecuada es necesario conocer la historia del lugar, contar con información actualizada y de calidad del territorio, y tener conocimiento, como mencionamos anteriormente, sobre la percepción de los distintos actores. Si bien vienen tomando relevancia, incluso a nivel mundial, las investigaciones enfocadas en servicios ecosistémicos (Nelson y otros 2009, Zhang y otros 2007, Wu 2013, Koschke y otros 2012, entre otros), todavía son escasas aquellas que integran los procesos sociales a los procesos medioambientales y ecológicos (Cowling et al. 2008). En nuestra región contamos con numerosos estudios realizados en los últimos años que indagan en la percepción y los conocimientos, especialmente de las familias productoras sobre el ambiente en el que desarrollan su trabajo y sobre sus prácticas productivas (Blandi et al. 2011, Blandi et al. 2013, Blandi 2016, Gargoloff et al. 2013, Gargoloff 2019, Bonnicatto 2019)

Los estudios realizados por Blandi (2016) en el CHP, mediante la realización de entrevistas y la formulación de indicadores de sustentabilidad, evidencian que no siempre los cambios tecnológicos pueden conducir a una mayor sustentabilidad; y que en el caso de los sistemas hortícolas en el partido de La Plata, la mayor tecnificación condujo a sistemas 
menos sustentables (Blandi 2016). En relación a esto, numerosos autores han evidenciado diversas consecuencias negativas del modelo productivo basado en la tecnología del invernáculo (García 2011, Arias 2019, Mac Loughlin et al. 2017, entre otros). Blandi (2016) confirma que las prácticas de manejo convencionales en sistemas de cultivo bajo cubierta, pueden generar importantes externalidades negativas que impactarían sobre el agua subterránea, la atmósfera, el suelo y la biodiversidad, poniendo en riesgo la integridad del ecosistema global y afectando tanto al establecimiento productivo como a los que viven fuera de él. Es interesante destacar que esta autora plantea, entre los múltiples resultados a los que arriba, que la biodiversidad sufre una degradación severa ante este tipo de manejo, que las externalidades negativas derivadas de la producción bajo invernáculo afectan tanto dentro como fuera de las unidades productivas, y que desde el punto de vista social el mayor problema detectado fue la pérdida de capacidad de autogestión de las familias productoras, dependiendo en gran medida de los conocimientos de los técnicos, y de los vendedores de las casas de insumos.

En cuanto al rol del mercado asociado a este modelo productivo, algunos autores plantean que el mercado exige una alta calidad cosmética en la comercialización, la cual solo es lograda con una gran utilización de agroquímicos (Marasas et al. 2014); evidenciándose un avance en la presión ejercida desde la comercialización hacia las decisiones que habitualmente toma el agricultor (Hang et al. 2013), y una ciencia subordinada a los aspectos económicos del CHP, dedicada a generar técnicas rentables (Blandi 2016) en el marco del actual modelo hegemónico.

Frente a las dificultades plasmadas en los párrafos anteriores y a las externalidades negativas generadas por el modelo productivo impuesto en el CHP, extensamente detalladas en los capítulos anteriores de esta tesis, diversos trabajos han encontrado ciertos elementos presentes en el CHP que podrían facilitar la transición hacia un modelo productivo más sustentable. Blandi (2016) plantea que los agricultores que cultivan al aire libre, reconocen varias de las funciones ecológicas de la biodiversidad, necesarias para el buen funcionamiento del sistema; y Pérez (2010) afirma que los agricultores familiares del CHP y Gran Buenos Aires Sur, cuentan con un gran entendimiento de sus quintas y reconocen ciertos beneficios ecológicos de la biodiversidad. Sumado a esto, recientemente los productores bolivianos que cultivan al aire libre están desarrollando nuevos mecanismos de comercialización, vendiendo parte de su producción en ferias, vinculándose con un mercado de consumidores que se interesa por un tipo de alimento más saludable (Pérez 2010). Según Guzmán Casado y Mielgo (2007) y Garrido Fernández (2006), este tipo de mercados incentivan la agricultura agroecológica. Por otro lado, el origen de los agricultores bolivianos (principal grupo de productores presentes actualmente en el CHP), con valores y creencias campesinas podrían actuar, según Blandi (2016), como freno de las creencias y 
valores netamente capitalistas. Esta autora destaca la importancia de las diferentes cosmovisiones presentes en el CHP; una ciencia y un mercado en los que predomina una visión antropocéntrica, basada en maximizar resultados, reducir costos y conseguir una continua acumulación de capital, y que algunos agricultores han adoptado como propia, frente a otros agricultores que todavía cuentan con una visión más relacionada con la naturaleza, la tradición y la satisfacción más allá del beneficio económico (Blandi 2016)

Para lograr un manejo sustentable y resiliente de los agroecosistemas, se requiere una mejor comprensión de la agrobiodiversidad en los agroecosistemas y su vínculo con los conocimientos locales de los agricultores/as que incluye sus creencias, valores y prioridades (Gargoloff 2019), y de los diversos actores del territorio que influyen tanto en el manejo que hacen las familias productoras en sus quintas como en el mantenimiento (o no) de los ambientes semi-naturales presentes en el paisaje y su biodiversidad asociada. El conocimiento del ambiente y sus funciones y servicios ecosistémicos, que tengan los distintos actores que intervienen en la gestión del territorio va a influir en la calidad de las políticas públicas de planificación del territorio que se generen.

A continuación se retoman las tres hipótesis planteadas en esta tesis:

1. La amplia expansión de la tecnología del invernáculo, que tuvo lugar en los últimos 30 años en el CHP, fue posible a expensas de la ocupación de áreas semi naturales y del reemplazo de cultivos al aire libre; afectando su distribución, conectividad y superficie total.

2. La estructura del paisaje remanente permite sostener y profundizar estrategias de manejo y planificación de base agroecológica, tendientes a generar un cambio en el modelo productivo.

3. En las condiciones actuales los productores no cuentan con estrategias de gestión del territorio adecuadas para generar y sostener en el tiempo un cambio en el modelo productivo hacia un modelo de bases agroecológicas.

En el presente capítulo abordé principalmente la tercer hipótesis. Sin embargo los resultados de este capítulo aportaron herramientas para complementar el análisis de las otras dos hipótesis planteadas, que han sido tratadas con mayor detenimiento en los capítulos anteriores.

Los resultados del presente capítulo contribuyeron a los siguientes objetivos específicos:

1) Identificar los actores sociales claves vinculados al CHP e indagar acerca de su visión respecto del modelo productivo actual, las problemáticas del mismo y las posibilidades de transitar un cambio hacia otro modelo de base agroecológica 
2) Detectar fortalezas y debilidades de los cambios producidos en el territorio, desde un enfoque agroecológico.

3) Generar criterios que puedan ser utilizados en el rediseño de las áreas productivas y semi naturales presentes en el territorio, como estrategias de manejo, gestión y planificación del CHP y como herramienta para el desarrollo de políticas públicas, en el marco de la sustentabilidad.

Complementariamente, los resultados de este capítulo aportaron información que enriqueció el análisis realizado en los capítulos anteriores, contribuyendo también a los siguientes objetivos específicos:

4) Identificar, caracterizar e interpretar los ambientes que componen el paisaje del CHP en cuatro momentos clave de los últimos 30 años de desarrollo del territorio.

5) Analizar los cambios temporales y espaciales ocurridos en los ambientes cultivados y no cultivados que componen el paisaje del CHP.

\section{METODOLOGIA}

El análisis de los diversos actores sociales vinculados al cinturón hortícola lo realicé mediante una metodología de tipo cualitativa. Según Vasilachis de Gialdino (2006: 2) "La investigación cualitativa se interesa por la vida de las personas, por sus perspectivas subjetivas, por sus historias, por sus comportamientos, por sus experiencias, por sus interacciones, por sus acciones, por sus sentidos, e interpreta todos ellos de forma situada, es decir; ubicándolos en el contexto particular en el que tienen lugar. Trata de comprender dichos contextos y sus procesos y de explicarlos recurriendo a la causalidad local", por este motivo la consideré de gran utilidad para comprender las transformaciones que se han dado en el CHP, el lugar que han ocupado los diversos actores en ese proceso de cambio y cómo influyen en la posibilidad de transformación de la situación actual. Este tipo de abordaje es útil para profundizar y enriquecer estudios cuantitativos, permitiendo realizar un abordaje más profundo, al analizar significados, motivaciones, aspiraciones, actitudes, creencias y valores, expresados por el lenguaje común y en la vida cotidiana (Minayo y Sanches 1993, Sautu 2005). Minayo y Sanches (1993) consideran a la palabra como el principal insumo de una investigación cualitativa, tanto en las relaciones afectivas y técnicas, cómo en discursos intelectuales, políticos y burocráticos; el discurso se vuelve, según estos autores, un indicativo de las condiciones estructurales, sistemas de valores, normas y símbolos de ciertos grupos, determinados por condiciones históricas, características socioeconómicas y culturales específicas. A su vez, los métodos cualitativos son adecuados para identificar aquellos elementos que influyen de manera importante en las prácticas y concepciones de quienes intervienen en los distintos procesos sociales (Sautu 2005, Tadeo 2001), permiten estudiar organizaciones, instituciones, movimientos sociales, entre otros; y sus resultados 
inspiran y guían a la práctica, dictan intervenciones y producen políticas sociales (Vasilachis de Gialdino 2006). En este trabajo opté por utilizar la técnica de la entrevista, por ser considerada de gran utilidad para conocer la perspectiva de los actores sociales (Sautu 2005). La perspectiva teórica seguida en esta investigación fue principalmente de carácter microsocial, por centrarse en el análisis de las relaciones sociales, de los vínculos de las personas con su entorno físico y social, sus acciones y desempeños en sus posiciones o inserciones sociales, su interpretaciones de sus experiencias cotidianas (Sautu 2005).

Considero importante destacar que, en el período de tiempo en el que se desarrolló esta tesis, participé en diversos proyectos de extensión orientados a las familias productoras del CHP en los que se abordaron aspectos como la comercialización, problemáticas vinculadas a agroquímicos, procesos de transición agroecológica, sistemas participativos de garantía y acceso a un hábitat digno. Al mismo tiempo, participé activamente en una organización de productores y productoras; esto implicó una práctica de observación participante que permitió tener un conocimiento más acabado de las problemáticas locales, de los diversos actores que forman parte de las dinámicas territoriales y sus articulaciones, de las dificultades, aspiraciones, motivaciones de los productores y productoras familiares. En este marco realicé visitas semanales a quintas ubicadas en distintos sectores del Cinturón Hortícola entre los años 2015 y 2019, participé en reuniones de organizaciones de productores, talleres del INTA y de las propias organizaciones, formulé y coordiné proyectos especiales de ProHuerta (INTA) e impulsé y acompañé procesos colectivos de transición agroecológica. Estas diversas experiencias me permitieron tener un conocimiento de las particularidades del desarrollo del territorio que no hubieran sido posibles solo a través del análisis bibliográfico y de las entrevistas.

Una vez definida la metodología comencé por realizar un relevamiento bibliográfico, acompañado de entrevistas informales a investigadores y técnicos de la región. Para la realización de las entrevistas mencionadas anteriormente, busqué confeccionar un universo muestral que fuera representativo de los principales actores identificados en el territorio. En los estudios cualitativos no hay parámetros definidos para el tamaño de la muestra, el cual no es importante desde el punto de vista probabilístico, ya que no se busca generalizar los resultados del estudio a una población más amplia, sino que se pretende que la muestra ayude a entender el fenómeno de estudio y a responder a las preguntas de indagación (Hernández Sampieri et al. 2006). Teniendo en cuenta que en este caso no se busca tener una muestra estadísticamente representativa, ni realizar un análisis exhaustivo, sino que es un primer análisis exploratorio, que se aspira a profundizar en futuras investigaciones, se tuvieron en cuenta los siguientes grandes grupos de actores:

a. Representante de la Subsecretaría de Agricultura, Ganadería y Pesca de la Provincia de Buenos Aires (Funcionario Provincial) 
b. Representante de la Secretaría de Producción de la Municipalidad de La Plata (Funcionario Municipal)

c. Representante de la Dirección general de Planeamiento de la Municipalidad de La Plata (Funcionario Municipal)

d. Representantes del INTA locales y regionales (Funcionarios INTA)

e. Técnicos agrónomos (con diversos perfiles de asesoramiento)

f. Representante del Consejo Social de la Universidad Nacional de La Plata

g. Docente/Investigador de la Facultad de Ciencias Agrarias y Forestales, Departamento de Desarrollo Rural

h. Productores (Capitalizado, Mediano Productor, Pequeño Productor Agroecológico, Pequeño Productor Convencional)

Inicialmente busqué entrevistar a técnicos de Cambio Rural y técnicos privados, sin embargo no obtuve respuesta por parte de los técnicos privados contactados. Pese a ello, los técnicos Cambio Rural seleccionados tienen perfiles muy diferentes entre sí. Para la selección de los productores a ser entrevistados busqué, en la medida de lo posible, que estuvieran representados tanto productores como productoras, que hubiera productores pequeños, medianos y grandes, propietarios y arrendatarios y que los entrevistados desarrollaran su actividad productiva en distintos sectores del CHP, realizando entrevistas en las localidades de Gorina, Arana, Abasto y Lisandro Olmos. Inicialmente intenté entrevistar tanto a productores organizados como no organizados, pero probablemente debido al crecimiento exponencial del asociativismo en el CHP en los últimos años, no fue posible en los plazos de la tesis encontrar productores que no formaran o hubiesen formado en el pasado parte de ningún tipo de asociación.

A partir de estos criterios seleccióné 15 actores a ser entrevistados, cuyos contactos fueron obtenidos a partir de diversos informantes claves, con el objetivo de obtener una muestra heterogénea. Para preservar la identidad de los entrevistados se les asignó a cada uno una referencia (Cuadro 1).

Cuadro 1. Detalle de los actores sociales entrevistados

\begin{tabular}{|c|c|c|}
\hline ORGANISMO & ENTREVISTADO & REFERENCIA \\
\hline $\begin{array}{l}\text { Gobierno de la Provincia } \\
\text { de Buenos Aires }\end{array}$ & $\begin{array}{l}\text { Representante de la } \\
\text { Subsecretaría } \\
\text { Agricultura, Ganadería y } \\
\text { Pesca de la Provincia de } \\
\text { Buenos Aires - Dirección } \\
\text { de Horticultura, Floricultura } \\
\text { y Fruticultura }\end{array}$ & $\begin{array}{l}\text { Funcionario de la Dirección } \\
\text { de Horticultura, Floricultura } \\
\text { y Fruticultura }\end{array}$ \\
\hline Municipalidad de La Plata & $\begin{array}{lrr}\text { Representante } & \text { de } & \text { la } \\
\text { Dirección General } & \text { de } \\
\text { Planeamiento de } & \text { la }\end{array}$ & $\begin{array}{l}\text { Funcionaria de la Dirección } \\
\text { General de Planeamiento }\end{array}$ \\
\hline
\end{tabular}




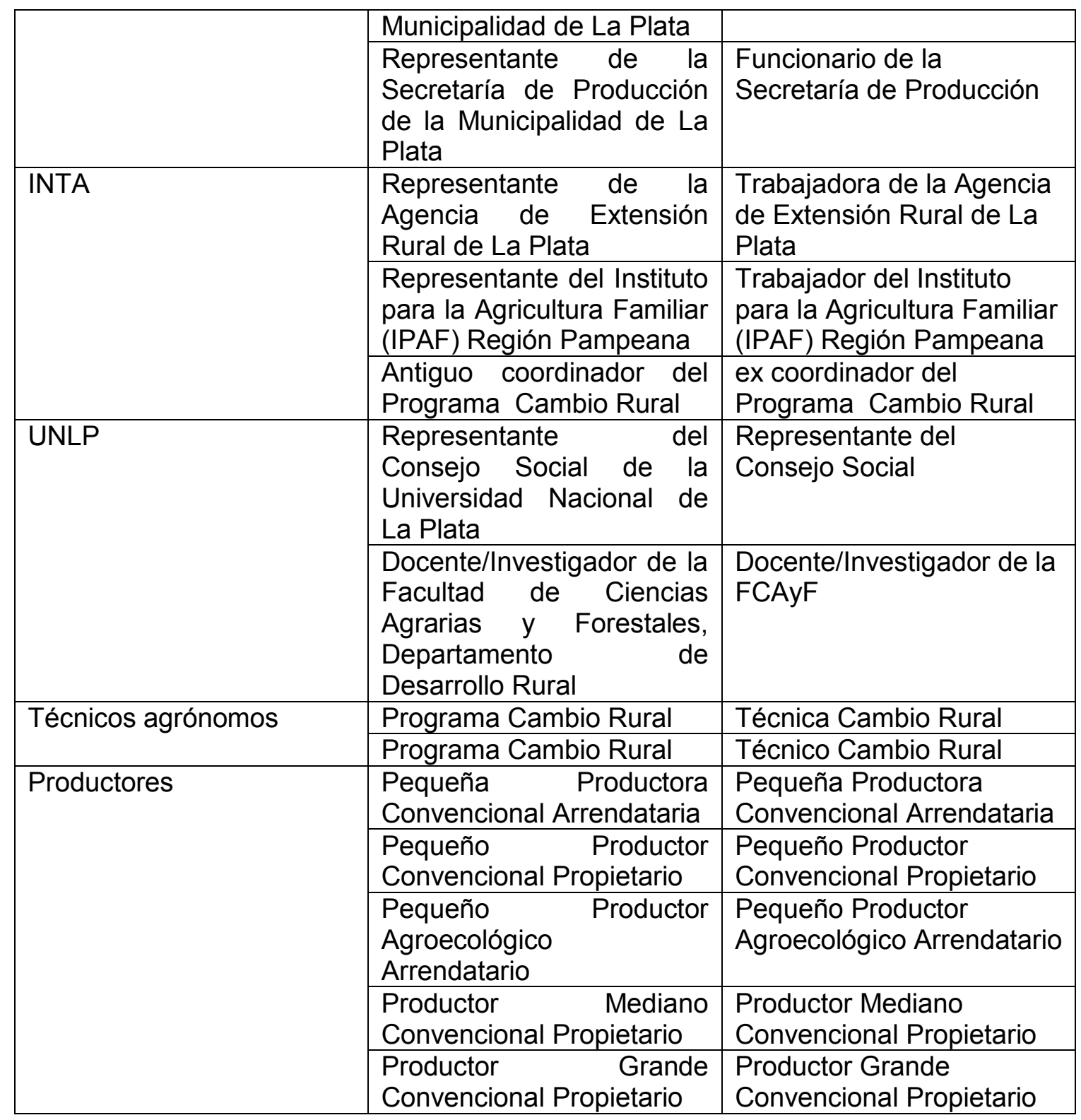

Posteriormente realicé entrevistas semi estructuradas, para las cuales confeccioné una guía de pautas (Anexo 1), con bloques comunes a todos los entrevistados y otros específicos para cada categoría de actor. Todas las entrevistas fueron grabadas previo consentimiento oral de los entrevistados. En el caso de los productores, les solicité adicionalmente que realizaran un esquema de la quinta donde trabajaban y de ser posible les solicité recorrer la quinta y tomar fotografías. Una vez realizadas las entrevistas las desgravé en su totalidad y las sistematicé mediante un grillado (Anexo 2), lo que me permitió organizar los discursos en diferentes categorías de análisis, facilitando la comparación entre las distintas categorías de entrevistados y al interior de ellas. En el análisis busqué tanto aspectos coincidentes como ideas innovadoras o disidentes que pudieran aportar a la investigación. 
Los posibles entrevistados fueron contactados previamente, vía telefónica o por correo electrónico. En esta primer instancia les expliqué el motivo de la investigación, los criterios y el formato de la entrevista, así como el carácter anónimo de la misma. Las entrevistas consistieron en tres momentos, un primer momento de presentación en el que les recordé los objetivos de la investigación y el carácter anónimo de las entrevistas y les solicité permiso para grabar; un segundo momento de desarrollo de las entrevistas y un tercer momento al finalizar las mismas en el que los entrevistados tenían la oportunidad de agregar cualquier comentario que consideraran pertinente. Como mencioné anteriormente, las entrevistas realizadas fueron semi estructuradas, por lo que si bien realicé preguntas orientadoras a lo largo de las entrevistas, los entrevistados podían explayarse con libertad sobre los temas que revistieran mayor interés para ellos.

Las categorías de análisis en base a las cuales agrupé las preguntas orientadoras y posteriormente los discursos de los entrevistados fueron:

- Aspectos generales: incluye preguntas orientadas a conocer aspectos generales del entrevistado/a (institución donde trabaja, rol, antigüedad). En el caso de los productores/as aspectos vinculados a su antigüedad en la actividad, origen, grado de escolarización, otros trabajos, etc.

- Producción y características de la quinta: esta categoría es exclusiva para los productores/as entrevistados y agrupa una serie de preguntas vinculadas a cómo realizan su actividad, los cambios que han hecho en sus prácticas y los motivos de ello.

- Gestión de la actividad productiva: en esta categoría se incluyen preguntas que buscan abordan aspectos vinculados a la gestión pública, las herramientas estatales disponibles para el desarrollo de la actividad productiva local (tanto convencional como agroecológica o afín) desde las esferas nacional, provincial y municipal. Se incluyen preguntas orientadas al diagnóstico de la calidad de las políticas públicas actuales. En el caso de los funcionarios y técnicos se incluyen preguntas orientadas a evaluar las herramientas que les brinda el estado para desempeñar sus funciones.

- Cambios ocurridos en el modelo productivo: incluye preguntas orientadas a identificar los principales cambios en tres períodos de desarrollo del cinturón hortícola. Idealmente se consideran los períodos de análisis de las imágenes satelitales (1985-1995/19952005/2005-2015), sin embargo para facilitar la ubicación temporal y considerando la influencia de los períodos de gobierno en las políticas públicas se tuvieron en cuenta también consideraron los períodos de gobierno de Alfonsín, Menem y Kirchner.

- Problemas de modelo productivo actual y posibilidades de cambio: se abordaron en esta categoría preguntas orientadas a establecer las fortalezas y debilidades del modelo productivo hegemónico, las posibilidades de cambio y la proyección ideal que tienen los distintos entrevistados de cómo debería ser el modelo productivo. 
- Paisaje: en la categoría de paisaje se abordan preguntas vinculadas a los cambios ocurridos en el paisaje en el partido de La Plata, las políticas públicas que traccionaron (por acción u omisión) dichos cambios y los criterios tenidos en cuenta para ello. También se aborda en este apartado los ambientes semi-naturales presentes y el rol de los mismos y se indaga en la proyección que realizan los distintos entrevistados sobre cómo debería ser el ordenamiento territorial del partido. En el caso de los productores/as se incluye un apartado en el que se analizan los ambientes semi-naturales en la quinta y en los alrededores.

A través de las mencionadas categorías analicé las visiones de los diferentes actores sobre aspectos vinculados a los modelos de producción, a las políticas públicas productivas y de gestión del territorio y al paisaje y sus funciones, con el fin de alcanzar los objetivos planteados en este capítulo.

Un aspecto a aclarar en este capítulo es que si bien la investigación y los análisis cualitativos realizados en los capítulos anteriores abarcan el período 1986-2015, considerando los cambios políticos y sociales trascendentales ocurridos en la región y en el país en el último período de gobierno de la alianza Cambiemos, período en el que se desarrolló esta investigación, algunas de las preguntas realizadas a los entrevistados/as incluyeron necesariamente un análisis de este período, como consecuencia de los diagnósticos y reflexiones tanto la entrevistadora como de los entrevistados/as.

\section{RESULTADOS Y DISCUSIÓN}

\subsection{Los principales problemas del CHP y su modelo productivo. Un acercamiento a las posibilidades de cambio}

En la introducción de esta tesis realicé un breve diagnóstico de la situación actual del CHP y de sus problemáticas, cada vez más visibles y que están siendo documentadas a través de diversas investigaciones. Los resultados del análisis de estas entrevistas refuerzan en gran medida este diagnóstico inicial. Es interesante destacar que al indagar sobre el modelo productivo actual, sus beneficios/fortalezas y dificultades, todos los productores entrevistados, a excepción del productor mediano, coincidieron en reconocerlo como un modelo sin ningún tipo de beneficio. Los trabajadores del INTA, de la UNLP y uno de los técnicos entrevistados coincidieron con la lectura realizada por los productores sobre la ausencia de beneficios/fortalezas del CHP bajo el modelo productivo convencional. Algunos de ellos destacaron la gran capacidad de organización de los productores de la región, la fuerte capacidad de trabajo de las familias bolivianas y la impronta familiar de la actividad, reconociéndolas como fortalezas del sector hortícola, pero que no se encuentran asociadas al modelo de producción convencional. 


\begin{abstract}
"Y creo que la fortaleza es esta capacidad de trabajo que tienen que es impresionante, y esta capacidad de ayudarse y de trabajar en comunidad también...acompañado por sectores de distintas dependencias del Estado que a lo largo de los años se han comprometido y que hoy siguen acompañando aunque las políticas públicas muchas veces son adversas..." (Representante del Consejo Social)
\end{abstract}

En el ejemplo anterior podemos identificar la relevancia que tiene el acompañamiento de ciertos sectores del Estado (INTA, UNLP), que perdura en el tiempo más allá de las gestiones políticas. La presencia de estos actores en el territorio y su vínculo con las familias productoras y sus organizaciones es uno de los aspectos que permite, aunque muy lentamente y generalmente en contextos adversos, ir generando mejoras en las condiciones del CHP.

“...para mí la gran fortaleza... igual me preguntás a mí que yo soy fanática, pero para mí es la organización del sector, para mí esta cuestión que se ha dado .... partir del 2010 sobre todo... Hoy es raro encontrar un productor que no está organizado. Hay distintos tipos de organización, algunas organizaciones son más chicas, más de base, cooperativas, asociaciones; pero después tenés las grandes organizaciones, como el MTE o la UTT, que bueno, que es un respaldo para el productor...porque ante la restricción del consumo, el retiro del Estado, los productores tienen sus organizaciones donde poder reclamar, donde poder exigir, donde poder por lo menos reunirse para charlar sobre sus problemas y ver cómo salir adelante" (Técnica Cambio Rural)

Entre los entrevistados que encontraron beneficios/fortalezas en el modelo productivo del CHP encontramos principalmente a los funcionarios públicos (municipales y provincial), al productor mediano y a uno de los técnicos. Los distintos beneficios que destacan estos actores tienen que ver con la rentabilidad del modelo y específicamente de la producción bajo invernáculos, la capacidad de abastecimiento a una gran parte del país y la cercanía a grandes centros urbanos.

"Yo creo que la principal es bueno, eso, abastecer de comida, de alimentos frescos, a mucha parte del país... La rentabilidad y la producción que genera la ciudad de La Plata es muy buena comparada a otras ciudades de otros países..." (Técnico Cambio Rural)

“...vos tenés una producción de hortalizas, de verduras a un precio razonable, en una cercanía de lo que es un gran consumo, es eso, una función de utilidad... permitió eso, nada más" (ex coordinador del Programa Cambio Rural) 
“...tenés muchas más variables controladas. Sobre todo teniendo el invernáculo...En un invernadero sacás una mercadería de calidad visual, mucho mejor que la que sacás afuera. $Y$ el consumidor te paga por algo que es lindo...si hacés a campo podés producir como mucho tres, cuatro ciclos de lechuga. Como mucho, en el mejor de los casos, cuatro ciclos de lechuga. Y adentro podés sacar siete, ocho, hasta nueve ciclos de lechuga. En la misma superficie. Es mucho más intensivo y aparte rinde superior. Y la vas a vender mejor que la de afuera" (Productor Mediano Convencional Propietario)

Dos aspectos interesantes que abordaron los entrevistados tienen que ver con la capacidad productiva y de abastecimiento del CHP y la cercanía a grandes centros urbanos. Aspectos de relevancia, pero que ameritan una reflexión respecto a la planificación del abastecimiento de alimentos frescos a nivel nacional. Hoy en día el CHP es el principal abastecedor de hortalizas del país, junto con el cinturón hortícola de General Pueyrredón; esto pareciera ser el resultado más de una política de mercado que de una planificación del Estado (nacional, provincial, municipal). A nivel mundial, la planificación urbana de alimentos se encuentra en la agenda de los principales países desarrollados (Dansero et al. 2017) por los altos niveles de concentración de la población mundial en zonas urbanas (World Bank 2018) y como respuesta a las externalidades negativas generadas por el sistema alimentario dominante (Dansero et al. 2017). En este sentido, es cada vez más reconocida la necesidad de promover el abastecimiento de alimentos de cercanía a las ciudades, frescos y saludables, que reduzcan el gasto de transporte favoreciendo a su vez la reducción en el consumo de combustibles fósiles y que permitan restablecer los vínculos productorconsumidor, reduciendo las cadenas de intermediarios, que además encarecen el precio final de los productos. Desde este punto de vista, el hecho de ser un centro de abastecimiento de regiones tan alejadas como Bahía Blanca, Río Negro o Córdoba no sería necesariamente una fortaleza. Por el contrario, promover la conformación de nuevos cinturones hortícolas y la recuperación de aquellos en retroceso podría conducir a un desarrollo nacional más adecuado, contribuyendo al desarrollo local, al arraigo rural y a la generación de empleo. Por otro lado, los análisis que frecuentemente se hacer respecto a la rentabilidad de la producción hortícola convencional y especialmente bajo invernáculos, suelen ser análisis sesgados, que dejan afuera muchas variables indispensables para poder llegar a una conclusión fundamentada. En primer lugar, generalmente se suele evaluar la cantidad de producción final obtenida (ej: cuantos kilos más de tomate obtuve por hectárea), sin tener en cuenta la inversión inicial y mucho menos las externalidades negativas que este modelo productivo genera (ej: contaminación, deterioro de la salud, alimentos con alto contenido de agroquímicos, deterioro del suelo). En el CHP se vienen realizando diversos trabajos de análisis de rentabilidad comparando producciones convencionales y agroecológicas (ej: Cataldi y Flores 2019), evidenciando que este modelo productivo no solo 
no es rentable para las familias productoras, sino que las termina endeudando, atrapándolas en un círculo de dependencia que en muchos casos culmina con la expulsión de la familia de la actividad. En segundo lugar, no suele tenerse en cuenta el elevado volumen de producción que, luego de meses de inversión y trabajo de la familia productora, termina siendo descartada por no poder comercializarla, especialmente en las producciones convencionales (Ennis 2019). Resulta necesario ante esta situación preguntarse, qué sentido tiene buscar incrementar constantemente la producción, si esto no se va a traducir en una mejora de la calidad de vida de la familia productora, ni en un mayor abastecimiento para la población, tampoco en una reducción de los precios de los alimentos y menos aún en la provisión de alimentos saludables. Es necesario que todos los actores formen parte de las esferas públicas donde se delinean (o no) las políticas alimentarias, y desde ese lugar empezar a instalar estas preguntas y debates en la población y en los funcionarios de turno. Un de las técnicas entrevistadas describe claramente esta situación:

“...Porque hay mucha oferta. Hay sobreoferta y entonces el camionero no la pasa a buscar, y el productor necesita desalojar el invernáculo para producir otra cosa. Entonces el productor se defiende produciendo, y cada vez produce más para tirar más, y cada vez son más costos. Entonces como que ese círculo debería romperse en algún momento..." (Técnica Cambio Rural)

Como vimos anteriormente, son pocos y al menos cuestionables los beneficios/fortalezas identificados para este modelo productivo. Por el contrario, los entrevistados enumeraron una larga lista de dificultades consecuencia de este modelo, que podemos agrupar en las siguientes categorías:

Condiciones de vida/trabajo. Una política de Estado en relación a la producción de alimentos tiene que partir necesariamente por generar las condiciones estructurales básicas para un desarrollo adecuado de la actividad. Esto incluye garantizar los servicios públicos básicos (luz, agua potable, cloacas, transporte público, infraestructura de caminos, acceso a centros de salud y educación, entre otros). En el caso de zonas como el CHP, donde la horticultura la realiza el sector de la agricultura familiar y cuyo acceso a la tierra productiva es principalmente mediante el arrendamiento (Ambort 2017, García 2015), los contratos de alquiler deberían exigir que los predios a arrendar se encuentren acondicionados para garantizar condiciones de vida dignas para las familias productoras y que los plazos de alquiler permitan la planificación de la actividad productiva. Sin embargo, vemos que en el CHP pocos o ninguno de estos criterios se cumplen, y menos aún en el caso de los pequeños productores arrendatarios provenientes de Bolivia. Las condiciones de vida de las familias que viven y trabajan en el CHP son críticas, con casillas de madera muy rudimentarias, sin aislamiento térmico, sin instalaciones sanitarias ni acceso a agua potable (Ambort 2017) y en muchas zonas con un sistema de recolección de residuos muy deficiente 
o directamente ausente. La falta de infraestructura de caminos y la deficiencia en el sistema de transporte público dificultan tanto el acceso a la salud y la educación, como la comercialización de la producción, como expresa una de las productoras entrevistadas y un trabajador del INTA:

"Cuando mi marido llegó ya mi cuñado estaba trabajando acá en La Plata. Él también alquilaba, después alquilaba allá en El Peligro. Pero era muy al fondo, muy adentro, no se podía salir con días de lluvia, en el último rincón, entonces... y como tengo la nena que es autista, que es discapacitada, la tenía que atender un médico. Entonces que sea más cerca, que medio la pueda llevar, la pueda tratar. Entonces estuvimos ahí como cuatro meses más ahí, entregamos todo y nos vinimos para acá”. (Pequeña Productora Convencional Arrendataria)

“...yo estoy ahí en Olmos, no sabes, ¿cómo te movés? Si estás como si fuera en el Chaco...un chico por ahí viene, que viene como empleado, un peón de una quinta, no tenés micro, estás ahí, vivís en la quinta, estás casi esclavo ahí adentro, entonces ¿qué proyecto de vida tenés personal, individual?..." (ex coordinador del Programa Cambio Rural)

Mis resultados coinciden con Blandi (2016), quien identificó como problemas sociales para los agricultores bolivianos la insatisfacción de sus necesidades básicas, principalmente la vivienda y la tenencia de la tierra.

De los productores entrevistados, los pequeños productores contaban sólo con estudios de nivel secundario (algunos sin finalizarlos). Estos productores se enfrentan a dificultades físicas, culturales y económicas para acceder a ámbitos educativos formales que les permitan continuar su formación, afectando sus posibilidades de crecimiento personal/profesional y condicionando las posibilidades de acceso a otros trabajos. Las dificultades para llegar a los centros educativos (generalmente ubicados en el centro de la ciudad), los mecanismos de ingreso a estos ámbitos muchas veces burocratizados, sumado a las dificultades producto de las diferencias culturales y la autoexplotación laboral a la que se someten como una forma de poder progresar económicamente (Ambort 2017) son algunas de las limitantes. Al mismo tiempo, estas restricciones de acceso a la educación pueden ser condicionantes para la formalización frente al Estado, generando dependencia de terceros, ya sea para trámites como el monotributo, que muchas veces son engorrosos y burocráticos, o a la hora de formular proyectos productivos para acceder a beneficios por parte de programa estatales. Los dos técnicos de cambio rural entrevistados son claros en este sentido:

“...fui técnica de cambio rural. Tuve varios grupos, pero siempre en el marco de organizaciones... La primer demanda fuerte de ellos era para el tema de formulación 214 Lic. Carolina Baldini Tesis doctoral - Territorio en movimiento 
de proyectos. Ellos necesitaban alguien que los vincule con las diferentes fuentes de financiamiento, y las veían... que bueno, que todas eran a través de proyectos. Ante distintas dependencias del Estado, pero siempre a través de proyectos" (Técnica Cambio Rural)

“...en realidad primero surgía porque ellos querían escribir básicamente...El primer laburo como tal que quería la asociación era que estuvieran uno o dos agrónomos que hicieran más trabajo de sentarse a plasmar demandas que ellos tenían y vincularlas a la facultad o al ministerio".

En cuanto al arrendamiento, dos de los pequeños productores entrevistados son arrendatarios actualmente. Sin embargo, excepto el PCGP de origen europeo, todos los otros productores, incluso aquellos que actualmente han accedido a la propiedad de la tierra, han pasaron por al menos tres arrendamientos en distintas localidades del partido, lo que muestra la alta movilidad a la que se ven forzadas las familias productoras. En general los productores entrevistados en los últimos 15-25 años vienen arrendando la misma quinta. El tiempo prolongado que hace que están produciendo en el mismo lugar haría pensar que estarían en condiciones de proyectar su producción; sin embargo. probablemente la experiencia de cambiar tantas veces de quinta al comienzo, sumado a los altos costos de vida y de producción actuales hace que les resulte difícil pensar en la posibilidad de decidir cómo quieren producir. En los siguientes ejemplos podemos ver las limitantes que identifican tanto los pequeños como el mediano productor frente a las condiciones de arrendamiento:

“...mis viejos siempre fueron... arrancaron como peones, después estuvieron como medianeros, en una quinta acá en Barrio Malvinas...de ahí nos fuimos a Hernández a alquilar, porque mi viejo ya no podía laburar, tenía problemas en los pulmones, entonces alquilamos una hectárea y media más o menos. Era una tapera. Ay dios, lo que era esa casa. Contrato por seis meses. Cada vez que llovía no sabía por dónde tapar las cosas. El viejo no quería comprar chapas nuevas. Estuvimos ahí, fueron los peores creo que tres, cuatro años. De ahí nos fuimos a Romero, una quinta chiquita en Romero". (Productor Mediano Convencional Propietario)

“...alquilamos, alquila mi viejo, que todavía está, mi hermano y yo, somos tres inquilinos. Alquilamos ya hace 15 años casi, vamos a cumplir. $Y$ cada tres años te renuevan el contrato, y cada vez es más alto el alquiler, no se puede sostener más, con toda la inestabilidad que tiene que ver con el dólar..." (Pequeño Productor Agroecológico Arrendatario).

Problemas productivos. Una de las problemáticas expresadas para desarrollar su actividad productiva, tiene que ver con las dificultades para afrontar los eventos climáticos extremos cada vez más frecuentes, por falta de infraestructura y equipamientos adecuados. 
"La dificultad que ahorita en mi casa estamos pasando es el tiempo de lluvia... el modo de sacar la verdura. Porque no tengo, tengo que sacar en el carrito. No tengo maquinaria, no tengo tractor, no tengo nada. Sacamos en el carrito. Y cuando está así seco está bien, pero cuando llueve ese es el tema...Mucho barro, no se puede trabajar y aunque esté la verdura tenés que hacerlo así. Y después el tiempo, el viento... cuando tenés adentro del invernadero viene un viento y te lo saca todo. Este año hemos cambiado todo el nylon..." (Pequeña Productora Convencional Arrendataria)

Por otro lado, en relación a la actividad productiva identificamos una fuerte tendencia a producir bajo invernáculos y una situación de vulnerabilidad asociada a ello. De los productores entrevistados, el productor grande fue el único con toda su producción bajo invernáculo. Sin embargo, tanto los pequeños productores como el productor mediano manifestaron haber tenido recientemente la mayor parte de su producción bajo invernáculos, con un pequeño porcentaje al aire libre; evidenciando la tendencia que existe en la región a la producción bajo cubierta. En el último tiempo, al haber sido afectados por sucesivos temporales que generaban, entre otras consecuencias, la destrucción total de gran parte de los invernáculos, los pequeños productores arrendatarios y el productor mediano plantearon un cambio en la tendencia mencionada, comenzando a producir al aire libre en aquellos sectores de la quinta con invernáculos que habían sido afectados por algún temporal. Entre los motivos de esta decisión, los pequeños productores plantean claramente una dificultad para afrontar la inversión que se requiere para construir o incluso arreglar un invernáculo; también hacen referencia a la especulación por parte de las empresas proveedoras frente a la necesidad de las familias productoras, lo que muestra claramente una falta de regulación por parte del Estado, dejando a los productores afectados en manos del mercado.

“...Pero vino el viento el año pasado... en enero, febrero, creo que fue como un tornado que hubo. Ahí me arrancó todos los palos...Me lo mandó todo a la quinta del vecino... A mí me lo arrancó todo, palo entero con alambre, manguera y todo. O sea que me lo dejó limpiecito...Por eso quedó todo campo. Ya no (no quiso volver a armar los invernáculos) porque es mucha inversión, y están las maderas muy caras. Encima los nylon y todas esas cosas...cuando viene un viento así, vos querés comprar un rollo de nylon y te suben el doble. Entonces mi marido ya no quiso más armar el invernadero" (Pequeña Productora Convencional Arrendataria)

“...hubo un temporal, nos dejó sin nada, esa vez no... fue imposible remontar todo lo que teníamos ya, y ahora nos dejó en la ruina eso, cuesta muchísimo armar un invernadero, para que tengas idea unos 80 ochenta mil pesos, más o menos." (Pequeño Productor Agroecológico Arrendatario) 
A diferencia de los motivos económicos que plantean los pequeños productores, el mediano productor, mas capitalizado, hace hincapié en la incertidumbre frente al cambio climático en la región.

“...En septiembre le pusimos los techos a todo lo que teníamos, que habían quedado de las 5 hectáreas y media más o menos una hectárea(al aire libre), me tiró en febrero, que no lo levanté, y terminé de techar en septiembre esto; y bueno, ahora me tiró otra tanda, así que voy a acomodar lo que... será una hectárea y media más o menos...el resto a campo. Más que por el costo por el tema de la incertidumbre del clima. Es lo que hablamos hoy, esto ya vino para quedarse. No creo que vaya a cambiar'.( Productor Mediano Convencional Propietario)

Al indagar en los motivos por los cuales eligen producir bajo invernadero, pese al riesgo que implica como vimos en los párrafos anteriores, tanto los productores pequeños como el productor mediano plantean motivos que tienen una estrecha relación con lo que podríamos llamar "las reglas del mercado". Entre estos motivos se destacan la necesidad de producir verdura rápido, para poder vender y cubrir los gastos fijos mensuales, propios de la actividad tal como la desarrollan hoy en día; y las características estéticas que debe tener la verdura para que sea aceptada por los consumidores (incluyendo en esta categoría al dueño de la verdulería que va a comprar al mercado central y al consumidor final que compra en la verdulería de barrio), en consonancia con los planteos de Marasas et al. (2014). En este sentido Blandi (2016) plantea que el mercado y el asesoramiento técnico juegan en contra de la sustentabilidad de los sistemas; o dicho de otra manera, a favor de la producción bajo invernáculo.

“...entonces a la espinaca, la albahaca, la lechuga, la manteca ya, o sea... no se puede plantar casi (al aire libre) por la lluvia, mucho cuando llueve o cae granizo lo pica mucho, y la gente no quiere llevar así. Vos vas... ni los camiones ahora tampoco, no te quieren sacar lechuga de campo... Cuando es lechuga de campo te pagan por la mitad de lo que es de invernadero...porque (antes) se consumía lechuga de campo, y ahora no quieren consumir...si es de campo no te lo llevan en el mercado... Entonces por eso es que los camiones al no tener venta, ¿para qué van a llevar una cosa que no lo van a poder vender? ¿Se vende? Sí, capaz, cuando no hay en los invernaderos lechuga..." (Pequeña Productora Convencional Arrendataria )

“...en invernadero vienen más rápido las verduras, (en relación al motivo por el cual eligen producir bajo invernáculo) una es por los alquileres, que nos agotan mes a mes... vos en el invernadero es como una verdura segura que vos sacás sí o sí." (Pequeño Productor Agroecológico Arrendatario) 
“...el tema es que en el invernadero justamente la mercadería está protegida, en un clima así como ahora... Y a su vez como decíamos hoy la gente paga lo estético, lo lindo. La berenjena de campo va a estar siempre manchada, y adentro está brillante, perfecta, pero mirá el reflejo. El consumidor te lleva esa berenjena (la que brilla). Entonces eso fue lo que nos hizo pasarnos al invernadero". (Productor Mediano Convencional Propietario)

“...La lechuga de ninguna variedad te la quieren llevar, excepto la capuchina. Después el apio tampoco te lo quieren llevar de campo. La acelga también, a veces de campo no quieren mucho. Hoy en día. Antes sí se la llevaban la acelga. Vos les decías acelga, y no les importaba si era de invernadero o de campo, para ellos era acelga. Pero hoy en día te preguntan: "tengo acelga”, “¿de dónde es, de invernadero o de campo?", te dicen. Te van como condicionando a que tenés que hacer de invernadero para poder vender este producto". (Pequeña Productora Convencional Arrendataria)

Al analizar cómo habían cambiado con el paso del tiempo la forma de producir, todos los entrevistados coincidieron en que antes producían más variedad de verduras y que con el paso del tiempo fueron reduciendo, llegando incluso algunos a sembrar casi en su totalidad tomate y morrón. La Pequeña Productora Convencional Arrendataria planteaba que también había empezado a producir menos cantidad, por las dificultades que encontraba en la comercialización.

“Antes sembrábamos más, más... cómo se puede decir, más variedades, más seguido y más variedades...Porque como te digo la acelga no te la quieren casi llevar. Hoy en día los camiones te preguntan si es de invernadero o es de campo. Bueno, el akusai también (siembra) poquito, porque por el clima se te llena mucho de bichos y no te quieren llevar... cuando tienen bichos no te lo quieren llevar en los camiones...No sé por qué, antes había más camiones que venían a sacar la verdura. Y hoy día no... antes entraban cuatro o cinco camiones que venían de Buenos Aires, se acercaban hasta acá, pero ahora ya no. Dicen que ahora hicieron... Viste que por acá (Arana) no vas a ver muchos invernaderos. Por Bavio dicen que se llenó de invernaderos, entonces los camiones van todo para allá, ya no entran acá..." (Pequeña Productora Convencional Arrendataria)

Dos aspectos entonces marcan las desventajas o lo poco sustentable de apostar a tener una amplia superficie bajo invernáculos. Por un lado los altos costos de inversión y la dificultad de recuperarse luego de un temporal, y por otro lado la frecuencia con que estos sucesos climáticos están ocurriendo. En este sentido, estamos en un momento en el que las familias productoras se encuentran más permeables a generar cambios, lo que lo hace 
propicio para fomentar una transición hacia otro tipo de producciones. Si bien tener una parte de la quinta con producción bajo invernáculos es, sin lugar a dudas, importante en las condiciones actuales que atraviesan las familias productoras; propiciar a través de políticas públicas el desarrollo de producciones más diversas, entendiendo la diversidad en un sentido amplio, donde se incluya diversidad productiva (de semillas, animales de granja, etc) y diversidad de ambientes (ambientes semi-naturales o zonas en descanso, producciones bajo cubierta y al aire libre), de la mano de mejoras en las condiciones de comercialización, va a ser lo que realmente contribuya a mejorar su capacidad de resiliencia.

En relación a los problemas productivos, un aspecto planteado por un trabajador del INTA pero que no formó parte de los problemas mencionados por los productores entrevistados es el de la falta de diversificación productiva, como se plantea a continuación:

“Después debilidades me parece que la cuestión de la escasa o nula diversificación productiva. La agricultura familiar, digamos, como estrategia de supervivencia, hablando a nivel general, siempre utiliza la diversificación productiva como una estrategia de supervivencia, ¿no? El productor familiar por ahí tiene gallina, tiene cerdo, tiene... y según las oportunidades que tiene va vendiendo uno u otro. Y acá son un poco... de alguna manera se replica el modelo de monocultivo de la soja pero a nivel de la horticultura..." (Trabajador del IPAF Región Pampeana)

Problemas de comercialización. Los problemas de comercialización planteados por los productores entrevistados tienen un fuerte vínculo con la falta de planificación y de intervención del Estado en la actividad. Todos los productores entrevistados plantearon como un inconveniente lo que es el principal mecanismo de comercialización en el CHP, que es la venta a través del mercado central, principalmente mediante la venta a "culata de camión", es decir que el camión va a la quinta a retirar la verdura, que luego se vende en los puestos del mercado central. En este sentido se destacan dos aspectos vinculados al libre mercado, por un lado al no existir una planificación de la producción por parte del Estado, hay momentos de sobre oferta que generan una baja de los precios en el mercado y momentos de faltante de ciertas verduras, en los que se incrementa su valor; por otro lado al no existir un acuerdo en relación a los precios de las verduras, los mismos fluctúan semanalmente e incluso diariamente. Estos aspectos hacen que sea imposible la planificación por parte de las familias productoras, dejándolas en una situación de extrema vulnerabilidad.

"El tema es que te queda cuando de golpe todo sale y después hay mucha variedad, los camioneros no te quieren cargar cuando hay mucho, digamos, o en toda la zona hay mucha, o está bajo el precio, entonces no te quieren llevar. Sí, nos sabemos quedar". (Pequeña Productora Convencional Arrendataria) 
"o sea mandas la carga, y cuando vuelve el camión, o a la semana o a los tres días que vuelva por más carga, te entrega la boleta. Ellos te pagan lo que puedan...eso es lo que yo digo que está muy mal. Tendríamos que ser más unidos y poner un precio a la verdura, porque hoy en día cuesta... son vivezas de los camioneros y del mercado. Porque por ahí te agarran y cuando sube vos nunca te enterás, te enterás a la semana..." (Pequeña Productora Convencional Arrendataria)

"...ponele viene un camionero y viene y te dice -te compro tu carga- y la consignación es bueno...-después te pago- y a veces no vuelven más...y vos por necesidad o vos porque ya no te queda, y otra vez tenés que terminar vendiéndola porque no... sino la vas a tener que tirar y es peor todavía". (Pequeño Productor Agroecológico Arrendatario)

“...planté morrón, todo el invernadero morrón. Y el campo tenía todavía brócoli para sacar. Pero vino así un temporal de lluvia que me lo cubrió todo al brócoli. No saqué ni una jaula de brócoli, todo ya estaba para sacar, para empezar a sacar. $Y$ en el invernadero tenía morrón, no valía nada. Cinco pesos el cajón de morrón me pagaban. Y encima mi marido... claro, él quería plantar morrón, le digo "plantá la mitad", no, él se encaprichó con plantar todo el invernadero. No valió el morrón, se nos hizo rojo en la planta(lo tuvieron que tirar). Valía cinco pesos nos querían pagar".

"...es muy difícil manejar un precio en horticultura. Porque siempre trabajás por oferta y demanda, entonces es muy difícil ponerle un número a lo que vos producís. Porque... digamos, a veces falta mercadería en la zona y en el mercado sube el precio. Requiere el mismo producto todo el mundo, y hay demanda y crece el precio. Y por ahí puede haber abundancia y ¿se deprime el precio porque no se vende? No, porque hay mucha producción". (Productor Grande Convencional Propietario)

Al no haber una planificación clara por parte del Estado respecto a la zona productiva, inversión en infraestructura vial y de servicios acorde a un área productiva, ni una proyección de su expansión, las familias productoras se van mudando, en busca de mejores suelos y/o de alquileres más bajos, a otras zonas del partido o incluso a partidos vecinos, como consecuencia de las presiones que ejercen tanto el mercado de alimentos como el inmobiliario. En los siguiente ejemplo podemos ver como esto no solo afecta a las familias desplazadas, sino que también genera cambios en las dinámicas comerciales que afectan a aquellos que aún permanecen en las mismas zonas productivas.

“... Viste que por acá (Arana) no vas a ver muchos invernaderos. Por Bavio dicen que se llenó de invernaderos, entonces los camiones van todo para allá, ya no entran acá..." (Pequeña Productora Convencional Arrendataria) 
“...un puestero del Central manda los camiones a levantar carga acá...la venta es como a culata de camión...es la lógica de recorrer la zona con el camión para completar las cargas para el mercado. En término de costos al tipo le conviene seguir por ruta 36, que está asfaltada y no rompe el camión, no gasta la cubierta, a meterse en las callecitas destrozadas de Etcheverry, de Los Hornos. Cuando vos te salís de las avenidas están las calles hechas mierda, porque no hay inversión, viste. Entonces ir a buscar una lechuga cinco cuadras para adentro, ocho, que perdés tiempo, qué sé yo, y rompés cubiertas, el tipo prefiere venir por la ruta 36 , se va a Poblet, carga el camión ahí y se vuelve. Esas lógicas tironean, traccionan por dónde te instalás..." (ex coordinador del Programa Cambio Rural)

Con el auge del supermercadismo en la década de 1990 los productores grandes tendieron a orientar su producción a estas grandes cadenas comerciales, una forma de comercialización que perdura hasta la actualidad. En los últimos años se ha visto también como algunos pequeños productores organizados en cooperativas comienzan a tener la posibilidad de comercializar con hipermercados y cadenas de comida rápida, favorecidos por la nueva ola de promoción de la agricultura familiar potenciada a partir de la sanción de la ley de reparación histórica de la agricultura familiar. Este es el caso de la cooperativa de la cual forma parte el Pequeño Productor Convencional Propietario, quien relata que recientemente incorporaron, además de la venta a culata de camión, en ferias y a través de bolsones, la venta de ciertas verduras (principalmente lechuga, y en mucho menor medida morrón, tomate, pepino) a una cadena de comidas rápidas. A continuación el Productor Grande Convencional Propietario relata su experiencia en este sentido:

"Nosotros tenemos ahora un poco de tomate, pimientos y estamos haciendo ahora... empezando con el tema de una hoja, lechuga... Hicimos en este caso una especie de contrato con una de las empresas que trabaja para... que le entrega a McDonald's, y bueno, nos piden unas variedades, trabajamos con esas variedades. Y esa misma empresa nos pide que tengamos Global Gap (certificación según buenas prácticas agrícolas), la certificación que te nombraba. Entonces uno se tiene que meter en el circuito ese para poder... es un negocio que se cierra... que está bien, porque vos pactás un poco el volumen y un precio..." (Productor Grande Convencional Propietario)

Este tipo de vínculo comercial tiene ventajas y desventajas. Por un lado estas grandes empresas suelen traccionar una mejora en la infraestructura de los galpones de acopio, salas de lavado y empaque, y en la "calidad" aunque en general estética de la producción, a través de los contratos. En este sentido, el Pequeño Productor Convencional Propietario menciona durante la entrevista como condición para poder firmar el contrato con la cadena de comida rápida, el haber contado a través de la cooperativa con un terreno con 
galpón de acopio y con el equipamiento y las condiciones adecuadas. La estrategia de conformación de cooperativas que se está dando en las distintas organizaciones de productores del CHP en los últimos años, facilitó en varias organizaciones el avance en el equipamiento y la mejora de la infraestructura, por ejemplo a través de programas como el Proderi, que facilitaron la construcción de galpones de acopio en 3 organizaciones del CHP. Sin embargo, por la magnitud de estas empresas y en consecuencia de las compras que realizan, las condiciones de negociación no dejan de ser extremadamente desiguales (Teubal y Rodríguez 2002), y los criterios de calidad definidos unidireccionalmente. En el caso de los grandes productores, que no están asociados, sino que venden individualmente a estas empresas, vemos a través del relato del productor entrevistado, cierto riesgo de que a través de estos acuerdos se condicione la posibilidad de diversificar la quinta; ya que en general estas empresas demandan pocos productos y en cantidades significativas, demanda que debe responder en este caso un único productor. Si bien este riesgo también se corre en el caso de los pequeños productores, consideramos que el hecho de estar organizados en cooperativas $u$ otras formas de asociativismo aporta herramientas a la hora de negociar, facilita a su vez la posibilidad de hacer un reparto equitativo al interior de la organización para responder a la demanda y permite un espacio de debate político en relación al horizonte que se persigue en cuanto al desarrollo productivo, quedando mejor posicionada al momento de la negociación. Este tipo de acuerdos es importante que exista, como una forma de fomentar la producción nacional y la agricultura familiar, como ocurre en otras partes del mundo. Sin embargo, es indispensable que el Estado intervenga, regulando estos acuerdos, estableciendo criterios de calidad en base a la salud y no a criterios estéticos o de moda, regulando los precios, fijando cupos para que la agricultura familiar abastezca a estas cadenas, y propiciando la mejora de la actividad productiva mediante el financiamiento de proyectos, entre otros.

El funcionario provincial entrevistado resume los problemas de comercialización existentes en el CHP de la siguiente manera:

“...el sector tiene un gran problema en la parte de comercialización, es una cadena muy viciada de actores innecesarios, mucha intermediación que encarecen los productos y que queda atrapado el productor a un precio siempre a la baja..." (Funcionario de la Dirección de Horticultura, Floricultura y Fruticultura)

“...la producción está saturada de productores, los mercados están colapsados, hay mucha concentración y están todos atomizados acá los productores, están todos en esta región entonces lo que pasa es que no hay un ordenamiento en las producciones, entonces cuando hay tomate hacen todos tomate y se saturan los mercados..." (Funcionario de la Dirección de Horticultura, Floricultura y Fruticultura) 
Problemas ambientales: contaminación por agroquímicos, acumulación de envases de agroquímicos, problemas con las perforaciones para riego, impermeabilización del suelo por invernáculos

El uso excesivo de agroquímicos y la contaminación de suelo, agua y alimentos han tomado estado público en los últimos años, con contundentes investigaciones que lo corroboran (Sarandón et al. 2015, Alonso et al. 2015, McLouguin 2017, Arias 2019). Uno de los pequeños productores, cuya producción es desde hace varios años agroecológica, describe las causas de este abuso en el uso de agroquímicos de esta manera:

“¿Cuál es el ingenio que nosotros hemos hecho si nosotros hemos envenenado la tierra? Porque la salud, la salud hoy por hoy del pueblo y de todos los pueblos, lamentablemente, va, lo han logrado los agrónomos y las farmacias, y ese...¿Por qué? Porque la misma empresa que te enferma la tierra y que te enferma a vos, $y$ que te infla, como te digo yo a vos, es la misma que después te quiere vender los venenos... los medicamentos supuestamente". (Pequeño Productor Agroecológico Arrendatario)

Un funcionario municipal describe la situación a la que se encuentran expuestos los productores hortícolas mediante el siguiente ejemplo:

"Yo he tenido productores acá que han venido con los brazos casi sin movilidad diciendo "no produzco más porque le agroquímico me está matando". (Funcionario de la Secretaría de Producción)

Uno de los técnicos y uno de los productores entrevistados coinciden en describir el rol de las agroquímicas en este contexto de la siguiente manera:

“...supuestamente hay productos que no se deberían vender, pero que tú te das cuenta que los venden, salen ventas de productos agroquímicos sin una receta agronómica. Entonces digamos que el productor queda medio ligado a la dosis que le dice la gente en el comercio, y a veces son dosis que son demasiado elevadas, entonces cuando el productor lo aplica, confiando en que lo que el comercio le está diciendo es verdad, luego viene por detrás lo que sale en los medios de comunicación, los estudios...digamos, cuando sale, no sé, una lechuga que hacen los estudios que tienen alto contenido de agroquímicos..." (Técnico Cambio Rural)

“...las garrafas (de Bromuro) también que está prohibido pero que las siguen trayendo, que las siguen haciendo o sea...las agroquímicas, sí, o sea, ellos es negocio, hoy por ejemplo, es negocio porque está 60 mil, 80 mil pesos una garrafa". (Pequeño Productor Agroecológico Arrendatario) 
Tanto el Pequeño Productor Agroecológico Arrendatario, como el Pequeño Productor Convencional Propietario, los cuales además tienen bastante antigüedad trabajando en el CHP (el Pequeño Productor Agroecológico Arrendatario desde 1995 y el Pequeño Productor Convencional Propietario desde 1983), coincidieron en que con el paso del tiempo se comenzaron a utilizar cada vez más agroquímicos en la producción, y que eso generaba el deterioro de los suelos, obligando a los productores a mudarse a otras zonas del partido. En este sentido ambos coincidieron en marcar a El Peligro como una localidad clave donde se dio este proceso.

"Y el modelo de producción cada vez era más veneno, más veneno y todos los años... se intensificaba más los venenos...Y cada vez la producción se fue dando cada vez más intensiva, cada vez que la tierra no servía, uno se iba...nosotros sabíamos producir radicheta, por ejemplo, te daba dos, tres años, y después de dos, tres años, no te daba más, o sea porque ya la tierra se cansaba" (Pequeño Productor Agroecológico Arrendatario).

“...en el Peligro la tierra no servía más, después se iba... se iban cambiando muchos compañeros, no sólo nosotros, sino muchos compañeros, por eso es que cada vez hay más quinta en todos lados... (la tierra no servía mas)más que nada por los químicos que se tiran, por los venenos que le tiran a la tierra... entonces todos los años ponen una misma cosa y cada vez los venenos más intensificados, más, y al final la tierra termina siendo como un talco que no sirve para nada... tiene que ser porosa y penetrar para adentro, más el tractor lo aplana y queda como un cemento, entonces no... no tiene vida el suelo" (Pequeño Productor Agroecológico Arrendatario).

Si evaluamos que una de las causas de la movilidad de los productores tendría que ver con el deterioro de los suelos, es interesante resaltar el siguiente comentario del productor agroecológico:

"Por ejemplo ahora estamos durando tantos años acá (en la misma quinta) también porque volvimos a hacer esto (producir agroecológico) y... sino ya la tierra no servía...la agroecología se trata de darle a la tierra, se trata de darle, devolverle la vida que se destruyó en el suelo, eso lo que trata la agroecología, entonces se hacen compost anaeróbicos, se hacen muchos biofertilizantes, con meo de vacas, cosas así, de hecho ahí tenemos tachos ahí que están para preparar, están preparados esos... se va dando cosas, entonces la verdura sale mucho mejor y es de mejor calidad". (Pequeño Productor Agroecológico Arrendatario)

Un problema generado por el uso excesivo de agroquímicos, pero menos abordado y con un fuerte impacto en la salud y en el ambiente es la acumulación de envases de 224 Lic. Carolina Baldini Tesis doctoral - Territorio en movimiento 
agroquímicos en las quintas de las familias productoras y sus alrededores (García 2011); problema que no ha sido considerado adecuadamente desde las esferas del Estado y cuya disposición final aún hoy no está resuelta. Pese a ser un tema que debería tener prioridad en la agenda pública, los gobiernos de turno suelen abordarlo en función del rédito político que les genera o de las ganancias que pueden obtener lucrando con la gestión de estos residuos. Las empresas de venta de agroquímicos por su parte, y ante la falta de regulación por parte del Estado, no se hacen responsables de la disposición final de los envases que ellas comercializan. Frente a esta situación, los envases terminan acumulándose en las propias quintas, tirándose junto con otros residuos o lo que es peor aún, incinerándolos junto con otros residuos, una práctica habitual en la región. A continuación un productor y un técnico hacen referencia a esta problemática:

“... a mí me daba por la pelota ver los envases tirados en la calle. Frente al colegio, un poquito más acá, yo de pedo encontré una nena que agarró un envase y cargó agua del arroyito. Lo vi de pedo. Un envase encima de un producto... Entonces se lo saqué, y justo vi una bolsa de residuos, que había un montón de envases que habían tirado ahí en el arroyito. "Pero la puta madre",entonces planteé en la cooperativa, "loco, quiero hacer esto"...habiamos arrancado a hacer un proyecto de una planta de reciclado de los envases plaguicidas. Conseguimos el predio del Parque Industrial, toda la bola, y después esta gestión nos puso cincuenta mil trabas y no pudimos avanzar...el municipio no nos da el permiso de obra del terreno". (Productor Mediano Convencional Propietario)

"Yo creo que hay una desregulación muy fuerte en el uso de agroquímicos, sobre todo en los comercios, que pueden vender cualquier cosa, un tema de desregulación, el tema de los envases de agroquímicos, qué pasa con esos envases, con el plástico, qué pasa con el plástico cuando se deja de utilizar. Comúnmente se quema. Yo creo que ese tema es bastante complicado. La recolección de envases de agroquímicos..." (Técnico Cambio Rural)

Otro problema ambiental mencionado en las entrevistas y fuertemente vinculado a la falta de regulación del Estado tiene que ver con problemas de contaminación producto de las perforaciones para riego y la impermeabilización del suelo por invernáculos, aspectos identificados también en García (2011). Los problemas vinculados con las perforaciones se ven agudizados en los últimos años por el cambio en el tamaño de las unidades productivas, mediante el subarrendamiento; las antiguas quintas de 6 a 8 ha se subdividen en fracciones de entre 0,5 y 1,5 ha (aproximadamente), y son trabajadas por distintas familias que comparten el alquiler o que se asocian en mediería, y viven todas en el mismo lugar (Ambort 2017). A continuación presentamos las palabras de un productor y de un trabajador del INTA haciendo referencia a esta problemática: 
"Tampoco hay ningún tipo de control en el tema de los pozos de riego, se han hecho perforaciones a rolete, y eso a futuro creo que lo vamos a pagar. Yo no sé si eso tiene control o no, pero yo creo que es un problema porque son muchísimos... Yo he ido a un predio, en 6 hectáreas había cuatro perforaciones, una locura. Yo en 7 tengo una". (Productor Mediano Convencional Propietario)

“...se parcelizó, aumentó la cantidad de unidades de producción, de una hectárea, una hectárea y media, sigue hoy, se te instala un modelo totalmente distinto bajo forma de arrendamiento, con alquileres y eso genera un despelote estructural pero descomunal, porque imaginate que alguien que alquila una hectárea de golpe, bueno, como el propietario sabe que es un alquiler trucho, no le permite construir una casa, entonces se arman todas casillas de madera precariamente, hacen perforaciones de agua que no están permitidas, vos en esas 4,5 hectáreas tenés una perforación, esto lo multiplicás por 4, por 5, mal hechas, bueno, todo un despelote estructural..." (ex coordinador del Programa Cambio Rural)

“...bueno, también problemas con el agua, con las perforaciones porque los poceros que hacen las perforaciones han hecho cualquier cosa, malhechas, sin encamisar, qué sé yo, los pozos ciegos cerca, buá, toda una situación que ha contaminado las napas, hoy tenés problema de recuento de coliformes en el agua como, viste, 70, 80 por ciento del agua acá está contaminada..." (ex coordinador del Programa Cambio Rural)

Falta de regulación del Estado. En el caso del Productor Grande Convencional Propietario, este hizo especial hincapié en los problemas de informalidad de gran parte de los pequeños productores, la fuerte carga impositiva que deben afrontar los productores que trabajan en blanco y la falta de apoyo a la actividad hortícola.

“Los costos de producción. Y la presión impositiva, que también está acarreándose cada vez más. O sea, hay una presión impositiva importante, a raíz de la competencia desleal que hay con los que están en el sistema y los que no están en el sistema"

"(en relación a la especulación financiera) Hoy teniendo la misma plata que harías un invernáculo decís: pará, si el banco me da más plata que (si) yo quisiera producir, ¿para qué carajo lo voy a poner en riesgo, si el banco te da más plata sin trabajar? ¿Y entonces vos qué haces? Y, no trabajo, lo pongo ahí (en el banco). Nosotros seguimos trabajando... no somos de ese tipo de gente, siempre la (plata) que producimos es la que gastamos, y somos tan necios que encima la reinvertimos" 
"La especulación deja más plata. Entonces vos decís: si hay gente que juega con eso... Están matando al que labura. En el caso nuestro nos están matando...Nosotros tenemos que mutar de lo que estamos haciendo, así no podemos seguir más. Porque no te da el bolsillo. Entonces es como que empezás a resignar cosas, entonces te vas apagando, apagando...A mí lo que me da no sé qué es -matamos a los que medianamente lo estoy mirando, lo mato, así, lo quiero matar, porque este no tiene que existir más. Yo quiero productores chicos, porque así es mejor- (en referencia al accionar del Estado). Así tenga un mercado más informal todavía".

En los ejemplos anteriores podemos ver como ante la falta de planificación de la actividad productiva por parte del Estado y abriendo el juego al libre mercado, se termina afectando tanto a los pequeños como a los grandes productores, quienes tampoco se sienten a gusto con la actividad tal cual la desarrollan en la actualidad. Por otro lado, como en otras problemáticas del CHP vemos que se desdibujan las responsabilidades, generando una confrontación entre productores y una vez más responsabilizando al más débil de la cadena, cuando los principales responsables son el modelo neoliberal a través de sus agentes de mercado y el Estado por su connivencia y falta de planificación/regulación.

Otro aspecto vinculado a la falta de regulación por parte del Estado tiene que ver con la especulación inmobiliaria en zonas productivas. Un funcionario provincial lo describe de la siguiente forma:

"...hoy la puja entre lo inmobiliario y lo productivo es algo que al productor le juega en contra, le genera incertidumbre, no sabe a donde va a estar dentro de dos años, no puede hacer una inversión, no puede tener una vivienda digna, queda atrapado a muchas cosas..." (Funcionario de la Secretaría de Producción)

Asesoramiento. En los últimos tiempos, con el crecimiento del interés en la agroecología se vienen reflexionando al interior de las distintas facultades de agronomía respecto a las deficiencias en la formación de sus profesionales, que salen de estas facultades con una formación muy "empresarial", orientada a resolver problemas exclusivamente mediante la aplicación de agroquímicos, sin entender los procesos propios de los agroecosistemas. En este sentido, en las entrevistas pude constatar esta misma crítica, tanto en el productor grande como en el pequeño productor agroecológico; en coincidencia con Blandi (2016) y Seibane et al. (2014), quienes hallaron en sus investigaciones que el sector privado promueve la incorporación del invernáculo junto con su paquete tecnológico. Sin embargo, los pequeños productores convencionales destacaron como una de las pocas ayudas que recibían del Estado, a los técnicos del INTA o de la facultad. Es interesante destacar que esos técnicos a los que hacía referencia, son técnicos de Cambio Rural, los cuales en esta 
región han desarrollado un interés por la transición agroecológica y se han capacitado para poder promover y acompañar estos procesos. Esto coincide con el análisis de Bonnicatto (2019), quien plantea que la percepción de los profesionales ligados a las ciencias agrarias, manifiesta avances en el reconocimiento de la necesidad de un manejo sustentable de los agroecosistemas, donde se permita cambiar el objetivo productivista y cortoplacista que prevalece actualmente. Otro indicador en este sentido es la conformación en años recientes del MALP (Movimiento Agroecológico de La Plata, que nuclea a estudiantes de diversas facultades de la UNLP interesados en la agroecología; y la conformación del espacio "Semilla Raíz", conformado por un grupo de estudiantes de la facultad de ciencias agrarias y forestales con el objetivo de capacitarse en el asesoramiento técnico a experiencias de transición agroecológica y difundir la agroecología entre los estudiantes de la facultad. A continuación vemos la opinión de algunos productores sobre este tema:

“...han venido a decir muchísimos agrónomos a ofrecernos veneno a nosotros...Sí. Porque ellos vienen a tirarte su tarjeta, que ellos son agrónomos y ellos quieren dar el asesoramiento que dicen ahí, ¿se entiende?" (Pequeño Productor Agroecológico Arrendatario)

"Entonces, de la formación que tienen por culpa de eso, porque ellos no aprenden de lo que es la vida del suelo, que hace la vida del suelo, qué interacción tiene todo eso, cuál es la dinámica que hay cuando un árbol está plantado, porque ellos lo que entienden es de la planta para arriba, qué es lo que necesita la planta, cuánto necesita, qué bicho le tiene, qué es lo que tiene, porque ellos tienen un mercado en la cabeza ¿me entendés? Porque le implantan eso, no le implantan otra cosa, entonces al implantarle el mercado, implanta en el mercado de las multinacionales" (Pequeño Productor Agroecológico Arrendatario)

“Acá vienen... bueno, por trayectoria de él, muchos técnicos... él... te hago hincapié en esto porque antes se producía sin ayuda técnica. La agronomía no se acercaba, los mismos ingenieros agrónomos no se acercaban al campo a ver: che, qué conviene. El mismo que estudiaba agronomía se iba a los campos extensivos: cereales, vacas, qué sé yo. La horticultura carecía de colaboración técnica...Antes no habían. No entendía el ingeniero, ¿por qué? Porque todos los técnicos tienen que ensayar. Estudian, pero...No hay práctica...Como una residencia, estudios. Entonces era con los conocimientos de cómo se producía el tomate, o las enfermedades de tomate, lechuga... era mucho más difícil, y bueno, con el tiempo se logró que los agrónomos se incorporaran en los campos. Las quintas que más o menos medianamente están ordenadas, tienen un agrónomo" (Productor Grande Convencional Propietario) 
En general la mayoría de los entrevistados coinciden en remarcar los problemas en torno a las características de los arrendamientos y la imposibilidad de acceso a la tierra, los problemas vinculados a la comercialización (sobre oferta, bajos precios de las hortalizas, intermediarios), la superficie bajo invernáculos y la impermeabilización generada por estos, la auto explotación como modo de subsistencia y los problemas vinculados a los agroquímicos. En relación a los agroquímicos vemos una gran diversidad de aspectos desplegados en las entrevistas, entre los que podemos mencionar la disposición de los envases de agroquímicos, el uso excesivo, la contaminación, el no ajuste a los criterios de las Buenas Practicas Agrícolas (BPA), el deterioro de los recursos naturales por el uso de agroquímicos, problemas vinculados al funcionamiento de las agroquímicas y falta de asesoramiento técnico.

Algunos entrevistados han marcado a su vez aspectos puntuales que consideran problemáticos. En este sentido, uno de los técnicos y una trabajadora del INTA entrevistados hacen referencia a la xenofobia hacia las familias productoras de origen boliviano, como se expone a continuación:

"Yo lo que veo ya más en un plano social es una xenofobia muy grande hacia el productor de origen boliviano. Cuando tú visitas un productor grande lo primero que te menciona es que el productor boliviano produce mal, vive mal...También se ancló eso acá. Antes la producción la hacían, no sé, el italiano, el portugués, el español, y eso era concebido como lo que estaba bien, como los que tenían el conocimiento de cómo realizar la producción" (Técnico Cambio Rural)

"Hay un desprecio al productor boliviano, al saber hacer boliviano. Hay mucho desprecio en eso, tanto en municipio como en provincia" (Trabajadora de la Agencia de Extensión Rural de La Plata)

En las entrevistas realizadas se ha insinuado esta tendencia tanto en el productor grande como en el funcionario municipal, quienes hacían hincapié de manera reiterada en los pequeños productores bolivianos y la situación de informalidad en la que viven, evidenciando también la confrontación generada entre productores, como se ve a continuación:

"Es toda una pelea cultural, decimos nosotros, de hacerle entender al pequeño productor cómo tiene que llevar adelante su actividad para lograr potenciar su trabajo. Es ponerse en blanco, es regularizarse, es empezar a pagar tributos...La problemática hoy está centrada en los pequeños productores" (Funcionario de la Secretaría de Producción) 
"Pero vos estás en el mercado formal medianamente. Pero cuando vos ayudás a la parte informal, ¿a quién estás ayudando? O sea, estás colaborando con que siga la parte informal. Digo: listo, ya está, entendimos el mensaje. Va a seguir existiendo eso, nosotros no nos vamos a pelear entre productores para entender un sistema. No nos corresponde a nosotros. Le corresponde al Estado de alguna manera" (Productor Grande Convencional Propietario)

“...Porque vos me podés matar acá, y si sabemos la actividad vamos a producir en otro lugar, o sea, vamos a seguís produciendo. ¿Cómo cerrás la quinta? Vos le cerrás la quinta y alquila en un lugar donde no lo viste más y sigue estando el tipo. Pero ese no es un mal tipo porque hace eso, no entendamos mal. Lo que quiero decirte con esto es: lo informal fue que hizo el crecimiento desmesurado...Lo que veo es una competencia desleal, porque quienes figuramos siempre somos los que siempre tenemos que pagar el pato por quienes no están en el sistema. Y eso es lo que jode" (Productor Grande Convencional Propietario)

Otro aspecto mencionado por funcionarias vinculadas al área de planificación del municipio tiene que ver con el paisaje, como se evidencia a continuación:

"En desventajas el paisaje sería. La morfología, la tipología, la gente se queja de que sea todo nylon... Para mí el paisaje. La destrucción del paisaje natural. La pérdida de un paisaje natural, de un paisaje como producto de. Esa es una de las mayores transformaciones, la transformación del paisaje para mi" (Funcionaria de la Dirección General de Planeamiento)

"El área hoy del periurbano no está vista como un paisaje a proteger. No es un área valorizada. Te digo más, hoy le preguntás a cualquier platense cuál es la actividad principal de la ciudad de La Plata y te dicen -universitario-, nadie sabe que hoy el $40 \%$ del territorio de La Plata es actividad primaria intensiva, y que es la más importante en América Latina" (Funcionaria de la Dirección General de Planeamiento)

Finalmente, otro aspecto destacado por uno de los trabajadores de INTA tiene que ver con el bajo nivel de diversificación productiva, como se describe a continuación:

"Después debilidades me parece que la cuestión de la escasa o nula diversificación productiva, la agricultura familiar, digamos, como estrategia de supervivencia, hablando a nivel general, siempre utiliza la diversificación productiva como una estrategia de supervivencia, ¿no? El productor familiar por ahí tiene gallina, tiene cerdo, tiene... y según las oportunidades que tiene va vendiendo uno u otro. Y acá 
son un poco... de alguna manera se replica el modelo de monocultivo de la soja pero a nivel de la..."

Este último aspecto es de gran importancia a la hora de pensar en las familias productoras y en la generación de un cinturón hortícola más resiliente. Al analizar los discursos de los funcionarios municipales y provinciales se puede ver un fuerte sesgo a la horticultura; en ninguna de las entrevistas a funcionarios se mencionó la posibilidad de diversificar la producción, ni siquiera como estrategia para mejorar los ingresos de las familias productoras, al hablar de los problemas productivos y de comercialización de la producción. Desde el INTA y diversos técnicos enmarcados en el programa Cambio Rural si han existido algunos intentos de contribuir a esta diversificación. Por otro lado, la gran mayoría de las familias productoras tienen en sus quintas animales de granja (gallinas, patos e incluso en algunos casos cerdos) que utilizan para autoconsumo, lo que muestra una ventaja para pensar políticas de diversificación productiva.

A partir del análisis realizado en base a los discursos de los funcionarios municipales y provinciales, pude observar que tienen un conocimiento bastante minucioso de las problemáticas existentes en el CHP, abordando aspectos productivos, ambientales, comerciales, de acceso a la tierra, falta de infraestructura y servicios públicos, entre otros. Sin embargo, a la hora de abordar estos problemas vemos una simplificación extrema, aspirando a resolver todo a través de la formalización de los pequeños productores y responsabilizando principalmente a estos actores del "caos" en el que se encuentra el cinturón hortícola.

“...los pequeños productores los grandes problemas que tienen, más allá del acceso a la tierra es la formalización que ellos no tienen. Hoy ellos venden a culata de camión mucha de su producción, a intermediarios, porque no pueden salir a un mercado o a diferentes canales de comercialización por su informalidad. No pueden salir a venderle a una cadena de supermercados toda su producción..." (Funcionario de la Secretaría de Producción)

"Con la inmobiliaria muchas veces eso también estaba muy informalizado..."( Funcionario de la Secretaría de Producción)

“...no tenían la formalización necesaria como para poder sacar un crédito, bancarizarse..."( Funcionario de la Secretaría de Producción)

"Muchos productores han vivido mucho tiempo en una actividad totalmente en negro, totalmente... siempre decimos, vendiendo con los billetes y comprando todo al contado, y vendiendo al contado, y no han entrado en ese circuito económico formal 
que les daría toda esta posibilidad de crecer."( Funcionario de la Secretaría de Producción)

"Hoy tenés muchos productores que reclaman por la luz, y tenés... necesitan trifásica para su producción por goteo, para el riego, y usan esa misma luz para su domicilio, entonces tienen tarifas altas de luz. Entonces cómo hacer para que ellos tengan...tenés un montón de informalidad también en el tema de la luz."( Funcionario de la Secretaría de Producción)

"Nosotros recorriendo quintas todo este año, año y medio de gestión, hemos visto el gran desorden que hay también, de los envases vacíos, de que no se cumple con las normas del triple lavado..."( Funcionario de la Secretaría de Producción)

"...agricultura familiar, por ahí tenemos otro tipo de herramientas que trabajamos como son formalización, es un sector sumamente informal..." (Funcionario de la Dirección de Horticultura, Floricultura y Fruticultura)

Finalmente, del análisis realizado en este apartado, podemos dimensionar la complejidad territorial existente en el CHP, lo que plantea necesariamente soluciones complejas y desde un abordaje multiactoral. Ni una organización de productores, ni un grupo de académicos, ni una dependencia del Estado por si sola podrá resolver las actuales problemáticas del cinturón, ni encausar el desarrollo territorial y de la producción de alimentos hacia la sustentabilidad. Es importante tener en cuenta la multiplicidad de aspectos que llevan a una producción hortícola insustentable, que no se agotan en un problema de formalización de la actividad. No se puede pretender mejorar la producción de hortalizas sin resolver aspectos estructurales como poder tener agua potable, un baño, una vivienda que no se inunde cada vez que llueve, poder salir de la quinta para acceder a una atención médica o llevar a los hijos a la escuela. De la misma manera, difícilmente se pueda avanzar en una mejora de la actividad productiva si no se reconoce desde el Estado las relaciones de poder presentes en el territorio y no se toman medidas para regular al mercado.

A continuación presento un cuadro resumen de las principales fortalezas y debilidades evidenciadas para el CHP y su principal modelo productivo:

\section{FORTALEZAS \\ - En términos generales se plantea la ausencia de beneficios/fortalezas del CHP bajo el modelo productivo} DEL CINTURÓN HORTÍCOLA Y SU PRINCIPAL MODELO PRODUCTIVO convencional

- Capacidad de organización de los productores (no asociadas al modelo de

232 Lic. Carolina Baldini

\section{DEBILIDADES}

- Insatisfacción de las necesidades básicas, falta de infraestructura de caminos, viviendas precarias, condición de arrendatarios y frecuentes desplazamientos

- Dificultades para afrontar los eventos climáticos extremos cada vez más

Tesis doctoral - Territorio en movimiento 
producción convencional)

- Fuerte capacidad de trabajo de las familias bolivianas y la impronta familiar de la actividad (no asociadas al modelo de producción convencional)

- Relevancia que tiene el acompañamiento de ciertos sectores del Estado (INTA, UNLP), perdurando en el tiempo más allá de las gestiones políticas

- Rentabilidad del modelo

- Capacidad de abastecimiento a una gran parte del país y la cercanía a grandes centros urbanos frecuentes

- Importantes pérdidas por destrucción de invernáculos en eventos climáticos y dificultades para reponerse. Especulación de empresas proveedoras de materiales

- Necesidad de producir verdura rápido, para poder vender y cubrir los altos gastos fijos mensuales

- Exigencias de calidad estética por parte de consumidores

- Dificultades en la comercialización a través de venta a culata de camión a mercados concentradores. Sobreoferta y fuerte fluctuación en los precios

- Falta de diversificación productiva

- Presión por parte del mercado inmobiliario

- Problemas ambientales incluyendo contaminación por agroquímicos, acumulación de envases de agroquímicos, problemas con las perforaciones para riego, impermeabilización del suelo por invernáculos, deterioro de los suelos

- Falta de asesoramiento técnico y rol de asesoramiento de las agroquímicas

- Xenofobia hacia las familias productoras de origen boliviano

- Alto grado de informalidad de los pequeños productores familiares

\subsection{La transición agroecológica en el CHP, sus dificultades y sus posibilidades de expansión}

Al analizar la situación actual del CHP y sus principales problemáticas, indagué respecto a las dificultades que se encontraban en las condiciones actuales para realizar producciones agroecológicas. Entre las dificultades para producir de manera agroecológica los entrevistados plantearon que es un tipo de producción que requiere más trabajo, el riesgo que implica empezar a producir así y que no te funcione y pierdas la producción, las dificultades para comercializar la producción agroecológica y el bajo rendimiento que se obtiene. Otro aspecto que se evidenció fue la imposibilidad de aquellos productores que trabajan como peones en otras quintas, de decidir cómo producir, ya que en esos casos deben producir como el patrón les indica. En relación a las distintas dificultades planteadas, es interesante destacar que se ven contradicciones entre los distintos entrevistados. Mientras que la Pequeña Productora Convencional Arrendataria plantea que el camión no quiere llevar la verdura agroecológica porque no cumple con los estándares estéticos que se exigen, el Productor Mediano Convencional 
Propietario plantea que se puede vender la producción en los canales tradicionales pero que no la pagan como un producto diferenciado; finalmente, el Pequeño Productor Agroecológico Arrendatario, quien efectivamente produce agroecológico hace dos años, plantea que la producción se puede vender sin problema, que tiene el mismo rendimiento, que se ahorra dinero por el menor costo de producción y que incluso se logra una mejor calidad en relación a la verdura convencional.

"Siempre lo hemos evaluado (hacer producción agroecológica), el tema es que todo eso necesitás... no te digo que capital. Sí capital en personal, digamos. Alguien que salga, haga la venta. Porque el otro factor es la venta, si no la tenés organizada no va a funcionar... porque por ejemplo acá en el mercado no se puede vender...Ahora, si nosotros salimos por ahí puerta en puerta, con una camionetita, como lo hacen algunos en Varela... bueno, ahí podría andar. Pero tenés que buscarle el nicho, tenés que dedicarle tiempo a la venta, para que te sea rentable." (Productor Mediano Convencional Propietario).

"Y hoy por hoy, qué sé yo, ves a los compañeros y ves a vecinos que también tira veneno y vos no tiras y sacas las mismas calidad, quizás mejor calidad, y de mejor calidad y... y lo mandás al mercado y el mercado viene, al otro día lo mismo". (Pequeño Productor Agroecológico Arrendatario).

"No tienen posibilidad de elegir cómo producir (cuando son peones). Es producir como les dice el patrón. Esa es la dinámica... hay muchos (peones). Pero no es que son grandes patrones tampoco. Tienen su quinta, que deben tener tres hectáreas, y usan un peón, dos peones. No usan más. Y están igual que ellos, viven en la misma casilla de madera que ellos, tampoco es que viven en otro planeta". (Pequeño Productor Agroecológico Arrendatario).

Esto podría estar evidenciando la existencia de ciertos "mitos" en relación a la producción agroecológica, que podrían estar actuando (junto con otros aspectos vinculados a deficiencias en las políticas públicas productivas) como un impedimento para avanzar en la difusión de esta forma de producir. Al mismo tiempo, se evidencia la existencia de productores que pueden mediante el relato de su propia experiencia derribar al menos algunos de ellos.

“...estuvimos en la organización trabajando, luchando ahí en el tema esto de cómo poder cambiar el modelo de producción, y en eso fuimos encontrando que no hacía falta los venenos, $y$ hoy por hoy estas cinco hectáreas estamos produciendo sin veneno, sin químicos...Ya hace dos años... prácticamente de esa vez que nos rompió el invernadero directamente dijimos ¿qué hacemos acá? ¿Cómo hacemos para seguir?...y empezamos a ver...y estaba el tema de la agro ecología o 
agricultura orgánica como queramos llamarle y empezamos, y empezamos a ver, a ver cómo funcionaba, y nos dimos cuenta que antes se producía así, que antes era...antes éramos sin venenos, o sea, vivíamos sin venenos, los venenos fueron inventados y ahí nos fuimos dando cuenta que las multinacionales eran las que controlaban todo eso y al pequeño productor. $Y$ hoy por hoy, qué sé yo, ves a los compañeros y ves a vecinos que también tiran veneno $y$ vos no tiras y sacas la misma cantidad...y de mejor calidad...y lo mandás al mercado y el mercado viene, al otro día lo mismo". (Pequeño Productor Agroecológico Arrendatario).

Del relato anterior se desprenden dos aspectos que se traducen en potencialidades para avanzar hacia un desarrollo territorial que promueva la agroecología. Por un lado se evidencia que existen actualmente en el CHP familias de pequeños productores que producen de manera agroecológica y que están en condiciones de transmitir sus conocimientos a otras familias productoras, derribando mitos y mostrando su propia experiencia. Al mismo tiempo, como expone el entrevistado, producir agroecológico implicó conectar con saberes y prácticas que ellos tenían en el pasado, por su historia campesina en Bolivia. Según Gargoloff (2019), la historia agrícola familiar es clave en el conocimiento y manejo de la agrobiodiversidad. En su investigación, esta autora encontró que aquellos agricultores con tradición en la horticultura tenían un mayor conocimiento del componente vegetal (cultivado y espontaneo) de la agrobiodiversidad, respecto a aquellos agricultores sin tradición y, una mayor valoración respecto del uso y la funcionalidad de la misma (Gargoloff 2019). Esto es un potencial importante para un cambio en el modelo productivo y por otro lado deja entrever la necesidad y la importancia de espacios colectivos de intercambio de saberes que permitan perpetuar y difundir entre quienes no cuentan con una historia productiva familiar, aquellos conocimientos necesarios para establecer prácticas agrícolas más sustentables.

Otro planteo interesante en torno a las limitantes para comenzar una transición agroecológica surgió de la Pequeña Productora Convencional Arrendataria, quien puso en duda la eficacia de producir alimentos sin uso de agroquímicos cuando se encuentra rodeado de producciones convencionales. Es interesante por un lado remarcar la conciencia de la productora respecto a la ruta que siguen los químicos una vez liberados al ambiente, y por otro se evidencia la necesidad de pensar en una zonificación al menos transitoria de las producciones agroecológicas en el CHP. Este aspecto es de suma relevancia, y que como plantea Tomasoni (2013), las aplicaciones con plaguicidas son incontrolables, haciendo imposible la prevención de las contaminaciones sobre el ambiente y las poblaciones expuestas luego de las aspersiones, ya que las moléculas de agroquímicos no pueden ser controladas luego de arrojarlas al ambiente. 
“...Pero yo no curo. Pero (nombre de productor vecino) está al otro lado, ahí enfrente, y ellos día por medio los veo que están fumigando. Para ser agroecológico tiene que ser lejos, donde no haya contaminación. Si contamina el aire, contamina el agua, ya aunque yo no lo fumigue igual te contamina..." (Pequeña Productora Convencional Arrendataria)

Otro aspecto que mencionaron tres de los productores entrevistados tiene que ver con la toma de conciencia de los consumidores sobre los alimentos que consumen. En este sentido la Pequeña Productora Convencional Arrendataria plantea lo siguiente:

“...para producir agroecológico también tiene que haber un mercado para esas cosas. Porque viste que la verdura agroecológica no es como prolijita, mucha gente se va por la vista y no por lo que es bueno. Entonces tiene que haber primero una educación de la gente, del consumidor, y también un mercado donde se consume esta verdura. Porque si vos querés vender un camión no tiene salida, el camión no te lo va a llevar. Ese es el problema" (Pequeña Productora Convencional Arrendataria)

Esta misma entrevistada cuenta su experiencia fallida de transición agroecológica de la siguiente manera:

“...Estaría bueno hacer todo el trabajo que también sea reconocido, como todo...El tomate...pusimos tomate, y después apio, y teníamos patchoy, en invernadero al fondo, había patchoy, tomate... ¿qué más era? Acelga, remolacha también creo que había. Pero no lo podíamos comercializar. Porque mi cuñado dice -no, tiene que valer más-, porque supuestamente tiene más valor, pero la gente...el camión que venía a levantar nos decía que para él era acelga y punto. No decía que era agroecológico, nada, para él era acelga. Primero hay que concienciar a la gente y después recién hacer un mercado, que la gente sepa qué está consumiendo." (Pequeña Productora Convencional Arrendataria)

Se evidencia en los distintos extractos de las entrevistas citados anteriormente, que el impedimento en la comercialización a culata de camión tiene más que ver con el origen de la producción (al aire libre o bajo invernáculo) independientemente que esta se haya producido utilizando o no agroquímicos. Por otro lado, las dificultades para comercializar las verduras agroecológicas tendrían más que ver con la expectativa de los productores/as de obtener una ganancia extra, al considerar que esa verdura debería tener un costo diferencial por ser producida sin agroquímicos. En este sentido y al analizar la concepción que tienen los distintos productores sobre lo que es una producción agroecológica, podemos observar diferencias sustanciales entre quienes han tenido experiencias aisladas de formación (teórica y/o práctica) en esta temática y quien efectivamente produce 236 Lic. Carolina Baldini Tesis doctoral - Territorio en movimiento 
agroecológico. El productor agroecológico evidencia haber atravesado un proceso de reflexión sobre su práctica, mostrando tener una concepción compleja y multidimensional de la agroecología; en contraste, los otros productores asocian la agroecología solo con la producción sin agroquímicos, o en el mejor de los casos con el control biológico de plagas, dejando por fuera los aspectos sociales, culturales, económicos de la agroecología, entre ellos el comercio justo.

A continuación se exponen algunos extractos del dialogo con el productor agroecológico que evidencian los cambios en la calidad de vida al comenzar a producir agroecológico:

"Y otra práctica es el comer, o sea nosotros antes comíamos totalmente distinto, vivíamos comiendo cualquier cosa y hoy por hoy el paladar de nosotros, del propio quintero ha cambiado...antes yo qué sé, ponele, una radicheta no sabía comer, lo hacía para el mercado nada más, tomate qué sé yo, me lo comía pero bueno era tomate y ahora no, ahora te da gusto comerlo porque le encontrás sabor a las cosas, antes no le encontrabas sabor porque la agricultura convencional no se trata de buscar sabores, sino se trata de venderles por los ojos a la gente..."

"Y para mí es una alegría enorme (producir agroecológico) porque antes... antes produciamos ponele, todo este invernadero, tomate $y$ todo tomate era, y no teníamos la lechuga para hacer la ensalada y era como algo... antes vos decías qué sé yo, -bueno me voy al campo a desestresarme- y el que está en el campo vivía más estresado, porque lo único que sabía era del tomate y los químicos y ahí, nada más".

“...cambió nuestra economía también, o sea antes se nos iba un montón de guita, por todos lados, y hoy qué sé yo, esa guita que se ahorra, vos lo podés qué sé yo, hasta podes descansar y podés dar un trabajo también a otra persona ¿me entendés?"

"Y para nosotros hoy la agroecología es salud primeramente..."

"...que te cambia totalmente la mentalidad, primeramente, porque es un nuevo pensar, es un nuevo ser, naces de nuevo como decirle de alguna manera..."

Los consumidores se evidencian como actores considerados clave en los discursos de todos los productores entrevistados, a excepción del productor grande. Es interesante destacar que el productor grande no hace referencia en ningún momento a los consumidores ni sus demandas, mostrando una visión acotada al productor y el comprador directo de la producción (sea este el mercado central, un hipermercado o una cadena de comida rápida); una visión capitalista, de mercado, donde la producción de alimentos 237 Lic. Carolina Baldini Tesis doctoral - Territorio en movimiento 
pareciera considerarse como una actividad productiva más, donde lo que se busca es exclusivamente rentabilidad. Por el contrario, los pequeños productores y el productor mediano consideran al consumidor como uno de los principales actores que terminan definiendo qué y cómo se produce, guiados por parámetros como el precio, la estética, la moda, la practicidad.

"Hay mucha comparación que el del campo sale más rayadito o con puntitos, cualquier cosa. En cambio del invernadero sale bien lisito y el del campo no... la gente se va más por la vista de los productos, no por la calidad...que no tengan puntitos, no tengan rayaditos. En cambio si vos hacés una comparación de la verdura de campo y la de invernadero, la mejor es la de campo, por el sabor, por todo. Porque tienen contacto directo con el sol que también hace que esté bien la planta". (Pequeña Productora Convencional Arrendataria)

"Mientras el consumidor paga el verdulero no te va a bajar el precio. Ese es el problema: que el consumidor pague".

"Y lo mismo pasó que el consumidor hizo que se acoten... porque hoy se habla de por qué no hay tanto tomate platense, tanto alcaucil... ponele, coliflor, brócoli, el repollo, están cada día limitándose más porque es el consumidor el que va sugiriéndote que eso se vaya resumiendo en tomates, morrones, tomates cherry, lechuga, rúcula y una albahaquita. Ahí termina".

"Pero se ve, no es que te diga una boludez. Por más que sea una boludez por ejemplo los programas de cocina te hacen dos días o tres días una receta con brócoli, olvidate que el mercado del brócoli hizo así (seña indicando que creció). Eso se ve clarito en el mercado. En la rúcula por ejemplo, un yuyo la rúcula, que hoy la rúcula se pone y vos mandás $100,200,300 \ldots$ no, es rúcula. Y es un yuyo. Pero por eso, porque hoy es la moda y se consume..."

"Te busca un tomatito lindo, perfecto, parejito. Por más que tenga 50 mil químicos, no le va a importar. Quiere el tomate lindo. Si vos vas con un picado con un gusanito, que es más orgánico... te lo castiga, no lo quiere. Es un error".

“...qué sé yo, mi vieja es de la vieja escuela, que te va a cocinar cualquier cosa, me decís a mí: un tomate, una ensaladita, un churrasco y ya está. Yo creo que es el ritmo de vida o... pero es lo más práctico. Yo no veo a nadie que se ponga a hervir un alcaucil...Se cocina menos. El delivery también... no se funden, yo no he visto ni una casa de delivery que se funda".

“...una lechuguita de afuera que está orgánica, que tenga todas las cosas que vos quieras, pero te agarra una lluvia, salpica la tierra adentro de la lechuga, y el 238 Lic. Carolina Baldini Tesis doctoral - Territorio en movimiento 
consumidor no quiere, "no, que es mucho para lavarla". Pero sí, es eso, es reloco pero es asi".

Los párrafos anteriores exponen claramente la necesidad de políticas públicas orientadas al consumidor. Como sostiene Gliessman et al. (2007), la alta demanda de consumidores no interesados o no educados en sostenibilidad, normalmente inducidos por prácticas de mercadotecnia o por bajos precios/salarios, ejercen una presión de tal magnitud que empujan a las familias productoras a incrementar sus niveles de insostenibilidad, influyendo en el diseño y manejo de sus quintas. En La Plata, y en el país en general, muy recientemente se está comenzando a tomar conciencia de la importancia de una alimentación sana, y comenzando a problematizar qué consumir, cómo se produce lo que consumimos, donde se produce, quienes lo producen. Los consumidores suelen hacer foco, desde hace varias décadas, en las propiedades estéticas y en el mejor de los casos en las calorías que proveen los alimentos; esto ha sido promovido por el mercado, en la búsqueda de maximizar las ganancias de las empresas agroalimentarias, y por la falta de políticas adecuadas del Estado, que por acción u omisión facilitó la instalación de publicidad engañosa, la presencia de médicos y nutricionistas en los medios de comunicación al servicio de las empresas agroalimentarias, la intromisión de empresas del sector en escuelas $^{9}$. Dos aspectos que también es importante considerar son, la falta de políticas de etiquetado de los alimentos (como los existentes en Chile, Uruguay y Perú y más recientemente México), que permitan a los consumidores acceder a la información nutricional, pero que también contemplen cómo y quienes producen dichos alimentos; y la falta de organización de los consumidores. Las organizaciones de consumidores podrían contribuir a impulsar la formulación de políticas públicas adecuadas, y a fortalecer el dialogo y la articulación entre productores y consumidores. Sería deseable que el Estado contribuya a avanzar en este sentido.

Otro aspecto importante que surgió al analizar las entrevistas, sobre el que se requiere una reflexión, tiene que ver con las múltiples estrategias de producción y los diversos nombres que se les asignan, entre los que encontramos los términos "agroecológico", "orgánico", "ecológico”, "diferenciado”, "biológico”. En los discursos de los entrevistados encontré, por un lado que designan con un mismo nombre a formas de producir que no son necesariamente iguales, y por otro detecté la utilización de ciertas palabras que pueden resultar "engañosas" a la hora de describir la forma en que se produce. Al indagar en las entrevistas respecto a qué entendían por producción agroecológica, encontré definiciones reduccionistas que se focalizaban en el no uso de agroquímicos, frente a otras más complejas que abordaban distintas dimensiones de la agroecología, además del no uso de agroquímicos (mencionando por ejemplo aspectos

\footnotetext{
${ }^{9}$ https: / / www.lavaca.org/mu99/la-corporacion-va-a-la-escuela/ 239 Lic. Carolina Baldini Tesis doctoral - Territorio en movimiento
} 
vinculados al cuidados del suelo, la conservación de semillas, la salud, el comercio justo, el tiempo libre). A su vez, encontré que el productor mediano le asignaba el nombre de "orgánico" a lo que los otros consideraban agroecológico. El productor grande, por su parte, definió a su producción como "biológica", por incorporar prácticas como la introducción de enemigos naturales comerciales en los cultivos para controlar ciertas plagas; sin embargo, el resto del manejo que realiza se ajusta a una producción convencional. A continuación ejemplifico lo mencionado anteriormente a través de la propia palabra de los entrevistados:

"Que no tenga nada de insecticidas". (Pequeña Productora Convencional Arrendataria)

"La agroecología se trata de darle a la tierra, se trata de darle, devolverle la vida que se destruyó en el suelo... se hacen compost anaeróbicos, se hacen muchos biofertilizantes, con meo de vacas, cosas así, de hecho ahí tenemos tachos ahí que están para preparar, están preparados esos... entonces la verdura sale mucho mejor $y$ es de mejor calidad...Y para nosotros hoy la agroecología es salud primeramente...te cambia totalmente la mentalidad, primeramente, porque es un nuevo pensar, es un nuevo ser, naces de nuevo como decirle de alguna manera...Y otra práctica es el comer, o sea nosotros antes comíamos totalmente distinto, vivíamos comiendo cualquier cosa y hoy por hoy el paladar de nosotros, del propio quintero ha cambiado, prácticamente el mío, te diría de alguna manera...cambió nuestra economía también, o sea antes se nos iba un montón de guita, por todos lados, y hoy qué sé yo, esa guita que se ahorra... hasta podes descansar y podés dar un trabajo también a otra persona ¿me entendés?" (Pequeño Productor Agroecológico Arrendatario)

"Lo agroecológico es un manejo diferenciado, usando distintas técnicas para bajar obviamente le uso del agroquímico...porque muchos confunden el agroecológico con orgánico, y nada que ver...lo orgánico es cero cero cero de usos... según la definición, cero de usos de productos químicos...(en cambio en lo agroecológico es) baja cantidad, productos... digamos, lo que son plaguicidas específicos para la plaga. Entonces usando eso, haciendo recorridos manejando umbrales, no aplicar por aplicar sino cuando vos tengas un nivel claro, un nivel de plagas, que... bueno, si en este momento estamos en el umbral de aplicar... y aplicando como te decía hoy, aplicando solamente donde esté la plaga. Haciendo eso, haciendo después mucho deshoje, cortando el ciclo, sacás las pupas de muchas moscas o de otra plaga, esa hoja la sacás afuera, la tapás y con las temperaturas muere toda Entonces ir mezclando manejos orgánicos con lo convencional, yo lo considero agroecológico". (Productor Mediano Convencional Propietario) 
"nosotros hacemos producción biológica... se hace una guerra biológica, es luchar contra el insecto depredador hacia la plaga que te ataca, a la planta. ¿Se entiende? (un insecto) que devora a esa plaga, entonces sembrás esos insectos... qué sé yo, en el caso del trips (plaga) ¿lo conocés? Hay un bichito que se llama orius... come ese tipo de insectos (a los trips)...(fungicidas y fertilizantes)Sí, eso es todo convencional digamos...nosotros no estamos curando casi nada con insecticida, estamos usando, qué sé yo, un sistema con silicio, ponele, engruesa más la hoja y los insectos chupadores les cuesta mucho más romper la hoja o romper el esquema biológico que tiene la planta. Y bueno, entonces capaz que naturalmente la defendés a la planta...hoy se está trabajando en una certificación, en un BPA (Buenas Prácticas agrícolas) en Global Gap, queriendo tratar de llevarlo a un mejor lugar los productores que uno produce". (Productor Grande Convencional Propietario)

“...generalmente los orgánicos sí, tratan de sacar su semilla, de que no esté curada la semilla...y es como que la quinta parece que la tenés pero parece que está abandonada. Porque te dejan venir los yuyos altos, no te controlan la maleza, te dejan... hacen competencia de plagas entre distintos variedades de producción. Para cortar las plagas, por ejemplo. Hacen una tanda de lechuga, al lado te ponen una franja de lechuga, al lado te ponen un perejil, y después te ponen a producir rabanitos. $Y$ es como que si te ataca una plaga no te va en todas las variedad, $y$ una... no sé, el perejil te rechaza a los que vuelan, por el aroma. Y el de la lechuga no va al perejil. Entonces es como que se ayudan con los productos en las... distintas variedades de productos, para separar la plaga". (Productor Grande Convencional Propietario)

Es importante avanzar en una definición común de agroecología entre los distintos actores que venimos trabajando en la construcción de un territorio productivo de base agroecológica (organizaciones de productores, técnicos, INTA, UNLP, etc.), para poder avanzar en un proyecto común, evitando que se distorsione su significado y que se diluyan los esfuerzos de construcción de muchos años. En este sentido la Vía Campesina hace una fuerte crítica al uso que hacen de la agroecología ciertos sectores políticos, académicos y empresariales. Este movimiento internacional que agrupa organizaciones de campesinos, agricultores pequeños y medianos y diversos trabajadores agrícolas de todo el mundo, sostiene que la presión popular ha propiciado que múltiples instituciones, gobiernos, universidades y centros de investigación, algunas ONG (Organizaciones No Gubernamentales) y demás organizaciones, finalmente reconozcan la importancia de la agroecología; sin embargo, plantea que estos actores han tratado de redefinirla como un conjunto exiguo de tecnologías, para ofrecer así algunas herramientas que aparentan 
mitigar la crisis de sostenibilidad de la producción alimentaria industrial, mientras las estructuras existentes de poder permanecen incólumes (La Vía Campesina 2016).

Otro aspecto que detecté en dos entrevistas fue cierta desconfianza respecto a la producción orgánica que se comercializa actualmente, expresado de la siguiente manera:

"Y hay algunos que dicen que son orgánicos que no son orgánicos, pasa también. Nosotros como no queremos trampear el sistema decimos: no somos orgánicos". (Productor Grande Convencional Propietario)

"Lo orgánico es certificado. Pero acá por ejemplo unos productores cerca, los conozco, sé a quiénes va, dónde sale el certificado, sé el productor de acá que sé que tiene la certificación de orgánico. Pero el tipo va a comprar verdura al mercado. El tipo directamente te compra el tomate...entonces van, le preparan su cajita y va como orgánico. Y está certificado, ojo. Pero es así, es Argentina". (Productor Mediano Convencional Propietario)

Es importante tener esto en cuenta y pensar estrategias para llegar a ciertos acuerdos/consensos, respecto a los nombres que se les asignan a las distintas prácticas productivas. Estos consensos deberían trabajarse conjuntamente entre los diversos organismos estatales, productores y consumidores; de lo contrario, se corre el riesgo de generar una gran diversidad de nombres y "etiquetas", poco claras y muchas veces teñidas de "verde", que terminan siendo engañosas para los consumidores y generando rispideces y competencia entre los distintos productores. Al mismo tiempo, avanzar en estrategias de Sistemas Participativos de Garantía, como el que se está comenzando a generar desde la Facultad de Ciencias Agrarias y Forestales (Gargoloff et al. 2019), donde intervengan los distintos actores del territorio; esto permite afianzar los lazos entre los actores, tener una multiplicidad de vías de control y generar un mayor compromiso de todos los actores, reduciendo los riesgos y obteniendo múltiples beneficios.

Respecto a la necesidad de experiencias prácticas para avanzar en la masificación de la agroecología, el productor agroecológico platea:

“...sacarlo de ese eje al compañero es muy difícil, sacarlo de esa rutina que ya tiene, decirle "che, acá hay otra manera de producir" lo que el campesino, lamentablemente, él tiene orejas de adorno porque cuando ve hacer recién entiende. O sea, por más que vos le digas, si yo te estoy diciendo a vos, no lo entiende, "cuando lo ve recién hace fe", dice el campesino" (Pequeño Productor Agroecológico Arrendatario)

Al indagar en las posibilidades que ven los distintos entrevistados de avanzar hacia un cinturón hortícola agroecológico, entre los productores encontré dos visiones muy 242 Lic. Carolina Baldini Tesis doctoral - Territorio en movimiento 
diferentes. Por un lado el productor agroecológico convencido de que sí es posible y que podría ser posible hoy mismo si hubiera decisión política para impulsarlo; por el otro lado, el productor mediano, con una mirada técnica, que considera que no es posible aún, porque es necesario un proceso de investigación/experimentación para comprender el funcionamiento de las plagas, de los enemigos naturales y de cómo influyen las prácticas de manejo en el control de plagas. Este entrevistado hace hincapié en la necesidad de que ese proceso esté conducido por el Estado, resguardando a los productores que realicen esas prácticas de experimentación.

"Yo no solo creo que es posible, yo creo que se puede. Simplemente que no hay decisión política de parte de los gobernantes, de hacerlo...Decisión política. Porque los venenos es una decisión política" (Pequeño Productor Agroecológico Arrendatario)

"Por el momento no (no se puede tener un cinturón hortícola agroecológico)...(falta) Trabajo, laburos de...ahí sí más de parte del Estado diría, INTA. Es muy difícil...yo te digo, lo he querido manejar y se me complica, y yo digo: bueno, loco, hagamos un lugar con diez quintas, un lugar que si no sale, se pierde, el productor no pierda guita; hasta encontrarle la vuelta. Se puede, se puede, te puedo asegurar que si lo laburás más fino se puede..." (Productor Mediano Convencional Propietario)

"Entonces para mí sería hacer un laburo bien serio de parte del Estado, de decir: bueno, abramos un lugar, un predio, no sé, en tal lugar, y arranquemos de cero, a ver qué... no sé, plantemos albahaca, porque la albahaca atrae la mosca blanca... por ahí... es verdad, ¿pero qué pasa cuando sale esa mosca blanca?...Cuando se muera la albahaca, ¿a dónde se va a ir la mosca? Bueno, buscamos otra alternativa...Pero todo ese laburo, cosa que no tenga que correr el riesgo el productor..." (Productor Mediano Convencional Propietario)

En estos ejemplos podemos ver dos tendencias claras, que se observan también en lo académico, una vertiente que busca tener un conocimiento acabado del sistema y tener todas las variables bajo control, frente a otro que busca incorporar prácticas que contribuyan a restablecer el funcionamiento natural del agroecosistema, confiando en que en un agroecosistema saludable hay múltiples mecanismos de control de las plagas que se pueden activar.

Independientemente de las distintas visiones sobre las formas de llegar a una producción agroecológica, ambos productores fueron contundentes en la necesidad de un Estado presente y decidido a llevar adelante ese cambio. Esta idea de una decisión política y una fuerte intervención del Estado fue compartida por todos los entrevistados 
(productores, trabajadores de la UNLP, técnicos, trabajadores de INTA), excepto por los funcionarios municipales y provinciales vinculados a la producción hortícola.

"Nada, para mí tendría que existir política pública fuerte en torno a esto (la agroecología)...No pueden subsistir las experiencias agroecológicas desde lo voluntario en un mundo convencional". (Trabajadora de la Agencia de Extensión Rural de La Plata)

“...yo hago muchas veces la analogía con el tema de las energías renovables, ¿no?...Alemania es, digamos, en materia de energías renovables son pioneros son los que más desarrollo tienen...Ahora, los tipos te dicen que el mérito no es solamente del desarrollo de tecnología de los científicos, sino es compartido, un cincuenta por ciento del desarrollo tecnológico y un cincuenta por ciento las políticas públicas que fomentaron, que impulsaron, y que propician el uso de las energías renovables; con políticas de incentivo, con políticas de subsidio, con políticas de financiamiento a tasas bajas para que los productores puedan encarar proyectos de energías renovables."(Trabajador del IPAF Región Pampeana)

“Un apoyo fuerte que les garantice que con lo que ellos están haciendo van a poder mantener sus familias, que las van a poder alimentar, que van a poder evolucionar. $Y$ eso es organización, educación, salud, vivienda, es desarrollo rural en el sentido bien integrador...Es decir, es un proceso donde vos tenés que pensar en que si hay una decisión de ir para allá, bueno, tenés que incrementar investigadores, tenés que aumentar la capacidad de formación dentro de las aulas, de los profesionales que van a salir... Todo eso lo tenés que hacer. Y es un proceso, no lo lográs en tres años o en cuatro o en cinco...Pero yo creo que eso se puede hacer cuando hay una decisión política muy fuerte...Bueno, si existe un poder suficiente y hay decisión y vocación esto lo podés hacer. Acá en un rato conseguís cuarenta, cincuenta chicos que están dispuestos a salir y convivir con los productores. En un rato. Te estoy hablando de agrónomos, ¿no? Necesitás médicos, arquitectos, necesitás... porque esto es una apuesta a transformar la vida en el territorio, transformar la manera en que esa gente que hoy está viviendo como puede, pasan de una situación a otra...Bueno, todo eso hay que darle un anclaje totalmente distinto, y el único que lo puede hacer es el Estado". (Docente/Investigador de la FCAyF)

Los funcionarios del área de producción municipal y provincial plantearon que la posibilidad de lograr un cinturón hortícola agroecológico dependía de lo que podríamos llamar la "ley del más fuerte", donde la agroecología debería "ganarle" a los agroquímicos, y de que exista una sociedad que demande esos productos. La falta de reconocimiento de estos funcionarios públicos de su rol para impulsar procesos de transición hacia 
producciones más sustentables muestra un claro obstáculo no solo para concretar un proyecto a largo plazo sino para conseguir en la actualidad apoyo del Estado para avanzar en establecer las condiciones para un crecimiento de las experiencias de transición agroecológica.

"Hoy en La Plata acá está muy incipiente, está como muy verde la agroecología. Pero ya te digo, es por una cuestión cultural de cómo el productor produce hoy...También hay una realidad con los agroquímicos, que también hay un entramado de un mercado, un mercado atrás de todo eso, y que tampoco quieren que se vaya a ese modelo de agroecología y mantener, porque es un negocio...los intereses de los diferentes sectores que vos quieras pensar, desde la agroquímica, hasta sectores también de productores que producen más intensivamente y no les importa el medioambiente" (Funcionario de la Secretaría de Producción)

“...hoy vivimos en una vorágine... hoy es producís, vendés, es el mundo capitalista que vivimos... Y creo que tiene que ver un poco eso también, el agroquímico, la producción intensiva, el tener cosecha cada seis meses y salir y vender. Es un problema social para mí ese..." (Funcionario de la Secretaría de Producción)

“...será un proceso que por ahí en diez, veinte años vos decís: bueno, la agroecología le gana al agroquímico." (Funcionario de la Secretaría de Producción)

"Si la sociedad lo demanda si (es posible un cinturón hortícola agroecológico)... Si el consumidor se involucra mucho más si, el productor cambia" (Funcionario de la Dirección de Horticultura, Floricultura y Fruticultura)

La mayoría de los entrevistados piensan que es posible tener un cinturón hortícola agroecológico y dos de los entrevistados consideran que en un futuro van a convivir ambos modelos.

"Yo creo, y se lo digo a la gente, viste cuando antes, ponele, mi mamá fumaba arriba del colectivo. Y yo le digo: dentro de unos años, cuando ustedes piensen en el uso de químicos que hacen hoy, en cómo se maneja la carne y demás, dentro de unos años va a ser como pensar en fumar arriba del colectivo. Entonces, a mí me parece que hay cosas que necesariamente van a modificarse en el manejo de las quintas. O sea, que necesariamente le modelo convencional ya no se sostiene, y que ante esto se van a ir modificando muchas cosas, en el mediano plazo y demás. Ahora, el negocio, el agronegocio es muy difícil de que tome un papel tan secundario, y de que el negocio esté a disposición de los procesos, como que existan en función de la necesidad y no en función de la ganancia propia de ese negocio...Entonces desde 
ahí me cuesta pensar en la viabilidad de... en la realidad del modelo agroecológico como más puro." (Trabajadora de la Agencia de Extensión Rural de La Plata)

Al consultar respecto a qué condiciones se tenían que dar para poder avanzar hacia un modelo productivo agroecológico, productores, técnicos, trabajadores del INTA y de la UNLP coincidieron en la necesidad de facilitar el acceso a la tierra y en una planificación que delimite la zona destinada a la actividad productiva y destine un área para la producción agroecológica.

“O sea, cuando ellos tienen acceso a la tierra producen su papa, producen la quinoa, producen amaranto, hacen producción escalonada, variada, diversificada. Como que surge, la agroecología surge. Entonces me parece que el acceso a la tierra sería el sueño" (Técnica Cambio Rural)

Otros aspectos en los que coincidieron varios de los entrevistados tienen que ver con la necesidad de fortalecer otros mecanismos de comercialización, con la generación de líneas de crédito accesibles para las familias productoras y el otorgamiento de beneficios a aquellos productores que se volcaran a producir agroecológico. De esta manera lo resumen algunos de los entrevistados:

“...tiene que haber política para la generación de bioinsumos, y tiene que haber política para la distribución de la tierra, y tiene que haber política para la comercialización en centros de proximidad, y tiene que haber política que habilite los procesos de certificación participativa, y política que habilite inversiones si querés durante esos procesos de transición. Pueden ser políticas de precios diferenciados, gestionar canales de comercialización, políticas que pongan un freno al negocio inmobiliario..." (Trabajadora de la Agencia de Extensión Rural de La Plata)

“...nosotros lo vemos muy atado a la comercialización, porque muchos productores que ahora que se ha consolidado el espacio de venta acá y otras ferias que existen en la universidad, están pudiendo modificar su estrategia de producción para dejar de producir grandes volúmenes, pensando en vender a culata de camión, sabiendo que lo que ellos produzcan, si bien es menor cantidad, la pueden vender a un precio mucho más conveniente en los espacios directos, y entonces están empezando a poner algunas hectáreas a producir con menos agroquímicos, con otras estrategias" (Representante del Consejo Social)

“...un producto donde esté garantizado todo un proceso que está realizado bajo un marco teórico-conceptual determinado. Y bueno, para eso seguramente vas a necesitar un financiamiento, una política fiscal que ayude. Es decir, si vos producís agroecológicamente, bueno, no pagás este impuesto, no pagás el otro. Tendrás un 
financiamiento... una línea de financiamiento que te permita pagar esto... no con sobreprecios por ser agroecológico, porque eso termina matando al consumidor, y el consumidor tiene que ser un socio en esto." (Docente/Investigador de la FCAyF)

Finalmente, otros aspectos mencionados por los distintos entrevistados incluyen la necesidad de capacitación para formar técnicos en el marco de la agroecología, trabajar en la reeducación del consumidor, garantizar condiciones de vida dignas para las familias productoras, apoyar el desarrollo de procesos de certificación participativa, promover el desarrollo de bioinsumos a escala, facilitar la reproducción y conservación de semillas y poner freno al negocio inmobiliario. Todos estos aspectos deberían estar promovidos y garantizados por el Estado. Así describe uno de los entrevistados las herramientas del Estado para abordar un proyecto de este tipo:

"Fijate lo que es La Plata. Acá tenemos un Ministerio de Agroindustria, tenés la universidad: Facultad de Agronomía, tenés Exactas, Humanidades, de todo. Tenés municipalidad. Tenés un mercado. Tenés todo. Tenés todo. Si querés realmente hacer algo... Yo vengo proponiendo desde hace tiempo la posibilidad de tener un organismo que concentre todo lo que tiene que ver con la horticultura" (Docente/Investigador de la FCAyF)

A continuación resumo en un cuadro las principales dificultades y potencialidades encontradas por los entrevistados para avanzar en el desarrollo de un cinturón hortícola agroecológico.

\begin{tabular}{|l|c|}
\hline \multicolumn{1}{|c|}{ DIFICULTADES PARA AVANZAR EN EL DESARROLLO DE UN CINTURÓN HORTíCOLA } \\
AGROECOLÓGICO
\end{tabular}


- Falta de conciencia de los consumidores sobre calidad de los alimentos, guiados por parámetros como el precio, la estética, la moda, la practicidad

- Diferentes definiciones sobre lo que es una producción agroecológica

- Falta de una decisión política y una fuerte intervención del Estado para avanzar en la masificación de la agroecología. Actividad productiva librada a las leyes del mercado.

- Falta de acceso a la tierra por parte de las familias productoras y de condiciones de vida dignas

- Falta de delimitación de un área en el cinturón hortícola para las producciones agroecológicas

- Falta de mecanismos de comercialización alternativos, de generación de líneas de crédito accesibles para las familias productoras y de beneficios a aquellas familias que comienzan la transición agroecológica

- Falta de técnicos capacitados en agroecología

- Falta promover procesos de certificación participativa, el desarrollo de bioinsumos a escala y la reproducción y conservación de semillas

\subsection{La gestión de la actividad productiva en uno de los principales cinturones hortícolas del país}

Otro aspecto abordado en las entrevistas tiene que ver con la visión que tienen los distintos actores respecto a la gestión de la actividad productiva. En cuanto a los representantes del Estado, tanto nacional como provincial y municipal, según los productores entrevistados no hay un apoyo a la actividad, y menos aún a la producción agroecológica, reconociendo solo la eventual e insuficiente ayuda en eventos climáticos extremos, mediante la entrega de algunos royos de nylon para reparar parte de los invernáculos afectados. Al mismo tiempo lo reconocen en algunas situaciones como un obstáculo, dificultando la implementación de proyectos o mediante mecanismos de control y regulación que consideran arbitrarios. Algunos pequeños productores reconocen cierto apoyo por parte de la Facultad de Ciencias Agrarias y Forestales y del INTA, facilitando asesoramiento y apoyo técnico, brindando apoyo para la formulación de proyectos y difundiendo oportunidades de financiamiento, facilitando la participación en experiencias como el Banco Social o la feria Manos de la Tierra y realizando talleres de diversas temáticas. A continuación podemos ver ejemplos de la opinión de distintos productores:

“...no sé, la otra vez vino un temporal, en el caso nuestro nos bajaron 7 hectáreas. Y

fuimos, nos reunimos de nuevo, -vamos a ayudarlo a ver cómo...-, y nos dieron un 
crédito que a nosotros no nos ayuda en nada. O sea, lo tomamos pero es chico, no colabora con nada. Y lo más triste es que esos tipos piensan que ayudaron". (Productor Grande Convencional Propietario)

"y le hemos reclamado que no... nada, o sea tierra para quien la trabaja, o sea tan simple, tampoco estamos pidiendo regalías o sea, estamos pidiendo que nos dé un crédito blando para poder comprar nuestra propia tierra y poder trabajarla, y pagarla, así como pagamos un alquiler. Es tan simple como eso, o sea que haga eso, pero ni eso ha hecho". (Pequeño Productor Agroecológico Arrendatario)

"A ningún gobierno le interesa la producción hortícola. Porque es insignificante, en el $P B I$ sigue siendo insignificante a lo que es por ejemplo la producción de soja. Entonces nunca... es más, por eso te digo, hacen cortes, todo, algunas organizaciones, -sí, tomá-, te tiran tres, cuatro rollos de nylon para que no hagas quilombo" (Productor Mediano Convencional Propietario)

"No hay una línea de crédito por ejemplo para el campo, andá, sacate un tractor a una tasa de tanto que te lo financia el Estado. Acá no. Si sacás un tractor, "ah no, pero son para tractores de arriba de 80 caballos", y acá no puede ser porque son muy grandes". (Productor Mediano Convencional Propietario)

Los pequeños productores plantean un agravamiento de la situación durante el mandato de la alianza Cambiemos, planteando que en estos últimos años se han perdido los pocos derechos y beneficios que tenían como productores familiares, como la quita del monotributo social agropecuario, la reducción de técnicos del INTA y el despido de trabajadores de la Secretaria de Agricultura Familiar, como se puede ver a continuación:

"El estado no ha promovido jamás las producciones hortícolas, menos el pequeño productor. Sí ha promovido de las grandes multinacionales, o sea, ha promovido la soja, las cosas de grano, eso sí ha promovido, pero no han promovido... las verduras o los alimentos que todos los días comemos, eso jamás lo ha hecho, ni nacional, ni provincial, ni municipal. Municipal todavía estamos mucho peor porque el otro día fuimos al municipio, jamás hace nada, o sea, todas las políticas que vienen haciendo son en contra, de hecho, teníamos un monotributo social agropecuario que teníamos, $y$ el estado lo dio de baja, directamente, o sea ahora ya no podemos facturar, no podemos tener... directamente o sea, como agricultores, pequeños productores no podemos facturar directamente...no podemos facturar, y no podemos tener una obra social, no podemos tener acceso a... o sea, no somos sujetos de derechos, digamos" (Pequeño Productor Agroecológico Arrendatario) 
El productor grande muestra cierto descontento por el accionar de los funcionarios del Estado, quienes considera que no solo no facilitan su actividad, sino que favorecen a los trabajadores "informales" y exigen en mayor medida a los trabajadores que "hacen bien las cosas".

"Lo que pasa es que cuando se empiezan a mezclar que la horticultura es como una industria, ahí se mezcla todo...Y aparte donde tenés el concepto de decir: che, vamos a regularizar esta parte, esa parte no la saben hacer. Esa es la parte que no saben cómo actuar. Y si no lo hacen entre productores colaborando con el gobierno, no lo van a poder hacer nunca. Porque vos me podés matar acá, y si sabemos la actividad vamos a producir en otro lugar, o sea, vamos a seguís produciendo. ¿Cómo cerrás la quinta? Vos le cerrás la quinta y alquila en un lugar donde no lo viste más y sigue estando el tipo". (Productor Grande Convencional Propietario)

"Pasa lo siguiente, que el gobierno tiene... sabe lo que se produce. Pero lo que está en blanco. No sabe lo que está en negro, que es el $80 \%$. Ellos saben que lo que nosotros producimos, que ustedes son diez quinteros que los tiene identificados, pero sobre los blancos, no sobre los negros" (Productor Grande Convencional Propietario)

"Lo que más jode es que haya un mercado informal, que no se pueda controlar, y que el gobierno, si bien sabe cuáles son las falencias que tiene, no sabe cómo controlarlas, no tiene cómo controlarlas. ¿Se sabe cómo hacer? Sí se sabe. ¿Saben cómo chequear? Sí pueden. No lo hacen...Y, porque no se anima. Tiene miedo a quedarse sin comida. Entonces, no cuida al que está haciendo bien las cosa, o medianamente bien, porque nosotros tampoco tenemos todo perfecto. Medianamente bien. $Y$ ayuda, con ese sentido común, al que sigue trabajando informal. Entonces vos entendés que al gobierno le conviene ese sistema, no el nuestro". (Productor Grande Convencional Propietario)

De lo expuesto hasta el momento podemos ver como todos los productores se encuentran desconformes y consideran deficiente la gestión pública de la actividad, y al mismo tiempo tanto productores grandes como productores pequeños consideran que desde el Estado se está "apañando" al otro productor.

En relación a la agroecología tanto los pequeños como el mediano productor coinciden en la falta de fomento de este tipo de producciones, reconociendo solo la existencia de ciertos sectores de la universidad y del INTA interesados en esta temática, como se muestra a continuación: 
"Políticas primeramente para la agroecología en este momento es imposible, porque como ya te dije, o sea, el gobierno este no está a favor de la agroecología, no le interesa, ni mucho menos lo va a tomar en serio una cosa así." (Pequeño Productor Agroecológico Arrendatario)

“O sea, recién como que la facultad misma está, digamos, interesada en que se produzca agroecológico. Porque ellos ahora nos van a, una vez al mes vamos a tener una reunión en la facultad donde nos están hablando, porque ya tuvimos dos clases con ellas, para que... o sea, es de parte de extensión, no sé cómo se llama. Ellos nos están enseñando, nos están dando talleres para que le dediquemos un pedacito de lo que producimos para hacer agroecológico". (Pequeña Productora Convencional Arrendataria)

Al igual que los productores, los técnicos y trabajadores de la UNLP coinciden en la ausencia de políticas orientadas al desarrollo de la horticultura y de la agroecología en la región. Plantean en este sentido una falta de interés por la actividad, pese a ser el sector que provee de verduras frescas a gran parte del país y que genera una fuente de trabajo considerable. Se plantea a su vez cierta lógica de "marketing", apareciendo solo en momentos de crisis climática (temporales, granizo, fuertes vientos), con medidas paliativas y extremadamente insuficientes.

"Lo que nosotros vemos en general es que no hay un plan estratégico de desarrollo del sector...No hay una regulación, no hay una protección, no hay una definición del municipio de decir: bueno, estos son zonas de producción hortícola y no está sujeta a los valores de mercado inmobiliario... Si nosotros no protegemos la zona nos vamos a quedar sin cordón...Nosotros lo venimos planteando en provincia, lo venimos planteando en los municipios de la región. La provincia de Buenos Aires inclusive debería tener un tratamiento diferencial respecto de otras provincias, en relación a que contiene los principales cordones que abastecen el fresco de la Argentina". (Representante del Consejo Social)

“...por lo menos, a nivel nacional, al dar de baja todos los grupos de Cambio Rural, y al considerar a la agricultura familiar dentro de Desarrollo Social y no dentro del Ministerio de Agroindustria, para ellos la producción de alimentos... denota que no les interesa que esté en manos de los agricultores familiares. Ni siquiera sé si les interesa la producción de alimentos...Y entonces la función que asumen los gobiernos locales son más de regulación y de control y de fiscalización". (Técnica Cambio Rural)

"A ver, ahora, y eso por cuestiones más ligadas al trabajo que tengo ahora, sé que hay un plan de Hortalizas 20-20 que anda dando vuelta por la zona, pero no le dan 
mucha importancia...cuando leés el documento base lo que te dice es que hay que dejar de atomizar tanto la producción. Segregar la cantidad de productores que hay como... no sé, volver mega empresas, y que allí estén trabajando... Para mí es como expulsar todo el tema de agricultura familiar y volver el cinturón hortícola de La Plata una gran... cinco, seis campos inmensos que producen verdura". (Técnico Cambio Rural)

En este sentido, se mencionaron iniciativas como las Buenas Prácticas Agrícolas Obligatorias o el control de las verduras que se comercializan a culata de camión a través de la fiscalización de los camiones; iniciativas fuertemente sostenidas desde lo discursivo, pero que luego no cuentan con las herramientas necesarias para implementar o que peor aún no tienen un criterio lógico que les dé sentido.

"En realidad lo que yo vengo escuchando... por lo menos siempre que arrancó una gestión nueva en el área específica del municipio aparecen con alguna propuesta de ordenanza que castiga el uso de determinados agroquímicos. Después nadie se pregunta cómo algunos agroquímicos llegan a las quintas, donde los productores van con el problema y se van de la química con lo que les dieron para poner. Y nadie se pone a cuestionar cuál es el rol de los profesionales que están llevando adelante esa tarea, y siempre se piensa en cortar por lo más delgado." (Representante del Consejo Social)

“...algunos productores hace poquito tiempo, a principios de este año (2018), saliendo de las quintas por ahí les frenaban los camiones y les retenían cajones de determinada producción y demás, pero medio aleatoriamente....No lo podés rastrear (de que quinta proviene la mercadería incautada). No parece tener un sentido que tenga que ver con la salud pública ni nada por el estilo. La verdad que no sé bien por qué viene. $Y$ además si los camiones están llevando al mercado, el mercado tiene su propio control de calidad y demás. Así que la verdad que no... nada muy coherente aparece en términos de políticas para el sector". (Representante del Consejo Social)

A diferencia de los otros entrevistados, una de las trabajadoras del INTA plantea que en comparación con otras épocas, caracterizadas más por un "dejar hacer" por parte del Estado en relación a la actividad hortícola, en los últimos años hay cierta preocupación desde el municipio y provincia por la actividad hortícola, aunque con una línea cuestionable, como plantea a continuación:

“Mirá, para el municipio la horticultura es un problemón, no sabe qué hacer con la horticultura del partido de La Plata. No sabe qué hacer porque hay un nivel de desorden, de conflictividad ligada a la horticultura, que ellos quisieran como ordenarlo y ponerlo en regla y no lo logran, no pueden. Para provincia un poco también, pero 252 Lic. Carolina Baldini Tesis doctoral - Territorio en movimiento 
provincia ya más ligado a lo que es la política de nación... o sea, de agroindustria a nivel nacional... tienen esta mirada de lo que sería la horticultura en Almería, en España. Esta cuestión de producir intensivamente pero en espacios mucho más concentrados que garanticen inocuidad y calidad visual, o calidad comercial...calidad de exportación. Y que esos productos puedan exportarse. Entonces es como una horticultura mucho más concentrada en manos de pocos que tengan los medios para acceder a la exportación...y esto de meter tecnología de punto en la horticultura ¿Qué es la tecnología de punta en la horticultura? No lo saben bien, no lo tienen claro" (Trabajadora de la Agencia de Extensión Rural de La Plata)

“...Por ejemplo: a través del programa Proderi bajaron la construcción de los tres galpones, galpones de acopio (proyectos otorgados a tres cooperativas de productores hortícolas de la región)...ellos quisieran que estas organizaciones dieran un salto y se transformaran en empresas, en empresas que se viabilicen a partir de estos galpones de acopio. En estos galpones de acopio llegue toda la mercadería a granel, se acondicione y salga embalada para el exterior. $Y$ bueno, esta es una política de ese tipo. Cómo lograr más escala, lograr calidad, a partir de estos espacios concentrados. Lo que pasa es que obviamente, cuando esto cae en manos de organizaciones politizadas, que tienen otros objetivos y demás, todo esto puede ser de esta manera o puede ser de otra" (Trabajadora de la Agencia de Extensión Rural de La Plata)

El ejemplo de Proderi es interesante para analizar las diferencias en objetivos y prioridades de quienes desarrollan las políticas públicas y quienes son beneficiarios. Al mismo tiempo, las formas de apropiarse de estas políticas son muy diferentes cuando los beneficiarios no formaron parte de las instancias donde se definieron las mismas; la participación de los diversos actores en las instancias donde se formulan estas políticas es necesaria para mejorar la efectividad de las mismas y orientarlas a un proyecto de desarrollo común.

Otro ejemplo de la desconexión entre quienes elaboran las políticas públicas y quienes las reciben se describe a continuación a través de la palabra de otro trabajador del INTA:

“...Sin guita, lo que van haciendo es articulando mecanismos más, de poco dinero más electrónico, digamos ¿qué van haciendo? Meten, suponete, el DTV, que es el Documento de Tránsito Vegetal, entonces dicen -bueno, a partir de mañana es obligatorio, toda la verdura que circula a los mercados...vos tenés que estar acá en Olmos con tu máquina, viste, imaginate el boliviano de una hectárea que alquila una hectárea con su máquina que tiene que tener banda ancha, tener fibra óptica cerca, 
alguna empresa que le brinde el servicio, entrar online en la página de la AFIP con su clave fiscal, vos vas al DTV que es un documento...Bueno, ¿entendés? El tipo emite un documento que imprime y le da la copia al camionero...El tipo que armó eso está en Capital federal, nunca en su puta vida caminó en la zona..."

En contraposición con las opiniones encontradas en las entrevistas y mencionadas anteriormente, según Ambort (2017), la gestión 2008-2015 del municipio de La Plata, en comparación con períodos anteriores, tuvo una intensa labor de intervención en el cinturón hortícola; encontrando que en las gestiones previas La Plata había carecido de políticas, oficinas o funcionarios/as abocados a atender, planificar y/o dialogar con el cinturón productivo más importante del país.

Uno de los trabajadores de la UNLP entrevistados destaca la importancia durante el gobierno de Cristina Fernández de Kirchner, del reconocimiento de la agricultura familiar:

“...(2004-2005) ahí se reconoce, por primera vez, la agricultura familiar. Eso lo reconoce el INTA, a través de la creación de los IPAF, y del Cipaf, y también lo reconoce... se reconoce a través de la creación en el Ministerio de Agricultura de una Subsecretaría de Agricultura Familiar. Es la primera vez. Entonces cuando se incorpora, cuando se identifica, se caracteriza y se visibiliza oficialmente a la agricultura familiar, bueno, empieza a tener una posibilidad de apoyo específica, que antes no la tenía. Nunca hubo investigación para la agricultura familiar". (Docente/Investigador de la FCAyF)

En relación a políticas de fomento de la agroecología, se mencionan algunos organismos aislados que vienen trabajando desde hace varios años en el tema como el IPAF-INTA (Instituto Para la Agricultura Familiar), algunos proyectos de extensión de la universidad que contribuyen a promover algunas políticas públicas en este sentido y el Consejo Social de la UNLP. En relación al INTA, se mencionaron políticas como la generación de la Red de Agroecología, para vincular las distintas experiencias agroecológicas en el país, la Escuela de Agroecología para productores, que tuvo un gran desarrollo en esta región y los proyectos territoriales con enfoque agroecológico. Todas estas acciones fueron impulsadas durante los gobiernos Kirchneristas.

“El Consejo (Social) construyó su agenda a principios de 2011. Desde entonces venimos trabajando esto: empezando por el fortalecimiento de la comercialización, pero aportando a procesos de capacitación, a procesos que tenían que ver con que los productores familiares pudieran ir hacia una transición agroecológica, que eso también nosotros lo vemos muy atado a la comercialización" (Representante del Consejo Social) 
"Por ahí desde el INTA sí dieron...en la época en que yo trabajaba como Cambio Rural (2013-2017), sí sentía que, no solo con la organización en la que estaba sino en las demás organizaciones, estaban dando un impulso muy fuerte (a la agroecología)". (Técnico Cambio Rural)

“...y desde nación yo creo que las pocas intervenciones que hay (en relación a la agroecología) han tenido que ver con la incidencia del INTA; para mí, con la incidencia de las universidades. No veo otros programas específicos...que se ha avanzado, pero que son temas que están en disputa dentro de los propios ámbitos institucionales, por lo menos en el INTA". (Trabajadora de la Agencia de Extensión Rural de La Plata)

"Hoy en día la red de agroecología no existe, los proyectos territoriales no existen, se está armando una nueva cartera de proyectos en donde se habla de la cuestión ambiental, de la contaminación, de las prácticas productivos saludables y la mar en coche, pero la palabra -agroecología- prácticamente no...seguimos laburando en esto, con menos guita...todavía no nos han censurado absolutamente. Y no creo que puedan hacerlo demasiado. Bah, si ganan el gobierno que viene no sé, puede ser. Pero el INTA como institución, yo creo que la mirada que puede llegar a tener hoy tiene más que ver con: la eficientización biológica del modelo convencional ligado al agronegocio que la viabilidad de la agroecología como paradigma transformador..." (Trabajadora de la Agencia de Extensión Rural de La Plata)

El programa Cambio Rural en el año 2003 es incorporado al Programa Federal de Apoyo al Desarrollo Rural Sustentable (ProFeder) impulsado por el INTA. Desde este programa el espacio productivo no es pensado ya de manera aislada, sino como parte de un territorio, involucrado con la política local y con una multiplicidad de actores sociales, poseedor de una identidad y una historia; a partir de ello, la principal estrategia de intervención por parte de INTA fue la conformación y acompañamiento de grupos de Cambio Rural, enmarcados en un proyecto regional de desarrollo territorial desde un enfoque agroecológico (Ambort 2017)

Desde el INTA y la Facultad de Ciencias Agrarias y Forestales se vienen realizando desde hace muchos años proyectos de fortalecimiento de los procesos de transición agroecológica, en conjunto con las organizaciones de productores del CHP. Como describen Sarandón y Marasas (2015), la propuesta agroecológica surge en las diferentes organizaciones e instituciones, como una reacción a las consecuencias, cada vez más evidentes, de un modelo productivo ambientalmente insustentable y socialmente excluyente; y es llevada adelante por sectores marginales de estas instituciones públicas. Muchas de estas iniciativas han encontrado un impulso en el período posterior a la "crisis 
del campo" en el año 2008, momento en el que se reorientan las políticas públicas hacia el sector de la Agricultura Familiar. Pese ello, esta reorientación de las políticas públicas para el sector tiene importantes limitaciones, ya que no han pasado de ser una integración subordinada al modelo agroexportador, en la medida en que no son incorporadas dentro de una política articulada de intervención, con una mirada coherente y consensuada respecto del desarrollo rural (Ambort 2017).

Uno de los entrevistados trabajadores de la UNLP plantea la importancia de contar con políticas públicas que promuevan la agroecología de esta manera:

“...el desarrollo rural, la agroecología, sí o sí tienen que estar unidos por el accionar político. Si eso no lo lográs van a ir caminando por veredas distintas. Entonces, en la medida en que no exista un proyecto político que apunte sí a lo técnico, sí a la organización de los productores, sí al empoderamiento, sí a esto... bueno, está bien, la transición se podrá hacer, se avanzará de determinada manera... Pero tenés que generar capacidad y empoderamiento como para que se tenga la fuerza necesaria para lograr que existan políticas públicas que apoyen a los productores que avanzan en este sentido". (Docente/Investigador de la FCAyF)

Por otro lado, diversos actores plantean haber intentado establecer algún vínculo con el municipio o provincia, acercando proyectos para el sector, sin recibir respuesta alguna; esto muestra las dificultades que existen hoy en día para articular actores que están trabajando en el tema, cuyo acervo de conocimientos y de trabajo en el territorio es esencial para construir políticas públicas adecuadas, cuya implementación sea factible.

“Mirá, nosotros lo hemos charlado con la secretaría de producción del municipio, inclusive le mandamos una agenda de trabajo conjunta que nunca nos respondieron (año 2018). Lo hemos charlado con algunos actores provinciales, sobre todo a nivel legislativo. Pero salvo por las emergencias no parece haber hoy mucho interés de los ejecutivos por intervenir activamente en preservar un espacio productivo que a nuestro entender es central para la región" (Representante del Consejo Social)

Los funcionarios municipal y provincial entrevistados, representantes del área encargada de la producción hortícola, evidencian una gestión orientada casi exclusivamente a la promoción y fiscalización en torno a las Buenas Prácticas Agrícolas, y en menor medida a la promoción de algunos puntos de comercialización directa del productor al consumidor. Ambos entrevistados hacen hincapié en la fuerte articulación que existe actualmente entre el municipio, provincia y nación, y reconocen el apoyo para la implementación de ciertas políticas del INTA y SENASA. Si bien esta articulación parecería a primera vista ser positiva, vemos por un lado que la articulación se restringe a las áreas vinculadas a la producción, sin contemplar otros organismos del Estado que podrían aportar a abordar la complejidad 256 Lic. Carolina Baldini 
social, ambiental, política del cinturón hortícola, indispensables si se piensa el territorio productivo desde una mirada agroecológica. Como vengo planteando a lo largo de este capítulo, el CHP es un territorio complejo, con muchos intereses en pugna e innumerables problemáticas, muchas de ellas estructurales; en este contexto es ilusorio pensar en gestionar la producción hortícola sin contemplar políticas públicas que aborden otras dimensiones de esta realidad, para lo cual es indispensable articular con otras dependencias del Estado (salud, educación, desarrollo social) y por supuesto con las Facultades que vienen desarrollando investigaciones y formando profesionales especializados en las problemáticas de este territorio. Finalmente, si bien uno pensaría que la articulación entre distintas dependencias del Estado potenciaría el desarrollo de más y mejores políticas públicas, lo que encontramos a partir del análisis de estas entrevistas son principalmente dos o tres políticas públicas que son gestionadas articuladamente, que exponemos a continuación:

"Nosotros tenemos... ya desde el año pasado (2017) tenemos, con diferentes asociaciones y pequeños productores, tenemos primero el programa provincial, que es "El mercado en tu barrio...Es un programa del Ministerio de Producción de provincia, articulado con todos los municipios de la provincia... nosotros tenemos...un "Mercado en tu barrio" itinerante, con pequeños productores, no solo de hortalizas, tenemos también avícola, tenemos de cerdo, de carne, de pollo, tenemos panificados...en donde fuimos recorriendo... 22 puntos diferentes en 12 localidades, todo el año pasado" (Funcionario de la Secretaría de Producción)

“...nosotros también tenemos el programa Compra Pyme en provincia, que es provincial. Que relacionamos a pequeños productores con diferentes cadenas de supermercados en donde ellos pueden hacer un vínculo comercial' (Funcionario de la Secretaría de Producción)

"Nosotros hoy hicimos una convocatoria para ingeniero o veterinario (para hacer un relevamiento en el territorio), y todos con título universitario de técnico. De hecho se anotaron 120 y no conozco a ninguno" (Funcionario de la Secretaría de Producción)

"...todas las acciones que tenemos y todas las herramientas que tenemos son articuladas con el municipio y tanto a nivel municipal como nacional, bajamos todos juntos (las políticas públicas)“. (Funcionario de la Dirección de Horticultura, Floricultura y Fruticultura)

“Las políticas están direccionadas a los BPA en todas las producciones, más allá de orgánico o agroecológico, para nosotros es importante que cumplan las BPA, es una política de estado que se van a empezar a exigir para renovación de documentación, sea de RENSPA, sea de DTV, va a estar y se viene fuerte...Nosotros hacemos 
capacitaciones hace no más de 20 días en Gorina, salieron los primeros 40 implementadores de BPA, que son los técnicos que van a implementarle al productor las Buenas Prácticas Agrícolas, que le van a decir -che, si, cumplís las Buenas Prácticas Agrícolas-, es un "checklist" sencillo y se puede hacer...tanto público como privado, hay de todo, digamos... el curso es gratis, se puede anotar cualquiera" (Funcionario de la Dirección de Horticultura, Floricultura y Fruticultura)

"Próximamente estamos lanzando la mesa de producciones orgánicas y trabajamos con muchas organizaciones que hacen agroecológico...la idea es que estén todos los actores que representan lo orgánico para definir políticas públicas en base a la producción orgánica." (Funcionario de la Dirección de Horticultura, Floricultura y Fruticultura)

En general los funcionarios actuales (gestión de la alianza Cambiemos) responsabilizan a las gestiones anteriores de la situación en la que se encuentra actualmente el cinturón hortícola, por la falta de políticas públicas. Es interesante destacar por ejemplo la visión del funcionario municipal sobre el programa Cambio Rural, un programa destacado por todos los demás actores entrevistados.

“Hoy los pequeños productores, las pequeñas asociaciones de pequeños productores reclaman cómo el Cambio Rural o el programa este del INTA se desarticuló. Pero se desarticuló por estas cuestiones. Por estas cuestiones de que realmente no se llevaba adelante el trabajo que se tenía que llevar" (Funcionario de la Dirección de Horticultura, Floricultura y Fruticultura)

"El problema viene del 85. Entonces no hubo un Estado presente en donde vos decís: se hizo esto bien, esto bien, esto bien, falta mejorar esto. No, no se hizo nada. El productor venía, se instalaba, producía... De hecho, por eso te digo: realizaron toda su vida una actividad en negro y hoy cambiarles ese... cambiarles culturalmente la forma de producir es complicado". (Funcionario de la Dirección de Horticultura, Floricultura y Fruticultura)

Dos trabajadores del INTA analizan los cambios en la gestión de la actividad hortícola de la siguiente manera:

"En el pasado sin duda que había más herramientas, había más financiamiento, más instrumentos, mayor apoyo al sector de la agricultura familiar, lo que también por ahí hay que decir que de lo estructural no se cambió demasiado" (Trabajador del IPAF Región Pampeana)

"En el pasado suponete, en general no, siempre fue una cosa marginal, una actividad... qué sé yo... en el mejor de los casos ignorada, digamos, salvo algunas 258 Lic. Carolina Baldini Tesis doctoral - Territorio en movimiento 
cosas. Suponete, Alak, que fue intendente, ya no me acuerdo si fue tres periodos acá en La Plata qué sé yo, en un momento había una ordenanza que prohibía la construcción urbana en las zonas declaradas como zonas rurales, digamos, lo que era zona rural, eso se mantuvo y estaba como una prohibición de la instalación de los countries y todo, eso le dio cierta protección (al área productiva)..." (Trabajador del IPAF Región Pampeana)

"En ese sentido sí, (la gestión nacional durante el kirchnerismo) tenía esta política de mucho apoyo económico, a nosotros nos fortaleció un montón. Estaba la secretaria de agricultura familiar de Nación, trabajando, o sea, hubo mucha gente, hubo muchos otros actores que armaron esta red, había mucha gente del ministerio laburando en terreno, y con cartera de posibilidades de créditos blandos, de subsidios, de apoyo, programas estos de salud, digamos, las tarjetas, la posibilidad de tener obra social" (Trabajador del IPAF Región Pampeana)

\title{
BALANCE DE LA GESTIÓN DE LA ACTIVIDAD PRODUCTIVA EN EL CHP
}

- No hay ni ha habido un apoyo claro a la actividad, y menos aún a la producción agroecológica, reconociendo solo la eventual e insuficiente ayuda en eventos climáticos extremos, mediante la entrega de algunos royos de nylon. Todos los productores se encuentran desconformes y consideran deficiente la gestión pública de la actividad.

- Se reconoce apoyo por parte de la Facultad de Ciencias Agrarias y Forestales y del INTA, facilitando asesoramiento, apoyo técnico y talleres de diversas temáticas, brindando apoyo para la formulación de proyectos y difundiendo oportunidades de financiamiento.

- Presencia de organismos aislados que vienen trabajando desde hace varios años en agroecología como el IPAF-INTA (Instituto Para la Agricultura Familiar), algunos proyectos de extensión de la universidad que contribuyen a promover algunas políticas públicas en este sentido y el Consejo Social de la UNLP. Las pocas medidas tomadas en este sentido habrían sido tomadas durante el gobierno kirchnerista. Importancia durante dicho gobierno del reconocimiento de la agricultura familiar.

- El productor más capitalizado considera que el Estado actualmente beneficia a productores que están en condiciones de informalidad y viceversa

- Manifiestan haber perdido durante el mandato de la alianza Cambiemos de los pocos derechos y beneficios que tenían los productores familiares, mediante la quita del Monotributo Social Agropecuario, la reducción de técnicos del INTA y el despido de trabajadores de la Secretaria de Agricultura Familiar.

- Gestión de la alianza cambiemos orientada casi exclusivamente a la promoción y fiscalización en torno a las Buenas Prácticas Agrícolas, y en menor medida a la promoción de algunos puntos de comercialización directa. Fuerte articulación entre el municipio, provincia y nación, y apoyo del INTA y SENASA para la implementación de ciertas políticas.

- La gestión de la alianza cambiemos no cuenta con las herramientas necesarias para implementar las medidas de control que propone. Evidencia una lógica de "marketing", apareciendo solo en momentos de crisis climática.

- Se evidencian dificultades para acercar propuestas al Estado y que sean tenidas en cuenta

\subsection{Las condiciones históricas que dieron forma al actual CHP con sus deficiencias pero también con un enorme potencial}

\author{
3.4.1 El gobierno de Alfonsín y un cinturón hortícola incipiente
}


Respecto a este período son pocos los actores entrevistados que tienen conocimiento. En este sentido es destacable el amplio conocimiento del territorio y la mirada integral que tienen los trabajadores del INTA entrevistados, destacando especialmente a los técnicos de Cambio Rural y de la Agencia de Extensión Rural, quienes aún pese a ser jóvenes y no haber estado trabajando en el sector en ese período, conocen el contexto histórico y político en el que se desarrolló la actividad hortícola en la región. Esto tiene que ver sin lugar a dudas con su vínculo con ámbitos de investigación y formación de la UNLP, con una amplia experiencia de trabajo en el territorio y de interacción con las familias productoras, y con el propio interés en la temática producto de un fuerte compromiso político con la agricultura familiar. Por el contrario, los funcionarios municipales y provinciales entrevistados (pertenecientes a la gestión de la alianza Cambiemos) mostraron un bajo nivel de conocimiento de la historia de la actividad hortícola en la región, pudiendo solo hacer una descripción de la situación actual, desde una mirada reduccionista.

La caracterización que hacen los entrevistados respecto a la actividad hortícola en la región en el período del gobierno de Alfonsín es la de una horticultura poco desarrollada y con bajo componente tecnológico, en manos de productores italianos y portugueses principalmente propietarios. Las producciones eran mayormente al aire libre y había unos pocos invernaderos de vidrio destinados a la producción de flores, lo cual coincide con las observaciones realizadas a partir del análisis de imágenes satelitales, en el capítulo 2 de esta tesis. Algunos entrevistados destacan que en ese período se producían verduras de estación y se acostumbraba guardar las semillas para la próxima siembra, y si bien algunos compraban semillas, estas eran de polinización abierta. El uso de agroquímicos era mucho menor, y uno de los productores entrevistados destaca que las plagas que había en esa época eran diferentes. La extensión de las producciones era mucho mayor y había gran diversidad, aunque según distintos entrevistados la productividad era menor.

“...todavía yo alcancé a ver acá productores...había un productor que llegaba a hacer... producía 400 hectáreas de lechuga, los (apellido de productor) hacian choclo y alcaucil, la zona de Arana era, los tanos estos eran muy alcaucileros, que era una comida italiana, digamos, bueno y te hacian, (apellidos de productores) por ahí hacian 200, 300 hectáreas de alcaucil, para el lado ya de Arana" (ex coordinador del Programa Cambio Rural)

“...tenías una semilla que no tenía tanta fuerza como las que tienen hoy las híbridas, o la nueva generación de semillas. Entonces producías, qué sé yo, 30 mil kilos por hectárea...(con la nueva generación de semillas)vos en vez de cosechar 30 mil kilos, podés llegar a cosechar hasta, en la mejor de las suertes, 200 mil kilos por hectárea". (Productor Grande Convencional Propietario) 
En cuanto a la comercialización, uno de los pequeños productores entrevistados plantea que en ese momento había menos mercados mayoristas y el mecanismo de acceso era diferente a la actualidad.

"...todo se trabajaba con mercado central, con sus propios camiones, el mercado venía a consignación. Ahora los camiones son de los puestos...mucha cantidad de mercados, hay el de La Plata, el Campito, La Matanza, 3 de Febrero, Beccar y otros...Morón, en Luján hay otro. Hay competencia de mercaditos. Después vienen de afuera también, de Bahía Blanca, Neuquén, Rio Cuarto..." (Pequeño Productor Convencional Propietario)

Otro aspecto interesante que surge de las entrevistas, es que en ese período la urbanización se encontraba más separada de lo que era el sector de producción hortícola, lo cual se constata en los análisis a través de imágenes satelitales realizados en el capítulo 2 de esta tesis. A su vez, se menciona la existencia de un antecedente de cierta zonificación de la actividad hortícola, a través de las "Colonias Hortícolas", enmarcadas en la creación de colonias agrícolas de abastecimiento de productos frescos al área metropolitana, a instancias del Consejo Agrario Nacional en el marco del segundo plan quinquenal en los inicios de la década de 1950 (Cieza et al., 2015).

“...la provincia de Buenos Aires tiene una dirección de colonias, de colonización, tuvo desde el ministerio de asuntos agrarios...Bueno, vos acá tenés la Colonia Urquiza, una colonia, ¿qué significa? Eran tierras del estado o eran tierras fiscales, que el estado las compró, e hizo un concurso de colonos, dividió, dijo "bueno, ¿cuál es la unidad mínima? Bueno, no baja ningún lote de 4, 5 hectáreas" y se anotaban los colonos que querían concursar por los lotes. Colonia Armonía, colonia La Plata, uno, dos, la Armonía ahí en la entrada a Arana, la Colonia Urquiza, tenés montones de ejemplos, son de esa época...60 hasta los 70, yo alcancé a ver y debe haber sido... hasta los 70 estaba" (ex coordinador del Programa Cambio Rural)

Respecto a la incorporación del invernáculo en la producción hortícola se plantea como un tema que tuvo cierta resistencia y que habría sido incorporado como una forma de obtener mayores ganancias, al romper con la estacionalidad de la producción. Al producir bajo invernáculo podían acelerar los tiempos productivos, sacando antes que otras regiones sus productos al mercado, ganando una renta diferencial. En consonancia con Gargoloff (2019) la trabajadora de la Agencia de Extensión Rural de La Plata entrevistada hace referencia al rol estratégico que cumplió el INTA en este sentido, promoviendo la inserción de esta tecnología en la región.

"La producción en invernaderos al principio era una discusión, digamos, al principio fue una oportunidad de ganar más plata, por esto de irme más a invierno a producir 261 Lic. Carolina Baldini Tesis doctoral - Territorio en movimiento 
una verdura de calidad en una época que no había acá" (ex coordinador del Programa Cambio Rural)

“En la época del ochenta empieza a bajar acá todo el paquete tecnológico ligado al invernáculo. Si bien en el mundo todo ese modelo empieza antes acá empieza fuertemente, desde la intervención del Estado incluso... yo tengo compañeros de INTA grandes que en esa época difundían fuertemente el modelo de producción bajo cubierta, con riego en goteo, la entrada de los híbridos, la utilización de... bueno, esos híbridos que demandaban un contenido muy preciso de potasio, de nutrientes. Entonces empieza el comercio de los fertilizantes..." (Trabajadora de la Agencia de Extensión Rural de La Plata)

Complementariamente, el Docente/Investigador de la FCAyF entrevistado plantea que la rápida adopción de esta tecnología tuvo que ver con la presencia de un grupo de productores italianos y españoles con un interés innato por innovar. Esto se puede identificar, a su vez, en los relatos del productor grande entrevistado.

"Porque dentro de los quinteros más grandes había un grupo de quinteros, algunos italianos, españoles, estaban todo el día pensando en... a ver qué podían hacer para innovar. Permanentemente. El frío, que esto, que el otro. Siempre andaban con proyectos y con cosas que escuchaban que en otras partes se hacían...Eran innovadores natos." (Docente/Investigador de la FCAyF)

“...fue una primera etapa en donde no había, nadie se animaba, fue muy costoso. Hacer una hectárea de invernáculo...bueno, como se pudo se fue generando una hectárea, y era una gran locura hacer eso" (Productor Grande Convencional Propietario)

"Nosotros, en el caso de mi papá, él arranca iniciando en su momento...una empresa que se armó entre productores. $Y$ se puso en la vanguardia de correr contra toda la tecnología que haya dando vuelta. Con un técnico que lo apoyaba, que le traía información para mejorar lo que hacía, y demás. Hasta se llegó a hacer un túnel de enfriado en hoja..." (Productor Grande Convencional Propietario)

Este aspecto también es importante para entender los modos de producción que vemos fuertemente arraigados en las familias productoras de origen boliviano, mayoritarias en la actualidad. Como vimos en el capítulo introductorio de esta tesis, las primeras familias productoras que entraron al país desde Bolivia se incorporaron a la actividad hortícola en la región como peones de los productores grandes, mientras que aquellas que ingresaron a fines de los noventa/principios del 2000 lo hicieron como medieros de aquellos peones que habían "ascendido en la escalera boliviana" al arrendar sus propias tierras (García y Kebat 
2008, Ambort 2017). En ambos casos vemos que son familias productoras que están en una situación de dependencia que les impide decidir cómo quieren producir, replicando las prácticas productivas convencionales arraigadas en sus patrones. Esto se ve reforzado en aquellas familias productoras que ingresaron en el 2000, al encontrarse con una fuerte presión de mercado y condiciones estructurales con grandes limitaciones para la reproducción de la vida, que los lleva a potenciar aún más esas prácticas basadas en el modelo convencional, aspirando a mejorar su rentabilidad y poder cubrir los elevados costos de producción.

Ya entrando en los 90, dos aspectos que destacan algunos entrevistados como estructurantes de los cambios producidos en ese período; por un lado la consecuencia de la hiperinflación desatada durante los últimos años del gobierno de Alfonsín, y por otro lado, el ingreso al país y a la región de los hipermercados como consecuencia de las políticas de apertura del menemismo. El ingreso del supermercadismo habría, según distintos entrevistados, generado una diferenciación entre productores grandes y pequeños. Los productores grandes se habrían volcado en gran medida a abastecer esta nueva demanda, ajustando sus estrategias productivas a las demandas de estos nuevos actores.

“...aparecen las grandes cadenas de supermercados. Entonces aparece Walmart, Carrefour y qué sé yo y había que abastecer. Entonces empieza como a darse también en estos modelos más tecnificados, se empiezan a diferenciar los productores más grandes..." (Trabajadora de la Agencia de Extensión Rural de La Plata)

\subsubsection{El menemismo y los efectos de la desregulación}

La década de los 90 se relata como un período de "explosión tecnológica", en el que ingresan en la actividad hortícola local, como resultado de la política nacional del gobierno menemista y con un fuerte impulso, la tecnología del invernáculo, posteriormente el fertirriego y finalmente la incorporación de galpones de empaque, como otro mecanismo de innovación, al que habrían podido acceder aquellos productores más capitalizados. Junto con este paquete tecnológico habría empezado a crecer la incorporación de agroquímicos en la actividad productiva, favorecido por el bajo costo de los mismos en una economía dolarizada, como relata uno de los productores:

“...en la época de Menem, te digo, fue cuando se empezó con el invernadero, con todos los quilombos que se mandaron en su momento, cagadones, cagadones para la parte ecológica sobre todo, porque ahí es donde surgió la famosa receta de "por las dudas": fumigar tres veces por semana, sacudirle con lo que tenías, el cultivo siempre tenía que estar perfecto" (Productor Mediano Convencional Propietario) 
Las estrategias para comercializar la producción hortícola, seguían girando en torno al mercado regional, que era chico aún, y era abastecido principalmente por los grandes productores. En este periodo se da también el surgimiento del supermercadismo, con el ingreso al país de cadenas como Walmart y Carrefour, que ante un Estado no intervencionista moldean fuertemente la producción hortícola en la región. Según Teubal y Rodriguez (2002), las ventas en escala que realizan los supermercados les permiten comprar a gran escala a sus proveedores, y por ende negociar mejor las condiciones de compra; pudiendo vender a precios más altos y comprar a precios más bajos, además de las ventajas comparativas que tienen en cuanto al acceso más abundante, rápido y barato a créditos.

"antes había grandes empresarios o grandes quintas que ellos acaparaban qué sé yo, por ejemplo 20 camiones, 10 camiones, 30 camiones y llenaban el mercado. Durante el menemismo y durante un poco el kirchnerismo, pero no tanto, pero el menemismo fue así, o sea, ellos llenaban el mercado..." (Productor Mediano Convencional Propietario)

“(en los 90) había cambios estructurales, tanto en la comercialización, empiezan a aparecer las cadenas internacionales de Carrefour, Walmart, el supermercadismo, la gran distribución se instala, se empieza a instalar en la Argentina...todo ese impacto de apertura de mercados y la instalación de esta visión, más moderna de las concentraciones a través de las grandes distribuciones de las cadenas comerciales, empieza a generar demandas distintas...las cadenas que hicieron empezaron a instalarse y empezaron a pagar más para empezar a generar una cadena de proveedores, de tener un desarrollo de proveedores, pagaban más por los productos y empieza a ser muy buen negocio venderle a esas cadenas. Eso duró un tiempo, después chau..." (ex coordinador del Programa Cambio Rural)

Los diferentes entrevistados destacan además a este período como un momento en el que hubo una importante incorporación de pequeños productores bolivianos a la actividad de la región y en el que muchos de ellos empiezan a tener capacidad de arrendamiento.

"El gran cambio que hubo en el menemismo fue, primero que nada el tema de los pequeños productores que empezaban a alquilar sus propias quintas, que empezaban a tener su propia quinta pero como mucho, con muchos problemas porque no podían venderlos, se les complicaba o era muy adentro, y las tierras que estaban cerca de la ruta no las alquilaban, o sea, era muy, muy... en ese tiempo era muy jodido poder producir" (Productor Mediano Convencional Propietario)

En paralelo uno de los entrevistados analiza la capacidad de asesoramiento técnico frente a la llegada de esta serie de innovaciones y la capacidad para dar respuesta y 264 Lic. Carolina Baldini Tesis doctoral - Territorio en movimiento 
contención a las familias productoras frente a situaciones de crisis como la que devino a finales de los 90 y comienzos del 2000, describiéndolo de la siguiente manera:

"Los noventa es el período de la explosión tecnológica. Sí, los noventa...Y los técnicos que estaban preparados, porque eran nuestros egresados, no estaban preparados para eso...vos veías que los que andaban bien en el tema hortícola era porque se habian formado afuera. Y bueno, varios de los técnicos de la actividad privada que son reconocidos y referentes a nivel nacional y algunos internacional, son tipos que han hecho toda su formación afuera. $Y$ no formaciones... digamos, no una capacitación formal, sino iban quince días, un mes, dos meses, se iban a Holanda, se iban a Israel, se iban a España, se iban a Estados Unidos, y se traían todo, y bueno, tipos inteligentes empezaron a manejar La Plata, Corrientes Mendoza, Salta, Tucumán. Entonces bueno, andaban por todas las regiones productoras de hortalizas, $y$ asesorando emprendimientos realmente grandes...A los pequeños productores no les daba bolilla nadie...Y hubo cambios en lo que fue toda la extensión agropecuaria, diciendo: ¿para qué vamos a tener gente trabajando en los territorios si están los técnicos de la actividad privada? Entonces empezaron a cerrar agencias de extensión, el Ministerio de Asuntos Agrarios dejó de tener técnicos que trabajaban con los productores..." (Docente/Investigador de la FCAyF)

Lo planteado por el entrevistado expone como las políticas de Estado de ese período contribuyeron claramente a que los pequeños productores, que a duras penas lograban alcanzar un mínimo grado de capitalización y cierta independencia y posibilidades de decisión, no contaran con el apoyo y las herramientas adecuadas para poder generar un cambio productivo que se tradujera en mejoras económicas, ambientales y sociales. Por el contrario, las políticas públicas (o la ausencia de ellas) de ese período parecen orientadas a la precarización y explotación de la pequeña agricultura familiar, sin demostrar tampoco un mayor interés por garantizar la adecuada alimentación de la población. Los productores bolivianos ingresaron al país y a la producción en un período muy diferente al que lo hicieron los productores italianos, españoles, portugueses, quienes ingresaron en un período donde había ciertas facilidades para acceder a la propiedad de la tierra y donde la presión de mercado (a través del negocio de las agroquímicas, el supermercadismo y la especulación inmobiliaria) no tenía la relevancia que tuvo posteriormente. De este modo, vemos que las actuales condiciones de producción y de vida en el cinturón Hortícola no fueron el resultado de una "forma de hacer" de las familias productoras, una cuestión "cultural", de "costumbre", como mencionan algunos entrevistados, sino que fue el resultado de un mercado internacional en expansión y una decisión política del Estado nacional de no intervención. 
"Y hubo cambios en lo que fue toda la extensión agropecuaria, diciendo: ¿para qué vamos a tener gente trabajando en los territorios si están los técnicos de la actividad privada? Entonces empezaron a cerrar agencias de extensión, el Ministerio de Asuntos Agrarios dejó de tener técnicos que trabajaban con los productores..." (Docente/Investigador de la FCAyF)

"El Estado en la década de los noventa, hasta el 2001, yo digo: metieron parches en las políticas sectoriales, metieron parches a través de los programas... del Prohuerta, Cambio Rural y el Programa Social Agropecuario. ¿Por qué digo que metieron parches? Porque vos tenés una política macroeconómica, que es la política que es expulsora. Entonces vos tenés esto, que te expulsa, te va corriendo gente. $Y$ vos arreglás acá para ver que la gente no se vaya, pero esto sigue echándote gente. Que es la política macro". (Docente/Investigador de la FCAyF)

La situación descripta anteriormente, junto con la historia de inserción de estos pequeños productores en la región, como peones y medieros, que debían producir según pautas establecidas por sus patrones, en un período caracterizado por la intensificación productiva, fueron delineando la difícil realidad que atraviesan los pequeños productores familiares de la región, junto con los problemas ambientales y las graves deficiencias en cuanto al acceso a alimentos saludables para la población que vemos en la actualidad. Es un claro ejemplo de cómo influyen en los territorios las políticas de mercado y un Estado ausente o promotor de estas mismas políticas. Finalizando la década de los 90 y con la crisis del 2001 esta situación queda aún más evidenciada, afectando tanto a grandes como pequeños productores, como podemos ver en los relatos de los entrevistados:

"Bueno, esa locura tecnológica que se da durante los noventa, cuando llega el 2001 los encontró... bueno, (apellido de productor grande) que tenía 60 hectáreas de alcaucil, lo mató todo, lo... la devaluación y la modificación del tipo de cambio y todo eso lo descuartizó. Había algunos de estos productores que se habían comprado invernáculos de cerca de 300.000 dólares la hectárea. Viste esos que apretás el botón y te salen los tomates. Bueno, en el 2001 no pudieron plantar... 2002, no pudieron plantar. Porque con la devaluación se les transformó todo, entonces no tenían plata...el INTA que era el que les tenía que dar una respuesta, no sabían qué hacer. No había un modelo alternativo, no había una propuesta alternativa" (Docente/Investigador de la FCAyF)

“...se coparon con la locura tecnológica (los productores grandes), y nosotros les decíamos: si llega a pasar algo, ¿qué van a hacer? Siempre hemos advertido, porque los que seguían estando en la trinchera eran ellos. Nosotros volvíamos y teníamos sueldo... pero ellos estaban enloquecidos" (Docente/Investigador de la FCAyF) 
"Porque algunos de ellos tuvieron que... parte de las quintas las transformaron en canchas de fútbol. Entonces dejaron un pedacito así como para despuntar el vicio, pero... varios de ellos, transformaron todo...Otros empezaron a arrendar. Algunos después de un tiempo empezaron a tener mediero" (Docente/Investigador de la FCAyF)

En cuanto a las políticas de ordenamiento territorial y de planificación de la actividad productiva podemos ver una tendencia similar, caracterizada por la desregulación, pasando de políticas como la de las colonias hortícolas a políticas orientadas principalmente al área urbana.

"el área (productiva) ha tenido una cierta desvalorización con respecto al... Antes era un área de reserva, hoy no se la considera un fuelle de reserva. No tiene una política ambiental hoy el marco normativo. Creo que es una de las mayores críticas que uno le podría hacer. La Plata no tiene un código rural, de hecho. Tiene un código urbanístico" (Funcionaria de la Dirección General de Planeamiento)

\subsubsection{El kirchnerismo y el bum de la intensificación productiva}

Como consecuencia de la crisis del 2001 muchos de los grandes productores dejaron la actividad, quedando representada mayormente por pequeños productores familiares de Bolivia, como se evidencia a continuación:

“...venís de una crisis tremenda, la figura del boliviano que está arrendando y bueno, es el que sostiene la producción. Porque yo creo que, dicho por los propios productores, los quinteros más grandes, si no estaban estos (los productores bolivianos) en el 2002 no había producción, en el 2003 no había producción. Porque estos laburan, tienen la plata en el bolsillo, toda en negro. Bueno, les dan con un caño, pero dicen: si no hubiesen estado estos, no había producción. Porque nosotros no nos podíamos jugar. En ese sentido les han reconocido su rol importante..." (Docente/Investigador de la FCAyF)

Al mismo tiempo, los entrevistados marcan la movilidad que se dio dentro de la comunidad boliviana, pasando muchos de ser medieros a ser arrendatarios, con mayor intensidad a partir del 2013. En este contexto se vio una reducción del tamaño de las unidades productivas a través de subarrendamientos informales. Frente a este movimiento generado en quienes realizan la actividad productiva, podemos ver a través de los relatos, como el Estado ha contribuido a la precarización de la actividad y a la informalidad que hoy se busca solucionar, responsabilizando generalmente al eslabón más débil de la cadena, el pequeño productor familiar. 
“...hay una ley de arrendamiento rural, qué sé yo, pero lo que pasa es que no encuadra, digamos, acá la esquivaron olímpicamente, antes era excepcional hacer algo, viste, pero esto va toda una economía que está totalmente en negro, el productor no figura ni como productor, alquila en negro, viste, vos ves los contratos, no están timbrados, digamos, es como un papel, es como un acuerdo cuasi de palabra, digamos, este..." (ex coordinador del Programa Cambio Rural)

“...técnicamente vos no podés dividir, qué hicieron acá, las inmobiliarias de acá, y también en conjunto con los propietarios, empezaron a alquilar en negro parcelas de una hectárea, viste, porque por ahí este tipo que había sido empleado o medianero no tenía capital para poder alquilar las cuatro hectáreas y transformarse en productor, digamos, en gestionar toda una unidad mucho más grande. Entonces, empezaron a aparecer esos alquileres truchos, eso en el marco de las crisis del 2001, 2002, que la gente comía de la basura, de los tachos, de este país en default, rota la cadena de pago, todo el despelote, corralito, bueno. Así que esto era una cosa que pasó, así totalmente desapercibida porque era... pero generó un recambio donde se parcelizó, aumentó la cantidad de unidades de producción, de una hectárea, una hectárea y media, sigue hoy, se te instala un modelo totalmente distinto bajo forma de arrendamiento, con alquileres y eso genera un despelote estructural pero descomunal, porque imaginate que alguien que alquila una hectárea de golpe, bueno, como el propietario sabe que es un alquiler trucho, no le permite construir una casa, entonces se arman todas casillas de madera precariamente, hacen perforaciones de agua que no están permitidas, vos en esas 4,5 hectáreas tenés una perforación, esto lo multiplicás por 4, por 5, mal hechas, bueno, todo un despelote estructural..." (ex coordinador del Programa Cambio Rural)

Con el crecimiento de los productores arrendatarios y su mayor independencia, los productores entrevistados también identifican, un incremento en el uso de agroquímicos, en la instalación en la zona de agroquímicas (empresas de venta de agroquímicos) y consecuentemente un agravamiento del problema en torno a la disposición final de sus envases, especialmente a partir de la llegada a la presidencia de Cristina Fernández de Kirchner. Esto puede estar ligado a la falta de asesoramiento técnico adecuado, ya que cuando trabajaban como peones o medieros de los grandes productores, sus patrones eran los que compraban los agroquímicos, y estos al estar más capitalizados contaban con el asesoramiento de un técnico privado. Al comenzar a ser arrendatarios, los pequeños productores que no podían pagar a un asesor privado fueron recurriendo a la información que tenían más accesible, como se observa en el siguiente relato:

“...en 2007, 2005 ya empezó la gente a empezar a alquilar, alquilar, alquilar tierras, y ahí empezó como... ahí conocí un poco más los venenos también porque ahí los iba 
a comprar yo, antes era el patrón nomás que compraba y quizás estaba en la misma situación ¿no? Pero yo no lo compraba, yo solamente lo echaba, era el que lo hacía ¿no? $Y$ en ese tiempo. Y después ya empecé yo a comprarlos, ahí ya cambió totalmente la dinámica, y era donde, nada, ponele, yo iba a la casa de aquel -no, sí, echale este, echale este- o sea, era el voz a voz era ese...era recomendación y a veces venía una agrónoma y nos decía "che, este, esto es así, esto es así" nos daba un par de tips y no, re contento -mirá, vamos a comprar- y ese era nuestro hobbie". (Pequeño Productor Agroecológico Arrendatario)

"Yo creo que aumentó (el uso de agroquímicos) porque se aumentaron también (las agroquímicas), yo empecé a ver, yo mismo, a ver más agroquímicas también, porque antes había una, dos, o sea no había... no había tantas agroquímicas, o sea porque iban qué sé yo, los patrones grandes nomás iban y compraban ¿se entiende? Y después nada, se empezó a ver agroquímicas, en Olmos está lleno de agroquímicas, o sea, hay una en cada cuadra como así por decirte..." (Pequeño Productor Agroecológico Arrendatario)

“...empezó a haber agricultores, pequeños productores que se alquilaban sus tierras y producian ellos, iban al mostrador y le decian "che, ¿qué se hecha para esto? ¿qué se echa para lo otro?" Y el que estaba ahí o es agrónomo o ya está capacitado para decirte qué es lo que sirve o lo que no sirve". (Pequeño Productor Agroecológico Arrendatario)

Esto coincide con los planteos de Blandi (2016) y Seibane et al. (2014), quienes destacan la gran presencia de las empresas que producen semillas y agroquímicos en el Cinturón Hortícola Platense a través de las casas de ventas de agroquímicos y organizando a nivel local ensayos y demostraciones para difundir sus productos; lo que genera una gran influencia sobre los agricultores, ya que se encuentran en permanente contacto con ellos (Bonicatto 2018)

Las dificultades de estos "nuevos arrendatarios" para cubrir los costos fijos de producción, alquiler, luz, etc. los llevaron a intensificar sus producciones mediante la tecnología del invernáculo, con el objetivo de incrementar su productividad. En concordancia con esto, algunos de los entrevistados identifican en este período un incremento muy fuerte en la superficie bajo invernáculos (el Productor Grande Convencional Propietario destaca especialmente el período 2003- 2010 y el funcionario del área de producción del municipio el período 2005-2010), principalmente en la zona de Lisandro Olmos; lo cual coincide en gran medida con nuestros resultados del análisis de imágenes satelitales presente en el capítulo 2. Es interesante resaltar que en esa zona es donde también identifican la instalación de una mayor cantidad de agroquímicas; a 269 Lic. Carolina Baldini Tesis doctoral - Territorio en movimiento 
diferencia por ejemplo de Arana, donde se produce principalmente al aire libre y no existen o son escasas las agroquímicas. Al mismo tiempo, se observa en coincidencia con Blandi (2016), como la intensificación del modelo productivo generó una pérdida de autogestión, pasando a depender cada vez más del asesoramiento de las agroquímicas y de los proveedores de insumos. A su vez, la artificialización de los agroecosistemas asociada a los cultivos bajo invernáculo, que reemplaza los procesos ecológicos propios del agroecosistema por un alto uso de insumos externos, lleva a un menor conocimiento de la agrobiodiversidad, necesario para manejar procesos como la regulación biótica (Gargoloff 2019)

Otro cambio que identifica el productor grande, tanto en este periodo como en el posterior gobierno de la alianza Cambiemos, tiene que ver con el crecimiento de la informalidad incluso en relación a los mercados

Un aspecto trascendental de este período, y que le da al CHP una característica propia que lo diferencia de otras regiones del país, además de la amplia superficie de cultivos bajo invernáculo, tiene que ver con la capacidad organizativa de los pequeños productores familiares. Hasta la década del 2000, los procesos asociativos en la horticultura platense son relativamente escasos y atomizados (Ambort 2017). Varios entrevistados destacan un crecimiento del número de organizaciones de productores y de la cantidad de productores organizados, en sintonía con lo planteado por Ferraris y Bravo (2014). Los entrevistados evidencian este crecimiento de la organización especialmente a partir del 2008; y sostienen que habría sido acompañado e incluso impulsado por algunos sectores del Estado, como el INTA a través del programa Cambio Rural. Según Ferraris y Bravo (2014) y Ambort (2017) este fenómeno responde al cada vez mayor grado de formalidad que se les exige a las diferentes formas asociativas para ser destinatarias de las políticas públicas. Una de las trabajadoras del INTA considera, en un sentido similar, que el surgimiento de estas organizaciones de productores habrían tenido que ver inicialmente con la posibilidad de acceder a recursos del Estado.

“...sobre todo en los momentos de emergencia algunas que se gestan desde Cambio Rural, y algunas otras que se gestan más con mirada política, pero siempre desde la negociación del recurso con el Estado. Si nosotros estamos juntos bajamos el Programa de agricultura familiar, porque el Programa de agricultura familiar urbana y periurbana está destinado solo a organizaciones. Todos los subsidios que se dan durante esa época se destinaban a organizaciones, y había mucha intervención del Estado también tratando de laburar para conformar esas organizaciones..." (Trabajadora de la Agencia de Extensión Rural de La Plata) 
Por otro lado, desde la Dirección de Planeamiento del municipio, en coincidencia con la mirada de productores y trabajadores de la UNLP, destacan el avance de la urbanización sobre zonas tradicionalmente productivas, especialmente a partir del 2007 , con el avance de los countries y más recientemente de los loteos para los planes procrear. Al mismo tiempo destacan un avance de la especulación inmobiliaria y de los costos de los lotes. Estas transformaciones traen aparejado por un lado el desplazamiento de la actividad productiva, hacia sectores donde el alquiler o la compra de tierras sea más accesible; y por el otro lado se empiezan a generar conflictos por la cercanía entre usos del suelo incompatibles. Estas observaciones tienen coincidencia con el análisis de la distancia entre el área productiva y el área urbana para el año 2015 realizado en el capítulo 3 de esta tesis.

"El otro día había una queja... también nos caen algunas denuncias de, por ejemplo: yo me fui a vivir ahí, mi vecino tiene todos chanchos en el... bueno, pero es el medio del campo, ¿qué pretendés que tenga? El hombre está bien, vos sos el que te fuiste a vivir ahí, y no..." (Funcionaria de la Dirección General de Planeamiento)

"Y después otro de los mayores cambios, el valor de uso del suelo. El valor... cien veces más que lo que salía hace treinta años. De hecho los countries implantan ahí por el valor bajo del suelo. De hecho están todos sobre las redes hídricas, el Grand Bell atraviesa el arroyo, en el 2007 quedó bajo la cota...porque se vende como tierra rural, y después se viene el cambio de zona y te la dan como área urbana, y ahí los precios obviamente...especulación inmobiliaria..." (Funcionaria de la Dirección General de Planeamiento)

Nuevamente vemos una evidencia de la falta de intervención del Estado, y la connivencia con ciertos sectores empresarios, dejando el cinturón hortícola en manos del mercado, como indicaran Merchán (2016), Frediani (2010) y Barsky (2007) entre otros autores.

Una de las técnicas entrevistadas menciona que en este proceso de desplazamiento de la actividad hortícola hacia la zona de Poblet, traccionada por el avance urbano, la horticultura está comenzando a avanzar sobre zonas con actividad típicamente ganadera, un aspecto detectado en los análisis a través de imágenes satelitales desarrollados en el capítulo 2. Esta entrevistada hace la siguiente observación al respecto:

"Ya ahora avanzan sobre la ganadería (los invernáculos). Todavía no es muy importante, pero es una preocupación de algunas municipalidades". (Técnica Cambio Rural) 


\subsubsection{El macrismo y la decadencia}

Todos los entrevistados coinciden en que en el periodo de gobierno de la alianza Cambiemos la situación se agravó fuertemente. El excesivo costo de los insumos para la producción (en gran medida dolarizados), los aumentos en las tarifas y en los alquileres y la baja en las ventas han expulsado a muchos pequeños productores. Los que se mantienen en la actividad están cambiando las variedades de verduras que cultivan, dejando de producir las verduras llamadas "de fruto" (como el tomate y el morrón), cuya producción es más costosas, y priorizando la producción de verduras "de hoja", de ciclos más cortos, que requieren menos inversión y menos cuidados, como una forma de asegurarse la permanencia en la actividad. En este sentido también se observa que muchos productores están volviendo a trabajar como medieros.

"Mucha gente está dejando la quinta, porque no hay mucho... ya no se ve mucha... no te rinde mucho ya, porque está todo caro". (Pequeña Productora Convencional Arrendataria)

"Y, yo creo que hubo mucha desaparición de pequeño productor, o productor que tuvo que... digamos, en esa escalera boliviana que llama Matías (García) volver a ser medianero de otro que por ahí la pudo bancar mejor en esta época con el tema del dólar. Yo creo que hubo una gran... hubo muchos productores que tuvieron que dar un paso atrás en su actividad. Es muy notorio eso" (Técnico Cambio Rural)

"El tomate está carísimo, la semilla de tomate. Los remedios para curar el tomate están carísimos. $Y$ todos los que ponen en invernadero... tiene muchas más plagas dentro del invernadero el tomate, entonces los remedios hacen todo más caro. Y la gente, hoy en día, el año pasado, dejó de poner tomate, porque está muy caro. Por eso es que está caro el tomate (en la verdulería)...Mil semillas (de tomate) te venden como \$20.000". (Pequeña Productora Convencional Arrendataria)

“...por ejemplo, el brócoli que yo planto tengo que sacarlo en tres meses, y tres meses tengo que pagar alquiler, tengo que pagar... regar, que lleguemos con la bomba, tengo que pagar la luz. Tres meses me cuesta un montón. En tres meses tengo que carpirlo..." (Pequeña Productora Convencional Arrendataria)

Otro aspecto que destacan es el incremento en la especulación en torno al precio que los intermediarios pagan las verduras en las quintas, en la venta a "culata de camión".

"El que más gana es el verdulero, el último intermediario. Porque no es que gana un $20,30 \%$ más, como puede ganarte... ponete que te saque un 40,50 , el camionero, el que va y vende. Pero el verdulero, el precio que paga en el mercado, él te marca un $100 \%$ o más. Aparte lo ves, hay los que marcan hasta 300, 400. Yo he visto 
lechugas, cuando vale 50, 60 pesos una jaula de lechuga, los tipos te dan a 30 pesos el kilo". (Productor Mediano Convencional Propietario)

“...no me dieron ni ganas de preguntar porque me iba a enfermar más, porque el tipo (en el puesto del mercado) le saca $\$ 1000$ a un cajón de un día para el otro, y vos tenés cuántos meses para sacar (para cosechar)." (Productor Mediano Convencional Propietario)

A su vez se han tomado durante este gobierno una serie de medidas que han generado un recorte en ciertos derechos a los que tenían acceso los pequeños productores familiares, como el Monotributo Social Agropecuario, generando condiciones de mayor precarización laboral. La quita del Monotributo Social Agropecuario es una medida que se contradice claramente con el discurso de los funcionarios municipal y provincial entrevistados, cuya prioridad seria la formalización de estas familias productoras, evidenciando que no hay un real interés por mejorar las condiciones del sector.

"...teníamos un monotributo social agropecuario que teníamos, y el estado lo dio de baja, directamente, o sea ahora ya no podemos facturar...no podemos facturar, y no podemos tener una obra social..." (Pequeño Productor Agroecológico Arrendatario)

“...directamente de agroindustria que antes era un ministerio, lo degradó ahora es una secretaría de agroindustria, lo mismo agricultura familiar, ya era una secretaría, ahora es una oficina nada más, o sea es un mostrador donde están dos, tres personas que dicen que son de agricultura familiar, pero no saben qué caramba hacer tampoco..." (Pequeño Productor Agroecológico Arrendatario)

“...de hecho, de todas las áreas de lo que es el campo para el pequeño productor le ha ido sacando mucho, del INTA, el asesoramiento que iban teniendo los pequeños productores, también lo redujeron. Después también está todo lo que es el ministerio, el ministerio de agroindustria lo redujeron a secretaría, agricultura familiar también echaron la mitad de la gente..." (Pequeño Productor Agroecológico Arrendatario)

Finalmente, también se observa un cambio en relación al crecimiento de los invernáculos. Uno de los entrevistados plantea que entre el 2013 y el 2015 hubo una merma en la construcción de invernáculos y que luego del 2015 se dio un crecimiento acelerado de los mismos. Si bien este período de tiempo no fue considerado en el análisis realizado en el capítulo 2, a través del análisis visual de imágenes satelitales y del recorrido a campo del territorio se han identificado nuevas zonas de producción hortícola bajo invernáculos en el partido de La Plata, en coincidencia con las apreciaciones de varios entrevistados.

“...es como que hizo un boom en la hectárea (de invernáculos)...del 2015 en adelante...en superficie, y te digo porque allá se ve clarito, clarito...la zona Poblet, 273 Lic. Carolina Baldini

Tesis doctoral - Territorio en movimiento 
esa zona. Porque yo te digo, yo voy a pescar mucho por aquellos lugares, y vos lo ves el día a día, vas hoy y los tipos siguen armando, te arman dos o tres hectáreas de un saque. Es muchísimo." (Productor Mediano Convencional Propietario)

Un aspecto positivo en el marco de todos los cambios que se dieron en este período producto de la acentuación de la crisis económica, que han marcado tanto trabajadores del INTA como de la UNLP y el funcionario de producción de provincia tiene que ver con el incremento de las experiencias de transición agroecológica en el CHP y la visibilización del productor como actor de la región.

“...hay una tendencia fuerte ahí hacia lo agroecológico, de los productores, se anima el productor más a vender de forma directa y creo que eso está bueno y hay un cambio en poder defender y contarle a la gente que produce y como produce..." (Funcionario de la Dirección de Horticultura, Floricultura y Fruticultura)

“...(con el crecimiento de las organizaciones) al tener nuevas alternativas de comercialización poder repensar las estrategias de producción al interior de cada una de las quintas. Por ahí dentro de una misma organización conviven distintas estrategias de producción y distintas estrategias de comercialización. Pero nosotros vemos este intento de ir hacia lo agroecológico. También creo yo, impulsado de alguna manera por los costos excesivos por la dolarización de las tarifas y la disparada del dólar" (Representante del Consejo Social)

Al igual que en otras partes del mundo, frente al crecimiento de las experiencias agroecológicas, a la creciente demanda de la población de alimentos producidos sin agroquímicos y a la inminente crisis del modelo de producción convencional, el mercado se reacomoda y las empresas productoras de agroquímicos van reperfilando su estrategia. En este sentido, en el CHP se viene difundiendo lo que denominan producción biológica, especialmente con los productores más capitalizados, como el productor grande entrevistado, quien realiza producción biológica, importando del exterior organismos que funcionan como controladores de las plagas. De esta forma lo describe un trabajador del INTA:

“Suponete, acá una empresa se trae... está vendiendo... se importa de Bélgica. En Europa, viste, Syngenta, todas las... dejan de fabricar drogas de síntesis químicas, y están fabricando bichos. Reemplazan el insumo. En Almería, en los lugares más grandes, va todo hacia el control biológico, que es la salida empresarial de la sustentabilidad" (Trabajador del IPAF Región Pampeana) 


\subsection{El territorio visto más allá del mercado. El Paisaje entendido por los distintos actores del territorio}

A través de las entrevistas busqué analizar la percepción que tenían los distintos actores respecto a las transformaciones en el paisaje y en la presencia y el rol de las áreas seminaturales en este paisaje. A su vez, al entrevistar a los productores indagué en el paisaje que rodea a sus quintas y en el manejo de la vegetación espontanea que ellos realizan.

\subsubsection{La quinta y su paisaje}

Todos los productores entrevistados mencionaron tener algún sector de la quinta que no estaba bajo producción, pero en ninguno de los casos fue intencional. Los motivos en general tuvieron que ver con falta de tiempo para trabajar toda la tierra, ser pocas personas trabajando en la quinta, problemas económicos que les impiden comprar semillas/plantines o pagar el tractor o la bosta para preparar la tierra, y condiciones climáticas como lluvias frecuentes. Otro aspecto que mencionaron dos productores tuvo que ver con las características del terreno, zonas con suelos muy bajos o cercanas a arroyos o a canales donde desaguan los invernaderos. En cuanto al manejo de la vegetación en los cultivos y en sus bordes, todos hacían algún tipo de manejo de esa vegetación principalmente porque en días de lluvias les generaban inconvenientes en el drenaje del agua. Tanto los productores convencionales como el agroecológico plantearon la necesidad de tener todo el tiempo el suelo bajo producción para cubrir los costos, incluso en los casos de productores propietarios.

"Sí. Pero en nuestro caso la tierra la alquilamos, no es nuestra. Entonces medio quilombete dejarlo (dejar descansar el suelo), medio al pepe. Pero pequeñas parcelas sí las hacemos, pequeñas, no grandes". (Pequeño Productor Agroecológico Arrendatario)

“...es la realidad que tenés que amortizar el invernadero, tenés que tratar de amortizar lo más rápido posible" (Productor Mediano Convencional Propietario)

Sin embargo, es interesante destacar que pese a que las quintas en general tenían una amplia superficie bajo invernáculos, como describimos al comienzo de este capítulo, en los últimos años y como consecuencia de la crisis y de los sucesivos temporales que afectaron a la región, muchos productores están comenzando a producir al aire libre en sectores que antes estaban ocupados por invernáculos.

Entre los beneficios de producir al aire libre, el Pequeño Productor Convencional Propietario plantea que él ubicó los cultivos al aire libre cercanos a la zona donde se encuentran las casas para que hubiera aire, porque si estaban muy cerca los invernáculos elevaban mucho la temperatura. Este productor también plantó una hilera de frutales para 
separar las casas de los cultivos y tener a su vez una vista más "linda", destacando cierta función "estética" de la vegetación. Es importante mencionar que en general los productores y productoras arrendatarios ven esta condición como un impedimento para plantar árboles (ya sea frutales o como cortinas rompe viento); por un lado porque en muchos casos los dueños no se lo permiten, y por otro lado por el carácter transitorio de sus arrendamientos, que les genera incertidumbres respecto a si podrán o no disfrutar los beneficios de plantar esos árboles. Esto es claramente una limitante más para la diversificación productiva y de ambientes en las quintas. Sarandón et al. (2016) plantean que todos los componentes bióticos que hay en un agroecosistema y su ensamblaje e interacciones, dependen, por acción u omisión de la decisión del agricultor/a. A partir del análisis que venimos realizando podemos ver que, si bien es cierta esa afirmación, las decisiones que toman las familias productoras la mayoría de las veces están condicionadas por actores externos de mayor poder, que influyen directamente en las posibilidades de reproducción de la vida de estas familias, condicionando el modelo de producción, las prácticas de manejo en la quinta y consecuentemente la diversidad de animales, de plantas y de ambientes presentes en ella.

Bonnicatto (2019) plantea que en el contexto de crisis actual, las estrategias de manejo basadas en recursos y saberes locales, que generan independencia y permiten ahorrar dinero, están siendo consideradas y revalorizadas; generando una coyuntura oportuna para la difusión de estrategias de conservación in situ de agrobiodiversidad. Mi análisis refuerza esta idea, al detectar en los discursos de los entrevistados una tendencia a incrementar las producciones al aire libre, a dejar (por distintos motivos) sectores de la quinta sin uso o en descanso, y a incorporar corredores de biodiversidad en aquellas experiencias cada vez más frecuentes de transición agroecológica, como exponemos continuación:

"Nosotros cada dos o tres años, cuando cambiamos... ahora más seguido por esto (temporales), pero cuando cambiamos los techos dejamos descansar el lote unos meses, dos o tres meses. Que le llueva, le lave, que crezca todo lo que tiene que crecer y ahí empezamos de vuelta. Se mejora la estructura del suelo." (Productor Mediano Convencional Propietario)

"hacemos corredores biológicos que les llamamos. Entre medio de los palos, donde están los cosos, hacemos corredores biológicos, que son aromáticas, todo eso. Entonces se deja siempre. Son para espantar los bichos o confundirlos, cosas así. Tampoco los matamos". (Pequeño Productor Agroecológico Arrendatario)

“...ahí quedan todavía como unos 50 metros para sembrar. Pero lo hemos dejado. Uno, porque es muy bajo, otro porque tampoco tenemos mucho tiempo para atenderlo...(los "yuyos" que crecen ahí) los dejamos y a veces los combatimos. Si es 
que están molestando mucho sí, los sacamos. No es que los fumigamos, nada, lo hacemos pasar a rastra, digamos. Porque a veces cuando llueve se tranca el agua..." (Pequeña Productora Convencional Arrendataria)

Al analizar el entorno que rodea a las quintas se puede observar que en general todas las quintas están rodeadas en gran medida por otras quintas que producen al menos la mitad (o todo) bajo invernáculos, incluso en las quintas de los entrevistados que viven en Arana, una delegación municipal con menor superficie de producción bajo invernáculos según los análisis realizados para el año 2015 (ver capítulo 3). Los ambientes seminaturales identificados en los entornos de las quintas fueron arroyos, montes y cortinas de árboles implantadas, en algunos casos hicieron alusión a algún campo en alquiler o sin uso donde crecía vegetación espontanea.

La Pequeña Productora Convencional Arrendataria, cuya quinta se encuentra aledaña a un arroyo, lo identificó como un ambiente con efectos negativos sobre la quinta porque en días de lluvia desborda y el agua invade su quinta, ingresando a los invernaderos. Esta productora mencionó incluso que tenía un sector de la quinta bajo (al lado del arroyo) que era el único lugar de la quinta donde no podía producir. Otro aspecto que resaltó la productora es que ante esas tormentas el arroyo arrastra basura que se queda atrapada en las raíces de los árboles que bordean al arroyo incrementando los anegamientos. Finalmente un aspecto sumamente interesante que mencionó esta productora es que, desde que aguas arriba del arroyo (zona de colonia La Armonía) se habían incrementado los campos con producción bajo invernáculo, el arroyo traía más caudal de agua en los temporales generando mayores anegamientos, en coincidencia con el planteo de muchos técnicos e investigadores como García (2011) respecto a los efectos de la impermeabilización del cinturón hortícola.

"ese es el canal... cuando llueve se inunda y entonces esos árboles, al estar ahí, están las raíces, digamos, y toda la basura que tira la gente como que la amontona y cuando llueve todo tranca, entonces todo el agua esa se viene para acá". (Pequeña Productora Convencional Arrendataria)

Si bien en un principio se podría interpretar que los arroyos son un problema para la producción hortícola, el verdadero problema reside en la cercanía de las producciones a estos cuerpos de agua, sin respetar las áreas de inundación naturales de los arroyos, como pudimos constatar en los análisis realizados a través de imágenes satelitales (ver capítulo $3)$.

Todos los productores entrevistados plantearon que las fumigaciones con agroquímicos en las quintas vecinas afectaban sus producciones, que eran atacadas por las plagas que migraban de los campos vecinos; y también hicieron alusión a la deriva de los 277 Lic. Carolina Baldini Tesis doctoral - Territorio en movimiento 
agroquímicos por el aire y al olor que llegaba a sus quintas; en coincidencia con Blandi (2016), quien plantea que el modelo de producción intensivo pone en riesgo la integridad del ecosistema global y afecta tanto al establecimiento productivo como a los que viven fuera de él. Tanto el productor agroecológico como una pequeña productora que ha hecho algunos intentos de empezar a producir una parcela agroecológica lo mencionaban como una fuerte desventaja en este sentido.

"Sí, porque estamos trabajando ahí y se siente el olor fuerte del remedio que echan. Por eso digo, ¿para qué hacer agroecológico si igual por el viento me llega el olor?". (Pequeña Productora Convencional Arrendataria)

"Yo creo que sí (afecta estar rodeado de producciones convencionales), porque ellos tiran venenos y yo no tiro e influyen mucho, y tener mucho cuidado también con eso, ¿no? Ellos por ahí tiran cantidad...entonces cuando tiran veneno ponele acá al costado, o enfrente, se siente el olor" (Pequeño Productor Agroecológico Arrendatario)

"Es más, acá atrás hay unos productores. Que es conocidísimo, cuando levantan el cultivo automáticamente me atacan (las plagas) en este invernadero".

"Sí, no, te puede pasar hasta acá mismo, a nosotros mismos nos ha pasado de llevar un lote a otro... algún insecto y nos ha producido daños. Te puede, no sé, nosotros no curamos, el vecino cura, y te llega un poco de deriva de esa cura, te viene...y, viste, a veces hacés la vista gorda y no te ponés a detallar. Pero sí, hicimos como una zanja de desagote, e hizo un poco de... distancia un poco más. Pero bueno, no podés decir nada. Vos también estás produciendo y le podés producir algo al otro sin saber". (Productor Grande Convencional Propietario)

Un aspecto que la mayoría de los productores entrevistados mencionaron como negativo de la vegetación semi-natural, tiene que ver con la presencia de algunos árboles con raíces muy largas, que si se encuentran en cercanías de los invernáculos dificultan el trabajo de la tierra y absorben la humedad.

"por ejemplo lo que son las moras, o los sauces, sí (afectan la producción), porque tiene unas raíces muy largos, entonces te llega hasta 15 metros y te saca mucho la humedad de los cultivos. Pero después los eucaliptos, los robles (no)..." (Productor Mediano Convencional Propietario)

"Nosotros teníamos unos invernaderos frente a la casa que puso mi cuñado ahí... ¿qué puso al lado de su casa? Ah, sauce. Que los sauces, cada vez que metíamos el tractor, estaban las raíces. Troncos grandes por ahí abajo del invernadero" (Pequeña Productora Convencional Arrendataria). 
Sin embargo fueron muchos más los beneficios que identificaron los productores que los perjuicios por la presencia de estos ambientes naturales en los alrededores de la quinta, complementando las observaciones realizadas por Blandi (2016) y Pérez (2010). Los principales beneficios que destacaron tuvieron que ver con la belleza "escénica" y el beneficio visual de tener esos ambientes cerca, el efecto que tienen ciertas cortinas de árboles como corta viento y la capacidad de los montes de vegetación de funcionar como barrera para la dispersión de plagas de quintas vecinas. En menor medida mencionaron que es vegetación que sirve para purificar el aire, como refugio de enemigos naturales y que brindan material para bioinsumos. A continuación mencionamos algunos ejemplos:

"Debería haber más (árboles). Se ve más bonito también. Pero árboles que sean bonitos también" (Pequeña Productora Convencional Arrendataria)

"El tema, siempre yo digo, el tema de la vegetación y eso, siempre me gustó por el tema de lo estético también. Siempre quisimos que sea un contraste lo verde... porque sino todo invernadero, aparte, no es lindo." (Productor Mediano Convencional Propietario)

“...uso las hojas que caen al suelo (de un monte vecino) para hacer bokashi (fertilizante natural para el suelo)...y todos muchas veces nos miran qué hacemos, parecemos locos. Pero ellos no saben que nosotros reducimos el costo con eso. Bah, sí saben, lo que no quieren es entender". (Pequeño Productor Agroecológico Arrendatario)

De este análisis preliminar podemos concluir que los productores entrevistados identifican bastantes beneficios en la vegetación semi-natural y demuestran cierto interés en poder acceder a esos beneficios; sin embargo, el modelo de producción intensiva y la dificultad de acceder a la propiedad de la tierra parecerían estar actuando como limitantes. Otra conclusión que podemos sacar de este análisis tiene que ver con la necesidad de regular el uso del suelo, las distancias a los arroyos y a las urbanizaciones; y comenzar su vez a evaluar formas de separar las producciones convencionales de aquellas agroecológicas o en transición agroecológica.

\section{MANEJO DE VEGETACIÓN EN LAS QUINTAS Y PERCEPCION DEL ENTORNO QUE LAS RODEA}

- Tendencia a incrementar las producciones al aire libre, a dejar (por distintos motivos) sectores de la quinta sin uso o en descanso, y a incorporar corredores de biodiversidad en el caso de las experiencias de transición agroecológica

- Los ambientes semi-naturales identificados en los entornos de las quintas fueron arroyos, montes y cortinas de árboles implantadas, en algunos casos hicieron alusión a algún campo en alquiler o sin uso donde crecía vegetación espontanea

- Perciben una clara influencia de quintas vecinas convencionales por deriva de agroquímicos y migración de plagas

ASPECTOS NEGATIVOS DE VEGETACIÓN BENEFICIOS DE VEGETACIÓN SEMI- 


\section{SEMI-NATURAL}

- Presencia de algunos árboles con raíces muy largas que dificultan el trabajo en las parcelas productivas

- Estancamiento del agua durante las lluvias en zonas con vegetación alta provocando inundaciones en sectores de las quintas

\section{NATURAL}

- Belleza "escénica" y el beneficio visual de tener esos ambientes cerca

- Efecto de control del viento de cortinas de árboles

- Capacidad de los montes de vegetación de funcionar como barrera para la dispersión de plagas de quintas vecinas.

- Vegetación que sirve para purificar el aire

- Refugio de enemigos naturales

- Vegetación que brinda material para bioinsumos

\subsubsection{El paisaje del partido de La Plata}

Al ser consultados los distintos entrevistados sobre los ambientes semi-naturales que reconocían en el partido de La Plata, se puede observar que los ambientes que son reconocidos por todos los entrevistados como semi-naturales son aquellos de grandes dimensiones, y que en general pertenecen al Estado o tienen algún tipo de regulación que los protege. Se destacan el Parque Pereyra, el Parque Ecológico, Punta Lara, La Balandra y toda la zona ribereña, aun cuando algunos de estos ambientes no se encuentran dentro de los límites del partido. Respecto a los ambientes semi-naturales presentes en el cinturón hortícola todos coinciden en que son escasos a nulos, destacando la zona de Estancia Chica. En este punto es interesante destacar que frente a la visión de un cinturón hortícola fuertemente transformado, muchos de los entrevistados destacaron como ambiente seminatural la calle "Casuarinas", una calle de Abasto cuya particularidad es justamente ser una calle con una arboleda compuesta por casuarinas. Otro ambiente que fue en menor medida destacado como ambiente semi-natural fue el de los pastizales ganaderos naturales o poco intervenidos, destacando la zona que limita con Magdalena y las dos "patas" al oeste del partido entre ruta 2 y ruta 6 . La presencia de estos ambientes fue reconocida por diversos actores, vinculados al mundo académico (un técnico, un trabajador de INTA, el funcionario municipal y la funcionaria del área de planeamiento de provincia). Algunos entrevistados indicaron, aunque con poca claridad, ciertos sectores acotados de ambientes seminaturales, lotes baldíos o descampados, en algunos sectores de la ruta 2, de la calle 44 y de Arana.

"El cinturón hortícola está, el nivel de modificación y de impacto que tenés del ambiente es impresionante. Es terrible. Porque, a ver, te vas entrando por las calles laterales estas, las quintas, qué sé yo, quedan algunos pedazos pero, o que están en litigio, o qué sé yo...nada, son como baldíos que quedan que vos decís: acá hubo 
algún quilombo de papeles y no pudieron dividir o qué sé yo... Bueno, había muchas denuncias, hubo muchas denuncias de las inmobiliaria que se apropiaban de terrenos que estaban de sucesiones que se morían la familia y no había un sucesor...acá las inmobiliarias son unos pistoleros pero infernales" (Trabajador del IPAF Región Pampeana)

"Las Casuarinas...había un arbolado ahí hermoso...Bueno, esa calle antes era de tierra. Tiene un cierto trecho de cemento ahora, pero no es todo. Para mí es un poco más de bosque, y en los alrededores creo que sigue siendo un poco de bosque..." (Pequeño Productor Agroecológico Arrendatario)

“Estancia Chica, es un pulmón...ojalá que se mantenga eso, que no se haga ninguna boludez. Pero ahora hace poco escuché que gran parte de Estancia Chica pertenece a Gimnasia, y bueno...hay un plan de loteo... sí, como mil viviendas. O sea, para sacar guita para el club" (Productor Mediano Convencional Propietario)

Un aspecto importante a destacar es que pese a ser el partido de La Plata un partido atravesado por una importante red de drenaje, como se describió en el capítulo 1, y pese a estar las cabeceras de los arroyos ubicadas en el cinturón hortícola, solo dos entrevistados se refirieron a los arroyos presentes en el partido como ambientes semi-naturales, y ninguno de los productores los reconoció como tales, pese a que forman parte del paisaje cotidiano de muchas quintas e incluso muchas de ellas se ven afectadas por el desborde de los mismos ante eventos climáticos. Probablemente esto tenga que ver con que estos ambientes nunca han sido considerados por los municipios como ambientes a proteger, ni adecuados para uso recreacional de la población; por el contrario han sido contaminados por residuos, por múltiples industrias y por la actividad hortícola intensiva (un caso emblemático en este sentido es el Arroyo del Gato) (Arias 2019, Karol y San Juan 2018), y a excepción del arroyo El Pescado, el resto han sido entubados o canalizados en gran parte de su recorrido.

“...tenemos áreas naturales de reserva, por ejemplo el arroyo El Pescado, que bueno, eso está como paisaje natural por ejemplo. Que por un lado se quiere preservar y por el otro lado urbanizamos ahí, y seguimos viva la pepa...y así vas urbanizando y generando más problemas ambientales de lo que te generaría decir: no, esto es un área de protección, por favor preservemos, hagamos un parque si quieren, una plaza, un lugar de esparcimiento recreativo y las casas que se vayan a otro lado. Pero no hay una decisión..." (Funcionaria de la Dirección General de Planeamiento)

“(el arroyo el pescado) Es el único lugar... el único arroyo a cielo abierto que queda en la ciudad. Es el único, con todo su recorrido a cielo abierto...es el único área de 281 Lic. Carolina Baldini Tesis doctoral - Territorio en movimiento 
pastizal y de bioma natural que queda, creo, en el partido de La Plata...Ahora habían querido poner, no sé qué pasó, un parque industrial en la cabecera..." (Funcionaria de la Dirección General de Planeamiento)

"(en la cabecera del arroyo El Pescado) el Parque Industrial 2, tenemos ahora la Autoridad del Agua, ADA y el OPDS que nos dieron la prefactibilidad, son 92 hectáreas, y nosotros ahí hacemos un parque ecosustentable, y lo proyectamos a treinta, cincuenta años, con el director de industria acá de la secretaría. Pero hacemos reservorios de agua, hacemos espacios verdes. $Y$ hoy tenemos en los planos hechos y aprobados por OPDS y por ADA, para hacer toda la infraestructura necesaria para que se instalen cincuenta industrias o empresas, pero hacerlo ecosustentable en todo, con la energía solar...que en realidad son los nuevos paradigmas que las Naciones Unidas va a pedir en exportación ahora, dentro de poco..." (Funcionario de la Secretaría de Producción)

Al indagar respecto a las funciones de estos ambientes semi-naturales, se puede ver que en general, a excepción de los funcionarios del área de producción municipal y provincial, y de uno de los trabajadores del INTA, todos los otros entrevistados reconocieron que esos ambientes semi-naturales brindan numerosos servicios ecosistémicos, que enumeramos a continuación:

- Paisaje

- Recreación

- Posibilidad de Turismo Rural

- Control de la expansión urbana e industrial

- Control de la contaminación ambiental (incluidos agroquímicos)

- Control de los vientos

- Control de inundaciones

- Pulmón verde

- Purificación del aire

- Reducción de la temperatura

- Sombra

- Reservorio de biodiversidad

- Control de plagas (roedores)

- Refugio de enemigos naturales de las plagas

- Preservación del suelo

Si bien al analizar los relatos de los entrevistados por categoría de entrevistados, vemos que se reconocen variados servicios ecosistémicos, si analizamos al interior de cada categoría (por ejemplo entre productores o entre funcionarios), vemos que el 
reconocimiento es menor, reconociéndose generalmente las funciones de contención del crecimiento urbano, paisajística y de "pulmón verde", y en menor medida control de inundaciones y preservación de biodiversidad. Esto muestra la importancia de interactuar entre distintos actores a la hora de definir políticas públicas, para contemplar las distintas miradas y enriquecer las propuestas con los conocimientos de los diversos actores.

En cuanto al beneficio de estos ambientes para el CHP, más allá de funcionar como reservorios de biodiversidad y de enemigos naturales de las plagas, si bien no fue reconocido como tal, muchos de los servicios ecosistémicos mencionados son sumamente importantes para el cinturón hortícola: el control de las inundaciones, control de los vientos, control de roedores, purificación del aire, preservación de suelos, y otros menos reconocidos en este sentido como el paisaje y la posibilidad de espacios de esparcimiento. Es importante comenzar a tener un abordaje más integral del CHP y trabajar sobre el reconocimiento de estas funciones, no solo por parte de las familias productoras, sino también entre los otros actores que también contribuyen a delinear las políticas públicas, para poder avanzar en la preservación y mejoramiento de estos ambientes en pos de un territorio más sustentable y resiliente.

"Como una... la fauna de los animalitos chiquititos, los insectos, que se crían... mariposas... Vos no los querés en la quinta, pero que estén allá está bien... allá se ven bonitos esas cosas, pero en la quinta estaría mal que estén...Las langostas te comen las hojitas. Allá están bien. Las maripositas ponen gusanitos, entonces...y viste que hay gusanitos que se los comen a las plantitas. O sino se meten al cogollito de las plantas, de los brócolis, de... y también, te friegan. Acelga también vienen y se meten en el cogollito" (Pequeña Productora Convencional Arrendataria)

“...los árboles tienen la capacidad también de poder absorber todo eso. Toda materia y todo eso, pueden absorber hasta los químicos mismos...más que nada eso, un árbol da vida y puede cambiar el sistema, cambiar tu misma salud". (Pequeño Productor Agroecológico Arrendatario)

Diversos entrevistados hicieron alusión, de una u otra manera, a la falta de ambientes semi-naturales en el cinturón hortícola y a la importancia de contar con áreas de esparcimiento para las familias productoras y ambientes que contribuyan a mejorar la "belleza escénica" del cinturón hortícola.

“...te vas a La Plata, yo estoy un día en La Plata, una tarde, me quiero rajar a la mierda. Ya no quiero saber nada. O como veo la zona de allá, que he ido un par de veces a la zona de producción de invernadero, quiero rajar a la mierda. Vos te metés por un camino, y ves que se pierden de vista los invernáculos y no ves una planta 
aunque sea para tomar un mate a la sombra". (Productor Mediano Convencional Propietario)

"...Ya ir por la ruta y no ver un techo de invernadero es satisfactorio". (Trabajadora de la Agencia de Extensión Rural de La Plata)

"También desde el punto de vista estético, paisajístico para el productor, para la familia, recreativo... No sé, no hay una puta plaza en El Peligro, en... o por lo menos plaza grande, con juegos. En El Pato por ahí hay alguna, pero en Etcheverry, en Olmo, no sé, hay tan poco de todo eso. El productor sale del invernáculo o de la casilla al asfalto del centro comercial, viste, del pueblo, de Olmos o de Abasto. No hay como mucha otra alternativa". (Trabajadora de la Agencia de Extensión Rural de La Plata)

“...(necesidad de) pensar en corredores agroecológicos, no sé de qué manera... dentro del mismo cordón hortícola. Porque si se impermeabiliza todo, si se tapa todo con plástico, es recontra complicado." (Técnica Cambio Rural)

A continuación cito un extracto de la entrevista a uno de los trabajadores de la UNLP, quien mediante el ejemplo de la zona de la rivera en Berisso, expresa claramente la importancia de estos espacios inmersos en un ambiente fuertemente modificado, para la vida social, el esparcimiento, para el mantenimiento de las costumbres, tradiciones:

“...de Buenos Aires lo que es La Balandra, lo que es toda la zona de acá de Berisso donde se hace el vino de la costa, poder producir de la forma en que se lo hace, todo eso... Poder conservar algo que no ha sido invadido todavía por una modernización que te rompe todo, te mantiene tradición, cultura, estilo de vida...que para mí es fundamental, mantener esa diversidad y no estandarizarnos". (Docente/Investigador de la FCAyF)

Salvo excepciones, los entrevistados no hicieron mención a los arroyos existentes en el partido al referirse a los ambientes semi-naturales, lo que podría estar evidenciando una falta de apropiación por parte de la población, un aspecto que convendría abordar con el fin de poder transformarlos en espacios de esparcimiento y conservación de biodiversidad

Si bien no fueron reconocidos como tales, muchos de los servicios ecosistémicos mencionados son sumamente importantes para el cinturón hortícola, entre ellos: el control de las inundaciones, control de los vientos, control de roedores, purificación del aire, preservación de suelos; y otros menos reconocidos en este sentido como el 
paisaje y la posibilidad de espacios de esparcimiento

Diversos entrevistados hicieron alusión, de una u otra manera, a la falta de ambientes semi-naturales en el cinturón hortícola

\subsection{Las principales transformaciones en el paisaje y los criterios de ordenamiento territorial}

Todos los entrevistados coincidieron de manera unánime en la lectura que realizaron de las transformaciones en el paisaje del partido de La Plata. Esta amplia diversidad de actores entrevistados (productores, universitarios, técnicos, funcionarios, INTA) han identificado dos procesos principales: la expansión urbana y el crecimiento hortícola acompañado por una expansión de las producciones bajo invernáculos. La expansión urbana se considera como el principal motor que tracciona los cambios en el uso del suelo, sustentado en un fuerte sector inmobiliario, con capacidad de influencia entre los principales funcionarios del gobierno municipal, desatando en los últimos 10-15 años un fuerte proceso de especulación inmobiliaria. Los cambios más drásticos en el uso del suelo se identifican a partir del 2003 aproximadamente, en coincidencia con la salida de la crisis del 2001, la reactivación económica y productiva; en este periodo se comenzaría a ver con mayor magnitud el proceso de ascenso en la "escalera boliviana", con un importante número de productores que pasaban a ser arrendatarios, pero que no tenían la posibilidad de sostener una unidad productiva de 3-5 hectáreas, comenzando un proceso de subarrendamiento de las quintas que generó un mayor número de unidades productivas pero de tamaños muy reducidos (11.5 hectáreas en promedio), con un fuerte negocio inmobiliario detrás.

Diversos entrevistados coinciden con marcar como un momento visagra en la expansión urbana y el crecimiento de la especulación inmobiliaria, a la llegada a la intendencia de Pablo Bruera (año 2007). En este sentido se identifica un claro avance de las áreas urbanas sobre el espacio rural, especialmente en la zona norte (Colonia Urquiza, Las Banderitas, Gorina, entre otros), la zona oeste (Abasto y Olmos, en menor medida El Peligro), al sur (ciertos sectores de Arana, principalmente sobre la calle 137) y sobre la ruta 2. Este crecimiento urbano, los entrevistados lo identifican como un crecimiento diferencial. Por un lado el eje norte, el eje de la ruta 2 y la calle 137 en Arana, donde avanzaron en la construcción de countries, clubes de campo y barrios cerrados; por otro lado el crecimiento de las zonas de El Peligro, Abasto, Olmos y algunos sectores del sur del partido, con el avance de viviendas populares, con un fuerte impulso a partir de los créditos ProCreAr. En este período se fue dando, según los entrevistados, un avance de la urbanización sobre suelos rurales, incrementando el valor del suelo y generando la expulsión de muchos 
productores hortícolas hacia zonas más alejadas del partido, con un uso típicamente ganadero.

"Te puedo hablar desde el 97 para adelante... nosotros vivimos un momento que estuvo muy regulado, por ahí demasiado regulado, y donde había una planificación y vos sabías quizá para dónde quería crecer la ciudad. Y bueno, justamente zonas donde de alguna manera esa planificación que se había estudiado, había como un argumento por el cual creciera para ese lado o para el otro...y vamos a priorizar el cordón verde hortícola, o sea, el cinturón verde hortícola no se toca, o no se toca cierta parte del cinturón verde, o se prioriza tal arroyo, tal zona de... hubo ese momento. $Y$ después veo como el momento de: hay que traer inversores, no importa dónde, no importa qué, la importancia es radicar esas inversiones y después vemos cuáles son los otros problemas que se suscitan...y hoy tenemos desgraciadamente todas cuestiones a pagar por esos daños ambientales que estas cuestiones sin planeamiento ocasionan ...acá por lo menos en el municipio, entre Alak y Bruera fue un cambio importante, al menos desde la parte técnica..." (Funcionaria de la Dirección General de Planeamiento)

Estas observaciones coinciden en gran medida con los resultados de mi análisis a partir de imágenes satelitales (ver Capítulo 2). En mi caso observé efectivamente que en el período 2005-2015 hubo un avance de la producción hortícola (cultivos al aire libre y bajo invernáculos) sobre suelos bajo uso ganadero, respecto al periodo anterior (1996-2005). También constaté un mayor avance de la urbanización sobre suelos ganaderos en el período 2005-2015 respecto al anterior. Sin embargo, en cuanto al avance de la urbanización sobre suelos productivos, observé un mayor avance en el período 1996-2005 que en el período 2005-2015; esta diferencia puede tener que ver con que la urbanización puede haber crecido también sobre suelos ubicados en el cinturón hortícola que no estaban bajo producción, pero que por su ubicación o historia de uso son percibidos como suelos productivos. En los últimos años, a partir del 2015 aproximadamente, los entrevistados identifican un fuerte crecimiento de la horticultura, principalmente hacia el sur del partido (Poblet, Oliden) llegando a Bavio y al oeste hacia Brandsen sobre el eje de la ruta 6. De este modo vemos como la urbanización desplaza a la actividad hortícola y como consecuencia de ello la horticultura desplaza a la actividad ganadera, que se ve fuertemente reducida y expulsada hacia partidos vecinos (Magdalena, Bavio). Esta observación también coincide con mi análisis a partir de imágenes satelitales, en el cual observé una disminución de los suelos bajo uso ganadero en todo el período estudiado (1986-2015). Frente al desplazamiento de la actividad hortícola hacia zonas más alejadas del partido los entrevistados mencionan algunas problemáticas que ya se están evidenciando, como la falta 
de infraestructura y servicios públicos y el asentamiento de quintas en zonas inundables, generando condiciones de vida y de trabajo aún más precarias que las actuales:

"Y luego no sé, lo que es la ruta 36 hacia Bavio, etcétera, también es otra zona que se está yendo para actividad hortícola. O la ruta 6, hacia la 53, hacia Varela también se ve que se está creando otro polo productivo...son tierras muy bajas, que seguramente cuando se llueve mucho se inundarán, pero el productor a veces toma ese riesgo, y se va...y hay mucho productor que inclusive se ha ido a la ruta 6 y lo que ha hecho es: ha comprado tierra. Porque también los valores de la tierra cercanos a la urbanización son muchos más caros que tierras alejadas...otro ejemplo: la ruta 36 hacia Bavio, eso, ya son los lugares donde los productores pagan menores valor del alquiler, y yo lo asumo a que es porque por ahí no tienen micro, no tienen una accesibilidad como la que tiene la gente que está en Abasto, en Olmos..." (Técnico Cambio Rural)

"Donde nace. Que yo me acuerdo que había un arroyito, cuando era pibe, me acuerdo, que estaba un arroyito, que eso era una laguna, que son más o menos... hay una curva, creo que la única curva que hay grande de la ruta (ruta 36) que están en un pozo todos los invernáculos. Bueno, eso era una laguna. Nosotros íbamos a pescar con mi viejo cuando era chico ahí. Después lo han drenado un poco, pero bueno, porque se va para el arroyo...me acuerdo cuando fue la inundación grande estaba todo tapado con agua eso, me acuerdo clarito...yo sabía que siempre cada vez que llovía se inundaba eso. Cuando llovía fuerte, importante. Y bueno, los invernaderos los tenés abajo. Es una locura. Está bien, pagarán dos mangos el alquiler o lo habrán comprado por dos mangos, pero está lleno de quintas." (Productor Mediano Convencional Propietario)

Dos de los productores entrevistados describen una "ruta de migración" que suelen seguir las familias productoras desde su llegada al partido de La Plata, especialmente aquellas que llevan muchos años viviendo y produciendo en el CHP. Según esta ruta, los productores inicialmente se asentaban en El Peligro, luego migraban hacia Abasto, continuando por Olmos, Arana y finalmente más recientemente comienzan a trasladarse hacia Poblet y Oliden.

Respecto al avance de los invernáculos, los entrevistados identifican un mayor crecimiento en los últimos 15-20 años, a partir del 2000-2004 en adelante, concentrándose principalmente en Olmos, Etcheverry, Abasto, y más recientemente (a partir del 2015) avanzando intensamente hacia Poblet y Oliden. Esta percepción coincide por un lado con los resultados de mis análisis, en los que encontré que en el período 2005-2015 hubo 2516 nuevas hectáreas de invernáculos, en comparación con el período anterior (1996-2005) 
donde contabilicé 999 nuevas hectáreas de producción bajo invernáculos (ver Capitulo 2). A su vez, se confirman ciertas predicciones esbozadas en las discusiones de los capítulos anteriores, donde se planteaba que, de continuar sin una planificación clara en cuanto a los usos del suelo, se corría el riesgo de reproducir las lógicas de desarrollo de la actividad hortícola, que como venimos viendo ya han generado innumerables problemas, a otros sectores del partido, como estamos evidenciando actualmente en Poblet y Oliden. Otro aspecto que emergió al analizar la problemática de los invernáculos, tiene que ver con la falta de información estadística actualizada por parte del Estado y de información académica clara. Ante esa situación surgen distintas aproximaciones en cuanto a la superficie bajo invernáculos actual que varían entre las 4000 y las 6000 hectáreas. Mi investigación arrojó un valor de 4370,4 hectáreas bajo invernáculos para el año 2015. Sin embargo, la interpretación visual de imágenes satelitales actuales y el constante trabajo de campo evidencian un incremento en esta superficie desde esa fecha hasta la actualidad. Ante la velocidad que asumen las transformaciones en el territorio es necesario y urgente pensar un mecanismo para poder generar información actualizada de manera periódica.

En cuanto a las políticas de planificación del uso del suelo en el partido, todos los entrevistados, incluidos los funcionarios del área de producción municipal y provincial coinciden en que no hubo ni hay políticas de planificación y que lo que ha definido el paisaje que vemos actualmente en la región ha sido el mercado. Se reconocen algunas políticas públicas aisladas, como el control del desarrollo de urbanizaciones privadas durante la intendencia de Alak, o la planificación (aunque deficiente) de viviendas populares a través de los planes ProCreAr, pero ninguna de ellas formando parte de un plan integral de ordenamiento del territorio, lo que ha generado un crecimiento urbano desordenado, encontrando sectores del partido con un entramado de viviendas y actividad productiva con una conflictividad creciente. Esta cercanía entre lo urbano y lo rural expuesta por los entrevistados, coincide con los análisis realizados mediante la utilización de imágenes satelitales, donde calculé la distancia de los invernaderos al área urbana (ver Capitulo 3).

"Después también malas políticas porque el ProCreAr fue y es un programa bueno, de acceso a la vivienda, concreto, bueno, pero vos tampoco podés aprobar un ProCreAr en el medio de una zona productiva, porque automáticamente, acá hay uno en la 137, cuando vas para Arana. Un terrible chalet, levantás la persiana y tenés el invernadero a diez metros, cruzás la calle y tenés un productor con el motor prendido a la noche porque está regando, el camión que viene a las 3 de la mañana para cargar para el mercado, ruido, viene y le tira una parva, un camión de bosta fresca para, bueno, viste, es imposible, porque es zona rural, y permitís una excepción, armás un barrio, el conflicto lo tenés ahí..." (ex coordinador del Programa Cambio Rural) 
En relación al área productiva, los diversos entrevistado marcan que el único momento en el cual hubo una política de planificación de la actividad fue en los 80 , con la creación de las colonias hortícolas, pero que más allá de ese momento nunca se priorizo ni se valoró la actividad hortícola en la región. La funcionaria del área de planeamiento del municipio y uno de los técnicos hacen mención a la ordenanza 9231 del año 2000 en la que se crea una figura de protección del área productiva, pero que fue cambiada con la implementación de una nueva ordenanza, la 10703, del año 2010.

“...dentro de la ordenanza 9231, que es la que yo te estoy hablando, hay zonas que son zonas complementarias de reserva urbana, que es... o sea, si vos ves un mapa de esa ordenanza, las áreas complementarias de reserva urbana son las áreas en donde supuestamente la ciudad debería haberse expandido. Y no sobre las áreas rurales. O sea, vos tenés... esto por la ordenanza 8912 de usos de suelo de la provincia, que divide en área urbana, áreas complementarias y áreas rurales. Esas áreas complementarias, vas a ver, en la 10703, que es la ordenanza que sigue, que se redujeron muchísimo y que ocuparon parte de la zona rural también y parte del cinturón hortícola. Sobre todo, si vos hacés una lectura un poquito más profunda, te vas a dar cuenta que son donde hoy se localizan por ahí clubes de campo o barrios cerrados"

En cuanto a la ordenanza 9231, que regulaba el crecimiento urbano y daba una figura de protección al cinturón hortícola, vemos por un lado que su implementación no fue efectiva, como evidencian los análisis que vengo realizando; y por otro lado, vemos que en general el resto de los entrevistados desconoce dicha figura de protección, y que en la práctica todos coinciden en que el CHP no ha sido protegido de ningún modo.

“Lo más aproximado fue esto, esas leyes que estaban en el código de uso del suelo de la época de Alak que protegía de alguna manera la instalación dentro de la zona rural, que no te autoriza los countries, los barrios cerrados, pero después... Está el... yo lo tengo, vos ves el mapa, la definición de cada zona, y lo que prevén como zonas de avance urbano, pero se fueron autorizando y autorizando, viste, fue cambiando completamente" (ex coordinador del Programa Cambio Rural)

"Yo alguna vez leí en el Digesto de La Plata, quien regula toda la parte de urbanización, que en el año 2002 se había decretado una...se había declarado la protección del cinturón hortícola de La Plata. Lo que pasa es que siempre la gran pregunta es que nunca te lo delimitaron de tal lugar a tal lugar, de tal franja a tal franja. Entonces quedó todo muy... quedó en la teoría pero en la práctica...” (Técnico Cambio Rural) 
Finalmente, los entrevistados fueron consultados respecto a cuales son las causas de esta falta o deficiencia de políticas de planificación del territorio y de protección de un área productiva de tanta relevancia como es el CHP. Entre los entrevistados podemos encontrar una diversidad de opiniones, que no solo no son excluyentes, sino que consideramos complementarias. Tal como vengo abordando el tema en esta tesis, todo territorio y especialmente las áreas periurbanas son ámbitos complejos, de disputa de poder entre actores muy diversos y generalmente con distinto grado de poder y de influencia en las políticas públicas; las problemáticas territoriales, diversas y complejas, requerirán entonces necesariamente de soluciones complejas. Entre los discursos de los entrevistados observamos que las reflexiones no se limitan a lo que ocurre con la gestión municipal, sino que pueden ser transpolables a los otros niveles (provincial y nacional). En las entrevistas realizadas a los funcionarios del área productiva municipal y provincial encontré que estos funcionarios exponen un vínculo fluido entre los funcionarios del mismo área de nación, provincia y municipio, reforzado por la situación excepcional de pertenecer al mismo partido político; sin embargo no evidencian tener articulaciones con otras áreas del Estado en ninguno de los niveles analizados, lo que claramente dificulta cualquier acción territorial integral. Al mismo tiempo se puede ver un desconocimiento de las líneas de trabajo que vienen desarrollando otras áreas para el mismo sector y en algunos casos incluso desconocimiento de que área es la responsable de abordar una problemática determinada, diluyéndose las responsabilidades. En cuanto a los motivos de las dificultades que se observan en el Estado para abordar la gestión del territorio hemos encontrado los siguientes emergentes:

- Visión fragmentada de la realidad

- Desconocimiento del territorio de los funcionarios de turno al asumir su mandato

- Poner la prioridad en obtener rédito político

- Visión cortoplacista

- Prioridad de responder a situaciones de emergencia ante períodos de crisis recurrentes

- Sesgo profesional en la planificación del territorio, predominando la visión de los arquitectos

- Falta de mirada integral del territorio

- Falta de articulación entre diferentes actores

- Poder del mercado

A continuación expongo algunas reflexiones de los entrevistados que hacen explícitos los emergentes mencionados anteriormente: 
“...en las elecciones nadie piensa en la zona de producción, ningún intendente, ningún candidato, en la provincia de Buenos Aires. Les explota el tema cuando gana la elección, asume el tipo, ubica los amigos que participaron en la campaña y -uy, mirá, tengo cinturón... hay una zona de producción, che- y ahí se entera, y empieza otra vez..." (ex coordinador del Programa Cambio Rural)

"Creo que hay cuestiones culturales que se nos han forjado en nuestra cultura como mecanismos de resistencia, como estas miradas... las crisis recurrentes nos han generado un mecanismo de corto plazo absoluto...necesitás tiempo para estos acuerdos, como que... con los gobiernos que... obviamente, te imaginás el próximo gobierno... nada, la urgencia de que la gente morfe, que vuelva a tener trabajo, que se reactive la economía... viste, y los arroyos quedó en el lugar 48. Salís con el matafuego al otro día, otra vez a recuperar el laburo, otra vez...Los pibes, los chicos, las escuelas. Tenés todo... 8.000 prioridades del incendio cotidiano" (ex coordinador del Programa Cambio Rural)

“...yo creo que toda la parte de planeamiento siempre estuvo muy dirigida por arquitectos. Los arquitectos siempre tuvieron obviamente una visión urbanística. Se dedican a eso... A mí me parece que es falta un poco más de interdisciplina para cuestiones de la planificación, ya sea urbana o rural o del partido en general" (Funcionaria de la Dirección General de Planeamiento)

“...lamentablemente, en nuestro país no hay políticas de planificación a largo plazo. Son todas a corto plazo, lo que dura un período de gobierno, son cuatro años, y ahí como que borrón y cuenta nueva. Entonces no hay una continuidad. El que viene quiere hacer el plan estratégico, quiere hacer la nueva ordenanza, como que arranca de cero otra vez. $Y$ nosotros, que somos la parte... y otra cosa es la parte técnica, donde vos ves esas idas y vuelta y te encontrás con que hoy uno te dice una cosa $y$ mañana te dice otra... bueno, y hacés lo que podés a tu criterio, y obviamente que siempre dentro de la normativa vigente, porque es tu... nosotros desde el punto de vista técnico nos basamos en nuestro marco normativo, que es el que te dice hasta dónde podés hacer y hasta dónde no podés hacer, si tenés injerencia vos o la tiene provincia o la tiene nación. Entonces... depende qué se quiera impulsa" (Funcionaria de la Dirección General de Planeamiento)

"...por lo que yo vengo conociendo de distintas gestiones municipales y provinciales, es muy grande la fragmentación en los ejecutivos. O sea, cada área del ejecutivo ve su pedacito de la realidad y no interactúa con el resto. Entonces, si vos no tenés una mirada más integral desde la gestión municipal de tu propio territorio es muy difícil que puedas tener una planificación estratégica sobre cualquier cosa. Y después ya te 
digo, para mí en realidad lo que termina moviendo el amperímetro es el mercado centralmente. Cuando vos no tenés Estado, tenés mercado." (Representante del Consejo Social)

Como sostiene Tapella (2004), las políticas públicas han mostrado en Argentina una contradicción persistente entre las reformas económicas que generan concentración económica y exclusión de los más débiles, y las políticas sociales que, lejos de consolidar a la pequeña agricultura como sector activo dentro del proceso de desarrollo, han funcionado sólo como un alivio temporal frente a los efectos de la política económica.

Finalmente, a modo de síntesis y considerando los resultados y discusiones planteadas en este capítulo retomo los 8 impulsores claves identificados por Mier et al. (2019) en el proceso de llevar la agroecología a mayor escala: (1) el reconocimiento de una crisis que motiva la búsqueda de alternativas, (2) la organización social, (3) el procesos de aprendizaje constructivista, (4) las prácticas agroecológicas efectivas, (5) los discursos movilizadores, (6) los aliados externos, (7) los mercados favorables y (8) oportunidades políticas y marcos políticos favorables. En base al análisis realizado en este capítulo se puede observar que el territorio en el que está inmerso el CHP cuenta con un enorme potencial para avanzar hacia el desarrollo de un territorio sustentable, resiliente, saludable y socialmente más justo, acorde a los lineamientos de la agroecología. En base al conocimiento desarrollado sobre este territorio, destaco ciertos aspectos que estos autores consideran que actúan como limitantes para la masificación de la agroecología, y sobre los cuales hace falta avanzar; estos incluyen la generación de relaciones paternalistas/clientelistas, las políticas públicas que facilitan la concentración y acaparamiento de la tierra, las acciones gubernamentales/institucionales que promueven la expansión del agronegocio y los efectos de la colonialidad del saber (Mier et al. 2019).

\section{CONCLUSIONES PARCIALES}

De los resultados obtenidos en este capítulo concluyo que es importante tener presente la historia de las familias productoras y del modelo productivo en la región, para evitar que se siga reproduciendo una lógica de desarrollo del territorio altamente insustentable y expulsiva; y comenzar a pensar en políticas públicas que realmente se traduzcan en una mejora de las condiciones de vida y de trabajo de las familias productoras y en el desarrollo de un territorio productivo sustentable y resiliente. El acceso a la propiedad de la tierra sin lugar a dudas es una de las principales necesidades para la continuidad de la actividad. Sin embargo, como plantean diversos entrevistados es importante que estas políticas de acceso a la tierra estén enmarcadas en un proyecto más amplio y de largo plazo de desarrollo de la producción hortícola en la región, con criterios bien establecidos respecto al modelo productivo a incentivar, con control por parte del Estado del mercado y los agentes 
especuladores, regulando los precios de los alimentos y facilitando el acceso a maquinarias, financiamiento de proyectos productivos, capacitación, etc. Para ello, como pude constatar en las entrevistas, es indispensable que este proyecto de desarrollo territorial esté delineado por los distintos actores del territorio e incorporando profesionales de distintas disciplinas, y que sea un proyecto que trascienda los períodos de gestión municipal. Esto puede desarrollarse por ejemplo a través de una mesa intersectorial (con representantes de diferentes organizaciones de productores, INTA, SENASA, universidades públicas de la región, funcionarios públicos, etc). Es indispensable que los funcionarios de turno, que como se observó en las entrevistas muchas veces presentan miradas fragmentadas y son desconocedores de la historia del territorio, tengan la obligación de formar parte de esta mesa e interactuar de este modo con los actores territoriales con más conocimiento en el tema. Contar con una mesa de este tipo, que tenga injerencia en la agenda de los funcionarios de turno en cada gestión podría facilitar la construcción de un proyecto de desarrollo territorial a mediano-largo plazo.

En las entrevistas realizadas se evidencia que por muchos años ha primado una lógica que podríamos definir como de "autogestión del territorio", donde las lógicas de mercado fueron las que mayor influencia ejercieron en el territorio, generando enormes problemas, que con el pasar de los años ya se consideran estructurales. Al mismo tiempo, se encuentran actualmente grandes deficiencia en las políticas públicas dirigidas al sector hortícola, con una mirada muy reduccionista y una importante dificultad para articular con otros sectores del Estado con vasta experiencia en el territorio y canalizar los proyectos y la información por ellos formulados. Un aspecto pendiente sumado a lo anteriormente planteado tiene que ver con la necesidad de generar políticas públicas inclusivas, que contemplen las necesidades de los distintos actores del territorio, especialmente de aquellos sectores más vulnerables; para ello es necesario que estas políticas se piensen en conjunto con los actores que serán beneficiados por ellas, para que sean acordes a sus necesidades y que sean aplicables en el contexto territorial del CHP.

Otro de los aspectos que surgen de este análisis es la fragmentación del conocimiento, la segregación de distintas disciplinas que trabajan sobre el mismo territorio y la falta de articulación y de información entre las distintas dependencias del Estado. Sin embargo, simultáneamente se observa cómo, en parte por la propia iniciativa e interés de ciertos actores, vienen generándose múltiples conexiones en el territorio, articulando trabajos y experiencias que integran a actores del ámbito universitario, del INTA, SENASA, militantes de organizaciones de base, organizaciones de productores familiares, entre otros actores históricamente marginados desde la lógica de mercado que rige el territorio. Desde este trabajo cotidiano y articulado, viene creciendo una red de actores con mucho potencial; para consolidar y potenciar esta red de actores hace falta un espacio que los nuclee, para 
que con una participación activa de las organizaciones de productores se puedan generar proyectos más integrales, evitando duplicar esfuerzos y juntando el apoyo necesario para marcar agenda y traccionar las políticas de los funcionarios de turno, buscando trascender hacia una política a mediano largo plazo. Este espacio debe servir también para poner en común y poder debatir sobre los trabajos e investigaciones que se están generando en el territorio, garantizando que la información sea realmente accesible para los distintos actores. Existen diferentes experiencias en este sentido, impulsadas por distintos actores, como la mesa regional del INTA, el espacio del consejo social de la UNLP y aunque de carácter más nacional, el Foro por un Programa Agrario Soberano y Popular, del cual participan gran parte de los actores de este territorio. Sin embargo, estas experiencias si bien con avances importantísimos en el territorio, no terminan de tener la centralidad y organicidad que se plantea en los párrafos precedentes. Sería interesante indagar los logros y dificultades de estos espacios, qué características esperan los distintos actores que reúna un espacio como el planteado, quienes consideran que deberían impulsarlo, entre otros aspectos.

Otro aspecto emergente es el alto grado de asociativismo, con un elevado porcentaje de productores familiares nucleados en algún tipo de organización. Este aspecto es sumamente importante, por un lado porque habilita otro poder de negociación frente a los funcionarios del Estado responsables de definir las políticas públicas que afectan al sector; y por otro lado es una característica que potencia enormemente las posibilidades de masificación de un proyecto agroecológico.

Finalmente, otra conclusión que se desprende de este análisis tiene que ver con el gran potencial de contar con un cinturón hortícola conformado principalmente por familias productoras bolivianas, con tradición campesina; y a su vez, con un número creciente de productores con experiencia agroecológica y capacidad para transmitir sus conocimientos. En este sentido las políticas públicas de promoción de la agroecología debieran estar enfocadas en fortalecer los procesos de transmisión de conocimientos de campesino a campesino existentes.

Lo planteado en los párrafos precedentes son condicionantes a la hora de pensar en el desarrollo de un territorio productivo sustentable y resiliente. La masificación de la agroecología como modelo para el desarrollo del CHP requiere necesariamente de fortalecer los aspectos mencionados. La agroecología es política, y como tal exige que desafiemos y transformemos las estructuras de poder en la sociedad, poniendo el control de las semillas, la biodiversidad, los territorios, el conocimiento y la cultura, entre otros aspectos, en manos de los pueblos que alimentan al mundo (La Vía Campesina 2016). Desde este punto de vista no se puede pensar la agroecología como una práctica a implementar por productores individuales, sino que debe ser concebida de manera 
colectiva. En base a lo expuesto anteriormente puedo confirmar parcialmente la tercer hipótesis de esta tesis. Considero que los productores no cuentan con estrategias de gestión del territorio adecuadas para generar y sostener en el tiempo un cambio en el modelo productivo hacia un modelo de bases agroecológicas; pero que existe un importante trabajo de base articulado por diferentes actores del territorio, con un enorme potencial para colectivamente generar los cambios necesarios y exigir las políticas públicas adecuadas para una masificación de la agroecología.

Los distintos actores entrevistados han reconocido una multiplicidad de servicios ecosistémicos que brindan los ambientes semi-naturales e incluso los cultivos al aire libre frente a los cultivos bajo invernáculos. Sin embargo, es necesario trabajar explícitamente los beneficios de estos ambientes, en espacios colectivos y multiactorales, para poder debatir sobre los mismos y enriquecer las propias percepciones con los conocimientos de los otros. Encontré a través del análisis realizado que existe un interés generalizado por la preservación de estos ambientes, que consideran insuficientes, especialmente dentro del CHP; entre otras cualidades se reconoce a estos ambientes como espacios importantes para la recreación, la mejora de la salud y como ambientes que brindan al territorio de cierta "belleza escénica" que torna más disfrutables los ámbitos de trabajo y de reproducción de la vida. La escasez o insuficiencia de estos ambientes en las quintas y en el territorio no es el resultado de una decisión consciente de quienes viven y trabajan allí, sino que es la consecuencia de un modelo productivo y de desarrollo basado exclusivamente en la búsqueda de mayor productividad y rédito económico para un sector reducido de la población. Pese a la escasez mencionada anteriormente, se reconocen estrategias que permitirían preservar e incrementar estos ambientes, mediante políticas públicas adecuadas a ello; al mismo tiempo se observa una importante capacidad de recuperación de los ambientes degradados, que puede ser potenciada mediante diversas prácticas agroecológicas. En este sentido podría confirmar parcialmente la segunda hipótesis de esta tesis, ya que la estructura del paisaje remanente permite sostener y profundizar estrategias de manejo y planificación de base agroecológica, tendientes a generar un cambio en el modelo productivo, siempre y cuando se generen políticas públicas integrales que promuevan este modelo productivo y regulen al mercado.

Finalmente, los análisis realizados en este capítulo confirman parcialmente, desde la visión de los actores sociales entrevistados, la primer hipótesis de esta tesis, considerando que la amplia expansión de la tecnología del invernáculo, que tuvo lugar en los últimos 30 años en el CHP, fue posible a expensas de la ocupación de áreas semi naturales y del reemplazo de cultivos al aire libre; considerando muchos entrevistados a los pastizales ganaderos también como ambientes semi-naturales. 


\section{BIBLIOGRAFIA}

Alonso L, Bernasconi C, Ciciarelli A, De Castro C, Esteban C, Etchegoyen A, MacLoughlin T, Muntaner L, Ledesma R, Orofino L, Percudani C, Piccinini A, Rojo M, Santillán JM, Vittori S (2015). "Plaguicidas: los condimentos no declarados". XIII jornadas de jóvenes investigadores grupo Montevideo. Ciencia, tecnología e innovación para la inclusión social. La Plata, Buenos Aires.

Ambort ME (2017). Procesos asociativos en la agricultura familiar: un análisis de las condiciones que dieron lugar al surgimiento y consolidación de organizaciones en el cinturón hortícola platense, 2005-2015 (Bachelor'sthesis, Universidad Nacional de La Plata. Facultad de Humanidades y Ciencias de la Educación).

Arias M (2019). Efecto del uso de fertilizantes y pesticidas sobre organismos acuáticos en arroyos de la zona hortícola de La Plata. Tesis Doctoral, Facultad de Ciencias Naturales y Museo, Universidad Nacional de La Plata. 147 pp.

Barsky A, Vio M (2007) La Problemática del Ordenamiento Territorial en Cinturones Verdes Periurbanos sometidos a Procesos de Valorización Inmobiliaria. El caso del Partido del Pilar, Región Metropolitana de Buenos Aires. IX Coloquio Internacional de Neocrítica. Universidade Federal do Rio Grande do Sul. Porto Alegre.

Blandi ML, Sarandón SJ, Pereira Veiga IJ (2011). La "autoeficacia": un indicador de la conducta sustentable. Su importancia para el logro de sistemas hortícolas sustentables en La Plata, Argentina. VII Congreso Brasilero de Agroecología. Cuadernos de Agroecología 6 (2).

Blandi ML, Paleologos MF, Sarandón SJ, Veiga IJ (2013). Identificación de impedimentos para avanzar hacia una "conducta sustentable" en pequeños horticultores de La Plata, Argentina. VIII Congreso Brasilero de Agroecología. Cuadernos de Agroecología 8 (2).

Blandi ML, Sarandón SJ, Flores CC, Veiga I (2016). Evaluación de la sustentabilidad de la incorporación del cultivo bajo cubierta en la horticultura platense. Revista de la Facultad de Agronomía, La Plata, 114 (2): 251-264.

Bonicatto MM (2018). Sustentabilidad y agrobiodiversidad: análisis de la conservación de semillas y conocimientos asociados en agroecosistemas familiares del Cinturón Hortícola Platense. Doctoral dissertation, Universidad Nacional de La Plata. 260 Pp. 
Cataldi VI, Flores C (2019). Análisis comparativo entre sistemas convencionales y en transición agroecológica desde el punto de vista de la economía convencional y de la economía del medio ambiente en el Cinturón Hortícola de La Plata. Buenos Aires, Argentina. Primer Congreso Argentino de Agroecología. Facultad de Ciencias Agrarias de la Universidad Nacional de Cuyo, Mendoza. 18 al 20 de setiembre de 2019.

Ceceña AE (2012). Dominar la naturaleza o vivir bien: disyuntiva sistémica. Debates urgentes 1(1): 117-129.

Cieza RI, Ferraris G, Seibane C, Larrañaga G, Mendicino L (2015). Aportes a la caracterización de la agricultura familiar en el Partido de La Plata Revista de la Facultad de Agronomía de La Plata. Vol. 114 (Núm. Esp.1). Agricultura Familiar, Agroecología y Territorio: 129-142.

Cowling RM, Egoh B, Knight AT (2008). An operational model for mainstreaming ecosystem services for implementation. PNAS 105(28):9483-9488.

Dansero E, Pettenati G, Toldo A (2017). The relationship between food and cities and urban food policies: a space for geography?.Bollettino della società geografica italiana. 13 (5): 4-19.

Ennis RC (2019). Una aproximación a la pérdida y desperdicio de alimentos a partir de la producción del Cinturón Hortícola Platense (Tesis Doctoral, Universidad Nacional de La Plata. Facultad de Humanidades y Ciencias de la Educación).

Ferraris G, Bravo ML (2014). Organizaciones de productores hortícolas del Cinturón Verde de La Plata. Ensenada: VIII Jornadas de Sociología UNLP.

Frediani JC (2010). Lógicas y tendencias de la expansión residencial en áreas periurbanas. El Partido de La Plata, Buenos Aires, Argentina, entre 1990 y 2010 D. Tesis, Universidad Nacional de La Plata. Facultad de Humanidades y Ciencias de la Educación. 459 pp. On line: http://sedici.unlp.edu.ar/handle/10915/3203

García M (2011). El cinturón hortícola platense: ahogándonos en un mar de plásticos. Un ensayo acerca de la tecnología, el ambiente y la política. THEOMAI $n^{\circ} 23$.

García M (2015). Horticultura de La Plata (Buenos Aires). Modelo productivo irracionalmente exitoso. Revista de la Facultad de Agronomía, La Plata, 114(3): 190-201.

García M (2015b). Colonia hortícola o Barbarie: Diagnóstico y propuestas de cambio para el área hortícola platense. Boletín hortícola. 19 (53): 20-26. 
García M, Kebat C. (2008). Transformaciones en la horticultura platense. Una mirada a través de los censos. Realidad económica 237: 110-134.

Gargoloff NA, Sisterna M, Bonicatto MM, Scelso L, Velarde I, Tejerina Alfaro C, Barrionuevo C, Baldini C, Cataldi V, Delgado I (2019). Transición Agroecológica y Sistema Participativo de Garantía en la Horticultura Platense. Primer Congreso Argentino de Agroecología. Facultad de Ciencias Agrarias de la Universidad Nacional de Cuyo.

Gargoloff, NA, Riat P, Abbona EA, Sarandón SJ (2007). Análisis de la Racionalidad Ecológica en 3 grupos de horticultores en La Plata, Argentina. Revista Brasileira de Agroecología. 2(2): 468-471

Garrido-Fernández FE (2006). Los agricultores como actores de la política agroambiental. Un enfoque multidimensional. Papers: Revista de sociología, 81: 37-62.

Gliessman SR, Rosado-May FJ, Guadarrama-Zugasti C, Jedlicka J, Cohn A, Méndez VE, Jaffe R (2007). Agroecología: promoviendo una transición hacia la sostenibilidad. Revista Ecosistemas, 16 (1).

Guzman Casado G, Mielgo AA (2007). La investigación participativa en agroecología: una herramienta para el desarrollo sustentable. Revista Ecosistemas 16 (1).

Hang G, Bravo ML, Ferraris G, Larrañaga GF, Seibane C, Kebat CA, ... Blanco V (2013). Modalidades de trabajo y tenencia de la tierra en Sistemas Hortícolas localizados en el territorio Platense. República Argentina. Revista de la Facultad de Agronomía, 112(2), 131-140.

Hang GM, Bravo ML, Ferraris G, Larrañaga G, Seibane C, Kebat C (2015). El contexto, las políticas públicas y su relación con la horticultura en La Plata, Argentina. Revista de la Facultad de Agronomía, 114.

Hernández Sampieri R, Collado CF, Lucio PB (2006). Capítulo 13. Muestreo cualitativo. Metodología de la investigación 560-578 pp.

Hurtado MA, Giménez JE, Cabral MG (2006). Análisis ambiental del partido de La Plata: Aportes al ordenamiento territorial. Consejo Federal de Inversiones, La Plata. 124 pp.

Jensen K, Birche M (2018). El paisaje y la forma de expansión en la ciudad de La Plata: lineamientos y estrategias para la planificación del crecimiento urbano. In $\mathrm{X}$ Seminario Internacional de Investigación en Urbanismo, Barcelona-Córdoba. Departamentd' Urbanisme i Ordenació del Territori. Universitat Politècnica de Catalunya. 
Karol JL, San Juan GA (2018). Saber qué hacer: construcción de un sistema para la gestión integrada del riesgo hídrico en la región del Gran La Plata. Eds. Jorge L. Karol; Gustavo San Juan. - 1a edición especial - Universidad Nacional de La Plata. Facultad de Arquitectura y Urbanismo, La Plata. 347 pp. On line: http://sedici.unlp.edu.ar/handle/10915/67730

Koschke L, Fuerst C, Frank S, Makeschin F (2012). A multi-criteria approach for an integrated land-cover-based assessment of ecosystem services provision to support landscape planning. Ecological Indicators 21: 54-66.

La Vía Campesina (2016). Declaración del Foro Internacional de Agroecología. Boletín Nyéléni, nro. 28, diciembre 2016. Disponible en: https://viacampesina.org/es/laagroecologia-en-una-encrucijada-boletin-nyeleni-num-28/

Mac Loughlin TM, Peluso L, Marino DJ (2017). Pesticide impact study in the peri-urban horticultural area of Gran La Plata, Argentina. Science of the Total Environment 598: $572-580$.

Marasas ME, Fernández V, Dubrovsky Berensztein N. (2014). Agrobiodiversidad en sistemas hortícolas familiares. Revista Leisa, 30 (1): 26-28.

Merchán AG (2016). Valorización de la tierra en el Cinturón Hortícola Platense. Tesis Doctoral, Facultad de Ciencias Agrarias y Forestales. On line: http://sedici.unlp.edu.ar/handle/10915/53577

Mier M, Giménez-Cacho T, Giraldo OF, Aldasoro M, Morales H, Ferguson BG, Rosset P, Khadse A, Campos C (2019). Escalamiento de la agroecología: impulsores clave y casos emblemáticos. Cuaderno de trabajo No. 1. Grupo en masificación de la agroecología.

Disponible

en:

https://www.researchgate.net/profile/Omar_Giraldo/publication/333852555_Escalami ento_de_la_agroecologia_impulsores_clave_y_casos_emblematicos/links/5d08ef4f2 99bf1f539cd1a7c/Escalamiento-de-la-agroecologia-impulsores-clave-y-casosemblematicos.pdf

Minayo MCDS, Sanches O (1993). Quantitativo-qualitativo: oposição ou complementaridade?. Cadernos de saúde pública 9: 237-248.

Nelson E, Mendoza G, Regetz J, Polasky S, Tallis H, Cameron D, Shaw M (2009). Modeling multiple ecosystem services, biodiversity conservation, commodity production, and tradeoffs at landscape scales. Frontiers in Ecology and the Environment, 7(1): 4-11.

Otero J, Larrañaga G, Hang GM (2013). La organización del trabajo en la horticultura familiar de La Plata (Argentina). Revista de la Facultad de Agronomía. 112 (2): 79-90. 
Pérez M (2010) "Horticultura de base ecológica en el cordón bonaerense sur. Una aproximación desde sus prácticas". Trabajo de tesis Magíster Scientiae en Procesos Locales de Innovación y Desarrollo Rural (PLIDER). Universidad Nacional de La Plata - Facultad de Ciencias Agrarias y Forestales. La Plata, Argentina. 130pp

Saquet MA (2015). Por una geografía de las territorialidades y las temporalidades: una concepción multidimensional orientada a la cooperación y el desarrollo territorial. La Plata, Facultad de Humanidades y Ciencias de la Educación. 153 pp.

Sarandón SJ y Marasas ME (2015). Breve historia de la agroecología en la Argentina: orígenes, evolución y perspectivas futuras. Agroecología 10 (2): 93-102.

Sarandón SJ, Blandi ML (2016). Impactos del manejo hortícola sobre la biodiversidad y sus causas según agricultores de La Plata, Argentina. In Congreso Latinoamericano de Agroecología (La Plata, 2015).

Sautu R, Boniolo P, Dalle P, Elbert R (2005). Manual de metodología: construcción del marco teórico, formulación de los objetivos y elección de la metodología. CLACSO, colección Campus Virtual, Buenos Aires, Argentina. 192 pp.

Seibane C (2013). Estrategias de intervención públicas para el desarrollo territorial en el Cinturón Hortícola Platense: reflexiones y aportes sobre la dimensión comunicacional. Tesis Doctoral, Facultad de Periodismo y Comunicación Social, UNLP.

Seibane C, Larrañaga G, Kebat C, Hang G, Ferraris G, Bravo ML (2014). Redes para la promoción del desarrollo territorial en el cinturón hortícola platense. Mundo Agrario $15(28): 19$

Tadeo N (2001). "Cambios y persistencias en los nuevos procesos de organización del trabajo rural en la Argentina de los '90. El caso de la producción citrícola en el Nordeste Argentino". Proyecto enmarcado en el Programa de Incentivos a la Investigación, Secretaría de Políticas Universitarias, Ministerio de Cultura y Educación.

Tapella E (2004). "Reformas Estructurales en Argentina y su Impacto sobre la Pequeña Agricultura. ¿Nuevas Ruralidades, Nuevas Políticas?”. Estudios Sociológicos, 22(3): 669-700. Revista del Colegio de México. Disponible en: http://www.redalyc.org/articulo.oa?id=59806606.

Teubal M, Rodríguez J (2002). Agro y alimentos en la globalización: una perspectiva crítica. Ed. La Colmena, Buenos Aires. 208 pp. 
Tomasoni M (2013). Generación de derivas de plaguicidas. Red Universitaria de Ambiente y Salud.

Vasilachis de Gialdino I (2006). Estrategias de investigación cualitativa. Barcelona: Gedisa 42-50 pp.

World Bank. (2018). Understanding poverty. Land topic. On line: http://www.worldbank.org/en/topic/land

Wu J (2013). Landscape sustainability science: ecosystem services and human well-being in changing landscapes. Landscape Ecology 28(6): 999-1023.

Zhang W, Ricketts TH, Kremen C, Carney K, Swinton SM (2007). Ecosystem services and dis-services to agriculture. Ecological economics 64(2): 253-260.

\section{ANEXOS}

\subsection{Anexo 1. Guías de pautas de entrevistas \\ GUÍA DE PAUTAS FUNCIONARIOS/INVESTIGADORES}

\section{GENERALES}

1. ¿Para qué institución trabaja?

2. ¿Cuál es su rol en la institución?

3. ¿ Cuánto hace que trabajas allí?

\section{GESTIÓN DE LA ACTIVIDAD PRODUCTIVA}

4. ¿Qué herramientas te brinda el estado para desempeñarte actualmente en tu rol? ¿Y en el pasado?

5. ¿Crees que el gobierno local, provincial, nacional fomenta la horticultura? ¿De qué forma? ¿Y la horticultura agroecológica? ¿De qué forma? ¿A través de que instituciones?

6. ¿Las políticas públicas actuales para el sector hortícola son adecuadas? ¿Cuáles haría falta incorporar? ¿Por qué?

\section{CAMBIOS EN EL MODELO PRODUCTIVO}

7. ¿Qué cambios ha experimentado la producción hortícola en los últimos 30 años? Si consideramos los períodos entre 1985-1995, 1995-2005 y 2005-2015 (Alfonsin, Menem; Kirchner)

\section{PROBLEMAS DEL MODELO PRODUCTIVO ACTUAL Y POSIBILIDADES DE CAMBIO}

8. ¿Cuáles son para vos los principales problemas/debilidades del sector hortícola local?

9. ¿Y cuáles sus principales fortalezas? 
10. ¿Crees que es un modelo de producción adecuado? ¿Por qué? (en caso de que no...) ¿Cómo crees que debería ser?

11. ¿Cómo te imaginas el CHP en un futuro?

12. ¿Crees que es posible que el Cinturón Hortícola Platense se transforme en un cinturón agroecológico? ¿Por qué? ¿Qué cambios tendrían que darse para que fuera posible?

\section{PAISAJE}

13. ¿Cuáles son los principales cambios que identificas en el uso del suelo en el partido de La Plata en los últimos 30 años? Pensando en 3 grandes periodos (Alfonsin, Menem; Kirchner) que cambios identificas en cada periodo?

14. ¿Ha habido políticas públicas/normativa que direccionen de algún modo esos cambios en el territorio?

No......¿cuales crees que son las posibles causas de esa falta de polit. Pub.?

Si........¿Crees que han sido adecuadas?

15. ¿Qué ambientes a los que puedas considerar como naturales o semi naturales identificas dentro del Partido de La Plata? ¿Qué función crees que cumplen estos espacios? ¿Crees que los espacios existentes son suficientes para cumplir esas funciones? ¿Por qué?

16. ¿Cree que esos ambientes influyen (positiva o negativamente) de algún modo en la actividad productiva? ¿De qué modo?

17. ¿Y en el CHP que pasa con esos ambientes naturales o seminaturales?

18. ¿Crees que es importante conservar esos ambientes? ¿Crees que sería necesario incrementar la cantidad de ambientes naturales o semi naturales? ¿Cómo lo harías?

19. ¿Qué criterios crees que se tienen en cuenta a la hora de pensar en el ordenamiento territorial del Partido de La Plata? ¿Y para definir el área de producción intensiva?

20. ¿Coincidís con estos criterios? ¿Por qué? (si dice que no...) ¿Cómo crees que debería ser este ordenamiento?

\section{GUÍA DE PAUTAS TÉCNICOS}

\section{GENERALES}

1. ¿Para qué institución trabajas?

2. ¿Cuál es tu rol en la institución?

3. ¿Cuánto hace que trabajas allí?

4. ¿Con cuántos productores trabajas? ¿De qué sectores del CHP?

5. ¿Trabaja con productores convencionales, agroecológicos o en transición?

\section{GESTIÓN DE LA ACTIVIDAD PRODUCTIVA}

6. ¿Qué herramientas te brinda el estado para desempeñarte actualmente como técnica? ¿Y en el pasado?

7. ¿Y para asesorar a productores agroecológicos o en transición agroecológica?

8. ¿Crees que el gobierno local, provincial, nacional fomenta la horticultura? ¿De qué forma? ¿Y la horticultura agroecológica? ¿De qué forma? ¿A través de que instituciones? 
9. ¿Las políticas públicas actuales para el sector hortícola son adecuadas? ¿Cuáles haría falta incorporar? ¿Por qué?

\section{CAMBIOS EN EL MODELO PRODUCTIVO}

10. ¿Qué cambios ha experimentado la producción hortícola en los últimos 30 años? Si consideramos los períodos entre 1985-1995, 1995-2005 y 2005-2015

\section{PROBLEMAS DEL MODELO PRODUCTIVO ACTUAL Y POSIBILIDADES DE CAMBIO}

11. ¿Cuáles son para vos los principales problemas/debilidades del sector hortícola local?

12. ¿Y cuáles sus principales fortalezas?

13. ¿Crees que es un modelo de producción adecuado? ¿Por qué? (en caso de que no...) ¿Cómo crees que debería ser?

14. ¿Cómo te imagina el CHP en un futuro?

15. ¿Crees que es posible que el Cinturón Hortícola Platense se transforme en un cinturón agroecológico? ¿Por qué? ¿Qué cambios tendrían que darse para que fuera posible?

\section{PAISAJE}

16. ¿Cuáles son los principales cambios que identificas en el uso del suelo en el partido de La Plata en los últimos 30 años? Pensando en 3 grandes periodos (Alfonsin, Menem; Kirchner) que cambios identificas en cada periodo?

17. ¿Ha habido políticas públicas/normativa que direccionen de algún modo esos cambios en el territorio?

No......¿cuales crees que son las posibles causas de esa falta de polit. Pub.?

Si........¿Crees que han sido adecuadas?

18. ¿Qué ambientes a los que puedas considerar como naturales o semi naturales identificas dentro del Partido de La Plata? ¿Qué función crees que cumplen estos espacios? ¿Crees que los espacios existentes son suficientes para cumplir esas funciones? ¿Por qué?

19. ¿Crees que esos ambientes influyen (positiva o negativamente) de algún modo en la producción hortícola? ¿De qué modo?

20. ¿Y en el CHP que pasa con esos ambientes naturales o seminaturales?

21. ¿Crees que es importante conservar esos ambientes? ¿Crees que sería necesario incrementar la cantidad de ambientes naturales o semi naturales? ¿Cómo lo harías?

\section{GUÍA DE PAUTAS PRODUCTORES}

\section{Generales}

1. (Ubicación de la quinta)

2. Querés contarme dónde naciste? Hace cuanto tiempo que estás viviendo acá? $Y$ porque decidiste venirte?

3. Me podrías decir tu edad? 
4. Y vos fuiste a la escuela primaria? Secundaria? Estudiaste alguna otra cosa? Algún oficio?

5. ¿Y acá en la quinta, sos propietario o alquilas, mediero, otra forma de tenencia? ¿Compartís la quinta con otros productores? ¿Qué tipo de arreglo tiene al respecto?

6. Y vivís en la quinta?

7. ¿Cuánto tiempo hace que está produciendo en esta quinta? ¿y en total en el CHP?

8. Tenés algún otro trabajo? Por qué?

\section{Producción y características de la quinta}

9. ¿Qué superficie en producción tiene la quinta? ¿Cuánto de esa superficie es al aire libre y cuanto bajo cubierta? ¿Por qué elegís producir al aire libre y por qué bajo cubierta?

10. ¿Siempre produjo el mismo porcentaje al aire libre/bajo cubierta? (de no ser así...) ¿A qué se debió el cambio?

11. Si pensamos en distintas épocas (en los 80'Alfonsin-en los 90'menem- después del 2001 Kirchner) como fue cambiando tu producción?

12. ¿Qué cultivos producís? ¿y por qué elegís esos cultivos?

13. ¿De qué manera producís? ¿convencional (utiliza agroquímicos, fertilizantes químicos, semillas compradas), agroecológica? ambas?

14. Porqué producís en forma convencional? Estás conforme? ¿Ha intentado producir de otra manera en algún momento? ¿Qué dificultades tuviste? Si podrías cambiar, lo haría? Que le impide cambiar?

15. Si tiene los dos tipos de producción ¿Qué porcentaje de cada tipo? ¿Por qué?

16. Productor agroecológico: ¿Cómo definiría a una producción agroecológica, que practicas implica este tipo de producción? ¿Cuándo comenzó a producir de esa forma y por qué? ¿cómo aprendiste?

17. ¿A quién vendes tu producción?¿Logras vender todo lo que producis? Si responde que no ¿Por qué? ¿Y qué haces con lo que no vendes?

18. ¿Comercializa su producción directamente o se la vende a un tercero? ¿Cómo es la forma de comercialización? ¿Cuál es la forma de pago (contado, en el momento, etc)?

19. ¿Estos clientes te demandan algún tipo de tratamiento especial a tu producto o productos con alguna característica en particular (tamaño, forma, manchas, variedades, etc)?

\section{Visión del Modelo productivo actual}

20. ¿Qué beneficios encontrás en la actividad productiva, tal cual la desarrollas hoy en día?

21. ¿Qué dificultades encontrás hoy en día para desarrollar tu actividad laboral? ¿A qué crees que se deben esas dificultades? ¿Qué haces para afrontar esos problemas?

22. ¿Pertenece a alguna organización de productores? ¿Esta organización tiene algún tipo de política en relación a la producción agroecológica?

23. ¿Qué personas/organismos crees que podrían aportar a resolver esas dificultades? ¿De qué manera? 


\section{Gestión de la actividad productiva}

24. ¿y recibís algún tipo de ayuda del gobierno local, provincial, nacional, a través de que institución (inta, universidad o gobierno propiamente dicho)? ¿Qué tipo de ayuda? ¿Y en el pasado?

25. ¿Alguna vez hiciste llegar inquietudes o propuestas hacia el sector público? ¿Cuáles? ¿En forma individual o agrupada?

26. ¿Crees que el gobierno local, provincial, nacional fomenta la horticultura? ¿De qué forma? ¿Y la horticultura agroecológica? ¿De qué forma? ¿A través de que instituciones?

\section{Cambios en el modelo productivo}

27. Si pensamos en tres grandes momentos, los 80'Alfonsin / los 90'Menem / después del 2001 Kirchner ¿Qué cambios ha experimentado la producción hortícola local en esos períodos?

\section{Problemas del modelo productivo actual y posibilidades de cambio}

28. ¿Cuáles son para vos los principales problemas/debilidades del sector hortícola local? Y que fortalezas tiene?

29. Si consideramos el modelo productivo vigente actualmente en el CHP, es decir la actividad productiva en su conjunto (desde el productor hasta el consumidor) ¿Crees que es un modelo de producción adecuado? ¿Por qué? (en caso de que no...) ¿Cómo crees que debería ser?

30. ¿Cómo te imagina el CHP en un futuro? ¿Y tu quinta?

31. ¿Crees que es posible que el Cinturón Hortícola Platense se transforme en un cinturón agroecológico? ¿Por qué? ¿Qué cambios tendrían que darse para que fuera posible? ¿Te gustaría producir en un $\mathrm{CH}$ agroecológico? ¿por qué?

\section{Paisaje de la quinta}

32. ¿Tenés algún espacio de la quinta en el que no produzcas? ¿Por qué motivo? ¿Cómo es ese espacio libre de cultivos?

33. ¿Realizas alguna práctica de control o manejo de la vegetación espontánea en las zonas de la quinta donde no hay cultivos? Si dice que sí ¿En qué consiste? Si dice que no ¿por qué? ¿Y en las zonas de cultivos? ¿Por qué?

34. ¿Dejas zonas cultivadas en descanso o inmediatamente después de cosechar comienza a preparar la tierra para una nueva siembra? ¿Por qué?

\section{Paisaje que rodea la quinta}

35. ¿Cómo es el ambiente en el que está ubicada tu quinta? Me harías un croquis/esquema?

36. ¿Cómo es la actividad hortícola en el ambiente en el que está ubicada tu quinta? ¿hay muchos invernáculos? ¿las producciones de tus vecinos son intensivas, utilizan muchos agroquímicos?

37. ¿Hay vegetación espontanea en este ambiente, que no sean cultivos? ¿Mucha o poca? ¿De qué tipo? ¿Hay árboles/arbustos? ¿Arroyos, canales? 
38. ¿Crees que ese ambiente influye de algún modo en el funcionamiento de tu quinta? ¿de qué forma?

39. ¿crees que esa vegetación/cuerpos de agua cercanos a tu quinta influyen de algún modo en la producción hortícola de tu quinta? ¿cómo?

\section{Paisaje del Partido de La Plata}

40. ¿Conoce otras zonas/áreas del Partido de La Plata? ¿Cuáles?

41. ¿Cuáles son los principales cambios que identifica en el uso del suelo en el partido de La Plata en los últimos 30 años?

42. ¿Qué ambientes a los que puedas considerar como naturales o semi naturales identificas dentro del Partido de La Plata? ¿Qué función crees que cumplen estos ambientes? ¿Crees que los ambientes existentes son suficientes para cumplir esas funciones? ¿Por qué?

43. ¿Crees que esos ambientes influyen (positiva o negativamente) de algún modo en la producción hortícola? ¿De qué modo?

44. ¿Crees que es importante conservar esos ambientes? ¿Crees que sería necesario incrementar la cantidad de ambientes naturales o semi naturales? ¿Cómo lo harías? 
6.2 Anexo 2. Modelos de grillado de entrevistas

\begin{tabular}{|c|c|c|c|c|}
\hline \multirow{2}{*}{\multicolumn{2}{|c|}{ DIMENSIONES }} & \multicolumn{3}{|c|}{ FUNCIONARIOS } \\
\hline & & F-MUNCIPAL & F-PROVINCIAL & F-NACIONAL \\
\hline \multirow{2}{*}{\multicolumn{2}{|c|}{$\begin{array}{l}\text { INSTITUCIÓN } \\
\text { ROL }\end{array}$}} & & & \\
\hline & & & & \\
\hline \multicolumn{5}{|c|}{ ANTIGÜEDAD EN EL CARGO } \\
\hline \multirow{5}{*}{$\begin{array}{l}\text { GESTIÓN DE } \\
\text { LA } \\
\text { ACTIVIDAD } \\
\text { PRODUCTIV } \\
\text { A }\end{array}$} & \begin{tabular}{|l|} 
Herramientas \\
estatales \\
actuales y \\
pasadas
\end{tabular} & & & \\
\hline & $\begin{array}{l}\text { Fomento de } \\
\text { la } \\
\text { horticultura } \\
\text { (nación, } \\
\text { provincia, } \\
\text { municipio) }\end{array}$ & & & \\
\hline & $\begin{array}{l}\text { Fomento de } \\
\text { la } \\
\text { agroecología } \\
\text { (nación, } \\
\text { provincia, } \\
\text { municipio) } \\
\end{array}$ & & & \\
\hline & $\begin{array}{l}\text { Calidad de } \\
\text { políticas } \\
\text { públicas } \\
\text { actuales }\end{array}$ & & & \\
\hline & $\begin{array}{l}\text { Políticas } \\
\text { públicas } \\
\text { necesarias }\end{array}$ & & & \\
\hline \multirow{3}{*}{$\begin{array}{l}\text { CAMBIOS EN } \\
\text { EL MODELO } \\
\text { PRODUCTIV } \\
0\end{array}$} & Alfonsín & & & \\
\hline & Menem & & & \\
\hline & Kirchner & & & \\
\hline \multirow{6}{*}{$\begin{array}{l}\text { PROBLEMAS } \\
\text { DEL } \\
\text { MODELLO } \\
\text { ACTUAL/ } \\
\text { PSIBILIDADE } \\
\text { S DE } \\
\text { CAMBIO }\end{array}$} & $\begin{array}{l}\text { Problemas/de } \\
\text { bilidades del } \\
\text { sector } \\
\text { hortícola }\end{array}$ & & & \\
\hline & $\begin{array}{l}\text { Fortalezas del } \\
\text { sector } \\
\text { hortícola }\end{array}$ & & & \\
\hline & $\begin{array}{l}\text { Modelo } \\
\text { productivo } \\
\text { adecuado? } \\
\text { Como debería } \\
\text { ser? }\end{array}$ & & & \\
\hline & CHP ideal? & & & \\
\hline & $\begin{array}{l}\text { Es posible } \\
\text { CHP } \\
\text { agroecológico } \\
?\end{array}$ & & & \\
\hline & $\begin{array}{l}\text { Cambios } \\
\text { necesarios }\end{array}$ & & & \\
\hline
\end{tabular}




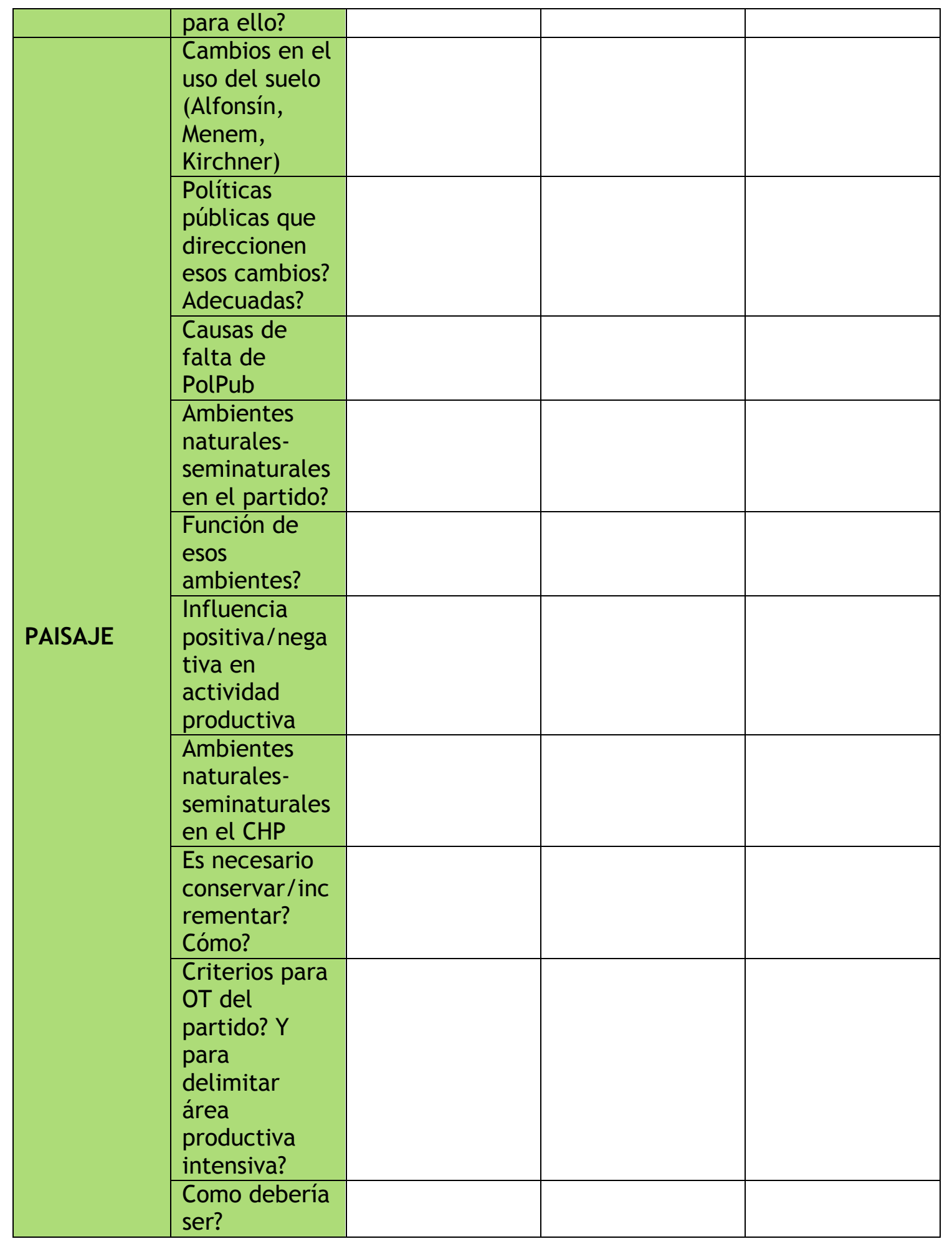

\begin{tabular}{|l|c|c|}
\hline \multirow{2}{*}{ DIMENSIONES } & \multicolumn{2}{c|}{ TÉCNICOS } \\
\cline { 2 - 3 } & \multicolumn{1}{|c|}{ T1 } \\
\hline INSTITUCIÓN & & \\
\hline ROL & & \\
\hline ANTIGÜEDAD EN EL CARGO & & \\
\hline CANTIDAD DE PRODUCTORES & & \\
Y ZONA & & \\
\hline CONVENCIONALES, & & \\
\hline
\end{tabular}




\begin{tabular}{|c|c|c|c|}
\hline \multicolumn{2}{|c|}{$\begin{array}{l}\text { AGROECOLÓGICOS O EN } \\
\text { TRANSICIÓN }\end{array}$} & & \\
\hline \multirow{6}{*}{$\begin{array}{l}\text { GESTIÓN DE } \\
\text { LA } \\
\text { ACTIVIDAD } \\
\text { PRODUCTIV } \\
\text { A }\end{array}$} & $\begin{array}{l}\text { Herramientas } \\
\text { estatales } \\
\text { actuales y } \\
\text { pasadas }\end{array}$ & & \\
\hline & $\begin{array}{l}\text { para asesorar } \\
\text { a productores } \\
\text { agroecológicos }\end{array}$ & & 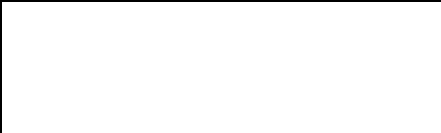 \\
\hline & $\begin{array}{l}\text { Fomento de la } \\
\text { horticultura } \\
\text { (nación, } \\
\text { provincia, } \\
\text { municipio) }\end{array}$ & & 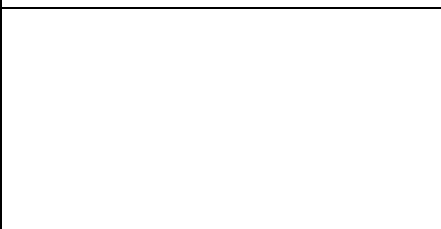 \\
\hline & $\begin{array}{l}\text { Fomento de la } \\
\text { agroecología } \\
\text { (nación, } \\
\text { provincia, } \\
\text { municipio) }\end{array}$ & & 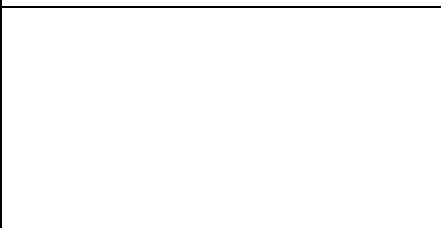 \\
\hline & $\begin{array}{l}\text { Calidad de } \\
\text { políticas } \\
\text { públicas } \\
\text { actuales }\end{array}$ & & 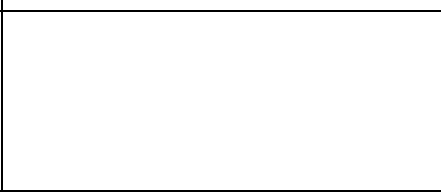 \\
\hline & $\begin{array}{l}\text { Políticas } \\
\text { públicas } \\
\text { necesarias }\end{array}$ & & \\
\hline \multirow{3}{*}{$\begin{array}{l}\text { CAMBIOS EN } \\
\text { EL MODELO } \\
\text { PRODUCTIV } \\
0\end{array}$} & Alfonsín & & \\
\hline & Menem & & \\
\hline & Kirchner & & \\
\hline \multirow{6}{*}{$\begin{array}{l}\text { PROBLEMAS } \\
\text { DEL } \\
\text { MODELO } \\
\text { ACTUAL/ } \\
\text { PSIBILIDADE } \\
\text { S DE } \\
\text { CAMBIO }\end{array}$} & $\begin{array}{l}\text { Problemas/de } \\
\text { bilidades del } \\
\text { sector } \\
\text { hortícola }\end{array}$ & & \\
\hline & $\begin{array}{l}\text { Fortalezas del } \\
\text { sector } \\
\text { hortícola }\end{array}$ & & \\
\hline & $\begin{array}{l}\text { Modelo } \\
\text { productivo } \\
\text { adecuado? } \\
\text { Como debería } \\
\text { ser? }\end{array}$ & & \\
\hline & CHP ideal? & & \\
\hline & $\begin{array}{l}\text { Es posible CHP } \\
\text { agroecológico? }\end{array}$ & & \\
\hline & $\begin{array}{l}\text { Cambios } \\
\text { necesarios } \\
\text { para ello? }\end{array}$ & & \\
\hline \multirow[t]{2}{*}{ PAISAJE } & $\begin{array}{l}\text { Cambios en el } \\
\text { uso del suelo } \\
\text { (Alfonsín, } \\
\text { Menem, } \\
\text { Kirchner) }\end{array}$ & & \\
\hline & $\begin{array}{l}\text { Políticas } \\
\text { públicas que } \\
\text { direccionen }\end{array}$ & & \\
\hline
\end{tabular}




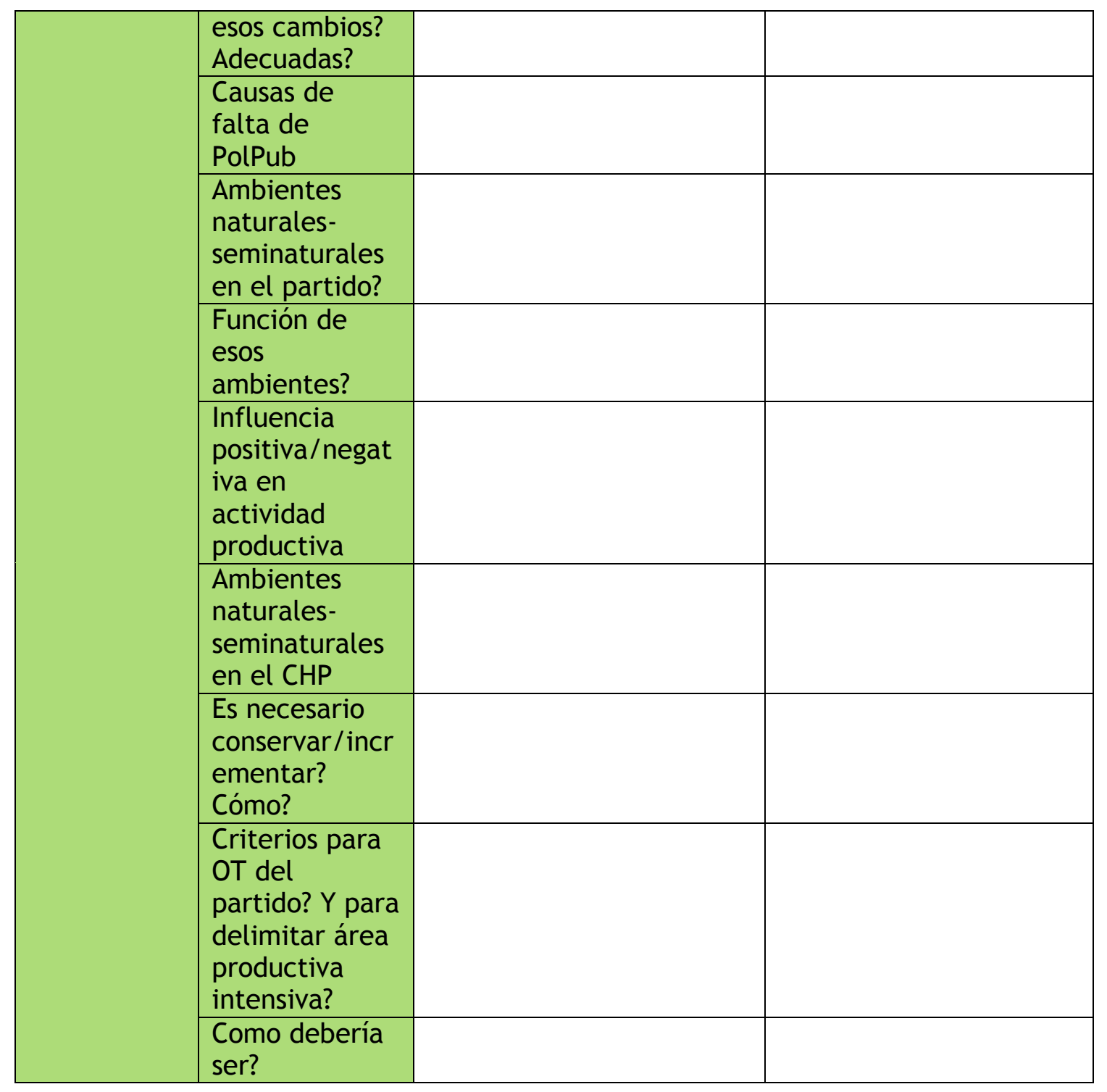

\begin{tabular}{|c|c|c|c|}
\hline \multirow{2}{*}{\multicolumn{2}{|c|}{ DIMENSIONES }} & \multicolumn{2}{|c|}{$\begin{array}{l}\text { PRODUCTORES } \\
\end{array}$} \\
\hline & & PRODUCTOR & PRODUCTOR \\
\hline \multicolumn{4}{|c|}{ UBICACIÓN } \\
\hline \multicolumn{4}{|c|}{$\begin{array}{l}\text { ORIGEN, TIEMPO EN } \\
\text { ARGENTINA, MOTIVO }\end{array}$} \\
\hline \multicolumn{4}{|c|}{ EDAD } \\
\hline \multicolumn{4}{|c|}{$\begin{array}{l}\text { ESCOLARIDAD/CAPACITACIÓ } \\
\mathrm{N}\end{array}$} \\
\hline \multicolumn{4}{|c|}{ TENENCIA DE LA TIERRA } \\
\hline \multicolumn{4}{|c|}{ TIEMPO PRODUCIENDO } \\
\hline \multicolumn{4}{|c|}{ OTROS TRABAJOS } \\
\hline \multirow{5}{*}{$\begin{array}{l}\text { PRODUCCIÓ } \\
\text { N Y } \\
\text { CARACTERÍS } \\
\text { TICAS D ELA } \\
\text { QUINTA }\end{array}$} & $\begin{array}{l}\text { Superficie } \\
\text { aire } \\
\text { libre/cubierta }\end{array}$ & & \\
\hline & Motivo & & \\
\hline & $\begin{array}{l}\text { Siempre } \\
\text { igual? }\end{array}$ & & \\
\hline & $\begin{array}{l}\text { Cambios en } \\
\text { producción }\end{array}$ & & \\
\hline & $\begin{array}{l}\text { Que produce } \\
\text { y motivo }\end{array}$ & & \\
\hline
\end{tabular}




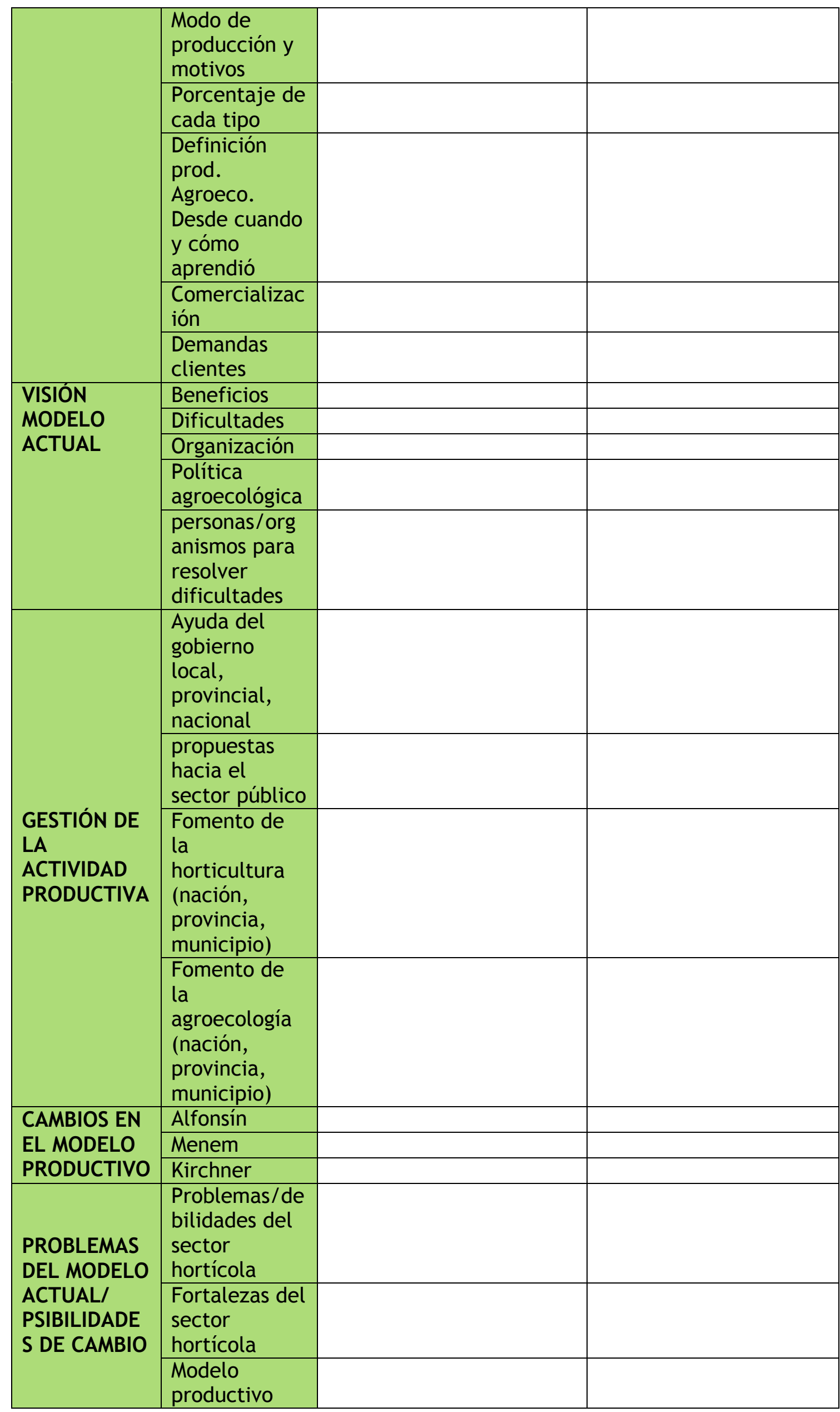




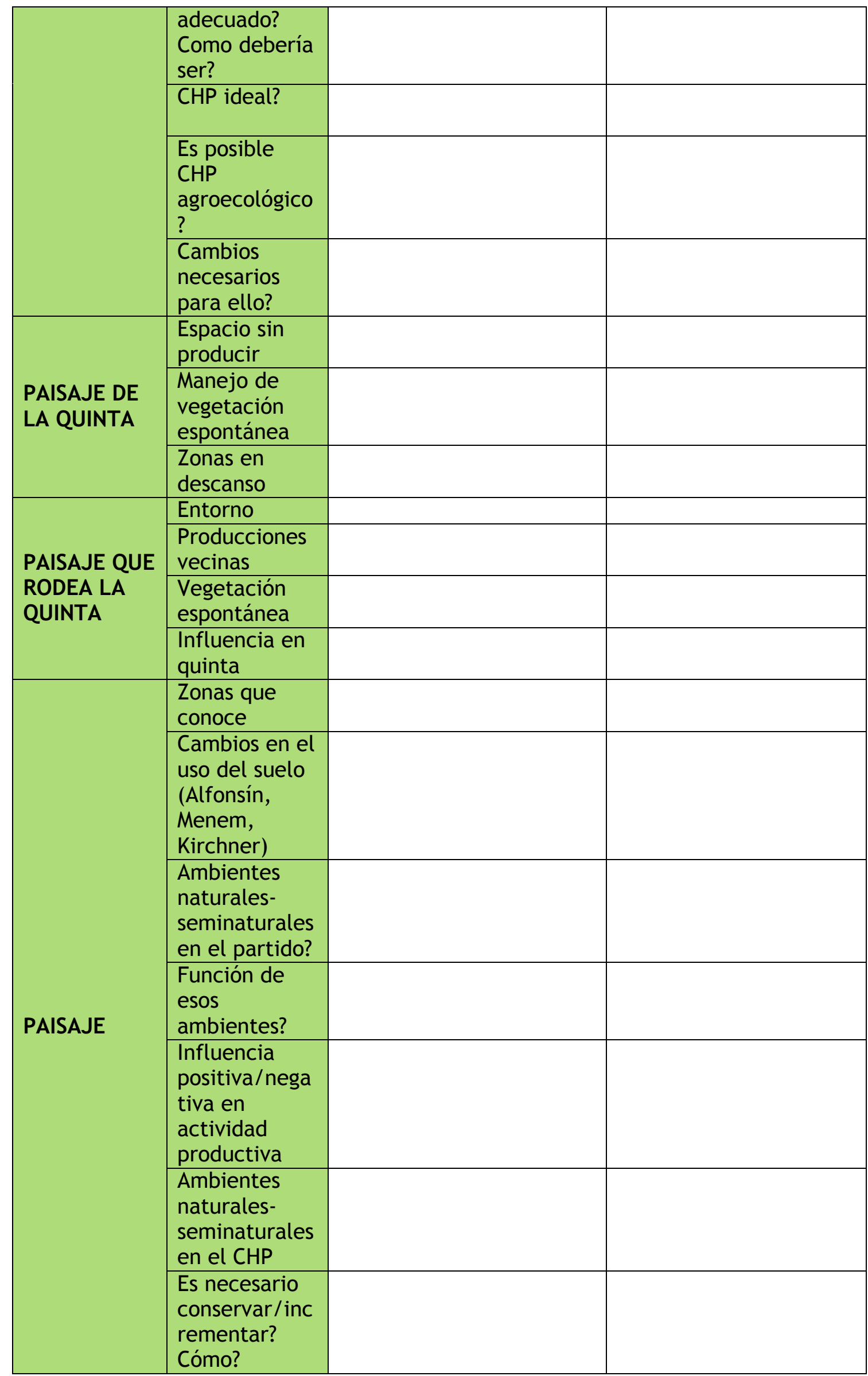




\section{CAPITULO 5}

\section{REFLEXIONES, DISCUSIÓN GENERAL, RECOMENDACIONES Y CONCLUSIONES}

"El desarrollo rural, la agroecología, si o sí tienen que estar unidos por el accionar político. Si eso no lo lográs van a ir caminando por veredas distintas. Entonces, en la medida en que no exista un proyecto politico que apunte sí a lo técnico, si a la organización de los productores, sí al empoderamiento... bueno, está bien, la

transición se podrá hacer, se avanzará de determinada manera... Pero tenés que generar capacidad y empoderamiento como para que se tenga la fuerza necesaria para lograr que existan politicas públicas que apoyen a los productores que avanzan en este sentido... Fijate lo que es La Plata. Acá tenemos un Ministerio de Agroindustria, tenés la universidad: Facultad de Agronomía, tenés Exactas, Humanidades, de todo. Tenés

municipalidad. Tenés un mercado. Tenés todo. Tenés todo, si querés realmente hacer algo... Yo vengo proponiendo desde hace tiempo la posibilidad de tener un organismo que concentre todo lo que tiene que ver

con la horticultura, donde habrá un espacio para la agricultura empresarial pero fundamentalmente que haya acciones concretas de politica que tiendan a favorecer todo el desarrollo de la horticultura familiar.... Y

La Plata tiene capacidad, porque tenés de todo para trabajar acá, como para atender a todo lo que es el cordón hortícola desde el punto de vista técnico. Pero necesitás tomar la decisión política de trabajar junto a los productores".

Docente/Investigador de la Facultad de Ciencias Agrarias y Forestales 
Este último capítulo está separado en tres apartados. En el primer apartado comienzo con una reflexión general sobre distintos modelos de desarrollo de periurbanos productivos en el mundo, aspectos prioritarios a considerar para planificar estos espacios, para finalizar analizando el contexto nacional y local y las posibilidades de desarrollar un territorio productivo sustentable y resiliente en esta región. En un segundo apartado abordo una breve discusión general sobre los resultados de la tesis en vinculación con los conocimientos generados por otros autores; en él incluyo una serie de propuestas para avanzar hacia la construcción de un territorio productivo más sustentable. Finalmente resumo las principales conclusiones de la tesis y propongo líneas de trabajo a futuro que se desprenden de esta tesis.

\subsection{ALGUNAS REFLEXIONES PARA PENSAR LOS TERRITORIOS PRODUCTIVOS}

La planificación urbana de alimentos es actualmente un tema relevante que se encuentra en la agenda de los principales países desarrollados (Dansero et al. 2017) por los altos niveles de concentración de la población mundial en zonas urbanas (World Bank 2018) y como respuesta a las externalidades negativas generadas por el sistema alimentario dominante (Dansero et al. 2017). Diversos organismos internacionales vienen planteando la necesidad de generar estrategia de producción sustentable de alimentos para el abastecimiento local y políticas alimentarias que contribuyan a garantizar seguridad y soberanía alimentaria, como se evidencia en los Objetivos de Desarrollo del Milenio, el informe de los Alimentos para las Ciudades, el Programa de Ciudades Saludables de la Organización Mundial de la Salud, la Agenda 2030 con los nuevos 17 Objetivos de Desarrollo Sustentable, la nueva Agenda Urbana definida en el marco de la III Conferencia de las Naciones Unidas para el Hábitat y en el caso específico de Argentina es ineludible el informe de la Relatora Especial de la ONU sobre el Derecho a la Alimentación como resultado de su visita a la Argentina en septiembre de 2018 (United Nations 2019). En este contexto, las áreas urbanas pioneras en la planificación urbana de alimentos fueron Toronto (Canadá) y Nueva York (Estados Unidos) y, más recientemente, algunas ciudades de Europa como Londres y algunas ciudades del Reino Unido (Dansero et al. 2017). Existen experiencias muy exitosas de planificación urbana de alimentos desarrolladas a nivel internacional, entre las que se pueden mencionar los Cinturones Verdes de Ontario, Munich y Milán o el Parque Agrario del Bajo Llovregat en Barcelona. Los Parques Agrarios son propuestas en las que se establece una zona para la producción de alimentos, que funciona bajo un programa de desarrollo integral de la actividad hortícola, las producciones silvopastoriles y las granjas con valor agregado (Giobellina et al. 2017, Barsky 2013). El concepto de cinturón verde, implementado inicialmente en Londres, Reino Unido, fue propuesto por primera vez por Ebenezer Howard en 1902, quien entendía al cinturón verde 
como un tramo de tierra conformado por tierras agrícolas, bosques y otras áreas naturales entre las ciudades. Según Ebenezer Howard, las principales funciones de los cinturones verdes eran: (1) separar las ciudades unas de otras; y (2) preservar las tierras agrícolas, los bosques, y otros ambientes naturales (Yang y Jinxing 2007). Algunos trabajos que abordan este tema son por ejemplo (Uy y Nakagoshi 2008, Yang y Jinxing 2007, Tian et al. 2011). Planificar la producción de alimentos y construir un sistema agroalimentario sustentable, son tareas que requieren ir más allá del espacio físico donde se desarrolla la actividad hortícola, exige pensar en toda la cadena desde la producción hasta la comercialización y el consumo; esto implica abordar el desarrollo de infraestructura acorde, acceso a servicios, salud y educación, preservación del ambiente y sus servicios ecosistémicos, estrategias de comercialización, trazabilidad, garantía de calidad y precio justo entre otros aspectos. Requiere además un profundo debate político como sociedad respecto a qué tipo de alimentos queremos consumir, quienes queremos que estén encargados de producir esos alimentos y como queremos que se produzcan; la discusión sobre la agricultura sostenible debe ir más allá de lo que sucede dentro de los límites de la unidad de producción individual (Gliessman et al. 2007). Pensando entonces la planificación de la producción de alimentos desde una mirada más integral, es importante destacar también que existen a nivel mundial experiencias de comercialización de alimentos de cercanía muy difundidas, como Quilómetro cero en Europa y el Xarxa de Mercats puntualmente en Barcelona (Barsky 2013) o los mercados locales en Bolivia. Por otro lado, la ecología de paisajes ha brindado un marco teórico muy valioso para diseñar estrategias que permitan integrar los ambientes naturales/semi-naturales con sistemas productivos y urbanos cuidando el ecosistema y preservando los servicios ecosistémicos que este brinda; a su vez, son cada vez más habituales los trabajos científicos que aplican estas estrategias para evaluar planificaciones en áreas urbanas y periurbanas (Li et al. 2005, Norton et al. 2016, Uslu y Shakouri 2013, Szlavecz et al. 2011, Vergnes et al. 2013).

El desarrollo de agroecosistemas sustentables implica incorporar prácticas productivas que preserven y potencien los procesos de la naturaleza, para garantizar las funciones y servicios ecosistémicos requeridos para la producción de alimentos sanos; para ello, la biodiversidad es esencial. En este sentido, es importante tener en cuenta que las unidades productivas (quinta, fincas, chacras, etc.) son sistemas abiertos, que están en constante intercambio de materiales y energía con su entorno; por lo cual, las condiciones para que la biodiversidad esté presente y de la manera adecuada para aportar sus funciones a la actividad productiva, requiere un escenario que excede los límites de la propia unidad productiva. La diversidad de paisajes, en este contexto, contribuye a mejorar procesos como la polinización, el control de plagas y el ciclo de nutrientes, entre otros servicios ecosistémicos de importancia en la producción de alimentos (Rositano et al 2012, MartinLópez et al. 2007). Desde los ámbitos de gestión, casi todas las ciudades en el mundo están 
planeando en mayor o menor medida reintroducir a la naturaleza en su paisaje urbano/periurbano, ya sea con fines estéticos, para el aprovechamiento de espacios que no tienen una utilidad concreta o buscando algunos de los tantos beneficios que brinda la naturaleza; todas ellas aunque motorizadas por distintos fines contribuyen al mantenimiento y al incremento de la biodiversidad urbana/periurbana y de los servicios ecosistémicos que ella provee. Como plantean Pengue y Rodríguez (2018), existen numerosas experiencias en distintas partes del mundo, donde han avanzado con programas de revegetación, mediante la introducción de jardines, corredores verdes, parches ecológicos, redes de canales reverdizados, lagunas urbanas y ríos reconvertidos, entre otras medidas; América del norte y Europa tienen importantes avances en este sentido, seguidos por Asia (particularmente Singapur y en menor medida, grandes ciudades como Tokio y Seúl), Australia, Sudamérica y África.

Pese a todas las iniciativas que actualmente están intentando avanzar hacia la construcción de sistemas agroalimentarios más saludables (para las personas y para el ambiente) y más justos; estas propuestas conviven con un sistema agroalimentario mundial pensado para beneficiar a unos pocos actores que concentran el poder, y en el cual como plantea Odum (1984), los productos agrícolas valen más como activos en el mercado que como alimento para la población y la tierra se valora más por su rendimiento a corto plazo que por su sustentabilidad productiva a largo plazo. El sistema alimentario en el que estamos inmersos, es un reflejo de los valores que guían las decisiones humanas tanto para el diseño y manejo de agroecosistemas como las decisiones de qué y porqué consumir productos provenientes de uno u otro sistemas (Gliessman et al. 2007). Cómo vamos a posicionarnos ante el sistema agroalimentario hegemónico, qué salida podemos encontrar al actual dilema alimentos-commodities y cómo respondemos a las gravísimas externalidades que está generando el actual modelo agroindustrial, es un debate pendiente y necesario no solo en los ámbitos productivos, sino y principalmente en las esferas públicas y en la sociedad en general. La agroecología (en todas sus dimensiones) se ha ido expandiendo en los últimos años entre las familias agricultoras y adquiriendo reconocimiento por parte de la sociedad; al mismo tiempo, sus múltiples beneficios ya no pueden ser ocultados, por lo que diversos organismos internacionales han tenido que reconocerla como "práctica alternativa" al modelo de agricultura industrial. Al igual que lo que Odum (1984) denominó como "agricultura conservacionista", la agroecología, es beneficiosa para el productor, para la sociedad y para la tierra, pero generalmente no lo es para aquellas naciones comprometidas con la exportación de alimentos, y la utilización de estos como comodities, constituyendo una pieza en el circuito que permite sostener los negocios con empresas transnacionales (Odum 1984), y dependiendo del perfil del gobierno de turno, traducir esto en mejoras económicas para los sectores más vulnerables de la sociedad. Por este motivo es indispensable avanzar en el debate respecto a cómo buscamos una alternativa a la 316 Lic. Carolina Baldini Tesis doctoral - Territorio en movimiento 
dependencia de los commodities, de lo contrario la producción de alimentos saludables, social y ambientalmente justos será siempre una experiencia marginal y subordinada al modelo hegemónico.

Finalmente, no es posible pensar una planificación de la producción de alimentos sin abordar la planificación del crecimiento urbano. Es indispensable articular estos aspectos en una planificación territorial más integral, para no caer en proyectos que en los papeles son ideales pero en la práctica el que finalmente ordena el territorio es el mercado inmobiliario. Para una transformación del territorio que apunte a generar condiciones de mejora social para las familias productoras, históricamente postergadas, y para la sociedad en general, es necesario identificar acciones de políticas que permitan ir transformando las relaciones de poder existentes históricamente, y aumentando la capacidad de intervención de los sectores postergados en la gestión de los recursos locales (Manzanal 2014). Siguiendo a Ostrom (2009), quien plantea la falta de éxito en la gestión de los bienes comunes tanto por parte del estado como por parte de privados, sería interesante poder avanzar hacia una planificación del territorio productivo construida realmente de manera colectica, donde los actores aporten propuestas en base a sus necesidades cotidianas, y estén involucrados tanto en la elaboración como en la posterior implementación de los mecanismos de regulación y control de las actividades que en ese territorio se desarrollan. Un territorio productivo gestionado colectivamente, entre el Estado y los actores locales, será probablemente un territorio con múltiples mecanismos de regulación y por lo tanto más difícil de ser erosionado por la especulación y el libre mercado, facilitando el avance hacia un desarrollo sustentable. En sintonía con esto, Yang y Jinxing (2007) han analizado el fracaso del primer cinturón verde planificado en Beijing, resaltando la necesidad de una mayor participación de los actores locales en este tipo de proyectos. Según Yang y Jinxing (2007) hubo tres factores que condenaron el plan al fracaso: 1) se basó en una previsión no realista de crecimiento urbano, 2) fue escrito sin la participación de las principales partes interesadas (los agricultores); y 3) exageró la función de separación del cinturón verde de la ciudad y descuidó otras funciones. Estos autores plantean que los agricultores que viven dentro de los límites de la zona verde son las personas más afectadas y deben jugar un papel importante en todo el proceso de toma de decisiones y ayudar a diseñar el plan; plantean a su vez la necesidad de que existan mecanismos para compensar adecuadamente a los agricultores, y de que los habitantes de la ciudad que se beneficiaron del cinturón verde ayuden a compartir los costos de su protección (Yang y Jinxing 2007). Bryant (2006) se refiere a la potencialidad del rol que es capaz de jugar la ciudadanía cuando se la hace participe en la planificación y desarrollo de estos programas, aportando al mantenimiento de un ambiente saludable y a la protección de la biodiversidad, a través por ejemplo de programas de restauración de ríos y arroyo y de desarrollo de corredores verdes, que son de gran utilidad en el diseño de territorios productivos sustentables y que 
proporcionan a su vez oportunidades de esparcimiento en las zonas periurbanas y urbanas densamente pobladas. Este tipo de acciones promueven el interés ciudadano y abren canales de diálogo entre diversos actores, generando oportunidades de debate y reflexión respecto a los territorios "vividos" y los territorios "deseados".

En Argentina, la expansión urbana está ejerciendo una fuerte presión sobre las tierras productivas en todo el país, lo que está motivando la reducción de la mayoría de los cinturones hortícolas (Giobellina 2018, Giobellina 2017, Medico 2016, Hurtado et al. 2006). Este problema se ve agravado por la intensificación del uso del suelo hortícola a través de la implementación de la tecnología del invernáculo, que se promovió en el Cinturón Hortícola de La Plata, y que influyó en la disminución o desaparición de varios cinturones verdes del país y de otros espacios productivos del Cinturón Verde Bonaerense, los cuales se vieron imposibilitados de competir con la producción de La Plata (Barsky 2013). Lo que está ocurriendo en los cinturones hortícolas de nuestro país es un claro ejemplo de cómo el mercado, con sus propias leyes actúa de manera integral en todo el territorio nacional; y evidencia la necesidad de avanzar en políticas públicas locales articuladas y a la vez amparadas por una política nacional integradora. Ante un mercado que actúa globalmente, un estado fragmentado deja a la población en una situación de extrema vulnerabilidad. El reconocimiento de los gobiernos (nacional, provincial, municipal) de su responsabilidad de garantizar el suministro de alimentos de calidad a la población es un paso fundamental para el desarrollo de políticas apropiadas de planificación de la producción y distribución de alimentos. Como señala Barsky (2013) no existe hasta el momento en nuestro país una política sectorial-territorial en horticultura que se proponga una coordinación entre las distintas zonas productivas del país, ni que priorice la agricultura de cercanías, la preservación de los cinturones verdes existentes, la regulación económica de los mercados y de la comercialización para evitar oscilaciones de precios, la reducción de las largas cadenas de intermediación, garantizar la inocuidad de los alimentos y ordenar la trazabilidad $\mathrm{u}$ origen de los mismos. Por el contrario, el Sistema Agroalimentario Argentino ha estado históricamente subordinado a las reglas impuestas por la agricultura industrial, y las propuestas hacia la agricultura familiar tienden a orientarse, en el mejor de los casos, a incrementar su productividad a través de la intensificación productiva. Algunas propuestas de Parques agrarios, que incluían un sistema productivo agro-ecológico, el desarrollo productivo y el establecimiento de zonas de reserva natural, fueron desarrollados para algunos cinturones hortícolas peri-urbanos del país (Giobellina et al. 2017, Garcia 2015). Sin embargo, por el momento, ninguna de las propuestas ha sido implementada. En el límite entre los partidos de La Plata y Berazategui se desarrolla el Parque Pereyra Iraola, único parque agrario que existe en Argentina (Barsky 2013) pero que dista ampliamente de 
funcionar como tal ${ }^{10}$. En cuanto a las experiencias de Cinturones Verdes (también llamados cinturones Hortícolas) en el país, en general son áreas que carecen de una protección real y de un plan de gestión de los mismos, quedando en manos de la especulación inmobiliaria, el avance de la agricultura industrial extensiva (monocultivo de soja especialmente) o los procesos de intensificación productiva bajo el paradigma de la Revolución Verde. Ante la falta de una política integral a nivel nacional y frente a los problemas estructurales y las sucesivas crisis que viene afrontando el sector de la pequeña agricultura familiar en todo el país, recientemente se ha generado un proyecto de ley impulsado por el MTE rural (Movimiento de Trabajadores Excluidos, rama rural) y conformado de manera colectiva junto con productores, técnicos e investigadores de todo el país, para la "Protección y Fortalecimiento de los Territorios Periurbanos Hortícolas: cinturones verdes, oasis y valles fruti-hortícolas", un intento de construcción de políticas públicas desde y para el pueblo. Al mismo tiempo, en mayo del presente año tuvo lugar un hecho inédito en nuestra historia, el desarrollo del 1er Foro por un Programa Agrario Soberano y Popular ${ }^{11}$, organizado por 100 organizaciones de pequeños productores familiares y con la participación de más de 2000 personas, incluyendo productores, técnicos, trabajadores de las universidades nacionales, entre otros. Este foro fue impulsado en gran medida por las deficientes políticas públicas hacia el sector de los pequeños y medianos productores y por la falta de una proyección como nación, con legitimidad social, del modelo productivo que se quiere impulsar; en este sentido el foro apostó a un amplio debate para la generación de propuestas de políticas públicas concretas que ayuden al desarrollo del sector y aporten a la soberanía alimentaria y a la transición agroecológica.

El periurbano de La Plata, es asiento de uno de los cinturones hortícolas más importantes del país, capaz de proveer de alimentos de proximidad a la principal población del país por la cercanía del área urbana a la zona hortícola y por ser un cinturón hortícola de gran envergadura, que ha sufrido una mínima retracción. La horticultura tal como se desarrolla actualmente, traccionada por el modelo productivo y de desarrollo impuesto por el capitalismo y la presión de la especulación inmobiliaria, está conduciendo a una pérdida de diversidad productiva en la región, con fuerte impacto en el paisaje y su biodiversidad; reduciendo al mismo tiempo la posibilidad de la población local de acceder a una

\footnotetext{
${ }^{10}$ El Parque Pereyra Iraola es un espacio verde de 10248 ha., de propiedad provincial producto de la expropiación por parte del estado, realizada en 1949. Este fue pensado desde sus orígenes como un parque agrario, destinando 1200 ha para la producción hortícola. Entre las limitaciones para que funcione como tal Barsky (2013) menciona: 1) falta de infraestructura (tendido eléctrico y agua potable) en la mayor parte del predio, 2) carencia de una administración adecuadamente equipada, 3) falta de un manual de gestión, 4) ausencia de estrategias mercadotécnicas de posicionamiento de sus productos o de una página web oficial que informe sobre sus actividades. Al mismo tiempo, existe una implementación parcial de las prácticas agroecológicas entre las familias productoras del parque, se observan situaciones de deterioro ambiental propias del periurbano y existe un mercado informal de arrendamiento

${ }^{11}$ http: / / foroagrario.org/ 
alimentación saludable, diversa y a precio justo. Como se expuso a lo largo de esta tesis, el CHP tiene enormes problemáticas y está actualmente condicionado por fuertes presiones de los sectores de poder de los cuatro mercados hegemónicos que plantea Ambort (2017) en base a García (2014): el mercado inmobiliario, el mercado financiero, el mercado de agroinsumos, y el mercado de hortalizas; las acciones del Estado han sido insuficientes e inadecuadas, sesgadas principalmente a tres aspectos: 1) implementación de Buenas Prácticas Agrícolas, 2) formalización de las familias productoras sin una estrategia clara y 3) incremento de la productividad mediante la intensificación. Es interesante destacar que, ante estas estrategias del Estado, las organizaciones de productores junto con técnicos e investigadores, tienen propuestas mucho más avanzadas para la gestión del CHP, que de ser escuchadas y abordadas por el Estado en conjunto con estos actores, otro territorio productivo sería posible. Tenemos numerosos ejemplos de cómo ante las deficiencias en la gestión del estado, estos actores han ido avanzando en la construcción de sistemas agroalimentarios más adecuados. Barsky (2013) destaca que en la Región Metropolitana de Buenos Aires, la creación de los circuitos alimentarios de proximidad fue efecto de la acción de los actores en el territorio, mientras que las preocupaciones gubernamentales y académicas por el sostenimiento y la sustentabilidad de estas actividades fueron posteriores a su desenvolvimiento. En el CHP, el avance en estrategias de comercialización más directas (ferias, bolsones) y las mejoras en los canales de comercialización tradicionales (transporte propio, puesto en el mercado, galpones de acopio), en el armado de precios justos y estabilizados, en la concientización del consumidor, la incorporación de semillas criollas y las estrategias de reproducción de semillas propias, los avances en los procesos de transición agroecológica y de formación de campesino a campesino, la búsqueda de procesos de certificación participativa, el acceso a la educación (escuelas primarias, secundarias y procesos de alfabetización y terminalidad educativa gestionados por las propias organizaciones), entre otros numerosos ejemplos, son acciones motorizadas principalmente por las organizaciones de productores, con un fuerte apoyo de sectores de la academia y del INTA, que actúan muchas veces desde la marginalidad. Estos ejemplos son contundentes y reflejan la necesidad de capitalizar estas experiencias, y que estos actores que desde la marginalidad vienen construyendo otro territorio posible, sean incorporados en el diseño e implementación de políticas públicas. Bonicatto (2018) encontró que en el marco de esta coyuntura compleja, las estrategias de manejo basadas en recursos y saberes locales, que generan independencia y permiten ahorrar dinero, fueron consideradas y revalorizadas; considerando que la conservación in situ de agrobiodiversidad encontró y encuentra una coyuntura oportuna para su difusión. Junto con Bonicatto (2018) las investigaciones de Gargoloff (2019), Blandi (2016), Dubrovsky Berensztein (2018), Fernández y Marasas (2015) y Stupino (2019) muestran la existencia en el CHP de prácticas de gestión de las unidades productivas que contribuyen a mantener la biodiversidad y los 
servicios ecosistémicos que ella provee, recuperando saberes y prácticas culturales. En este sentido, si se garantizaran desde el Estado las condiciones mínimas de vida y de producción, se cuenta con un enorme potencial para trabajar en conjunto en pos de reducir el poder de los actores del mercado mencionados anteriormente y construir un territorio más sustentable, con un proyecto regional a largo plazo y apoyando a las familias productoras para que puedan gestionar sus unidades productivas de manera sustentable y resiliente.

\subsection{DISCUSIÓN GENERAL, CRITERIOS DE ORDENAMIENTO TERRITORIAL Y RECOMENDACIONES}

Los resultados presentados en esta tesis evidencian dos principales transformaciones territoriales ocurridas en el partido de La Plata, la expansión urbana y la intensificación productiva (ver capítulo 2), las cuales no son procesos particulares de este territorio, sino que responden a tendencias mundiales; en consecuencia, los actores que traccionan estos cambios en el uso del suelo suelen ser actores con una importante acumulación de poder y generalmente muy influyentes. En el partido de La Plata Ambort (2017) identifica estos actores influyentes en base a García (2014), enmarcándolos en cuatro mercados hegemónicos: el mercado inmobiliario, el mercado financiero, el mercado de agroinsumos, y el mercado de hortalizas; estos mismos actores fueron a su vez identificados por los diversos entrevistados (ver capítulo 4).

En este sentido, como plantea Saquet (2015), el territorio está moldeado por procesos que se dan a distintos niveles (local, nacional, regional, mundial), a través de redes que se forman como resultado de relaciones internas y externas. De la misma forma, las transformaciones socio-económicas que afectan a las actividades productivas, son el resultado tanto de las tendencias globales, como de las especificidades locales y de los actores sociales que influyen en estas (Otero 2013). Los procesos que se dan en el partido de La Plata están por ende vinculados con procesos nacionales e internacionales; y los cambios políticos contextuales tienen un profundo impacto sobre las decisiones de política, afectando a su vez a los distintos actores sociales (Hang et al. 2015).

En sintonía con lo expuesto en los párrafos anteriores, se puede ver como en Argentina, la expansión urbana y en algunos casos del agronegocio a través de monocultivos (principalmente soja), están generando la reducción de la mayoría de los cinturones hortícolas del país y de otros espacios productivos del Cinturón Verde Bonaerense; la intensificación productiva a través de la implementación de la tecnología del invernáculo, que se promovió en el Cinturón Hortícola de La Plata agravó esta situación al dificultar a otros sectores productivos la competencia con la producción de La Plata (Giobellina 2018, Giobellina 2017, Medico 2016, Hurtado et al. 2006, Barsky 2013). Esto hace pensar en la necesidad de una política nacional de desarrollo de las áreas productivas, que permita una 
mínima planificación de la producción y que esté orientada al fortalecimiento de áreas productivas regionales para el abastecimiento de alimentos de cercanía, limitando la influencia del libre mercado que termina desdibujando el verdadero rol de la producción de alimentos. Esta política nacional debería ir necesariamente acompañada por políticas públicas provinciales y municipales que refuercen este proyecto nacional, y deben ser pensadas a largo plazo (ver capítulo 4). La participación de los productores/as familiares en el diseño de este tipo de políticas es esencial para que sean exitosas (Yang y Jinxing, 2007).

Pensar una planificación territorial que permita el desarrollo de un cinturón hortícola sustentable, basado en los lineamientos de la propuesta agroecológica, implica abrir el debate a una serie de preguntas, entre ellas: ¿hacia dónde es probable que se expanda la urbanización?, ¿es necesario que se expanda la horticultura? ¿hacia dónde se podría expandir la horticultura de ser necesario?, ¿en qué zonas podrían desarrollarse producciones más sustentables?, ¿qué implicancias tendría ello para el abastecimiento de circuitos cortos de comercialización?, ¿qué infraestructura debería desarrollarse para facilitar la comercialización?, ¿qué ambientes semi-naturales actuales se debería conservar para garantizar servicios ecosistémicos necesarios para la producción de alimentos?, ¿qué ambientes se podrían reconvertir o potenciar para funcionar como conectores en una red de ambientes semi-naturales?, ¿qué rol deberían cumplir productores, consumidores y Estado para el desarrollo y la implementación efectiva de una planificación territorial adecuada?. Los resultados de este trabajo brindan herramientas para comenzar a esbozar algunas posibles respuestas.

Dicho esto, es posible avanzar en la discusión respecto a las actuales condiciones del periurbano productivo de La Plata. Volante (2009) plantea que la distribución espacial y temporal de los distintos usos/coberturas del suelo ponen de manifiesto el ritmo productivo de una región, la estabilidad de los agroecosistemas y sus capacidades de brindar servicios ecosistémicos. Al mismo tiempo, la FAO plantea que para llegar a desarrollar agroecosistemas sustentables se requiere diversificación y una mejor integración de los sistemas de producción de alimentos en los complejos procesos ecológicos, creando sinergias con el hábitat natural y sin agotar los recursos naturales (FAO, 2016). Los resultados de esta tesis evidencian en términos generales, la necesidad de poner restricciones al avance urbano, planificar hacia qué sectores del partido es más adecuado que crezca la ciudad y generar una figura legal que proteja el área productiva, resguardando la producción de alimentos y los ambientes semi-naturales, reservorios de biodiversidad y proveedores de servicios ecosistémicos esenciales para la población.

En cuanto a la expansión urbana, la connivencia del Estado con el sector inmobiliario y la implementación deficiente de políticas públicas de acceso a la vivienda, como es el caso del plan ProCreAr, han conducido a un crecimiento urbano desordenado, avanzando sobre 
tierras de calidad para la producción hortícola y ganadera, perdiéndose a su vez la separación que existía en otros tiempos entre la actividad productiva y las viviendas e incrementándose por ende los conflictos urbano-rurales. Hasta el momento no hay evidencias de que esta tendencia este cambiando, por el contrario la especulación por el uso del suelo estaría incrementando su valor en zonas productivas desplazando a estas actividades hacia sectores marginales, con poco desarrollo de infraestructura y servicios, generando dificultades para la comercialización y deteriorando aún más las condiciones de vida y de trabajo de las familias productoras (ver capítulo 4). La percepción de los actores entrevistados respecto a los cambios en el uso del suelo, la preponderancia evidenciada de la urbanización en las áreas de mayor conflicto por la superposición de aptitudes de uso del suelo, la detección de urbanizaciones en suelos de calidad productiva, el incremento de la actividad hortícola en suelos tradicionalmente ganaderos, son algunos de los resultados de esta tesis que dan cuenta de esta situación. Además del evidente desplazamiento de la actividad productiva, el desarrollo urbano afecta la biodiversidad de diferentes maneras, a través de la perturbación de los suelos y la conversión a superficies impermeables, la remoción de la vegetación nativa, la introducción de especies exóticas, y la fragmentación y el aislamiento de las restantes áreas naturales, entre otros (Bryant, 2006). Partiendo de este diagnóstico y frente a la actual competencia por el uso urbano-rural, y la cercanía entre estos dos usos del suelo evidenciada en esta tesis (ver capítulo 3), es indispensable establecer un área de no fumigación, que proteja a la población de los agroquímicos utilizados en la producción intensiva, como se viene planteando en diversos municipios. Si bien estos planteos no son aún habituales en escenarios de producción hortícola intensiva, las consecuencias negativas que múltiples investigaciones han evidenciado en el ambiente (Sarandón et al. 2015, Arias 2019, Mac Loughlin, et al. 2017), y los problemas de salud de las familias productoras, que aunque aún no está sistematizado, diversos actores en el territorio lo mencionan como un emergente, evidencian la necesidad de avanzar en este sentido. Una ordenanza a destacar en la provincia de Buenos Aires es la Ordenanza 18.740/08 del municipio de General Pueyrredón (que contiene uno de los principales cinturones hortícolas de la provincia), que pese a las deficiencias en su cumplimiento, establece un área de 1000 metros al ejido urbano, donde no se puede fumigar con agroquímicos. Por otro lado, es necesario definir una estrategia de crecimiento de la ciudad y delimitar un área para la producción hortícola, imposibilitando que se pueda hacer un uso urbano de la misma. Existen diferentes tendencias en cuanto a las posibilidades de crecimiento urbano, asociadas a diversos "modelos de ciudad" (ciudad compacta, ciudad fragmentada, ciudad difusa). Continuar propiciando el desarrollo de barrios privados y countryies, vinculados a rutas y caminos principales, que conectan de manera cada vez más fluida con CABA, así como el desarrollo de planes de vivienda en zonas rurales alejadas del centro urbano y carentes de infraestructura, conduciría a consolidar un modelo de ciudad 
difusa. Este modelo de ciudad está asociado con la insustentabilidad ambiental, la fragmentación territorial, y la segregación socioespacial, donde el rol del espacio público es puesto en cuestión y los espacios públicos abiertos se convierten en espacios de tránsito, perdiendo su condición de espacios para la convivencia, el contacto y el intercambio (Frediani 2010). Por el contrario, detener el avance urbano sobre áreas productivas y promover un mejor aprovechamiento del espacio construido existente, invirtiendo en mejorar la infraestructura actual y en mejorar las condiciones de habitabilidad de la ciudad, permitiría por un lado mejorar el uso energético y por otro resguardar espacios periurbanos para la producción de alimentos sanos. En este sentido, Frediani (2014) advierte sobre la existencia de tierras urbanas que podrían ser convertidas a zonas residenciales o como áreas de esparcimiento, y sostiene que la discusión debería centrarse en las posibilidades de consolidación del suelo actualmente urbanizado y de utilización de terrenos urbanos existentes en lugar de utilizar nuevas extensiones periféricas.

A su vez, el mantenimiento de ambientes semi-naturales en el área urbana tiene un importante rol, no solo por los servicios que brinda a la ciudad y sus habitantes, sino también por la articulación que estos espacios pueden tener con los ambientes semi-naturales periurbanos, contribuyendo a mejorar el funcionamiento de los agroecosistemas que allí se desarrollen. En este sentido Uy (2008) plantea la necesidad de pensar la conectividad a distintas escalas (ej: quinta, barrio o delegación municipal, partido), y la necesidad de conectar los ambientes semi-naturales urbanos con el periurbano. Uy (2008) y Tian (2011) proponen como una forma de mejorar la conectividad entre estos ambientes, proveedores de biodiversidad, el diseño de una red de espacios verdes, que incluya corredores a lo largo de ríos y caminos, parches de vegetación natural/semi-natural de diversos tamaños y elementos aislados (ej: árboles) que sirvan como "piedra de paso". Pensando en la posibilidad de generar una red de espacios verdes, el partido de La Plata tiene un enorme potencial, por estar atravesado por una amplia red de drenaje; las zonas urbanas y hortícolas del partido son atravesadas por numerosos arroyos que forman parte de la vertiente del Río de la Plata, la cual cuenta con 14 arroyos principales (Morello et al. 2012), lo que se traduce en una importante oportunidad para el diseño de corredores biológicos, permitiendo potenciar el flujo de organismos y energía a través del sistema. Gilbert-Norton et al. (2010) consideran más efectivo proteger las características naturales del paisaje que funcionan como corredores que intentar crear nuevos corredores; si bien estas medidas no son excluyentes, las conclusiones de estos autores refuerzan la importancia de proteger y gestionar adecuadamente los ambientes semi-naturales que aún se conservan en el partido y que podrían funcionar como corredores naturales. En este sentido, el trabajo de Gómez et al. (2017) destaca la existencia en la cuenca alta del arroyo del Gato, de bañados de desborde fluvial, cuya conservación reviste importancia por la diversidad vegetal que alberga, la provisión de hábitat para variadas especies animales y la función de retención del 
agua de lluvia. Así mismo, Birche y Jersen (2018) señalan que en el área periurbana de La Plata más del $90 \%$ de los arroyos permanecen a cielo abierto, lo que implica un gran potencial para pensar en estrategias de intervención tendientes a generar espacios públicos asociados a ellos, que al mismo tiempo los protejan como fuente de biodiversidad y de servicios ecosistémicos. Sin embargo, como parte de los resultados de esta tesis hallé que un alto porcentaje de cultivos bajo invernáculo se desarrollan muy cerca de la red de drenaje, a distancias inadecuadas según diversas legislaciones (ver capítulo 3); por este motivo es necesario desarrollar mecanismos para resguardar estos ambientes riparios, y medidas tendientes a transformar dichas producciones en producciones sustentables, que no pongan en riesgo el ambiente aledaño ni la población que pueda hacer uso de él.

Finalmente, respecto al periurbano donde se desarrolla el CHP, los resultados de mi tesis han evidenciado en términos generales un crecimiento exponencial de las producciones bajo invernáculo, un avance de estas producciones sobre aquellas que se desarrollan al aire libre, y la agrupación de los invernáculos en sectores donde a su vez la vegetación semi-natural era escasa; al mismo tiempo detecté una expansión de este tipo de producciones sobre suelos típicamente ganaderos, lo que augura la expansión también de las consecuencias negativas que arrastra este modelo productivo intensivo (ver capítulos 2 y 3). Al mismo tiempo, los análisis de sustentabilidad en este tipo de producciones en la región, han mostrado que se encuentran asociadas a un aumento de problemas ecológicos, sociales y económicos comparados con la producción al aire libre (Blandi 2016). En este sentido y pensando en la necesidad de avanzar hacia un territorio productivo sustentable y resiliente, se requiere generar políticas públicas que regulen la superficie productiva bajo invernáculo, que propicien las producciones al aire libre y que resguarden y/o promuevan la presencia de ambientes semi-naturales en el territorio productivo. Como mencioné anteriormente, existen evidencias de que los cultivos al aire libre pueden contribuir a conformar redes de espacios verdes que aporten al mantenimiento de la biodiversidad necesaria para sostener el funcionamiento de agroecosistemas sustentables. En la presente tesis se identificaron zonas donde aún se conserva un importante porcentaje de cultivos al aire libre, y zonas de aptitud alta para el desarrollo de nuevas producciones, y se identificaron sectores donde sería conveniente propiciar una reconversión de los cultivos bajo invernáculo a cultivos al aire libre. Se destacaron también sectores del partido que conservan ambientes semi-naturales que sería conveniente preservar para formar parte de esta red de espacios verdes (ver capítulos 3 y 4). Sumado a esto, Birche y Jensen (2018b) mencionan que el número de espacio verde por habitante en la zona del cinturón verde $(2,8$ $\mathrm{m} 2 /$ habitante) está por encima del mínimo que requiere la OMS, pero la distribución espacial de estos resulta discontinua, dejando grandes sectores del CHP sin acceso a espacios verdes (Birche y Jensen 2018b), un aspecto detectado también en el análisis de las entrevistas realizadas para esta tesis (ver capítulo 4). La generación y conservación de 
espacios verdes y el fomento de su utilización por parte de la población local/regional, no solo aporta al mantenimiento de agroecosistemas resilientes, sino que genera beneficios sociales al aumentar la integración social y la interacción entre los vecinos (Coley et al. 1997 en Tian 2011); un aspecto de gran relevancia si consideramos que la actividad productiva en la zona es principalmente agricultura familiar, y que las familias productoras viven mayormente en las quintas que trabajan.

En sintonía con lo que vengo planteando hasta el momento, es necesario avanzar en propuestas de ordenamiento territorial que consideren no sólo el desarrollo urbano y las actividades industriales, sino también un diseño del paisaje más inclusivo. En este sentido, si bien de manera incipiente, desde la ecología del paisaje existen diferentes herramientas de análisis que están siendo incorporadas en los últimos tiempos al estudio de paisajes agrícolas, que permiten comprender mas acabadamente el rol de la heterogeneidad del paisaje sobre la biodiversidad, por ejemplo desde el análisis de la funcionalidad del paisaje, para desde allí pensar propuestas de diseño que promuevan la biodiversidad (Fahrig 2011). De todas maneras, existe ya un importante acervo de información generado desde esta disciplina que permite avanzar en ciertas estrategias de planificación. Como hemos visto, un punto de partida esencial en la planificación de paisajes agrícolas es considerar aquellas estrategias de uso de la tierra y políticas de gestión territorial que preserven y promuevan coberturas de vegetación semi-natural, como los pastizales y la vegetación riparia, por ser proveedores de servicios ecosistémicos y de hábitats para la biodiversidad y por facilitar la conectividad biológica entre las unidades productivas, mejorando la capacidad productiva del paisaje. Existen diversos autores que han generado criterios a tener en cuenta para el diseño de paisajes más resilientes y biodiversos, entre los que se encuentran Fischer et al. (2006), Matteucci (2004) y Herrera (2011). A continuación se mencionan sólo a modo de ejemplo diez criterios generales postulados por Fischer et al. $(2006)^{12}$, sin embargo es importante remarcar que este es un tema amplio que requiere un abordaje aparte. Este autor plantea las siguientes estrategias:

- Mantener y crear parches grandes y estructuralmente complejos de vegetación nativa

- Mantener la complejidad estructural de todo el paisaje

- Crear áreas buffer alrededor de las zonas sensibles

- Mantener o crear corredores y parches pequeños que funcionen como trampolín (steping stones) para la dispersión de especies

- Mantener la heterogeneidad del paisaje y capturar los gradientes ambientales

- Mantener las interacciones de las especies clave y la diversidad funcional

- Aplicar regímenes de perturbación apropiados

\footnotetext{
${ }^{12}$ Este autor utiliza terminología propia de la ecología de paisaje. De ser necesario se recomienda recurrir al apartado de ecología del paisaje presente en el capítulo 1 de esta tesis. 326 Lic. Carolina Baldini

Tesis doctoral - Territorio en movimiento
} 
- Controlar las especies agresivas, muy abundantes e invasoras

- Minimizar la amenaza a los procesos específicos de los ecosistemas

- Mantener especies de particular interés

A partir de los análisis realizados en esta tesis y considerando algunos de los criterios mencionados anteriormente se desprenden una serie de medidas más urgentes, que se pueden pensar como estrategias a corto plazo, y una serie de medidas que es necesario comenzar a abordar pero que su implementación requerirá de un mediano plazo.

Entre las estrategias consideradas necesarias a corto plazo se incluyen:

- La protección de la zona productiva, un comienzo necesario para evitar que se sigan perdiendo suelos productivos

- La delimitación de una franja de no fumigación, acompañada por políticas adecuadas de fomento de la transición hacia producciones agroecológicas; y en el mismo sentido, la protección de los márgenes de los arroyos estableciendo una primer zona protegida y una segunda zona que habilite la producción hortícola agroecológica. Este tipo de políticas requieren por supuesto de un correcto acompañamiento y resarcimiento de las familias productoras que se vean perjudicadas.

- La generación de áreas de amortiguamiento a los lados de los arroyos para el mantenimiento de la vegetación riparia, sobre todo en aquellas áreas urbanizadas o en proceso de urbanización, y en aquellas zonas donde predominan los invernáculos y la horticultura al aire libre, es una medida indispensable.

- La creación de reservas naturales en la zona periurbana donde se encuentra el cinturón hortícola, que funcionen como pulmones verdes, refugio para la biodiversidad y zonas recreativas para las familias productoras y la población local, es otra medida necesaria.

- La forestación con árboles nativos en las rutas y principales caminos periurbanos

A mediano plazo podría avanzarse en la conformación de una red de espacios verdes periurbanos, para lo cual sería necesario definir espacios a proteger, ambientes que se puedan mejorar por ejemplo mediante la forestación con especies nativas y ambientes que puedan constituirse como corredores verdes, conectando los otros ambientes. Además de la escala de paisaje, es necesario implementar políticas públicas para los propietarios de las tierras productivas y para las familias productoras.

- Un aspecto crucial es la posibilidad de acceder a la propiedad de la tierra por parte de las familias productoras, por ejemplo, a través de créditos blandos, con el apoyo del estado, permitiendo una planificación a largo plazo y la inversión en las tierras productivas tanto por parte de las familias productoras como por parte del gobierno. 
- En relación a las producciones hortícolas, es importante limitar la superficie bajo invernáculos en cada establecimiento productivo, que debe ir acompañada necesariamente por exenciones impositivas $u$ otras políticas de fomento para aquellas familias productoras que reconviertan parte de sus unidades productivas hacia producciones al aire libre o que conserven vegetación semi-natural dentro de sus unidades productivas, que promuevan la restauración del ambiente en aquellas tierras bajo producción hortícola intensiva, que establezcan cortinas rompe viento forestando con plantas nativas, y otras acciones que contribuyan al mejoramiento de las condiciones ambientales para el desarrollo de producciones más sustentables; considerando entre otras variables el Coeficiente de Absorción del Suelo (Jensen y Birche, 2018).

- En relación a las quintas con producción hortícola al aire libre (tanto las actuales como las que elijan en el corto plazo este tipo de producción), es importante poner en valor su potencial rol en el mantenimiento de la biodiversidad y pensarlas como unidades integrantes de una futura red de espacios verdes. Al mismo tiempo, estas medidas generarían condiciones favorables para el desarrollo de actividades de turismo rural, que acerquen a la población a la actividad productiva, fortaleciendo el vínculo productorconsumidor y fomentando el consumo responsable, una propuesta difundida con éxito en otros países

Para desarrollar una planificación territorial adecuada, que contemple aspectos como los abordados en los párrafos anteriores, que apunte a construir un territorio sustentable y resiliente, y que pueda concretarse en la práctica en el territorio en cuestión, esta debe estar acompañada de políticas públicas que garanticen su efectiva implementación, debe ser coconstruida, de manera colectiva, con los distintos actores involucrados, y debe contar con el compromiso del Estado para garantizar fondos públicos y personal técnico adecuado para su implementación. Una planificación de este tipo necesita estar enmarcada en un proyecto más amplio y de largo plazo de desarrollo de la producción hortícola en la región, con criterios bien establecidos respecto al modelo productivo a incentivar, con control por parte del Estado del mercado y los agentes especuladores, regulando los precios de los alimentos y facilitando el acceso a maquinarias, con financiamiento de proyectos productivos, capacitación y promoción de desarrollo científico y tecnológico orientado a tal fin, entre otros. Para ello, del análisis de las entrevistas se desprende la necesidad de que los actores locales intervengan activamente en este proyecto (ver capítulo 4); una propuesta en este sentido es la conformación de una mesa intersectorial (con representantes de diferentes organizaciones de productores, INTA, SENASA, universidades públicas de la región, organismos de ciencia y técnica, funcionarios públicos, etc) que trascienda los períodos de gestión municipal y que sea la responsable de delinear los aspectos trascendentales de este 
proyecto de desarrollo territorial. Los funcionarios de turno, muchas veces con miradas fragmentadas y desconocedores de la historia del territorio (ver capítulo 4), deberían tener la obligación de formar parte de esta mesa e interactuar de este modo con los actores territoriales con más conocimiento en el tema. Contar con una mesa de este tipo, que tenga injerencia en la agenda de los funcionarios de turno en cada gestión podría facilitar la construcción de un proyecto de desarrollo territorial a mediano-largo plazo. En el marco de generar una propuesta de planificación territorial como la planteada hasta el momento, es necesario también repensar el rol de la comunidad científica y del desarrollo tecnológico. Como sostiene Tittonell (2014) la agricultura convencional recibe no sólo la mayoría de la financiación gubernamental sino también casi la totalidad de la inversión en investigación por parte del sector privado; sumado a ello, la mayoría de los avances de la agronomía durante la segunda mitad del siglo pasado se basaron en el estudio de la ecología de poblaciones específicas (mono-cultivos), estudios de especies individuales en relación a su entorno. Para desarrollar una propuesta de planificación tendiente a generar un territorio productivo enmarcado en una propuesta agroecológica, es necesario fomentar desde el Estado un desarrollo científico-tecnológico desde la mirada de la complejidad y promoviendo estrategias como la investigación-acción-participativa (IAP).

Un importante desafío que se evidencia es lograr la integración de funcionarios públicos a estos espacios de construcción del territorio y la incorporación de las propuestas surgidas de estos espacios en políticas públicas concretas; y al mismo tiempo lograr una participación más activa de la sociedad. Partiendo de concebir al territorio como un espacio de disputa, es inviable pensar en un consenso entre los diferentes intereses, especialmente cuando se ponen en juego intereses populares con los intereses de actores influyentes dentro del sistema capitalista. Las clases y las relaciones sociales generan diferentes territorios y espacios que son reproducidos bajo condiciones de conflicto continuo; existiendo espacios de dominación y espacios de resistencia; y las disputas territoriales se llevan a cabo en todas las dimensiones posibles: económica, social, política, cultural, teórica e ideológica (Fernández, en Rosset y Martínez-Torres, 2013). En relación a esto, la fortaleza que se logre tener desde las redes que se constituyen en el trabajo cotidiano en el territorio puede ser un aspecto determinante a la hora de disputar espacios de poder (poder real y poder simbólico).

Un aspecto que emerge como resultado de las entrevistas tiene que ver con la presencia de diversos actores provenientes de instituciones públicas que, aunque desde un lugar de marginalidad, vienen trabajando desde hace años junto con las organizaciones de productores en diversos proyectos para mejorar las condiciones de vida y de trabajo en el CHP (ver capítulo 4). Desde este trabajo cotidiano y articulado, viene creciendo una red de actores con mucho potencial; para consolidar y potenciar esta red de actores hace falta un 
espacio que los nuclee, para que con una participación activa de las organizaciones de productores se puedan generar proyectos más integrales, evitando duplicar esfuerzos y juntando el apoyo necesario para marcar agenda y traccionar las políticas de los funcionarios de turno, buscando trascender hacia una política a mediano largo plazo. Sería deseable que este espacio sirviera también para poner en común y poder debatir los trabajos e investigaciones que se están generando en el territorio, garantizando que la información sea realmente accesible para los distintos actores.

La amplia y continua presencia de la UNLP en el territorio, a través de una diversidad de proyectos de extensión, especialmente pertenecientes a la FCAyF, y más recientemente de espacios como el Consejo Social; hace necesario avanzar en una política de promoción de proyectos de investigación interdisciplinarios gestados en coordinación con los diferentes actores sociales de la región, que permitan avanzar en la identificación de posibles escenarios futuros para el desarrollo urbano y productivo y para la selección de un escenario adecuado para un desarrollo sostenible en la región. Al mismo tiempo, es necesario rever la relevancia institucional que se da a los proyectos de extensión, que como ha quedado evidenciado en esta tesis en muchos casos son, junto con el INTA, quienes mantienen el trabajo cotidiano y a largo plazo en el territorio, en articulación con las familias productoras, generando un importante aporte a la construcción de un territorio más justo. En este sentido, sería deseable avanzar en una jerarquización de estas actividades y en un mayor financiamiento de las mismas, que permita generar nuevos proyectos y por períodos de tiempo más prolongados.

En cuanto al rol de la sociedad en general, como consumidores de los alimentos que en estos territorios se generan, en la Argentina, un país con una democracia representativa y fuertemente erosionada, la sociedad no está habituada a ser parte de procesos de planificación territorial; y en términos generales, a excepción de quienes forman parte de alguna organización social o participan activamente en política, la población no tiene fácil acceso a instancias donde reflexionar y debatir sobre el modelo de desarrollo y el tipo de sociedad que queremos construir. En este contexto, para llevar adelante procesos de planificación colectiva del territorio, la circulación de informaciones y el debate culturalpolítico-económico-ambiental son indispensables y deben partir de instancias de democracia local, para lograr una participación activa y elaborar propuestas concretas de desarrollo. Es necesario que la sociedad esté bien informada, formada y organizada políticamente para construir sus experiencias de desarrollo centradas también en políticas públicas municipales, estatales y federales (Saquet, 2015). Las entrevistas realizadas evidencian los efectos negativos que tiene sobre la actividad productiva la falta de compromiso y conciencia de la población en cuanto al consumo de alimentos (ver capítulo 4). Las experiencias de comercialización directa productor-consumidor en ferias y las visitas de 
consumidores a quintas del CHP como parte del trabajo que se viene desarrollando desde diversas organizaciones de productores, proyectos de la FCAyF y Consejo Social, entre otros, son instancias que pueden contribuir en el mediano plazo a generar una mayor conciencia y participación por parte de la ciudadanía.

Otro aspecto emergente de los análisis de esta tesis es el alto grado de asociativismo, con un elevado porcentaje de productores familiares nucleados en algún tipo de organización; y la importancia de ello, por un lado porque habilita otro poder de negociación frente a los funcionarios del Estado responsables de definir las políticas públicas que afectan al sector, y por otro lado porque potencia enormemente las posibilidades de masificación de un proyecto agroecológico. En este sentido las políticas públicas de promoción de la agroecología debieran estar enfocadas en fortalecer los procesos de transmisión de conocimientos de campesino a campesino existentes, y en poner en valor el potencial existente en el territorio a la hora de pensar el transición agroecológica a nivel territorial. Para esto último es necesario comenzar a abordar desde los espacios de promoción de la agoecología, a la misma más allá del manejo en la propia unidad productiva, incorporando la visión de paisaje y la importancia de la conectividad de los ambientes naturales y seminaturales para la conservación de la agrobiodiversidad existente. Esta visión de la agroecología a nivel de paisaje se ha detectado de manera muy incipiente en los diversos actores entrevistados, lo que evidencia la necesidad de profundizar en este abordaje (ver capítulo 4).

Lo planteado en los párrafos precedentes son condicionantes a la hora de pensar en el desarrollo de un territorio productivo sustentable y resiliente. La masificación de la agroecología como modelo para el desarrollo del CHP requiere necesariamente de fortalecer los aspectos mencionados. La agroecología, un enfoque multidimensional, basado en un nuevo paradigma, es también una propuesta política, y como tal exige que desafiemos y transformemos las estructuras de poder en la sociedad, poniendo el control de las semillas, la biodiversidad, los territorios, el conocimiento y la cultura, entre otros aspectos, en manos de los pueblos que alimentan al mundo (La Vía Campesina, 2016). Desde este punto de vista no se puede pensar la agroecología como una práctica a implementar por productores individuales, sino que debe ser concebida de manera colectiva. De las capacidades "ambientales" del territorio para sostener un cambio en el modelo productivo y las estrategias de intervención en el paisaje para potenciarlo ya hice referencia en la primer parte de este apartado. Ahora, retomo los 8 impulsores claves identificados por Mier et al. (2019) en el proceso de llevar la agroecología a mayor escala, para dimensionar desde otro punto de vista la potencialidad del CHP en este sentido; los mismos incluyen: (1) el reconocimiento de una crisis que motiva la búsqueda de alternativas, (2) la organización social, (3) el procesos de aprendizaje constructivista, (4) las 
prácticas agroecológicas efectivas, (5) los discursos movilizadores, (6) los aliados externos, (7) los mercados favorables y (8) oportunidades políticas y marcos políticos favorables. Del análisis de las entrevistas realizado en el capítulo 4 se puede concluir que el territorio en el que está inmerso el CHP cuenta con un enorme potencial para avanzar hacia el desarrollo de un territorio sustentable, resiliente, saludable y socialmente más justo, acorde a los lineamientos de la agroecología. En base al conocimiento desarrollado sobre este territorio, se destacan ciertos aspectos que estos autores consideran que actúan como limitantes para la masificación de la agroecología, y sobre los cuales hace falta avanzar; estos incluyen la generación de relaciones paternalistas/clientelistas, las políticas públicas que facilitan la concentración y acaparamiento de la tierra, las acciones gubernamentales/institucionales que promueven la expansión del agronegocio y los efectos de la colonialidad del saber (Mier et al., 2019).

Finalmente, el sistema agroalimentario actual (mundial y nacional) que sienta sus bases en el modelo de agricultura industrial modernizadora, atenta contra la diversidad de los sistemas productivos, a la vez que va afectando la trama cultural, homogeneizando y licuando las identidades territoriales de los alimentos, restando autonomía a los consumidores en cuanto a su capacidad de decidir sobre su alimentación e imponiendo el consumo de productos de dudosa calidad y bajo valor nutricional (May y Ciocchini, 2018). Las políticas públicas nacionales tienen que estar necesariamente orientadas a transformar ese sistema agroalimentario, y para ello se requiere avanzar en la generación de políticas públicas que permitan ir transformando las relaciones de poder existentes en este SAA y aumentando la capacidad de intervención en la gestión de los recursos locales de la población, y especialmente de los sectores más postergados (Manzanal, 2014).

\subsection{CONCLUSIONES GENERALES}

A partir del conjunto de análisis realizados en esta tesis se evidencia que por muchos años ha primado una lógica de "autogestión del territorio", donde las lógicas de mercado fueron las que mayor influencia ejercieron en el territorio, generando enormes problemas, que con el pasar de los años ya se consideran estructurales. En los 30 años analizados las lógicas del mercado quedaron plasmadas en el territorio por dos claros procesos, la expansión urbana sin criterios aparentes y la intensificación productiva especialmente vinculada a la producción bajo invernáculos.

Como evidencia del proceso de expansión urbana, asociado a la creciente especulación inmobiliaria, el avance de los countries y barrios privados y los loteos en el marco de los planes ProCreAr, la urbanización experimentó un importante crecimiento entre 1986 y 2015. La urbanización de baja densidad, que en este caso es indicadora de la expansión urbana, tuvo un amplio crecimiento en los períodos 1986-1996 y 1996-2005, y 
una reducción en el período 2005-2015, en el que dicha cobertura sufrió un proceso de densificación. El crecimiento en los primeros dos períodos se dió principalmente sobre pastizales y parquizaciones herbáceas, aunque en menor medida también avanzó sobre zonas con horticultura al aire libre. Para el año 2015 casi el 25\% del partido se encontraba ocupado por áreas urbanas y parte de estas (asociado a la construcción de countries y barrios privados) se encontraron inmersas en una zona preponderantemente ganadera. Al mismo tiempo, se detectó que más de la mitad del área urbana se asentó sobre suelos de aptitud agrícola, y que las producciones hortícolas bajo invernáculos y las producciones hortícolas al aire libre están comenzando a ocupar suelos de menor aptitud agrícola. Al superponer los mapas de aptitud de uso del suelo y analizar las zonas de conflicto, se confirmó la fuerte influencia de la urbanización a la hora de establecer en la práctica un uso del suelo en la zona de conflicto extremo, donde los tres usos del suelo (urbanización, horticultura al aire libre e invernáculos) tenían aptitud alta/muy alta.

En cuanto al proceso de intensificación productiva, en primer lugar se evidenció que contrariamente a lo que muchos actores en el territorio suponen, la horticultura (horticultura al aire libre e invernáculos), no sufrió modificaciones sustanciales, experimentando una leve reducción en su superficie, por lo que se podría decir que el CHP mantuvo su extensión, aunque sí se evidenciaron desplazamientos en la actividad. Otra transformación clave que se detectó tiene que ver con una intensificación productiva extremadamente elevada, reflejada en un crecimiento exponencial en la superficie de cultivos bajo invernáculos. La producción bajo invernáculos creció en todos los períodos estudiados (1986-1996/19962005/2005-2015), pero con especial énfasis en el período 2005-2015, identificándose procesos de creación y de aglomeración para esta cobertura, evidenciando este último proceso la concentración espacial de los Invernáculos. El aumento en superficie de esta cobertura se dio a expensas principalmente de áreas con horticultura al aire libre y en menor medida en zonas ganaderas. En consonancia con este proceso, la Horticultura (horticultura al aire libre) sufrió un proceso de disección, caracterizado por el incremento en el número de parches y la reducción en área. En este sentido, a través del análisis de superposición de aptitudes de uso, la competencia por el uso del suelo entre la horticultura al aire libre y los invernáculos quedó también evidenciada en la zona de conflicto alto, una zona de alta aptitud para ambas actividades, donde los invernáculos están más representados. Por su parte, la producción hortícola al aire libre disminuyó en superficie en todos los períodos estudiados, especialmente en el período 1996-2005; sin embargo, en todos los períodos hubo zonas ganaderas que fueron reemplazadas por nuevas producciones hortícolas. Pese a la fuerte intensificación registrada, para el año 2015, última fecha analizada, se evidenció que aún se conservaba una amplia superficie de cultivos al aire libre, encontrándose que el porcentaje de cultivos al aire libre y cultivos bajo 
invernáculos era prácticamente igual, diferenciándose en cuanto a la distribución espacial de los mismos.

Al analizar la ubicación espacial de la horticultura bajo invernáculo, se registró que gran parte de los invernáculos se encontraban a una distancia inadecuada respecto a los centros urbanos y a los principales arroyos de la región según diversas regulaciones existentes, evidenciando un claro problema en cuanto a la zonificación de esta actividad. En este sentido se encontró que más de la mitad de los invernáculos se ubicaron dentro de los 1000 metros del área urbana; y que casi la mitad se hallaron a una distancia menor a los 200 metros de los arroyos. Al mismo tiempo, se identificó una tendencia de las producciones hortícolas bajo invernáculo a agregarse, generándose zonas en el CHP donde este tipo de uso del suelo se encontraba más representado. En este sentido, la delegación municipal identificada con mayor concentración de invernáculos para el año 2015 fue Abasto, seguida por Etcheverry, El Peligro, Lisandro Olmos y Los Hornos. Además, se comprobó que en la zona de aptitud muy alta para los invernáculos, la vegetación natural/semi-natural es escasa.

Por otro lado, el análisis de las entrevistas ha evidenciado cierta deficiencia en la incorporación de la historia de las familias productoras y del modelo productivo en la región, a la hora de diseñar las políticas públicas y las propuestas de planificación, generando una lógica de desarrollo del territorio altamente insustentable y expulsiva. El acceso a la propiedad de la tierra sin lugar a dudas emerge como una de las principales necesidades para la continuidad de la actividad, junto con un mayor control por parte del Estado del mercado y los agentes especuladores, regulando los precios de los alimentos y facilitando el acceso a maquinarias, financiamiento de proyectos productivos, capacitación, etc. También se pudo constatar en las entrevistas una enorme dificultad en el diálogo con los funcionarios del Estado y en la incorporación de las propuestas que se les acercan. Se evidenció también la necesidad de un proyecto de desarrollo territorial que trascienda los períodos de gestión municipal. Los escasos proyectos de planificación del territorio se han ido adaptando en general a los intereses de los funcionarios de turno, y en el único caso en el que se ha contemplado un proceso de planificación más amplio y participativo, los actores intervinientes han estado sesgados a profesionales del ámbito de la arquitectura y la ingeniería, no teniendo injerencia ni los profesionales de las ciencias agrarias y forestales, ni las más de 5000 familias productoras que habitan y trabajan en el cinturón hortícola más importante del país; quienes tampoco han podido intervenir en la etapa de implementación de este plan. De la misma manera, las políticas públicas vinculadas a la agricultura familiar no han canalizado la experiencia ni las demandas de las familias productoras ni de los profesionales que trabajan en el territorio, y han intentado mejorar las condiciones de estas 
familias mediante un incentivo a la intensificación productiva, que en nuestro territorio ha mostrado claramente ser inadecuado.

Otro de los aspectos que surgen de este análisis es la fragmentación del conocimiento, la segregación de distintas disciplinas que trabajan sobre el mismo territorio y la falta de articulación y de información entre las distintas dependencias del Estado. Sin embargo, simultáneamente se observa cómo, en parte por la propia iniciativa e interés de ciertos actores, vienen generándose múltiples conexiones en el territorio, articulando trabajos y experiencias que integran a actores del ámbito universitario, del INTA, SENASA, militantes de organizaciones de base, organizaciones de productores familiares, entre otros actores históricamente marginados desde la lógica de mercado que rige el territorio. Existen diferentes experiencias que buscaron nuclear esta diversidad de actores para trabajar sobre las necesidades del sector hortícola, que fueron impulsadas por distintos actores; entre ellas se encuentra la mesa regional del INTA, el espacio del consejo social de la UNLP y aunque de carácter más nacional, el Foro por un Programa Agrario Soberano y Popular, del cual participan gran parte de los actores de este territorio. Sin embargo, estas experiencias si bien con avances importantísimos en el territorio, no terminan de tener la centralidad y organicidad necesaria para traccionar cambios en la planificación del territorio.

A su vez, emergieron del análisis ciertas características propias del CHP que los entrevistados consideraron como un potencial para el desarrollo de la actividad. Entre ellos se menciona el alto grado de asociativismo, con un elevado porcentaje de productores familiares nucleados en algún tipo de organización, la presencia de familias productoras bolivianas con tradición campesina, la gran capacidad de trabajo y el número creciente de productores organizados con experiencia agroecológica y capacidad para transmitir sus conocimientos.

Los párrafos anteriores evidencian la existencia de importantes problemas en el $\mathrm{CHP}$, pero también exponen ciertos aspectos productivos, sociales, culturales, que dejan entrever cierto potencial en la región para generar un cambio hacia un cinturón hortícola más sustentable, basado en los lineamientos de la agroecología. Los resultados alcanzados a partir del análisis de imágenes satelitales brindaron información relevante de la potencialidad del territorio para acompañar una transformación en este sentido.

En esta tesis, si bien se observó en términos generales un crecimiento de la superficie de Pastizales, se ha evidenciado una tendencia en todo el período estudiado a la conversión de pastizales a parquizaciones herbáceas (que implican una mayor influencia antrópica) y a urbanizaciones de baja densidad; de la misma manera, las parquizaciones herbáceas mostraron una tendencia a convertirse en urbanizaciones de baja densidad. A su vez se identificó a Los Hornos y Arana como dos delegaciones con una mayor tendencia a 
realizar producciones hortícolas al aire libre. Al superponer los mapas de aptitud de uso del suelo y analizar las zonas de conflicto, se identificó a la zona de conflicto muy alto como una zona con un enorme potencial para la planificación del territorio; por la baja representación en esta zona de áreas con aptitud urbana alta/muy alta y la baja superficie efectivamente urbanizada para el año 2015, y por ser una zona ocupada principalmente por actividad ganadera y pastizales, permitiendo planificar el desarrollo de actividad hortícola al aire libre en convivencia con estos usos del suelo funcionando como reservorios de biodiversidad. En esta zona existen aún suelos de aptitud alta para el desarrollo de producciones hortícolas al aire libre que aún no han sido aprovechados. Al mismo tiempo, los entrevistados evidenciaron una tendencia a la conversión de cultivos bajo invernáculo a cultivos al aire libre, como consecuencia de la crisis actual y los recurrentes temporales que están afectando la zona.

En cuanto a la vegetación semi-natural, para el año 2015 los ambientes riparios se encontraban desarrollados principalmente en la periferia del partido, con actividad casi exclusivamente ganadera, y los ambientes naturales o semi-naturales se encontraban mucho menos representados en la zona hortícola, y menos aún en aquella zona caracterizada por la concentración de producciones bajo invernáculo; otro aspecto negativo para la sustentabilidad de la actividad. Sin embargo, se observaron áreas de pastizal en las delegaciones de Arturo Segui y Melchor Romero de importancia para el mantenimiento de la biodiversidad, por su cercanía a los arroyos que atraviesan la zona, y por su potencial para conformar corredores biológicos que conecten con la zona de mayor densidad hortícola. Del mismo modo, se detectaron pastizales en las delegaciones de City Bell, Melchor Romero y Arturo Segui, de importancia para el mantenimiento de la biodiversidad, por su cercanía a los arroyos que atraviesan la zona, y por su potencial para conformar corredores biológicos que conecten con la zona de mayor densidad hortícola y generen pulmones verdes en el entramado urbano; y en Arana, donde estos ambientes juegan un rol importante como reservorios de biodiversidad en la zona hortícola.

Los distintos actores entrevistados han reconocido una multiplicidad de servicios ecosistémicos que brindan los ambientes semi-naturales e incluso los cultivos al aire libre frente a los cultivos bajo invernáculos, aunque de manera parcial. Esto evidencia la necesidad de trabajar explícitamente los beneficios de estos ambientes, en espacios colectivos y multiactorales, para poder debatir sobre los mismos y enriquecer las propias percepciones con los conocimientos de los otros. Se evidenció en las entrevistas que existe un interés generalizado por la preservación de estos ambientes, que se consideran insuficientes, especialmente dentro del CHP; entre otras cualidades se reconoce a estos ambientes como espacios importantes para la recreación, la mejora de la salud y como ambientes que brindan al territorio de cierta "belleza escénica" que torna más disfrutables 
los ámbitos de trabajo y de reproducción de la vida. La escasez o insuficiencia de estos ambientes en las quintas y en el territorio no es el resultado de una decisión consciente de quienes viven y trabajan allí, sino que es la consecuencia de un modelo productivo y de desarrollo basado exclusivamente en la búsqueda de mayor productividad y rédito económico para un sector reducido de la población. Pese a la escasez mencionada anteriormente, se reconocen a partir del diálogo con los entrevistados estrategias que permitirían preservar e incrementar estos ambientes, mediante políticas públicas adecuadas a ello; al mismo tiempo se relataron experiencias que evidencian una importante capacidad de recuperación de los ambientes degradados, que puede ser potenciada mediante diversas prácticas agroecológicas.

Finalmente, a partir de la integración de los resultados de los diversos análisis realizados en esta tesis concluyo que:

- Se acepta parcialmente la primer hipótesis que planteaba que la amplia expansión de la tecnología del invernáculo, que tuvo lugar en los últimos 30 años en el CHP, fue posible a expensas de la ocupación de áreas semi-naturales y del reemplazo de cultivos al aire libre; afectando su distribución, conectividad y superficie total. En relación a esta hipótesis se observó un mayor avance de los invernáculos sobre los cultivos al aire libre. También es interesante destacar que pese a que en esta tesis la ganadería no fue considerada como un ambiente semi-natural, diversos entrevistados la consideraban como tal, y teniendo en cuenta que la actividad ganadera en esta región es una actividad extensiva de bajo impacto puede ser importante considerarla dentro de esta categoría, incluso como un sector del partido de La Plata donde se pueden potenciar elementos del paisaje que funcionen como corredores biológicos y refugios de biodiversidad. Por otro lado sería necesario complementar el análisis de indicadores del paisaje realizado en esta tesis para evaluar con mayor profundidad el grado de conectividad de las áreas semi-naturales.

- Se acepta parcialmente la hipótesis que planteaba que la estructura del paisaje remanente permite sostener y profundizar estrategias de manejo y planificación de base agroecológica, tendientes a generar un cambio en el modelo productivo. Si bien existen aún importantes sectores con ambientes semi-naturales y cultivos al aire libre, y la crisis que está atravesando el sector productivo está propiciando el incremento de las producciones al aire libre; para sostener un cambio en el modelo productivo hacia uno de base agroecológico es indispensable generar en el corto plazo políticas públicas que limiten el avance de la urbanización, que regulen el crecimiento de los cultivos bajo invernáculo, que promuevan la producción al aire libre y que generen estrategias para la protección de ciertos ambientes semi-naturales necesarios para el mantenimiento de la biodiversidad. 
- Se acepta parcialmente la hipótesis que planteaba que en las condiciones actuales los productores no cuentan con estrategias de gestión del territorio adecuadas para generar y sostener en el tiempo un cambio en el modelo productivo hacia un modelo de bases agroecológicas. Si bien no existen actualmente estrategias de gestión del territorio adecuadas, existe un importante trabajo de base articulado por diferentes actores del territorio, con un enorme potencial para colectivamente generar los cambios necesarios y exigir las políticas públicas adecuadas para una masificación de la agroecología.

Esta tesis dista de ser un trabajo acabado y exhaustivo, por el contrario resta aún profundizar en innumerables aspectos que hacen a la planificación de un territorio tan complejo. Al mismo tiempo, si bien se buscó integrar información obtenida de distintas fuentes y analizada con diferentes enfoques metodológicos, con el fin de tener una mirada más integral de la problemáticas del CHP; como se planteó a lo largo de esta tesis, para pensar, diagnosticar, planificar y transformar el CHP en un territorio más sustentable, resiliente y socialmente justo, es necesario construir espacios multiactorales, donde circule la información, se debata, se enriquezca y se construya poder colectivo para poder avanzar en una gestión del territorio con protagonismo de quienes realmente habitan y trabajan en el territorio. Los análisis realizados abrieron a su vez interrogantes para nuevas investigaciones, algunos de los cuales menciono a continuación:

- Una línea interesante para seguir profundizando tiene que ver con poder avanzar en un análisis más exhaustivo de la conectividad (estructural y funcional) de los ambientes naturales presentes en el partido y de las posibles estrategias para potenciar esta conectividad. Para ello es necesario indagar más profundamente en los indicadores de paisaje para poder seleccionar aquellos que sean realmente adecuados en el caso en estudio. Este análisis debería a su vez complementarse con trabajo de campo que permita medir la biodiversidad existente en los distintos ambientes semi-naturales identificados. Complementariamente se podría desarrollar una línea de investigación vinculada al estudio del rol de la matriz en la conectividad del paisaje, considerando ciertas especies claves en el control biológico de plagas; y otra que permita ahondar en la evaluación de la heterogeneidad del paisaje y su rol en cuanto a la promoción de la biodiversidad. Un aspecto de suma importancia en el contexto de fuerte intensificación productiva del CHP tiene que ver con incorporar a los análisis del paisaje la influencia que pueden tener las prácticas de producción intensivas tanto sobre coberturas del paisaje composicionalmente similares como sobre coberturas diferentes pero cercanas espacialmente a producciones intensivas.

- Por otro lado, un análisis que está en marcha tiene que ver con poder hacer una caracterización más exhaustiva de los ambientes semi-naturales identificados en esta 
tesis, realizando muestreos a campo con identificación de las comunidades vegetales presentes y asociando esto con los trabajos existentes respecto a la presencia de enemigos naturales de las plagas en diferentes ambientes semi-naturales.

- Al mismo tiempo una línea de trabajo importante tiene que ver con integrar la información catastral con el mapeo de ambientes semi-naturales generado, para poder evaluar con más detalle la situación catastral de estas áreas y en función de ello poder evaluar las medidas más adecuadas para su protección.

- Existen a su vez estudios de ecología del paisaje que permiten diseñar paisajes agrícolas y evaluar en que medida los distintos diseños contribuyen a generar un territorio más resiliente. Este tipo de trabajos aportan interesantes herramientas para la gestión.

- Otra posibilidad que se abre a partir del trabajo realizado en esta tesis es la de generar proyecciones a futuro del territorio según distintos escenarios posibles. Un aspecto sobre el que se trabajó en esta tesis aunque aún de manera incipiente.

- El análisis de la percepción que tienen los distintos actores sociales sobre los ambientes semi-naturales y sus funciones brinda importante información para pensar en estrategias de educación formal y no formal que permitan abordar estos aspectos del territorio y para poder generar políticas públicas que sean apropiables por parte de los actores presentes en el territorio. Este tema si bien se abordó parcialmente en esta tesis, forma parte de una tesis de Maestría en Gestión Ambiental que está en proceso.

- Las dificultades para que los funcionarios del Estado (nacional, provincial y municipal) construyan su agenda en conjunto con los actores del territorio e incorporen su conocimiento y sus demandas en la gestión, es un aspecto que requiere una investigación más profunda, junto con las causas de la desarticulación entre distintos sectores del Estado que deberían trabajar articuladamente para poder gestionar un territorio de manera integral.

\subsection{BIBLIOGRAFÍA}

Ambort ME (2017). Procesos asociativos en la agricultura familiar: un análisis de las condiciones que dieron lugar al surgimiento y consolidación de organizaciones en el cinturón hortícola platense, 2005-2015 (Bachelor's thesis, Universidad Nacional de La Plata. Facultad de Humanidades y Ciencias de la Educación).

Arias M (2019). Efecto del uso de fertilizantes y pesticidas sobre organismos acuáticos en arroyos de la zona hortícola de La Plata. D. Tesis, Facultad de Ciencias Naturales y Museo, Universidad Nacional de La Plata. 147 pp. 
Barsky A (2013). Gestionando la diversidad del territorio periurbano desde la complejidad de las instituciones estatales implementación de políticas públicas para el sostenimiento de la agricultura en los bordes de la región metropolitana de Buenos Aires (20002013). Universitat Autónoma de Barcelona. Tesis doctoral. 340 Pp.

Birche M, Jensen KC, (2018). El paisaje en el espacio público como medio de integración entre la ciudad y el agua: el caso de la región La Plata, Argentina. Revista de Urbanismo 39: 1-16.

Birche ME, Jensen KC (2018b). Relevamiento y catalogación de los espacios verdes de uso público de la ciudad de La Plata, Argentina. Urbano, 21pp.

Blandi ML (2016). Tecnología del invernáculo en el Cinturón Hortícola Platense: análisis de la sustentabilidad y los factores que condicionan su adopción por parte de los productores (Doctoral dissertation, Facultad de Ciencias Agrarias y Forestales).

Bonicatto MM (2018). Sustentabilidad y agrobiodiversidad: análisis de la conservación de semillas y conocimientos asociados en agroecosistemas familiares del Cinturón Hortícola Platense. Doctoral dissertation, Universidad Nacional de La Plata. 260 Pp.

Bryant MM (2006). Urban landscape conservation and the role of ecological greenways at local and metropolitan scales. Landscape and urban planning, 76(1-4), 23-44.

Dansero E, G Pettenati y A Toldo (2017). The relationship between food and cities and urban food policies: a space for geography?. Bollettino della società geografica italiana. 13 (5): 4-19.

Dubrovsky Berensztein N (2018). Estudio de la entomofauna en agroecosistemas del Cinturón Hortícola de La Plata, para el diseño participativo de estrategias de control biológico por conservación (Doctoral dissertation, Universidad Nacional de La Plata). On line: http://sedici.unlp.edu.ar/handle/10915/71094

Dansero E, Pettenati G, Toldo A (2017). The relationship between food and cities and urban food policies: a space for geography?. Bollettino della società geografica italiana. 13 (5): 4-19.

FAO (2016). El estado mundial de la agricultura y la alimentación. Cambio climático, agricultura y seguridad alimentaria. Organización de las Naciones Unidas para la Alimentación y la Agricultura. Disponible en: http://www.fao.org/3/a-i6030s.pdf

Fernández V, Marasas ME (2015). Análisis comparativo del componente vegetal de la biodiversidad en sistemas de producción hortícola familiar del Cordón Hortícola de La 
Plata (CHLP), provincia de Buenos Aires, Argentina. Revista de la Facultad de Agronomía, 114 (Núm. Esp. 1): 15-29.

Fischer J, Lindenmayer DB, Manning AD (2006). Biodiversity, ecosystem function, and resilience: ten guiding principles for commodity production landscapes. Frontiers in Ecology and the Environment, 4(2), 80-86.

Frediani JC (2010). Lógicas y tendencias de la expansión residencial en áreas periurbanas. El Partido de La Plata, Buenos Aires, Argentina, entre 1990 y 2010 (Doctoral dissertation, Universidad Nacional de La Plata. Facultad de Humanidades y Ciencias de la Educación). On line: http://sedici.unlp.edu.ar/handle/10915/3203

Frediani JC (2014). La tierra vacante al interior del proceso de expansión urbana en el Gran La Plata. In XVI Jornadas de Investigación del Centro de Investigaciones Geográficas y del Departamento de Geografía (La Plata, 2014).

García M (2015). Horticultura de La Plata (Buenos Aires). Modelo productivo irracionalmente exitoso. Revista de la Facultad de Agronomía, La Plata, 114(3): 190-201.

García M (2014). Fuerza de trabajo en la horticultura de La Plata (Buenos Aires, Argentina): Razones y consecuencias de su competitividad. Trabajo y Sociedad, Núm. 22: 67-85.

Gargoloff NA, Sisterna M, Bonicatto MM, Scelso L, Velarde I, Tejerina Alfaro C, Barrionuevo C, Baldini C, Cataldi V, Delgado I (2019). Transición Agroecológica y Sistema Participativo de Garantía en la Horticultura Platense. Primer Congreso Argentino de Agroecología. Facultad de Ciencias Agrarias de la Universidad Nacional de Cuyo.

Gilbert-Norton L, Wilson R, Stevens JR, Beard KH (2010). A meta-analytic review of corridor effectiveness. Conservation biology 24(3): 660-668.

Giobellina B (2017). El cinturón verde de Córdoba: hacia un plan integral para la preservación, recuperación y defensa del área periurbana de producción de alimentos. Coordinadora Beatriz Giobellina; producción cartográfica Nicolás Mari, et al. 1a ed. Manfredi, Córdoba : Ediciones INTA. On line: https://inta.gob.ar/sites/default/files/intael-cinturon-verde-de-cordoba $0 . p d f$

Giobellina B (2018). Dinámicas territoriales del cinturón verde de Córdoba: Entre la extinción y su transformación en un parque agrario planificado y sustentable. En Giobellina, B. (Comp.) La alimentación de las ciudades. Ediciones INTA, Buenos Aires. 258 Pp. On line: https://inta.gob.ar/sites/default/files/inta la alimentacion de las ciudades.pdf 
Gliessman SR, Rosado-May FJ, Guadarrama-Zugasti C, Jedlicka J, Cohn A, Méndez VE, Jaffe R (2007). Agroecología: promoviendo una transición hacia la sostenibilidad. Revista Ecosistemas, 16(1).

Gómez N, Rodrigues Capítulo A, Colautti DC, Mariñelarena AJ, Licursi M, Cochero J, García de Souza J (2017). La puesta en valor de los servicios ecosistémicos que ofrecen los arroyos de llanura como una medida de mitigación de las inundaciones: el caso del $A^{\circ}$ Del Gato en el Partido de La Plata. Ecología y Manejo de Ecosistemas Acuáticos Pampeanos (EMEAP), 8.

Hang GM, Bravo ML, Ferraris G, Larrañaga G, Seibane C, Kebat C (2015). El contexto, las políticas públicas y su relación con la horticultura en La Plata, Argentina. Revista de la Facultad de Agronomía, 114.

Herrera JM (2011). El papel de la matriz en el mantenimiento de la biodiversidad en hábitats fragmentados. De la teoría ecológica al desarrollo de estrategias de conservación. Revista Ecosistemas, 20(2-3).Martin-López B, González J, Díaz S, Castro I y M García Llorente (2007). Biodiversidad y bienestar humano: el papel de la diversidad funcional. Ecosistemas. 16(3): 69-80.

Hurtado MA, Giménez JE, Cabral MG (2006). Análisis ambiental del partido de La Plata: Aportes al ordenamiento territorial. Consejo Federal de Inversiones, La Plata. 124 pp.

Jensen K, Birche M (2018). El paisaje y la forma de expansión en la ciudad de La Plata: lineamientos y estrategias para la planificación del crecimiento urbano. In $\mathrm{X}$ Seminario Internacional de Investigación en Urbanismo, Barcelona-Córdoba. Departamentd' Urbanisme i Ordenació del Territori. Universitat Politècnica de Catalunya.

La Vía Campesina (2016). Declaración del Foro Internacional de Agroecología. Boletín Nyéléni, nro. 28, diciembre 2016. Disponible en: https://viacampesina.org/es/laagroecologia-en-una-encrucijada-boletin-nyeleni-num-28/

Li F, Wang R, Paulussen J, Liu X (2005). Comprehensive concept planning of urban greening based on ecological principles: a case study in Beijing, China. Landscape and urban planning, 72(4), 325-336.

Mac Loughlin TM, Peluso L, Marino DJ (2017). Pesticide impact study in the peri-urban horticultural area of Gran La Plata, Argentina. Science of the Total Environment, 598: 572-580.

Manzanal MA (2014). Desarrollo: Una perspectiva crítica desde el análisis del poder y del territorio. Realidad Económica (283): 17-48. 
Martin-López B, González J, Díaz S, Castro I, García Llorente M (2007). Biodiversidad y bienestar humano: el papel de la diversidad funcional. Ecosistemas. 2007/3. On line: https://revistaecosistemas.net/index.php/ecosistemas/article/view/94

Matteucci, S. (2004). Los índices de configuración del mosaico como herramienta para el estudio de las relaciones patrón-proceso. Memorias: Primer Seminario Argentino de Geografía Cuantitativa, 1-29.

May MP, Ciocchini I (2018). Hortalizas locales y amaranto, producciones identitarias en el periurbano platense ¿una alternativa a la homogeneización de la producci"on y de las dietas?. En: Sistemas productivos periurbanos en el sur del Área Metropolitana de Buenos Aires. Cieza, R.I. (Coord). Ciudad Autónoma de Buenos Aires: Ediciones Ciccus. $175 \mathrm{Pp}$.

Médico CM (2016). La vegetación como posibilidad de integración espacial, ambiental y social en los paisajes de interfase urbano-rural de la provincia de Mendoza. Revista de las Facultades de Arquitectura e Ingeniería. On line: http://www.um.edu.ar/ojsnew/index.php/FAl/article/view/794

Mier M, Giménez-Cacho T, Giraldo OF, Aldasoro M, Morales H, Ferguson BG, Rosset P, Khadse A, Campos C (2019). Escalamiento de la agroecología: impulsores clave y casos emblemáticos. Cuaderno de trabajo No. 1. Grupo en masificación de la agroecología. Disponible en: https://www.researchgate.net/profile/Omar_Giraldo/publication/333852555_Escalami ento_de_la_agroecologia_impulsores_clave_y_casos_emblematicos/links/5d08ef4f2 99bf1f539cd1a7c/Escalamiento-de-la-agroecologia-impulsores-clave-y-casosemblematicos.pdf

Morello J, Matteucci SD, Rodriguez AF, Silva ME, Mesopotámica P, Llana P, Medanosa P (2012). "Ecorregiones y complejos Ecosistémicos de Argentina". Orientación Gráfica Editora, Buenos Aires

Norton BA, Evans KL, Warren PH (2016). Urban biodiversity and landscape ecology: patterns, processes and planning. Current Landscape Ecology Reports, 1(4), 178192.

Odum EP (1984). Properties of agroecosystems. Agricultural ecosystems, 5-11.

Ostrom E (2009). A general framework for analyzing sustainability of social-ecological systems. Science, 325(5939), 419-422. Otero J, Larrañaga G, Hang GM (2013). La organización del trabajo en la horticultura familiar de La Plata (Argentina). Revista de la Facultad de Agronomía. 112 (2): 79-90. 
Otero J, Larrañaga G, Hang GM (2013). La organización del trabajo en la horticultura familiar de La Plata (Argentina). Revista de la Facultad de Agronomía. 112 (2): 79-90.

Pengue W, Rodriguez AF (2018). Agroecología, Ambiente y Salud: Escudos Verdes Productivos y Pueblos Sustentables. Fundación Heinrich Böll. Buenos Aires y Santiago. $247 \quad \mathrm{pp}$ On line: https://www.researchgate.net/publication/329125037 Agroecologia Ambiente y Sal ud Escudos Verdes Productivos y Pueblos Sustentables

Rositano F, López M, Benzi P, Ferraro DO (2012). Servicios de los ecosistemas: un recorrido por los beneficios de la naturaleza. Agronomía \& Ambiente, 32(1-2): 49-60.

Saquet MA (2015). Por una geografía de las territorialidades y las temporalidades: una concepción multidimensional orientada a la cooperación y el desarrollo territorial. La Plata, Facultad de Humanidades y Ciencias de la Educación. 153 pp.

Sarandón SJ, Flores CC, Abbona E, lermanó MJ, Blandi ML, Oyhamburu M, Presutti M (2015). Subproyecto "Análisis del uso de agroquímicos asociado a las actividades agropecuarias de la Provincia de Buenos Aires". En: Relevamiento de la utilización de agroquímicos en la Provincia de Buenos Aires. Mapa de situación e incidencias sobre la salud. Defensor del Pueblo de la Provincia de Buenos Aires y UNLP.

Stupino SA (2019). Diversidad vegetal espontánea en agroecosistemas hortícolas de La Plata y su relación con diferentes estilos de agricultura: importancia para la sustentabilidad (Doctoral dissertation, Universidad Nacional de La Plata).

Szlavecz K, Warren P, Pickett S (2011). Biodiversity on the urban landscape. In Human Population (pp. 75-101). Springer, Berlin, Heidelberg.

Tian Y, Jim CY, Tao Y, Shi T (2011). Landscape ecological assessment of green space fragmentation in Hong Kong. Urban Forestry \& Urban Greening, 10(2), 79-86.

United Nations (2019). Visita a la Argentina. Informe de la Relatora Especial sobre el derecho a la alimentación. A/HRC/40/56/Add.3 (16 de enero de 2019). On line: http://ap.ohchr.org/documents/dpage e.aspx?si=A/HRC/40/56/Add.3

Uslu A, Shakouri N (2013). Urban Landscape Design and Biodiversity. In Advances in Landscape Architecture. IntechOpen.

Uy PD, Nakagoshi N (2008). Application of land suitability analysis and landscape ecology to urban greenspace planning in Hanoi, Vietnam. Urban Forestry \& Urban Greening, $7(1), 25-40$. 
Vergnes A, Kerbiriou C, Clergeau P (2013). Ecological corridors also operate in an urban matrix: a test case with garden shrews. Urban Ecosystems, 16(3), 511-525.

Volante J (2009). Monitoreo de la cobertura y el uso del suelo a partir de sensores remotos, resultados 2006-2009. Informe Técnico Unificado. Programa Nacional de Ecorregiones (PNECO1643), INTA. Disponible en: https://www.researchgate.net/publication/278962502_Monitoreo_de_la_Cobertura _y_el_Uso_del_Suelo_a_partir_de_sensores_remotos

World Bank. (2018). Understanding poverty. Land topic. On line: http://www.worldbank.org/en/topic/land

Yang $J$ Jinxing $Z$ (2007). The failure and success of greenbelt program in Beijing. Urban forestry \& urban greening, 6(4): 287-296. 


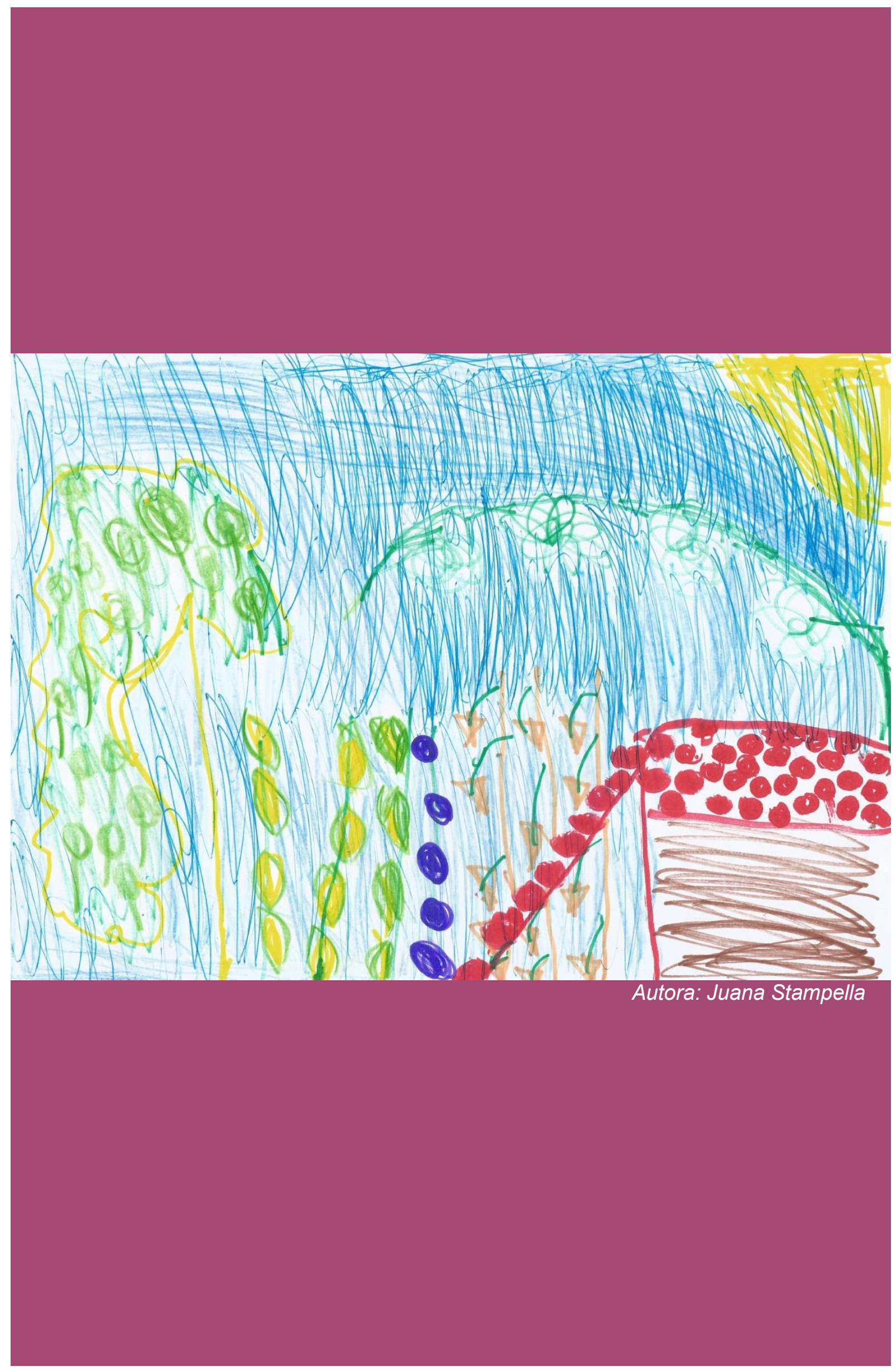

